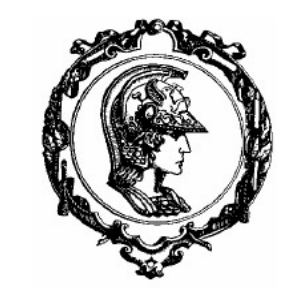

ESCOLA POLITÉCNICA DA UNIVERSIDADE DE SÃO PAULO DEPARTAMENTO DE ENGENHARIA DE CONSTRUÇÃO CIVIL

\author{
IARA NEGREIROS
}

Retrofit urbano:

uma abordagem para apoio de tomada de decisão 
IARA NEGREIROS

Retrofit urbano:

uma abordagem para apoio de tomada de decisão

Tese apresentada à Escola Politécnica da Universidade de São Paulo para obtenção de título de Doutora em Ciências.

Área de Concentração: Engenharia de Construção Civil e Urbana

Orientador: Prof. Dr. Alex Kenya Abiko

São Paulo 
Autorizo a reprodução e divulgação total ou parcial deste trabalho, por qualquer meio convencional ou eletrônico, para fins de estudo e pesquisa, desde que citada a fonte.

Este exemplar foi revisado e corrigido em relação à versão original, sob responsabilidade única do autor e com a anuência de seu orientador.

São Paulo, de de

Assinatura do autor:

Assinatura do orientador:

\section{Catalogação-na-publicação}

Negreiros, lara

Retrofit urbano: uma abordagem para apoio de tomada de decisão / I. Negreiros -- versão corr. -- São Paulo, 2018.

$299 \mathrm{p.}$

Tese (Doutorado) - Escola Politécnica da Universidade de São Paulo. Departamento de Engenharia de Construção Civil.

1.CIDADES DO FUTURO I.Universidade de São Paulo. Escola Politécnica. Departamento de Engenharia de Construção Civil II.t. 
Às minhas filhas gêmeas, Clara e Rosa, com amor. Que elas possam compor um futuro melhor. 


\section{AGRADECIMENTOS}

A Deus por guiar minhas escolhas e por me abençoar com perseverança para o desenvolvimento deste projeto e da minha carreira acadêmica.

Ao Efraim, meu esposo, pelo amor e companheirismo, além da paciência e do suporte efetivo em minhas ausências. Agradeço por acreditar que eu superaria limitações em muitos momentos em que eu mesma duvidei.

À minha família, pelo incentivo e apoio incondicional. Ao meu pai, Antonio Carlos Negreiros, e minha mãe, Josefa Roman Negreiros (in memorian), por me guiarem pelas mãos e sempre incentivarem o pensamento crítico e a dedicação aos estudos. Em especial, meu irmão, Tupã Negreiros, que muitas vezes me auxiliou nos contratempos relacionados ao sistema computacional. Agradeço também em particular minha madrinha, Delta de Negreiros, por sempre confiar que eu teria sucesso independentemente das dificuldades.

Ao Professor Dr. Alex Abiko pelo seu constante estímulo e pela confiança para o desenvolvimento desta pesquisa, fundamentais para meu crescimento pessoal e profissional.

Aos professores que participaram da banca de defesa, compondo a comissão examinadora, Prof. Dr. Ricardo Toledo Silva, Prof. Dr. Pedro Jacobi, Prof. Dr. Tadeu Fabricio Malheiros e Prof. Dr. Cheng Yang Lee, pelas valiosíssimas contribuições e sugestões, algumas que foram incorporadas no presente texto, e outras que certamente irão me guiar no desenvolvimento de pesquisas futuras.

Aos estudantes que realizaram pesquisas de Iniciação Científica, Felipe Marino Kühl, Isabela Comegna dos Santos, Filipe Batista Sena e Jonatan Nery, pelas valiosas contribuições às publicações e ao texto final.

À Lavínia de Alvarenga Vieira, por me ajudar a desenvolver a flexibilidade e o equilíbrio necessários neste processo, do início ao fim.

À CAPES pela bolsa durante os quatro anos de dedicação a esta tese. 
Ao Flávio Amary, que abriu portas e caminhos em Sorocaba para que o estudo de caso pudesse ser realizado.

À Danielle Paes Julião, pela insistência em colocar em prática o levantamento de indicadores pelos municípios paulistas, no âmbito do Programa Município VerdeAzul, e pela oportunidade de muitas conversas com interlocutores das mais diversas cidades, com as mais variadas dúvidas.

Aos profissionais que gentilmente participaram desta pesquisa, principalmente aqueles que dispuseram de seu tempo para a realização de levantamento de indicadores e verificação paciente de valores, em especial o Sr. Mário Arruda Mortara, a Sra. Sara Regina de Amorim e o Sr. Renan Rodrigues da Silva, todos da Prefeitura de Sorocaba.

À Wandréa Dantas, em especial, pela ajuda e colaboração. 
"Somos a memória que temos e a responsabilidade que assumimos. Sem memória não existimos, sem responsabilidade talvez não mereçamos existir." 


\section{RESUMO}

Acomodar adequadamente uma população urbana crescente terá implicações maiores não só para a indústria da construção, empregos e habitação, mas também para a infraestrutura associada, incluindo transporte, energia, água e espaços abertos ou verdes. Limitações da infraestrutura geralmente incluem o envelhecimento, subutilização e inadequação, assim como uma ausência de integração das estratégias de planejamento, projeto e gestão para o desenvolvimento futuro da cidade, em cenários de longo prazo. A exemplo do retrofit de edifícios, em que as intervenções ocorrem no âmbito do edifício isolado e seus sistemas constituintes, o retrofit urbano pode ser entendido como um conjunto de intervenções urbanas com vistas não somente à adequação da área urbana para atingir a sustentabilidade no momento presente, frente a problemas e demandas atuais, mas vislumbra a adequação para população e demandas futuras, fazendo a transição da situação atual da cidade para sua visão de futuro. Esta transição, o retrofit urbano em si, apresenta caráter abrangente e de larga escala, natureza integrada e deve ser mensurado por meio de indicadores e metas claramente definidos para monitoramento. Portanto, esta tese apresenta um método para implementação de retrofit urbano, na escala de cidades, para auxiliar a definição de metas de longo prazo e a tomada de decisão em processos de planejamento urbano. Utilizando as metas dos ODS Objetivos de Desenvolvimento Sustentável, os "indicadores de serviços urbanos e qualidade de vida" da NBR ISO 37120:2017 (ABNT, 2017a), análise de tendência por Média Móvel Simples e benchmarking por análise de agrupamento (clustering), o resultado é um painel visual (dashboard), adaptável e flexível, passível de agregações e filtros, tais como: seções e temas da ISO 37120, classificação de indicadores, diferentes escalas temporais e espaciais, entre outras. O dashboard é interativo e amigável, traz informações e resultados desta pesquisa e pode ser totalmente acessado em https://bit.ly/2EDnZ4J. Sorocaba, município de grande porte do Estado de São Paulo, é utilizada como estudo de caso, evidenciando os desafios e oportunidades gerados pelo rápido crescimento populacional e auxiliando a priorizar intervenções de retrofit para o desenvolvimento urbano na direção de cenários futuros.

Palavras-chave: Sustentabilidade urbana, Retrofit Urbano, Reurbanização, Indicadores Urbanos, Análise de Tendência, Análise de Agrupamento 


\title{
URBAN RETROFITTING:
}

\section{AN APPROACH TO SUPPORT DECISION-MAKING}

\begin{abstract}
Accommodating growing populations in cities will have major implications not only for employment, housing and the construction industry, but also for urban infrastructure including transportation, energy, water and open or green space. Infrastructure constraints currently include ageing, underutilized and inadequate existing built environment, as well as a lack of integration in planning, design and management strategies for future infrastructure development in long-term scenarios. As building retrofit, which interventions take place in isolated buildings and their constituting systems performance, urban retrofitting can be understood as a set of interventions designed to upgrade and sustain an urban area by providing a long-term practical response to its current problems and pressures. Such interventions must take into account the future population's needs by ensuring that the present urban infrastructure provides a firm basis for launching and achieving a city's ambitions for the future. One of the main requirements for urban retrofitting is a clearly defined set of goals and metrics for monitoring purposes. This thesis presents a method for urban retrofit implementation at city scale using a visual tool to support decision-making and urban planning processes. Using Sustainable Development Goals (SDGs) targets, the 100 ISO 37120:2014 'indicators for city services and quality of life', Simple Moving Averages (SMA) trend analysis, clustering and city benchmarking, this method proposes creating an adaptative and flexible dashboard, that could aggregate and filter data, such as: ISO 37120 sections, indicators classification, time and spatial levels, etc. The resulting dashboard is interactive and friendly, and can be fully accessed in https://bit.ly/2EDnZ4J. We use Sorocaba, a medium sized, well-located city in São Paulo State in Brazil, as a case study, focusing on the challenges and opportunities arising from exceptional urban population growth, and ranking key retrofit interventions in Sorocaba as possible forerunners of future urban development scenarios.
\end{abstract}

Key-words: Urban Sustainability, Urban Retrofitting, Urban Redevelopment, Trend Analysis, Clustering Analysis, City Benchmarking 


\section{LISTA DE FIGURAS}

Figura 1: Evolução da população total no mundo e previsões para 2100 .................................2

Figura 2: Evolução da população total na América do Sul e previsões para 2100.....................2

Figura 3: Evolução da população total do Brasil e previsões para 2100 .................................... 3

Figura 4: Evolução da População Urbana e Rural no mundo 1950 - 2050 ...............................3

Figura 5: Expansão Urbana no mundo 1900 - 2000 ...............................................................

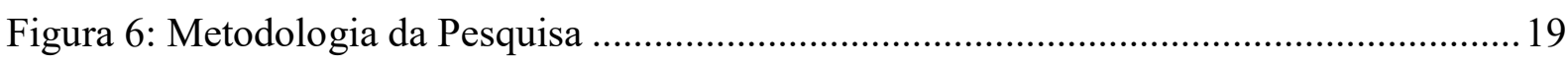

Figura 7: Categorias de trabalho por nível de intervenção................................................. 25

Figura 8: O desenvolvimento de programas para inclusão digital ........................................ 34

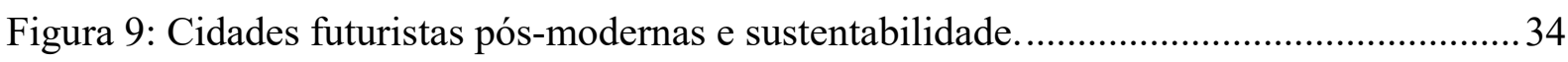

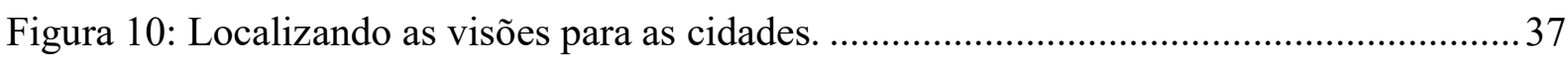

Figura 11: Área de Fornebu (a) antes do retrofit urbano e (b) após. .........................................55

Figura 12: Imagens do Projeto High Line - Nova Iorque .................................................5

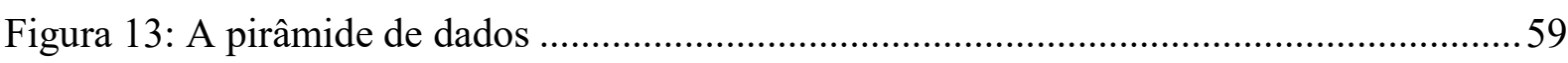

Figura 14: Espectro das características de desenvolvimento sustentável no processo de

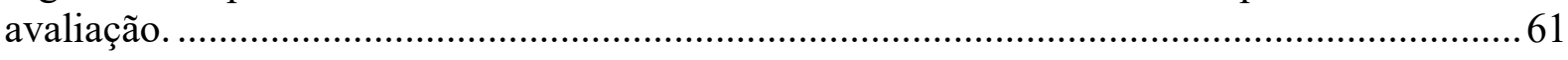

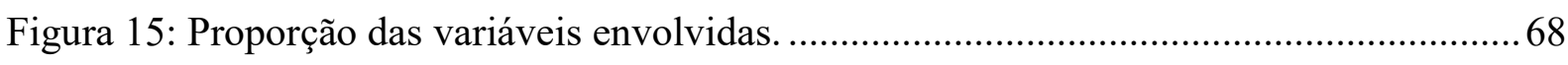

Figura 16: Big Data urbano e inteligência geográfica.......................................................... 72

Figura 17: Estrutura hierárquica do ISO/TC-268 ............................................................ 76

Figura 18: Integração dos indicadores da ISO 37120 com as demais normas ........................ 80

Figura 19: Níveis de certificação pela ISO 37120:2014 praticado pelo WCCD..................... 86

Figura 20: As 58 cidades que receberam certificação pela ISO 37120:2014 do WCCD........86

Figura 21: Necessidades de investimentos para infraestrutura urbana até 2030, em todo o

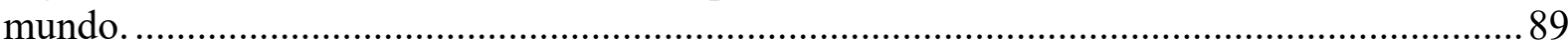

Figura 22: Visão São Paulo 2040: a cidade que queremos.................................................. 94

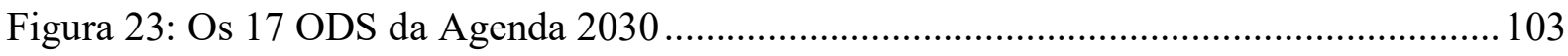

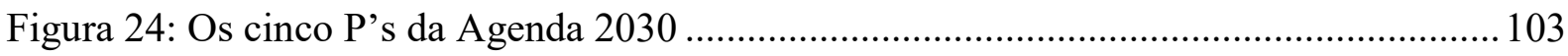

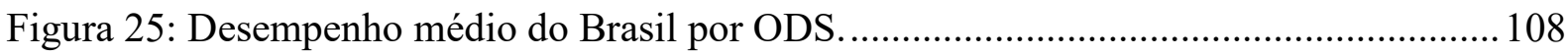

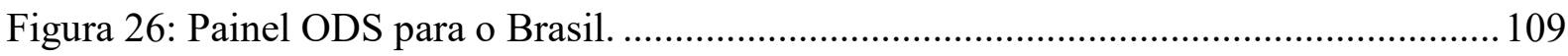

Figura 27: Nova agenda urbana para alcançar os ODS.................................................... 110

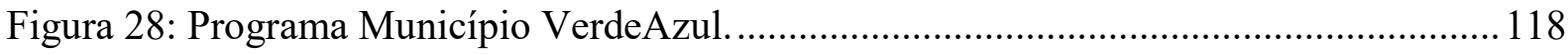

Figura 29: Mandala ODS para o município de Sorocaba - 2018 .......................................... 119

Figura 30: Relação entre o modelo PDCA e a NBR ISO 37101:2017.................................. 122

Figura 31: O Planejamento Estratégico para o Programa Cidades Sustentáveis, com recorte da tese. 
Figura 32: Tela do Planeja Sampa para o indicador "Mortes no trânsito por 100 mil habitantes".

Figura 33: Tela do Índice de Desenvolvimento Sustentável dos Municípios Catarinenses 2018.

Figura 34: Tela do Índice de Efetividade da Gestão Municipal - IEGM para Sorocaba....... 131

Figura 35: Sistemas de informação para planejamento urbano............................................ 133

Figura 36: Fluxograma do método para retrofit urbano. .................................................... 142

Figura 37: Classificação dos indicadores em quatro categorias, aplicando matriz tricolor. .. 145

Figura 38: Localização da RAS - Região Administrativa de Sorocaba.

Figura 39: Os 77 municípios que compõem a RAS - Região Administrativa de Sorocaba. . 158

Figura 40: Os 27 municípios que compõem a RMS - Região Metropolitana de Sorocaba... 159

Figura 41: Uso do solo, estrutura urbana e conexões da RMS - Região Metropolitana de Sorocaba.

Figura 42: Disposição de resíduos sólidos urbanos na RMS - Região Metropolitana de Sorocaba.

Figura 43: Fundação de Sorocaba - Quadro de Ettore Marangoni. 165

Figura 44: Locomotiva recuperada da EFS- Estrada de Ferro Sorocabana...... 165

Figura 45: Evolução esquemática da mancha urbana de Sorocaba, de 1800 a 1996. 166

Figura 46: Mapas de uso do solo do território de Sorocaba a partir de imagens do satélite. . 166 Figura 47: Evolução da Ocupação Urbana de Sorocaba a partir de 1950 e Vetores de Crescimento.

Figura 48: Evolução da população do Município de Sorocaba de 1780 a 2010, com previsão para 2030

Figura 49: Cobertura da rede de abastecimento de água no município de Sorocaba.

Figura 50: Cobertura da rede de coleta de lixo no município de Sorocaba.

Figura 51: IPVS - Índice Paulista de Vulnerabilidade Social do município de Sorocaba..... 170

Figura 52: Densidades demográficas do município de Sorocaba.

Figura 53: Vistas aéreas do município de Sorocaba.

Figura 54: Parque Tecnológico de Sorocaba..

Figura 55: Objetivos estratégicos de governo de Sorocaba, distribuídos em seus quatro principais eixos estratégicos.

Figura 56: Mapa de ciclovias do município de Sorocaba (em vermelho).

Figura 57: (a) Ciclovia da Av. Camilo Júlio e (b) Estação de bicicletas para empréstimo gratuito.

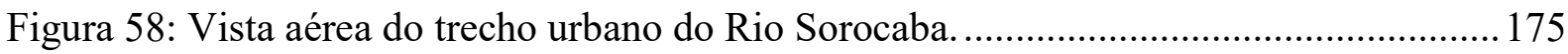

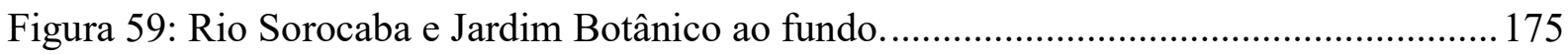

Figura 60: Gráfico de tendência padrão, exemplo para o indicador 8.2 - "Concentração de material particulado (PM 10)" com dados de Sorocaba. 
Figura 61: Resultados da classificação pela análise de tendência para os 100 indicadores da NBR ISO 37120:2017 com dados de Sorocaba.

Figura 62: Médias dos indicadores dos clusters com dados do SNIS para a Seção 16 Resíduos Sólidos

Figura 63: Detalhes dos clusters com dados do SNIS para a Seção 16 - Resíduos Sólidos.. 199 Figura 64: Médias dos indicadores dos clusters com dados do SNIS para a Seção 20 - Esgotos

Figura 65: Detalhes dos clusters com dados do SNIS para a Seção 20 - Esgotos

Figura 66: Evolução dos clusters com dados do SNIS para a Seção 20 - Esgotos, ao longo da série histórica 2010 a 2016 202

Figura 67: Médias dos indicadores dos clusters com dados do SNIS para a Seção 21 - Água e Saneamento. 204

Figura 68: Detalhes dos clusters com dados do SNIS para a Seção 21 - Água e Saneamento 204

Figura 69: Médias dos indicadores dos clusters com dados do WCCD para a Seção 16 Resíduos Sólidos 206

Figura 70: Detalhes dos clusters com dados do WCCD para a Seção 16 - Resíduos Sólidos

Figura 71: Médias dos indicadores dos clusters com dados do WCCD para a Seção 20 Esgotos

Figura 72: Detalhes dos clusters com dados do WCCD para a Seção 20 - Esgotos

Figura 73: Médias dos indicadores dos clusters com dados do WCCD para a Seção 21 - Água e Saneamento

Figura 74: Detalhes dos clusters com dados do WCCD para a Seção 21 - Água e Saneamento

Figura 75: As 26 cidades agregadas nos 3 clusters com dados do WCCD para as Seções 16, 20 e 21

Figura 76: Detalhes dos clusters com dados do WCCD para as Seções 16, 20 e 21, para indicadores da Seção 16

Figura 77: Detalhes dos clusters com dados do WCCD para as Seções 16, 20 e 21, para indicadores da Seção 20

Figura 78: Detalhes dos clusters com dados do WCCD para as Seções 16, 20 e 21, para indicadores da Seção 21

Figura 79: Médias dos indicadores dos clusters com dados do WCCD para as Seções 16, 20 e 21

Figura 80: Resultados da classificação final do método para retrofit urbano para os 100 indicadores da NBR ISO 37120:2017 com dados de Sorocaba.

Figura 81: Dashboard para o indicador 7.2 - "Porcentagem de habitantes da cidade com fornecimento regular de energia elétrica", exemplo de tendência estável.

Figura 82: Dashboard para o indicador 8.2 - "Concentração de material particulado (PM 10)", exemplo de tendência favorável e resultado final bom. 
Figura 83: Dashboard para o indicador 17.1 - "Número de conexões de internet por 100.000 habitantes", exemplo de tendência favorável e resultado final médio.

Figura 84: Dashboard para o indicador 12.2 - "Número de leitos hospitalares por 100.000 habitantes", exemplo de tendência desfavorável e resultado final ruim....

Figura 85: Dashboard para o indicador 21.7 - "Porcentagem de perdas de água (água não faturada)", exemplo de tendência desfavorável e resultado final médio. 


\section{LISTA DE QUADROS}

Quadro 1: Conceituação de termos relacionados a retrofit.....................................................27

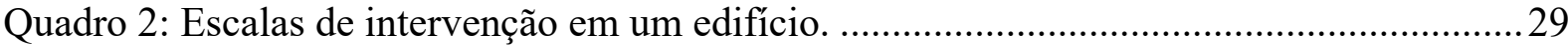

Quadro 3: Características e indicadores chave das visões do Retrofit 2050 ..........................37

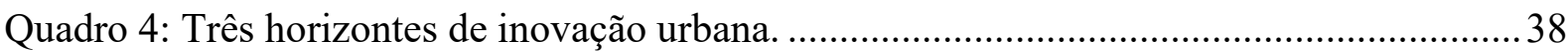

Quadro 5: Modelos de simulação utilizados em Retrofit Urbano .......................................... 41

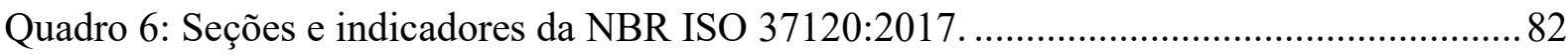

Quadro 7: As 58 cidades já certificadas pela ISO 37120:2014 pelo WCCD, com respectivo

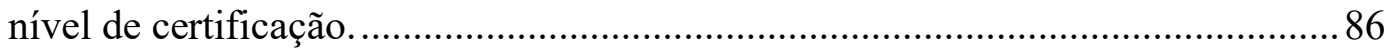

Quadro 8: Quatro categorias de cidades com características e perspectivas diferentes...........90

Quadro 9: Documentos com visões de futuro para o Brasil................................................... 91

Quadro 10: Documentos com cenários de futuro para o Município de São Paulo....................92

Quadro 11: Relação entre os Eixos Temáticos do Programa Cidades Sustentáveis .............. 117

Quadro 12: Evolução da Administração Pública.................................................................. 121

Quadro 13: Propósitos de sustentabilidade da NBR ISO 37101:2017 ................................ 123

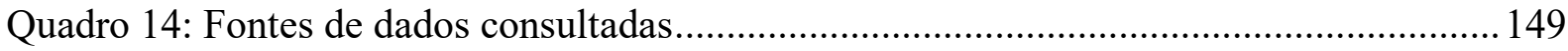

Quadro 15: Representação esquemática das ocorrências policiais na RMS e Estado de São Paulo, considerando os anos de 2001 e 2016. Fonte: EMPLASA (2017). ....... 163

Quadro 16: Documentos com cenários de futuro para o Município de Sorocaba.................. 168

Quadro 17: Consultas, entrevistas e visitas técnicas realizadas. .......................................... 177 


\section{LISTA DE TABELAS}

Tabela 1: Previsões da expansão territorial urbana para países e regiões, $2000-2050$............5

Tabela 2: As 30 variáveis envolvidas mais utilizadas nos sistemas de indicadores................69

Tabela 3: Desempenho geral do Brasil em relação aos ODS................................................. 107

Tabela 4: Indicadores essenciais (E) e de apoio (A) da NBR ISO 37120:2017 levantados para

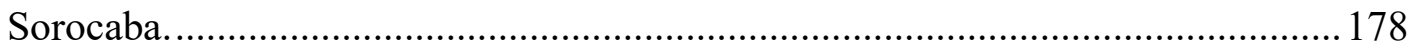

Tabela 5: Indicadores de Perfil da NBR ISO 37120:2017, levantados para Sorocaba ao ano de 2010

Tabela 6: Fronteiras de eficiência para cada um dos indicadores da NBR ISO 37120:2017.187

Tabela 7: Metas adotadas para cada um dos indicadores da NBR ISO 37120:2017............. 192

Tabela 8: Clusters com dados do WCCD para as Seções 16, 20 e 21 ..................................210

Tabela 9: Resultado final da simulação de aplicação do método para retrofit urbano em Sorocaba.

Tabela 10: Comparativo de indicadores da ISO 37120:2014 e da sua revisão de 2018 249 


\section{SUMÁRIO}

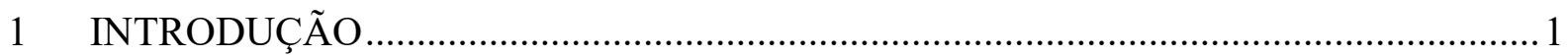

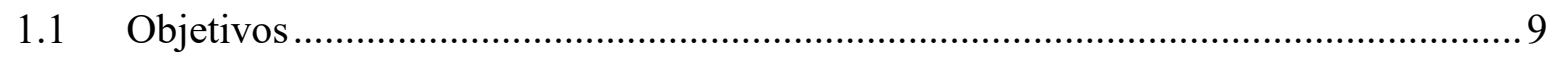

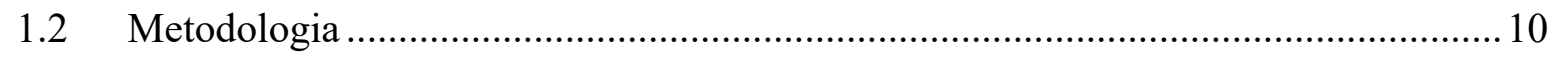

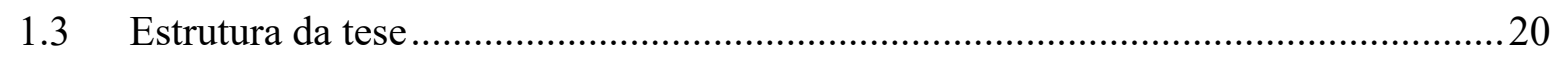

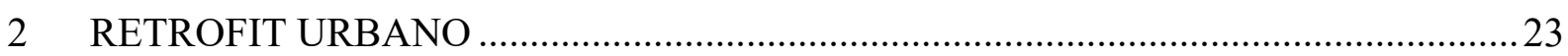

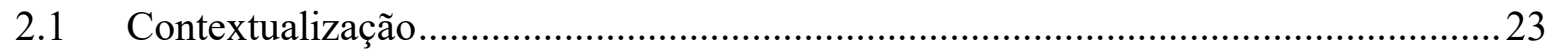

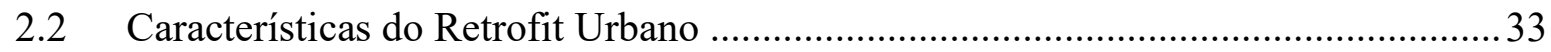

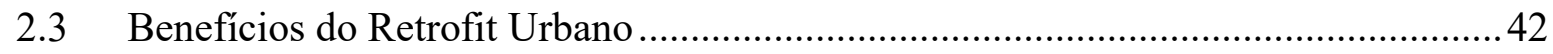

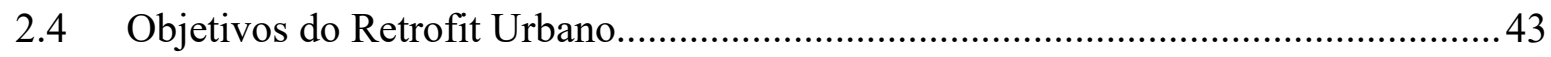

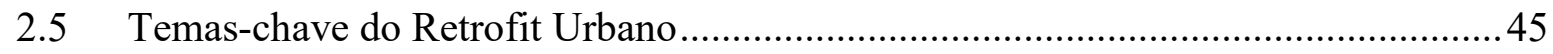

2.6 Diretrizes para Retrofit Sustentável de Ambientes Urbanos ................................... 46

2.7 Casos e Exemplos de Retrofit Urbano .............................................................. 48

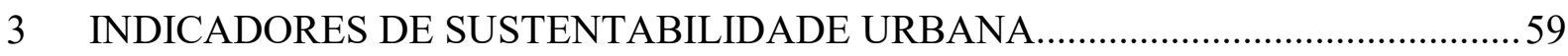

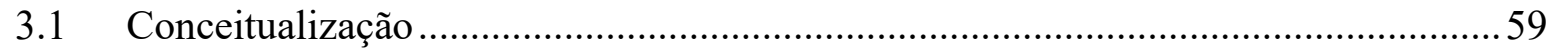

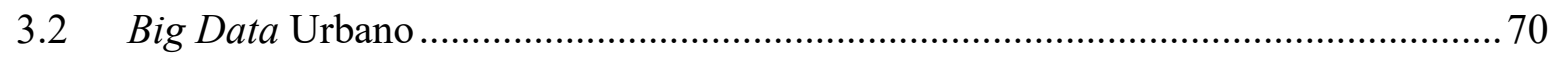

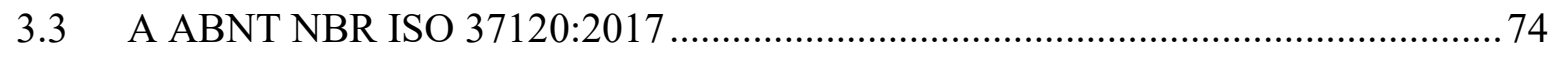

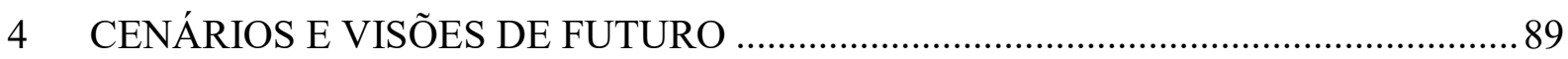

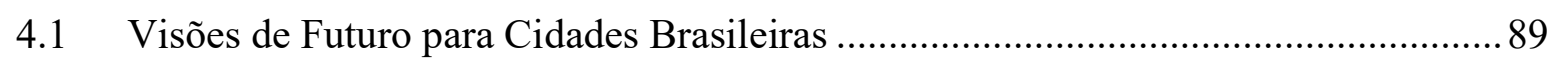

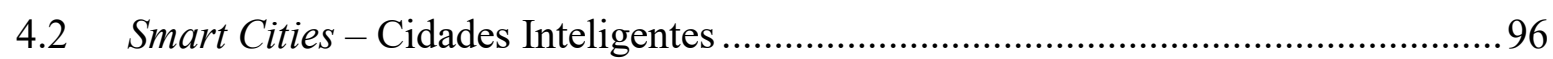

4.3 ODS - Objetivos de Desenvolvimento Sustentável ............................................. 101

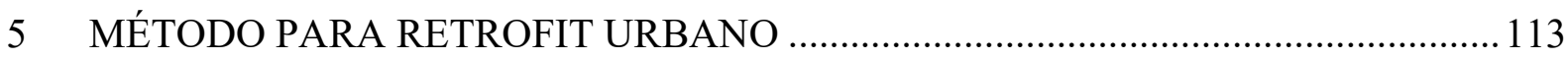

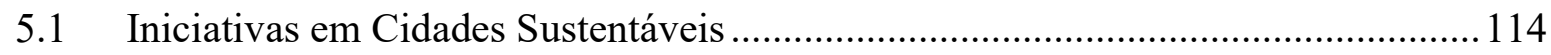

5.2 Planejamento Urbano Integrado e a ABNT NBR ISO 37101:2017 ....................... 119

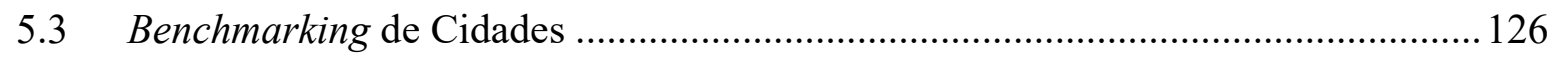

5.4 Comunicação Visual - Dashboards para Cidades................................................ 128

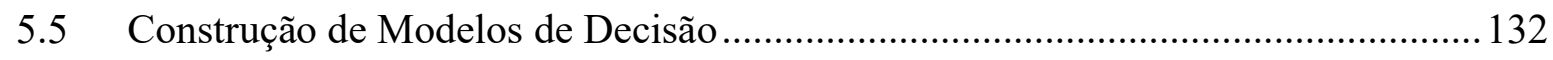

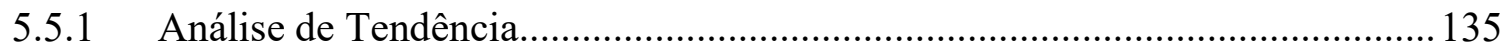

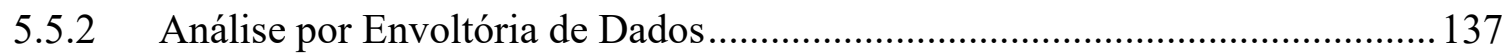

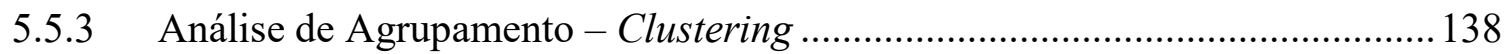

5.6 Método Proposto para Retrofit Urbano .............................................................. 140

5.7 Principais Fontes de Dados de Indicadores Urbanos no Brasil ............................. 149

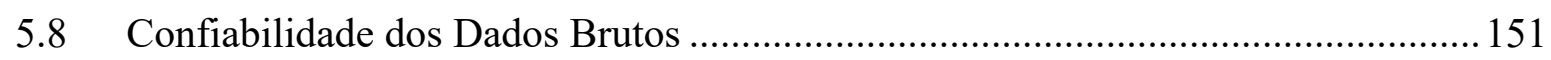


6 ESTUDO DE CASO - SOROCABA-SP

6.1 Características da Região Administrativa de Sorocaba - RAS e da Região Metropolitana de Sorocaba - RMS 157

6.2 Características do Município de Sorocaba................................................................ 164

6.3 Diagnóstico de Sorocaba pela ABNT NBR ISO 37120:2017 ............................... 176

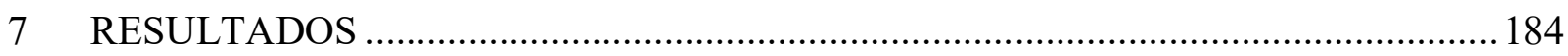

7.1 Simulação de Aplicação do Método para Retrofit Urbano em Sorocaba ................. 184

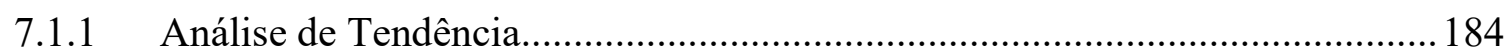

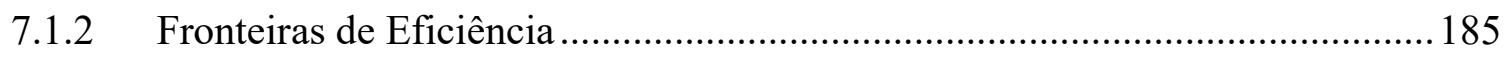

7.1.3 Clustering para Benchmarking de Cidades ................................................... 196

7.2 Resultado da Aplicação do Método para Retrofit Urbano em Sorocaba .................212

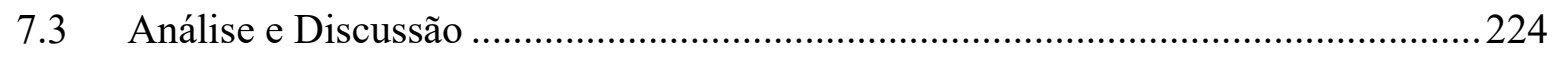

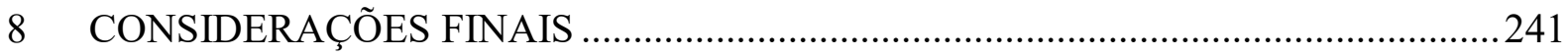

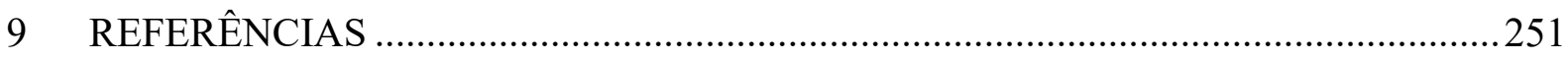

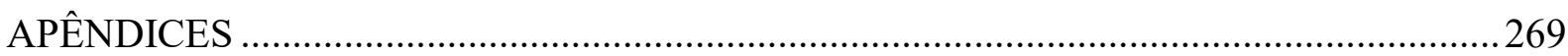

Apêndice A - Sistemas de indicadores de sustentabilidade urbana analisados .................269

Apêndice B - Indicadores da NBR ISO 37120:2017 e suas respectivas metas ODS ........272

Apêndice C - Aplicação da NBR ISO 37120:2017 (ABNT, 2017a) em Sorocaba ............293

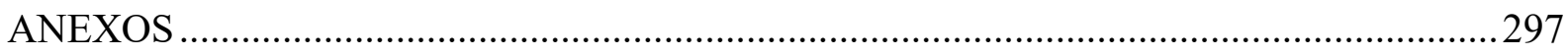

Anexo A - Folheto do IBGE sobre Sorocaba, para ocasião das eleições de 2016. ............297 


\section{INTRODUÇÃO}

Vários estudos estatísticos comprovam o constante crescimento da população mundial. Conforme o histórico citado pelo WWI - WorldWatch Institute (WWI, 2012), em 1804 a população humana atingiu o primeiro bilhão, e 130 anos depois, em 1930, chegou a 2 bilhões. Com os avanços da ciência e da tecnologia e a queda da mortalidade infantil, o ritmo acelerou, e a população mundial chegou a 3 bilhões em 30 anos depois, em 1960. Em períodos cada vez menores, mais bilhões de pessoas foram acrescidos à população mundial, atingindo em 1974, 4 bilhões; 1987, 5 bilhões; 1998, 6 bilhões (UNITED NATIONS, 2014). Segundo a ONU - Organização das Nações Unidas, a população total mundial atual é de 7,6 bilhões de pessoas, com previsão de alcançar a marca de 9,8 bilhões até 2030, e de 9,7 bilhões em 2050 (UNITED NATIONS, 2018).

Do ponto de vista das cidades, também se observa o crescimento constante da população urbana mundial e, consequentemente, a expansão de áreas urbanizadas no mundo, segundo dados de frequentes publicações da ONU relativas a este fenômeno. A ONU aponta que a população urbana do mundo tem crescido rapidamente desde 1950, de 746 milhões a 4,2 bilhões em 2018. O crescimento contínuo da população e da urbanização projeta um adicional de 2,5 bilhões de pessoas na população mundial urbana em 2050, chegando a 6,7 bilhões de pessoas vivendo em cidades no mundo (UNITED NATIONS, 2018). As Figuras 1, 2 e 3, a seguir, mostram a evolução e a previsão para 2100, da população mundial, da América do Sul e do Brasil, respectivamente.

Ainda segundo a ONU, atualmente mais pessoas vivem em áreas urbanas que em rurais, $54 \%$ da população mundial vive em zonas urbanas em 2018, cifra que era 30\% em 1950 e que se projeta atingir 66\% em 2050, conforme ilustra a Figura 4, a seguir (UNITED NATIONS, 2018).

De acordo com o IPCC - Intergovernmental Panel on Climate Change, ou Painel Intergovernamental sobre Mudanças Climáticas, organização científico-política criada no âmbito da ONU pela iniciativa do PNUMA - Programa das Nações Unidas para o Meio Ambiente, a expansão de áreas urbanas vem ocorrendo com maior velocidade do que o 
crescimento populacional. Isto pode ser verificado nas estatísticas levantadas entre 1990 e 2000, ilustradas na Figura 5 a seguir (IPCC, 2014).

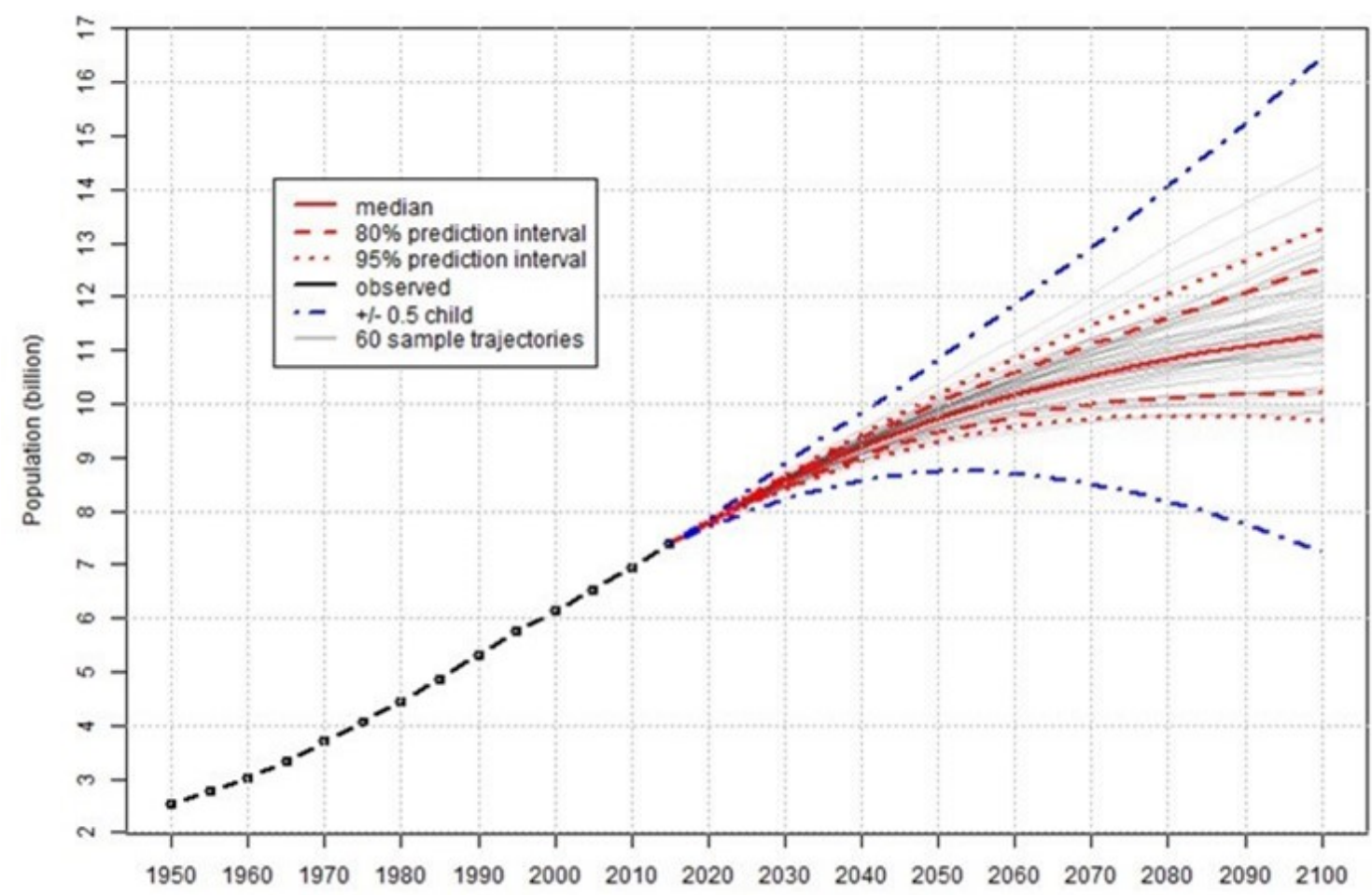

Figura 1: Evolução da população total no mundo e previsões para 2100. Fonte: (UN-DESA, 2017a)

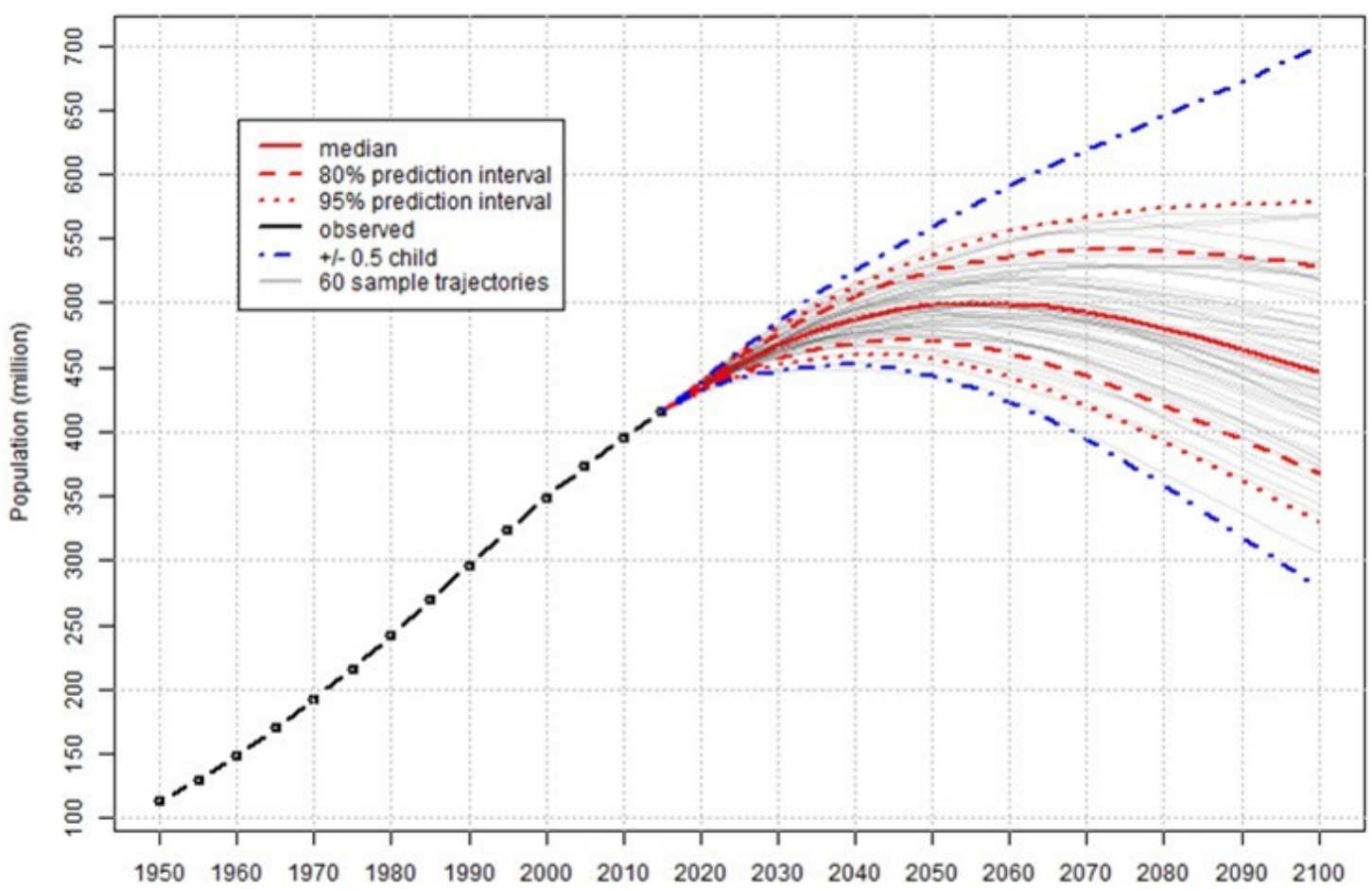

Figura 2: Evolução da população total na América do Sul e previsões para 2100. Fonte: (UN-DESA, 2017a) 


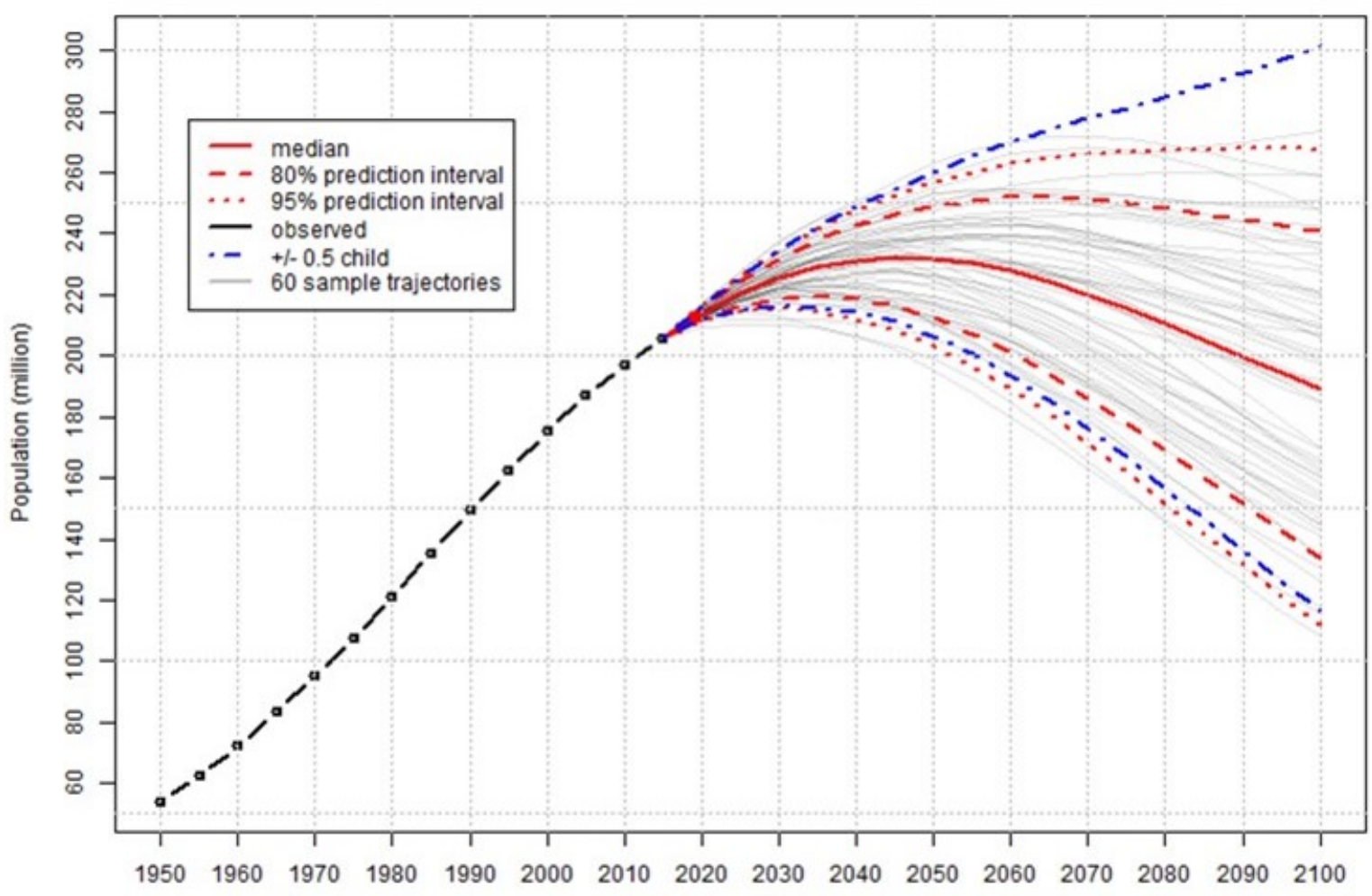

Figura 3: Evolução da população total do Brasil e previsões para 2100. Fonte: (UN-DESA, 2017a)

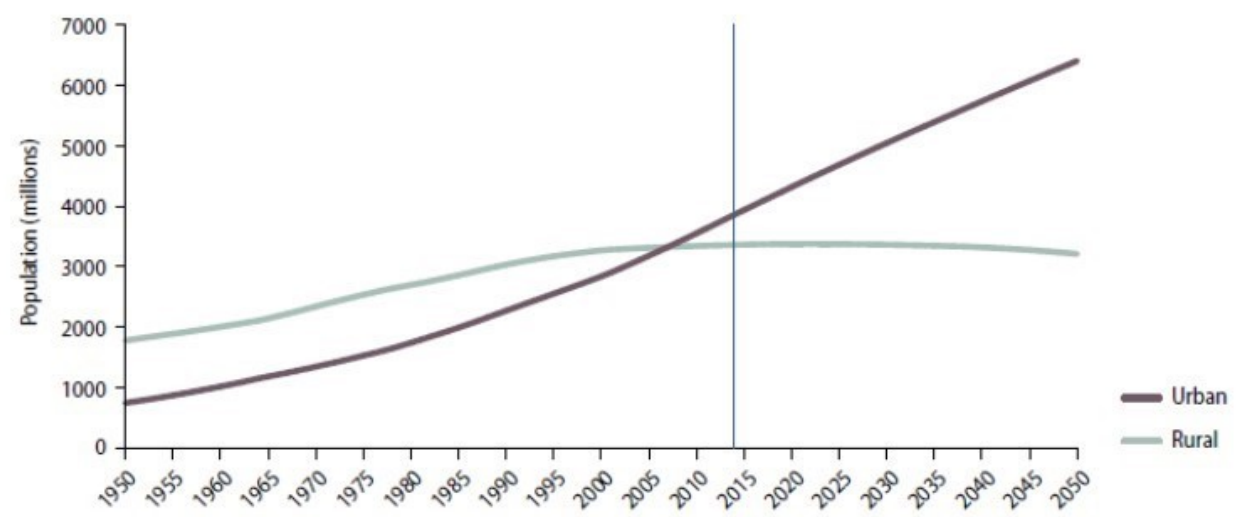

Figura 4: Evolução da População Urbana e Rural no mundo 1950 - 2050. Fonte: (UNITED NATIONS, 2018).

Average Annual Change in Density [\%]

\begin{tabular}{llllll}
-5 & -4 & -3 & -2 & -1 & 0 \\
\hline & & & & &
\end{tabular}

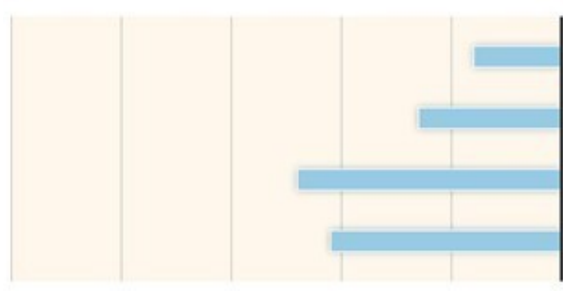

City Size

More than $4,180,000$

$1,490,000-4,180,000$

$528,000-1,490,000$

$100,000-528,000$
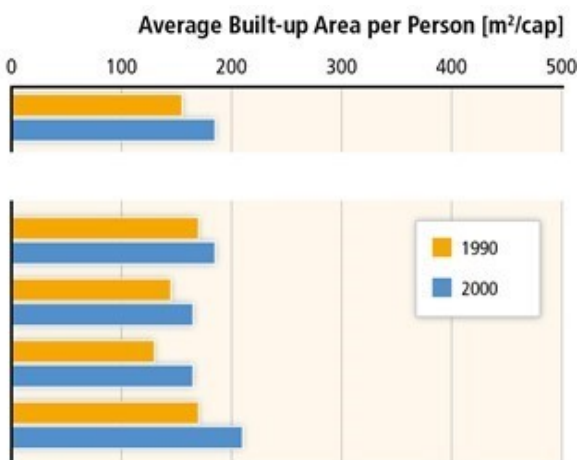

1990

2000

Figura 5: Expansão Urbana no mundo 1900 - 2000. Fonte: (IPCC, 2014). 
Mais áreas urbanas foram edificadas durante as primeiras três décadas do Século 21 do que em toda a história. A despeito dos diferentes motivos da expansão de solo urbano ao redor do mundo, esta expansão pode ser explicada tanto pelo aumento populacional como também pelo aumento de renda per capita (IPCC, 2014). As forças que guiam a expansão urbana mundial são: crescimento populacional, urbanização, aumento de renda per capita, terras agrícolas mais baratas, eficiência em transporte, e a proliferação de assentamentos informais. Assim, com a inexistência de políticas efetivas de intervenção, há pouca razão para uma contenção da expansão urbana mundial a curto prazo (ANGEL et al., 2011).

Na região da América Latina e Caribe, por sua vez, desde o início do século passado, a população total se multiplicou por nove, passando de 60 milhões de habitantes para aproximadamente 588 milhões em 2010. Apesar do território urbanizado da região da América Latina e Caribe corresponder a somente $0,45 \%$ da área territorial total, a participação da região no total da área territorial urbana mundial é de 15,1\% (ANGEL et al., 2011), e da população mundial é de $8,5 \%$, uma proporção que, segundo as projeções, diminuirá ligeiramente até o ano de 2030 (UN-HABITAT, 2012). Dentro da região, a distribuição demográfica é desigual, havendo uma concentração elevada de população em dois países, México e Brasil, que juntos somam mais da metade da população regional, sendo 18,5\% e 33,0\% de população respectivamente (UN-HABITAT, 2012).

Com relação a expansão urbana, Angel et al (2011) aponta uma preocupação com os países em desenvolvimento, onde o maior crescimento populacional, e a consequente maior expansão urbana, ocorrerão nas próximas décadas. Evidencia-se que, em 2050, a área ocupada por cidades no Brasil sofrerá um acréscimo de 70\%, passando de 4 milhões, em 2000, para 6,8 milhões de hectares. A Tabela 1, a seguir, pontua as previsões da expansão urbana no mundo, na região da América Latina e Caribe, e no Brasil.

De acordo com o Instituto Brasileiro de Geografia e Estatística (IBGE, 2013), no Brasil, entre 1991 e 2012, o número de domicílios cresceu a uma taxa mais de duas vezes maior que o de habitantes. Os domicílios brasileiros passaram de 32 para 62,3 milhões, uma expansão acumulada de $85 \%$, sendo que a população cresceu de 147 para 198 milhões no período, um aumento de $25 \%$. Uma das explicações para este fenômeno é que a média de moradores por domicílio diminuiu de 4,2 para 3,1 pessoas, entre 1991 e 2012. Em 2012, os domicílios urbanos eram 54 milhões e a população urbana no Brasil era $84,8 \%$, ou seja, 168 milhões. As 
projeções de crescimento populacional para o Brasil também mostram as mesmas tendências mundiais, a população prevista para 2050 é de 226 milhões de habitantes (IBGE, 2015).

Tabela 1: Previsões da expansão territorial urbana para países e regiões, 2000 - 2050 (parcial).

Fonte: (ANGEL et al., 2011).

\begin{tabular}{|c|c|c|c|c|c|c|}
\hline \multirow{3}{*}{ Local } & \multicolumn{6}{|c|}{ Área Territorial Urbana (Hectares) } \\
\hline & \multirow{2}{*}{2000} & \multicolumn{5}{|c|}{ Previsões } \\
\hline & & 2010 & 2020 & 2030 & 2040 & 2050 \\
\hline Mundo & 60.587 .544 & 73.853 .415 & 85.335 .546 & 96.800 .931 & 107.566 .148 & 117.057 .463 \\
\hline $\begin{array}{l}\text { América Latina } \\
\text { e Caribe }\end{array}$ & 9.129 .990 & 10.955 .230 & 12.621 .844 & 14.020 .883 & 15.122 .734 & 15.892 .480 \\
\hline Brasil & 4.046 .935 & 4.927 .630 & 5.635 .089 & 6.167 .287 & 6.556 .035 & 6.804 .321 \\
\hline
\end{tabular}

Neste cenário, áreas urbanas no mundo todo estão enfrentando enormes desafios e mudanças que não haviam 20 anos atrás, uma vez que as cidades operam em ecologias econômicas, sociais e culturais radicalmente diferentes do modelo urbano do Século XX. Temas urbanos persistentes durante os últimos 20 anos incluem: crescimento urbano, mudanças nos padrões familiares, número crescente de população urbana vivendo em favelas e assentamentos informais, e o desafio de prover serviços urbanos (UN-HABITAT, 2016).

O atual modelo de urbanização global é insustentável, sendo necessário criar novos padrões para responder a desafios como desigualdades sociais e a proliferação de favelas, especialmente nos países em desenvolvimento (UN-HABITAT, 2016). Como o mundo continua a se urbanizar, os desafios do desenvolvimento sustentável estarão cada vez mais concentrados nas cidades, particularmente nos países de rendimento médio inferior, em que o ritmo da urbanização é mais rápido (UNITED NATIONS, 2018).

A expansão acelerada da área urbana torna maior o desafio de prover infraestrutura para as cidades. As cidades se tornaram agentes essenciais para desenvolvimento sustentável nos âmbitos local, nacional e internacional ao longo do século passado, em função da pressão da urbanização sem precedentes (ISO, 2016a). A consequência é a necessidade de criar mais espaço nas áreas urbanas, observando os limites de expansão das cidades e os cerca de 80 milhões de novos habitantes consumidores acrescidos anualmente à população humana (WWI, 2012). 
Em vista destes dados, segundo Serge Latouche (2009) e demais defensores da teoria do decrescimento, os recursos naturais são limitados e nosso planeta é finito, portanto, não podem coexistir com um sistema baseado em crescimento infinito. A melhoria das condições de vida deve, portanto, ser obtida sem aumento do consumo, mudando-se o paradigma dominante, que prega crescimento e acumulação ilimitados. Decrescimento não deve ser confundido com declínio econômico, mas sim o desvio intencional de uma economia de crescimento perpétuo. Decrescimento não significa a decadência ou o sofrimento diante de uma recessão generalizada, mas uma retração planejada e controlada, tendo em mente o realinhamento com os limites do planeta e a criação de um futuro sistema econômico em estado estável que esteja em equilíbrio com os limites da Terra. Ao contrário de declínio da economia, o decrescimento pode ser comparado a uma dieta saudável, praticada de modo voluntário, para melhorar o bem-estar individual, e o crescimento econômico negativo pode ser equiparado à inanição (WWI, 2012). O decrescimento não se trata de um crescimento negativo, mas sim uma proposta concreta de como entrar num "círculo virtuoso" de decrescimento sereno, representado por oito mudanças interdependentes que se reforçam mutuamente: reavaliar, reconceituar, reestruturar, redistribuir, relocalizar, reduzir, reutilizar, reciclar (LATOUCHE, 2009, p. 42). Estas mudanças são necessárias também no ambiente urbano, para fazer frente ao crescimento populacional previsto e atender suas demandas visando a sustentabilidade das cidades.

De acordo com Newton (2013), a trajetória da regeneração urbana que permitirá a evolução para cidades mais resilientes e sustentáveis, tanto em sociedades desenvolvidas quanto em desenvolvimento, envolve a capacidade de planejar efetivamente para implementar transições sociais e técnicas nos setores urbanos principais - transporte, habitação, energia, água, resíduos - assim como uma regeneração urbana mais abrangente no contexto de um planejamento estratégico de longo prazo. Newton (2013) resume os temas críticos para as cidades, que provavelmente serão intensificados, a menos que se iniciem brevemente intervenções integradas:

- Mudanças climáticas

- Limitação de recursos

- Mudanças populacionais

- Mudanças sociais e demográficas

- Intensificação da urbanização 
- Envelhecimento da infraestrutura

- Base econômica urbana

- Incerteza financeira

Paralelamente, a própria Organização das Nações Unidas, em seu programa para assentamentos humanos (UN-HABITAT, 2016) indica que, globalmente, temas urbanos envolvem mudanças climáticas, exclusão e crescente desigualdade e insegurança, e as recentes tendências para gestão ambiental e planejamento urbano englobam:

- Governança nacional, local e em vários níveis

- Abordagem integrada para planejamento ambiental

- Papel preponderante para planejamento participativo

- Urbanismo sustentável direcionado tecnologicamente

- Iniciativas setoriais para ambientes urbanos mais saudáveis

De fato, a expectativa de vida e a subsistência de centenas de milhões de pessoas são afetadas pelo que for feito (ou não) em centros urbanos com relação à adaptação a mudanças climáticas durante a próxima década. Segundo UN-HABITAT (2012), a ação é urgentemente necessária, tanto para enfocar riscos atuais quanto iniciar a construção da resiliência de tecidos e sistemas urbanos frente a riscos futuros prováveis. A maioria dos edifícios e infraestrutura urbanos são tradicionais; consequentemente o que é desenhado e construído agora terá que arcar com as mudanças climáticas várias décadas a frente. Como resultado, é geralmente mais fácil fazer provisões agora para riscos futuros prováveis relacionados ao clima - em expansão da infraestrutura, novos edifícios e novos assentamentos urbanos - do que realizar retrofit em edifícios, refazer a infraestrutura e reajustar layouts de assentamentos no futuro.

Milhares de cidades no mundo estão levando em conta planos de ação para as mudanças climáticas, mas poucos com foco no crescente uso de solo urbano, priorizando antes: (1) eficiência energética dos edifícios, (2) transporte, (3) resíduos sólidos e (4) fornecimento de energia, nesta ordem (IPCC, 2014).

O impacto das emissões de dióxido de carbono $\left(\mathrm{CO}_{2}\right)$ pelos veículos a base de petróleo nas mudanças climáticas está se tornando melhor compreendido e isso irá também encorajar a 
mudança das cidades dependentes. Vários centros urbanos e cidades do mundo que foram planejadas com a premissa de altos níveis de utilização de veículos individuais irão, em algum estágio, requerer retrofit (UN-HABITAT, 2012).

Adaptação ao clima requer uma reavaliação verdadeiramente de cada aspecto da forma e função do ambiente construído. Além do crescimento populacional, cidades e assentamentos estarão sujeitos a uma ampla série de impactos em relação a risco e vulnerabilidade incluindo movimentos demográficos e migratórios, devido a eventos climáticos mais frequentes e extremos.

Mudanças preponderantes em padrões climáticos, assim como eventos imprevisíveis de curta duração, irão afetar a disponibilidade de recursos, segurança, resiliência da comunidade e oportunidade econômica. Uma abordagem adaptada para planejamento e gerenciamento será fundamental para resposta efetiva e integrada com o projeto urbano e os processos e consequências do retrofit, para aplicação em todas as escalas.

Limitações da infraestrutura geralmente incluem o envelhecimento, infraestrutura existente subutilizada e inadequada, assim como uma ausência de integração das estratégias de planejamento, projeto e gestão para o desenvolvimento futuro da infraestrutura, a fim de otimizar a adaptação climática e os resultados de sustentabilidade. Frequentemente também há insuficiente reconhecimento e gerenciamento da capacidade, seja existente ou futura, de renovação da infraestrutura, assim como da potencial função das estratégias em infraestrutura verde e integrada em alavancarem lucros em sustentabilidade ao longo de ampla série de escalas da paisagem.

Acomodar uma população crescente terá implicações maiores não só para a indústria da construção, empregos e habitação, mas também para a infraestrutura associada, incluindo transporte, energia, água e espaço aberto ou verde. $\mathrm{O}$ aumento de densidade urbana e o preenchimento de vazios urbanos são frequentemente propostos como uma solução rápida e mágica para estes problemas, entretanto raramente consideram impactos por meio de uma série de fatores distintos, escalas demográficas ou de paisagem.

Diante do cenário apresentado, a rápida e crescente urbanização, tanto nos países desenvolvidos quanto nos em desenvolvimento, e as consequentes e progressivas demandas 
ao planeta, vêm trazendo desafios para as autoridades locais, nacionais e regionais correlacionarem a distribuição espacial de pessoas e recursos, e o uso e o consumo de território.

Esta pesquisa tem o intuito de auxiliar as cidades a melhorarem seus sistemas de gestão, para estabelecerem objetivos e definirem uma estratégia para desenvolvimento sustentável localmente, levando em consideração as perspectivas de todas as partes interessadas, para promover o desenvolvimento urbano sustentável.

Sem a pretensão de recriar sistemas de gestão já utilizados, tampouco de discutir cenários futuros de longo prazo, a proposta consiste em direcionar processos de intervenção e retrofit urbanos, norteados por objetivos claramente definidos de desenvolvimento urbano sustentável. A intenção é que a proposta auxilie a definição de metas claras, para propiciar o desenvolvimento de um plano de ação e um respectivo cronograma de intervenções, priorizadas entre várias alternativas, da transição do momento atual da cidade, diagnosticado por indicadores de sustentabilidade urbana escolhidos, e o seu cenário futuro, definido a partir de objetivos já estabelecidos para a cidade.

O desenvolvimento do método para priorização de planos de longo prazo permitirá avaliar adequadamente as distâncias entre diagnóstico atual e objetivos e metas futuros, e traçar um plano de ação, com priorização de atividades e, por consequência, de financiamento, podendo se tornar um referencial para gestores urbanos e cidadãos.

\subsection{Objetivos}

A partir de um cenário futuro desenvolvido para uma área urbana, é possível desenvolver um retrofit urbano que propicie a transição da situação atual para a proposta no cenário, por meio de diferentes caminhos e escolhendo amplo espectro de intervenções. Em posse de indicadores de sustentabilidade atuais e respectivas metas para a área urbana, é possível organizar um conjunto de ações integradas que atendam, passo a passo, o desenvolvimento do retrofit urbano na direção do cenário pretendido.

Isto posto, o objetivo da presente tese é o desenvolvimento de uma proposta metodológica para o retrofit urbano, como uma ferramenta prática que auxilie os processos de 
tomada de decisão e de planejamento urbano. A metodologia proposta objetiva auxiliar na definição de metas futuras claras, baseadas em observações de série histórica e em valores de melhor desempenho de cidades. Por meio da mensuração por indicadores de sustentabilidade urbana do diagnóstico atual da cidade e definição de respectivas metas futuras, é possível estabelecer um conjunto de intervenções integradas do processo de retrofit urbano, que irão contribuir para atingir os desafios de cenários futuros. Uma vez que a proposta metodológica pontuará valores para o plano de metas de uma cidade, tomadores de decisão poderão escolher entre alternativas de soluções de implantação do retrofit urbano, visando adequar a área a melhores condições ambientais e de eficiência, na direção do atingimento destas metas.

A hipótese em que se baseia a presente tese de doutorado é de que a abordagem integrada de soluções em retrofit urbano propicia áreas urbanas mais sustentáveis, que apresentem maior eficiência e melhor qualidade ambiental.

\subsection{Metodologia}

A partir da justificativa e dos objetivos expostos anteriormente, pode-se estruturar a delimitação da pesquisa, que será apresentada a seguir, quanto:

- à tipologia urbana;

- ao nível de decisão e ambiente de análise das informações;

- ao período de análise.

Esta pesquisa limita-se ao estudo dos processos de retrofit urbano e sua interface com os aspectos de sustentabilidade urbana. No escopo da presente tese, o retrofit urbano envolve os seguintes temas centrais:

- Densidade urbana, a cidade compacta em contraponto a urbanização dispersa (urban sprawl)

- Indicadores de sustentabilidade urbana

- Edificações existentes (comerciais, residenciais e industriais)

- Smartness, smart cities, cidades inteligentes

- Cenários e visões de futuro, e metas correlatas

- Infraestrutura urbana existente e saneamento ambiental 
Apesar do estudo dos elementos básicos de todos estes temas, para compor um conhecimento prévio estruturado no tema maior de retrofit urbano, a proposta para o desenvolvimento desta tese é um recorte abordando somente parte dos itens acima, com foco na transição em si do momento atual para o futuro de uma cidade.

Portanto, a proposta metodológica apresenta as seguintes limitações:

- A cidade considerada nas análises é a cidade "real", já existente, passível de ter seu momento atual diagnosticado por indicadores. Não foram consideradas cidades desenhadas, projetadas a partir do "zero", de um terreno livre. Campi e cidades universitárias, por conta de suas especificidades, também foram excluídos, apesar da reconhecida necessidade de retrofit urbano também nestes casos.

- Os limites da cidade são os existentes atualmente, e as delimitações urbanas futuras são as determinadas pelo seu Plano Diretor / Zoneamento, quando existir. Considerou-se que a transição pelo retrofit urbano, em especial o retrofit urbano sustentável, busca o aumento de densidade urbana e o preenchimento de vazios urbanos.

- Como é imensa a profusão de sistemas indicadores de sustentabilidade urbana, após extenso estudo os indicadores selecionados foram os propostos pela norma ABNR NBR ISO 37120:2017 - “Desenvolvimento Sustentável de Comunidades Indicadores para Serviços Urbanos e Qualidade de Vida” (ABNT, 2017a).

- O retrofit dos edifícios existentes faz parte do retrofit urbano da cidade em que eles estão contidos, sendo considerado para atingir metas, principalmente de eficiência energética e de recursos. A menos de indicadores macro correlatos, não são considerados no detalhe projetos de retrofit de edifícios existentes.

- Apesar dos muitos estudos de retrofit urbano no sentido de tornar a cidade uma Smart City, ou Cidade Inteligente, o tema ainda é muito novo no país, tratando mais de Smart Gadgets, ou dispositivos inteligentes, focando mais a avaliação de produtos e menos a relação custo-benefício da tecnologia, envolvendo questões como: aplicabilidade, funcionalidade, escala, manutenção, etc. É considerado o cenário futuro da cidade, a longo prazo, independente se será ou não uma Cidade Inteligente.

- Visões de futuro de longo prazo não fazem parte da cultura e da pesquisa científica do país e, tendo em vista a dificuldade de obtenção de cenários futuros, os 
objetivos e metas considerados para as cidades consistem na Agenda 2030, os ODS - Objetivos de Desenvolvimento Sustentável (PNUD, 2015a).

- A infraestrutura urbana existente no país, muitas vezes envelhecida, subutilizada e inadequada, traz importantes oportunidades de renovação, de retrofit com finalidade de proporcionar saneamento ambiental, compondo várias metas dos ODS - Objetivos de Desenvolvimento Sustentável (PNUD, 2015a).

A proposta de apresentar uma abordagem para o processo de retrofit urbano, orientados ao desenvolvimento urbano sustentável, tem como premissa que o retrofit urbano gera informações de suporte a uma extensa gama de decisões, durante todo processo de transição da situação atual para o futuro pretendido. Assim, o foco principal desta pesquisa está relacionado ao retrofit urbano e a sua integração com aspectos de desenvolvimento urbano sustentável, com o intuito de auxiliar as cidades a melhorarem seus sistemas de gestão, para estabelecerem um plano de ação para atingir objetivos e metas de longo prazo.

Delimitada a pesquisa, a metodologia adotada para o desenvolvimento da pesquisa envolve quatro etapas de trabalho, que serão detalhadas a seguir:

\section{1) Pesquisa Bibliográfica}

A pesquisa bibliográfica, inicialmente de caráter exploratório, teve como principal objetivo o conhecimento prévio, o reconhecimento do estado da arte sobre o tema de retrofit urbano e desenvolvimento urbano sustentável, com ênfase em projetos e processos de retrofit existentes, permitindo assim uma análise crítica e síntese dos requisitos conceituais de retrofit urbano. Esta etapa de pesquisa propiciou a apreensão e uniformização dos termos, primeiramente de retrofit no âmbito de edifícios isolados, e posteriormente de retrofit urbano, no âmbito de áreas urbanas e/ou cidades. Esta pesquisa apoiou-se basicamente em artigos publicados em periódicos, livros, teses, dissertações, sites de internet, etc.

Tal pesquisa foi ainda ponto de partida para a etapa de caracterização e delimitação do tema de estudo: o diagnóstico de uma cidade por indicadores de sustentabilidade, a definição de uma visão de futuro de longo prazo, e o modelo de transição de da situação atual para o atingimento de objetivos futuros. 
Assim, a investigação seguinte foi quanto aos indicadores de sustentabilidade urbana utilizados globalmente, analisando-os quanto a:

- Representatividade para o retrofit urbano

- Modelo matemático em que se baseia

- Variáveis internas consideradas

- Outros

Ainda na investigação de indicadores de sustentabilidade urbana, foi estudado o recente tema de utilização de Big Data para ambientes urbanos, quando há necessidade de coletar, armazenar, processar e analisar valores de indicadores de sustentabilidade urbana em grande volume, variedade, velocidade e confiabilidade. Também recente, a publicação de uma série de novas normas ISO - International Organization for Standardization para cidades trouxe um sistema de indicadores urbanos padronizados por meio da NBR ISO 37120:2017 "Desenvolvimento Sustentável de Comunidades - Indicadores para Serviços Urbanos e Qualidade de Vida” (ABNT, 2017a), que foi elemento de estudo nesta pesquisa.

Paralelamente, foi realizada uma investigação quanto a cenários e visões de futuro para cidades, tanto brasileiras quanto ao redor do mundo, procurando identificar documentos e publicações que proporcionassem objetivos e metas mensuráveis e comparáveis, de longo prazo. Especificamente, foram buscados documentos que refletissem visões de futuro para as cidades do Estado de São Paulo. Na investigação de visões de futuro, foi estudado o tema de Smart Cities, ou Cidades Inteligentes, uma vez que esta é a visão de futuro, a finalidade, para alguns projetos de retrofit urbano, principalmente europeus. Como decorrência da revisão da literatura no tema de cenários e visões de futuro para as cidades, a pesquisa abarcou a recém adotada Agenda 2030, que traz os 17 ODS - Objetivos de Desenvolvimento Sustentável (PNUD, 2015a).

O corpo de conhecimento sobre retrofit urbano, bem como a caracterização inicial do cenário de estudo, proporcionou a estruturação inicial da pesquisa, caracterizando o problema e definindo os objetivos. A partir desta estruturação a pesquisa bibliográfica explorou a investigação e coleta de métodos e modelos utilizados globalmente em pesquisas em retrofit urbano, para posterior análise crítica, de maneira comparativa, focando vantagens e desvantagens e avaliando sua aplicabilidade localmente. 
Cabe mencionar o grande dinamismo dos temas envolvidos, o que confere dificuldade em manter a atualidade das publicações relativas, extremamente frequentes, com novidades a cada mês. Exemplo disso é que o próprio tema de retrofit urbano não está consolidado, novos sistemas de indicadores de sustentabilidade urbana surgem frequentemente, normas novas para cidades estão sendo desenvolvidas e serão em breve publicadas, e os indicadores envolvidos para mensuração dos ODS foram recentemente acordados globalmente. Faz-se necessário acompanhar atentamente novas publicações e manter a revisão bibliográfica como uma atividade constante ao longo do processo desta pesquisa.

\section{2) Desenvolvimento do Método}

Com base na revisão bibliográfica inicial, que proporcionou o reconhecimento do estado da arte sobre retrofit urbano, a pesquisa foi estruturada e um projeto de pesquisa foi redigido. Neste projeto de pesquisa, o problema, justificativas, o objetivo geral e os específicos, metodologia e plano de trabalho foram definidos. Traçou-se um cronograma atribuindo prazos para as atividades do projeto de pesquisa, cujo andamento foi monitorado até sua finalização.

Cabe destacar a importância da participação desde o início, em outubro de 2015, das discussões da ABNT/CEE-268 - Comissão de Estudo Especial de Desenvolvimento Sustentável em Comunidades, que tem por finalidade a internalização das normas internacionais para cidades no Brasil. Em um processo multidisciplinar e participativo, que envolve diversas instituições e órgãos públicos, tais como a Caixa, Ministério das Cidades, Sabesp, Conselho de Arquitetura e Urbanismo (CAU), Câmara Brasileira da Indústria da Construção (CBIC), Sindicato da Habitação (Secovi), Conselho Brasileiro da Construção Sustentável (CBCS), Faculdade de Arquitetura e Urbanismo da USP (FAU-USP), Companhia de Desenvolvimento Habitacional e Urbano do Estado de São Paulo (CDHU), Instituto de Engenharia, entre outras, a ABNT/CEE-268 realiza uma importante participação da discussão de novas normas internacionais para cidades, pois aproxima o Brasil de outros países e instituições internacionais, possibilitando colocar nas normas internacionais as questões específicas do país. Tais discussões com especialistas destas várias instituições propiciaram um amplo espectro de conhecimento e, em contraponto, questionamentos e olhar crítico sobre o tema. 
A oportunidade de interação com agentes e interlocutores ambientais do Programa Município VerdeAzul, desde o ano de 2017, também é um ponto a destacar. Os interlocutores do Programa, representantes da gestão municipal de várias cidades paulistas, bem como os técnicos e analistas da Secretaria do Meio Ambiente do Estado de São Paulo, proporcionaram discussões, questionamentos e necessidades acerca do tema de sustentabilidade urbana, sua mensuração e monitoramento, trazendo as dificuldades práticas e ensinamentos valiosos.

De posse dos indicadores de sustentabilidade urbana e cenários futuros para a cidade, iniciou-se o objetivo principal deste trabalho, que consiste na elaboração de metodologia própria, utilizando ferramenta científica apropriada. A fim de atingir este objetivo, se faz necessário a utilização de um sistema de apoio a decisão, ao qual se coloque à luz dos diversos critérios estabelecidos as alternativas propostas. Após revisão bibliográfica de métodos relacionados a apoio de tomada de decisão, optou-se por uma combinação de análise de tendência e de valores de melhor desempenho de cidades (city benchmarking).

Para a análise de tendência, buscou-se primeiramente o levantamento de uma série temporal dos indicadores que compõem o diagnóstico da cidade. De posse da série temporal de vários indicadores, optou-se por utilizar o método de Média Móvel Simples, devido a possibilidade de aplicação mesmo com um pequeno número de observações, apresentando flexibilidade em virtude da variabilidade de número de períodos adotados para análise.

O levantamento de valores de melhor desempenho de cidades, por sua vez, se dá por meio da definição de fronteiras de eficiência, parte inicial do método de Análise de Envoltória de Dados, do inglês Data Envelopment Analysis - DEA, e por análise de agrupamento, ou clustering. A análise por clustering permite agrupar um conjunto de cidades, com características similares entre si, em algum sentido. Definido um intervalo de variáveis, o clustering propicia a análise de padrões ocultos em dados que podem não ser imediatamente óbvios apenas pela observação.

No âmbito desta tese, de posse do diagnóstico atual de uma cidade, por meio de indicadores de sustentabilidade, bem como de sua visão de futuro, é possível estabelecer metas de longo prazo, pode-se calcular matematicamente a distância entre o valor de cada indicador e sua respectiva meta numérica. Estas distâncias compõem critérios de um processo de decisão. 
Por meio de análise da aplicabilidade da metodologia, com o estudo de caso em Sorocaba, município do Estado de São Paulo, aliam-se os aspectos teórico e prático do conceito de sustentabilidade, no sentido da busca de soluções integradoras viáveis para o retrofit urbano, contribuindo para que o desenvolvimento urbano seja ambientalmente sustentável.

\section{3) Estudo de Caso}

A partir da definição de um método para retrofit urbano, a modalidade de estudo de caso se mostrou mais adequada aos propósitos da pesquisa, uma vez que esta metodologia permite avaliar a adequação da aplicabilidade da metodologia em um contexto específico. Desta forma, o estudo de caso teve como principal objetivo promover uma reflexão crítica junto às premissas assumidas na caracterização do problema de partida para a pesquisa, reconhecendo com maior profundidade os principais aspectos relacionados ao retrofit urbano.

Como se trata de questão de pesquisa do tipo "como" e uma análise "sobre um conjunto contemporâneo de acontecimentos sobre o qual o pesquisador tem pouco ou nenhum controle" (YIN, 2010), leva-se ao uso de estudo de caso explanatório. Ainda segundo Yin (2010), a elaboração e condução de um estudo de caso devem contemplar o conjunto de etapas destacado a seguir:

- definição da unidade de caso e do número de casos;

- elaboração do protocolo;

- análise de múltiplas fontes de evidência.

A unidade de caso é um processo de retrofit urbano, em uma cidade que atenda às características iniciais e pré-delimitações de cenários e visões de futuro descritas anteriormente. $\mathrm{O}$ estudo foi conduzido como um caso único de estudo, uma vez que, de acordo com Yin (2010), foi utilizado na intenção de "determinar se as proposições de uma teoria são corretas ou se algum outro conjunto alternativo de explanações possa ser mais relevante". Buscou-se uma cidade para estudo com características passíveis de satisfazer as várias condições para simular e testar o método para retrofit urbano, de forma a confirmar, contestar ou estender as proposições teóricas do método. 
Um protocolo de trabalho, em um estudo de caso, tem o intuito de prover confiabilidade metodológica, zelando pela integridade de sua condução, ao estabelecer uma visão global do projeto, procedimentos de campo, definir instrumentos de coleta de dados e a conduta a ser adotada para sua aplicação, certificando-se que as hipóteses foram analisadas no estudo de caso e que foram obtidos dados que possibilitaram a reflexão sobre a adequação da proposta da pesquisa. Desta forma, o protocolo do estudo de caso, abrange as seguintes etapas:

- levantamento de todos os indicadores de sustentabilidade urbana necessários

- coleta de dados físicos da cidade (mapas, censos, relatórios, etc.);

- coleta de documentação legal (Plano Diretor, Plano Plurianual, Zoneamento, Plano de Mobilidade, etc)

- entrevistas com agentes envolvidos: representantes do Poder Público, empreendedores, prestadores de serviços urbanos, órgãos certificadores, entre outros.

\section{4) Abordagem e análise}

A partir do reconhecimento dos conceitos de retrofit urbano, da identificação dos indicadores de sustentabilidade urbana e dos objetivos e metas futuros e da análise crítica dos requisitos conceituais sobre o tema por meio da revisão bibliográfica, pode-se elaborar o método para retrofit urbano. A partir da simulação de aplicação do método em um estudo de caso, pode-se analisar sua aplicabilidade, seus pontos críticos e possibilidades.

Assim, esta etapa destina-se à reflexão crítica da estrutura de abordagem para o processo de retrofit urbano orientado ao desenvolvimento urbano sustentável, por meio do método proposto.

Após a atividade de abordagem e análise, a partir de todos os resultados obtidos, foi finalizada a tese, com a redação das considerações finais e conclusões, bem como a revisão final do texto completo e sua formatação.

A Figura 6, a seguir, demonstra por meio de um fluxograma como se relacionam e como se dá a ordenação das etapas desta metodologia. Na própria figura podem-se observar as respectivas relações das etapas da metodologia com os capítulos propostos para a tese. 
A pesquisa trouxe dados concretos sobre retrofit urbano, compondo um instrumento de apoio para tomada de decisão e priorização das intervenções urbanas a serem implementadas para que seja realizada a transição da área urbana da situação atual para o cenário de longo prazo proposto. Em outras palavras, o resultado final consiste em uma metodologia, com ferramenta visual, para auxiliar tomadores de decisão a selecionar locações, projetos e padrões melhores para o retrofit urbano.

Da mesma maneira com que estão sendo incentivados os processos de retrofit de edifícios, com construções que incorporam práticas de sustentabilidade ambiental por meio de diversos métodos de avaliação e certificação, pode-se obter um impacto positivo similar sobre o desenvolvimento urbano, incorporando as melhores práticas de retrofit, demonstrando resultados - ambientais, sociais e econômicos - semelhantes àqueles vistos nos métodos voltados ao edifício isoladamente. Aliados à viabilidade econômica e ao bem-estar social, os indicadores mensuráveis de sustentabilidade urbana serão analisados crítica e comparativamente, incorporando-os à metodologia para proporcionar a possibilidade de comparar as vias alternativas de transição da situação atual de uma cidade para seu cenário proposto. 


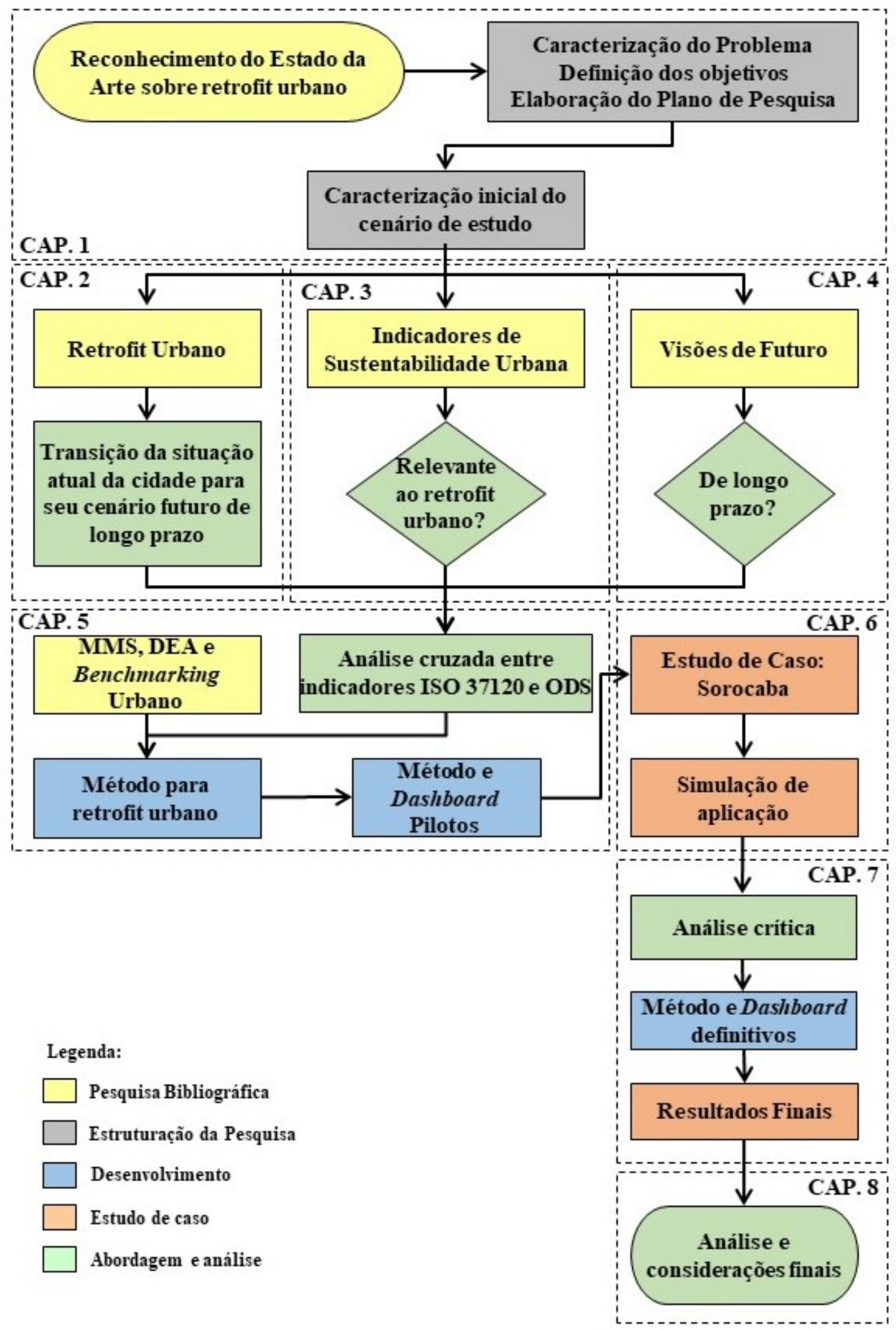

Figura 6: Metodologia da Pesquisa (elaborada pela autora) 
Isto posto, por meio dos resultados obtidos nesta pesquisa, diversos agentes, tais como: empreendedores, consumidores, Poder Público, órgãos licenciadores e certificadores, sociedade, entre outros, terão acesso à metodologia, evitando-se soluções desarticuladas e sem complementariedade, que podem culminar em gasto desnecessário de recurso público e ineficiência.

\subsection{Estrutura da tese}

O conteúdo desta tese foi estruturado em nove capítulos, descritos a seguir.

No Capítulo 1 - "Introdução", este que se apresenta, são destacadas as justificativas e relevância do tema, as premissas de partida, caracterização do problema, justificativas, os objetivos gerais e específicos, delimitação da pesquisa e metodologia. Parte da revisão bibliográfica encontra-se também neste primeiro Capítulo, e permeia também os demais capítulos, especialmente os Capítulos 2, 3 e 4.

O Capítulo 2 - "Retrofit Urbano" traz o estado da arte sobre o tema de retrofit urbano, fruto da revisão bibliográfica, e uniformização dos termos, primeiramente de retrofit no âmbito de edifícios isolados, e posteriormente de retrofit urbano, no âmbito de áreas urbanas e/ou cidades. O Capítulo abarca também as características, benefícios, objetivos, temas chave e diretrizes do retrofit urbano, bem como alguns casos e exemplos de projetos internacionais.

O Capítulo 3 - "Indicadores de Sustentabilidade Urbana" aborda os conceitos básicos relacionados ao diagnóstico de uma cidade por indicadores de sustentabilidade. São apresentados os sistemas de indicadores identificados e analisados, bem como suas variáveis envolvidas mais utilizadas classificadas e agrupadas conforme as áreas da sustentabilidade (ambiental, social, econômica e de governança). O Capítulo 3 traz ainda o tema de utilização de Big Data para ambientes urbanos, e a recente publicação de uma série de novas normas ISO - International Organization for Standardization para cidades, que trouxe um sistema de indicadores urbanos padronizados por meio da NBR ISO 37120:2017 - "Desenvolvimento Sustentável de Comunidades - Indicadores para Serviços Urbanos e Qualidade de Vida" (ABNT, 2017a). Estes indicadores de sustentabilidade são utilizados para a etapa de diagnóstico da situação atual da cidade no método para retrofit urbano proposto no Capítulo 5. 
O Capítulo 4 - "Cenários e Visões de Futuro" decorre da revisão da literatura no tema, pontuando os documentos e publicações com objetivos e metas futuras para cidades, principalmente do Estado de São Paulo. O Capítulo 4 traz também o tema de Smart Cities, ou Cidades Inteligentes, e das Operações Urbanas, especificamente para o Brasil, uma vez que ambas constituem a visão de futuro, a finalidade, para projetos de retrofit urbano. Por fim, o Capítulo 4 aborda a recém adotada Agenda 2030, que traz os 17 ODS - Objetivos de Desenvolvimento Sustentável (PNUD, 2015a), que são utilizados como metas futuras para a cidade no método para retrofit urbano proposto no Capítulo 5.

O Capítulo 5 - "Método para Retrofit Urbano" apresenta o processo de elaboração do método de transição da situação atual de uma cidade, diagnosticada por indicadores de sustentabilidade urbana, e sua visão de futuro, pontuada por metas estabelecidas. O Capítulo 5 traz ainda conceitos básicos sobre Planejamento Urbano Integrado e demais instrumentos de gestão urbana, relevantes para a estratégia de transição, para o processo do retrofit urbano. Um dos conceitos de gestão urbana, o Sustainable Cities Programme (UN-HABITAT; UNEP, 2009), com seus exemplos internacionais, e no Brasil, com a Gestão Pública Sustentável do Programa Cidades Sustentáveis (REDE NOSSA SÃO PAULO, 2016) são também apresentados neste Capítulo 5. Os métodos de análise de tendência por Média Móvel Simples e de levantamento de valores de melhor desempenho de cidades (city benchmarking) são analisados e aplicados para compor a proposição de uma metodologia própria. São apresentadas as principais fontes para levantamento dos valores dos indicadores e também as dificuldades de obtenção de alguns dados. O método é aplicado em um estudo de caso detalhado no Capítulo 6, os resultados e discussões acerca dos mesmos são expostos no Capítulo 7.

O Capítulo 6 - "Estudo de Caso - Sorocaba-SP” traz uma descrição e caracterização do município escolhido, Sorocaba, bem como seu contexto na Região Administrativa e na Região Metropolitana. É apresentado o diagnóstico atual pela aplicação dos indicadores da NBR ISO 37120:2017 (ABNT, 2017a), e uma discussão sobre o levantamento destes valores para o munícipio, dentre os temas da Norma.

O Capítulo 7 - "Resultados" apresentada a simulação de aplicação do método para retrofit urbano apresentado no Capítulo 5 para aferição da metodologia proposta. Tanto são analisadas a tendências das séries históricas dos indicadores levantados para Sorocaba, no 
Capítulo 6, quanto as fronteiras de eficiência e os valores de melhor desempenho (benchmarks) para os mesmos. São calculadas e analisadas as distâncias em relação às metas futuras propostas pelos ODS (PNUD, 2015a), discutindo suas peculiaridades e gerando as considerações e conclusões a serem apresentadas no Capítulo 8.

O Capítulo 8 - "Considerações Finais e Conclusões" aborda as principais considerações sobre o trabalho, as conclusões gerais e específicas, os objetivos alcançados, as contribuições da pesquisa realizada e a proposição para continuidade e desdobramento de trabalhos futuros.

O Capítulo 9 - "Referências Bibliográficas" apresenta a relação de publicações consultadas para a elaboração deste trabalho, e que se encontram citadas e referenciadas no corpo deste documento. 


\section{RETROFIT URBANO}

\subsection{Contextualização}

Da mesma forma que os oito "erres" das citadas mudanças propostas pela teoria do decrescimento (LATOUCHE, 2009) - reavaliar, reconceituar, reestruturar, redistribuir, relocalizar, reduzir, reutilizar, reciclar - o termo retrofit é mais um "erre" que precisa ser melhor conceituado, discutido e compreendido.

No sentido literal, "retrofit é uma palavra criada a partir da junção do termo retro, do latim, que significa movimentar-se para trás e do termo fit, do inglês, que significa ajustar-se, que resulta no conceito, em português: "reconversão"' (CBCS; ASBEA, 2013, p. 1). Do dicionário Oxford, retrofit pode ser definido como: prover (algo) um componente ou característica não embutida durante a fabricação; adicionar (componente ou característica) a algo que não foi adicionado quando construído originalmente (Oxford Dictionary of English, STEVENSON; PEARSALL, 2010). No âmbito de edifícios, retrofit é "a intervenção realizada em um edifício com o objetivo de incorporar melhorias e alterar seu estado de utilidade" (CBCS; ASBEA, 2013, p. 1). Contudo, esta não aparenta ser uma definição na escala da cidade ou de retrofit urbano amplamente aceita, apesar de que o conceito de recuperação de um patrimônio que esteja subutilizado e/ou inutilizado, não encerra na escala do edifício, mas se estende ao entorno urbano.

$\mathrm{Na}$ literatura acadêmica, muito se debate sobre o significado de retrofit e sua distinção de reforma e renovação. O termo se originou nos Estados Unidos no final da década de 1940 e início da 1950, e é essencialmente uma fusão das palavras "retroactive", ou retroativo, que se aplica ou refere ao passado, e "fit", ou equipar. No contexto do ambiente construído, o termo tem sido utilizado para pressupor mudanças físicas significativas a um ou mais edifícios, para melhoria de eficiência energética, por exemplo. Geralmente o termo retrofit é associado ao conceito de adaptação, ou seja, intervenção para ajustar, reutilizar ou modernizar um edifício para adequá-lo a novas condições ou exigências. O termo tem sido utilizado de forma intercambiável com outros termos como reforma, conversão, renovação, entre outros. Entretanto, no ambiente urbano pode-se argumentar que o termo retrofit difere destes termos, 
por conta das características de: escala mais ampla e abrangente e caráter integrado (DIXON, 2014).

No Brasil e no âmbito do edifício, o termo retrofit é muitas vezes adotado como designação para reforma, equivocadamente. A NBR 16280:2015, específica de reformas em edificações, define reforma como a "alteração nas condições da edificação existente com ou sem mudança de função, visando recuperar, melhorar ou ampliar suas condições de habitabilidade, uso ou segurança, e que não seja manutenção" (ABNT, 2015, p. 2).

O retrofit não se refere somente a uma reforma, mas também a uma troca ou substituição de componentes específicos que se tornaram inadequados ou obsoletos com o passar do tempo ou em função de evolução tecnológica. O termo retrofit refere-se especificamente ao que os norte-americanos chamam de renovation, ou renovação. Ou seja, aumentar a competitividade do empreendimento, conferindo-lhe características físicas modernas equipando-o com as facilidades e amenidades de última geração que o segmento alvo demanda (ASMUSSEN, 2005).

Meirelles (2007) propõe categorias de trabalho por nível de intervenção (Figura 7) de acordo com o código National Applicable Recommended Rehabilitation Provision - NARRP, publicado em 1997 nos Estados Unidos, que define categorias de trabalho na reabilitação de acordo com a natureza e a extensão da obra, como segue:

a) Reparo: pequeno trabalho de remendo, restauração e/ou troca de materiais, componentes, equipamentos e/ou instalações com o propósito de manutenção destes mesmos em boas condições de uso;

b) Renovação ou reabilitação: trabalho de alteração, troca, reforço, suporte, atualização ou extenso reparo em materiais, componentes, equipamentos e/ou instalações que não envolva reconfiguração de espaços no edifício;

c) Alteração: trabalho que envolve reconfiguração de espaços, adição ou eliminação de janelas e portas ou reconfiguração e/ou extensão do sistema elétrico, hidráulico ou mecânico;

d) Reconstrução: trabalho que envolve reconfiguração de espaços, incluindo corredores e saídas que sejam divididos por diferentes ocupantes, bem como trabalho de renovação ou alteração que necessite a desocupação da área por conta de exigências de segurança e acessibilidade; 
e) Adição: trabalho que envolve adição de nova área construída;

f) Mudança de Uso: mudança no propósito ou no padrão de atividade do imóvel.

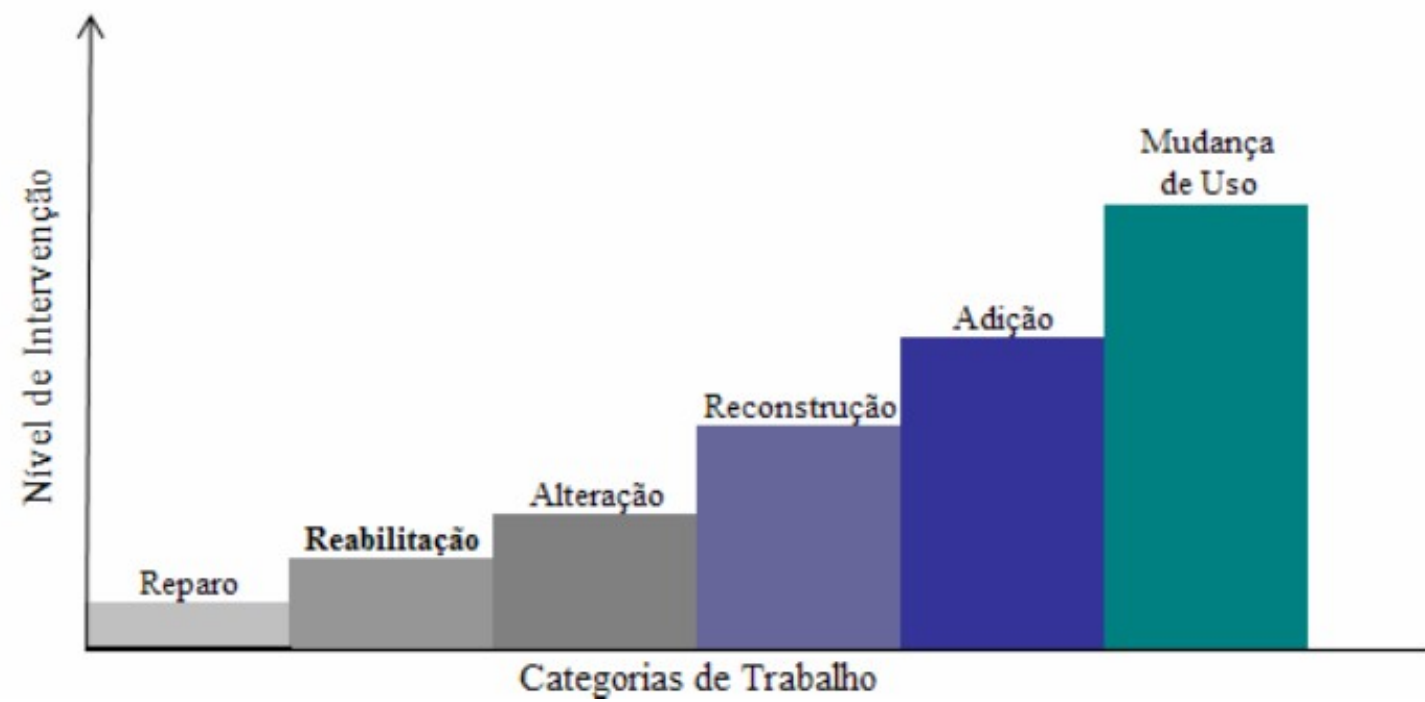

Figura 7: Categorias de trabalho por nível de intervenção propostas por (MEIRELLES, 2007), a partir de (BUILDING TECHNOLOGY INC., 2001)

O surgimento do termo retrofit remonta a discussão sobre a preservação da memória e do patrimônio histórico-arquitetônico, associada à indisponibilidade de espaço para novos empreendimentos em cidades já consolidadas (CBCS; ASBEA, 2013). No âmbito do edifício isolado, na Europa e nos Estados Unidos, o termo retrofit é geralmente utilizado quando um conjunto de ações é aplicado a um bem objetivando a melhoria de seu desempenho, a um custo viável e mantendo um padrão de qualidade (DO VALE, 2006). Tanto na Europa quanto nos Estados Unidos sua expansão foi impelida pela necessidade de espaço em um ambiente de proteção legal ao patrimônio já construído.

No Brasil, por sua vez, na ausência de uma normatização própria, a atividade é exercida sob a ABNT NBR 15575, aprovada em 2013 e comumente conhecida como "Norma de Desempenho", que define o retrofit como a "remodelação ou atualização do edifício ou de sistemas, por meio da incorporação de novas tecnologias e conceitos, normalmente visando a valorização do imóvel, mudança de uso, aumento da vida útil e eficiência operacional e energética" (ABNT, 2013). Além da ausência de legislação específica, o retrofit é uma prática ainda pouco disseminada no Brasil, por conta de diversos fatores, tais como: o retorno financeiro em comparação com empreendimentos novos; a escassez de recursos tecnológicos disponíveis, sendo que em sua maioria são inadequados a obras em edificações existentes e 
mais voltados para edificações novas; a falta de familiaridade com essa prática por parte de projetistas e indústria (CBCS; ASBEA, 2013).

No município de São Paulo, no dia 11 de maio 2016 foi aprovada em primeira votação na Câmara o Projeto de Lei PL 466/2015, que trata da revisão do COE - Código de Obras e Edificações da capital paulista, cuja Lei atual, a 11.228/1992, está em vigor há mais de 20 anos. O Projeto de Lei traz o conceito de retrofit para requalificação de edificações construídas antes de 1992, consistindo em toda uma Seção do PL, a Seção III, que trata "da requalificação", permitindo assim a modernização de edificações já existentes e abrindo caminho para o aproveitamento e a regularização de imóveis (SÃO PAULO, 2015).

Fruto de uma pesquisa sobre o termo retrofit e outros termos correlatos, tanto no âmbito do edifício isolado quanto relacionados a áreas urbanas, apresenta-se o Quadro 1, a seguir, uma contextualização de vários termos encontrados na literatura, com respectivos autores. Frente a várias questões de semântica e de tradução de um idioma para outro, a tabela não tem a pretensão de encerrar todas as definições existentes dos termos, mas tão somente contextualizá-los e trazer os conceitos mais larga e comumente utilizados no mercado imobiliário e também no meio acadêmico.

Isto posto, a partir do entendimento dos vários termos isolados, contextualizando termos correlacionados a retrofit, pode-se compreender melhor o termo em si. Retrofit de edifícios, segundo Devecchi (2010, p. 102), é uma reforma “com atenção para adequação da eficiência energética do edifício, com utilização de tecnologias de reuso de água, painéis de energia solar, isolamento térmico". Já para Marques de Jesus (2008, p. 16), retrofit é a "troca ou substituição de componentes ou subsistemas específicos de um edifício que se tornaram inadequados ou obsoletos, seja pelo passar do tempo, ou em função da evolução tecnológica ou de novas necessidades dos usuários". Para o Projeto de Lei PL 466/2015, revisão do COE - Código de Obras e Edificações de São Paulo, requalificação é a "intervenção em edificação existente, visando a adequação e modernização das instalações, com ou sem mudança de uso" (SÃO PAULO, 2015). Ainda segundo Karvonen (2013), o termo retrofit denota uma atualização para uma habitação existente atender normas e padrões contemporâneos ou preparar para condições futuras. Retrofit é, para Karvonen (2013), sinônimo de renovação, modernização, restauração e reabilitação, e descreve aquelas atividades empreendidas pelos moradores que vão além dos reparos e manutenções rotineiras. Além disso, o foco é limitado 
Quadro 1: Conceituação de termos relacionados a retrofit.

\begin{tabular}{|c|c|c|c|c|c|c|}
\hline Conceito & $\begin{array}{c}\text { Revitalização } \\
\text { Reurbanização }\end{array}$ & Renovação & Restauração & Reforma & Reabilitação & Reconstrução \\
\hline $\begin{array}{c}\text { Termo(s) } \\
\text { originário(s) }\end{array}$ & Redevelopment & $\begin{array}{l}\text { Renovation } \\
\text { Regeneration }\end{array}$ & $\begin{array}{c}\text { Restoration } \\
\text { Restitution } \\
\text { Reconstitution }\end{array}$ & Refurbishment & Rehabilitation & Rebuilding \\
\hline Definições & $\begin{array}{l}\text { Envolve: } \\
\text { "Mudança de } \\
\text { uso e ocupação } \\
\text { do solo } \\
\text { Remediação de } \\
\text { áreas } \\
\text { contaminadas } \\
\text { Remoção da } \\
\text { população } \\
\text { residente e/ou } \\
\text { usuária } \\
\text { Demolição de } \\
\text { estruturas } \\
\text { obsoletas e } \\
\text { construção de } \\
\text { novas } \\
\text { edificações" } \\
\text { (Devecchi, } \\
\text { 2010, p. 101) }\end{array}$ & $\begin{array}{l}\text { "Adaptação } \\
\text { das estruturas } \\
\text { existentes às } \\
\text { novas } \\
\text { necessidades } \\
\text { Respeito às } \\
\text { características } \\
\text { da população } \\
\text { usuária e suas } \\
\text { funções" } \\
\text { (Devecchi, } \\
\text { 2010, p. 102) }\end{array}$ & $\begin{array}{l}\text { "Recuperação física de } \\
\text { espaços e construções } \\
\text { considerando os } \\
\text { detalhes construtivos e } \\
\text { as técnicas utilizadas" } \\
\text { (Devecchi, 2010, p. } \\
\text { 102) } \\
\text { “Corresponde a um } \\
\text { conjunto de ações } \\
\text { desenvolvidas de } \\
\text { modo a recuperar a } \\
\text { imagem, a concepção } \\
\text { original ou o momento } \\
\text { áureo da história da } \\
\text { edificação em } \\
\text { questão" (Vale, 2006, } \\
\text { p. 14) } \\
\text { Compreende } \\
\text { restituição (restitution) } \\
\text { e reconstituição } \\
\text { (reconstitution), } \\
\text { reparar danos, } \\
\text { consolidar fissuras, } \\
\text { etc, em harmonia com } \\
\text { a estética do edifício } \\
\text { (Roders, 2007) }\end{array}$ & $\begin{array}{l}\text { "Adequar o edifício às } \\
\text { novas demandas relati- } \\
\text { vas ao uso original” } \\
\text { (Devecchi, 2010, p. 102) } \\
\text { "Intervenção que } \\
\text { consiste na restituição } \\
\text { do imóvel à sua } \\
\text { condição original” } \\
\text { (Vale, 2006, p. 131) } \\
\text { Trabalho de renovação } \\
\text { abrangente (para reparo } \\
\text { de todos os defeitos) } \\
\text { (Roders, 2007) } \\
\text { "Intervenção na } \\
\text { edificação que impli- } \\
\text { que alteração da área } \\
\text { construída ou da volu- } \\
\text { metria, com a simultâ- } \\
\text { nea manutenção de } \\
\text { parte ou de toda a área } \\
\text { existente, com ou sem } \\
\text { mudança de uso" } \\
\text { (SÃO PAULO, } \\
\text { 2015)Art. } 3 \text { - XXVI) }\end{array}$ & $\begin{array}{l}\text { Combina atividades das } \\
\text { escalas de intervenções } \\
\text { anteriores e posteriores; } \\
\text { restando o que for } \\
\text { possível, reduzindo } \\
\text { apenas o excedente e } \\
\text { adicionando simples- } \\
\text { mente o requerido, etc } \\
\text { (Roders, 2007) } \\
\text { “Ação que pode envolver } \\
\text { atividades de restauro, } \\
\text { manutenção, alteração, } \\
\text { retrofit, reparo ou reforma } \\
\text { visando dotar o edifício } \\
\text { de atributos econômicos } \\
\text { ou funcionais } \\
\text { equivalentes aos exigidos } \\
\text { a um edifício novo para o } \\
\text { mesmo fim” (Marques de } \\
\text { Jesus, 2008, p. 22) } \\
\text { “Ações com o objetivo de } \\
\text { recuperar e beneficiar } \\
\text { edificações, por meio de } \\
\text { mecanismos de atualiza- } \\
\text { ção tecnológica” (Vale, } \\
\text { 2006, p. 131) }\end{array}$ & $\begin{array}{l}\text { Reconstrução parcial ou } \\
\text { total do edifício, com base } \\
\text { nos resultados do } \\
\text { inventário (Roders, 2007) } \\
\text { Construção de novos } \\
\text { edifícios, reutilizando os } \\
\text { tecidos, infraestrutura e } \\
\text { serviços urbanos } \\
\text { existentes (Roders, 2007) } \\
\text { "Renovação total ou } \\
\text { parcial das edificações } \\
\text { desativadas ou destinadas } \\
\text { à reabilitação" (Vale, } \\
\text { 2006, p. 131) } \\
\text { “obra destinada à } \\
\text { recuperação e } \\
\text { recomposição de uma } \\
\text { edificação, motivada pela } \\
\text { ocorrência de incêndio ou } \\
\text { outro sinistro, mantendo- } \\
\text { se as características } \\
\text { anteriores” (SÃO PAULO } \\
\text { (MUNICÍPIO), 2015)Art. } \\
3^{\circ} \text { - XXIV) }\end{array}$ \\
\hline
\end{tabular}


a eficiência energética e redução de emissões de carbono. Entretanto, é também importante reconhecer que proprietários de imóveis são motivados a realizar o retrofit de suas casas para melhorar o conforto, conveniência e estética. De fato, do Vale (2006, p. 132) também observa que "retrofit arquitetônico vem a ser a busca pela sincronicidade do edifício com o tempo presente, de modo a vitalizá-lo com novos materiais e tecnologias, evitando que se torne obsoleto e permitindo que acompanhe o desenvolvimento tecnológico dos grandes centros urbanos".

Indo além do termo retrofit, no âmbito do edifício isolado, existe também o termo Rearchitecture ${ }^{\circledR}$, um sistema de apoio à metodologia de projeto, foi desenvolvido, testado e verificado com estudantes de arquitetura e arquitetos, quando envolvidos em intervenções de reabilitação. Trata-se de reabilitação do patrimônio construído, fruto de uma pesquisa de doutorado, fundado pela Fundação para a Ciência e Tecnologia de Portugal, e ambientado na Universidade de Tecnologia de Eindhoven (TU/e - Eindhoven University of Technology), durante o período de janeiro de 2004 a dezembro de 2007 (RODERS et al., 2007). Este trabalho apresenta uma extensa e interessante tabela com várias escalas de intervenção em um edifício, reproduzida no Quadro 2, a seguir.

Outro termo encontrado na pesquisa foi o SuRE - Fit, ou Sustainable Refurbishment of High-Rise Residential Buildings, que pode ser entendido como Reforma Sustentável de Edifícios Residenciais Elevados (W/E CONSULTANTS, 2007). O SuRE - Fit foca edifícios multifamiliares de 4 andares (térreo mais 4 pavimentos no máximo), como estudo de condições físicas, sociais e urbanas, tratando também a restruturação das áreas do entorno. $\mathrm{O}$ estudo englobou 25 países europeus, com foco em extensão de edifícios acima da sua cobertura (roof-top extension).

Ainda na escala do edifício, abordagens sustentáveis na prática de retrofit levam em consideração os novos padrões em termos de eficiência e desperdício energético. Edifícios antigos são dispendiosos especialmente do ponto de vista energético. Quando submetidos a projetos de renovação e restauração, o principal resultado é fazer estes edifícios sustentáveis e reduzir o consumo de energia. A necessidade de restaurar e renovar: retrofit é o desafio, promovendo o arcabouço histórico destas urbanizações, mas ao mesmo tempo dando uma interpretação contemporânea que adapta a era atual a partir de diferentes perspectivas (social, 
arquitetônica, econômica, etc). Mudança e continuidade dependem uma da outra (FERRANTE; SEMPRINI, 2011).

Quadro 2: Escalas de intervenção em um edifício. Fonte: Roders (2007)

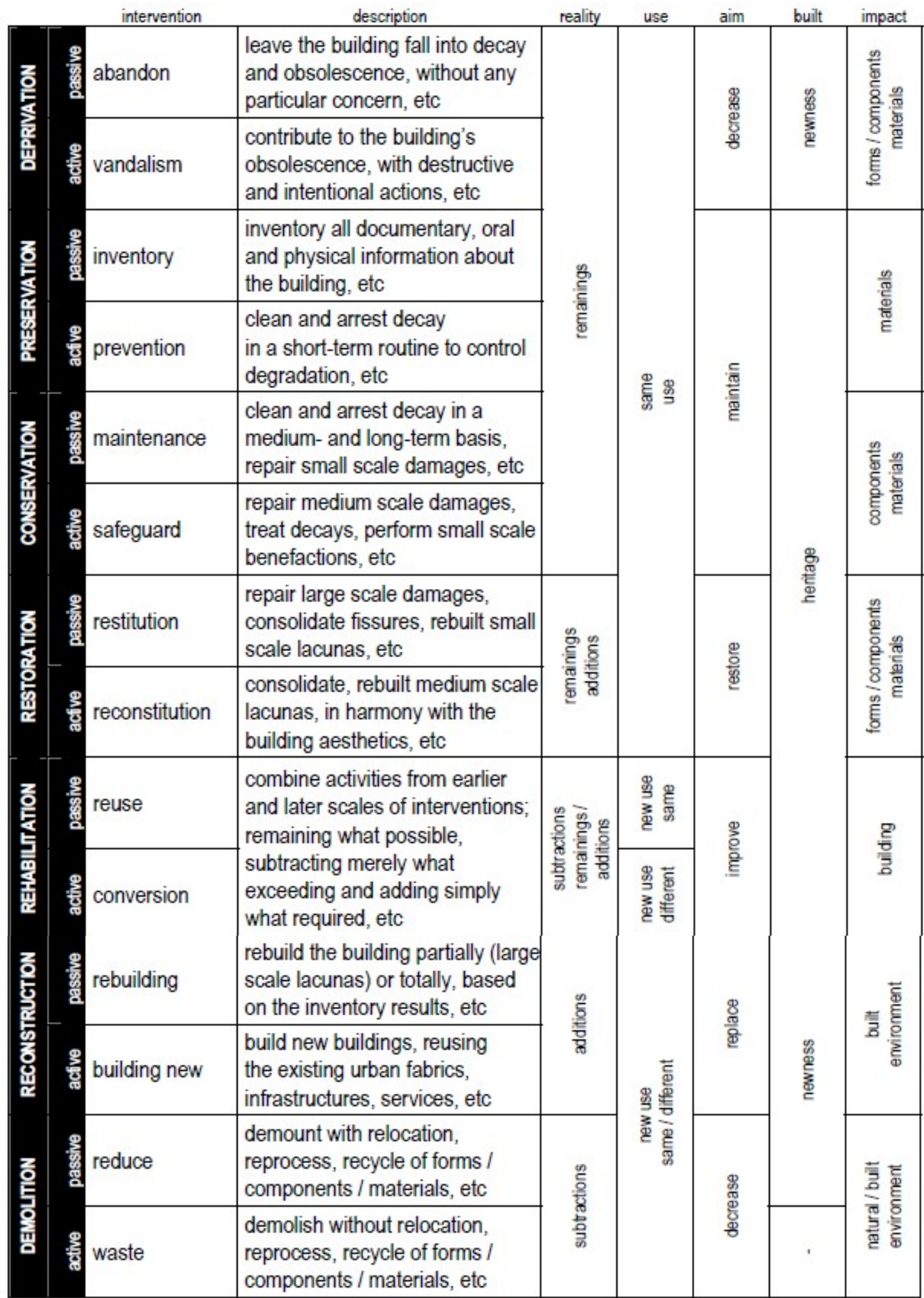


Percebe-se na revisão da literatura uma evolução no termo retrofit, no âmbito de edifícios, com o ganho de adjetivos, tais como:

- Retrofit Verde (Green Retrofit): adaptar um edifício existente visando melhorar a qualidade ambiental internamente e otimizar sua eficiência, com vistas a certificação como Edifício Verde (Green Building), conforme Lester (2013) e USGBC (2011). Um exemplo emblemático é o Empire State Building, em Nova Iorque, cujo retrofit viabilizou sua certificação no sistema LEED (Leadership in Energy and Environmental Design) na categoria Ouro. No Brasil, o Panorama Paulista Corporate, foi um dos primeiros edifícios a passar pelo processo de retrofit no país para também receber a certificação LEED Gold (GOMES, 2015).

- Retrofit tecnológico: adaptar o edifício a novos usos, visando "aumentar o valor arquitetônico e econômico de um edifício existente, ou mesmo restaurar o seu valor inicial", para tanto "deve incluir o tratamento da estrutura, da envoltória, dos espaços internos e dos sistemas prediais de uma maneira integrada" (GONÇALVES; DUARTE, 2006). Neste retrofit, podem ser integrados equipamentos de inteligência predial como sensores, comandos, detectores e termostatos, dentro de um sistema de automação predial.

- Retrofit em massa: do setor residencial, para reduzir consumo de energia e nível de emissões de carbono em linha com os padrões de sustentabilidade ambiental que são exigidos pelo governo (DEAKIN; CAMPBELL; REID, 2012).

Ferrante e Semprini (2011) trazem ainda o conceito de Balanço Zero de Energia (Zero Energy Balance - ZEB) em práticas de retrofit de edifícios, afirmando que a reabilitação energética do estoque de edifícios existentes, especialmente se é combinada com o aprimoramento abrangente dos espaços urbanos do entorno e integrada com componentes socioambientais e valores dos espaços públicos, é uma das maiores oportunidades de reduzir o consumo energético e, em um mesmo momento, melhorar a qualidade de vida nos contextos urbanos. $\mathrm{O}$ chamado retrofit energético abrange:

- reforço da proteção térmica das áreas opacas da envoltória;

- reforço das propriedades dos vãos envidraçados

- uso de sistemas solares passivos: utilização da capacidade de armazenamento térmico dos materiais, ventilação natural, sistemas de sombreamento, dispositivos de captação de luz natural, etc; 
- uso de sistemas solares ativos: solar térmico e solar fotovoltaico;

- melhoria da eficiência de equipamentos e redução da energia gasta em iluminação.

No âmbito do edifício isolado, o retrofit pode ainda ser classificado segundo o sistema a ser adaptado: envoltória, envelope, instalações, estrutura e fundações, e interiores (MASOTTI et al., 2011). Outra classificação para o retrofit apresentada por Masotti et al (2011) é segundo a finalidade: arquitetônico, térmico e energético, acústico, quanto a segurança contra incêndios, quanto a segurança patrimonial, funcional, estrutural ou sísmico.

O retrofit pode trazer o conforto, a segurança e a funcionalidade necessários para atender às normas atuais de construção e às expectativas dos usuários, ainda mantendo a viabilidade econômica do projeto, uma vez que é prevista valorização do imóvel pela melhoria dos seus sistemas, padrão de conforto e segurança (GOMES, 2015). De fato, reabilitar os edifícios existentes, ao invés de empreender construções novas, preserva o patrimônio natural e a estética da paisagem e proporciona um melhor aproveitamento do recurso econômico que é o parque já edificado (GONÇALVES; DUARTE, 2006).

Portanto, o retrofit, no âmbito do edifício isolado, consiste na modernização construtivoarquitetônica e pode, além de revitalizar fachadas e áreas internas das edificações, agregar modernas tecnologias, comumente agrupadas dentro do conceito de inteligência predial, integrando sistemas elétricos, de telecomunicações, hidráulicos, de segurança, conforto ambiental e climatização, e, principalmente, o uso racional da energia elétrica. Por isso, o retrofit se apresenta como um mercado estratégico, crescente e promissor, que além de melhorar o bem-estar e produtividade dos usuários, otimiza a utilização de recursos, reduzindo custos de operação e manutenção, e proporciona valorização imobiliária.

$\mathrm{Na}$ escala da cidade, por sua vez, o retrofit apresenta um escopo mais amplo e abrangente. O retrofit urbano pode ser visto como um sistema integrado de desafios de inovação, com ênfase em transições de múltiplas escalas, perspectivas integradoras de longo prazo em inovação, identificação de tecnologias sustentáveis e disruptivas para retrofit e entendimento do retrofit como um processo de mudança evolutivo, tanto social quanto técnico (DIXON; LANNON; EAMES, 2017). 
Um dos primeiros termos relativos a retrofit urbano que surgiu na revisão da literatura é o "urban upgrading", ou modernização urbana, que pode ser definido por melhorias físicas, sociais, econômicas, organizacionais e ambientais, desenvolvidas cooperativamente entre cidadãos, grupos comunitários, empresas e autoridades locais para garantir melhorias na qualidade de vida dos indivíduos. Mais especificamente, as metas principais de projetos de modernização são prover segurança na posse de terrenos em áreas informais e geralmente ilegais, e melhorar a infraestrutura básica e a prestação de serviços (WORLD BANK, 2004). Mais recentemente, o termo é mais empregado é "upgrading slums", no sentido de urbanização de favelas.

Na literatura, apresentam-se duas formas de definição do termo 'renovação urbana'. O convencional especifica a forma, ao passo que a abordagem moderna se refere ao processo. Com uma estrutura que associa várias disciplinas e conceitos chave, renovação urbana é um tipo de regeneração ou reurbanização, a demolição em massa de edifícios em locais designados seguida da construção de novos edifícios nestes mesmos locais (LAI; CHAU; CHEUNG, 2018). Carmon (1999) identifica três períodos históricos das políticas em renovação urbana. O primeiro período é caracterizado por demolições, com enfoque no ambiente construído, ao passo que o segundo tem uma abordagem mais abrangente, de reabilitação dos bairros, levando em conta problemas sociais. O terceiro e último período tem como característica a revitalização, especialmente dos centros das cidades, uma abordagem voltada ao mercado e com foco no desenvolvimento econômico. O termo reurbanização, por sua vez, compreende projetos que são mais extensos, prolongados e complexos, que envolvem os setores público e privado várias inter-relações (AMIRTAHMASEBI et al., 2016).

Entretanto, o retrofit urbano apresenta três etapas importantes que o caracterizam. Primeiramente, várias visões de futuro para a cidade podem ser elaboradas por meio de processos participativos. Uma segunda etapa compreende o comprometimento de diversos atores, o que pode proporcionar estratégias tangíveis para enfrentar as previsões do ambiente futuro e das mudanças socioeconômicas. Em terceiro lugar, o desenvolvimento de redes de especialistas pode trocar e disseminar conhecimento e resultados para vários atores e tomadores de decisão (EAMES et al., 2018). 
No ambiente urbano, apresenta-se ainda o termo 'urbanização adaptativa', que consiste no desenho, construção e constante evolução de áreas urbanas para antecipar e reagir às mudanças no ambiente e na sociedade. A urbanização adaptativa leva em conta estratégias e tecnologias que podem ser utilizadas para adaptar áreas urbanas a mudanças desafiadoras, que incluem tanto os processos internos quanto externos da cidade. Os quatro objetivos da urbanização adaptativa são (GRAAF, 2012):

- aumento da disponibilidade de território

- diminuição do risco de enchentes

- produção de energia, alimentos, água e nutrientes, ao invés de apenas consumir recursos e produzir resíduos

- impacto positivo em ecossistemas e criação de habitat ecológico

\subsection{Características do Retrofit Urbano}

Várias cidades ao redor do mundo vêm buscando, nas últimas décadas, a sustentabilidade urbana. Mais do que atender a uma agenda verde com as tendências anteriormente citadas, as cidades vêm passando por um processo constante de transformação, e historicamente foram sendo rotuladas com termos aceitos e consolidados pela sociedade.

Apesar do foco nos programas de inclusão digital, parcerias inovadoras e criativas propiciam aprendizado digital em áreas urbanizadas que, por sua vez, torna possíveis aplicações e serviços online que integram a transferência de conhecimento e de capacidade construtiva. Plataformas digitais permitem que os cidadãos, comunidades e organizações colaborarem e edifiquem competências e habilidades, identificando o treinamento necessário, na direção do desenvolvimento de serviços online requeridos para apoiar os programas de renovação urbana, para uma regeneração de vilas e bairros urbanos para se tornarem comunidades autossustentáveis (DEAKIN; AL WAER, 2011). A transição de cidades inteligentes, intelligent cities para smart cities, passa pelo desenvolvimento de programas para inclusão digital, conforme ilustra e detalha a Figura 8, a seguir. 


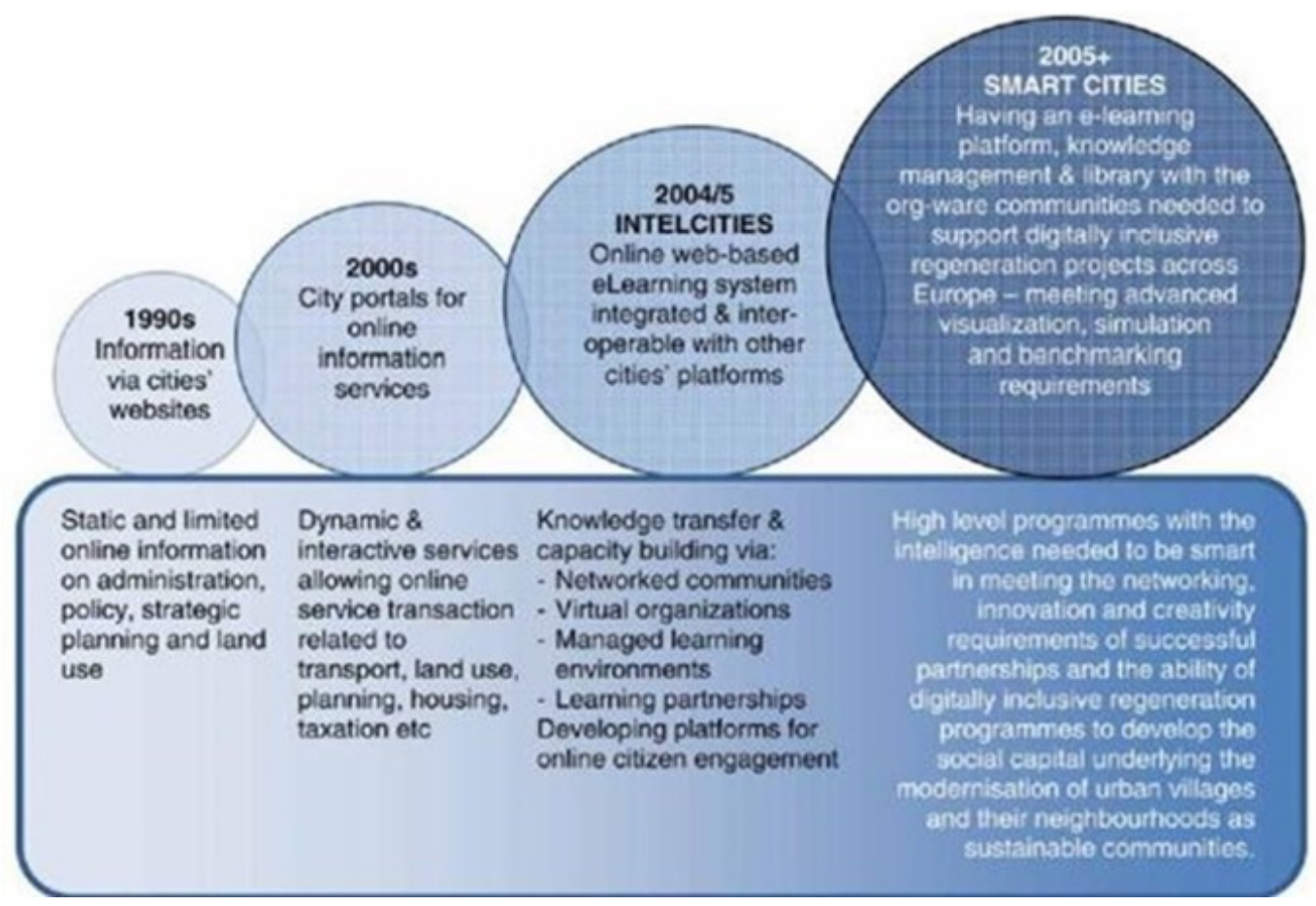

Figura 8: O desenvolvimento de programas para inclusão digital. Fonte: Deakin e Al Waer (2011)

A smart city também é citada no trabalho de Eames e Dixon (2013), que, por sua vez, analisam várias visões futuristas das cidades e seu respectivo grau de sustentabilidade urbana, conforme Figura 9, preconizando o que se tornaria o projeto Retrofit 2050, do Reino Unido, que consiste em estabelecer caminhos para a transição das cidades, da situação atual em direção às visões de longo prazo.

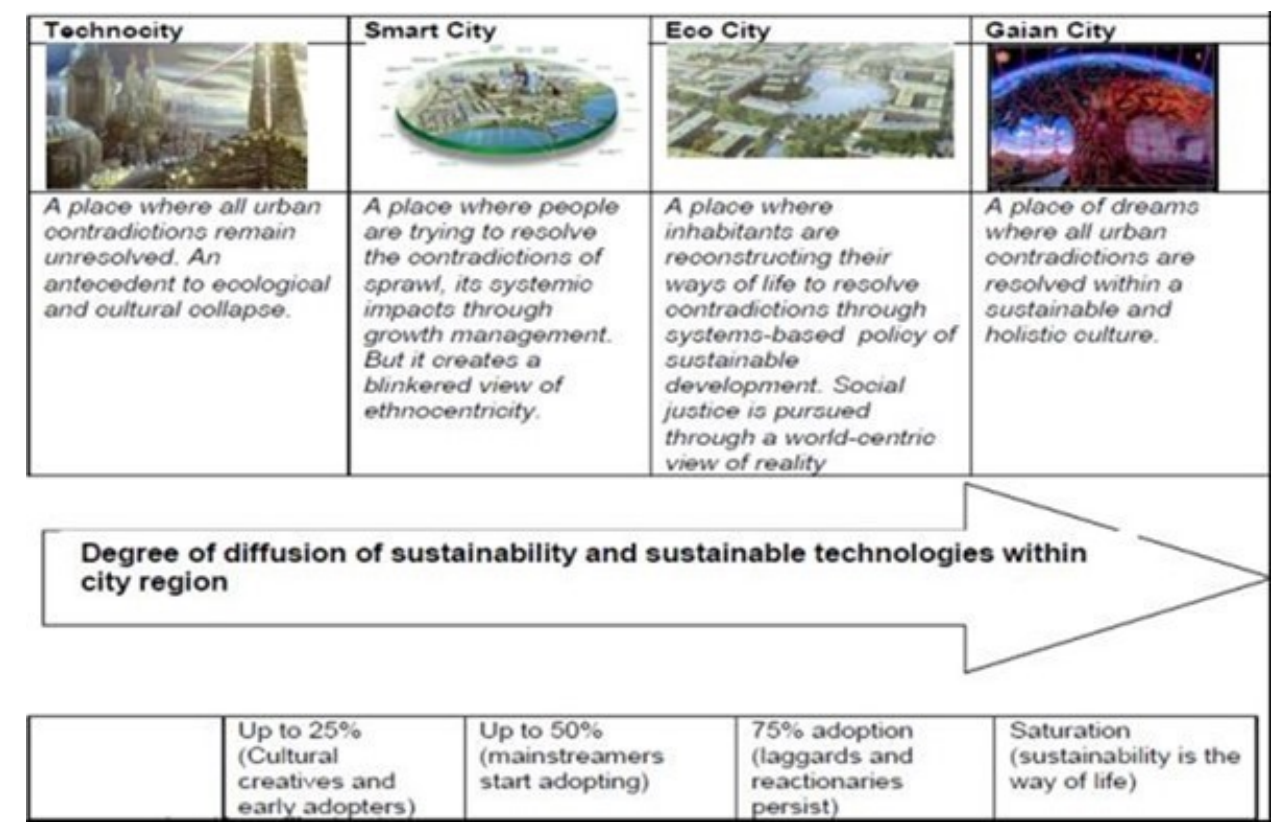

Figura 9: Cidades futuristas pós-modernas e sustentabilidade. Fonte: Eames e Dixon (2013) 
Eames et al (2013b) estabelecem e descrevem três visões de longo prazo, que tratam do futuro sustentável que deve figurar em importantes regiões urbanas do Reino Unido em 2050. Os cenários não são previsões: eles pretendem abrir o debate e informar escolhas atuais da sociedade, por meio da ilustração de uma série de possíveis futuros urbanos. Cada uma das visões representa uma articulação distinta de sustentabilidade urbana:

- Cidade de Redes Inteligentes (Smart-Networked City): prevê a cidade como um centro em que transita uma sociedade conectada, altamente móvel e globalmente competitiva, com as características de:

○ Maior crescimento econômico

- Maiores densidades urbanas e reurbanização dos subúrbios

○ TIC - Tecnologias de Informação e Comunicação pervasivas: monitoramento onipresente das informações e em tempo real

- Investimento de capital em sistemas de infraestrutura centralizados

- Difusão generalizada de integração de energias renováveis

- Descarbonização do transporte privado: prevalência de automóveis privados elétricos ou movidos a hidrogênio

- Mecanismos de mercado voltados a reciclagem e recuperação de recursos

- Melhor desempenho das fachadas dos edifícios existentes

○ Ampliação de "smart grids" e dispositivos para energia e água

- Retrofit da infraestrutura com novas tecnologias que serão integradas ao ambiente construído existente

- Cidade Compacta (Compact City): prevê a cidade como um lugar de vida urbana intensiva e eficiente, que apresenta:

- Crescimento econômico moderado, com forte governança local

- Maiores densidades urbanas

○ Uso misto dos bairros, aumento da infraestrutura da vizinhança

- Iniciativas de base local para captação de águas pluviais

- Reduzida necessidade de deslocamento

- Comprometimento social da comunidade no nível da vizinhança

- Redes de aquecimento e energia na escala da cidade e provenientes dos resíduos sólidos

- Ganhos de eficiência por meio de integração de sistemas

- Melhorias nas fachadas dos edifícios e micro geração distribuída 
- Predominância de deslocamentos a pé, de bicicleta e por transporte público

- Uso intensivo de espaços verdes, incluindo telhados e paredes verdes

- Cidade Verde Autossuficiente (Self Reliant-Green City): prevê a cidade como uma biorregião autossuficiente, vivendo em harmonia com a natureza, com as características de:

○ Menor crescimento econômico

○ Queda das densidades urbanas

- Cooperação e valores coletivos fundamentados em novos modelos de compartilhamento

○ Diminuição significativa do consume total de energia

○ Relocação da produção e consume

- Aumento da agricultura urbana

- Espaço verde e azul, biomassa e biodiversidade local são aproveitadas e integradas à cidade

- Cultura de reparar e improvisar, com foco em reuso e reciclagem

- Isolação e melhorias das fachadas dos edifícios utilizando materiais reciclados e locais

- Vasta gama de redes de energias renováveis distribuídas e compartilhadas pela comunidade: fotovoltaica, eólica, biomassa, solar

○ Predominância de deslocamentos a pé e de bicicleta

○ Corredores verdes substituindo os cinturões verdes

○ Elevado nível de diversidade e experimentação de soluções locais

Cada um destes futuros é alocado dentro de espaços possíveis descritos por duas dimensões chave do que Eames et al (2013b) denominam retrofit urbano sistêmico (Figura 10): (1) a mudança do uso da terra e da forma urbana e (2) valores e instituições sociais.

Ou seja, prevê-se uma evolução da Cidade de Redes Inteligentes para a Cidade Compacta que, por sua vez, seria a transição para a Cidade Verde Autossuficiente. Uma comparação das características e indicadores chave das três cidades das visões do Projeto Retrofit 2050 é ilustrada no Quadro 3. 


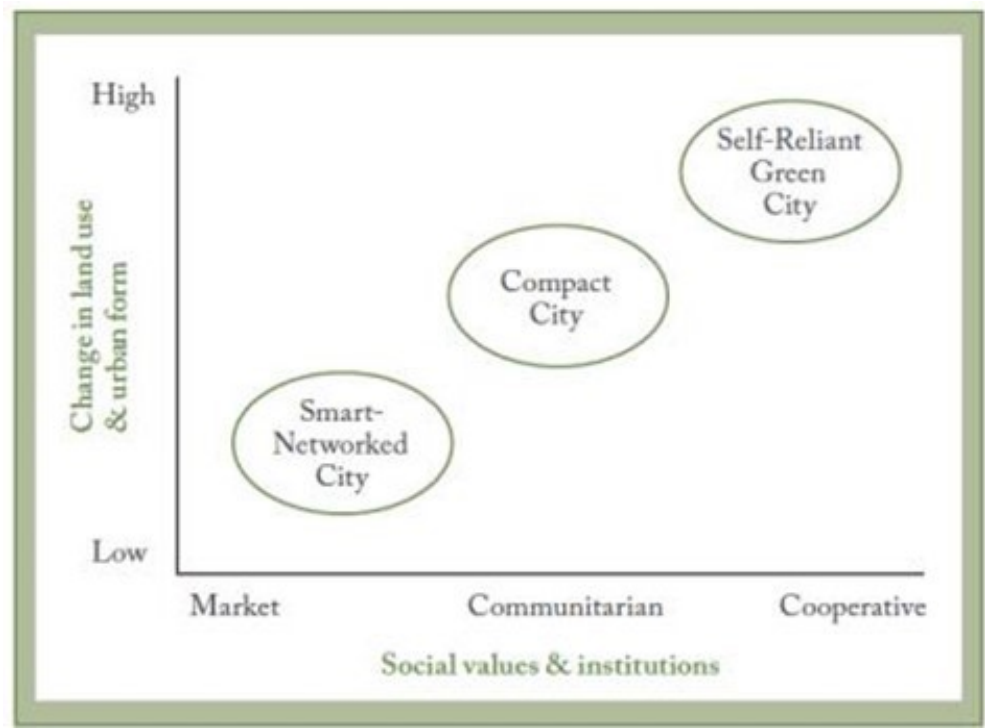

Figura 10: Localizando as visões para as cidades. Fonte: Eames et al (2013b)

Quadro 3: Características e indicadores chave das visões do Retrofit 2050. Fonte: Eames et al (2013b)

\begin{tabular}{|c|c|c|c|}
\hline & Smart-Networked City & Compact City & Self Reliant-Green City \\
\hline Change in land-use and urban form & Low-moderate & Moderate (densification) & High (extensification) \\
\hline Social Values $\&$ Institutions & $\begin{array}{l}\text { Market oriented values, with } \\
\text { emphasis on private consumption. } \\
\text { Light touch, networked } \\
\text { governance with public sector, } \\
\text { local authority and intermediary } \\
\text { organisations acting as facilitators } \\
\text { for business. }\end{array}$ & $\begin{array}{l}\text { Commanitarian and localist } \\
\text { values expressed at a city and } \\
\text { neighbourhood level, coupled } \\
\text { with strong local governance } \\
\text { and planning systems and an } \\
\text { emphasis on social investment. }\end{array}$ & $\begin{array}{l}\text { Coopenative and collectivist } \\
\text { values underpin new models } \\
\text { of participation and shared } \\
\text { ownership, in which mutualism } \\
\text { and local self-reliance are coupled } \\
\text { with strong concerns for social } \\
\text { equity and a questioning of } \\
\text { materialism. }\end{array}$ \\
\hline Economic Growth & $3.0 \% \mathrm{pa}$ & $2.3 \% \mathrm{pa}$ & $4.616 \mathrm{pa}$ \\
\hline UK Population by 2050 & 86.4 million & 76.4 million & 66.8 million \\
\hline $\begin{array}{l}\text { Urban Density (2050) } \\
\text { (assuming a large city) }\end{array}$ & $\begin{array}{l}\text { No significant change } \\
40 \text { dwellings per ha } \\
\text { (or } 160 \text { people/ha) }\end{array}$ & $\begin{array}{l}\text { Dense } \\
70 \text { dwellings per ha } \\
\text { (or } 275 \text { people/ha) }\end{array}$ & $\begin{array}{l}\text { Less dense } \\
30 \text { dwellings per ha } \\
\text { (or } 120 \text { people/ha) }\end{array}$ \\
\hline
\end{tabular}

Sobre cidades compactas, em contraponto, Neuman (2005) afirma que há uma "falácia da cidade compacta", e sustenta que a expansão compacta não é uma condição necessária e suficiente para uma cidade ser sustentável, e que a tentativa de tornar cidades mais sustentáveis somente por uso de estratégias de forma urbana é contraproducente. Ao invés disso, conceber forma urbana como resultado de um processo de urbanização abre uma concepção nova e dinâmica de planejamento urbano baseado em uma inversão do foco do século passado, regido por ferramentas estáticas de planejamento e zoneamento. Medidas de sustentabilidade e indicadores podem ser aplicados a inúmeros fatores adicionalmente ao ambiente construído: ecológicos, sociais, econômicos, civis, fiscais e de infraestrutura. Se 
pontos de vista emergentes e convergentes de sustentabilidade sugerem que a cidade é um processo coevolutivo, então a ideia e o ideal de que a cidade sustentável é viável vale o esforço (NEUMAN, 2005).

Newton (2013), em seu trabalho sobre a renovação dos subúrbios australianos, também apresenta uma evolução das cidades em três horizontes, divididos em temas ambientais urbanos que trariam inovações cada vez mais sustentáveis ao longo da transição da área urbana da situação atual para a pretendida no futuro, conforme detalhado no Quadro 4.

Quadro 4: Três horizontes de inovação urbana. Fonte: Newton (2013)

\begin{tabular}{|c|c|c|c|}
\hline \multirow{2}{*}{$\begin{array}{l}\text { Urban } \\
\text { environmental } \\
\text { domain }\end{array}$} & \multicolumn{3}{|c|}{ Level of innovation } \\
\hline & Horizon 1 & Horizon 2 & Horizon 3 \\
\hline Energy & $\begin{array}{l}\text { Energy efficiencies in housing and } \\
\text { industry; dwelling energy rating; } \\
\text { appliance rating; methane bridge } \\
\text { (substitution of gas for coal) }\end{array}$ & $\begin{array}{l}\text { Distributed, renewable and low- } \\
\text { emission energy-generation } \\
\text { systems }\end{array}$ & $\begin{array}{l}\text { Renewables-based solar- } \\
\text { hydrogen or solar-electric } \\
\text { economy }\end{array}$ \\
\hline Water & $\begin{array}{l}\text { Water-smart appliances; domestic } \\
\text { rainwater tanks; desalination }\end{array}$ & $\begin{array}{l}\text { Sewer mining; water-sensitive } \\
\text { urban design }\end{array}$ & $\begin{array}{l}\text { Integrated urban water systems } \\
\text { (recycled storm water and } \\
\text { waste water) }\end{array}$ \\
\hline Waste & $\begin{array}{l}\text { Product stewardship, waste separation } \\
\text { and recycling; domestic composting }\end{array}$ & $\begin{array}{l}\text { Extensive cradle-to-cradle } \\
\text { manufacturing based around } \\
\text { single enterprises, e.g. motor } \\
\text { vehicles, computers, building } \\
\text { products }\end{array}$ & $\begin{array}{l}\text { Eco-industrial clusters based on } \\
\text { the utilization of multiple waste } \\
\text { streams }\end{array}$ \\
\hline Buildings & $\begin{array}{l}\text { Checkbox system for green building } \\
\text { design; tall buildings }\end{array}$ & $\begin{array}{l}\text { Real-time Iffecycle sustainability } \\
\text { performance assessment during } \\
\text { design; building information } \\
\text { models; hybrid buildings }\end{array}$ & $\begin{array}{l}\text { Ultra-smart buildings and linked } \\
\text { infrastructures; green building } \\
\text { materials with embedded } \\
\text { sensors and intelligence }\end{array}$ \\
\hline
\end{tabular}

Estas visões de futuro e transições intermediárias são passíveis de serem alcançadas por meio de retrofit urbano, segundo seus autores e idealizadores.

Na escala da cidade, e com base no guia do Living Cities (2010) pode-se argumentar que o termo retrofit é diferenciado daqueles voltados ao edifício uma vez que as características que definem retrofit urbano são:

1. Seu caráter abrangente e de larga escala;

2. Sua natureza integrada, exigindo um alto grau de acordos de parceria públicaprivada;

3. O caráter sustentável de suas finanças; 
4. Uma estratégia sistemática para comprometimento e favorecimento da população de baixa renda; e

5. Um conjunto de metas e medidas claramente definido para monitoramento

Newton (2013) afirma que regeneração, renovação, reurbanização, reconstrução, restauração e retrofit urbano são todos termos que têm sido utilizados de uma forma intercambiável na literatura para descrever processos que objetivam a revitalização do ambiente construído existente, de comunidades e economias locais. Elas sumarizam as múltiplas dimensões representadas na revitalização urbana, incluindo: escopo, posse e governança.

Portanto, o termo "retrofit urbano", à luz da revisão da literatura, pode ser entendido como um conjunto de intervenções urbanas com vistas não somente à adequação da área urbana para atingir a sustentabilidade no momento presente, frente a problemas e demandas atuais, mas vislumbra a adequação para população e demandas futuras, em cenários de longo prazo. Geralmente envolve áreas antigas, envoltórias de estações de transporte público, áreas industriais, isto é, áreas ambientalmente frágeis que foram ou são esvaziadas populacionalmente. Abrange ampla série de temas relacionados à sustentabilidade urbana, tais como: habitação, energia, água, resíduos, caminhabilidade (walkability), edificações e construções existentes.

Dixon e Eames (2013) adotam ainda a definição do termo "retrofit urbano sustentável", que consiste em: alteração dirigida do tecido, forma ou sistemas que constituem o ambiente construído na intenção de melhorar a eficiência energética, de água e de resíduos (DIXON; EAMES, 2013). Retrofit envolve a modificação do que já existe nas cidades: alterar os meios pelos quais os edifícios existentes são aquecidos e resfriados, direcionando cidadãos, empresas e organizações ao uso de fontes renováveis de energia ao invés de combustíveis fósseis, encorajando o uso de equipamentos energeticamente eficientes, alterando a infraestrutura urbana de energia e transporte na direção de fontes renováveis. Assim, promover uma política de ordenamento sustentável do território, contrariar a expansão urbana dispersa, fruto de incorretas políticas e de inadequadas formas de criação de receitas municipais, contabilizando as externalidades econômicas e ambientais resultantes, principalmente em termos de transporte, pela indução ao uso de transporte individual, 
degradação e ineficiência do transporte coletivo, alterações do uso do solo e degradação dos centros históricos, conferindo prioridade a reabilitação dos espaços existentes. Desta forma, retrofit é um desafio tanto social quanto tecnológico (DOWLING; MCGUIRK; BULKELEY, 2014).

Nas cidades da América Latina, observa-se que o território vem sendo utilizado de maneira pouco eficiente, em especial no que diz respeito às áreas urbanas mais centrais, incluindo regiões de antiga industrialização, áreas degradadas em função do seu uso anterior e áreas de infraestrutura como ferrovias, portos e pátios. Estas áreas contaminadas, ou brownfields, apresentam bom potencial de revitalização e reintegração ao ciclo econômico, podendo contribuir para contrabalançar a decadência social de alguns centros urbanos, para melhorar ou recuperar as funções do solo e das águas subterrâneas, e ainda abrigar usos sociais urgentemente necessitados nos centros urbanos, como parques, habitação social, praças públicas, entre outros. Uma vez que o espaço livre está cada vez mais escasso, a revitalização de brownfields é apenas um aspecto no desenvolvimento urbano sustentável, mas representa um desafio especial, porque os brownfields podem apresentar potencial de contaminação causada pela atividade anterior realizada em seu território (MARKER, 2013).

Gonçalves e Duarte (2006) argumentam a favor do retrofit urbano pois pode trazer vida e fazer a cidade contemporânea respirar, não só para habitação, como para outras funções: escritórios, parques ou instalações esportivas podem ser construídas nas coberturas. De fato, expandir as cidades em direção a ocupar terrenos naturais e áreas verdes (greenfields), onde maximizam-se os impactos ambientais e ecológicos e infraestrutura urbana tem de ser construída, parece uma alternativa pouco sustentável frente a elaborar áreas urbanas de diferentes configurações e usos com vistas a ocupação de áreas degradadas e desvalorizadas (brownfields). Em um período de crise econômica, ao invés de pensar em planos de urbanização de grande expansão, é mais sábio sugerir operações de retrofit urbano concebidas como eventos pontuais de um plano de longo prazo, pois elas têm o potencial para gerar novos processos similares na escala urbana (Ferrante e Semprini, 2011). Ainda segundo Gonçalves e Duarte (2006), demolir e reconstruir cidades não é uma opção muito realista e abandonar a cidade ou partes dela não é uma opção desejável. 
Por fim, como característica do retrofit urbano, há uma grande necessidade de elaboração de ferramentas de simulação e de sistemas de indicadores de sustentabilidade urbana para avaliar futuras políticas de desenvolvimento (MAOH; KANAROGLOU, 2009). Algumas pesquisas em retrofit urbano analisadas na revisão da literatura apresentam métodos e modelos para simulação da transição da situação atual para a situação no cenário futuro, tais como as listadas no Quadro 5, a seguir.

Quadro 5: Modelos de simulação utilizados em Retrofit Urbano

\begin{tabular}{|c|c|c|}
\hline \multicolumn{2}{|c|}{ Modelo } & Características \\
\hline $\begin{array}{l}\text { DECoRuM - } \\
\text { Domestic Energy, } \\
\text { Carbon Counting } \\
\text { and Carbon } \\
\text { Reduction Model }\end{array}$ & $\begin{array}{l}\text { Modelo de } \\
\text { Energia } \\
\text { Doméstica, } \\
\text { Contagem de } \\
\text { Carbono e } \\
\text { Redução de } \\
\text { Carbono }\end{array}$ & $\begin{array}{l}\text { Ferramenta baseada em SIG (Sistema de Informações Geográficas) para } \\
\text { planejamento de redução de emissões de carbono com a capacidade de } \\
\text { estimar a atual energia relacionada a emissões de } \mathrm{CO}_{2} \text { e testar a } \\
\text { efetividade de várias estratégias de adaptação e mitigação em domicílios } \\
\text { existentes (WILLIAMS et al., 2013) }\end{array}$ \\
\hline $\begin{array}{l}\text { TURN - } \\
\text { Technologies and } \\
\text { Urban Resource } \\
\text { Networks }\end{array}$ & $\begin{array}{l}\text { Tecnologias e } \\
\text { Redes de } \\
\text { Recursos } \\
\text { Urbanos }\end{array}$ & $\begin{array}{l}\text { Seu objetivo é criar um plano de estratégia energética para uma área } \\
\text { urbana, levando em conta variações espaciais e temporais na demanda } \\
\text { por energia. Como dado de entrada, usuários especificam demandas de } \\
\text { energia elétrica, variando espaço e tempo, assim como as tecnologias de } \\
\text { suprimento de energia e combustíveis disponíveis. Assuntos } \\
\text { relacionados, tais como da população ou do crescimento econômico na } \\
\text { demanda por energia, devem ser modelados separadamente e estes } \\
\text { resultados são importados para o modelo TURN. A princípio a dimensão } \\
\text { tempo tem sido para dois períodos, representados por exemplo como } \\
\text { média / pico de demanda, ou verão / inverno, mas a versão atual também } \\
\text { questiona qual é a melhor estratégia energética para um horizonte } \\
\text { planejado para várias décadas (KEIRSTEAD; CALDERON, 2012) }\end{array}$ \\
\hline VantagePoint & $\begin{array}{l}\text { Posição de } \\
\text { Vantagem }\end{array}$ & $\begin{array}{l}\text { Ferramenta utilizada em vários estágios do ciclo político, preferida por } \\
\text { vários conselhos da região nordeste da Inglaterra, desenhada para } \\
\text { auxiliar autoridades locais a desenvolver estratégias de mitigação. Os } \\
\text { usuários selecionam a partir de uma série de intervenções (incluindo } \\
\text { medidas de eficiência energética, tecnologias de baixa emissão de } \\
\text { carbono, mudanças comportamentais, medidas relativas ao transporte, e } \\
\text { matriz energética mais verde) e interagem desenvolvendo associações } \\
\text { tecnológicas que vão de encontro a uma meta específica de emissões de } \\
\text { carbono. O cenário é então ajustado, refinando-se as prioridades para } \\
\text { medidas de implementação, e o resultado é um plano de ação para a } \\
\text { autoridade local (KEIRSTEAD; CALDERON, 2012) }\end{array}$ \\
\hline $\begin{array}{l}\text { Urban Futures } \\
\text { Interactive Tool }\end{array}$ & $\begin{array}{c}\text { Ferramenta } \\
\text { Interativa } \\
\text { Futuros Urbanos }\end{array}$ & $\begin{array}{l}\text { Foi desenvolvida em Maio de } 2008 \text { pelo Conselho de Pesquisa em } \\
\text { Engenharia e Ciências Físicas (Engineering and Physical Sciences } \\
\text { Research Council), liderado pelo Prof. Chris Rogers da Universidade de } \\
\text { Birmingham (University of Birmingham) Fonte: http://www.urban- } \\
\text { futures.org/ }\end{array}$ \\
\hline $\begin{array}{l}\text { ITLUMs- } \\
\text { Integrated } \\
\text { Transportation } \\
\text { and Land Use } \\
\text { Models }\end{array}$ & $\begin{array}{l}\text { Modelos de } \\
\text { Integração de } \\
\text { Transporte e } \\
\text { Uso do Solo }\end{array}$ & $\begin{array}{l}\text { Há ao menos } 20 \text { modelos urbanos operacionais desenvolvidos por várias } \\
\text { cidades ao redor do mundo. Foi criado no Canadá o Módulo SUSTAIN, } \\
\text { para avaliar sustentabilidade de cidades (MAOH; KANAROGLOU, } \\
\text { 2009). }\end{array}$ \\
\hline
\end{tabular}

Elaborado pela autora 


\subsection{Benefícios do Retrofit Urbano}

Segundo o CBCS - Conselho Brasileiro de Construção Sustentável e a AsBEA Associação Brasileira dos Escritórios de Arquitetura, a prática de retrofit pode ser promovida como ferramenta para a sustentabilidade na construção civil, proporcionando benefícios ambientais e sociais aos usuários, empreendedores, a cidade e à sociedade (CBCS; ASBEA, 2013). A requalificação de edificações e espaços urbanos traz diversos benefícios e agrega sustentabilidade, em suas três dimensões fundamentais:

- Ambiental: por meio da diminuição da demanda por recursos e, portanto, da pressão sobre os recursos naturais

- Econômica: com potencial incremento por valorização imobiliária do entorno, viabilização financeira de obras que devem aumentar o valor agregado de espaços antes subutilizados ou degradados, e o incremento da vida útil

- Social: com a melhora da qualidade de vida daqueles que utilizam ou vivenciam tais espaços.

Gonçalves e Duarte (2006) resumem os seguintes benefícios do retrofit urbano na busca pela sustentabilidade:

- preservação e liberação de áreas naturais pelos efeitos e vantagens da compacidade urbana;

- proximidade, diversidade e uso misto (socialização do espaço público);

- maior eficiência energética (e menor poluição) pelo sistema de transporte;

- microclimas urbanos mais favoráveis ao uso do espaço público e ao desempenho ambiental das construções;

- reuso e reciclagem (diminuição do impacto ambiental proveniente da geração de resíduos em geral).

Novotny (2013) ainda traz exemplos dos benefícios tangíveis da gestão integrada de recursos das Cidades do Futuro (Cities of the Future), convém que uma visão futurista inclua:

- Aumento do valor das moradias e receitas para a comunidade

- Valor da eletricidade e aquecimento produzidos ou recuperados, para venda do excedente para a rede regional ou municipal

- Venda de biogás e hidrogênio para companhias de transporte 
- Economia de combustível

- Valor econômico dos negócios e emprego em estabelecimentos comerciais

- Efeitos econômicos da restauração urbana

- Vendas de fertilizantes recuperados e oportunidade de benefício em redução de emissões de gases de efeito estufa pelo não uso de fertilizantes industriais

- Economia pela diminuição de demanda de água

- Economia pela eliminação de galerias de águas pluviais (por conta de medidas para diminuição do escoamento superficial, tais como: telhados verdes, pavimentos permeáveis, maior área verde, etc) e taxas de aluguel obtidas pelo uso da capacidade excedente das canalizações enterradas por outras utilidades (telefone e cabos, como praticado em Tóquio, por exemplo)

- Taxas para processamento de resíduos orgânicos e economia pela eliminação das taxas de transporte para aterros

- Taxas pela água recuperada (por exemplo, para irrigação de jardins)

A regeneração de área urbana pouco utilizada contribui para a criação de comunidades sustentáveis nas cidades. Estas comunidades são bem-sucedidas por conta da sustentabilidade ambiental, resiliência a desastres naturais, inclusão e competitividade. Ambientalmente, os processos de regeneração podem acelerar a recuperação de terrenos e corpos d'água poluídos (AMIRTAHMASEBI et al., 2016).

\subsection{Objetivos do Retrofit Urbano}

É de suma importância reconhecer o papel estratégico da gestão, do planejamento e do desenho urbano na abordagem das questões ambientais, sociais, econômicas, culturais e da saúde, para benefício de todos. O planejamento urbano deve englobar os objetivos de (REDE NOSSA SÃO PAULO, 2012):

- Reutilizar e regenerar áreas abandonadas ou socialmente degradadas;

- Evitar a expansão urbana no território, dando prioridade ao adensamento e desenvolvimento urbano no interior dos espaços construídos, com a recuperação dos ambientes urbanos degradados, assegurando densidades urbanas apropriadas; 
- Assegurar a compatibilidade de usos do solo nas áreas urbanas, oferecendo adequado equilíbrio entre empregos, transportes, habitação e equipamentos socioculturais e esportivos, dando prioridade ao adensamento residencial nos centros das cidades;

- Assegurar uma adequada conservação, renovação e utilização/reutilização do patrimônio cultural urbano;

- Adotar critérios de desenho urbano e de construção sustentáveis, respeitando e considerando os recursos e fenômenos naturais no planejamento.

Responder aos desafios de larga escala do retrofit urbano de uma forma objetiva e dirigida também requer cidades que reúnam quatro importantes questões, conforme Eames et al (2013a), as quais são frequentemente tratadas de maneira desconectada:

1. O que será feito para a cidade? (por exemplo: conhecimento técnico, metas, opções tecnológicas, custos); Newton (2013) também cita: projeto de melhorias e processos inovadores construtivos e industriais.

2. Quem está envolvido neste processo? (por exemplo: redes e atores chave) Newton (2013) também cita: planejadores, financiadores e comunidade local.

3. Por que é importante? (por exemplo: expectativas e funções individuais, organizacionais e culturais); e

4. Como será implementado? (por exemplo: instituições, capacidade, público e governança).

Newton (2013) apresenta, em sua pesquisa sobre os subúrbios australianos, dois caminhos para a regeneração urbana, ambos essenciais para a transição para cidades mais sustentáveis e resilientes:

- Inovação em planejamento e projeto urbanos, capazes de produzir cidades mais compactas por meio da restrição à urbanização em áreas verdes e encorajando a urbanização mais intensiva em tradicionais subúrbios já estabelecidos, de baixa densidade.

- Inovação tecnológica em infraestruturas urbanas chave - capacitando cidades a realizarem substituições transformadoras e regenerativas onde os sistemas existentes começam a mostrar sinais de falência. 
Gonçalves e Duarte (2006) resumem os principais objetivos de planos de retrofit urbano como:

- ocupar áreas degradadas inseridas na cidade, otimizando o uso da infraestrutura disponível com base em parâmetros de densidade e uso misto;

- conectar áreas da cidade, superando os obstáculos físicos existentes;

- melhorar a qualidade ambiental da área como um todo;

- otimizar o consumo de energia nos edifícios e na cidade; e

- aumentar o valor ambiental e socioeconômico de uma área existente, ou restaurar o seu valor inicial.

\subsection{Temas-chave do Retrofit Urbano}

Os três temas principais do retrofit urbano englobam (EAMES et al., 2018):

- Governança e dinâmica: desenvolvimento de estruturas metropolitanas mais amplas para as intervenções de retrofit, incluindo o setor de investimento privado, parcerias, relacionamentos com a comunidade local, terceiro setor, entre outros

- Modelagem da transição urbana: ferramentas e princípios para orientar os tomadores de decisão, políticos e demais atores, de maneira mais integrada e abrangendo não só mudanças mensuráveis, mais também a natureza espacial e temporal das transformações urbanas

- Gestão de transformações urbanas sustentáveis: ênfase no desenvolvimento e implementação de políticas e ferramentas orientadas a governança, e estruturas institucionais mais abrangentes, de forma a lidar com as complexidades e incertezas, participação e inclusão, aprendizado e avaliação integrados, desafios e oportunidades

O AILA - Australian Institute of Landscape Architects, ou Instituto Australiano de Arquitetos Paisagistas, cita a agenda australiana para retrofit urbano, pontuando temas tais como: uso de recursos e eficiência, nas escalas local e urbana, incluindo água, energia, saúde, habitação e transporte. A atual falta de integração entre planejamento e gerenciamento, ao longo de setores relacionados aos recursos e ao projeto, aumenta as ineficiências e o potencial 
para resultados distorcidos das estratégias de adaptação climática e sustentabilidade (AILA, 2010).

A identidade da comunidade e o senso de lugar devem ser levados em conta (AILA, 2010), ou seja, será necessário adaptar a forma urbana existente, ao invés de reconstruir do início, para acomodar efetivamente futuros impactos das mudanças climáticas e demográficas. Isso irá requerer respostas sensíveis e sofisticadas para adensamento e retrofit urbanos equilibrando entendimento e expressão dos processos naturais e culturais - na intenção de proteger, melhorar e regenerar as características mais valiosas pelos atuais indivíduos e comunidades, assim como para futuras gerações.

Setores de negócios e investimentos necessitarão olhar em direção à gestão da corrente sustentabilidade econômica - em particular, propostas para adensamento e reurbanização deverão contribuir para o surgimento de caminhos alternativos para economias "verdes" e/ou "limpas", baseadas em equilíbrio dos fatores de resiliência social, econômica e ambiental.

\subsection{Diretrizes para Retrofit Sustentável de Ambientes Urbanos}

Segundo AILA (2010), propostas de adensamento e renovação urbana devem:

1. Responder aos desafios significativos de prover habitação, recreação e oportunidades de emprego apropriadas em uma séria de escalas para uma população crescente, em equilíbrio com a capacidade de suporte ambiental.

2. Reconhecer que os desafios de projeto para assentamentos urbanos estão consubstancialmente ligados a desafios da sustentabilidade ampla (nacional) incluindo os impactos das mudanças climáticas, degradação ambiental, crescimento populacional e desenvolvimento econômico.

3. Ser guiadas por sistemas adaptáveis, baseados em desempenho, com planejamento integrado por escalas do distrito, bairro ou metrópole, para suportar, articular e promover valores e aspirações da comunidade.

4. Promover proativamente a saúde, segurança e bem-estar da comunidade, assim como amplamente a saúde do ambiente natural, para gerações atuais e futuras. 
5. Promover conexões entre indivíduos e comunidades para expandir oportunidades para interação social positiva e reforçar a identidade social e o orgulho cívico, encorajar inclusão social e melhorar a saúde pública e a resiliência da comunidade.

6. Reconhecer a função do planejamento integrado ao projeto de paisagens e edifícios como um mecanismo chave para atingir soluções em retrofit urbano de resposta mais rápida, mais socialmente justas e mais acessíveis.

7. Demonstrar compromisso mensurável para excelência de projeto e inovação.

8. Demonstrar compromisso em melhorar o gerenciamento de paisagens urbanas na intenção de revelar, promover e regenerar o valor do dos serviços do ecossistema ao longo de ampla série de escalas da paisagem.

9. Incorporar estratégias de planejamento e projeto integrados, colaborativos e inclusivos, em escalas espaciais relevantes.

10. Incorporar processos para estabelecer melhores práticas, metas de desempenho e monitorar e avaliar o progresso em relação a todos os itens acima.

Enfim, ao final do último milênio, especialistas perceberam que, se a urbanização continuar como atualmente, então a pressão aos recursos e a demanda de água e o uso de energia associado serão insustentáveis. Uma mudança de paradigma é observada para novos edifícios e retrofit de comunidades de importância histórica, em um esforço a reduzir o consumo de recursos limitados e a poluição.

Segundo Ryan (2013), o desafio do retrofit se tornou um tema recorrente, conselhos reportam muitos casos onde o desenvolvimento e a implementação de retrofit urbano objetivaram o direcionamento para os desafios das mudanças climáticas - reduzindo consumo de energia e emissões de carbono, alterando o meio de transporte de automóvel para a bicicleta ou caminhada, aumentando a densidade de moradias, reciclando a água, introduzindo aquecimento solar, apoiando produção urbana de comida, entre outros - encontrou significativo retorno por parte dos moradores e instituições.

Regimes sociais, o mercado conceitual e a experiência de vida da urbanização influenciam diretamente na forma de percepção individual, coletiva e institucional do que é admissível, desejável e possível. O processo de projeto e visualização coletivo de novos futuros com resiliência requer que estas visões sejam suficientemente discutidas e possam 
finalmente ser aceitas como possíveis e plausíveis. Não é necessário prover um futuro potencial detalhado, modelado e testado para motivar o interesse em trajetórias novas e inovadoras. Entretanto, torna-se claro que a credibilidade de futuros planejados é significativamente melhor percebida se puderem ser identificados nichos de urbanização espaços de encubação de inovações - que consolidariam um possível ponto de partida para uma trajetória de urbanização na direção do futuro concebido (Ryan, 2013).

\subsection{Casos e Exemplos de Retrofit Urbano}

Entendendo o termo retrofit urbano como um conjunto de intervenções urbanas com vistas não somente à adequação da área urbana para atingir a sustentabilidade no momento presente, frente a problemas e demandas atuais, mas vislumbrando a adequação para população e demandas futuras, em cenários de longo prazo, vários são os exemplos internacionais e nacionais que podem ser citados como retrofit urbano.

Em revitalização urbana, existem três escalas urbanas diferentes e, portanto, três níveis distintos de gerenciamento: portfólio, programas e projetos. O portfólio é mais abrangente e engloba os programas, que, por sua vez, abarcam os projetos. Cada nível de gerenciamento demanda habilidades interpessoais próprias e interdependentes, isto é, o resultado do gerenciamento de projeto depende, mas não somente, de um bom desempenho do

gerenciamento do programa, que também está vinculado a um bom desempenho do gerenciamento de todo o portfólio (MARCHESIN, 2015).

Alguns projetos de retrofit urbano são mais abrangentes no espaço, compreendendo a cidade como um todo; outros são mais holísticos, pois além de se estenderem a toda a área urbana, integram vários aspectos e dimensões da sustentabilidade. Porém, podem ser observados exemplos de retrofit urbano mais pontuais, limitados a áreas dentro da cidade, geralmente vazios urbanos ou espaços degradados que sofrem intervenções para se reintegrar ao entorno urbano. Estes vários tipos de projeto de retrofit urbano são descritos a seguir, agrupados por internacionais ou nacionais, abrangentes ou pontuais. 


\section{1) Casos internacionais, de caráter mais abrangente}

\section{Projeto 2050 - Reino Unido}

O Projeto Retrofit 2050 ocorreu entre outubro de 2011 e outubro de 2014, com o objetivo de proporcionar um salto qualitativo no entendimento de processos de transição em direção a sustentabilidade do ambiente construído nas cidades do Reino

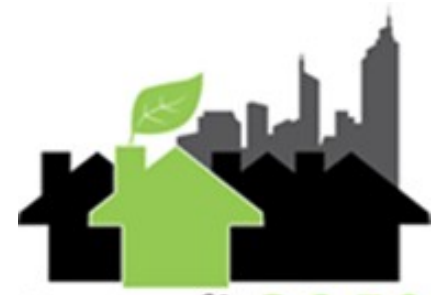

Retrofit Unido, procurando desenvolver várias percepções que permitam políticas de mudança nas cidades no sentido de utilizar energia e outros recursos de maneiras mais sustentáveis.

O projeto compreende cinco conjuntos de trabalho distintos, mas interligados:

- Análise de transição, que diz respeito ao entendimento teórico e prático das transições para sustentabilidade no ambiente construído, assim como o retrofit é praticado em estudo de caso nas regiões da Grande Manchester e Sudeste do País de Gales, ambas no presente e no futuro

- Laboratório de previsões, explorando as inovações tecnológicas e sociais que fundamentam a transição nas cidades do Reino Unido, assim como a investigação de retrofit no setor comercial

- Modelagem de percursos, envolvida com adaptação e desenvolvimento de ferramentas de modelagem para a tarefa de representar mudanças em longo prazo e larga escala, e seus usos práticos para tomadores de decisão

- Processo de cenários, um conjunto de oficinas participativas, sendo três nacionais e duas regionais, envolvendo especialistas e partes interessadas para explorar diferentes aspectos das transições e desenvolver as visões do Retrofit 2050

- Transferência de conhecimento, com o objetivo de disseminar e partilhar conhecimento com acadêmicos, profissionais e o público em geral

As cidades não são uma página em branco: muito do ambiente construído que permanecerá em 2050 é similar ao que já está construído agora, então é necessário adaptar, ou propiciar retrofit, para alcançar os desafios futuros de viver em cidades. Após Outubro de 2014, o projeto evoluiu para "Re-engineering the city 2020-2050: urban foresight and transition management", ou Reengenharia da cidade 2020-2050: previsão urbana e gestão da transição (EAMES et al., 2014). 


\section{Londres 2062}

London 2062 é um projeto que convida acadêmicos e estudantes da University College London - UCL, localizada na região central de Londres, e parceiros e atores da cidade a considerar os temas chave

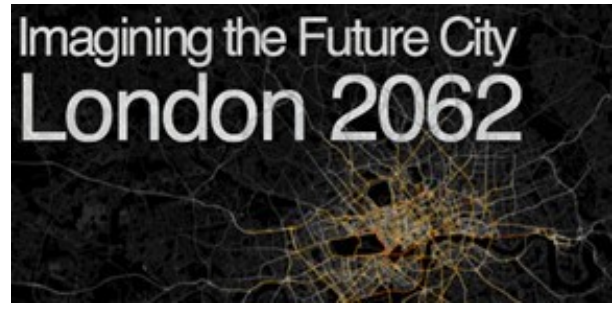
na elaboração do futuro da cidade. Ferramentas interligadas de modelagem auxiliam na elaboração de técnicas de previsão e cenários, que são explorados para propiciar um senso integrado para propor o desenvolvimento de transformações urbanas e caminhos para o futuro (EAMES et al., 2018).

\section{GPRU - Gran Projet Renouvellement Urbain - Paris - França}

Segundo a Prefeitura de Paris (2010), o GPRU - Gran Projet Renouvellement Urbain, ou Grande Projeto de Renovação Urbana, iniciou em março de 2001, voltado para melhorar a estrutura e qualidade de vida em onze bairros prioritários, mais distantes do

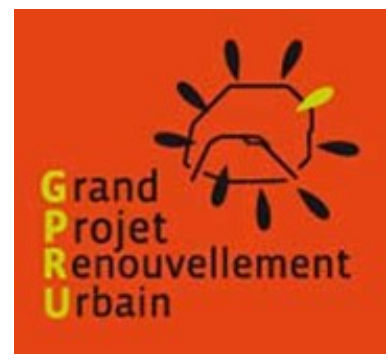
centro, abrangendo 200 mil moradores e 7 distritos, por meio de ações participativas, consultas públicas, projetos de longo prazo, incluindo a revitalização e renovação urbana de uma grande área na região nordeste de Paris.

Situado na região nordeste de Paris, o Paris Nord-Est é um dos onze bairros, e iniciou em 2002 pelo conselho municipal, compreendendo significativo retrofit do bairro adjacente ao Plaine Saint-Denis, subúrbios ao norte de Paris, que recentemente se tornou uma área economicamente dinâmica. O objetivo do projeto é transformar uma área afastada em um novo centro econômico e urbano, por meio do retrofit da infraestrutura decadente e de uma promoção mais eficiente de infraestruturas existentes como o Periphérique Boulevard ou o Al Motorway. Paris Nord-Est irá se tornar uma área de uso misto, com escritórios, residências e equipamentos urbanos. Todas as ações do projeto de retrofit têm previsão de finalização em 2020 (TRÉGUER; NEGREIROS; ABIKO, 2016).

O objetivo do projeto é transformar uma área afastada em um novo centro econômico e urbano, por meio do retrofit da infraestrutura decadente e de uma promoção mais eficiente de 
infraestruturas existentes como o Periphérique Boulevard ou o Al Motorway. Paris Nord-Est irá se tornar uma área de uso misto, com escritórios, residências e equipamentos urbanos. Todas as ações do projeto de retrofit têm previsão de finalização em 2020 (TRÉGUER; NEGREIROS; ABIKO, 2016).

A área do projeto é caracterizada pela considerável presença de redes de transporte, com linhas férreas a partir da Gare du Nord e Gare de l'Est, a Al motorway, o Peripheral Boulevard - que pode ser considerado um limite físico à cidade de Paris, o Boulevard des Maréchaux - um boulevard que também circunda o centro da cidade, e o canal Saint-Denis. Apesar de consistir em uma grande gleba, a área é desvalorizada. Em 2013, a região apresentava somente 13.000 habitantes e 16.000 empregos. O objetivo do projeto de retrofit urbano é revitalizar esta área central com a criação de 25.000 novos empregos e provendo domicílio para 10.000 novos habitantes. As prioridades do projeto são:

- aumentar a qualidade de vida de toda a área pela requalificação de espaços públicos e das infraestruturas principais, tais como boulevards, praças, portas de Paris, canais, entre outros

- tornar o bairro acessível, com melhor aproveitamento de sua proximidade com as importantes redes de transporte da cidade

- criar novos centros econômicos dentro da metrópole de Paris com atividades, lojas, transporte ferroviário e serviços urbanos que irão criar empregos para os habitantes deste bairro desfavorecido

\section{PlaNYC - Nova Iorque - EUA}

Iniciado em 2007, PlaNYC pode ser citado como referência de ações de retrofit, pois foi reuniu mais de 25 agências da cidade para trabalhar na direção de uma Nova Iorque "maior e mais verde", preparando a cidade para um milhão de habitantes a mais, fortalecendo

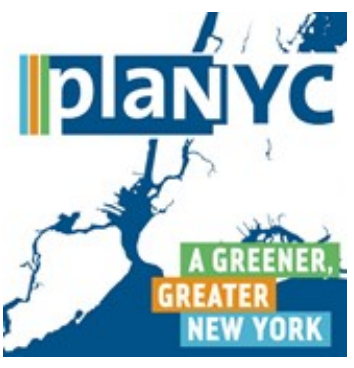
a economia, combatendo as mudanças climáticas e assegurando qualidade de vida para todos os nova-iorquinos. O PlanNYC propôs em 2007 metas de longo prazo, a serem atingidas na totalidade até 2030, por meio de 127 iniciativas, distribuídas nos seguintes temas: habitação e bairros, brownfields ou áreas degradadas, parques e espaços públicos, hidrovias, 
abastecimento de água, transporte, qualidade do ar, resíduos sólidos e mudanças climáticas (NEW YORK CITY, 2011).

Para atingir os objetivos em 2030, o PlaNYC monitora o progresso das iniciativas por meio de 29 indicadores de sustentabilidade, de forma a obter transparência e responsabilidade, avaliando mais de 400 metas parciais, a serem atingidas gradativamente durante o período para direcionar a situação frente às metas definitivas de 2030.

\section{Sustainable Sydney 2030 - Austrália}

O Programa Sydney Sustentável 2030 compreende um conjunto de objetivos que

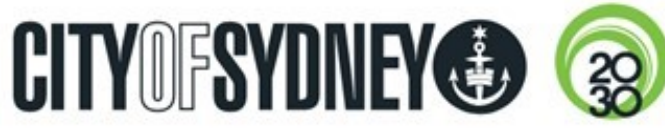

intencionam transformar a cidade o mais verde, global e conectada possível até 2030. O programa questionou moradores, visitantes, trabalhadores e empreendedores, para elaborar a visão de cidade que eles queriam, resultando nas seguintes características principais (CITY OF SYDNEY, 2016):

- Verde: ser internacionalmente reconhecida como cidade líder em desempenho ambiental e com novas indústrias "verdes" guiando o crescimento econômico, reduzindo a emissão de carbono, com uma rede de infraestrutura para reduzir as demandas de energia, água e esgoto, oportunidades de novas moradias integradas com transporte, facilidades e espaço aberto;

- Global: permanecer como a cidade global da Austrália e reconhecida internacionalmente por atrações turísticas e investimento em infraestrutura cultural, com espaços para negócios, instalações culturais e recreativas, incluindo inovação e novas tecnologias para estimular a criatividade e colaboração

- Conectada: fácil acesso à região central, seja à pé ou pela rede de ciclovias, e rotas de trânsito conectando as vilas, centro e restante da cidade, de forma que os bairros continuem a ser pontos fortes para a comunidade, estimulando o senso de pertencimento.

Os 17 ODS - Objetivos de Desenvolvimento Sustentável são utilizados como diretriz e contribuem para as 10 metas estratégicas do programa para 2030 (CITY OF SYDNEY, 2016):

1. Redução de $70 \%$ de emissões de gases de efeito estufa, e em 2050 atingir zero emissões 
2. $50 \%$ da demanda de energia por fontes renováveis e aumento zero de uso de água portável

3. Ao menos 138.000 domicílios na cidade, incluindo mais 48.000 para aumento de diversidade de tipos de residentes

4. $7.5 \%$ do total de habitação da cidade para habitação social

5. Ao menos 465.000 empregos, incluindo 97.000 novos empregos

6. Aumento de $80 \%$ nas viagens a trabalho utilizando transporte público

7. Ao menos $10 \%$ do total de viagens realizadas por bicicleta e $50 \%$ a pé

8. Todos os moradores estarão a uma distância razoável de caminhada a maioria dos serviços locais

9. Todos os moradores estarão a 3 minutos caminhando $(250 \mathrm{~m})$ de corredores verdes contínuos para parques

10. Aumento da coesão da comunidade e da interação social

\section{2) Casos internacionais, de caráter mais pontual}

\section{Subúrbios da Inglaterra e País de Gales}

Williams et al (2013) apresentou a adaptação dos subúrbios na Inglaterra e País de Gales, cujo processo identificou vários desafios, resumidos a seguir:

- A escala do problema: a vasta maioria das propriedades residenciais da Inglaterra e do País de Gales estão nos subúrbios e revestem uma proporção significativa da área de terra urbanizada da Inglaterra. Uma adaptação urbana bem-sucedida nesta escala requer maiores atividades de retrofit e, em alguns lugares, re-projeto urbano.

- Falta de adaptação às mudanças climáticas: muitos investidores envolvidos em adaptação dos subúrbios são desinformados quanto a mudanças climáticas e seus impactos, ou como elas estão relacionadas ao ambiente natural. Há ainda pouca informação quanto às soluções de adaptação disponíveis e quando e onde elas são apropriadas.

- Falta de recursos: o retrofit de casas e espaços públicos em subúrbios efetivamente requer significativo investimento público e privado. Sinais de que as mudanças climáticas não são um tema forte o suficiente para que moradores, profissionais e 
investidores institucionais ou políticos priorizem os gastos em adaptações (exceto quanto há ameaça extrema, a exemplo de enchentes)

- Falta de distinção de quem é responsável pelas mudanças (governança fraca ou confusa): subúrbios são áreas com pouca história de governança local. Há confusão quanto a quem deveria fazer (ou liderar) a adaptação física e isso resulta em inércia. Moradores pensam que o governo é responsável por liderar as mudanças, enquanto há no governo central muita confiança nas ações da própria comunidade. Muitos investidores locais vêm sua própria função como empreendedores, mais poucos moradores estão motivados a se envolverem nas ações comunitárias no que diz respeito a este tema.

A pesquisa também destacou a necessidade de considerar a totalidade do ambiente suburbano, não somente edifícios isolados. Mudanças realizadas nas ruas e no domínio público afetam os lares, e vice-versa. Cuidado também deve ser tomado para entender os efeitos conjugados de mitigação e adaptação mensurados em casas e os espaços no entorno delas, tais como: jardins, ruas e espaço público.

\section{Fornebu - Oslo - Noruega}

O retrofit dos 340 hectares de Fornebu - aeroporto de Oslo até 1998 - é um dos maiores e ambiciosos projetos de urbanização da Noruega, incluindo novas habitações, comércios, recreação e projetos de conservação. O novo Fornebu combina zonas residenciais e comerciais, com amplos parques, espaços verdes e áreas de recreação, ilustradas na Figura 11 (ÅSTEBØL; HVITVED-JACOBSEN; SIMONSEN, 2004).

O programa abrange cinco áreas:

1. Transporte

2. Abastecimento e consumo de energia

3. Materiais das edificações, gerenciamento em massa de resíduos

4. Conservação natural e cultural

5. Poluição e barulho 


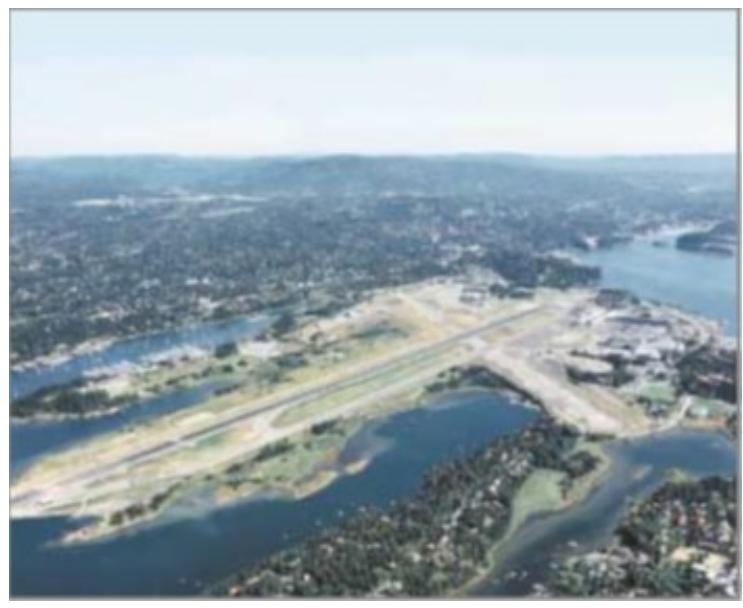

(a)

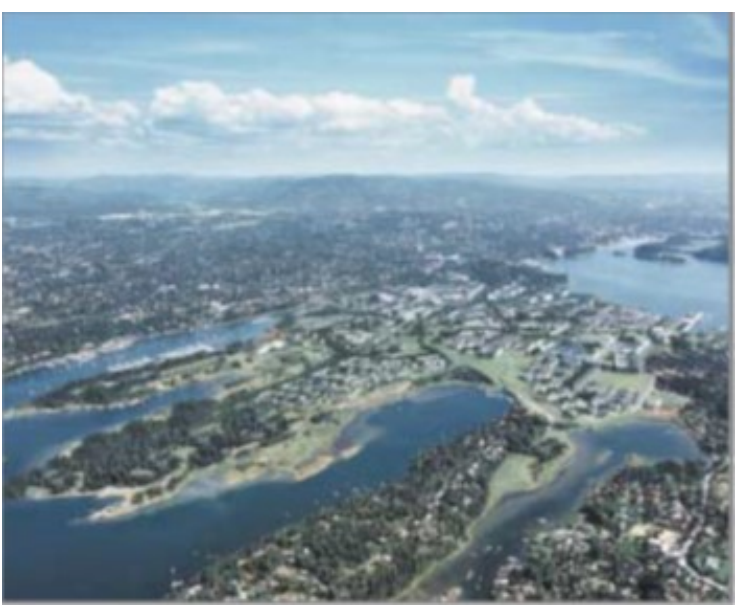

(b)

Figura 11: Área de Fornebu (a) antes do retrofit urbano e (b) após. Fonte: (ÅSTEBØL; HVITVED-JACOBSEN; SIMONSEN, 2004).

\section{Campus da Universidade de Columbia - Manhattan - EUA}

O LEED-ND - Leadership in Energy and Environmental Design for Neighborhoods, que pode ser entendido como Liderança em Projeto Energético e Ambiental para Bairros, foi desenvolvido nos Estados Unidos pela parceria do CNU - Congress For New Urbanism, NRDC - Natural Resources Defense Council e USGBC - U.S. Green Building Council, cuja versão final foi publicada em 2009. Até setembro de 2015, o USGBC certificou 148 projetos LEED-ND no mundo, em diferentes estágios de desenvolvimento. A grande maioria destas certificações foram para projetos planejados, ao invés de projetos já totalmente construídos. O LEED-ND emprega um número de medidas agora largamente utilizadas para avaliar sustentabilidade urbana, por exemplo: acessibilidade, densidade e diversidades de uso (USGBC, 2011).

Segundo Talen et al (2013), o sistema de pontuação LEED-ND provê uma medida para auxiliar comunidades a priorizar padrões futuros de urbanização. Ele também pode ser utilizado para ajudar a determinar quanto potencial a comunidade possui para ser certificada LEED-ND e, assim, quanto do crescimento previsto pode teoricamente incorrer sobre o consumo de recursos e os níveis típicos de emissões de poluentes dos padrões LEED-ND. Distinto da maioria das análises LEED-ND que caracteristicamente têm foco em locações de projetos isolados, o método LEED-ND oferece também uma análise parcial de jurisdição inteira, onde o resultado final é um inventário de locações adequadas à certificação LEEDND. A metodologia produz, de fato, um inventário de locações de crescimento verde, cuja 
urbanização poderia, se estrategicamente alavancada, melhorar profundamente a sustentabilidade da comunidade a longo prazo.

Em 2012, o Campus da Universidade de Columbia, de Manhattan, obteve a primeira certificação LEED-ND Platino, a mais alto nível de certificação LEED, do Estado de Nova Iorque. O campus é uma renovação urbana de uma área sensível da cidade, que possui uma variedade de medidas adotadas para ser tornar mais amigável aos pedestres da comunidade, que passaram a ter acesso aos parques públicos. A prioridade do projeto foi a criação de edifícios energeticamente eficientes e o estabelecimento de uma economia local para fortalecimento dos laços com a comunidade do entorno.

\section{High Line - Manhattan - EUA}

Segundo os escritórios de urbanismo JCFO - James Corner Field Operations e DS+R Diller, Scofidio \& Renfro, o Projeto High Line em Manhattan (Figura 12) foi possível pois algumas associações comunitárias defenderam que uma linha de trem abandonada que cruzava 22 quadras em Nova Iorque fosse convertida em um parque linear de 2,7 hectares. Eles impulsionaram o longo corredor de $2,4 \mathrm{~km}$ a um espaço recreativo, uma atração turística, e um gerador de desenvolvimento econômico. A primeira fase do High Line inaugurou, com muita aprovação do público, em junho de 2009. Seu sucesso sugere um modelo de como territórios urbanos abandonados podem ser transformados em algo benéfico para a comunidade (JCFO; DS+R, 2015).

Se, por um lado, o CNU - Congress For New Urbanism é um dos fundadores do LEEDND, caracterizando o sistema pelo Novo Urbanismo, o projeto do High Line de Nova Iorque é emblemático no chamado landscape urbanism, ou urbanismo paisagista. A premissa básica para o urbanismo paisagista consiste no conceito de que a paisagem deveria ser a parte fundamental construída para o desenho urbano. No urbanismo tradicional, alguma estrutura um muro, estradas, ou edifícios - direciona a urbanização. Os espaços verdes são relegados a áreas remanescentes, inadequadas à construção, ou utilizados para ornamentação. Por meio do urbanismo paisagista, processos culturais e naturais ajudam o projetista a organizar a forma urbana (STEINER, 2011). 

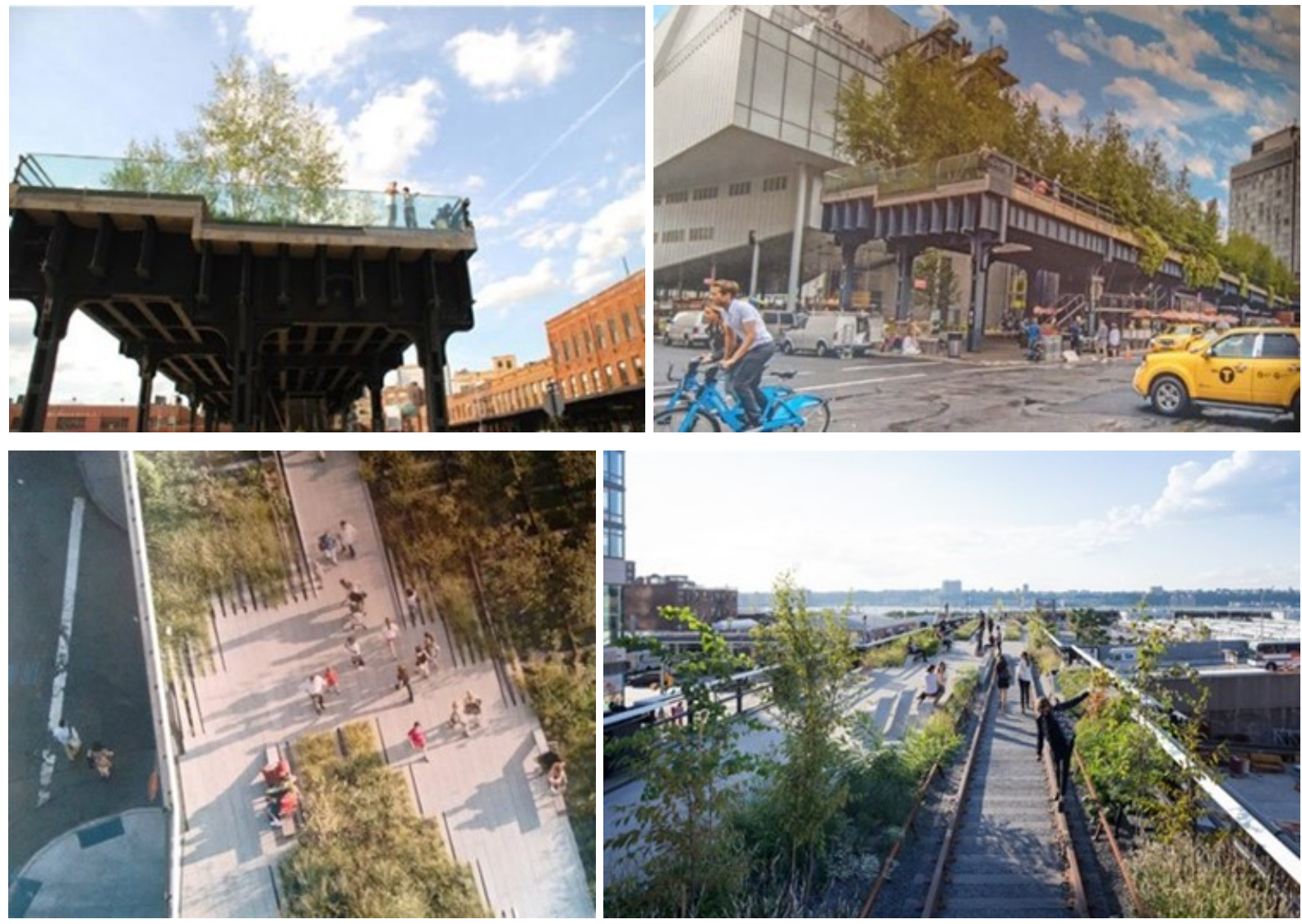

Figura 12: Imagens do Projeto High Line - Nova Iorque. Fonte: JCFO e DS+R (2015).

\section{3) Casos nacionais}

No caso do Brasil, há vários projetos de ordenamento e reestruturação urbana, sendo possível citar como exemplos de retrofit urbano:

- Recente conjunto de intervenções urbanas para adaptação e preparação da cidade do Rio de Janeiro para sediar os Jogos Olímpicos de 2016, dentre elas o Projeto Porto Maravilha, que tem um horizonte de prazo mais longo, 2040 (FERRARIN, 2016)

- Ampla implantação de ciclovias em grande extensão das zonas urbanas de várias cidades brasileiras, inclusive os Municípios de São Paulo - Capital, Sorocaba - SP, entre outros.

- Ampla implantação dos denominados PIU - Projetos de Intervenção Urbana, em vários municípios brasileiros. 
Os PIU - Projetos de Intervenção Urbana, elaborados pelo Poder Público, objetivam apresentar propostas de transformações urbanísticas, habitacionais, ambientais e econômicas nos perímetros onde forem aplicados os instrumentos de ordenamento e reestruturação urbana, como OUC - Operações Urbanas Consorciadas, AIU - Áreas de Intervenção Urbana, AEL - Áreas de Estruturação Local, Concessão Urbanística e Reordenamento Urbanístico Integrado (PMSP, 2012a). Estes projetos podem compreender um caráter integrado, objetivando planos de maior extensão, como por exemplo, o Projeto Arco Tietê, no município de São Paulo, ou apresentar caráter mais pontual, restritas às áreas de intervenção, sem articulação com um plano mais extenso, de longo prazo, para a cidade. Atualmente há vários projetos em desenvolvimento no município de São Paulo, a saber:

- PIU Anhembi (http://minuta.gestaourbana.prefeitura.sp.gov.br/piu-anhembi-1/\#/)

- Arco Jurubatuba

- Nações Unidas

- NESP - Novo Entreposto de São Paulo

- Pacaembu

- Terminais (Campo Limpo, Capelinha e Princesa Isabel)

- Vila Leopoldina-Villa Lobos (http://minuta.gestaourbana.prefeitura.sp.gov.br/piuvila-leopoldina/\#/)

- Vila Olímpia

Em estudo, encontram-se o PIU Arco Tietê e PIU Rio Branco.

Há algumas OUC - Operações Urbanas Consorciadas comentadas anteriormente, mais isoladas em seu conjunto de intervenções, como por exemplo no município de São Paulo, a OUC Água Branca e a OUC Faria Lima.

Outros projetos de retrofit urbano mais pontuais podem ser citados nas construções de arenas para a Copa do Mundo em 2014, por exemplo em Manaus e Fortaleza, que não apresentaram a finalização do conjunto de intervenções urbanas previstas para adaptação e integração da região das arenas com seu entorno e com o restante da cidade, por meio da execução de obras de mobilidade, como a implantação de VLTs - Veículos Leves sobre Trilhos ou BRT - Bus Rapid Transit, ou Transporte Rápido por Ônibus. 


\section{INDICADORES DE SUSTENTABILIDADE URBANA}

\subsection{Conceitualização}

Como exposto anteriormente, uma das características do retrofit urbano é possuir um conjunto de metas e medidas claramente definido para monitoramento (Living Cities, 2010). Para tal, o uso de indicadores de sustentabilidade urbana faz-se necessário, na intenção de iniciar o processo de transformação do retrofit com o diagnóstico atual da área urbana, para assim definir metas mensuráveis e que permita, inclusive, melhor estruturar investimentos públicos. A proposta é que padrões sustentáveis de desenvolvimento, que considerem aspectos ambientais, econômicos e sociais, sejam aplicados. Para isso, "torna-se necessário definir indicadores que mensurem, monitorem e avaliem esses padrões sustentáveis, para nortear nossos rumos" (Louette, 2007, p. 1)

Um conjunto de dados pode ser somente uma coleção de parâmetros que foram mensurados, geralmente a fonte para dados específicos utilizados pelos indicadores. O indicador, por sua vez, é um parâmetro, uma propriedade que é mensurada ou observada, ou um valor derivado de parâmetros, que aponta, proporciona informação e/ou descreve a situação de um fenômeno, ambiente ou área, com um significado além do associado diretamente ao valor do parâmetro. Um índice é um conjunto de parâmetros ou indicadores agregados ou ponderados (EUROPEAN COMMISSION et al., 2015). Estas definições podem ser observadas na Figura 13.

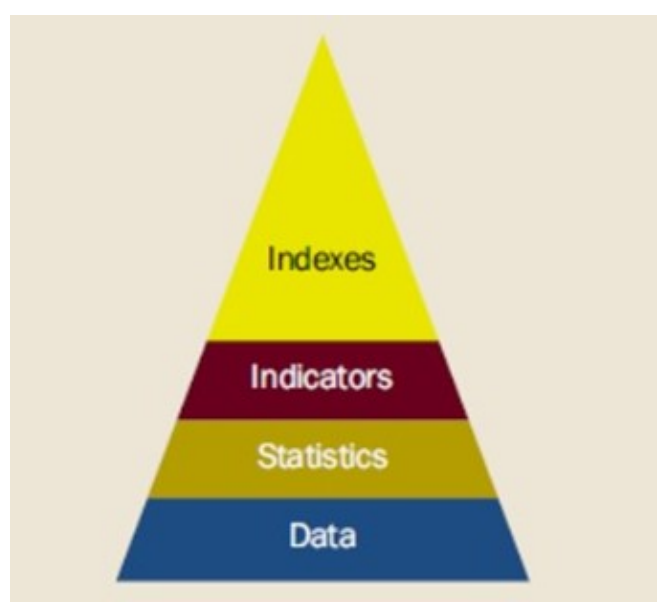

Figura 13: A pirâmide de dados. Fonte: (WESTFALL; DE VILLA; ASIAN DEVELOPMENT BANK, 2001) 
É essencial levar em consideração os vários propósitos, escopos, escalas para os quais cada indicador é utilizado, bem como identificar os atores, escopo de influência e possibilidades de ação que podem resultar em progresso positive no tema ao qual o indicador pertence. Uma classificação usual corresponde à divisão dos indicadores entre objetivos e subjetivos. Os indicadores objetivos referem-se a ocorrências concretas ou a entes empíricos da realidade, construídos a partir das estatísticas públicas disponíveis, como o percentual de domicílios com acesso à rede de água, a taxa de desemprego, a taxa de evasão escolar ou o risco de acidentes de trabalho. Os indicadores subjetivos, por outro lado, correspondem a medidas construídas a partir da avaliação dos indivíduos ou especialistas com relação a diferentes aspectos da realidade, levantados em pesquisas de opinião pública ou grupos de discussão, como a avaliação da qualidade de vida, o nível de confiança nas instituições, a percepção da corrupção, a performance dos governantes (JANNUZZI, 2001).

Uma outra distinção entre tipos de indicadores pode ser pontuada entre duas abordagens de elaboração dos mesmos (LÜTZKENDORF; BALOUKTSI, 2017):

- "top-down", ou guiada por especialistas: baseada em conhecimento e considera, por exemplo, padrões internacionais e nacionais e, se existem, estratégias para a sustentabilidade nacionais, regionais ou locais

- "bottom-up", ou guiada pelos cidadãos: baseada em experiências e redes locais, envolvimento do público, proporcionando uma base de identificação de deficiências e problemas locais

Há tensões entre os modelos top-down e bottom-up de desenvolvimento de indicadores, e a combinação das duas abordagens representa uma solução efetiva. Além dos requisitos técnicos, é interessante distinguir os indicadores em termos de sua mensuração, se objetivos/quantitativos ou subjetivos/qualitativos, ou em termos de sua posição na cadeia de impacto, se mais próximos às causas ou aos efeitos. Também é importante diferenciar (LÜTZKENDORF; BALOUKTSI, 2017):

- Indicadores que podem ser "diretamente influenciados" pelas intervenções de atores locais, pertencentes a um distrito individual. Por exemplo, consumo de energia em edifícios residenciais. Estes indicadores podem ser considerados como "orientados para ações" e auxiliar tomadores de decisão na formulação de metas e estratégias claras. 
- Indicadores que não podem ser influenciados, ao menos não diretamente, pelas intervenções de atores locais, e servem apenas para propósitos de informação. Por exemplo, taxa de desemprego. Metas não podem ser definidas para estes indicadores no nível do distrito. Eles podem ser considerados indicadores de contexto ou de perfil. Entretanto, alguns deles podem fornecer avisos antecipados de problemas futuros. Neste caso, atores locais podem desenvolver estratégias para lidar com as consequências.

Quanto ao tema do desenvolvimento sustentável, a avaliação de sustentabilidade é muitas vezes utilizada para referenciar formas especializadas de avaliação estratégica, que apenas compreendem características limitadas da estrutura, como ilustra a Figura 14. Entretanto, a abordagem deve integrar os pilares ambiental, social e econômico na tomada de decisão em iniciativas propostas em todos os níveis, de políticas a projetos e, particularmente, com uma estrutura de princípios, indicadores e estratégias. A definição clara de metas, de valores de melhor desempenho de cidades utilizados e a cobertura espacial e temporal são características que determinam a estratégia, abrangência e integração para contribuir com a avaliação de sustentabilidade (HACKING; GUTHRIE, 2008).

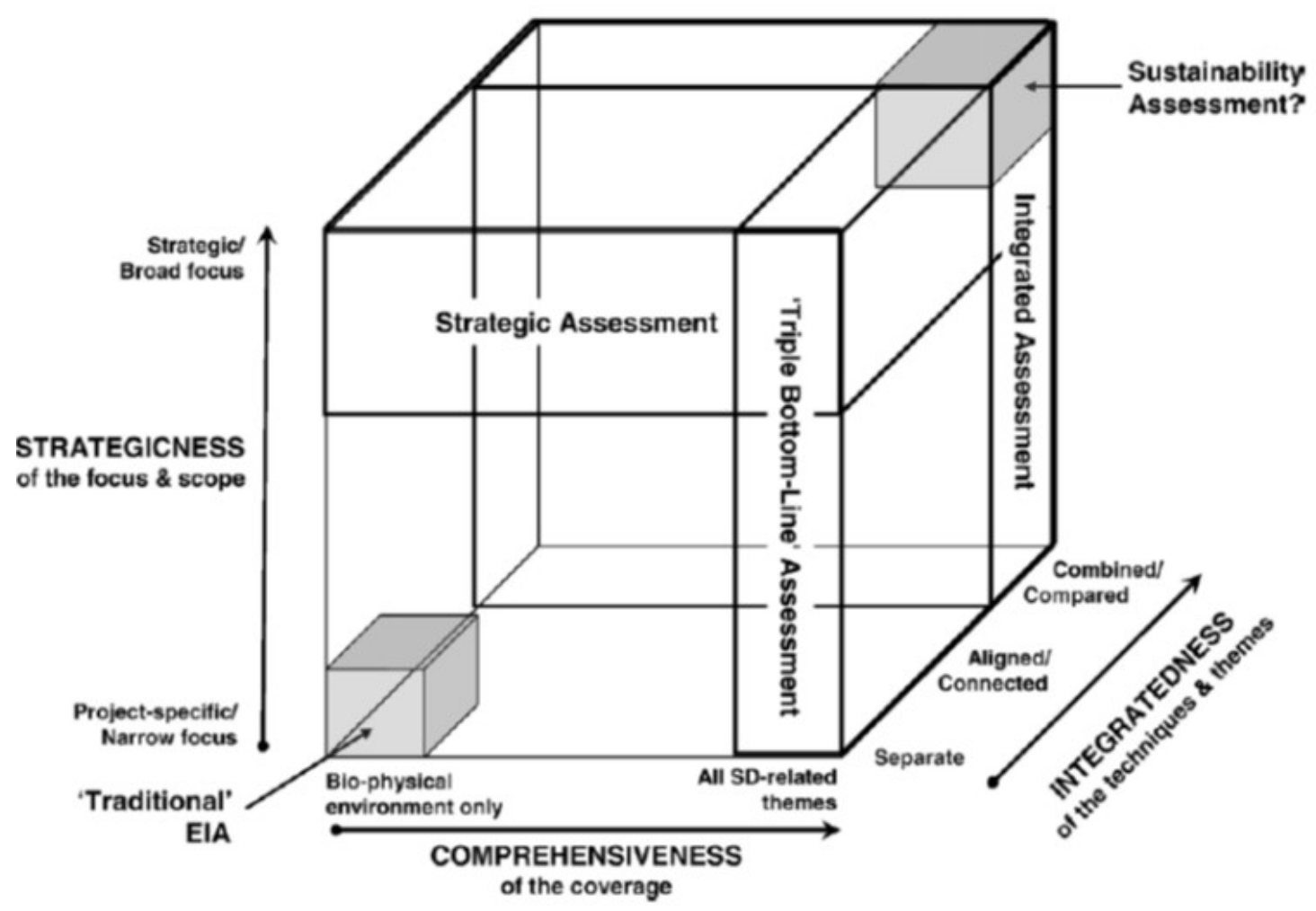

Figura 14: Espectro das características de desenvolvimento sustentável no processo de avaliação. Fonte: (HACKING; GUTHRIE, 2008) 
A avaliação de sustentabilidade compreende processos que devem (BOND; MORRISON-SAUNDERS; POPE, 2012):

- Direcionar imperativos de sustentabilidade a evolução positiva

- Estabelecer um conceito viável de sustentabilidade no contexto de decisões e avaliações individuais

- Adotar mecanismos formais lidar com relações inversas (trade-offs) inevitáveis de uma forma aberta, participativa e responsável

- Incluir as inevitabilidades plurais da avaliação de sustentabilidade

- Gerar aprendizado

Ainda quanto ao tema do desenvolvimento sustentável, os indicadores podem ser diferenciados de acordo com o efeito sobre uma ou mais dimensões da sustentabilidade. Por exemplo, mudanças climáticas (dimensão ambiental) podem gerar problemas relacionados a saúde e conforto (dimensão social) e a custos externos para a sociedade (dimensão econômica). Esta questão da discussão dos múltiplos efeitos e dimensões relativas aos indicadores pode ser transferida aos indicadores de sustentabilidade urbana (LÜTZKENDORF; BALOUKTSI, 2017).

Há várias iniciativas em padronizar indicadores para avaliar, monitorar e comparar desenvolvimento sustentável nos diversos níveis territoriais. Indicadores de desenvolvimento sustentável para cidades, regiões, países, etc intencionam avaliar, levantar melhores práticas e identificar tendências no tempo e no espaço, para monitorar o progresso na direção de metas, informar planejamento e tomada de decisão, conscientizar, estimular mudanças políticas e de comportamento, promover participação pública e melhorar a comunicação em sustentabilidade (MORENO PIRES; FIDÉLIS; RAMOS, 2014).

Segundo Cedano e Martinez (2010) e Malheiros, Coutinho e Philippi Jr (2012, p.8), nos últimos 20 anos ocorreu um trabalho extenso em indicadores urbanos, com "uma significativa profusão de modelos de suporte para análise dos indicadores de sustentabilidade". Os esforços das organizações internacionais consistiram na identificação de indicadores e índices que comparam a situação de diferentes cidades e no acompanhamento dos objetivos comuns na intenção de melhorar a qualidade de vida. Porém, de forma geral, "foram construídos para atender cenários específicos de tomada de decisão, cuja replicabilidade em diferentes 
realidades deve ser analisada com o devido cuidado" (MALHEIROS; COUTINHO; PHILIPPI JR, 2012, p. 8).

Paralelamente a uma inclinação a ganho de conscientização sobre desenvolvimento sustentável, a proliferação de sistemas de indicadores também apresenta inúmeros desafios. Diante de tantos sistemas propostos ou em uso, e cada um deles com diferentes objetivos, metas e definições de desenvolvimento sustentável, constata-se a dificuldade de entender a tendência mais ampla em termos nacionais. Um sistema que estivesse estreitamente vinculado a prioridades nacionais claras traria melhores resultados. Porém, apesar dessas limitações, extensas pesquisas e discussões envolvendo a comunidade acadêmica, lideranças de movimentos sociais e profissionais de outras áreas propiciaram a evolução do trabalho analítico a respeito dos indicadores de desenvolvimento sustentável, conferindo-lhes maior refinamento e resultando em um campo sólido de conhecimento sobre o tema (BIRCH; LYNCH, 2012).

Uma das áreas críticas da sustentabilidade de uma cidade é a infraestrutura urbana. Serviços de energia, transporte, disposição de resíduos, abastecimento de água e tratamento de esgotos são elementos chave da infraestrutura urbana que estão diretamente envolvidos no paradigma da sustentabilidade. Embora estes serviços sejam gerenciados pela administração pública municipal, colaboração e comprometimento da sociedade é um elemento crítico e necessário para assegurar a execução eficaz de temas urbanos complexos, tais como alcançar sustentabilidade em ambientes urbanos. Assim, a integração de processos cooperadores em planejamento urbano é um dos principais desafios na direção do desenvolvimento urbano sustentável. A elaboração de uma abrangente série de indicadores de sustentabilidade para a infraestrutura urbana não é só uma maneira de ter melhor informação para atingir a melhor definição de objetivos do plano e acompanhamento, mas também deve ser uma tarefa que envolva participação dos cidadãos e entre instituições em sua gestão (CEDANO; MARTINEZ, 2010).

Segundo Malheiros, Coutinho e Philippi Jr (2012), um dos fatores-chave na viabilização de bons indicadores de sustentabilidade é o estabelecimento de sistemas de monitoramento que viabilizem a coleta de dados com qualidade, regularidade e acesso pelos diferentes atores envolvidos na tomada de decisão. Outro desafio a ser trabalhado é a viabilização de sistemas 
de indicadores para as diferentes escalas de gestão - do local ao global. Esses sistemas devem individualmente atender especificidades locais, captando esforços e medindo o desempenho de cada unidade. Ao mesmo tempo, é preciso identificar indicadores que possam comparar unidades, criando uma nova unidade de análise - regional ou global. A questão da institucionalização desses indicadores talvez seja um dos pilares ainda mais fragilizados, pois dependem de que as estruturas de governança - pública e privada - se tornem mais robustas, mais comprometidas e mais transparentes. Assim, a questão dos indicadores de sustentabilidade deve ser uma ferramenta presente e constante nos processos decisórios. E, além disso, é necessário que se construam indicadores de automonitoramento dos sistemas gestores, numa perspectiva de aprendizado contínuo, de melhoria progressiva, que responda às complexas redes de decisão política nos diferentes níveis de atuação.

Louette (2007) aborda, em seu "Compêndio de Indicadores", os principais Indicadores de Sustentabilidade de Nações em processo de aplicação no exterior e no Brasil, visando "ilustrar a imensa gama de instrumentos que estão disponíveis, servindo, assim de parâmetro para análise do que está acontecendo ao redor do mundo sob o tema sustentabilidade" (LOUETTE, 2007, p. 1). A lista apresentada por Louette (2007) compreende 25 sistemas de indicadores e índices que levantam o estado da biodiversidade no mundo, as desigualdades e a pobreza, o progresso em direção a sociedades sustentáveis, o progresso real e a qualidade de vida das nações, o uso de recursos naturais, a vulnerabilidade do meio ambiente, a eficiência ecológica, etc.

Esta etapa da pesquisa consistiu no estudo dos indicadores de sustentabilidade urbana, por meio de uma pesquisa bibliográfica, leitura de artigos científicos e sites da internet. A partir de indicadores de sustentabilidade urbana identificados em Holden (2013), Louette (2007), Malheiros, Coutinho e Philippi Jr (2012) e ISO (2014), e outros que foram identificados na pesquisa bibliográfica, foi realizado o preenchimento detalhado de tabelas e planilhas em Excel, identificando nos índices listados as seguintes características, quando disponíveis: instituição de origem, país de origem, data de criação, modelo matemático e variáveis envolvidas. Ao todo, foram 186 sistemas de indicadores pesquisados, dos quais 66 foram analisados. A tabela completa com os 66 indicadores de sustentabilidade analisados é apresentada no Apêndice A. A tabela não tem a pretensão de encerrar todos os indicadores de 
sustentabilidade urbana já desenvolvidos globalmente, mas tão somente mostrar a vasta gama de ferramentas propostas, bem como respectivas origens e ano de criação.

Isto posto, destacam-se alguns indicadores inseridos nesta vasta lista. Um deles é o Green City Index Europeu, que pode ser entendido como Índice de Cidade Verde, avalia 16 indicadores quantitativos e 14 qualitativos. A metodologia para a Europa foi adaptada para outros índices regionais, levando-se em conta ponderações e particularidades dos indicadores locais, e já foi aplicado em 120 cidades no mundo, inclusive Belo Horizonte, Brasília, Curitiba, Rio de Janeiro e São Paulo (SIEMENS, 2012).

Outro destaque é o trabalho de Leite (2012), com os Indicadores de Sustentabilidade no Desenvolvimento Imobiliário Urbano, que observou que algumas questões foram tratadas pela grande maioria das referências, demonstrando sua importância, que, portanto, definiram 9 temas agregadores dos 176 indicadores de sustentabilidade urbana, a saber:

1. Construção e Infraestrutura Sustentáveis

2. Governança

3. Mobilidade

4. Moradia

5. Oportunidades

6. Planejamento e Ordenamento Territorial

7. Questões ambientais

8. Segurança

9. Serviços e Equipamentos

O LEED-ND - Leadership in Energy and Environmental Design for Neighborhoods, que pode ser entendido como Liderança em Projeto Energético e Ambiental para Bairros, foi incluído na lista da tabela do Apêndice A pois a pesquisa de Holden (2013) mostra que a operacionalização de uma política de sistemas de indicadores de sustentabilidade é possível por meio do LEED-ND, no contexto de múltiplos níveis de governança. De fato, o Crédito 5 do LEED-ND: Reuso de edifícios existentes, da categoria Infraestrutura e Edifícios Verdes, pontua o retrofit de edifícios. O NRDC (2011) apresenta um Guia de Melhorias para Bairros Existentes, afirmando que a proposta básica do LEED-ND é avaliar ou certificar uma nova 
urbanização, mas que se pode utilizá-lo para guiar o planejamento e o investimento em bairros existentes. Para a maioria dos bairros, este processo envolverá três etapas básicas:

1. Avaliar o bairro: trabalho com a liderança local ou outras organizações comunitárias para conduzir uma auditoria do bairro utilizando as categorias, pré-requisitos e créditos do LEED-ND. Pode-se utilizar a própria lista de verificação do método.

2. Foco em forças e fraquezas: identificam-se áreas onde o desempenho do bairro ou comunidade é boa, segundo o LEED-ND. Quando não for, solicita-se investimento nas necessidades da comunidade.

3. Resposta com um plano: propor retrofits, reurbanização com metas, melhorias na infraestrutura, ou outras medidas que sejam fundamentadas nas forças do bairro e dirigidas às suas fraquezas. O nível de detalhe e esforço pode apresentar amplas variações - de uma lista informal de sugestões até uma proposta detalhada de projeto e política que se torne a espinha dorsal do plano para o bairro. Se o bairro já é o foco de um esforço planejado, participar deste processo para assegurar que será dirigido às necessidades que foram identificadas e à proteção das forças do bairro.

A criação de índices é uma das maneiras de simplificar a análise e apresentar, de forma resumida, o desempenho de cidades e a qualidade de vida de seus moradores. Entretanto, na agregação de indicadores, os índices muitas vezes aprisionam a realidade, que é complexa e multifacetada. De qualquer forma, índices compõe uma ferramenta que proporciona reflexão sobre um determinado tema. Alguns índices existentes para municípios brasileiros podem ser destacados:

- Índice de Desenvolvimento Humano Municipal - IDHm: calculado pelo PNUD, é uma variação do IDH calculado em nível nacional, e baseia-se em três sub-índices: Longevidade, Educação e Renda. Cada uma delas recebe um sub-índice, de 0 a 1 , baseados principalmente nos dados do Censo Demográfico, e depois reunidos no IDHm;

- Índice Paulista de Responsabilidade Social - IPRS: criado pela parceria da Assembleia Legislativa do Estado de São Paulo com a Fundação Seade, tem por objetivo avaliar a qualidade de vida nos municípios paulistas e exprime sinteticamente um conjunto de dimensões para mensurar as condições de vida da população, a saber: riqueza, longevidade e escolaridade (http://www.iprs.seade.gov.br/) 
- Índice Paulista de Vulnerabilidade Social - IPVS: também criado pela parceria da Assembleia Legislativa do Estado de São Paulo com a Fundação Seade, tem por objetivo levar ao gestor público e à sociedade uma visão mais detalhada das condições de vida do seu município, com a identificação e a localização espacial das áreas que abrigam os segmentos populacionais mais vulneráveis à pobreza, por meio de uma tipologia de situações de vulnerabilidade que considera, além dos indicadores de renda, outros referentes à escolaridade e ao ciclo de vida familiar, identificando áreas geográficas segundo os graus de vulnerabilidade de sua população residente (http://www.iprs.seade.gov.br/ipvs2010/)

- Índice FIRJAN de Desenvolvimento Municipal - IFDM: calculado pela FIRJAN Federação das Indústrias do Estado do Rio de Janeiro, apresenta três aspectos: "Emprego e Renda", "Educação" e "Saúde";

- Ranking de Eficiência dos Municípios - REM-F: calculado pela Folha de São Paulo, engloba "Educação", "Saúde", "Saneamento" e "Receita".

Como dito anteriormente, foram então identificados 66 sistemas de indicadores de sustentabilidade urbana que apresentam representatividade para o retrofit urbano. $\mathrm{Na}$ intenção de analisar as variáveis internas envolvidas no modelo, os indicadores mais conceituais, que não possuem modelagem matemática, foram excluídos do estudo, tais como: Princípios de Bellagio (Canadá), DS - Dashboard of Sustainability (Canadá e outros países), Social Footprint (EUA e Holanda), OECD Environmental Indicators, entre outros. Excluíram-se também aqueles cujas informações relevantes não estavam disponíveis, ou estavam em linguagem de difícil tradução (por exemplo, finlandês). Restaram, portanto, 39 indicadores de sustentabilidade urbana, que foram efetivamente analisados e apresentados no trabalho de Kühl, Negreiros e Abiko (2015).

Esta análise não teve a pretensão de cobrir a totalidade dos indicadores de sustentabilidade ambiental existente internacionalmente, mas tão somente analisar os temas mais relevantes, principalmente no que se refere ao retrofit urbano, levando em conta a complexidade de utilização, bem como a facilidade de compreensão dos indicadores selecionados. Assim, identificados os 39 sistemas indicadores de sustentabilidade urbana, foram elaborados alguns gráficos estatísticos, para verificar algumas informações e 
características relevantes, a fim de analisar sua importância e a melhor expor seus significados.

A Figura 15 representa a proporção das variáveis envolvidas, os "sub-indicadores", que compõem matematicamente o indicador de sustentabilidade urbana, nas grandes áreas-pilares da sustentabilidade. Nota-se uma proporção maior do pilar das questões ambientais (56\%), e proporções menores dos demais pilares: sociais $(23 \%)$, econômicas $(11 \%)$ e de governança $(10 \%)$.

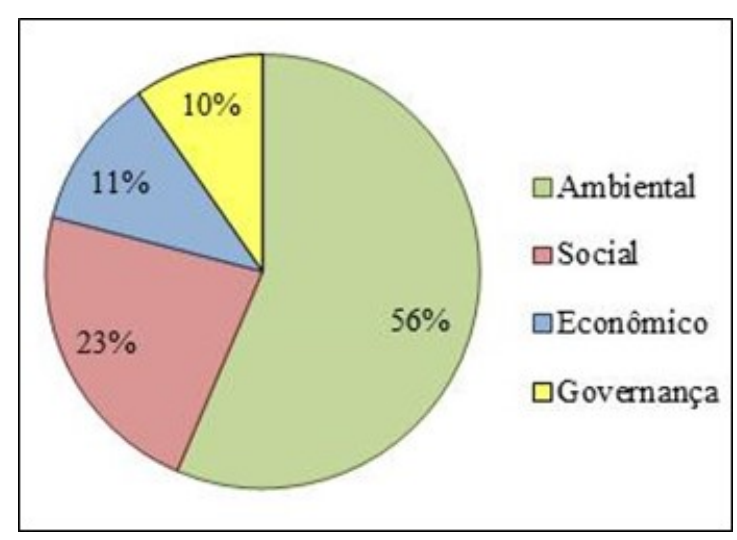

Figura 15: Proporção das variáveis envolvidas. Fonte: Kühl, Negreiros e Abiko (2015)

A Tabela 2, a seguir, lista as 30 variáveis envolvidas mais utilizadas, independente da classificação da mesma nas áreas da sustentabilidade (ambiental, social, econômica e de governança). Nota-se que as ambientais (destacadas em verde) são as que mais se sobressaem.

Em contraponto à existência de diversas correntes de pensamentos envolvidas no estudo de indicadores de sustentabilidade urbana, criando assim um grande número de indicadores e caminhos a serem seguidos, verifica-se uma convergência dos mesmos em algumas variáveis adotadas em seus modelos. Esta etapa do trabalho contribuiu para compreender a origem e avaliar a importância de cada indicador analisado, evidenciando que os estudos e usos mais atuais dos indicadores de sustentabilidade mostram a formação de conceitos e índices de sustentabilidade bastante peculiares. 
Tabela 2: As 30 variáveis envolvidas mais utilizadas nos sistemas de indicadores analisados.

Fonte: Kühl, Negreiros e Abiko (2015).

\begin{tabular}{|c|c|c|}
\hline Ranking & $\begin{array}{c}\text { Número de } \\
\text { indicadores } \\
\text { que utiliza a } \\
\text { variável } \\
\end{array}$ & Variável envolvida \\
\hline \multirow[t]{3}{*}{$1^{\circ}$} & 23 & Concentração de nitrogênio no ar (óxidos de nitrogênio) \\
\hline & 23 & Concentração de ozônio no ar \\
\hline & 23 & Número de habitantes \\
\hline $4^{\circ}$ & 22 & Emissão de dióxido de carbono \\
\hline $5^{\circ}$ & 20 & Concentração de enxofre no ar (dióxido de enxofre) \\
\hline \multirow[t]{4}{*}{$6^{\circ}$} & 19 & Concentração de $\mathrm{CO} 2$ atmosférico \\
\hline & 19 & Porcentagem de esgoto tratado \\
\hline & 19 & Renda anual média por educação e gênero \\
\hline & 19 & Taxa de escolarização \\
\hline \multirow[t]{5}{*}{$10^{\circ}$} & 18 & Consumo de água \\
\hline & 18 & Consumo de substâncias destruidoras da camada de ozônio \\
\hline & 18 & Destino de lixo adequado \\
\hline & 18 & Disponibilidade de água potável \\
\hline & 18 & Proporção de áreas cobertas por florestas \\
\hline \multirow[t]{2}{*}{$15^{\circ}$} & 17 & Consumo anual de energia \\
\hline & 17 & Concentração de materiais particulados \\
\hline \multirow[t]{4}{*}{$17^{\circ}$} & 16 & Concentração de chumbo no ar \\
\hline & 16 & Concentração de monóxido de carbono no ar \\
\hline & 16 & Expectativa de vida \\
\hline & 16 & Geração de resíduos \\
\hline $21^{\circ}$ & 15 & Mortalidade Infantil \\
\hline \multirow[t]{5}{*}{$22^{\circ}$} & 13 & Presença de coliformes fecais em água doce \\
\hline & 13 & Níveis de oxigênio dissolvido na superfície das águas \\
\hline & 13 & Proporção de emprego para a população \\
\hline & 13 & PIB \\
\hline & 13 & Divisão modal de transporte de passageiros \\
\hline \multirow[t]{3}{*}{$27^{\circ}$} & 12 & Desperdício de água \\
\hline & 12 & Tratamento de dejetos \\
\hline & 12 & Taxa de desemprego por gênero, idade e cor de pele \\
\hline \multirow[t]{3}{*}{$30^{\circ}$} & 11 & Diferença anual da cobertura florestal \\
\hline & 11 & Participação de fontes renováveis na oferta de energia \\
\hline & 11 & $\begin{array}{l}\text { Proporção da população vivendo abaixo da linha de } \\
\text { pobreza nacional }\end{array}$ \\
\hline
\end{tabular}

A maior proporção de variáveis ambientais denota que os indicadores analisados são na maioria voltados às questões do meio ambiente, apesar de que os pesos das variáveis intrínsecas não foram analisados neste trabalho. A maioria dos indicadores que explicitamente 
divide as variáveis nas conhecidas áreas da sustentabilidade afirmam que dão pesos iguais no final para cada um dos temas. Os histogramas observados neste trabalho evidenciam que as variáveis ambientais são mais repetidas. Isso também se deve ao fato da desagregação de algumas destas variáveis, como, por exemplo, as que se relacionam à qualidade do ar. Ao invés de uma variável que aborde um índice de qualidade ou poluição do ar, o indicador de sustentabilidade mensura uma gama de variáveis, tais como concentrações ou emissões de diversos poluentes (KÜHL; NEGREIROS; ABIKO, 2015).

\subsection{Big Data Urbano}

A oportunidade de utilizar bases de dados e análises de larga escala para abordar importantes desafios urbanos é fruto da convergência de dois fenômenos: (1) a capacidade de coletar, armazenar, e processar um volume crescente de dados reunidos a partir de uma profusão de fontes, e (2) a crescente urbanização global que resultou em mais de $50 \%$ da população mundial vivendo em cidades.

Para que os centros urbanos consigam passar por transformações sustentáveis eles devem apoiar-se em mudanças inovadoras e tecnológicas (NEWTON, 2013). A recente evolução tecnológica promoveu a miniaturização de dispositivos eletrônicos, além de ampliar a capacidade de armazenamento e processamento de informações, associados à conectividade sem fio. As inovações tecnológicas e a ubiquidade de produtos equipados com sensores, processadores, softwares e portas de comunicação têm permitido a coleta de uma grande quantidade de dados pertencentes às cidades, sendo esses dados provenientes, por exemplo, de sensores convencionais, como medidores de consumo de energia, e GPS em veículos, que permitem capturar a dinâmica urbana (KITCHIN, 2014).

Tornou-se mais barato e acessível o armazenamento de dados devido ao avanço da informática e ciência. Ou seja, a tecnologia propicia a acumulação e obtenção de um conjunto de dados variados, detalhados, dinâmicos, inter-relacionados e de baixo custo que podem ser utilizados de diversas maneiras (KITCHIN, 2014). 
O debate entre as novas tecnologias de informação e comunicação e o espaço urbano teve início a partir da década de 1990, quando o objetivo era criar uma infraestrutura digital eficiente, visando gerar processos inovadores nas diversas instâncias do governo, empresas, etc (KITCHIN, 2013).

É neste contexto urbano que surgem os conceitos de Big Data e análises Big Data. Kitchin (2014) define Big Data como um conjunto muito extenso de dados que são produzidos por pessoas utilizando a internet, e que só podem ser armazenados, compreendidos e utilizados com o auxílio de ferramentas e métodos especiais. Como características, Big Data são (KITCHIN, 2013, p. 262):

- imensos em volume, consistindo em terabytes ou petabytes de dados (respectivamente, 1024 gigabytes ou 1024 terabytes);

- de alta velocidade, sendo criados em tempo real, ou praticamente em tempo real;

- diversificados na variedade de tipos, sendo de caráter estruturados e não estruturados, e frequentemente temporal e espacialmente referenciados;

- de escopo abrangente, buscam capturar por completo populações ou sistemas;

- de fina e alta resolução, a fim de serem tão detalhados quanto possível, e com identificações unicamente indexadas;

- de caráter relacional, contendo campos comuns que são capazes da conjunção de diferentes conjuntos de dados, e

- flexíveis, com possibilidade de extensão (pode-se facilmente adicionar novos campos) e de escalabilidade (pode-se rapidamente expandir o tamanho).

Compreender como adaptar as cidades requer uma análise complexa e integrada do espaço. Este tipo de análise está centrado em três fatores: quais informações são relevantes, que tipo de dados podem produzir estas informações e que tipo de sensores, também quantidade e distribuição no espaço, são necessários para adquiri-los, qual o processamento ou processo de integração dos dados é o mais adequado para subsidiar as análises. Tais análises deverão ocorrer sobre os grandes bancos de dados produzidos nas cidades, ainda mais nos tempos atuais de tecnologia ubíqua ou onipresente, conforme ilustra a Figura 16, a seguir (FRANCISCO, 2014). 
Para se obter um direcionamento das adaptações às cidades, análises sobre grandes massas de dado não-estruturadas ou Big Data podem proporcionar uma abordagem estratégica otimizada, dado que é capaz de suprir a atual falta de informações sobre a dinâmica urbana.

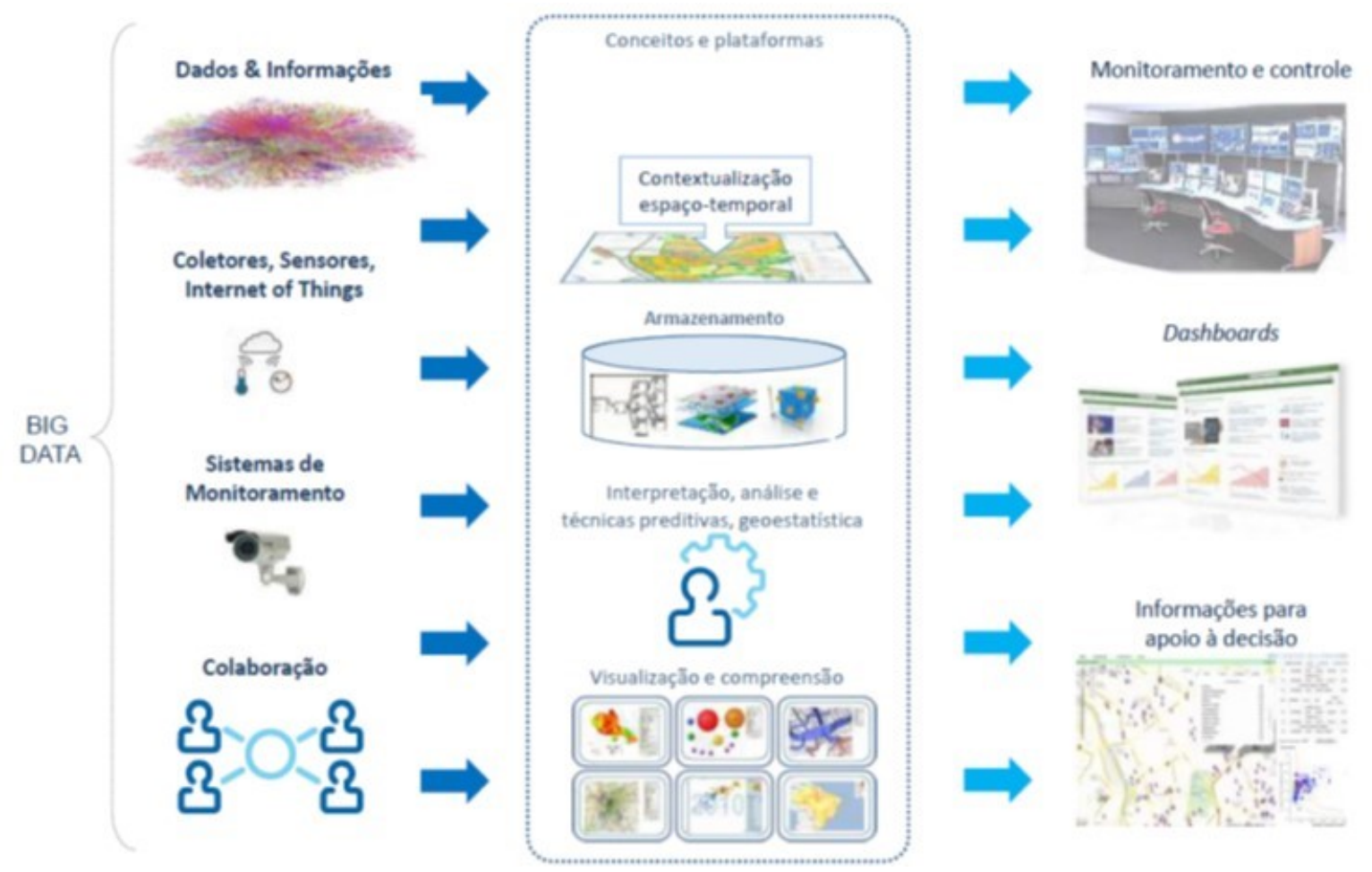

Figura 16: Big Data urbano e inteligência geográfica. Fonte: Francisco (2014).

A infraestrutura dedicada às análises Big data fornece formas abundantes, dinâmicas, bem definidas e relativamente baratas de desempenho em tempo real, e consequentemente de formas de adaptação de governança para os planejadores urbanos, como aponta Kloeckl, Senn e Ratti (2012). Além disso, argumenta-se que ela fornece a base para uma cidade mais transparente, competitiva, eficiente e sustentável (KITCHIN, 2014).

A utilização dos dados provenientes dos produtos de tecnologia da informação e comunicação propicia oportunidades para as empresas que trabalham com processamento de informação e análise de Big Data. Se governos concentrarem os dados dispersos e passarem a disponibilizá-los para as empresas de tecnologia da informação, elas serão beneficiadas e poderão beneficiar a comunidade, ao realizar pesquisas e desenvolver ainda mais seus produtos. 
Também vale destacar que apesar de toda tecnologia existente no momento, um dos maiores problemas é que possíveis soluções no âmbito das cidades demandam mudanças drásticas em sua infraestrutura e nos subsistemas que atualmente mantém a vida urbana (CARVALHO, 2015). É preciso considerar que em alguns casos, ou para algumas cidades, aplicar Big Data para os problemas urbanos demandaria transformar primeiro a cidade numa Smart City.

Além do termo Big Data urbano, foram encontrados na literatura outros termos correlatos, tais como:

- informática urbana: coleta, integração e análise de dados para compreender e melhorar sistemas urbanos e qualidade de vida, ou seja, construir uma cidade instrumentada que produzirá dados para pesquisadores coletarem, analisarem e interpretarem, a fim de melhorar o cotidiano dos cidadãos e a eficiência e saúde a longo prazo das cidades ao redor do mundo

- IoT - Internet of Things, ou Internet das Coisas: a crescente aplicação de dados e de está fornecendo suporte para uma relação muito mais colaborativa entre a gestão das cidade, cidadãos e empresas (UN-HABITAT, 2016)

- CIM - City Information Modeling: BIM - Building Information Modeling, ou Modelagem de Informação da Construção, aplicado à cidade, voltado para a gestão e produção de espaços urbanos, ou Modelagem de Informação da Cidade

- 5D Smart City: modelos 5D que fornecem informações para qualquer projeto de construção para 100 cidades em 12 países, incluindo dados abertos e serviços web, edifícios 3D e outras camadas de infraestrutura, imagens de satélite, redes viárias e de tráfico, clima e serviços de IoT (https://www.cityzenith.com/).

Cabe lembrar que, conforme elucidado anteriormente, as informações pesquisadas acerca de Big Data Urbano contribuíram para compor o conhecimento prévio sobre o assunto, mas que a delimitação do tema da tese não abrange este tópico como essencial para o desenvolvimento do método para retrofit urbano. 


\subsection{A ABNT NBR ISO 37120:2017}

Seja em nível local, regional ou nacional, em países desenvolvidos ou em desenvolvimento, em áreas urbanas ou rurais, comunidades, partes interessadas, seus fornecedores e prestadores de serviços necessitam de diretrizes para melhorar sua resiliência e sustentabilidade. Em um contexto de crescimento populacional global, rápido aumento da urbanização, escassez de recursos e mudanças climáticas, provavelmente estas necessidades não só permanecerão, como também se tornarão cada vez mais incontornáveis (ISO, 2013).

Segundo a ISO - International Organization for Standardization (2013), o número de conferências e seminários internacionais dedicados a cidades e comunidades sustentáveis, verdes, resilientes ou inteligentes, e o número de declarações, diretrizes, relatórios e outras publicações cresce exponencialmente. Mas todos concordam em afirmar que:

- É urgente a elaboração de abordagens de desenvolvimento sustentável para e em comunidades;

- Devido à falta de harmonização, partes interessadas geralmente recorrem a várias diretrizes, benchmarks ou ferramentas de classificação. $\mathrm{O}$ custo financeiro relacionado é significativo e não é compensado por um aumento correspondente em eficiência (ISO, 2013).

O impacto de desafios ecológicos globais, tais como as mudanças climáticas, deve excluir negócios habituais como uma opção acessível e, em algumas partes do mundo, o custo para promoção da sustentabilidade será significativo. Ao mesmo tempo, quanto maior a demora na ação, maiores serão os custos. Como consequência, há a necessidade, e até a urgência, de adoção de abordagens holísticas, intersetoriais e integradas para desenvolvimento sustentável em comunidades de todos os tipos e tamanhos, em seus respectivos níveis de responsabilidade, dentro de um território definido. Algumas normas e documentos de referência também enfatizam a necessidade de seguir abordagens integradas para priorizar propostas de projetos, promovendo a sustentabilidade desde os estágios iniciais, monitorando as alterações de desempenho e melhorando a eficiência econômica (ISO, 2013).

Isto posto, em novembro de 2013 foi criado o Technical Comitee, ou Comitê Técnico, da ISO - International Organization for Standardization de número ISO/TC 268 - 
"Sustainable cities and communities", ou Cidades e comunidades sustentáveis. O escopo deste comitê consiste na normalização no tema e inclui o desenvolvimento de requisitos de sistema de gestão, estruturas, instruções, métodos e ferramentas relevantes para auxiliar comunidades de todos os tipos e tamanhos, partes interessadas, fornecedores e prestadores de serviços, a se tornarem mais sustentáveis e resilientes ao longo de seu ciclo de vida e a demonstrarem seus resultados obtidos neste sentido (ISO, 2013).

Segundo ISO (2013), o ISO/TC 268 tem por objetivo o desenvolvimento de uma abordagem integrada, holística e intersetorial, para que comunidades, suas subdivisões e partes interessadas possam traduzir em sistemas de diretrizes, métodos de apoio e ferramentas personalizadas para suas próprias características e necessidades, levando em conta as especificidades do território ao qual pertencem. Isto pode contribuir, em níveis local, regional e global, em vários aspectos, listados a seguir em ordem alfabética e não em prioridade:

- Aumento da capacitação e governança participativa;

- Aumento de resiliência às consequências das mudanças climáticas;

- Educação;

- Eficiência econômica e sustentabilidade fiscal;

- Envolvimento das partes interessadas;

- Gestão de riscos naturais, industriais e tecnológicos;

- Integração das minorias;

- Integração social e coesão da comunidade;

- Melhoria da segurança e saúde no trabalho;

- Mitigação e adaptação de emissões de gases de efeito estufa;

- Promoção da cultura e patrimônio;

- Proteção e uso sustentável da biodiversidade e dos serviços ecossistêmicos;

- Qualidade dos empregos;

- Redução da pobreza;

- Resiliência aos impactos negativos ambientais e sociais.

Tendo em vista a lista de objetivos, é importante notar a semelhança com vários ODS Objetivos de Desenvolvimento Sustentável, revelando que o ISO/TC 268 tem a intenção de contribuir com os ODS por meio de seu trabalho de normalização. 
Frequentemente, há confusão por conta da uma vasta gama de documentos de referência em desenvolvimento sustentável, de metodologias e ferramentas de avaliação, especialmente pelo acesso limitado a detalhes do sistema pelas autoridades da cidade e partes interessadas. Portanto, um dos principais benefícios de um processo ISO aberto e transparente é permitir que representantes das cidades participem da elaboração de normas e colaborem com suas próprias experiências e contribuições para que ferramentas úteis e globalmente relevantes para sustentabilidade e resiliência de comunidades e cidades possam ser criadas (ISO, 2013).

A estrutura hierárquica do comitê ISO/TC 268 é ilustrada na Figura 17.

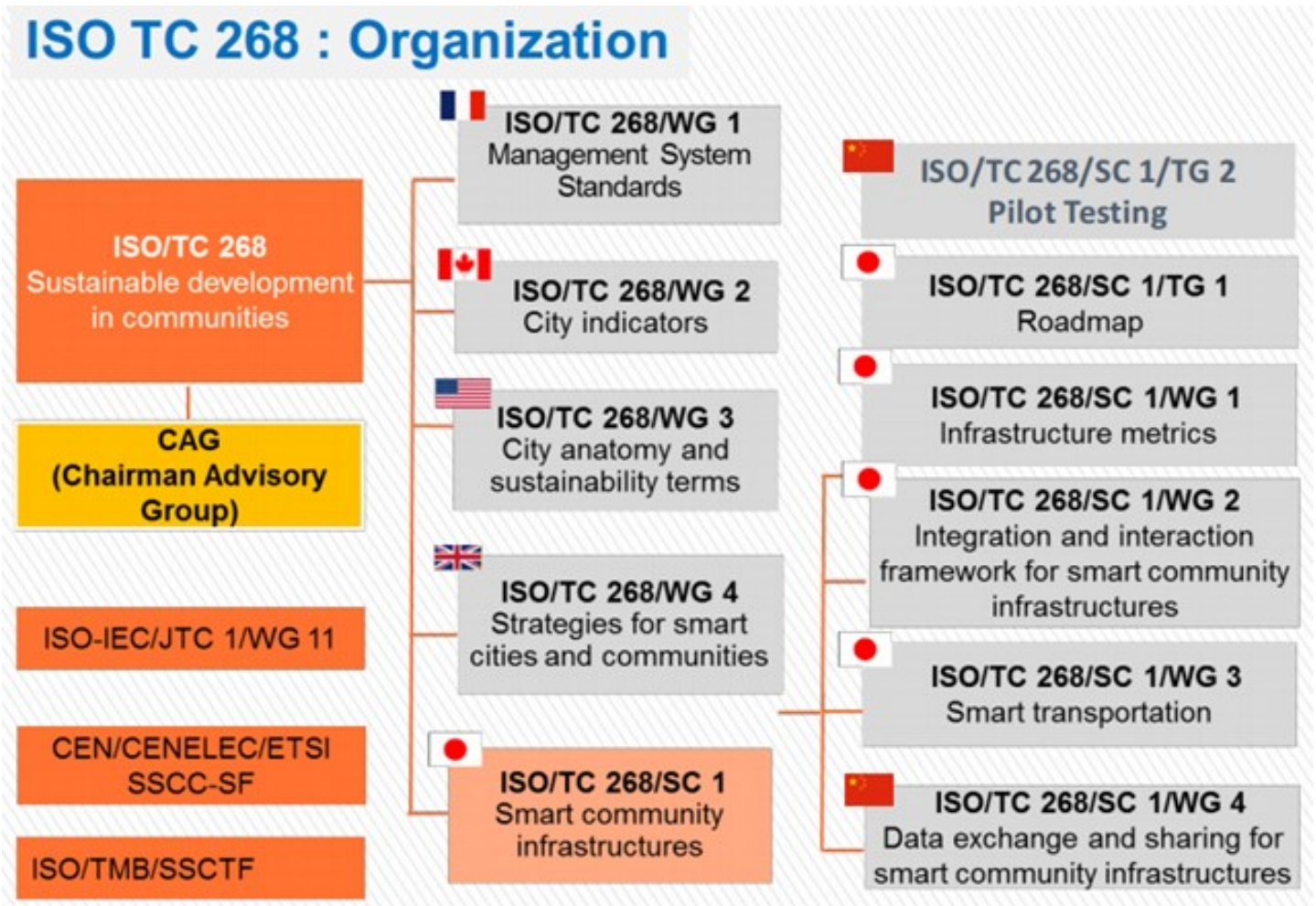

Figura 17: Estrutura hierárquica do ISO/TC-268. Fonte: (GINDROZ, 2017).

Antes do trabalho do ISO/TC 268 não havia nenhuma norma internacional, ISO ou não, sobre o tema de desenvolvimento sustentável e resiliência em comunidades. Entretanto, a série proposta de normas internacionais do ISO/TC 268 está sendo desenvolvida a partir de normas internacionais relevantes e relacionadas a atividades de avaliação de conformidade para auxiliar as comunidades a atingir um melhor desempenho para sustentabilidade e resiliência (ISO, 2013). 
Pode-se questionar se o trabalho do ISO/TC 268 contribui para aliviar ou para aumentar a atual proliferação de documentos de referências ou ferramentas de avaliação. A expectativa é de promover consenso internacional em princípios gerais e em suas aplicações a vários tipos de comunidades urbanas (ISO, 2013).

O programa de trabalho do ISO/TC 268 consiste em uma série de normas internacionais, que inclui MSS - Management System Standards, ou Normas de Sistema de Gestão, que estabelecem uma série de requisitos e princípios gerais que devem ser utilizados por uma comunidade e suas subdivisões para demonstrar o progresso em alcançar a sustentabilidade e resiliência (ISO, 2013).

A série proposta de normas internacionais a serem elaboradas pelo ISO/TC 268 pretende promover o desenvolvimento, implementação, avaliação e melhoria contínua de abordagens holísticas e integradas para desenvolvimento sustentável e resiliência de comunidades. As normas irão auxiliar as comunidades a atender as suas necessidades, a desenvolver a colaboração de todos os envolvidos em seu respectivo nível de responsabilidade, e a comunicar seu desempenho. A série prevista de normas internacionais do ISO/TC 268 intenciona facilitar o desenvolvimento de estratégias eficientes e coerentes, promovendo a comunicação e colaboração entre as partes interessadas, proporcionando o surgimento de novas comunidades sustentáveis e resilientes e contribuindo para desenvolver as existentes (ISO, 2013).

Mais especificamente, a série proposta de normas internacionais irá contribuir com:

- o encontro e a construção de consenso em modos integrados de operação;

- a adoção de políticas orçamentárias intersetoriais, multidisciplinares, de ciclo de vida;

- a melhoria de eficiência, resiliência e sustentabilidade de recursos; e

- a orientação e avaliação do desempenho de comunidades em sustentabilidade e resiliência (ISO, 2013).

Consequentemente, pretende-se que comunidades tornem-se capazes de conceber políticas, programas e especificações relacionadas a objetivos de desenvolvimento sustentável que elas próprias adotam, em linha com políticas públicas e em conformidade com a 
legislação, e de estabelecer sistemas de monitoramento relativos a um conjunto de metas de sustentabilidade segundo princípios “do berço ao túmulo" (ISO, 2013).

Um dos benefícios previstos da série proposta de normas internacionais do ISO/TC 268 é proporcionar a contratantes uma estrutura operacional para facilitar e melhorar suas interações com as comunidades. Além disso, as normas podem contribuir para consolidar as competências, desenvolver produtos e serviços voltados a sustentabilidade sob medida para a comunidade, e direcionar o surgimento de novos ramos de atividade na gestão de sustentabilidade. Cidadãos e usuários também podem ser beneficiados com a série proposta de normas internacionais do ISO/TC 268, pois as comunidades serão capazes de proporcionar um ambiente sustentável de subsistência e oportunidades para campanhas de conscientização, participação e envolvimento, e estimulando, assim, estilos de vida ambientalmente amigáveis (ISO, 2013).

Prováveis representantes de partes interessadas em participar do ISO/TC 268 seriam: agências e secretarias de governo, gestores e autoridades locais, grupos comunitários de residentes, empreendedores públicos e privados, e investidores, projetistas, construtores e provedores de serviços municipais (ISO, 2013).

Desde sua criação, em novembro de 2013, o ISO/TC 268 já publicou sete normas ISO, as primeiras da organização voltadas exclusivamente a cidades, listadas em ordem de numeração:

- ISO 37100:2016 - Sustainable development of communities - Vocabulary (ISO, 2016b), adotada como ABNT NBR ISO 37100:2017 - Desenvolvimento Sustentável em Comunidades - Vocabulário (ABNT, 2017b)

- ISO 37101:2016 - Sustainable development in communities - Management system for sustainable development - Requirements with guidance for use (ISO, 2016a), adotada como ABNT NBR ISO 37101:2017 - Desenvolvimento Sustentável em Comunidades - Sistema de gestão para desenvolvimento sustentável - Requisitos com orientação para uso (ABNT, 2017c)

- ISO 37106:2018 - Sustainable cities and communities - Guidance on establishing smart city operating models for sustainable communities, ou Cidades e comunidades 
sustentáveis - Diretrizes para estabelecimento de modelos operacionais de cidades inteligentes para comunidades sustentáveis

- ISO 37120:2014 - Sustainable development of communities - Indicators for city services and quality of life (ISO, 2014), adotada como ABNT NBR ISO 37120:2017 - Desenvolvimento Sustentável de Comunidades - Indicadores para serviços urbanos e qualidade de vida (ABNT, 2017a)

- ISO 37153:2017 - Smart community infrastructures - Maturity model for assessment and improvement, ou Infraestruturas inteligentes da comunidade Modelo de maturidade para avaliação e melhoria

- ISO 37154:2017 - Smart community infrastructures - Best practice guidelines for transportation, ou Infraestruturas inteligentes da comunidade - Diretrizes de melhores práticas para o transporte

- ISO 37157:2018 - Smart community infrastructures - Smart transportation for compact cities

A primeira Norma publicada pelo ISO/TC 268, a ISO 37120:2014, mencionada anteriormente, passou por um processo de revisão e foi publicada em julho de 2018 a nova versão desta norma, a ISO 37120:2018 (ISO, 2018b), que cancela e substitui a versão anterior.

Além das já publicadas, há uma série de novas normas em desenvolvimento pelo ISO/TC 268, a saber:

- ISO 37104: Sustainable development in communities - Guide to establishing strategies for smart cities and communities

- ISO 37105: Sustainable cities and communities - Descriptive framework for cities and communities

- ISO 37122: Sustainable development in communities - Indicators for Smart Cities

- ISO 37123: Sustainable Development in Communities - Indicators for Resilient Cities

- ISO 37155: Framework for integration and operation of smart community infrastructures - Part 1: Opportunities and challenges from interactions in smart community infrastructures from all aspects through the life-cycle 
- ISO 37156: Smart community infrastructures - Guidelines on Data Exchange and Sharing for Smart Community Infrastructures

- ISO 37158: Smart community infrastructures - Battery-powered bus transportation systems to solve environmental and safety issues in cities

- ISO 37159: Smart community infrastructures - Smart transportation for rapid transit in/between large city zones and the surrounding areas

- ISO 37160: Smart community infrastructure - Electric power infrastructure Measurement method for quality of thermal power station infrastructure and requirement for plant operation and maintenance practice

- ISO 37161: Smart community infrastructures - Guidance on smart transportation to save energy consumption in transportation services in cities

- ISO 37162: Smart community infrastructures - Smart transportation for new towns

- ISO 37163: Smart community infrastructures - Guidance on smart transportation for allocation of parking lots in cities

A Figura 18 ilustra a integração dos indicadores propostos pela ISO 37120:2018 (ISO, 2018b) com demais indicadores propostos pelas outras normas em desenvolvimento pelo ISO/TC 268, principalmente a ISO 37122 e ISO 37123 relacionadas acima.

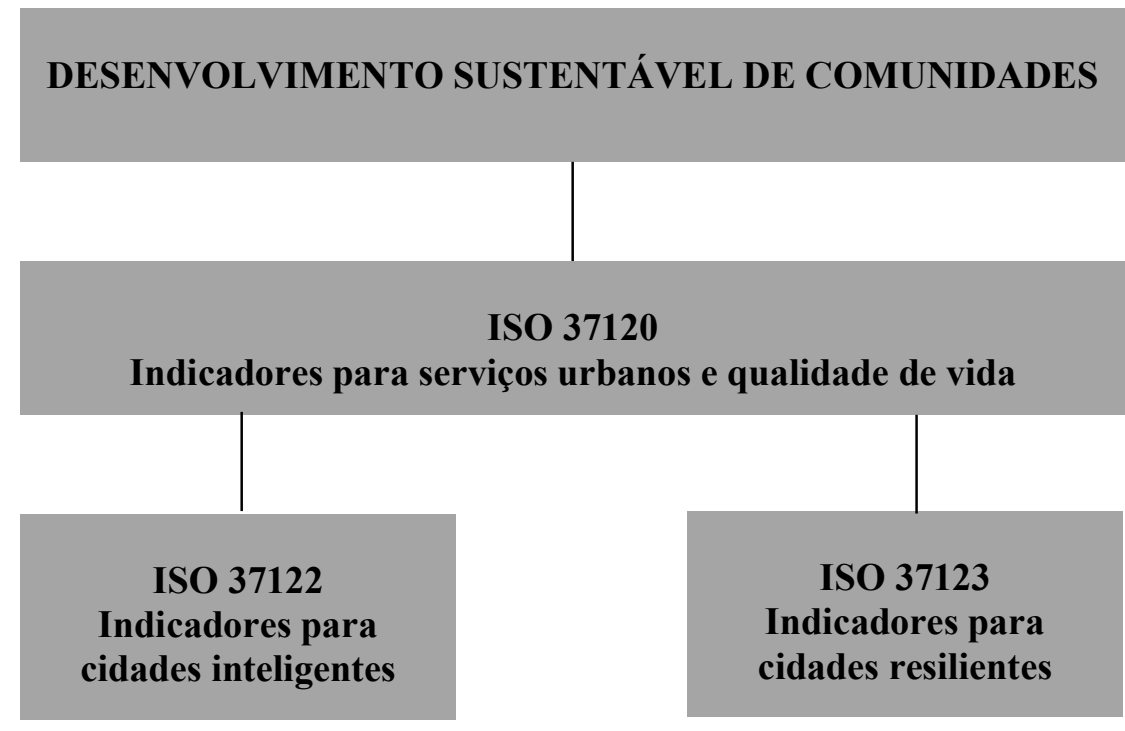

Figura 18: Integração dos indicadores da ISO 37120 com as demais normas em elaboração pelo ISO/TC 268. Fonte: (ISO, 2018b).

No Brasil, em outubro de 2015, foi criada pela ABNT - Associação Brasileira de Normas Técnicas, a ABNT/CEE-268 - Comissão de Estudo Especial de Desenvolvimento 
Sustentável em Comunidades, de mesmo número 268 do ISO/TC, pois se trata de uma comissão espelho, nos moldes da ABNT, ou seja, reflete o estudo e a eventual adoção das publicações do ISO/TC-268 para o país. A ABNT/CEE-268 realizou a adoção das três normas já publicadas, elaborando a NBR ISO 37120:2017, a NBR ISO 37100:2017 e a ISO 37101:2017, adaptadas tecnicamente à realidade brasileira.

A NBR ISO 37120:2017 - "Desenvolvimento Sustentável de Comunidades Indicadores para serviços urbanos e qualidade de vida", é a primeira norma internacional para indicadores urbanos. Trata-se de uma norma ISO de referência delineando medidas-chave para avaliar a prestação de serviços de uma cidade e a qualidade de vida, com a intenção de auxiliar gestores municipais, políticos, pesquisadores, empresários, urbanistas, designers e outros profissionais a se concentrarem em questões-chave, e pôr em prática políticas para cidades mais habitáveis, tolerantes, sustentáveis, resilientes, economicamente atraentes e prósperas. Cabe salientar que a NBR ISO 37120:2017 não traz valores de referência, tampouco metas para serem seguidas.

Os indicadores incluídos na NBR ISO 37120:2017 podem ajudar as cidades a avaliar o seu desempenho e medir o seu progresso gradativamente, com o objetivo final de melhorar a qualidade de vida e sustentabilidade. A abordagem uniforme da norma permite que as cidades comparem onde estão em relação a outras cidades, e esta informação pode, por sua vez, ser usada para identificar as melhores práticas e aprender uma com a outra (ABNT, 2017a).

A NBR ISO 37120:2017 pode ser usada por qualquer cidade, município ou governo local que desejam medir o seu desempenho de forma comparável e verificável, independentemente do tamanho, localização ou nível de desenvolvimento. Esta norma define e estabelece os métodos de mensuração de um abrangente conjunto de indicadores que permite que uma cidade, independentemente do seu tamanho, possa monitorar e medir seu desempenho social, econômico e ambiental em relação a outras cidades (ABNT, 2017a).

Em suma, a utilização dos indicadores contidos na NBR ISO 37120:2017 pode trazer os seguintes benefícios (ABNT, 2017a):

- Gestão e prestação de serviços mais eficazes

- Referências internacionais e metas 
- Benchmarking local e planejamento

- Tomada de ações informadas por políticos e gestores das cidades

- Aprendizado transversal entre cidades

- Alavancagem de financiamento e reconhecimento em entidades internacionais

- Alavancagem de financiamento por cidades com níveis superiores de governo

- Estrutura para planejamento sustentável

- Transparência e dados abertos para atratividade de investimentos

- Dados comparáveis para tomadas de ação, discernimento e benchmarking global

O termo "cidade" é definido pela NBR ISO 37100:2017 (ABNT, 2017b, p. 4) como "comunidade urbana sob uma delimitação administrativa específica", às vezes referida como uma municipalidade ou um governo local. O termo "comunidade", por sua vez, é definido como "grupo de pessoas com um arranjo de responsabilidades, atividades e relações" (ABNT, 2017b, p. 4). Em muitos contextos, mas não todos, uma comunidade é definida por uma delimitação geográfica.

A NBR ISO 37120:2017 apresenta 17 Seções que dividem, ao todo, 100 indicadores, sendo que 46 são considerados essenciais e 54 são de apoio, conforme pontuados na Quadro 6. Além destes, há 39 indicadores de perfil, que servem para caracterizar a cidade.

Quadro 6: Seções e indicadores da NBR ISO 37120:2017. Fonte: (ABNT, 2017a).

\begin{tabular}{||c|c|c|l||}
\hline \multirow{2}{*}{ Seção } & No. & Tipo & \multicolumn{1}{|c||}{ Tema/Indicador da NBR ISO 37120:2017 } \\
\hline \hline \multirow{4}{*}{$\begin{array}{c}\text { Seção 5 } \\
\text { Economia }\end{array}$} & 5.1 & Essencial & Taxa de desemprego da cidade \\
\cline { 2 - 5 } & 5.2 & Essencial & $\begin{array}{l}\text { Valor de avaliação de propriedades comerciais e industriais como uma } \\
\text { porcentagem do valor de avaliação total de todas as propriedades }\end{array}$ \\
\cline { 2 - 5 } & 5.3 & Essencial & Porcentagem da população abaixo da linha de pobreza \\
\cline { 2 - 5 } & 5.5 & Apoio & Porcentagem da população com emprego em tempo integral \\
\cline { 2 - 5 } & 5.6 & Apoio & Taxa de desemprego de jovens \\
\cline { 2 - 5 } & 5.7 & Apoio & Número de empresas por 100.000 habitantes novas patentes por 100.000 habitantes por ano \\
\hline \multirow{5}{*}{\begin{tabular}{c} 
Seção 6 \\
\cline { 2 - 5 }
\end{tabular}} & 6.1 & Essencial & Porcentagem da população feminina em idade escolar matriculada em escolas \\
\cline { 2 - 5 } & 6.2 & Essencial & $\begin{array}{l}\text { Porcentagem de estudantes com ensino primário completo (taxa de } \\
\text { sobrevivência) }\end{array}$ \\
\cline { 2 - 5 } & 6.3 & Essencial & $\begin{array}{l}\text { Porcentagem de estudantes com ensino secundário completo (taxa de } \\
\text { sobrevivência) }\end{array}$ \\
\cline { 2 - 5 } & 6.4 & Essencial & Relação estudante/professor no ensino primário \\
\cline { 2 - 5 } & 6.5 & Apoio & Porcentagem de população masculina em idade escolar matriculada em escolas \\
\cline { 2 - 5 } & 6.6 & Apoio & Porcentagem de população em idade escolar matriculada em escolas \\
\cline { 2 - 5 } & 6.7 & Apoio & Número de indivíduos com ensino superior completo por 100.000 habitantes \\
\hline
\end{tabular}




\begin{tabular}{|c|c|c|c|}
\hline & & & Tema/Indicador da NBR ISO 37120:2017 \\
\hline Seção & No. & Tipo & Descrição \\
\hline \multirow{7}{*}{$\begin{array}{l}\text { Seção } 7 \\
\text { Energia }\end{array}$} & 7.1 & Essencial & Uso de energia elétrica residencial total per capita (kWh/ano) \\
\hline & 7.2 & Essencial & $\begin{array}{l}\text { Porcentagem de habitantes da cidade com fornecimento regular de energia } \\
\text { elétrica }\end{array}$ \\
\hline & 7.3 & Essencial & Consumo de energia de edifícios públicos por ano $\left(\mathrm{kWh} / \mathrm{m}^{2}\right)$ \\
\hline & 7.4 & Essencial & $\begin{array}{l}\text { Porcentagem da energia total proveniente de fontes renováveis, como parte do } \\
\text { consumo total de energia da cidade }\end{array}$ \\
\hline & 7.5 & Apoio & Uso total de energia elétrica per capita (kWh/ano) \\
\hline & 7.6 & Apoio & Número médio de interrupções de energia elétrica por consumidor por ano \\
\hline & 7.7 & Apoio & Duração média das interrupções de energia elétrica (em horas) \\
\hline \multirow{8}{*}{$\begin{array}{c}\text { Seção } 8 \\
\text { Meio } \\
\text { Ambiente }\end{array}$} & 8.1 & Essencial & Concentração de material particulado fino (PM 2.5) \\
\hline & 8.2 & Essencial & Concentração de material particulado (PM 10) \\
\hline & 8.3 & Essencial & Emissão de gases de efeito de estufa medida em toneladas per capita \\
\hline & 8.4 & Apoio & Concentração de $\mathrm{NO}_{2}$ (dióxido de nitrogênio) \\
\hline & 8.5 & Apoio & Concentração de $\mathrm{SO}_{2}$ (dióxido de enxofre) \\
\hline & 8.6 & Apoio & Concentração de $\mathrm{O}_{3}$ (ozônio) \\
\hline & 8.7 & Apoio & Poluição sonora \\
\hline & 8.8 & Apoio & Variação percentual em número de espécies nativas \\
\hline \multirow{4}{*}{$\begin{array}{l}\text { Seção } 9 \\
\text { Finanças }\end{array}$} & 9.1 & Essencial & $\begin{array}{l}\text { Taxa de endividamento (expansão do serviço da dívida como uma porcentagem } \\
\text { da receita própria do município) }\end{array}$ \\
\hline & 9.2 & Apoio & Despesas de capital como porcentagem de despesas totais \\
\hline & 9.3 & Apoio & Porcentagem da receita própria em função do total das receitas \\
\hline & 9.4 & Apoio & Porcentagem dos impostos recolhidos em função dos impostos cobrados \\
\hline \multirow{6}{*}{$\begin{array}{l}\text { Seção } 10 \\
\text { Resposta a } \\
\text { Incêndios } \\
\text { e Emer- } \\
\text { gências }\end{array}$} & 10.1 & Essencial & Número de bombeiros por 100.000 habitantes \\
\hline & 10.2 & Essencial & Número de mortes relacionadas a incêndios por 100.000 habitantes \\
\hline & 10.3 & Essencial & Número de mortes relacionadas a desastres naturais por 100.000 habitantes \\
\hline & 10.4 & Apoio & Número de bombeiros voluntários e em tempo parcial por 100.000 habitantes \\
\hline & 10.5 & Apoio & Tempo de resposta dos serviços de emergência a partir do primeiro chamado \\
\hline & 10.6 & Apoio & Tempo de resposta do Corpo de Bombeiros a partir do primeiro chamado \\
\hline \multirow{6}{*}{$\begin{array}{c}\text { Seção } 11 \\
\text { Gover- } \\
\text { nança }\end{array}$} & 11.1 & Essencial & $\begin{array}{l}\text { Porcentagem de participação dos eleitores nas últimas eleições municipais em } \\
\text { função do total de eleitores aptos a votar }\end{array}$ \\
\hline & 11.2 & Essencial & $\begin{array}{l}\text { Porcentagem de mulheres eleitas em função do número total de eleitos na } \\
\text { gestão da cidade }\end{array}$ \\
\hline & 11.3 & Apoio & Porcentagem de mulheres empregadas na gestão da cidade \\
\hline & 11.4 & Apoio & $\begin{array}{l}\text { Número de condenações de servidores da cidade por corrupção e/ou suborno } \\
\text { por } 100.000 \text { habitantes }\end{array}$ \\
\hline & 11.5 & Apoio & $\begin{array}{l}\text { Representação de cidadãos: número de autoridades locais eleitas para o cargo } \\
\text { por } 100.000 \text { habitantes }\end{array}$ \\
\hline & 11.6 & Apoio & $\begin{array}{l}\text { Porcentagem de eleitores registrados em função da população com idade para } \\
\text { votar }\end{array}$ \\
\hline \multirow{7}{*}{$\begin{array}{l}\text { Seção } 12 \\
\text { Saúde }\end{array}$} & 12.1 & Essencial & Expectativa média de vida \\
\hline & 12.2 & Essencial & Número de leitos hospitalares por 100.000 habitantes \\
\hline & 12.3 & Essencial & Número de médicos por 100.000 habitantes \\
\hline & 12.4 & Essencial & $\begin{array}{l}\text { Taxa de mortalidade de crianças menores de cinco anos a cada } 1.000 \text { nascidos } \\
\text { vivos }\end{array}$ \\
\hline & 12.5 & Apoio & $\begin{array}{l}\text { Número de pessoas da equipe de enfermagem e obstetrícia por } 100.000 \\
\text { habitantes }\end{array}$ \\
\hline & 12.6 & Apoio & Número de profissionais de saúde mental por 100.000 habitantes \\
\hline & 12.7 & Apoio & Taxa de suicídio por 100.000 habitantes \\
\hline \multirow{2}{*}{$\begin{array}{l}\text { Seção } 13 \\
\text { Recreação }\end{array}$} & 13.1 & Apoio & Área em $\mathrm{m}^{2}$ de espaços públicos de recreação cobertos per capita \\
\hline & 13.2 & Apoio & Área em $\mathrm{m}^{2}$ de espaços públicos de recreação ao ar livre per capita \\
\hline \multirow{4}{*}{$\begin{array}{l}\text { Seção } 14 \\
\text { Segurança }\end{array}$} & 14.1 & Essencial & Número de agentes de polícia por 100.000 habitantes \\
\hline & 14.2 & Essencial & Número de homicídios por 100.000 habitantes \\
\hline & 14.3 & Apoio & Crimes contra a propriedades por 100.000 habitantes \\
\hline & 14.4 & Apoio & Tempo de resposta da polícia a partir do primeiro chamado \\
\hline
\end{tabular}




\begin{tabular}{|c|c|c|c|}
\hline \multicolumn{4}{|r|}{ Tema/Indicador da NBR ISO 37120:2017 } \\
\hline Seção & No. & Tipo & Descrição \\
\hline & 14.5 & Apoio & Taxa de crimes violentos por 100.000 habitantes \\
\hline \multirow{3}{*}{$\begin{array}{l}\text { Seção } 15 \\
\text { Habitação }\end{array}$} & 15.1 & Essencial & Porcentagem da população urbana morando em favelas \\
\hline & 15.2 & Apoio & Número de sem-teto por 100.000 habitantes \\
\hline & 15.3 & Apoio & Porcentagem de moradias sem títulos de propriedade registrados \\
\hline \multirow{10}{*}{$\begin{array}{l}\text { Seção } 16 \\
\text { Resíduos } \\
\text { Sólidos }\end{array}$} & 16.1 & Essencial & Porcentagem da população urbana com coleta regular de lixo (domiciliar) \\
\hline & 16.2 & Essencial & Total de coleta de resíduos sólidos municipais per capita \\
\hline & 16.3 & Essencial & Porcentagem de resíduos sólidos urbanos que são reciclados \\
\hline & 16.4 & Apoio & Porcentagem de resíduos sólidos urbanos dispostos em aterros sanitários \\
\hline & 16.5 & Apoio & Porcentagem de resíduos sólidos urbanos descartados para incineração \\
\hline & 16.6 & Apoio & Porcentagem de resíduos sólidos urbanos queimados a céu aberto \\
\hline & 16.7 & Apoio & Porcentagem de resíduos sólidos urbanos dispostos a céu aberto \\
\hline & 16.8 & Apoio & Porcentagem de resíduos sólidos urbanos dispostos por outros meios \\
\hline & 16.9 & Apoio & Geração de resíduos perigosos per capita \\
\hline & 16.10 & Apoio & Porcentagem de resíduos urbanos perigosos que são reciclados \\
\hline \multirow{3}{*}{$\begin{array}{c}\text { Seção } 17 \\
\text { Telecomu- } \\
\text { nicações e } \\
\text { Inovação } \\
\end{array}$} & 17.1 & Essencial & Número de conexões de internet por 100.000 habitantes \\
\hline & 17.2 & Essencial & Número de conexões de telefone celular por 100.000 habitantes \\
\hline & 17.3 & Apoio & Número de conexões de telefone fixo por 100.000 habitantes \\
\hline \multirow{9}{*}{$\begin{array}{l}\text { Seção } 18 \\
\text { Transporte }\end{array}$} & 18.1 & Essencial & Quilômetros de sist. de transporte público de alta capacidade por 100.000 hab. \\
\hline & 18.2 & Essencial & Quilômetros de sist. de transporte público de média capac. por 100.000 hab. \\
\hline & 18.3 & Essencial & Número anual de viagens em transporte público per capita \\
\hline & 18.4 & Essencial & Número de automóveis privados per capita \\
\hline & 18.5 & Apoio & $\begin{array}{l}\text { Porcentagem de passageiros que se deslocam para o trabalho de forma } \\
\text { alternativa ao automóvel privado }\end{array}$ \\
\hline & 18.6 & Apoio & Número de veículos motorizados de duas rodas per capita \\
\hline & 18.7 & Apoio & Quilômetros de ciclovias e ciclofaixas por 100.000 habitantes \\
\hline & 18.8 & Apoio & Mortalidades de trânsito por 100.000 habitantes \\
\hline & 18.9 & Apoio & Conectividade aérea (número de partidas de voos comerciais sem escalas) \\
\hline \multirow{4}{*}{$\begin{array}{c}\text { Seção } 19 \\
\text { Planeja- } \\
\text { mento } \\
\text { Urbano }\end{array}$} & 19.1 & Essencial & Áreas verdes (hectares) por 100.000 habitantes \\
\hline & 19.2 & Apoio & Número de árvores plantadas anualmente por 100.000 habitantes \\
\hline & 19.3 & Apoio & $\begin{array}{l}\text { Porcentagem de área de assentamentos informais em função da área total da } \\
\text { cidade }\end{array}$ \\
\hline & 19.4 & Apoio & Relação empregos/habitação \\
\hline \multirow{5}{*}{$\begin{array}{l}\text { Seção } 20 \\
\text { Esgotos }\end{array}$} & 20.1 & Essencial & $\begin{array}{l}\text { Porcentagem da população da cidade atendida por sistemas de coleta e } \\
\text { afastamento de esgoto }\end{array}$ \\
\hline & 20.2 & Essencial & Porcentagem do esgoto da cidade que não recebeu qualquer tratamento \\
\hline & 20.3 & Essencial & Porcentagem do esgoto da cidade que recebe tratamento primário \\
\hline & 20.4 & Essencial & Porcentagem do esgoto da cidade que recebe tratamento secundário \\
\hline & 20.5 & Essencial & Porcentagem do esgoto da cidade que recebe tratamento terciário \\
\hline \multirow{7}{*}{$\begin{array}{c}\text { Seção } 21 \\
\text { Água e } \\
\text { Sanea- } \\
\text { mento }\end{array}$} & 21.1 & Essencial & $\begin{array}{l}\text { Porcentagem da população da cidade com serviço de abastecimento de água } \\
\text { potável }\end{array}$ \\
\hline & 21.2 & Essencial & $\begin{array}{l}\text { Porcentagem da população da cidade com acesso sustentável a uma fonte de } \\
\text { água adequada para consumo }\end{array}$ \\
\hline & 21.3 & Essencial & Porcentagem da população da cidade com acesso a saneamento melhorado \\
\hline & 21.4 & Essencial & Consumo doméstico total de água per capita (litros/dia) \\
\hline & 21.5 & Apoio & Consumo total de água per capita (litros/dia) \\
\hline & 21.6 & Apoio & $\begin{array}{l}\text { Valor médio anual de horas de interrupção do abastecimento de água por } \\
\text { domicílio }\end{array}$ \\
\hline & 21.7 & Apoio & Porcentagem de perdas de água (água não faturada) \\
\hline
\end{tabular}

A partir da publicação da ISO 37120:2014, foi realizada uma comparação com os indicadores da norma e os demais sistemas de indicadores de sustentabilidade urbana 
estudados nesta pesquisa. Primeiramente, tomando as 30 principais variáveis nos 39 sistemas de indicadores de sustentabilidade urbana analisados (ver Tabela 2, pág. 69), a proporção média destas variáveis é de $48 \%$, ou seja, a cada 100 variáveis em cada sistema de indicadores, 48 são estas 30 mais importantes, ou principais. Esta proporção se verifica na ISO 37120:2014, uma vez que 46\% dos seus indicadores são considerados essenciais.

Comparando-se as 30 variáveis principais da pesquisa com os 100 indicadores da ISO 37120:2014, observam-se 27 coincidências. Portanto, nota-se que, dentre as variáveis mais utilizadas, há uma forte correlação com aqueles que foram escolhidos pela ISO 37120:2014.

Um ponto a salientar é o maior enfoque político e social da ISO, com variáveis que avaliam o poder de voto e participação em eleições de gêneros e classes diferentes, por exemplo. Além de que as variáveis ambientais são também em menor número, o que pode ser explicado pela abordagem em relação às cidades já construídas e a vida nelas, deixando de lado atividades que possam ser necessárias nestes locais, porém que ocorram distantes deles, como, por exemplo a desertificação e esgotamento de recursos não renováveis.

Ademais, têm-se diferenças entre os índices de países desenvolvidos e aqueles em desenvolvimento, como indicadores americanos que consideram proporção de obesos na população, enquanto que sistemas de indicadores de Singapura e Vietnã, por exemplo, chegam a desconsiderar qualidade do ar e da água. O que traz a questão da dificuldade de determinação de um índice global único, que se viu com a ISO 37120:2014.

Internacionalmente, o grupo WCCD - World Council on City Data, em parceria com agências das Nações Unidas, a saber UNEP - United Nations Environment Programme e UNISDR - United Nations International Strategy for Disaster Reduction, e associações e redes como ICLEI - International Council for Local Environmental Initiatives e outras, reúne informações sobre indicadores e apresenta um sistema de certificação de cidades pela ISO 37120:2014. A Figura 19 mostra os níveis e critérios de certificação pela ISO 37120:2014 do WCCD, a Figura 20 localiza as 58 cidades e o Quadro 7 lista estas cidades já certificadas pela ISO 37120:2014 pelo WCCD, até julho de 2018, informando os respectivos níveis de certificação obtidos. Nenhuma cidade brasileira foi ainda submetida ao processo de certificação pela ISO 37120:2014 do WCCD, até o momento de publicação deste texto. 


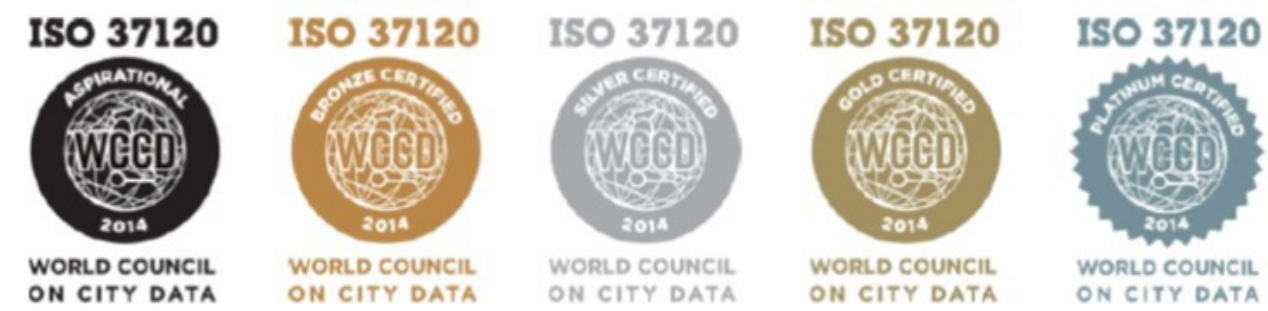

\begin{tabular}{|c|c|c|c|c|}
\hline ASPIRATIONAL & BRONZE & SILVER & GOLD & PLATINUM \\
\hline $\begin{array}{l}30-45 \text { Core } \\
\text { Indicators }\end{array}$ & $\begin{array}{c}46-59 \\
\text { Indicators } \\
\text { (46 Core }+0-13 \\
\text { Supporting) }\end{array}$ & $\begin{array}{c}60-75 \\
\text { Indicators } \\
\text { (46 Core }+14- \\
29 \text { Supporting) }\end{array}$ & $\begin{array}{c}76-90 \\
\text { Indicators } \\
\text { (46 Core }+30- \\
44 \text { Supporting) }\end{array}$ & $\begin{array}{c}91-100 \\
\text { Indicators } \\
\text { (46 Core }+45-54 \\
\text { Supporting) }\end{array}$ \\
\hline
\end{tabular}

Figura 19: Níveis de certificação pela ISO 37120:2014 praticado pelo WCCD. Fonte: WCCD (2015).

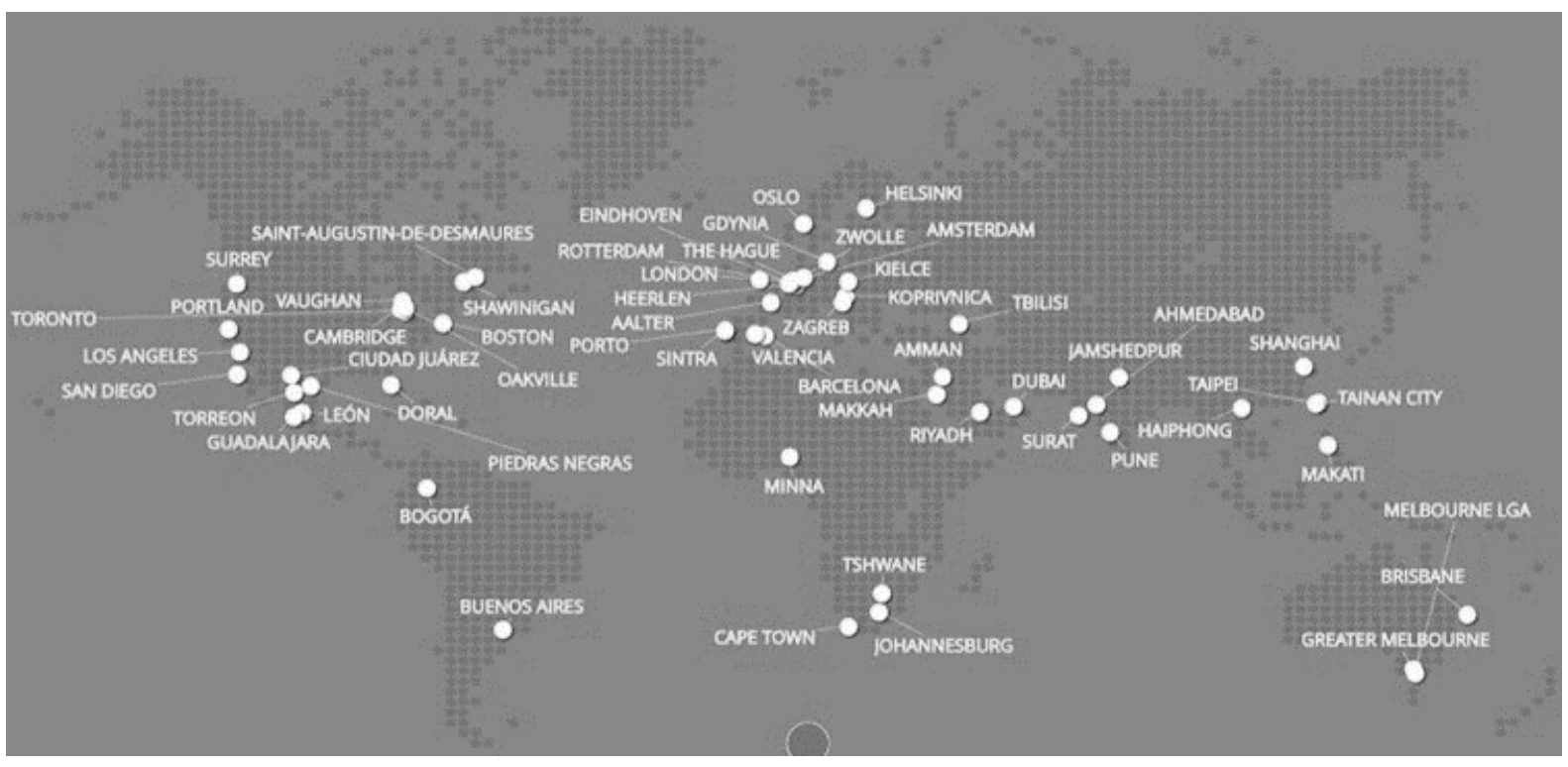

Figura 20: As 58 cidades que receberam certificação pela ISO 37120:2014 do WCCD. Fonte: (WCCD, 2018).

Quadro 7: As 58 cidades já certificadas pela ISO 37120:2014 pelo WCCD, com respectivo nível de certificação.

Fonte: http://www.dataforcities.org/global-cities-registry (WCCD, 2018).

\begin{tabular}{|c|c|c|c|c|}
\hline & Cidade & País & Ano & $\begin{array}{c}\text { Nível de } \\
\text { Certificação }\end{array}$ \\
\hline 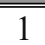 & Aalter & Belgium & 2017 & Platinum \\
\hline 2 & Ahmedabad & India & 2017 & Platinum \\
\hline 3 & Amman & Jordan & 2014 e 2015 & Platinum \\
\hline \multirow{2}{*}{4} & \multirow{2}{*}{ Amsterdam } & \multirow{2}{*}{ Netherlands } & 2014 & Aspirational \\
\hline & & & 2015 e 2016 & Gold \\
\hline 5 & Riyadh & Saudi Arabia & 2016 & Gold \\
\hline 5 & Barcelona & Spain & 2014 & Platinum \\
\hline 6 & Bogotá & Colombia & 2014 & Aspirational \\
\hline 7 & Boston & United States of America & 2014 a 2017 & Platinum \\
\hline 8 & Brisbane & Australia & 2016 e 2017 & Platinum \\
\hline
\end{tabular}




\begin{tabular}{|c|c|c|c|c|}
\hline & Cidade & País & Ano & $\begin{array}{c}\text { Nível de } \\
\text { Certificação }\end{array}$ \\
\hline \multirow{2}{*}{9} & \multirow{2}{*}{ Buenos Aires } & \multirow{2}{*}{ Argentina } & 2014 & Gold \\
\hline & & & 2015 e 2016 & Platinum \\
\hline 10 & Cambridge & Canada & 2016 e 2017 & Platinum \\
\hline 11 & Cape Town & South Africa & 2016 & Aspirational \\
\hline 12 & Ciudad Juárez & Mexico & 2017 & Aspirational \\
\hline 13 & Doral & United States of America & 2016 & Platinum \\
\hline 14 & Dubai & United Arab Emirates & 2014 e 2015 & Platinum \\
\hline 15 & Eindhoven & Netherlands & 2016 & Platinum \\
\hline 16 & Gdynia & Poland & 2017 & Aspirational \\
\hline 17 & Greater Melbourne & Australia & 2015 e 2016 & Aspirational \\
\hline 18 & Guadalajara & Mexico & 2014 a 2016 & Platinum \\
\hline 19 & Haiphong & Vietnam & 2014 & Aspirational \\
\hline 20 & Heerlen & Netherlands & 2016 & Platinum \\
\hline 21 & Helsinki & Finland & 2014 & Aspirational \\
\hline 22 & Jamshedpur & India & 2016 & Gold \\
\hline 23 & Johannesburg & South Africa & 2014 e 2016 & Aspirational \\
\hline 24 & Kielce & Poland & 2017 & Platinum \\
\hline 25 & Koprivnica & Croatia & 2016 & Platinum \\
\hline 26 & León & Mexico & 2015 & Platinum \\
\hline 27 & London & United Kingdom & 2014 e 2015 & Platinum \\
\hline 28 & Los Angeles & United States of America & 2015 e 2017 & Platinum \\
\hline 29 & Makati & Philippines & 2014 e 2015 & Platinum \\
\hline \multirow{2}{*}{30} & \multirow{2}{*}{ Makkah } & \multirow{2}{*}{ Saudi Arabia } & 2014 & Gold \\
\hline & & & 2015 & Platinum \\
\hline \multirow{2}{*}{31} & \multirow{2}{*}{ Melbourne } & \multirow{2}{*}{ Australia } & 2014 & Gold \\
\hline & & & 2015 e 2016 & Platinum \\
\hline 32 & Minna & Nigeria & 2014 & Aspirational \\
\hline 33 & Oakville & Canada & 2016 e 2017 & Platinum \\
\hline 34 & Oslo & Norway & 2016 & Platinum \\
\hline 35 & Piedras Negras & Mexico & 2018 & Platinum \\
\hline 36 & Portland & United States of America & 2017 & Platinum \\
\hline \multirow{2}{*}{37} & \multirow{2}{*}{ Porto } & \multirow{2}{*}{ Portugal } & 2016 & Gold \\
\hline & & & 2017 & Platinum \\
\hline 38 & Pune & India & 2016 & Platinum \\
\hline 39 & Riyadh & Saudi Arabia & 2016 & Gold \\
\hline 40 & Rotterdam & Netherlands & 2014 & Platinum \\
\hline 41 & Saint-Augustin-de-Desmaures & Canada & 2016 e 2017 & Platinum \\
\hline 42 & San Diego & United States of America & 2016 & Platinum \\
\hline 43 & Shanghai & China & 2014 & Aspirational \\
\hline 44 & Shawinigan & Canada & 2015 a 2017 & Platinum \\
\hline 45 & Sintra & Portugal & 2017 & Platinum \\
\hline 46 & Surat & India & 2016 & Gold \\
\hline 47 & Surrey & Canada & 2016 & Platinum \\
\hline 48 & Tainan City & Taiwan & 2017 & Platinum \\
\hline 49 & Taipei & Taiwan & 2015 a 2017 & Platinum \\
\hline 50 & Tbilisi & Georgia & 2017 & Platinum \\
\hline 51 & The Hague & Netherlands & 2017 & Platinum \\
\hline 52 & Toronto & Canada & 2014 e 2015 & Platinum \\
\hline 53 & Torreón & Mexico & 2016 & Platinum \\
\hline 54 & Tshwane & South Africa & 2016 & Aspirational \\
\hline 55 & Valencia & Spain & 2015 & Platinum \\
\hline 56 & Vaughan & Canada & 2015 e 2016 & Platinum \\
\hline 57 & Zagreb & Croatia & 2016 & Platinum \\
\hline 58 & Zwolle & \begin{tabular}{|l} 
Netherlands \\
\end{tabular} & 2017 & Platinum \\
\hline
\end{tabular}


É importante salientar que o procedimento de certificação proposto pelo WCCD tem em vista somente a quantidade de indicadores da ISO 37120:2014 para os quais a cidade levantou valores, contudo sem uma análise qualitativa e de consistência destes indicadores, muitas vezes apresentados para anos distintos. Isto posto, observa-se muita heterogeneidade dos valores levantados para os indicadores pelas 58 cidades certificadas. O WCCD também não apresenta uma acreditação para este sistema de certificação, que foi buscada e solicitada, porém não foi obtida por esta pesquisa.

Enquanto espera-se que uma padronização internacional colabore para retificar a falta de consenso em diretrizes para sustentabilidade em comunidades, convém que fique claro que pensar globalmente e agir localmente deve priorizado frente a pensar localmente e agir globalmente. Tendo isto em vista, soluções em sustentabilidade para preservação e melhoria do ambiente natural e humano, o desempenho de serviços disponíveis e qualidade de vida em comunidades, mesmo que se mantenham competitivos, eficazes e economicamente eficientes, serão bastante diferentes ao redor do mundo, dependendo de suas respectivas condições econômicas, climáticas e culturais (ISO, 2013).

Ainda que sistema de indicadores da ISO 37120:2014 possa a vir ser utilizado com vistas à visibilidade da cidade, e/ou sua projeção internacional por meio da "etiqueta" recebida por um questionável sistema de certificação, entende-se que a estruturação de indicadores proposta pela norma pode trazer vantagem efetiva para a gestão municipal, possibilitando o diagnóstico da situação atual da cidade e direcionando a transição para sua visão de futuro.

O sistema de indicadores da NBR ISO 37120:2017 foi, portanto, escolhido para ser utilizado para o diagnóstico da situação atual de uma cidade no âmbito desta pesquisa, e da posterior proposta de método para retrofit urbano. Sem a pretensão de questionar quais indicadores são mais ou menos adequados à sustentabilidade urbana, os 100 indicadores da NBR ISO 37120:2017 foram aqui adotados por conta da reconhecida e ampla aceitação global de uma norma da série ISO. Ademais, o estudo detalhado de 39 sistemas de indicadores de sustentabilidade urbana, mais relevantes ao retrofit urbano, comparativamente ao sistema da ISO 37120:2014, mostra que há coerência na adoção desta norma para os fins desta pesquisa. 


\section{CENÁRIOS E VISÕES DE FUTURO}

\subsection{Visões de Futuro para Cidades Brasileiras}

A urbanização mundial crescente vai propiciar oportunidades de negócios no mundo todo, mas especialmente em países em desenvolvimento com a transição das economias centradas em agricultura para aquelas voltadas para produtos e serviços. Algumas estimativas sugerem que até 2030 serão necessários investimentos de 40 trilhões de dólares em infraestrutura urbana em todo o mundo (WBCSD, 2010), divididos conforme o gráfico da Figura 21.

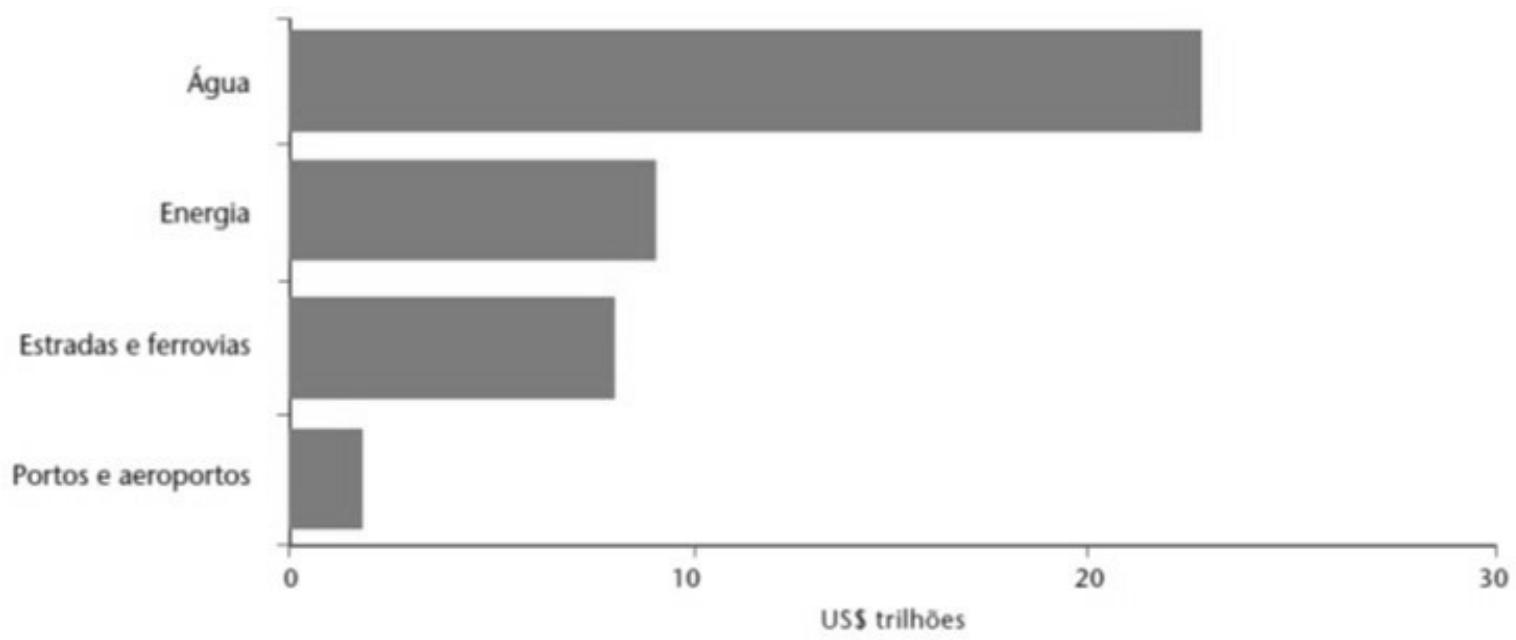

Figura 21: Necessidades de investimentos para infraestrutura urbana até 2030, em todo o mundo. Fonte WBCSD (2010).

As necessidades urbanas do futuro não serão uniformes. As necessidades e oportunidades serão avaliadas separadamente para as cidades existentes, bem como para os novos assentamentos que surgirem em decorrência de populações crescentes e migrantes. Embora cada cidade tenha seus próprios recursos, desafios e cultura únicos, existem quatro categorias básicas de cidade, ou partes da cidade, que precisarão de investimentos distintos em planejamento, projeto e gerenciamento, e apresentarão diferentes tipos de oportunidades, conforme o Quadro 8. 
Quadro 8: Quatro categorias de cidades com características e perspectivas diferentes. Fonte: WBCSD (2010).

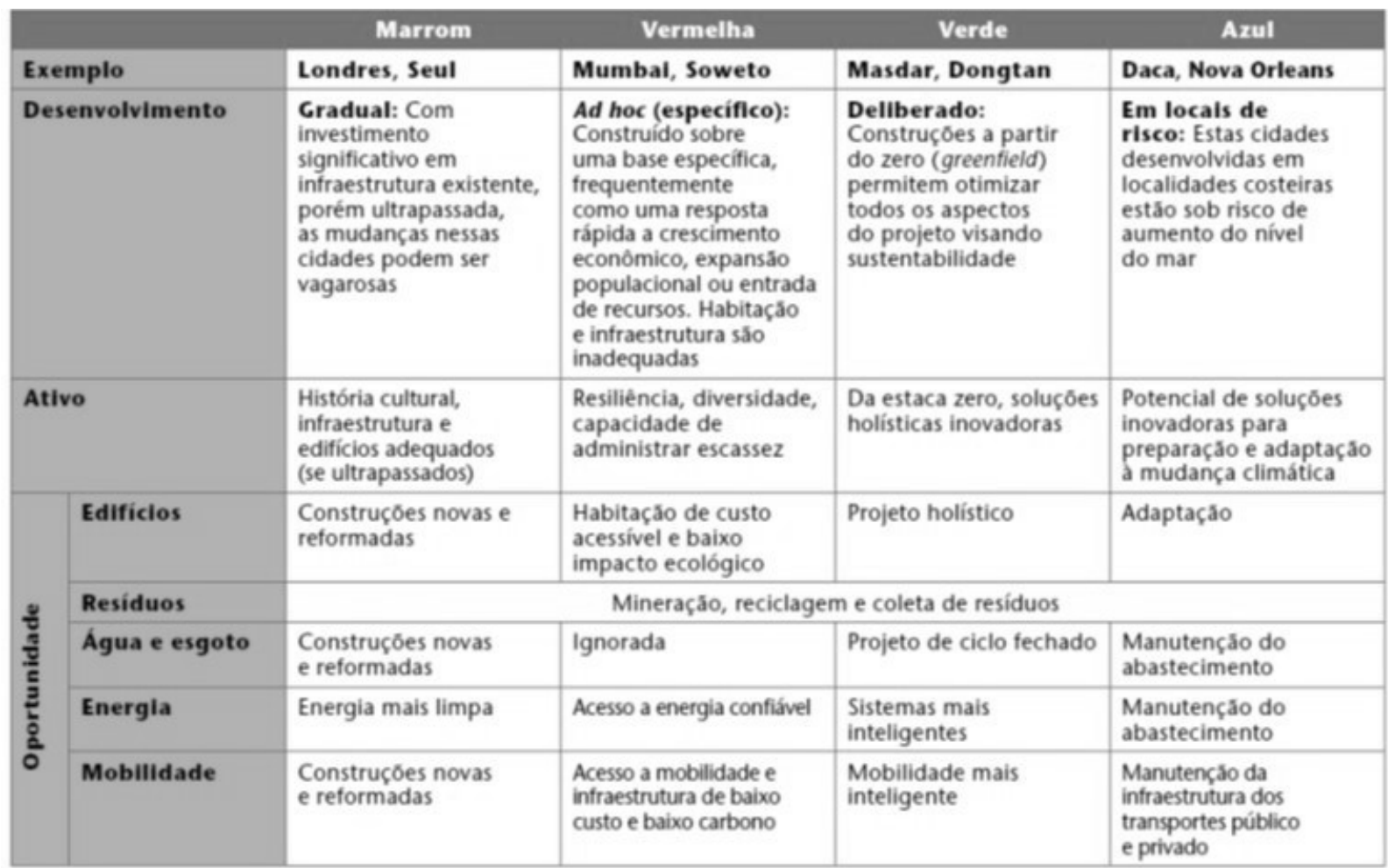

Internacionalmente, há vários estudos de previsão de futuro para a sustentabilidade, inclusive processos participativos, evitando o risco de previsões elitistas, que podem obscurecer diferenças significativas de experiências atuais vivenciadas particularmente por grupos marginalizados e socialmente excluídos da sociedade (EAMES; EGMOSE, 2011). Métodos participativos de criação de uma visão de futuro levam em conta a importância de se introduzir maior reflexão e cuidadosa atenção às dinâmicas sociais e às poderosas interações de leigos e especialistas.

Eames e Egmose (2011) trazem o termo backcasting, significando uma previsão retrospectiva, ou seja, um processo de previsão de futuro baseado na análise do momento presente, conectando o futuro ao presente em uma direção oposta, de trás para a frente. A força do backcasting como uma ferramenta de previsão de sustentabilidade é provavelmente a ênfase em prever futuros desejáveis de longo prazo, permitindo que os participantes pensem além das mudanças incrementais nas suas relações ambientais, socioeconômicas e culturais, e incluam mudanças sociais e tecnológicas mais radicais e revolucionárias, que podem ser necessárias para atingir a sustentabilidade (EAMES; EGMOSE, 2011). 
Porém, no âmbito nacional, a maior dificuldade encontrada na pesquisa em retrofit urbano é a falta de documentos que reportem cenários de longo prazo para as cidades. Ao passo que o Reino Unido apresenta um projeto de retrofit urbano com visão para 2050 (EAMES et al., 2014), a pesquisa bibliográfica no Brasil resultou em poucos documentos, muitas vezes qualitativos e sem metas claramente definidas, bem como sem prazo para atingir as metas, conforme listados no Quadro 9.

Quadro 9: Documentos com visões de futuro para o Brasil.

\begin{tabular}{|c|c|c|}
\hline Documento & Referência & Comentários \\
\hline $\begin{array}{l}\text { Visão } 2050 \text { - A nova } \\
\text { agenda para as empresas }\end{array}$ & $\begin{array}{l}\text { (WBCSD, } \\
2010)\end{array}$ & $\begin{array}{l}\text { Apresenta perspectivas para } 2050 \text { no cenário de } \\
\text { negócios convencional, apontando também as } \\
\text { necessidades de investimentos para infraestrutura urbana } \\
\text { até } 2030 \text { e oportunidades de negócios, visando } \\
\text { planejamento urbano sustentável. }\end{array}$ \\
\hline $\begin{array}{l}\text { O desafio de pensar o } \\
\text { futuro das cidades }\end{array}$ & $(\mathrm{CBIC}, 2012)$ & $\begin{array}{l}\text { Propõe um Novo Modelo de Gestão Urbana } \\
\text { Compartilhada, baseado em cinco eixos: (1) Ouvir o } \\
\text { cidadão. (2) Planejar a vocação da cidade. (3) Planejar } \\
\text { parâmetros comparativos. (4) Gerenciar com eficácia. } \\
\text { (5) Continuar as ações. }\end{array}$ \\
\hline $\begin{array}{l}\text { Por uma Nova } \\
\text { Cultura Urbana: } \\
\text { Caderno de Referência }\end{array}$ & $(\mathrm{CBIC}, 2017)$ & $\begin{array}{l}\text { Promove uma nova cultura urbana, pautada a } \\
\text { partir de boas práticas de planejamento e gestão, } \\
\text { apresentando orientações para apoiar principalmente os } \\
\text { municípios de porte médio (entre } 100 \text { mil e } 1 \text { milhão de } \\
\text { habitantes) a construir uma visão de longo prazo. }\end{array}$ \\
\hline $\begin{array}{l}\text { Políticas públicas para } \\
\text { cidades sustentáveis: } \\
\text { integração intersetorial, } \\
\text { federativa e territorial }\end{array}$ & $\begin{array}{c}\text { (IBAM; } \\
\text { MCTIC, 2016) }\end{array}$ & $\begin{array}{l}\text { Propõe subsídios à elaboração e implementação de } \\
\text { políticas públicas integradas de ciência, tecnologia, meio } \\
\text { ambiente e desenvolvimento urbano capazes de apoiar a } \\
\text { transição progressiva das cidades brasileiras a um padrão } \\
\text { mais sustentável. }\end{array}$ \\
\hline $\begin{array}{l}\text { Metas de Sustentabilidade } \\
\text { para os Municípios } \\
\text { Brasileiros }\end{array}$ & $\begin{array}{l}(\text { REDE } \\
\text { NOSSA SÃO } \\
\text { PAULO, 2012) }\end{array}$ & $\begin{array}{l}\text { Propõe um modelo de Gestão Pública Sustentável - } \\
\text { GPS, com } 100 \text { indicadores básicos, divididos em } 12 \\
\text { eixos-temáticos, e metas para cada um deles, porém sem } \\
\text { prazo definido. }\end{array}$ \\
\hline $\begin{array}{l}\text { Brasil 2022: Planejar, } \\
\text { Construir, Crescer }\end{array}$ & (FIESP, 2015) & $\begin{array}{l}\text { Apresenta um cenário macroeconômico para } 2022 \text { com } \\
\text { foco na cadeia produtiva da construção, e traça metas } \\
\text { para diversos temas, inclusive desenvolvimento urbano } \\
\text { (habitação, saneamento e mobilidade). }\end{array}$ \\
\hline $\begin{array}{l}\text { Brasil 2035: cenários para } \\
\text { o desenvolvimento }\end{array}$ & $\begin{array}{l}\text { (IPEA; } \\
\text { ASSECOR } \\
\text { 2017) }\end{array}$ & $\begin{array}{l}\text { Discute quatro cenários numa perspectiva ampla, quais } \\
\text { sejam: "Construção", "Vai levando", "Novo pacto } \\
\text { social" e "Crescer é o lema". }\end{array}$ \\
\hline
\end{tabular}

Elaborado pela autora 
Especificamente para o Estado, Região Metropolitana e Município de São Paulo, há uma pluralização de documentos com cenários de longo prazo para a região, desconectados e tampouco com visões unificadas e consensuais entre diversos setores. A pesquisa bibliográfica encontrou vários documentos, elaborados setorialmente, sem integração comum, e com âmbitos diferentes, como lista o Quadro 10, em ordem de horizonte do cenário, do prazo mais curto para o mais longo.

Quadro 10: Documentos com cenários de futuro para o Município de São Paulo.

\begin{tabular}{|c|c|c|c|}
\hline Documento & Âmbito & Horizonte & Referência \\
\hline $\begin{array}{l}\text { São Paulo 2022: Ideias, Diretrizes, Indicadores e } \\
\text { Metas para os Próximos } 10 \text { Anos da Cidade } \\
\end{array}$ & Município & 2022 & $\begin{array}{l}\text { (ESCOLA DA } \\
\text { CIDADE et al., 2011) }\end{array}$ \\
\hline Plano Municipal de Habitação 2009-2024 & Município & 2024 & (PMSP, 2010b) \\
\hline PITU - Plano Integrado de Transportes urbanos & $\begin{array}{c}\text { Região } \\
\text { Metropolitana }\end{array}$ & 2025 & $(2006 a)$ \\
\hline $\begin{array}{l}\text { PDDA - Plano Diretor de Abastecimento de } \\
\text { Água }\end{array}$ & $\begin{array}{c}\text { Região } \\
\text { Metropolitana }\end{array}$ & 2025 & Sabesp (2006) \\
\hline PDE - Plano Diretor de Esgotos & $\begin{array}{c}\text { Região } \\
\text { Metropolitana }\end{array}$ & 2030 & Sabesp (2010) \\
\hline $\begin{array}{l}\text { Vulnerabilidades das Megacidades Brasileiras às } \\
\text { Mudanças Climáticas }\end{array}$ & $\begin{array}{c}\text { Região } \\
\text { Metropolitana }\end{array}$ & 2030 & (NOBRE et al., 2010) \\
\hline PMSB - Plano Diretor de Saneamento Básico & Município & 2030 & (PMSP, 2010a) \\
\hline Matriz energética do Estado de São Paulo & Estado & 2035 & São Paulo (2011) \\
\hline $\begin{array}{l}\text { PMAPSP - Manual de Drenagem e Manejo de } \\
\text { Águas Pluviais de São Paulo }\end{array}$ & Município & 2040 & (PMSP, 2012b) \\
\hline SP 2040 - São Paulo: A cidade que queremos & Município & 2040 & (PMSP, 2012a) \\
\hline $\begin{array}{l}\text { Plano de Ação da Macrometrópole Paulista } \\
\text { 2013-2040: cenários e desafios da } \\
\text { macrometrópole }\end{array}$ & $\begin{array}{l}\mathrm{MMP}^{(*)}- \\
\text { Macrometró- } \\
\text { pole Paulista }\end{array}$ & 2040 & (EMPLASA, 2014) \\
\hline
\end{tabular}

Elaborado pela autora

(*) MMP - Macrometrópole Paulista: as Regiões Metropolitanas de São Paulo, Campinas, Baixada Santista, Vale do Paraíba e Litoral Norte e Sorocaba, além das Aglomerações Urbanas de Jundiaí e Piracicaba

O Plano Integrado de Transportes Urbanos da Região Metropolitana de São Paulo PITU 2025 prevê capacidades de suporte do sistema de circulação tendo em vista as viagens geradas por atividades definidas pela legislação de uso do solo.

O PDDA - Plano Diretor de Abastecimento de Água da Região Metropolitana de São Paulo (SABESP, 2006) projeta a demanda por água em dois cenários, tendencial e dirigido, 
até o horizonte de 2025, com base em projeções de crescimento populacionais e setoriais. De forma análoga ao PDAA, o PDE - Plano Diretor de Esgotos da Região Metropolitana de São Paulo (SABESP, 2010) projeta as vazões de esgoto em dois cenários, universalização em 2018 e em 2023, até o horizonte de 2030, com base em projeções de crescimento populacionais.

O Manual de Drenagem e Manejo de Águas Pluviais de São Paulo (PMSP, 2012b) descreve algumas medidas de controle na fonte mais relevantes, apresentando suas características e funções básicas:

- Condutos de Armazenamento: são condutos e reservatórios com medidas maiores que as usuais para armazenar temporariamente o volume escoado e amortecer o escoamento afluente da bacia de contribuição.

- Pavimentos Porosos ou Permeáveis: a adoção de pavimentos permeáveis e porosos contribui para o controle dos deflúvios superficiais no próprio sistema viário.

Alinhado com o Manual de Drenagem e Manejo de Águas Pluviais de São Paulo (PMSP, 2012b), a revitalização de bacias urbanas é uma tendência com uma visão sustentável que vem sendo aplicada mundialmente para a melhoria das condições ambientais do meio urbano, levando em conta a reaproximação e convivência da população com a água no ambiente urbano. Para tanto é preciso considerar novas estratégias que sejam dirigidas a revitalização dos rios e córregos urbanos. A recuperação destas áreas deverá trazer benefícios para a qualidade de vida da população, com a diminuição dos prejuízos econômicos causados pelas inundações, o controle de doenças de veiculação hídrica e a valorização do meio ambiente urbano.

O município de São Paulo apresentou um relatório intitulado "SP 2040: a cidade que queremos" (PMSP, 2012a), diagnosticando a situação de então e prevendo cenários para o ano de 2040. Tanto o diagnóstico quanto os objetivos e eixos principais para a transição para o cenário tendencial de 2040, bem como os projetos catalisadores para tal, estão resumidos e ilustrados na Figura 22. 


\section{Desequilibrios estruturais}

\begin{tabular}{c|c|c|c|c|c|}
\hline $\begin{array}{c}\text { MORADIA } \\
\text { VERSUS } \\
\text { EMPREGO }\end{array}$ & $\begin{array}{c}\text { SURAPROVETIAMENTO } \\
\text { DEAREAS COM BOA } \\
\text { INFRAESTRUTURA }\end{array}$ & $\begin{array}{c}\text { SEGREGACAO } \\
\text { SOCIOESPACIAL }\end{array}$ & $\begin{array}{c}\text { AGUA } \\
\text { (SEM QUALIDADE } \\
\text { VERSUS } \\
\text { EM EXCESSO) }\end{array}$ & $\begin{array}{c}\text { GOVERNANCA } \\
\text { MUNICIPAL VERSUS } \\
\text { DINAMICAS } \\
\text { METROPOLITANAS }\end{array}$ & $\begin{array}{c}\text { ECONOMIA } \\
\text { FORTE COM } \\
\text { CRESIMENTO DAS } \\
\text { DESECONOMIAS }\end{array}$ \\
\hline
\end{tabular}

\section{Eixos}

\section{COESÁO SOCIAL}

1. Reduçào das

vulnerabilidades

2. Acesso as

cportunidades

3. Valorizaçào

da cidadania
DESENVOLVIMENTO

URBANO

1. Cidade compacta

policentrica e equivalente

2. Valorizaçào

da paisagem

3. Integraça da cidade

ao seu ambiente natural
MEUHORIA AMBIENTAL.

1. Resqate da agua

e dos rios urbanos

2. Manejo sustentavel dos

residuos solidos

3. Aprimoramento da

infraestrutura verde

4. Controle da poluiçăo

atmosférica

MOBILIDADE E
ACESSIBILIDADE
1. Administraçăo
da demanda
2. Expansào do sistema
de transportes
3. Articulaçào regional
4. Gestào e financiamento

OPORTUNIDADE

DE NEGÓCIOS

1. Bom ambiente

de negocios

2. Qualificaçăo

da mào de obra

3.Atividades economicas

mais diversificadas

\section{Projetos catalisadores}

Rios VIVOS

\section{Financiamento, monitoramento e avaliação}

FINANCIAMENTO

GESTAO, INDICADORES E METAS

Figura 22: Visão São Paulo 2040: a cidade que queremos. Fonte: PMSP (2012a)

Como diagnóstico, listam-se vários desequilíbrios estruturais (PMSP, 2012b):

- Distribuição desequilibrada entre moradia e oferta de empregos: $75 \%$ das atividades ocupam apenas $1 / 4$ do território. A proporção de empregos por habitante é extremamente desigual, variando de 10 empregos por habitante nas áreas de maior densidade econômica a 100 habitantes por emprego nas áreas de menor presença da atividade produtiva $=$ grandes deslocamentos diários numa dinâmica pendular (casa-trabalho-casa).

- Subaproveitamento de áreas com boa infraestrutura versus urbanização dispersa: enquanto distritos periféricos cresciam a taxas de $3 \%$ ao ano, o centro expandido da cidade, apresentava áreas e bairros subutilizados, com uma densidade demográfica inferior à sua capacidade de suporte.

- Água sem qualidade para a vida versus águas em excesso nas chuvas: $97 \%$ dos domicílios estarem atendidos pela rede de abastecimento (e a meta da Sabesp é universalizar inclusive a coleta de esgoto até 2019) 
- Segregação socioespacial e precariedade habitacional: os mais pobres vivendo predominantemente nas áreas periféricas e seus assentamentos precários e os de maior renda, no centro expandido e seu entorno, onde existe maior oferta de infraestrutura e empregos. São 3.030 assentamentos precários, na sua maioria periféricos, dos quais 1.573 favelas e 1.235 loteamentos irregulares, concentrando cerca de $30 \%$ da população do município. Pior, há ainda 105 mil domicílios em áreas de risco, dos quais $27 \%$ estão em áreas consideradas de risco muito alto ou alto e $73 \%$ em áreas de risco considerado médio ou baixo.

PMSP (2012b) apresenta um cenário tendencial para 2040, com a projeção dos problemas atuais. Estima-se que a população da cidade será de cerca de 12,1 milhões de habitantes em 2040, enquanto a população da região metropolitana chegará a 22,5 milhões de habitantes. Focando o eixo "Desenvolvimento Urbano" do plano, o modelo conceitual para o cenário tendencial para 2040 é uma cidade compacta, policêntrica e equivalente. Para tal, seguem os principais objetivos do plano:

1. Acomodar o crescimento da cidade com qualidade urbanística nas áreas dotadas de infraestrutura

2. Expandir de forma vigorosa as redes de transporte de alta e média capacidade

3. Estender a qualidade urbana para todos

4. Resgatar a qualidade ambiental da cidade

5. Orientar a economia para a inovação

As operações urbanas surgiram de forma pioneira em São Paulo por meio do Plano Diretor de 1988, sendo esse instrumento inserido, em 1990, na Lei Orgânica do Município, como uma forma de viabilizar transformações urbanísticas em porções do território do município, ao mesmo tempo em que propiciaria a participação do setor privado na implementação das intervenções e no seu financiamento.

Além dos documentos citados para análise de futuro para o país e para o município de São Paulo, foram identificadas algumas publicações para os municípios:

- Bento Gonçalves-RS: http://www.cicbg.com.br/produtos/viva-bento

- Brasília-DF: http://www.codesedf.com.br/index.php

- Goiânia-GO: http://www.codesegoiania.com.br 
- Santa Cruz do Sul-RS: http://www.santacruznovosrumos.com.br

- Santa Maria-RS: http://adesm.org.br/a-santa-maria-que-queremos

- Uberlândia-MG: http://uberlandia2100.com.br/noticias/coden/

Além disto, diretrizes e visões de futuro devem estar contempladas no Plano Diretor e no Plano Plurianual. Exigido pela Constituição para municípios com mais de 20 mil habitantes, o Plano Diretor é o instrumento da política de desenvolvimento urbano, com objetivo principal objetivo de oferecer condições para o desenvolvimento local, ao possibilitar uma compreensão dos fatores políticos, econômicos e territoriais relativos ao município. Os princípios que norteiam o Plano Diretor estão contidos no Estatuto da Cidade, documento no qual o plano está definido como instrumento básico para orientação da política de desenvolvimento e de ordenamento da expansão urbana do município. Também determinado pela Constituição Federal, o Plano Plurianual (PPA) especifica os gastos anuais da administração municipal que serão destinados a obras e projetos estabelecidos no plano de ação governamental ou no Plano Diretor. O PPA deve ser elaborado no primeiro ano de gestão do prefeito eleito, abrangendo o período de quatro anos da gestão municipal, com vigência a partir do segundo ano da administração, até o primeiro ano da gestão posterior.

\subsection{Smart Cities - Cidades Inteligentes}

Atualmente, um dos cenários futuros de longo prazo propostos atualmente é a possibilidade do planejamento das cidades na direção de se tornarem smart cities, ou cidades inteligentes. A transformação digital dos últimos anos traz possibilidades e tecnologias que transformarão a forma como as pessoas vivem nas cidades, e o planejamento de cenários fornece um senso de direção, para compor um futuro mais tangível (PHILIPS LIGHTING RESEARCH, 2017).

O termo "smartness" é definido pela ISO 37101:2016 (ISO, 2016) como "qualidade de contribuição ao desenvolvimento sustentável e resiliência, por meio de tomada de decisão consistente e de adoção de uma perspectiva de longo e curto prazos". Smartness está incorporada ao processo de desenvolvimento sustentável, isto é, desenvolvimento sustentável 
é o processo abrangente, enquanto smartness é uma característica. Isto implica em uma abordagem holística, incluindo boa governança e organização, processos e comportamento adequados, e uso apropriado e inovador de técnicas, tecnologias e recursos naturais. Smartness é abordada em termos de desempenho, relevante a soluções implementáveis tecnologicamente (ISO, 2016).

O termo "cidade inteligente" (smart city) é definido pela ISO/DIS 37122 (ISO, 2018a), ainda em elaboração, como aquela que aumenta ritmo à medida que fornece resultados de sustentabilidade sociais, econômicos e ambientais. Cidades inteligentes respondem aos desafios, tais como: mudanças climáticas, rápido crescimento populacional, e instabilidade política e econômica, fundamentalmente melhorando o envolvimento da sociedade, aplicando métodos de liderança colaborativa, trabalhando transversalmente as disciplinas e sistemas urbanos, e utilizando informação de dados e tecnologias modernas para prover serviços melhores e qualidade de vida para aqueles que estão na cidade (moradores, empreendedores, visitantes), no momento presente e em um futuro previsível, sem desvantagens injustas para outros e sem degradação do ambiente natural. Uma cidade inteligente também enfrenta o desafio dos respectivos limites do planeta e levar em consideração estas restrições que estes limites impõem (ISO, 2018a).

A definição de uma Smart City continua a evoluir, mas um componente consistente é a aplicação de TIC - Tecnologias de Informação e Comunicação e a IoT - Internet of Things, ou Internet das Coisas, para direcionar os desafios urbanos. Muitos conceitos de uma Smart City também consideram sustentabilidade, inovação, e governança como componentes importantes somados à aplicação de TIC. A International Telecommunication Union, ou União Internacional de Telecomunicações, define Smart City sustentável como uma cidade inovadora que utiliza TIC e outros meios para melhorar sua qualidade de vida, eficiência de operação e serviços urbanos (UN-HABITAT, 2016).

O próprio termo CIM - City Information Modeling, ou Modelagem da Informação da Cidade, pode ser confundido nos trabalhos propostos no contexto das smart sities ou cidades inteligentes. Mas entende-se que um CIM é tanto um elemento quanto uma filosofia que será incorporada no desenvolvimento das cidades inteligentes do futuro (CORREA; SANTOS, 2015). 
Uma cidade inteligente pode orientar melhor a tomada de decisão a respeito da prosperidade, sustentabilidade, resiliência, gestão de emergências, ou prestação de serviços efetiva e igualitária. Soluções tecnológicas e o uso eficaz de dados estão proporcionando liderança de cidades com novas ferramentas e oportunidades para mudanças efetivas.

Como exemplo, Barcelona é uma das primeiras cidades inteligentes por sua aplicação de soluções inovadoras de melhoria de serviços urbanos e da qualidade de vida de seus cidadãos. O modelo de smart city de Barcelona tem por objetivo utilizar TIC a fim de transformar os processos de negócios da administração pública, para que sejam mais acessíveis, eficientes, eficazes e transparentes. Singapura é outro exemplo do movimento smart city, seu Smart Nation Programme, ou Programa Nação Inteligente, busca o aproveitamento de TIC, redes e dados para apoiar uma melhor convivência, criação de mais oportunidades, e comunidades mais fortes (UN-HABITAT, 2016). Londres, por sua vez, apresenta uma abrangente combinação de iniciativas desde dados abertos e padronização, até retrofit da infraestrutura e inovação. Além disto, soluções inteligentes não são necessariamente baseadas em TIC, mas projeto e pessoas inteligentes contribuem também (ANTHOPOULOS, 2017).

Uma possibilidade proposta por Ahvenniemi et al (2017) é o uso do termo "cidades sustentáveis e inteligentes", ao invés de simplesmente cidades inteligentes. Recomenda-se que a avaliação de desempenho de uma cidade inteligente deve utilizar não só resultados de indicadores que mensuram a eficiência da implantação de soluções inteligentes, mas também o impacto de indicadores que medem a contribuição na direção dos objetivos finais para a sustentabilidade ambiental, econômica e social (AHVENNIEMI et al., 2017). A cidade que pretende ser considerada uma cidade inteligente deve assegurar não somente a sustentabilidade ambiental e econômica por meio de soluções baseadas em TIC, mas também a sustentabilidade social, por meio da preservação do direito à cidade aos seus cidadãos, sobretudo por meio de políticas sociais. E esta é a responsabilidade de instituições de normalização na elaboração de normas e métricas que mensurem o desempenho com relação a sustentabilidade social (MARSAL-LLACUNA, 2017).

Estimativas mostram que o mercado de cidades inteligentes no mundo irá crescer $14 \%$ anualmente, de aproximadamente US\$ 500 bilhões em 2012 para US\$ 1,3 trilhão em 2019. Durante as próximas duas décadas, nos Estados Unidos, as cidades irão investir cerca de US\$ 
41 trilhões para melhorar sua infraestrutura e aproveitar a Internet das Coisas. As cidades da China têm crescimento previsto de 350 milhões de pessoas durante os próximos 20 anos, espera-se que o investimento em cidades inteligentes exceda os US\$ 159 bilhões em 2015 e US\$ 320 bilhões em 2024. Em 2014, a Índia anunciou planos de construir 100 cidades inteligentes em resposta ao crescimento populacional do país e a consequente pressão em sua infraestrutura urbana (UN-HABITAT, 2016).

$\mathrm{Na}$ intenção de reconhecer o potencial da TIC na direção do desenvolvimento sustentável, um ambiente facilitador deve ser criado, com modelos de governança participativa, com infraestrutura e plataformas técnicas adequadas, assegurando inclusão e transpondo as diferenças de acesso digital. As cidades que adotaram as TIC como estratégia de desenvolvimento, utilizando-as para regulação e para fins empresariais, foram chamadas de formas variadas (KITCHIN, 2014):

- $\quad$ wired cities, ou cidades conectadas, por cabeamento;

- cyber cities, ou cidades cibernéticas, com ampla utilização de computadores e internet;

- digital cities, ou cidades digitais, com uso de TIC para aproximar cidadãos, governos e instituições;

- intelligent cities, smart cities, ou cidades inteligentes, com incorporada capacidade de processamento de mais e mais informações sobre a infraestrutura urbana;

- sentient cities, ou cidades sensíveis, que exploram a experiência de vivenciar lembranças, correlações e previsões;

- real-time city, ou cidade em tempo real, com análise em tempo real para gestão de aspectos e funções urbanas, por exemplo, sensores para mobilidade e trânsito.

As cidades inteligentes lidam com um enorme volume de dados, sensíveis ao ambiente, produzindo e distribuindo informações para tornar o meio urbano mais eficiente e sustentável. Elas focam nas tecnologias da informação e comunicação e usam-nas na gestão e regulação da cidade de um modo tecnocrático e tecnológico, englobando políticas relacionadas com o capital humano, educação, desenvolvimento econômico e governança que são influenciadas pela tecnologia (KITCHIN, 2013). 
Estratégias para cidades inteligentes desempenham um papel decisivo de como as cidades irão escolher entre tirar proveito da tecnologia para favorecer o desenvolvimento de redes de inovação, sociedades mais saudáveis e economias dinâmicas. Pode-se também buscar fornecer soluções para muitos problemas de urbanização e sustentabilidade. Embora visionárias, cidades inteligentes representam políticas de urbanização bastante reais, que incluem maiores investimentos e consequências para os anos seguintes. Por isso é essencial estudar as estratégias para cidades inteligentes, metódica e coerentemente, tanto no nível da elaboração quanto na implementação de políticas. Para atingir resultados tangíveis de desenvolvimento econômico, social e urbano, cidades inteligentes podem e devem ser planejadas de uma forma estratégica, e mais pesquisa é necessária nesta direção (ANGELIDOU, 2015).

Cabe lembrar que, conforme elucidado anteriormente, as informações pesquisadas acerca de cidades inteligentes contribuíram para compor o conhecimento prévio sobre tão recente e interessante assunto, mas que a delimitação do tema da tese não abrange este tópico como essencial para o desenvolvimento do método para retrofit urbano. Um desdobramento possível será abarcar os indicadores para cidades inteligentes a serem publicados na norma em desenvolvimento pelo ISO/TC-268, ISO 37122: Sustainable development in communities Indicators for Smart Cities (ISO, 2018a), no momento do diagnóstico da situação atual da cidade, em conjunto com os já adotados indicadores da NBR ISO 37120:2017 (ABNT, 2017a).

O conhecimento do assunto também mostrou que, no Brasil, os estudos de Smart Cities estão mais fundamentados em Smart Gadgets, ou dispositivos, sensores, equipamentos voltados a levantamento de dados. A preocupação atual é mais com a análise e avaliação de produtos, e como eles vão se comportar no ambiente da Smart City, e menos da relação custobenefício da tecnologia, envolvendo questões como: aplicabilidade, funcionalidade, escala, manutenção, necessidade efetiva do cidadão, etc. Faz-se necessária uma dose de cautela para a jornada de uma cidade para compor uma Smart City, uma vez que as mudanças devem ser escaláveis, abrangentes e mantidas atualizadas ao longo do tempo. 


\subsection{ODS - Objetivos de Desenvolvimento Sustentável}

Segundo o PNUD - Programa das Nações Unidas para o Desenvolvimento (2015a), o documento final da Conferência das Nações Unidas sobre Desenvolvimento Sustentável Rio+20 dispõe que o desenvolvimento de metas poderia ser útil na busca do desenvolvimento sustentado por meio de ações focadas e coerentes, tal qual aplicado em relação aos ODMs Objetivos de Desenvolvimento do Milênio, cuja data limite para serem alcançados era o final do ano de 2015. O documento afirma que os SDGs - Sustainable Development Goals, ou ODS - Objetivos de Desenvolvimento Sustentável, deveriam ter embasamento científico para a criação de metas e para a utilização de indicadores que afiram corretamente seu progresso. O texto determinou ainda a criação de processos para o estabelecimento desses objetivos.

Segundo PNUD (2015b), desde então, um amplo e inclusivo sistema de consulta foi empreendido sobre muitas questões de interesse global, com valiosas contribuições efetuadas a partir de uma ampla gama de partes interessadas, a saber:

- de grupos organizados da sociedade civil, consolidados no relatório "Um milhão de vozes: o mundo que queremos" e a pesquisa online "Meu mundo"

- de líderes, no âmbito de um Painel de Alto Nível sobre Sustentabilidade Global

- de acadêmicos e cientistas convocados por meio da Rede de Soluções para o Desenvolvimento Sustentável

- do setor privado, consubstanciados no relatório do Pacto Global das Nações Unidas

- do Sistema da ONU apresentado em um relatório sobre a agenda Pós-2015

Todos esses subsídios foram importantes para as deliberações de um grupo intergovernamental, o GTA-ODS - Grupo Ad Hoc de Trabalho Aberto sobre os Objetivos de Desenvolvimento Sustentável, que contou com a participação de mais de setenta países, inclusive o Brasil, criado com vistas a desenvolver esses objetivos. Em julho de 2014, o Grupo apresentou uma proposta de 17 objetivos, sendo 16 temáticos e um último transversal, sobre os meios de implementação para o alcance de tais objetivos (PNUD, 2015b). Eles compõem a "Agenda 2030 para o Desenvolvimento Sustentável” adotada em setembro de 2015 em cúpula que reuniu 193 chefes de Estado e de governo do mundo todo, que traz 169 metas, que especificam 17 ODS - Objetivos de Desenvolvimento Sustentável, a saber: 
- Objetivo 1: Acabar com a pobreza em todas as suas formas e em todos os lugares;

- Objetivo 2: Acabar com a fome, alcançar a segurança alimentar, a melhoria da nutrição e promover a agricultura sustentável;

- Objetivo 3: Assegurar uma vida saudável e promover o bem-estar para todos, em todas as idades;

- Objetivo 4: Assegurar a educação inclusiva, equitativa de qualidade e promover oportunidades de aprendizagem ao longo da vida para todos;

- Objetivo 5: Alcançar a igualdade de gênero e empoderar todas as mulheres e meninas;

- Objetivo 6: Assegurar a disponibilidade e a gestão sustentável da água e saneamento para todos;

- Objetivo 7: Assegurar o acesso confiável, sustentável, moderno e a preço acessível à energia para todos;

- Objetivo 8: Promover o crescimento econômico sustentado, inclusivo e sustentável, o emprego pleno e produtivo e o trabalho decente para todos;

- Objetivo 9: Construir infraestruturas resilientes, promover a industrialização inclusiva e sustentável e fomentar a inovação;

- Objetivo 10: Reduzir a desigualdade dentro dos países e entre eles;

- Objetivo 11: Tornar as cidades e os assentamentos humanos inclusivos, seguros, resilientes e sustentáveis;

- Objetivo 12: Assegurar padrões de produção e de consumo sustentáveis;

- Objetivo 13: Tomar medidas urgentes para combater a mudança do clima e seus impactos;

- Objetivo 14: Conservar e promover o uso sustentável dos oceanos, dos mares e dos recursos marinhos para o desenvolvimento sustentável;

- Objetivo 15: Proteger, recuperar e promover o uso sustentável dos ecossistemas terrestres, gerir de forma sustentável as florestas, combater a desertificação, deter e reverter a degradação da terra e deter a perda da biodiversidade;

- Objetivo 16: Promover sociedades pacíficas e inclusivas para o desenvolvimento sustentável, proporcionar o acesso à justiça para todos e construir instituições eficazes, responsáveis e inclusivas em todos os níveis, e 
- Objetivo 17: Fortalecer os meios de implementação e revitalizar a parceria global para o desenvolvimento sustentável.

A seguir, a Figura 23 ilustra os 17 ODS acima e a Figura 24 os 5 P's da Agenda 2030.
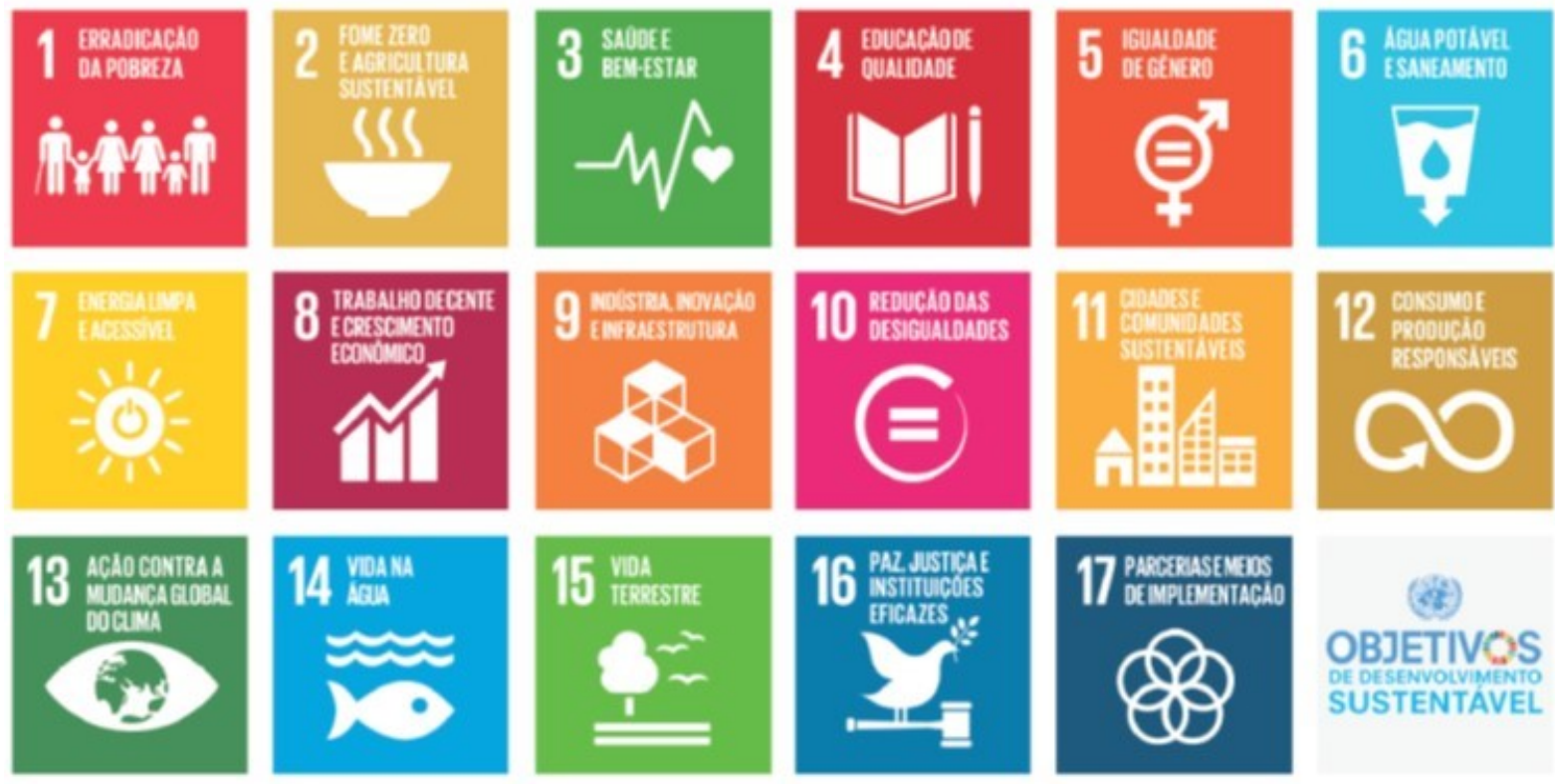

(6)

OBJETIVQS SUSTENTAVEL

Figura 23: Os 17 ODS da Agenda 2030. Fonte: PNUD (2015a).

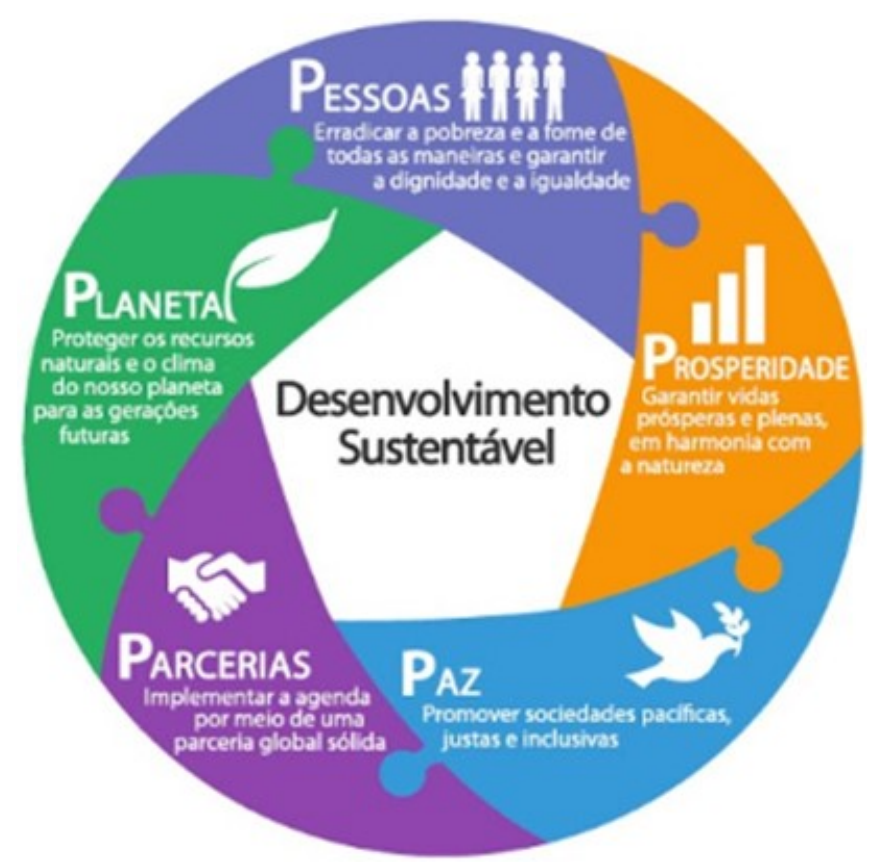

Figura 24: Os cinco P's da Agenda 2030. Fonte: PNUD (2015a). 
Os ODS, observados em sua totalidade, refletem uma agenda que se baseia nos ODMs Objetivos de Desenvolvimento do Milênio, ou seja, foram construídos sobre as bases estabelecidas pelos ODMs, procurando completar o trabalho inacabado em relação a eles e responder a novos desafios (PNUD, 2015a). Cabe dizer que nenhum dos ODMs, que vigoraram no período 2001-2015, foram globalmente cumpridos. Ao mesmo tempo, "esta pretensiosa e excessiva preparação foi a experiência, até agora na História, mais participativa em termos de formulação de política global" (VEIGA, 2016). Os ODMs proporcionaram ações coletivas para cumprir suas metas, propiciando um processo de capacitação de agentes estatais, lideranças da sociedade civil e até mesmo políticos profissionais. "E foi justamente o entusiasmo gerado pelo poder persuasivo destes ODMs, anteriores, e o papel esclarecedor que eles acabaram por engendrar, que houve muito excesso na preparação dos ODS. Basta dizer que vão ser necessários 200 indicadores para monitorar os ODS” (VEIGA, 2016).

Cada governo deve estabelecer suas próprias metas nacionais, orientados pelo nível global de ambição, mas tendo em conta suas circunstâncias nacionais. Objetivos e as metas serão desenvolvidos por meio de indicadores focados em resultados mensuráveis, que terão de levar em conta as diferentes realidades nacionais, capacidades e níveis de desenvolvimento, bem como respeitar as políticas e as prioridades nacionais (UN-DESA, 2017).

A Comissão Estatística das Nações Unidas iniciou um processo para desenvolvimento de uma estrutura global de indicadores para os 17 ODS e as 169 metas. A Comissão aprovou um conjunto 232 indicadores em julho de 2017, baseado no trabalho da IAEG-SDGs - InterAgency and Expert Group on SDG Indicators (IAEG-SDGS, 2018). A menos de 5 indicadores que apresentam classificação em múltiplos níveis, a IAEG-SDGs dividiu os demais 227 indicadores em 3 níveis, a saber:

- Nível I: compreende 93 indicadores (40\% do total de 232 indicadores), que são conceitualmente claros e possuem metodologia e padrões estabelecidos internacionalmente, para os quais dados são regularmente produzidos por ao menos $50 \%$ dos países e para a população nas regiões em que os indicadores são relevantes.

- Nível II: 72 indicadores (31\%), que são conceitualmente claros, há metodologia e padrões internacionais disponíveis, mas os dados não são regularmente produzidos pelos países. 
- Nível III: 62 indicadores (27\%), que ainda não possuem padrões ou métodos internacionais estabelecidos, mas que estão sendo desenvolvidos e testados.

O número de 232 indicadores surpreende, não só pelo volume, mas por alguns deles serem inéditos. Por comparação, os ODMs - Objetivos de Desenvolvimento do Milênio utilizaram 60 indicadores globalmente compatibilizados, e mesmo este limitado número de indicadores não foi totalmente implementado em todos os países até 2015. Portanto, levará tempo para se obter de uma estrutura de indicadores ODS amplamente suportada por dados abrangentes, operacionalizados pelas agências nacionais de estatística. Enquanto isso, se fazem necessárias mensurações provisórias para auxiliar países na operacionalização dos ODS e na identificação de prioridades para suas primeiras ações (SDSN, 2016).

No Brasil, foi estabelecida, em dezembro de 2014, uma Força-Tarefa conjunta sobre a agenda de desenvolvimento Pós-2015 com o objetivo de trabalhar em estreita cooperação com o governo federal a fim de desenvolver atividades nas áreas relacionadas com esta agenda, visando a contribuir com a definição e a futura implementação da agenda de desenvolvimento Pós-2015 no país. Decidiu-se então fazer um mapeamento dos principais indicadores brasileiros - sociais, econômicos e ambientais - existentes, com suas respectivas fontes e níveis de desagregação, que estivessem relacionados aos 16 objetivos temáticos e metas a eles relacionados. Além disso, foi realizado um exercício de identificação das lacunas existentes no conjunto de indicadores atualmente disponíveis no Brasil à luz desses objetivos e metas (PNUD, 2015b).

A SDSN - Sustainable Development Solutions Network, ou Rede de Soluções em Desenvolvimento Sustentável, foi criada em 2012 como uma iniciativa global das Nações Unidas na intenção de mobilizar mundialmente especialistas técnicos e científicos para promover soluções práticas para o desenvolvimento sustentável, inclusive o projeto e implementação dos ODS. O relatório publicado pela SDSN (2016) oferece um primeiro olhar do chamado SDG Index, ou Índice ODS, com Painéis ODS que abrangem 149 dos 193 países membros das Nações Unidades que possuem adequada cobertura de dados. Cabe enfatizar que os Índices e Painéis ODS não são os instrumentos oficiais de monitoramento dos ODS, o que lhes confere importantes limitações e ressalvas, mas são baseados sempre que possível nos indicadores ODS oficiais, na intenção de permitir que os países diagnostiquem onde estão em 2016 em relação ao cumprimento dos ODS. 
Para compor o Índice ODS, SDSN (2016) organizou o valor de cada indicador, levantado para 149 países, do pior para o melhor. Em alguns casos, o maior valor numérico do indicador representa o pior, por exemplo: taxa de mortalidade infantil, enquanto para outros indicadores o maior valor numérico é o melhor, por exemplo: expectativa de vida. Para determinar o pior valor de cada indicador, foram desconsideradas as $2,5 \%$ piores observações, na intenção de que a pontuação não fosse excessivamente influenciada pelos valores extremos. Foram identificados os valores próximos dos piores em cada indicador e aplicados este valor para a porcentagem 2,5 inferior da distribuição.

De maneira similar, também foi criada uma pontuação superior. Em muitos casos, a pontuação melhor é o "perfeito" natural e a meta tecnicamente viável, em linha com o princípio de "não deixar ninguém para trás", por exemplo: pobreza extrema zero, subnutrição zero, 100\% conclusão de ensino. Em alguns casos não existe tal meta "perfeita" como um ótimo teórico não pode ser atingido ou definido. Foi utilizada a média dos 5 maiores valores na amostra de países para este indicador. Todos os países que excederam a média dos melhores valores foram pontuados com o melhor valor (SDSN, 2016).

Para cada país foi criado uma pontuação do indicador ajustada, que se encontra entre 0 e 100, marcando a localização do país entre o pior (0) e o melhor (100) casos. Uma pontuação de 70 , por exemplo, significa que o país está a $70 \%$ do caminho da pior para a melhor pontuação. O Índice ODS foi desta forma calculado para cada um dos 17 ODS e criado um Índice ODS geral, significando a posição do país entre o pior (0) e o melhor (100) casos. A Suécia apresenta o Índice ODS geral de 84,5, por exemplo, significando que a Suécia está na média a 84,5\% do caminho para o melhor resultado possível entre os 17 ODS (SDSN, 2016).

Os três países escandinavos (Suécia, Dinamarca e Noruega) apresentam os maiores Índices ODS, o que significa que estão atualmente mais perto de alcançar as metas previstas para 2030, mas ainda com pontuação significativamente abaixo do máximo de 100, ou seja, o desempenho relativo demonstra que até estes países têm muito trabalho pela frente. Em geral, o Índice e os Painéis ODS mostram que muitos países, mesmo os de alta renda, estão longe de alcançar os ODS. Como o desenvolvimento sustentável inclui três pilares, é possível ser um 
país de alta renda, mas apresentar significativa desigualdade, ou práticas ambientalmente insustentáveis (SDSN, 2016).

É também o caso, entretanto, da tendência de que os países mais pobres do mundo se situem próximos ao limite inferior da classificação do Índice ODS, o que não surpreende, tendo em vista o fato de que muitos dos ODS clamam pelo fim da pobreza extrema (ODS 1) e da fome (ODS 2), para acesso universal a assistência médica (ODS 3), educação (ODS 4), água potável e saneamento (ODS 6), serviços modernos de energia (ODS 7), empregos dignos (ODS 8), e infraestrutura sustentável (ODS 9). Enfim, tudo o que permanece como importantes desafios para muitos dos países mais pobres do mundo (SDSN, 2016).

O Brasil apresenta um Índice ODS de 64,4, na 52 posição da classificação dos 149 países, como pode ser observado na Tabela 3, que apresenta o desempenho geral do país em relação aos ODS. A Figura 25 mostra o desempenho médio do Brasil em cada um dos 17 ODS.

Tabela 3: Desempenho geral do Brasil em relação aos ODS. Fonte: SDSN (2016).

\begin{tabular}{lccc}
\hline OVERALL SDG PERFORMANCE & Global rank & Score or value & Regional average \\
SDG Index & $\mathbf{5 2}$ (of 149) & $\mathbf{6 4 . 4 / 1 0 0}$ & $\mathbf{5 7 . 8 / 1 0 0}$ \\
& & & \\
\hline \multicolumn{2}{l}{ Comparison with other development metrics } & & $0.7 / 1$ \\
Human Development Index, 2014 & 75 (of 188) & $0.76 / 1$ & $6.1 / 10$ \\
Subjective Wellbeing, 2015 & 16 (of 149) & $7 / 10$ & US 12912 \\
GDP per capita, PPP, 2015 & 66 (of 149) & US\$ 15690 & $3.9 / 10$ \\
Global Competitiveness Ind., 2016 & 75 (of 140) & $4.1 / 10$ & $71.7 / 100$ \\
Environmental Perf. Index, 2016 & 46 (of 180) & $78.9 / 100$ & \\
\hline
\end{tabular}




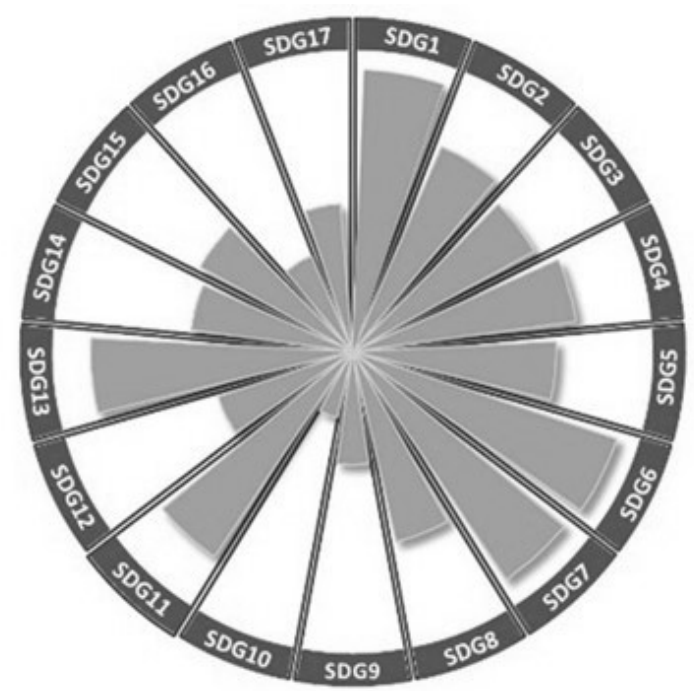

Figura 25: Desempenho médio do Brasil por ODS. Fonte: SDSN (2016).

A Figura 26, a seguir, é o Painel ODS para o Brasil, considerando que a cor verde significa que o país já alcançou a meta, em contraponto a cor vermelha significa que o país está seriamente distante da meta, e a cor amarela é uma faixa de cautela, situada entre o verde e o vermelho.

Para determinar métricas adequadas para inclusão no Índice e Painéis ODS, foram identificados indicadores quantitativos tecnicamente sólidos para cada objetivo que satisfazem 5 critérios de qualidade para seleção de dados:

1. Relevância global e aplicabilidade a uma vasta gama de situações dos países

2. Adequação estatística

3. Periodicidade

4. Qualidade dos dados

5. Cobertura 

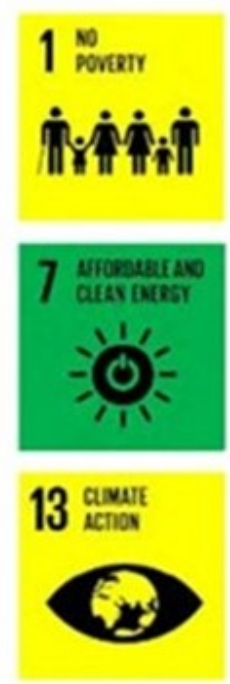
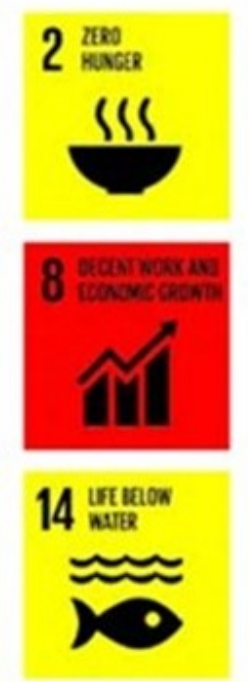
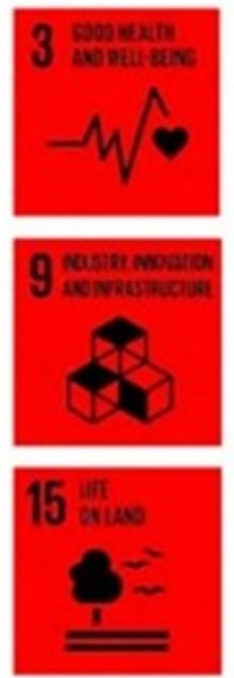
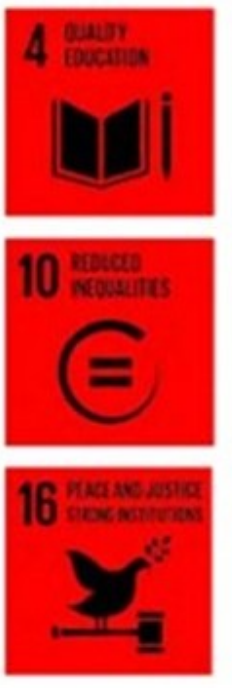
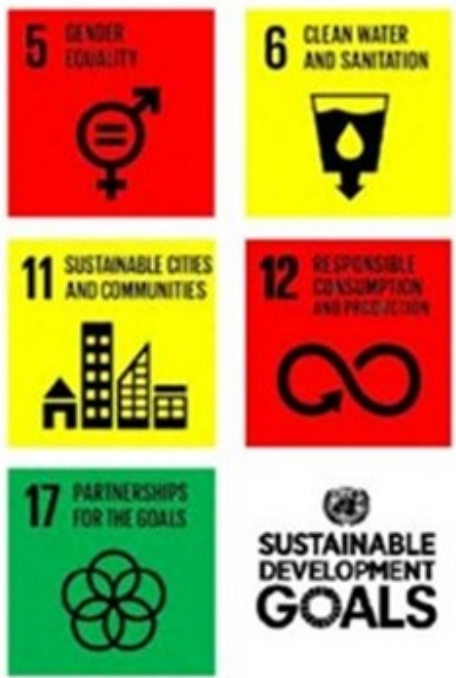

(4i)

SUSTAINABLE GOALS

Figura 26: Painel ODS para o Brasil. Fonte: SDSN (2016).

Analisando a publicação, é importante salientar que se trata de indicadores mais voltados para o âmbito nacional, refletidos no ODS 14, por exemplo, com Ocean Health Index Goal, ou Meta Índice de Saúde dos Oceanos, que não podem ser desagregados para unidades menores da nação, como estados e municípios. Este é um problema detectado em publicações e mesmo políticas de fórum internacional, que muitas vezes não levam em conta as especificidades da gestão local, em cada caso e contexto, em contraponto com a gestão nacional.

Cabe destacar alguns indicadores interessantes para monitorar alguns ODS, cuja escolha reflete os critérios e posturas da rede SDSN - Sustainable Development Solutions Network. No ODS 11, relativo a "cidades e comunidades sustentáveis", há o indicador de "cômodos por pessoa", por exemplo. Para o ODS 16, relativo a "paz, justiça e instituições eficazes", por sua vez, um dos indicadores apresentados é "proporção da população que se sente segura caminhando sozinha à noite na cidade ou na área em que reside (\%)".

Também na escala de nações, a publicação da Eurostat - Statistical Office of the European Communities, ou Gabinete de Estatísticas da União Europeia (Eurostat 2016) apresenta 51 indicadores que, com poucas exceções, refletem conjuntos de indicadores já monitorados por políticas da União Europeia, e alguns deles já estabelecidos pela Comissão Estatística das Nações Unidas. 
Especificamente no caso de cidades, o UN-Habitat - United Nations Human Settlements Programme, ou Programa das Nações Unidas para Assentamentos Humanos, associa a Agenda 2030 a uma nova agenda urbana global, conforme ilustra a Figura 27 (UNHABITAT, 2016).

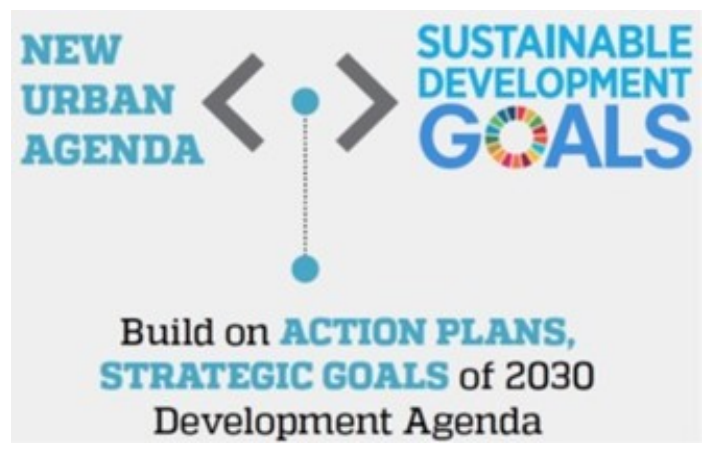

Figura 27: Nova agenda urbana para alcançar os ODS. Fonte: UN-Habitat (2016).

Segundo UN-Habitat (2016), a nova agenda urbana:

- Deve ser ambiciosa, com visão de futuro e fortemente focada na solução de problemas

- Convém que tenha meios claros de implementação

- Adote uma abordagem a cidade como um todo

- Proponha estratégias e ações concretas para a cidade como um todo

- Crie uma relação mutuamente reforçada entre urbanização e desenvolvimento

- Sustente uma mudança de paradigma

- Elabore um ativo conjunto de estratégias

- Transforme a urbanização em uma ferramenta de desenvolvimento

- Constitua uma estrutura de cooperação

- Transmita um senso de urgência

De fato, o senso de urgência pode ser percebido no fato de que as próximas gestões municipais, de 2017 a 2020, que representam 4 anos dos 14 que restam até 2030, horizonte dos ODS. Como Nação e Estado são unidades mais abrangentes, faz-se necessário desagregar os ODS para o nível dos municípios já para a próxima gestão, o que traz questões de territorialização, identidades, nível de desagregação.

No Brasil existem diversos dados disponíveis para que indicadores sejam monitorados, mas nem todos estão disponíveis no nível municipal, e muitos dos que estão podem apresentar 
dados levantados com frequência superior a quatro anos. Nesse contexto, a seleção de indicadores propostos para cada ODS deve levar em conta o alinhamento com as políticas públicas prioritárias da gestão municipal. A partir das estratégias definidas pelo município para o seu desenvolvimento, devem ser definidas as metas e indicadores aplicáveis localmente. Práticas de monitoramento são fundamentais para que os compromissos sejam alcançados, para que as etapas sejam realizadas e os investimentos sejam garantidos. Neste sentido, quanto mais qualidade há nas práticas de monitoramento, maiores são as chances de sucesso no município (CNM, 2016).

Com o horizonte parcial de 2020, é importante destacar a Meta 17.18: "até 2020, reforçar o apoio ao desenvolvimento de capacidades para os países em desenvolvimento (...), para aumentar significativamente a disponibilidade de dados de alta qualidade, atuais e confiáveis, desagregados por renda, gênero, idade, raça, etnia, status migratório, deficiência, localização geográfica e outras características relevantes em contextos nacionais" (PNUD, 2015a).

A despeito do extenso volume de indicadores, muitas vezes sem unificação, cabe salientar que metas ODS envolvem simultaneamente vários temas, podem ser acompanhadas a partir de uma diversa gama de indicadores. Isto acarreta em referências cruzadas de indicadores e metas, ou seja, para uma meta há vários indicadores, e um indicador pode se referir a várias metas ao mesmo tempo. Um exemplo é a Meta 1.4: “até 2030, garantir que todos os homens e mulheres, particularmente os pobres e vulneráveis, tenham direitos iguais aos recursos econômicos, bem como acesso a serviços básicos, propriedade e controle sobre a terra e outras formas de propriedade, herança, recursos naturais, novas tecnologias apropriadas e serviços financeiros, incluindo microfinanças” (PNUD, 2015b). Esta meta pode envolver indicadores relativos a renda, a moradias inadequadas e irregulares, a gênero, a população indígena e quilombola, a serviços de água, esgoto e energia, entre muitos outros.

Ao mesmo tempo, indicadores e metas são importantes instrumentos de planejamento e de participação da sociedade civil, para tanto os ODS proporcionam um aprofundamento da cultura de metas e indicadores, e envolvem uma fundamental metodologia de fortalecimento dos mesmos. No acompanhamento e monitoramento da Agenda 2030, entretanto, há a necessidade de se enfatizar as tendências, sejam de melhoria ou de regresso, e de monitorar 
políticas e desafios políticos, e não somente valores medidos. A análise estatística deve ser complementada, e não substituída, por avaliações qualitativas.

O desenvolvimento de capacidades é uma das grandes virtudes da Agenda 2030, pois de fato promove o conhecimento sobre o desenvolvimento sustentável, seja pela tomada de consciência sobre a vastidão das deficiências das atuais métricas, e também da falta de articulação e intersetorialidade de políticas, e de integração de agências e setores da sociedade civil. No mínimo, os ODS proporcionam um olhar mais amplo para atendimento de metas e geram uma multiplicação de práticas sociais para engajamento na direção do desenvolvimento sustentável.

Isto posto, e na ausência de outros instrumentos de cenário e visão das cidades brasileiras para o longo prazo, a Agenda 2030 e os ODS são adotados nesta tese como parâmetro para direcionar o retrofit urbano, a transição da situação atual da cidade para seu futuro pretendido. Ainda que as cidades possam individualmente estabelecer visões próprias de futuro, convém que estas visões não estejam dissociadas das metas acordadas no âmbito nacional e internacional. Comparativamente a projetos de longo prazo internacionais para retrofit urbano, como por exemplo o Retrofit 2050 do Reino Unido, a Agenda 2030 apresenta um prazo 20 anos mais curto, mas também a vantagem de ser proveniente de um acordo internacional mais amplo, que provavelmente terá desdobramentos após 2030, a exemplo dos ODMs de horizonte 2015. 


\section{MÉTODO PARA RETROFIT URBANO}

Como definido no Capítulo 2, o retrofit urbano compreende um conjunto de intervenções com vistas não somente à adequação da área urbana para atingir a sustentabilidade no momento presente, frente a problemas e demandas atuais, mas vislumbra a adequação para população e demandas futuras, em cenários de longo prazo. Indo além, o retrofit urbano sustentável consiste em alteração dirigida do tecido, forma ou sistemas que constituem o ambiente construído na intenção de melhorar a eficiência energética, de água e de resíduos (DIXON; EAMES, 2013).

Fazendo uso de indicadores e métricas relevantes, o resultado de estratégias, programas, projetos, planos e serviços pode ser adequadamente mensurado em comunidades e áreas urbanas. Apesar de serem desenvolvidos para diferentes razões e objetivos, indicadores são ferramentas importantes no processo de diagnóstico de sustentabilidade urbana do momento atual de uma cidade. Como visto no Capítulo 3, indicadores como os propostos na NBR ISO 37120:2017 são medidas quantitativas, qualitativas ou descritivas definidas para uso presente no monitoramento e avaliação do desempenho geral de uma comunidade ou uma cidade. Os indicadores de sustentabilidade podem ser utilizados separadamente ou em conjunto, mas a experiência demonstrada na literatura prova que há mais eficácia quando indicadores são avaliados conjuntamente.

Os 17 ODS - Objetivos de Desenvolvimento Sustentável adotados em setembro de 2015 determinam ambiciosos objetivos nas três dimensões do desenvolvimento sustentável desenvolvimento econômico, inclusão social, e sustentabilidade ambiental, fundamentados por boa governança. Medidas e dados sólidos são críticos para transformar os ODS em ferramentas práticas para solução de problemas por:

- Mobilização de governos, academia, sociedade civil e empresas

- Proporcionar um painel para monitorar o processo e assegurar responsabilidades, e

- Servir como um instrumento de gestão para as transformações necessárias para alcançar os ODS em 2030.

Isto posto, o ponto de partida para a proposição de uma metodologia própria para retrofit urbano, na intenção de facilitar o processo de priorização de intervenções na transição da 
situação atual da cidade para sua visão de futuro, foi uma análise comparativa cruzada entre os 100 indicadores da NBR ISO 37120:2017 e indicadores das metas dos ODS. Porém, como já foi mencionado, os indicadores das metas dos ODS foram definidos e acordados somente em maio de 2018, em parte, pela Comissão Estatística das Nações Unidas. Os indicadores propostos para os ODS, em sua maioria, não são produzidos regularmente pelos países, e muitos não se referem a indicadores de cidades, e sim a valores de âmbito nacional.

A pesquisa bibliográfica realizada auxiliou neste processo de análise comparativa cruzada, fazendo uso de alguns trabalhos e programas que, por sua vez, já realizaram uma análise e um direcionamento às metas dos ODS. Desta forma, foram levados em conta o Índice e Painéis ODS, da SDSN - Sustainable Development Solutions Network (2016), já mencionados anteriormente, e os Indicadores do Programa Cidades Sustentáveis (REDE NOSSA SÃO PAULO, 2012) e (REDE NOSSA SÃO PAULO, 2016), abordado a seguir.

\subsection{Iniciativas em Cidades Sustentáveis}

Algumas iniciativas para cidades sustentáveis foram identificadas na pesquisa bibliográfica que são mencionados a seguir.

\section{ICES - Iniciativas Cidades Emergentes e Sustentáveis}

O BID - Banco Interamericano de Desenvolvimento criou a ICES - Iniciativa Cidades Emergentes e Sustentáveis em 2010, no âmbito da região da América Latina e Caribe, com a intenção de oferecer apoio às cidades participantes no desenvolvimento de planos de ação que abordam sustentabilidade ambiental, o desenvolvimento urbano sustentável e a sustentabilidade fiscal e boa governabilidade. A metodologia da ICES consiste na realização de um diagnóstico da cidade com base em uma análise de indicadores temáticos, classificados em três categorias, de acordo com o valor do indicador (BID, 2013):

- Verde: sustentável, bom desempenho;

- Amarelo: desempenho potencialmente problemático

- Vermelho: não sustentável, desempenho altamente problemático 


\section{Programa Cidades Sustentáveis}

O SCP - Sustainable Cities Programme, ou Programa Cidades Sustentáveis, é uma parceria criada em 2007 entre UN-Habitat - United Nations Human Settlements Programme, ou Programa das Nações Unidas para Assentamentos Humanos, e a UNEP - United Nations Environment Programme, ou Programa das Nações Unidas para o Ambiente, com o objetivo de assegurar desenvolvimento local ambientalmente sustentável, por meio das contribuições essenciais que as áreas urbanas promovem para o desenvolvimento social e econômico. $\mathrm{O}$ SCP promove uma boa governança ambiental em todos os níveis, para apoiar parceiros locais e nacionais a adotar processos de EPM - Environmental Planning Management, ou Planejamento e Gestão Ambiental, e integra boas práticas à política nacional e estruturas jurídicas (UN-HABITAT; UNEP, 2009).

No Brasil, desde 2011, a Rede Nossa São Paulo, a Rede Social Brasileira por Cidades Justas, Democráticas e Sustentáveis e o Instituto Ethos, em parceria com diversas outras organizações e redes nacionais e internacionais, integram o Programa Cidades Sustentáveis (REDE NOSSA SÃO PAULO, 2012). A Rede Nossa São Paulo é uma rede apartidária que 700 organizações da sociedade civil na cidade de São Paulo. É importante mencionar que o Programa conta com o apoio e participação:

- Da FNP - Frente Nacional de Prefeitos, criada em 1989, entidade municipalista suprapartidária que reúne municípios brasileiros incluindo a participação de 26 capitais brasileiras e de mais de 100 cidades de médio e pequeno porte. Em um universo de 5.570 municípios, a FNP prioriza sua atuação em 400 destes, o que diz respeito a $7 \%$ do total de municípios brasileiros, $60 \%$ da população total do país, $75 \%$ do Produto Interno Bruto (PIB) e 100\% das capitais.

- Da ABM - Associação Brasileira de Municípios, fundada em 1946, sociedade civil, de âmbito nacional, operando num regime de cooperação com as municipalidades, instituições congêneres e afins, bem como Entidades, Estaduais, Federais e Internacionais.

Em 2012, o Programa Cidades Sustentáveis lançou uma Carta-Compromisso destinada aos partidos políticos, candidatos e prefeitos, com o intuito de orientar os gestores públicos e garantir que atuem, de fato, em prol do desenvolvimento sustentável nas cidades. Na prática, 
essa carta representa um compromisso por parte dos gestores em trabalhar prioridades administrativas que levem em consideração as variáveis econômicas, sociais, ambientais e culturais, de acordo com o contexto local. Para a gestão 2013-2016, em 2012, mais 650 candidatos a prefeitos assinaram uma carta-compromisso do Programa Cidades Sustentáveis, se responsabilizando pelo posterior preenchimento do relatório dos 100 indicadores básicos da cidade, via plataforma do Programa. Na ocasião, o Programa Cidades Sustentáveis reunia mais de 300 indicadores gerais atrelados aos eixos da Plataforma, escolhidos em um processo de construção coletivo. O Programa teve a adesão de 285 municípios brasileiros, incluindo 22 capitais e o Distrito Federal, e contribuindo para o surgimento de observatórios de indicadores em 105 destes municípios (REDE NOSSA SÃO PAULO, 2012).

Para as eleições de 2016, o Programa Cidades Sustentáveis incorporou as metas e indicadores ODS, especialmente os que podem ser implementados na escala local e regional, onde a gestão municipal tem papel de governança. Assim, o Programa Cidades Sustentáveis lançou em maio de 2016 o Guia GPS - Gestão Pública Sustentável, que traz um conjunto de conceitos, ferramentas, metas, indicadores e práticas exemplares de políticas públicas em diversas cidades do mundo para que a gestão pública municipal possa se aperfeiçoar e avançar em planejamentos inovadores e alinhados com os ODS. Os ODS das Nações Unidas que correspondem ao âmbito municipal foram organizados nos 12 eixos temáticos do Programa Cidades Sustentáveis, assim como os respectivos indicadores que fundamentam o diagnóstico e planejamento das gestões municipais (REDE NOSSA SÃO PAULO, 2016). Até julho de 2018, 192 cidades brasileiras são signatárias do Programa para a gestão 2017-2020 ((http://www.cidadessustentaveis.org.br/cidades_signatarias).

Apesar do Programa Cidades Sustentáveis dialogar mais diretamente com os ODS 11 “Cidades e Comunidades Sustentáveis", 12 “Consumo e Produção Sustentáveis", 16 "Paz, Justiça e Instituições Eficazes" e 17 "Parcerias e Meios de Implementação", há uma relação mais ampla entre os indicadores dos 12 eixos temáticos do Programa Cidades Sustentáveis e os ODS, conforme lista o Quadro 11, a seguir.

Uma análise comparativa entre os 139 indicadores da NBR ISO 37120:2017 e os 260 indicadores do Programa Cidades Sustentáveis resultou em 47 indicadores comuns aos dois sistemas, ou seja, uma correspondência de 34\% (SENA; NEGREIROS; ABIKO, 2017). 
Quadro 11: Relação entre os Eixos Temáticos do Programa Cidades Sustentáveis com os ODS - Objetivos de Desenvolvimento Sustentável

\begin{tabular}{||c|c|c||}
\hline \multicolumn{2}{|c|}{ Eixo Temático do Programa Cidades Sustentáveis } & ODS \\
\hline \hline 1 & Governança & $5,10,16$ \\
\hline 2 & Bens Naturais Comuns & $2,6,11,12,14,15$ \\
\hline 3 & Equidade, Justiça Social e Cultura de Paz & $1,3,5,9,10,11,16$ \\
\hline 4 & Gestão Local para a Sustentabilidade & $11,12,16,17$ \\
\hline 5 & Planejamento e Desenho Urbano & 11 \\
\hline 6 & Cultura para a Sustentabilidade & 4,11 \\
\hline 7 & Educação para a Sustentabilidade e Qualidade de Vida & 4 \\
\hline 8 & Economia Local Dinâmica, Criativa e Sustentável & $2,7,8,9,12$ \\
\hline 9 & Consumo Responsável e Opções de Estilo de Vida & $6,7,11,12$ \\
\hline 10 & Melhor Mobilidade, Menos Tráfego & 3,11 \\
\hline 11 & Ação Local para a Saúde & $2,3,5$ \\
\hline 12 & Do Local para o Global & $7,11,13$ \\
\hline \hline
\end{tabular}

Elaborado pela autora a partir de Rede Nossa São Paulo (2016).

\section{Programa Município VerdeAzul - PMVA}

Lançado em 2007 pelo Governo do Estado de São Paulo, por meio da Secretaria de Estado do Meio Ambiente, o Programa Município VerdeAzul - PMVA tem o propósito de medir e apoiar a eficiência da gestão ambiental municipal, regional e estadual. O programa estimula atitudes ambientais locais e avalia o desempenho dos municípios paulistas ano a ano (ver Figura 28). O PMVA objetiva estimular o poder público local a fortalecer o planejamento ambiental em seu cotidiano e descentralizar a política ambiental no Estado de São Paulo, gerando eficiência na gestão. Através da proposição de parâmetros comuns a todos os 645 municípios do Estado, ao final de cada ciclo anual, é avaliada a eficácia dos Municípios na condução das tarefas propostas na Agenda Ambiental Municipal e emitido um certificado VerdeAzul. A participação do município no PMVA possibilita a preferência do mesmo junto ao FECOP - Fundo Estadual de Prevenção e Controle da Poluição.

No ciclo de 2017 foram incorporados 60 indicadores nos propósitos e critérios do PMVA, sendo 43 indicadores inspirados na NBR ISO 37120:2017. Estes indicadores compõem os resultados do Município Sustentável MS8 - "Desenvolvimento sustentável de comunidades - Indicadores para serviços urbanos e qualidade de vida." A utilização dos indicadores partiu da necessidade de acompanhar a evolução da eficácia das ações, despertando os municípios para a importância e oportunidade do uso de métricas para monitoramento. 


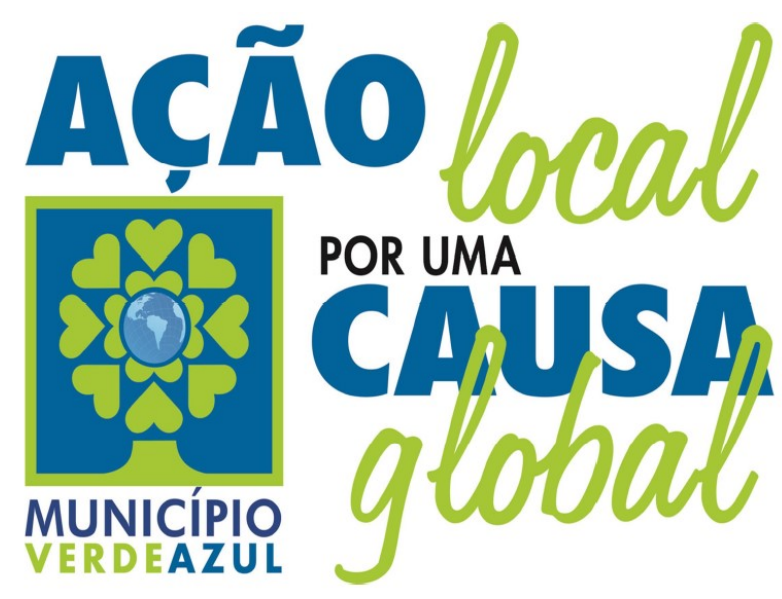

Figura 28: Programa Município VerdeAzul. Fonte: http://verdeazuldigital.sp.gov.br

O uso dos indicadores visa aproximar os interlocutores à temática e aos bancos de dados oficiais, proporcionando uma visão crítica para qualificar a informação, buscando a utilização de dados oficiais no diagnóstico e no monitoramento das ações. Desta forma, é possível subsidiar as decisões e a elaboração de políticas públicas municipais, estimular a sistematização e a transparência das informações, e impulsionar um processo educativo no uso de indicadores na Gestão Pública Municipal.

\section{Mandala ODS}

Organizada pela CNM - Confederação Nacional de Municípios, a Mandada ODS (http://ods.cnm.org.br/mandala-municipal) apresenta uma análise sobre somente 28 indicadores, frente ao número de 232 indicadores propostos pelas Nações Unidas. Estes indicadores são divididos nos temas econômico, institucional, ambiental e social. A visualização também se dá por meio de matriz tricolor (verde-amarelo-vermelho) e cada um dos indicadores possui uma "escala do índice da Mandala", contudo não é claro o método de adoção dos valores mínimo e máximo desta escala. A Figura 29, a seguir, ilustra a Mandala ODS para o município de Sorocaba, utilizado como estudo de caso no Capítulo 6. 


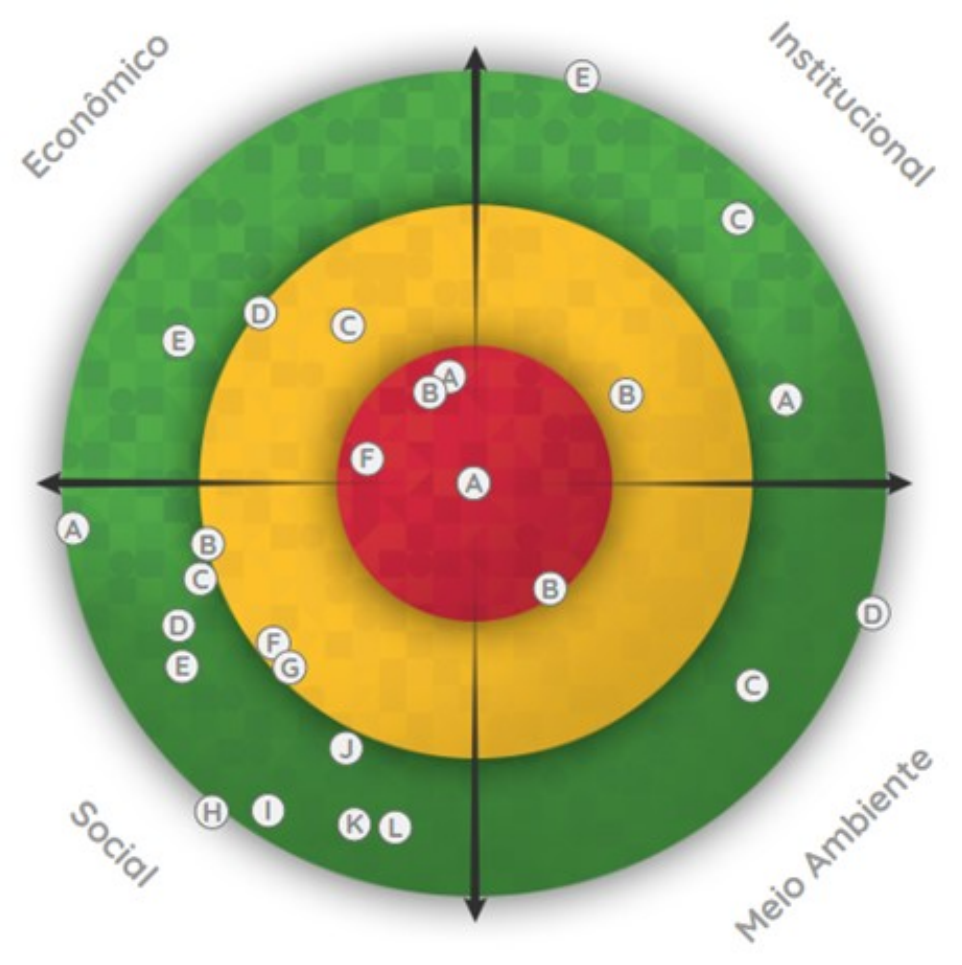

Figura 29: Mandala ODS para o município de Sorocaba - 2018. Fonte:

https://cidados.cnm.org.br/mandala/exportar/ano/2018/uf/SP/codIbge/3552205/codMunicipio/4141

\section{Plataforma dos Municípios}

A Secretaria de Desenvolvimento Econômico, Ciência, Tecnologia e Inovação do Estado de São Paulo iniciou em janeiro de 2018 a implantação do projeto Plataforma dos Municípios (http://www.plataformadosmunicipios.com.br/siteoficial) em fase piloto, contemplando 100 municípios paulista, entre os quais, Sorocaba.

\subsection{Planejamento Urbano Integrado e a ABNT NBR ISO 37101:2017}

Os municípios concentram problemas globais como pobreza, desigualdade social, poluição, dificuldades de mobilidade, falta de saneamento básico, habitações precárias, violência e impacto das mudanças climáticas. A gestão municipal é protagonista nos processos de decisão, portanto faz-se necessário estabelecer novos modos de planejar, governar, produzir e consumir nas cidades a fim de garantir a construção de cidades inclusivas, prósperas, criativas, educadoras, saudáveis e democráticas, que proporcionem uma 
boa qualidade de vida aos cidadãos e que permita a participação da sociedade em todos os aspectos relativos à vida pública (REDE NOSSA SÃO PAULO, 2016).

Enquanto o desafio do desenvolvimento sustentável é global, as estratégias para alcançálos no espaço da comunidade são locais, em grande parte, portanto podem ser diferentes em contexto de país para país, e de região para região. Estratégias da comunidade precisam refletir o contexto, condições prévias, prioridades e necessidades, particularmente no ambiente social, por exemplo: igualdade social, identidade e tradições culturais, patrimônio, saúde pública, segurança e conforto, e infraestrutura social (ISO, 2016).

De fato, cidades podem auxiliar a aliviar a crescente pressão no ambiente e recursos naturais causada pela urbanização global por meio do desenvolvimento de políticas holísticas e integradas (ISO, 2016a). Portanto, políticas integradas para melhoria da qualidade de vida se fazem necessárias (UNITED NATIONS, 2014). Os planos de longo prazo da cidade requerem métodos de planejamento integrado que conciliem a natureza multissetorial dos desafios urbanos. Uma vez que as regiões metropolitanas e a maioria das cidades deixaram de criar uma visão e um plano de desenvolvimento urbano inclusivo e sustentável de longo prazo, elas talvez precisem de um incentivo para fazê-lo. Tal estímulo poderia partir de um fundo nacional que contemplasse os custos de implantação de estruturas adequadas de governança regional e local, leis de reurbanização e capacitação para planejamento integrado (BELSKY, 2012).

De acordo com WBCSD (2010), faz-se necessário um planejamento urbano integrado, especialmente em cidades em rápido crescimento. Um exemplo é o fato de que o planejamento de cidades e transportes está mais bem integrado em nível mundial. As cidades introduzem SIT - Sistemas Inteligentes de Transporte, de forma a tornar o transporte público mais atraente e integrado, aumentando sua participação. Megacidades e áreas urbanas emergentes ignoram planejamentos não integrados (WBCSD, 2010).

O Programa Cidades Sustentáveis (REDE NOSSA SÃO PAULO, 2016) apresenta um modelo de gestão local para a sustentabilidade, que pressupõe mais transparência, forte abertura para as novas TIC - Tecnologias da Informação e Comunicação, e soluções organizacionais para assegurar a interatividade entre governo e cidadania, com maior 
participação dos cidadãos. A evolução da Administração Pública dita "tradicional” para uma gestão mais participativa, quanto ao monitoramento dos processos, é pontuada no Quadro 12, a seguir.

Isto posto, a gestão das cidades requer uma abordagem sistêmica e integrada, pautada na sustentabilidade, que seja capaz de captar as relações entre os diferentes campos que

Quadro 12: Evolução da Administração Pública. Fonte: Rede Nossa São Paulo (2016).

\begin{tabular}{|l|l|l|l|}
\hline & $\begin{array}{l}\text { Administração } \\
\text { Pública } \\
\text { Tradicional }\end{array}$ & $\begin{array}{l}\text { "Nova" Gestão } \\
\text { Pública }\end{array}$ & $\begin{array}{l}\text { Gestão } \\
\text { Participativa }\end{array}$ \\
\hline $\begin{array}{l}\text { Relação } \\
\text { cidadão-Estado }\end{array}$ & Obediência & Credenciamento & $\begin{array}{l}\text { Empoderamento } \\
\text { cidadão }\end{array}$ \\
\hline $\begin{array}{l}\text { Responsabilidade } \\
\text { da administração } \\
\text { superior }\end{array}$ & Politicos & Clientes & $\begin{array}{l}\text { Co-responsabili- } \\
\text { dade sociedade/ } \\
\text { Estado }\end{array}$ \\
\hline $\begin{array}{l}\text { Principios } \\
\text { orientadores }\end{array}$ & $\begin{array}{l}\text { Cumprimento } \\
\text { de leise regras }\end{array}$ & $\begin{array}{l}\text { Eficiência } \\
\text { e resultados }\end{array}$ & $\begin{array}{l}\text { Responsabilidade, } \\
\text { eficiência, transpa- } \\
\text { rência e planeja- } \\
\text { mento participativo }\end{array}$ \\
\hline $\begin{array}{l}\text { Critério } \\
\text { para sucesso }\end{array}$ & $\begin{array}{l}\text { Objetivos } \\
\text { quantitativos }\end{array}$ & $\begin{array}{l}\text { Objetivos } \\
\text { Quantitativos e } \\
\text { Qualitativos }\end{array}$ & $\begin{array}{l}\text { Visăo e metas de } \\
\text { curto, médioe } \\
\text { longo prazos }\end{array}$ \\
\hline Atributo chave & $\begin{array}{l}\text { Formalismoe } \\
\text { centralizaçăo }\end{array}$ & Profissionalismo & $\begin{array}{l}\text { Sustentabilidadee } \\
\text { controle social }\end{array}$ \\
\hline
\end{tabular}

interagem no município: econômico, cultural, social, ecológico, tecnológico, tributário, demográfico etc. Os planos de gestão precisam envolver os diversos órgãos municipais relacionados a estes temas e realizar uma análise integrada das informações. O planejamento urbano estratégico e integrado, baseado em uma abordagem sistêmica e participativa deve considerar, assim, a execução dos projetos sob uma visão de curto, médio e longo prazos, a fim de assegurar a continuidade dos programas, especialmente das obras de infraestrutura, que normalmente tomam mais tempo. Também deve estabelecer metas parciais que possam ser monitoradas publicamente ao longo do tempo, propiciando uma rápida análise sobre o caminho a percorrer até a meta do cenário futuro, de longo prazo.

Publicada em julho de 2016, a ISO 37101 - Sustainable development in communities Management system for sustainable development - Requirements with guidance for use (ISO, 2016a), ou Desenvolvimento Sustentável em Comunidades - Sistema de Gestão para 
Desenvolvimento Sustentável - Requisitos com Orientação para Uso, adota uma abordagem holística para estabelecer requisitos para um sistema de gestão para desenvolvimento sustentável em comunidades, inclusive cidades. Adotada para o Brasil como ABNT NBR ISO 37101:2017 (ABNT, 2017c), a norma estabelece uma estrutura coerente para permitir que a comunidade desenvolva seu propósito e visão, sem definir referências ou níveis de desempenho previstos. É aplicável a comunidades de todos os tamanhos, estruturas e tipos, em países desenvolvidos ou em desenvolvimento, nos níveis local, regional ou nacional, e em áreas definidas como urbanas ou rurais, em seu respectivo nível de responsabilidade.

A Figura 30 ilustra como a NBR ISO 37101:2017 segue uma abordagem PDCA - Plan - Do - Check - Act, para a gestão de desenvolvimento sustentável em comunidades.

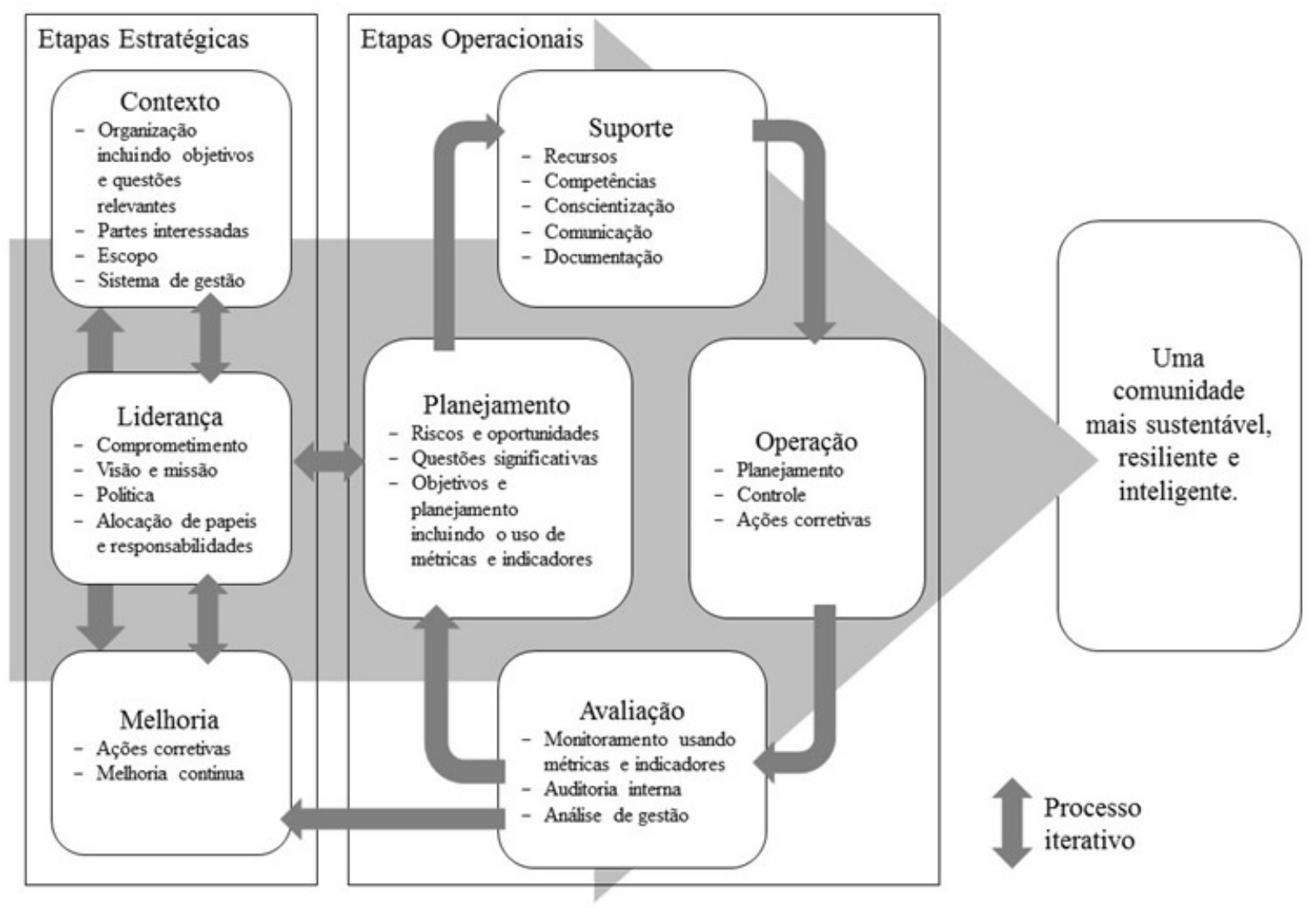

Figura 30: Relação entre o modelo PDCA e a NBR ISO 37101:2017. Fonte: (ABNT, 2017c).

Algumas etapas estratégicas são iterativas, enquanto etapas operacionais são sequenciais. É uma combinação de ambas que auxilia as comunidades a se tornarem mais sustentáveis, resilientes e inteligentes. 
As comunidades devem identificar, revisar e documentar todos os propósitos e temas que contribuem para alcançar os objetivos do sistema de gestão para desenvolvimento sustentável, considerando aos propósitos de sustentabilidade listados no Quadro 13.

Quadro 13: Propósitos de sustentabilidade da NBR ISO 37101:2017. Fonte: (ABNT, 2017c).

\begin{tabular}{|c|c|}
\hline $\begin{array}{c}\text { Propósito de } \\
\text { Sustentabilidade }\end{array}$ & Exemplos \\
\hline Atratividade & $\begin{array}{l}\text { Apelo a cidadãos e outras partes interessadas, tais como: } \\
\text { investidores; pertencimento; cultura; lugar; senso de identidade. }\end{array}$ \\
\hline $\begin{array}{l}\text { Preservação e melhoria do } \\
\text { meio ambiente }\end{array}$ & $\begin{array}{l}\text { Desempenho ambiental melhorado, incluindo redução de gases de } \\
\text { efeito estufa; proteção, recuperação melhoria da diversidade } \\
\text { biológica e serviços ecossistêmicos, incluindo proteção de } \\
\text { ecossistemas, diversidade de plantas e animais e migração, assim } \\
\text { como diversidade genética; reduzir risco à saúde. }\end{array}$ \\
\hline Resiliência & $\begin{array}{l}\text { Antecipação; mitigação e/ou adaptação frente a mudanças } \\
\text { climáticas; preparação para crises e impactos econômicos; evolução } \\
\text { social. }\end{array}$ \\
\hline Uso responsável de recursos & $\begin{array}{l}\text { Consumo; distribuição; melhor gestão do solo; reduzir, reutilizar e } \\
\text { reciclar materiais; respeito a escassez de todos os tipos de recursos } \\
\text { (natural, humano, financeiro); produção, estoque e transporte } \\
\text { sustentáveis. }\end{array}$ \\
\hline Coesão Social & $\begin{array}{l}\text { Acessibilidade; cultura; diálogo com partes externas não limitado } \\
\text { por fronteiras, diversidade; igualdade; patrimônio; inclusão; redução } \\
\text { de desigualdades; raízes; senso de pertencimento e mobilidade } \\
\text { social. }\end{array}$ \\
\hline Bem-estar & $\begin{array}{l}\text { Acesso a oportunidades; criatividade, educação; felicidade; } \\
\text { ambiente saudável; melhoria do capital humano; cidade habitável; } \\
\text { prosperidade; qualidade de vida; segurança; autoconfiança; } \\
\text { assistência social. }\end{array}$ \\
\hline
\end{tabular}

Segundo a NBR ISO 37101:2017 (ABNT, 2017c), para a avaliação da contribuição para alcançar os seis propósitos de sustentabilidade listados no quadro anterior, deve-se considerar os ODS, em particular o Objetivo 11: "tornar as cidades e os assentamentos humanos inclusivos, seguros, resilientes e sustentáveis", assim como sua potencial implementação em comunidades, e deve-se levar em conta os 12 temas de sustentabilidade listados abaixo:

- Governança, fortalecimento e engajamento

- Educação e capacidade construída

- Inovação, criatividade e pesquisa

- Saúde e assistência na comunidade

- Cultura e identidade da comunidade 
- Convivência, interdependência e reciprocidade

- Economia e produção e consumo sustentáveis

- Ambiente de vida e trabalho

- Segurança

- Infraestruturas da comunidade

- Mobilidade

- Biodiversidade e serviços ecossistêmicos

Não por coincidência, os temas anteriores dialogam com os 100 indicadores da NBR ISO 37120:2017. Apesar de que as comunidades devem focar os 12 itens de sustentabilidade acima, elas podem, entretanto, considerar questões adicionais se relevantes ou apropriadas, tendo em conta que os temas são passíveis de mudança ou evolução com o passar do tempo. A gestão deve estabelecer, com envolvimento e participação transparente das partes interessadas, e baseada em temas de sustentabilidade em comunidades identificados como relevantes e prioritários, objetivos de desenvolvimento sustentável em comunidades em funções e níveis relevantes (ABNT, 2017c).

Paralelamente, o Programa Cidades Sustentáveis orienta a um planejamento estratégico, composto por 5 etapas, conforme a Figura 31 (REDE NOSSA SÃO PAULO, 2016). Na figura, em linha tracejada, destaca-se o recorte de atuação do método para retrofit urbano proposto nesta tese.

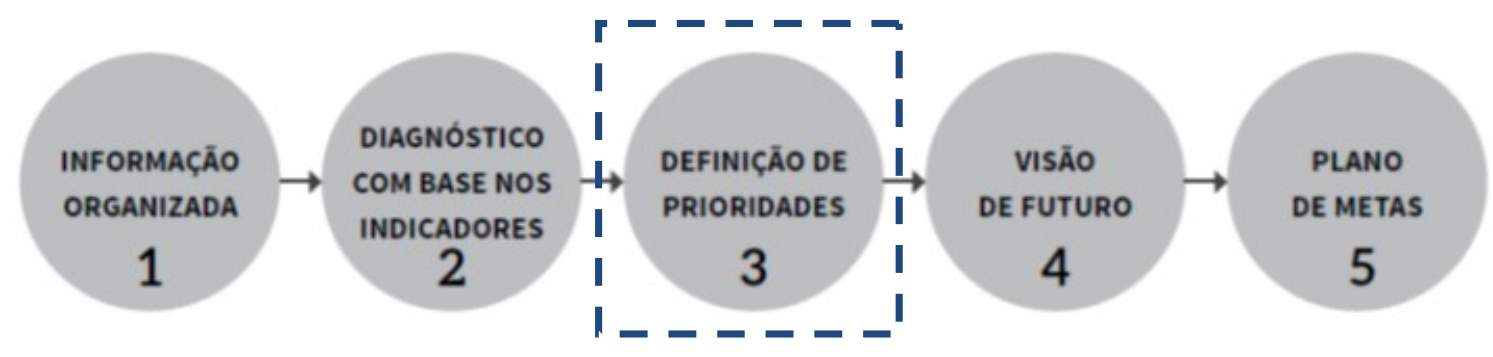

Figura 31: O Planejamento Estratégico para o Programa Cidades Sustentáveis, com recorte da tese. Fonte: Rede Nossa São Paulo (2016).

As 5 etapas propostas pela orientação do planejamento estratégico do Programa Cidades Sustentáveis (REDE NOSSA SÃO PAULO, 2016) são: 
1) Informação organizada: coleta, organização da informação e análise prévia de indicadores, para compor um diagnóstico preliminar.

2) Diagnóstico com base nos indicadores: deve exprimir as perspectivas interna e externa que se têm do município, considerando pontos fortes (quais os indicadores já atingiram as metas sugeridas ou estão próximos de atingir) e fracos (quais indicadores possuem valores distantes das metas sugeridas).

3) Definição de prioridades: identificar quais indicadores são mais críticos e requerem maior esforço da gestão pública, de forma a pautarem o planejamento municipal. É fundamental que as prioridades elencadas sejam construídas de forma participativa e sejam projetadas no tempo de sua realização, de forma que tenham permanência nas políticas públicas para além de uma gestão, sejam monitoradas pela sociedade e consigam atingir as metas de melhoria daquela área específica, no longo prazo.

4) Visão de futuro das cidades: pode ser turística, cultural, histórica, natural, científica, industrial ou com diversas combinações. Uma visão para o futuro do município deve ser descrita em termos claros, visando incentivar as ações e mostrar a direção a médio e longo prazos do Plano de Metas. Como um dos exemplos de tais visões está "alcançar todos os Objetivos de Desenvolvimento Sustentável até 2030" (REDE NOSSA SÃO PAULO, 2016, p. 12).

5) Elaboração do plano de metas: deve apontar as prioridades da gestão, ou seja, as ações estratégicas, os indicadores e metas quantitativas para cada um dos setores da administração pública municipal e deve considerar critérios, como a promoção do desenvolvimento sustentável, inclusão social e respeito aos direitos humanos. O Plano de Metas possibilita um roteiro de planejamento e execução orçamentária, proporcionando maior capacidade de previsibilidade, eleição de prioridades, supressão de desperdícios e ganhos de produtividade, permitindo ampliar a capacidade de realização da gestão e a consolidação programática das propostas eleitorais, bem como a participação, transparência e ampla corresponsabilidade social em relação à execução das políticas públicas.

No entendimento de que o planejamento integrado e estratégico é necessário para os processos de retrofit urbano sustentável, o método proposto nesta tese abrange essencialmente a $3^{\mathrm{a}}$ etapa do planejamento do Programa Cidades Sustentáveis (REDE NOSSA SÃO PAULO, 
2016), que compreende a definição de prioridades, de posse de um diagnóstico pautado pela NBR ISO 37120:2017 e tendo uma visão de futuro estabelecida por metas e indicadores ODS da Agenda 2030.

\subsection{Benchmarking de Cidades}

Os indicadores cumprem um papel fundamental na identificação dos temas de menor desempenho na cidade. Nesse sentido, embora o ponto de referência teórico possa se basear em normas internacionais e médias regionais, a função primordial dos indicadores na metodologia de levantamento de benchmarks não consiste somente na comparação de uma cidade com outras, mas sim em identificar áreas críticas da cidade. Ou seja, uma comparação com outras cidades ajuda a identificar os problemas enfrentados em nível local, mas esse não é o objetivo final e sim um meio de se determinar uma área problemática que precisa de soluções (BID, 2013).

O levantamento benchmarks é um método que teve origem no setor privado para melhoria da competitividade, mas atualmente se estendeu para diversas instituições do setor público. O processo de benchmarking envolve (WESTFALL; DE VILLA; ASIAN DEVELOPMENT BANK, 2001):

- identificar áreas que necessitam de melhoria

- decidir quais indicadores irão mensurar o desempenho

- encontrar outras organizações que apresentem desempenho melhor, ou o melhor dentre todos estes indicadores

- adotar ou adaptar as práticas destas organizações para direcionais melhores resultados

O benchmarking de cidades permite uma identificação comparativa de elementos chave e particularidades, que auxilia a definir estratégias futuras a serem implementadas. Esta análise utiliza estatísticas básicas e interpretação subjetiva de dados convertidos em informação. O benchmarking de cidades é definido como um sistema de indicadores socioeconômicos que constituem um painel de controle do estágio de diagnóstico do processo de planejamento urbano estratégico, proporcionando altos níveis de qualidade a serem atingidos na gestão pública dos serviços da cidade. Nesta estratégia, o benchmarking se 
apresenta como uma ferramenta analítica interessante para o sistema de informação estratégica. A partir de uma perspectiva externa de comparação, o benchmarking auxilia tomadores de decisão a realizarem escolhas baseadas em melhores informações, entre casos de estudo de valores de melhor desempenho. O benchmarking de cidades, por sua vez, pode ser definido como um método contínuo e sistemático que consiste em identificar aprendizado e implementar as práticas mais eficazes e capacidades de outras cidades, para que a própria cidade melhore suas ações (LUQUE-MARTÍNEZ; MUÑOZ-LEIVA, 2005).

Entre as características de benchmarking de cidades, pode-se elencar: identificação, conhecimento, adaptação, sistematização e continuidade. Alguns tipos de benchmarking podem ser levados em consideração no contexto urbano (LUQUE-MARTíNEZ; MUÑOZLEIVA, 2005):

- Competitivo

- Cooperativo

- Colaborativo

- Interno ou intraurbano

Basicamente, o benchmarking urbano intenciona responder dois tipos de questão. A primeira é genérica, referente ao quê comparar, e com quê, ou seja, quais temas e tópicos considerar, e/ou quais cidades e metas são adequados para a comparação. A segunda questão corresponde a identificar o quê as cidades em estudo estão fazendo, como elas estão fazendo, e quais resultados de sucesso estão sendo obtidos, para comparação com o quê a cidade de referência está fazendo. A principal vantagem do benchmarking se refere a possibilidade de realizar avaliações entre cidades ao longo do tempo, propiciando uma base para tomada de decisão e alocação de recursos. As limitações do benchmarking correspondem a heterogeneidade de dimensões de natureza física ou social das cidades, a dispersão de informação proveniente de uma vasta gama de fontes e a diversidade de atores envolvidos no processo público, com inevitáveis opiniões e posicionamentos políticos (LUQUEMARTÍNEZ; MUÑOZ-LEIVA, 2005).

Se o objetivo é elaborar um mecanismo responsável que leva em conta que os cidadãos são auditores, é crucial que o público geral seja capaz de entender e utilizar os resultados do benchmarking (CRUZ; MARQUES, 2014). De fato, o benchmarking pode auxiliar as 
organizações do setor público a definir metas que reflitam sua missão estratégica, que é realística e viável, para criar desafios válidos, e proporcionar maior eficiência e responsabilidade no fornecimento de serviços e melhor compreensão das necessidades dos cidadãos (LO STORTO, 2016).

Keirstead (2013) apresenta uma revisão detalhada de métodos existentes para benchmarking de cidades, concluindo que comparações justas e plausíveis são aquelas que utilizam métodos não paramétricos, tais como DEA - Data Envelopment Analysis, ou Análise de Envoltória de Dados, e OLS - Ordinary Least Squares, ou Mínimos Quadrados Ordinários. Entre estes métodos, DEA é particularmente útil quando há entradas e resultados múltiplos, por conta disto DEA é selecionada como método de cálculo de eficiência energética. Uma combinação de DEA e K-means Clustering é proposta no estudo de LuqueMartínez e Muñoz-Leiva (2005).

Utilizando indicadores previamente definidos, cidades podem ser comparadas de três maneiras distintas (MORENO PIRES; FIDÉLIS; RAMOS, 2014):

1. Auto avaliação, observando o contexto local e tendências históricas para examinar o quanto a cidade progrediu quando comparada ao desempenho anterior em áreas específicas, e suas próprias metas

2. Benchmarking entre padrões e normas, quando disponíveis, como qualidade do ar e da água estabelecidos por organizações como OMS - Organização Mundial da Saúde, Nações Unidas, OIT - Organização Internacional do Trabalho, entre outras

3. Estudos comparativos com outras cidades de níveis similares de desenvolvimento

\subsection{Comunicação Visual - Dashboards para Cidades}

Uma das principais funções dos indicadores é a comunicação com as partes interessadas, pois diferentes atores podem interpretá-los de maneira distinta, devido às diferenças de valores, interesses e contexto cultural ou acadêmico. Distâncias significativas entre dados dos indicadores e percepção dos atores podem acarretar no fracasso do indicador em seu papel de comunicação. 
Ações locais bem direcionadas podem realocar temas para reconhecer um contexto de sustentabilidade mais global. Novas formas de abordagem são necessárias para lidar com a Nova Agenda Urbana e os ODS, com mais conhecimento sobre as interações, trade-offs e sinergias entre os processos urbanos e seus impactos. Convém que acadêmicos e pesquisadores se comprometam mais com as redes de política e práticas dos governos locais, mas também redes mais amplas, tais como: C40 Cities, ou Grupo C40 de Grandes Cidades para a Liderança Climática, ICLEI - Local Governments for Sustainability and United Cities, entre outras (BAI et al., 2018).

Plataformas de dados online podem compartilhar conhecimento e informação nacional e internacionalmente, para auxiliar pesquisadores, políticos, profissionais e cidadãos a diagnosticarem problemas, gerar soluções, testar e avaliar sua eficácia. Painéis ou dashboards urbanos estão se tornando mais comuns, como uma maneira de agrupar, processar, visualizar, analisar e compartilhar dados urbanos. Estas plataformas geralmente apresentam muitas características comuns na visão de dados relevantes para a operação de cidades, por meio da visualização de dados simples e aplicações analíticas (KITCHIN; MAALSEN; MCARDLE, 2016). A característica mais importante destes dashboards são suas funcionalidades integradas, graças a sua estrutura que permite combinar dados entre tópicos para detectar tendências, novos padrões e modelos de comportamento (MARSAL-LLACUNA; SEGAL, 2017).

A utilização contínua e constante dos dashboards de indicadores urbanos pelas partes interessadas é fundamental para melhoria da qualidade, disponibilidade e confiabilidade dos dados. A qualidade dos dados é vital para governos, organizações internacionais, sociedade civil, o setor privado e o público geral para tomar decisões com mais informação, para assegurar a implementação da Agenda 2030 das Nações Unidas (UN-DESA,2017). Entretanto, o levantamento de dados e a mensuração na prática é um desafio significativo, não só pela falta de dados na escala local, da cidade, mas também pelas dificuldades encontradas em mensurar situações urbanas reais. Em agências estatísticas, a maior parte dos dados tradicionais são levantados principalmente no nível nacional.

Exemplos de plataformas de dados urbanos desenvolvidos por governos municipais incluem o Boston CityScore Service (https://data.boston.gov/dataset/cityscore), o London 
Datastore (https://data.london.gov.uk/), o Greater Sydney Commission Dashboard (https://www.greater.sydney/performance-dashboard) (BARNS, 2017) e o Dublin Dashboard (http://www.dublindashboard.ie/pages/index) (KITCHIN; MAALSEN; MCARDLE, 2016). Um dashboard com os indicadores padronizados pela ISO 37120:2014 foi desenvolvido para a cidade de Skopje, capital da Macedônia (http://skopjeinfo.b1.finki.ukim.mk), com o objetivo de levar a plataforma mais próxima aos cidadãos, enquanto ferramenta para melhorar os serviços urbanos e a qualidade de vida (ZDRAVESKI et al., 2017).

No Brasil, há algumas ferramentas desenvolvidas, na intenção de agregar indicadores dos municípios, tais como: o Muove Brasil (https://www.muovebrasil.com/\#/sobre), o Datapedia (https://www.datapedia.info/public/), o DataViva (http://www.dataviva.info/pt/), o Meu Município (https://meumunicipio.org.br/), entre outros. Um observatório de vários indicadores urbanos foi desenvolvido pelo município de São Paulo, o Observa Sampa (http://observasampa.prefeitura.sp.gov.br/). O PlanejaSampa permite o acompanhamento da evolução dos indicadores e da conclusão dos marcos previstos para todas metas, projetos e ações do Programa de Metas da Cidade de São Paulo, para a gestão 2017-2020 (http://planejasampa.prefeitura.sp.gov.br/), como ilustra a Figura 32.

\begin{tabular}{|c|c|c|c|c|c|c|}
\hline \multicolumn{2}{|c|}{ Programa de Metas } & Metas & Projetos & & $\begin{array}{l}\text { parência e Dados } \\
\text { Abertos }\end{array}$ & Q \\
\hline$\frac{\text { META }}{25}$ & \multicolumn{3}{|c|}{$\begin{array}{l}\text { Secretaria Municipal de Mobilidade e Transportes } \\
\text { Reduzir o índice de mortes no trânsito } \\
\text { para valor igual ou inferior a } 6 \text { a cada } 100 \\
\text { mil habitantes ao ano até } 2020\end{array}$} & $\begin{array}{l}\text { Prog, de } \\
\text { Governo }\end{array}$ & 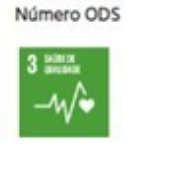 & $\begin{array}{l}\text { Projetos Associados: } \\
\text { Vida Urgente } \\
\text { Pedestre Seguro } \\
\text { Trânsito Seguro } \\
\text { Mobilidade inteligente }\end{array}$ \\
\hline
\end{tabular}

\section{Execuçăo da Meta}

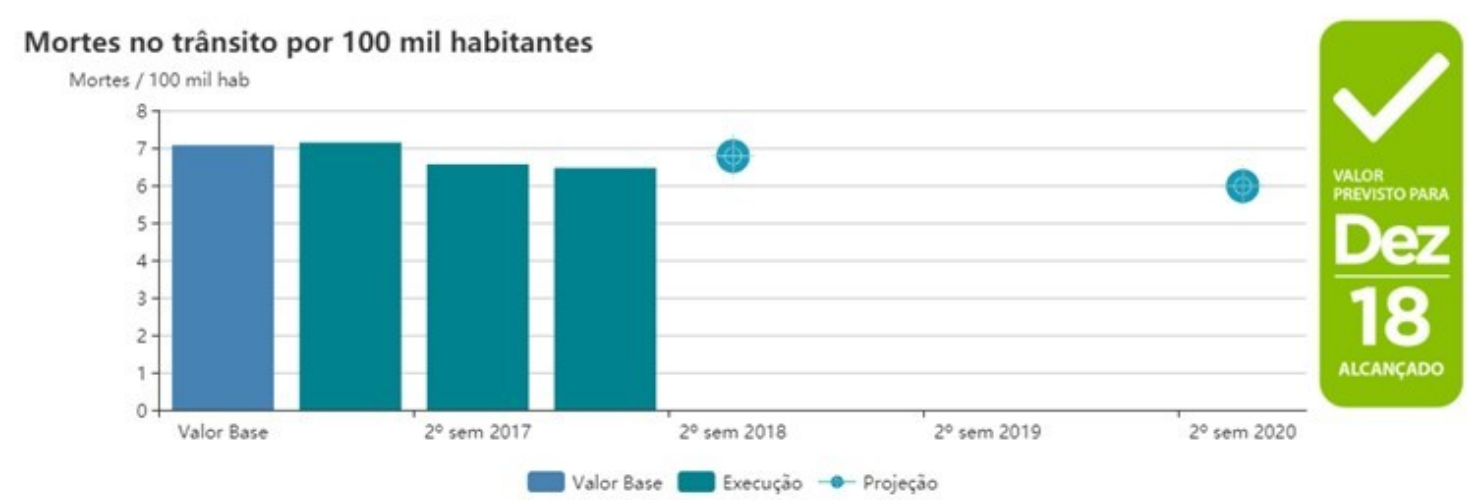

Figura 32: Tela do Planeja Sampa para o indicador "Mortes no trânsito por 100 mil habitantes". Fonte: http://planejasampa.prefeitura.sp.gov.br/meta/34 
Desenvolvido pela FECAM - Federação Catarinense de Municípios, no âmbito do Estado de Santa Catarina, o Índice de Desenvolvimento Municipal Sustentável - IDMS (https://indicadores.fecam.org.br/indice/estadual/ano/2018) é uma ferramenta de apoio à gestão capaz de evidenciar as prioridades municipais e regionais e situar as municipalidades em relação a um cenário futuro desejável (Figura 33).
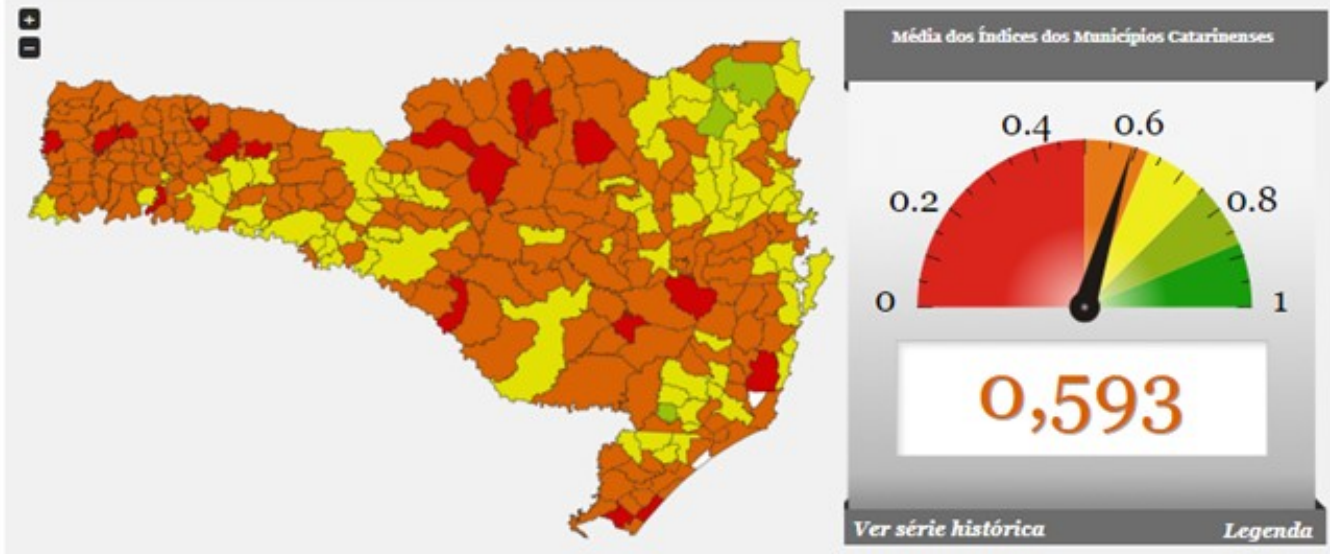

Composição do Índice Municípios

Selecione uma Dimensão para conhecer os indicadores que a compõe. Selecione o botão "mapa" para carregar os dados da dimensão cartografados.
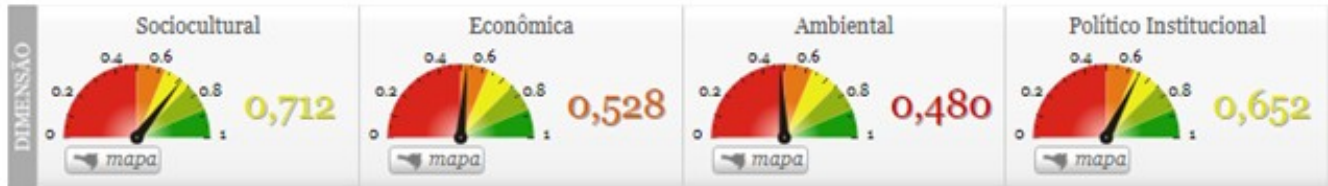

Figura 33: Tela do Índice de Desenvolvimento Sustentável dos Municípios Catarinenses - 2018. Fonte: https://indicadores.fecam.org.br/indice/estadual/ano/2018.

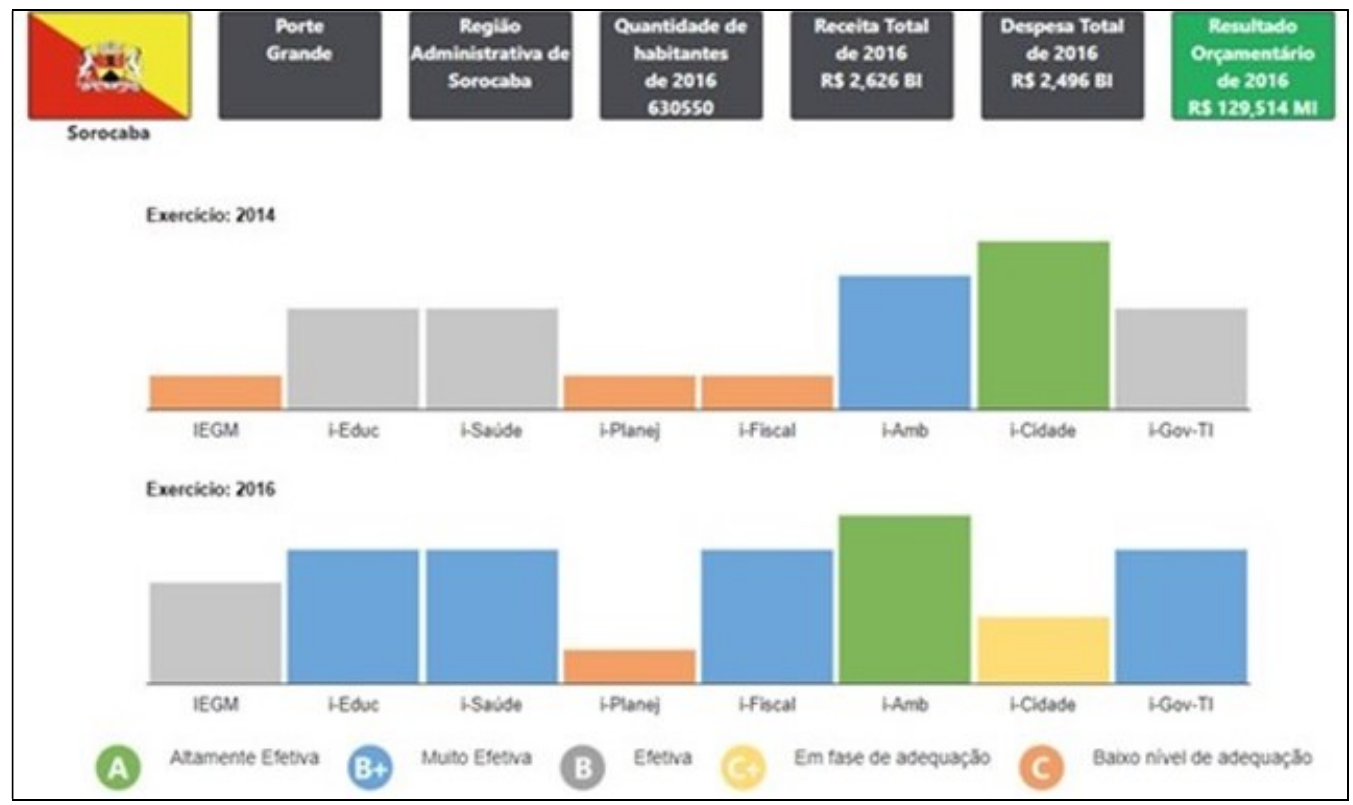

Figura 34: Tela do Índice de Efetividade da Gestão Municipal - IEGM para Sorocaba. Fonte: https://iegm.tce.sp.gov.br/indexRegiao.html\#Sorocaba\# 
A casa do conhecimento dos Tribunais de Contas do Brasil lançou em 2016 a Rede Nacional de Indicadores Públicos, com objetivo de compartilhar instrumentos de medição do desempenho da gestão pública brasileira, boas práticas e o conhecimento deles advindos na avaliação da gestão pública, bem como auxiliar e subsidiar a ação fiscalizatória exercida pelo controle externo, por meio da aplicação do Índice de Efetividade da Gestão Municipal IEGM. O Tribunal de Contas do Estado de São Paulo também propôs o IEGM (https://iegm.tce.sp.gov.br/), com objetivo avaliar a efetividade das políticas e atividades públicas desenvolvidas pelos gestores nas sete dimensões selecionadas: saúde, educação; meio ambiente, gestão fiscal, cidade protegida, planejamento e segurança em TI Tecnologias de Informação (CASTRO; CARVALHO, 2016). A Figura 34 ilustra o IEGM para o município de Sorocaba.

\subsection{Construção de Modelos de Decisão}

Diversas metodologias têm sido desenvolvidas para a construção de modelos de decisão, tais como: árvores de decisão, teoria dos jogos, programação linear, MCDM - Multicriteria Decision Making, MCDA - Multicriteria Decision Aid, ou AMD - Auxílio Multicritério à Decisão, DSS - Decision Support Systems, ou SAD - Sistemas de Apoio a Decisão, que são sistemas computacionais que fornecem informações e contribuem para o processo de tomada de decisão e permitem a realização de cálculos, projeções e análises por meio de gráficos comparativos.

Cedano e Martinez (2010) apresentam uma hierarquização para indicadores de sustentabilidade urbana, e afirmam que é quase impossível, ou ao menos é confuso e consome tempo, comparar uma vasta gama de indicadores ao mesmo tempo. A priorização na escolha de um portfólio de edifícios para realizar retrofit é proposta por McArthur e Jofeh (2016), fazendo uso do método AHP - Analytic Hierarchy Process, ou Processo de Análise Hierárquica (MCARTHUR; JOFEH, 2016).

As decisões também envolvem muitos aspectos intangíveis que necessitam ser compensados, por meio da mensuração paralela do que é tangível e concreto, e cujas medidas 
devem ser também avaliadas e o quanto servem para os objetivos do tomador de decisão (SAATY, 2008).

A Figura 35 ilustra como, no nível operacional, um sistema recebe dados, de natureza quantitativa ou qualitativa, relacionados não só às diferentes dimensões da própria cidade, mas também dados levantados para propósitos de referência. Por meio de interpretação subjetiva, os dados são convertidos em informação organizada para auxiliar a tomada de decisão (LUQUE-MARTÍNEZ; MUÑOZ-LEIVA, 2005).

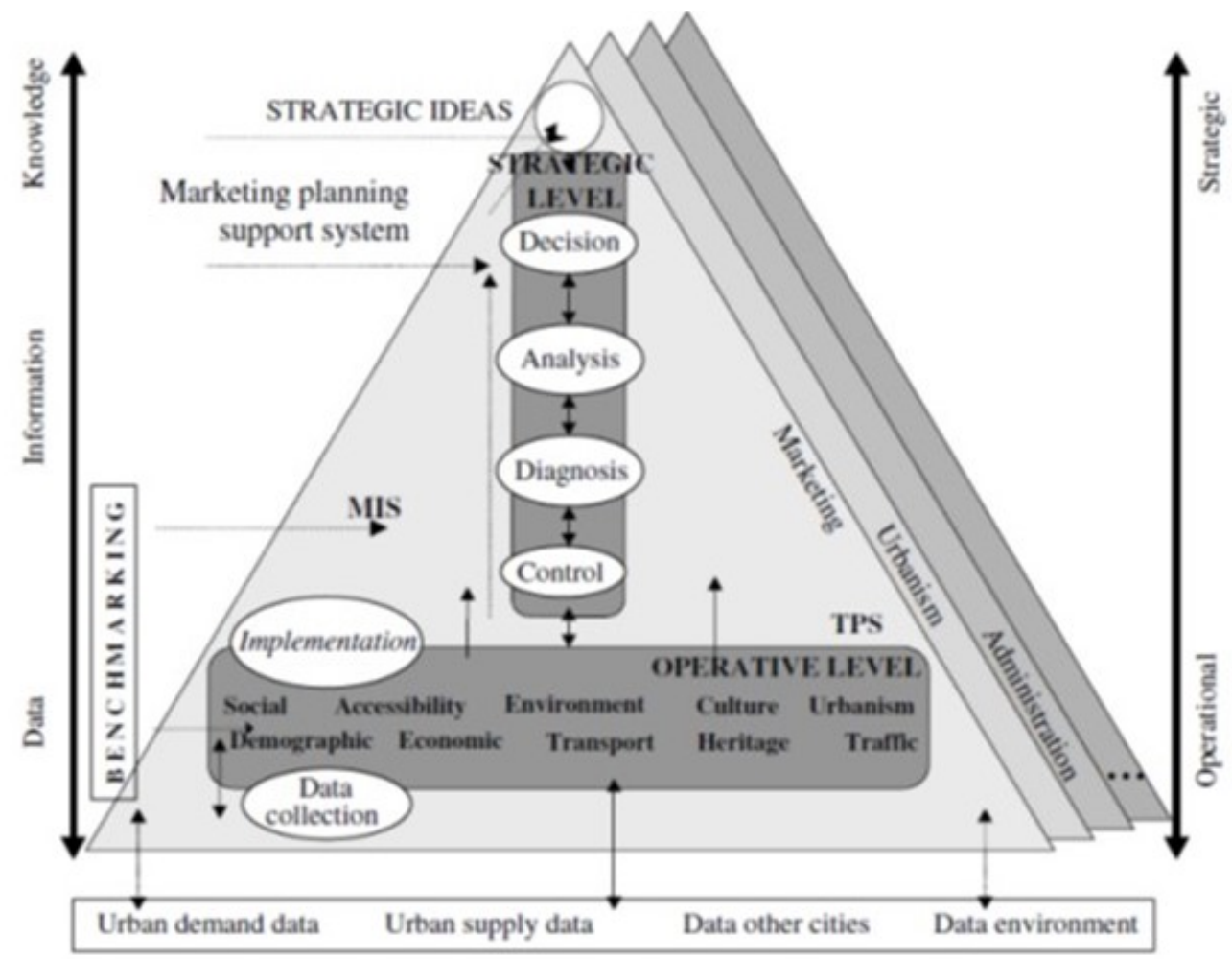

Figura 35: Sistemas de informação para planejamento urbano. Fonte: (LUQUE-MARTÍNEZ; MUÑOZ-LEIVA, 2005)

Tendo em vista o objetivo da presente tese, optou-se pelo desenvolvimento de um método de apoio a tomada de decisão baseado em três métodos de análise, a saber:

- Análise de Tendência: diz respeito ao diagnóstico da situação atual da cidade, com o levantamento dos valores dos indicadores de sustentabilidade urbana, dentro da escolha de uso da NBR ISO 37120:2017. Verifica-se quais são os valores atuais dos 
indicadores, bem como seu passado recente, adotando-se a série histórica de 2010 a 2017.

- Análise por Envoltória de Dados - DEA: diz respeito às metas para alcançar os cenários ou visões de futuro de longo prazo, dentro da escolha de uso dos ODS Objetivos de Desenvolvimento Sustentável, e realizando a primeira etapa de benchmarking de cidades, por meio do levantamento de valores de melhor desempenho para os indicadores, ou seja, a etapa de levantamento das fronteiras de eficiência do método DEA.

- Análise por Clustering: realiza-se a segunda etapa de benchmarking de cidades, por meio do agrupamento de cidades com dados similares, identificação do grupo ao qual a cidade de estudo pertence, e a identificação de valores de melhor desempenho dentro do grupo definido.

De posse de valores atuais de indicadores e com metas definidas, é possível confrontar indicadores e metas, identificando-se quais indicadores não possuem uma meta ou valor de referência numérico definido. Calcula-se a distância entre o indicador e a meta, de forma a avaliar o potencial geral de cada indicador utilizando as informações disponíveis, bem como sua importância e prioridade. Para a transição da situação atual para a visão de futuro, ou seja, o retrofit urbano em si, faz-se necessário, por fim, identificar o conjunto de intervenções necessárias para compor o retrofit urbano, de forma a eliminar, ou ao menos reduzir, a distância entre indicador atual e meta futura.

Uma limitação do método para retrofit urbano é a incorporação matemática de alguns componentes de suma importância, a saber:

- Projeções de população/migração, uma vez que metas de longo prazo podem ser mutáveis em função das variações populacionais

- Vida útil e envelhecimento da infraestrutura urbana no longo prazo

- Valores de investimento das intervenções de retrofit, que têm influência direta no balanço das prioridades das partes interessadas, e/ou custos enterrados e incrementais

- Compreensão do sistema de gestão e de seu contexto e escopo, para desenvolvimento sustentável 
A abordagem escalonada do método para retrofit urbano tem por intenção proporcionar vários benefícios, tais como:

- O nível de análise de cada indicador e meta da cidade é relacionado diretamente ao seu potencial para melhoria, direcionando os investimentos para questões com maior potencial ou prioridade.

- A abordagem é específica e customizada para se adaptar ao perfil de cada cidade, utilizando fatores de ponderação que refletem (a) a importância relativa de diferentes critérios, propósitos de sustentabilidade baseados na recente NBR ISO 37101:2017.

\subsubsection{Análise de Tendência}

Um conjunto de indicadores claramente estabelecido também permite comparar o desempenho da cidade com o de outras e ao longo do tempo. Saber se o desempenho da cidade está melhorando ou piorando pode ser tão importante quanto sua condição atual. Como percepções podem ser subjetivas, é importante avaliar sistematicamente, com a aplicação de critérios padronizados e dados objetivos (BID, 2013).

Em séries temporais, há várias formas de realizar uma análise de tendência, a saber: exponencial, linear, logarítmica, polinomial (várias ordens), potência, Média Móvel, seja Simples, Exponencial, entre outras. Largamente utilizada em análise técnica de dados financeiros, a análise por meio de média móvel proporciona tendências para preços de ações, lucros e volumes de negociação. A média móvel também é utilizada em economia para examinar dados como produto interno bruto, desemprego e outras séries temporais de macroeconomia (DROKE, 2001). Na indústria, prever a demanda é um desafio para todos os setores do mercado e, de uma forma ou outra, as empresas utilizam formas de previsão ou projeção, pois precisam direcionar sua estratégia de acordo com o objetivo do negócio. Quando o consumo é sazonal, pode-se realizar a previsão de demanda por meio de média móvel, um dos métodos de previsão de demanda mais utilizados na literatura. Segundo Morettin e Toloi (2008), além de realizar previsões futuras, podemos analisar uma série temporal para investigar as causas geradoras das variações, e para relatar seu comportamento quanto à presença de tendência, ciclos, sazonalidade e etc. 
Os modelos de média móvel utilizam como previsão para um determinado período no futuro a média das observações passadas. Segundo Morettin e Toloi (2008), o nome "média móvel" é utilizado porque "a cada período, a observação mais antiga é substituída pela mais recente, calculando-se uma nova média" (MORETTIN; TOLOI, 2008, p. 54). Ou seja, a cada novo dado, o primeiro da série anterior é descartado, fazendo com que a média se movimente ao longo do tempo.

A análise de tendência por meio de médias móveis é usualmente utilizada com dados de séries temporais para suavizar as flutuações de curto prazo e realçar as tendências de longo prazo. O limite entre curto e longo prazo depende da aplicação, e a média móvel pode ser ajustada adequadamente. Matematicamente, a média móvel é um tipo de convolução, operação matemática entre duas funções para produzir uma terceira (DROKE, 2001).

As principais vantagens da análise por meio de média móvel são a sua simples aplicação e a possibilidade de aplicação mesmo com um pequeno número de observações, além de apresentar flexibilidade em virtude da variabilidade de número de períodos adotados para análise. As desvantagens deste método consistem na limitação de aplicabilidade apenas em séries estacionárias, a complexidade de definição do número de períodos de observação, e a necessidade de armazenar o mínimo de períodos de observação (MORETTIN; TOLOI, 2008).

De acordo com Morettin e Toloi (2008), a denominação de Média Móvel Simples MMS, ou Aritmética, é aquela que é formada por meio do somatório de um conjunto de valores numéricos dividido pela quantidade de elementos somados. Considerando a série temporal $Z_{1}, Z_{2}, \ldots, Z_{n}$, estacionária e localmente constante, a técnica de média móvel consiste em calcular a média aritmética das $k$ observações mais recentes, conforme a Equação (1):

$$
M_{t}=\frac{Z_{t}+Z_{t-1}+\cdots+Z_{t-k+1}}{k}=M_{t-1}+\frac{Z_{t}-Z_{t-k}}{k}
$$

Onde $M_{t}$ é a média no instante $t, Z_{t}$ é o valor da série temporal no instante $t, t-1$ é um instante imediatamente anterior ao instante $t$, ao passo que $t+1$ é um instante imediatamente posterior ao instante $t$. Denota-se $k$ como sendo o comprimento da média. A determinação do 
comprimento da média, ou seja, da quantidade de observações utilizadas na média, influenciará no comportamento do método. O tamanho denominado para $k$ será inversamente proporcional à velocidade das variações durando o intervalo de tempo estudado. Desta forma, a representação gráfica da média móvel simples geralmente é feita por meio de uma linha, que se movimenta a cada novo dado recebido para cálculo (MORETTIN; TOLOI, 2008).

\subsubsection{Análise por Envoltória de Dados}

A Análise de Envoltória de Dados (do inglês Data Envelopment Analysis - DEA) é uma ferramenta matemática para a medida de eficiência de unidades produtivas. A DEA teve sua concepção no trabalho de Charnes et al (1978), que também criou o termo DMUs - Data Making Units, ou Unidades de Tomada de Decisão. Tomando-se várias empresas que desenvolvem atividades semelhantes, é possível comparar as suas produtividades e investigar porque razão umas são mais produtivas que outras. De forma genérica, uma empresa é mais produtiva que outra porque tomou decisões que lhe permitem aproveitar melhor os recursos. Essas decisões podem ser o uso de uma tecnologia mais avançada, a contratação de mão-deobra mais qualificada, melhores técnicas gerenciais, ou outras. O importante é que a maior produtividade é, via de regra, decorrente de alguma decisão tomada. Portanto, do ponto de vista deste tipo de análise, as unidades produtoras tomaram decisões e, por isso são denominadas DMUs.

A DEA é um modelo matemático não paramétrico, que não realiza nenhuma suposição funcional e considera que o máximo poderia ter sido produzido é obtido por meio da observação das unidades mais produtivas. A Fronteira de Eficiência indica o máximo que foi produzido para cada nível de recurso, como técnica de comparação entre entes produtivos, com o intuito de apontar os benchmarks ou parceiros de excelência, entre as organizações, com múltiplos insumos e produtos.

A aplicação do método DEA é focada em observações de práticas operacionais de uma amostragem de unidades comparáveis, as unidades apontadas como referência apresentam um maior apelo prático e funcionam de maneira mais adequada. Neste sentido, DEA é um método matemático cuja concepção vai de encontro ao que se deseja alcançar na presente tese, que é 
um indicador de desempenho quantitativo para a detecção das melhores práticas de um determinado segmento de atividade.

No caso de valores de melhor desempenho de indicadores de cidades, convém que o levantamento de um referencial teórico para compor a fronteira de eficiência da DEA leve em consideração os contextos locais, ao mesmo tempo que observa os padrões internacionais. Uma vez que há fontes que fornecem informações sobre muitas cidades, é interessante utilizar outras cidades também como referência.

Para avaliar o desempenho urbano baseado em valores de indicadores, a DEA foi utilizada neste estudo para definir as fronteiras de eficiência, ou seja, os melhores valores para os indicadores, que indicam a melhor unidade de desempenho atingida.

Cabe salientar que a definição de fronteiras de eficiência permite a visualização tão somente de valores de melhor desempenho de indicadores urbanos, porém não revelam os processos e as melhores práticas desenvolvidas pelas cidades para obtenção destes melhores valores, sendo necessária uma posterior análise de contexto para conhecimento dos meios e causas que resultaram nos números identificados.

\subsubsection{Análise de Agrupamento - Clustering}

Em um ambiente bidimensional de variáveis, o olhar humano pode distinguir grupos, ou clusters, apenas pela observação de um com outros. Com o aumento das dimensões e variáveis, a tarefa ser torna significativamente mais difícil e menos intuitiva. A análise por clustering, permite que, definido um intervalo de variáveis, sejam analisados padrões ocultos em dados que podem não ser imediatamente óbvios apenas pela observação. Ela permite agrupar um conjunto de objetos de forma que os objetos no mesmo grupo, ou cluster, são mais similares entre si do que com objetos de outros grupos. Clustering é um método de aprendizagem não supervisionada. Em geral, há três tipos de abordagem para o clustering, a saber: Hierarchical clustering, K-means clustering e Two-step clustering. Cada uma destas abordagens segue diferentes procedimentos para agrupar objetos similares em um grupo cluster. Uma das abordagens mais utilizadas é o K-means clustering, sendo $\mathrm{K}$ o número de 
clusters e Means é a média dos clusters, ou centroide. Isto significa que a classificação dos dados é baseada na sua distância média ao centro de cada cluster (EVERITT, 2011).

Os dados básicos para a maioria das aplicações de análise de clusters é uma matriz $\mathrm{X}$ de dimensões $n \times p$, usual e multivariada, contendo os valores variáveis que descrevem cada objeto a ser agrupado, ou seja:

$$
\mathrm{X}=\left[\begin{array}{cccc}
x_{11} & x_{12} & \cdots & x_{1 p} \\
x_{21} & \cdots & \cdots & \cdots \\
\vdots & \vdots & \ddots & \vdots \\
x_{n 1} & \cdots & \cdots & x_{n p}
\end{array}\right]
$$

A célula $x_{i j}$ fornece o valor da variável $j$ do objeto $i$ (EVERITT, 2011).

Análises comparativas permitem agrupar as cidades em vários grupos, em função de aspectos socioeconômicos, de população, de renda, entre outros. A maneira de analisar é útil para fornecer percepções que não emergem de comparações individuais de cidades utilizando somente a fronteira de eficiência, mas também identificando as principais necessidades políticas dentro de um grupo de cidades (BISCHOF et al., 2017).

Vários estudos de comparação de cidades utilizam clustering como método de análise, tais como: sustentabilidade urbana em água (NOIVA; FERNÁNDEZ; WESCOAT, 2016), sustentabilidade de sistemas de transporte de passageiros (ALONSO; MONZÓN; CASCAJO, 2015), eficiência energética (WANG et al., 2017), habitabilidade, compreendendo densidade populacional e habitacional e taxa de emprego (PAUL; SEN, 2017), indicadores de Educação, Saúde e Segurança das vinte e sete capitais brasileiras (AFONSO et al., 2015a) e das cidades alagoanas (AFONSO et al., 2015b), entre outras.

De posse da fronteira de eficiência levantada no item anterior, pode-se normalizar os dados para compará-los nos seus respectivos domínios, levando em consideração que os dados mantenham a mesma ordem de grandeza com a Equação (2)

$$
X_{i}=\frac{x_{i}-x_{\min }}{x_{\max }-x_{\min }}
$$


Onde $X_{i}$ representa cada um dos indicadores mensurados dentro do intervalo normalizado de $\left(x_{\min }=0\right)$ até o valor máximo $\left(x_{\max }=100 \%\right)$.

\subsection{Método Proposto para Retrofit Urbano}

O método proposto para retrofit urbano apresenta uma estrutura amigável e interativa de dashboard, disponível na web, de forma a facilitar o entendimento e manuseio de todos, sejam atores urbanos, ou qualquer indivíduo interessado em dados urbanos. O sistema foi desenvolvido em Microsoft Power Business Intelligence - Power BI. Alternativamente poderia ser utilizado o Tableau, mas este é um software de licença comercializada, diferentemente do Power BI, cujo acesso é gratuito.

O dashboard resultante em Power BI apresenta flexibilidade para adaptações a outros dados e indicadores. É possível alterar a formulação de cada indicador, por exemplo alterando a análise de tendência por outro meio que não a Média Móvel Simples, ou então alterar o comprimento de média $k$, o que é interessante em estudos futuros, permitindo optar pela análise de tendência mais adequada a cada tipo de indicador. É importante salientar que o dashboard pode ser rápida e facilmente alterado conforme metas são adotadas, de forma automática e apresentando nova classificação e nova estimativa para atingimento da meta para cada indicador. Facilmente pode-se adaptar o dashboard para outros indicadores, como para a nova versão da norma ISO 37120, de 2018, por exemplo. Novos dados da série histórica podem ser inseridos no dashboard e o gráfico de tendência será automaticamente alterado, bem como sua respectiva análise de redução ou aumento e, consequentemente, de classificação de tendência como favorável ou desfavorável. Pode-se também realizar agregações e filtros, sejam em seções e temas da NBR ISO 37120:2017, ou nas escalas temporal ou espacial, ou na classificação de indicadores, entre outras possibilidades.

O método para implementação de retrofit urbano na escala da cidade objetiva auxiliar os tomadores de decisão a definir metas de longo prazo para os indicadores propostos, assumidos com base na NBR ISO 37120:2017. Os prazos para atingir a meta podem ser estimados com base nas taxas de variação dos valores dos indicadores nos últimos anos da série histórica, o 
que proporciona um plano de intervenções de retrofit de longo prazo, baseado em alternativas de melhoria identificadas na análise.

O método envolve levantamento, interpretação e análise sistemática de dados urbanos, de acordo com as etapas descritas abaixo e ilustradas no fluxograma da Figura 36:

1) Diagnóstico da Cidade: levantamento e avaliação dos valores de cada um dos 100 indicadores da NBR ISO 37120:2017, levando em consideração uma série histórica mínima de 3 anos, não necessariamente consecutivos. Esta etapa envolve o levantamento de todos os dados relacionados aos indicadores, de fontes confiáveis, e a identificação de metas numéricas estabelecidas pela cidade, se existirem, para cada um dos 100 indicadores, e o respectivo prazo para atingir a meta. É de suma importância indicar a fonte, o ano, a cobertura geográfica e a definição precisa do indicador ao lado de cada entrada de dados obtidos sobre a cidade. Estas informações são fundamentais para se analisar e determinar a classificação dos indicadores, e essenciais também para a comparação de dados entre cidades.

2) Análise de Tendência: por meio de Média Móvel Simples, pode-se classificar a tendência do indicador em favorável, desfavorável ou estável. O comprimento da média ( $k$ ) para a Média Móvel Simples foi adotado como 3 anos, pois muitos dados dos indicadores não estão disponíveis em período de tempo maior. Porém, para aprimoramento do método, deve-se posteriormente testar e aferir o valor de $k$, inclusive independentemente para cada indicador. Em alguns casos, a tendência de aumento do valor do indicador será favorável, como por exemplo, para o indicador da Seção 6. Educação, 6.2 "Porcentagem de estudantes com ensino primário completo". Em outros casos, a tendência de redução é que será favorável, como por exemplo o indicador da Seção 18. Transporte, 18.8 "Mortalidades de trânsito por 100.000 habitantes". Para indicadores com tendência favorável, existindo uma meta numérica, pode-se calcular o prazo estimado para atingir a meta, dividindo-se a distância entre o valor atual do indicador e a meta respectiva, e dividindo-se pela taxa.

3) Benchmarking: por meio da definição das fronteiras de eficiência da DEA e também da análise por clustering, pode-se identificar melhores valores para cada um dos indicadores, aferindo se a meta existente está em concordância com os valores de referência. Também são levados em conta nesta etapa as metas dos ODS. 


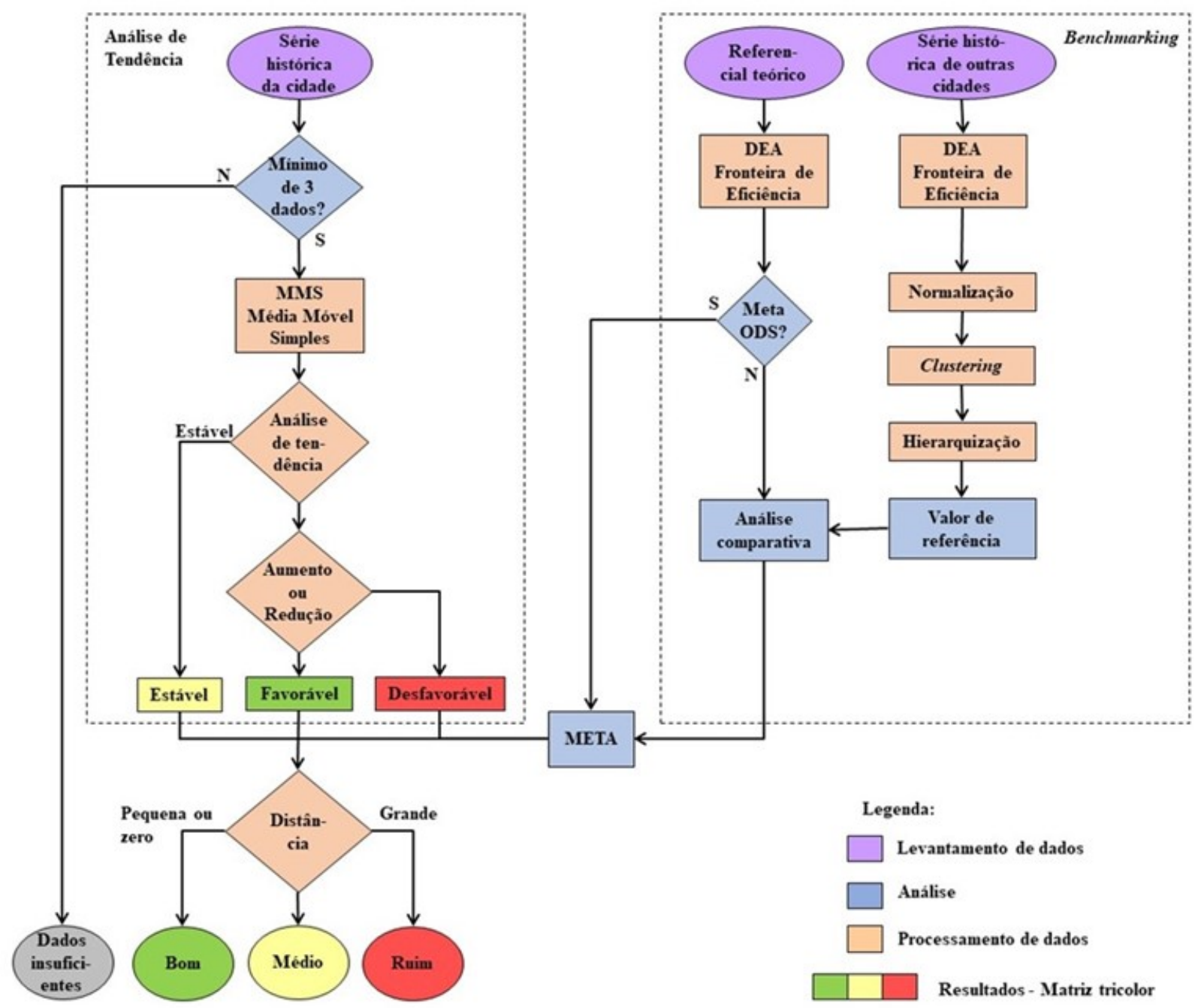

Figura 36: Fluxograma do método para retrofit urbano. Elaborada pela autora.

Com base nos valores levantados pelo benchmarking, pode-se identificar cenários futuros e tomadores de decisão podem definir metas futuras de longo prazo para cada um dos 100 indicadores da NBR ISO 37120:2017, bem como metas parciais para mensurar ações consecutivas para atingimento da meta final. Cenários futuros para a cidade podem ser elaborados com base nestas referências, levando em conta também a visão de futuro da cidade, nas projeções populacionais e nas tendências observadas atualmente e nos anos passados, alinhados e consistentes com a Agenda 2030. 
O método proposto e ilustrado no fluxograma da Figura 36 não encerra após a implementação das intervenções de retrofit, priorizadas de acordo com os cenários futuros e metas definidas. Dada a importância de realizar uma avaliação posterior às intervenções de retrofit urbano, e verificação de atingimento das metas, um novo ponto de referência deve ser introduzido como benchmark para o diagnóstico da nova situação da cidade, e o planejamento de atividades pode iniciar deste ponto em diante, para implementação de novas melhorias. A continua evolução da análise proporciona informação cada vez mais precisa para as decisões e para o redirecionamento de qualquer ação que se julgar necessária. As etapas mencionadas anteriormente têm a intenção de direcionar o planejamento urbano e propiciar continuidade no longo prazo.

Inicialmente é realizado o diagnóstico É de suma importância indicar a fonte, o ano, a cobertura geográfica e a definição precisa do indicador empregado ao lado de cada entrada de dados obtidos sobre a cidade. Estas informações são fundamentais para se analisar e determinar a classificação dos indicadores, e essenciais também para a comparação de dados entre cidades. Só e possível julgar se uma comparação é adequada quando se possui essas informações.

Tomando-se um indicador de determinada cidade, a análise de tendência por meio de média móvel simples permite agrupar os indicadores de diagnóstico da cidade em outras quatro situações distintas, a saber:

1) Dados insuficientes: Não há dados necessários para compor o comprimento da média $(\mathrm{k})$, adotado como 3 anos

2) Tendência Favorável: a linha de média móvel se apresenta com inclinação favorável.

3) Tendência Desfavorável: a linha de média móvel se apresenta com inclinação desfavorável, ou seja, o inverso da situação anterior.

4) Tendência Estável: a linha de média móvel não apresenta inclinação, ou inclinação desprezível. Desta forma, não se pode concluir que a tendência seja favorável ou não.

Para a sistematização desta análise de tendência em forma de painel (dashboard), podese adotar referências de cores para cada um destes grupos, proporcionando uma ferramenta visual de apoio ao processo de decisão e planejamento urbano do retrofit, de forma simples, 
clara e suficientemente direta para ser compreendido por todas as partes interessadas. A estas quatro situações associa-se uma matriz tricolor, ou semafórica, sendo a situação de dados insuficientes (1) cinza, tendência favorável (2) verde, tendência oposta ou desfavorável (3) vermelha, e a tendência estável (4) amarela.

Para cada um dos indicadores da NBR ISO 37120:2017, a análise conjunta de tendência do indicador e o seu respectivo benchmark propicia um resultado que pode levar fundamentalmente a quatro distintas situações:

1) Indicador com tendência favorável, e com o valor próximo ou já coincidente com seu benchmark

2) Indicador com tendência favorável, mas com o valor distante do seu benchmark

3) Indicador com tendência desfavorável, mas com o valor próximo ou já coincidente com seu benchmark

4) Indicador com tendência desfavorável, e com o valor distante do seu benchmark

Da mesma forma que a classificação de tendência, para a sistematização desta análise de classificação final dos indicadores associa-se uma matriz tricolor, sendo a situação (1) verde, a situação oposta (4) vermelha, e as demais situações (3) e (4) amarelas, conforme ilustra a Figura 37, a seguir. Foram adotados tons mais fortes da matriz para esta classificação final, ao passo que para a classificação de tendência foram adotados tons pastéis.

Na primeira situação, em que o indicador apresenta tendência favorável e com o valor próximo ou já coincidente com seu benchmark, identifica-se a melhor circunstância. Esta situação denota que, ou a meta para o indicador já foi atingida, ou os valores do indicador tendem a atingir a meta em um prazo factível. 


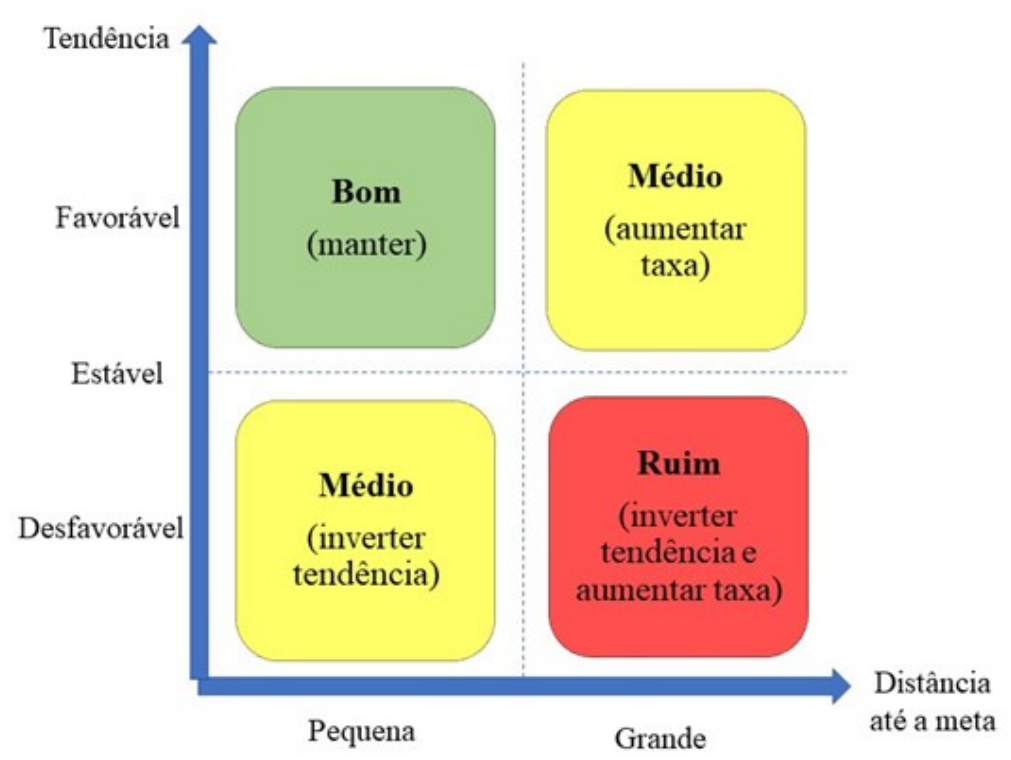

Figura 37: Classificação dos indicadores em quatro categorias, aplicando matriz tricolor. Elaborada pela autora.

Em contraponto, na segunda situação, em que o indicador apresenta tendência favorável, mas com o valor distante do seu benchmark, identificam-se alguns aspectos. A tendência favorável pode ser acompanhada de uma taxa de aumento ou redução, a depender do tipo de indicador, que propicie que os valores do indicador apresentem a tendência de atingir a meta em um prazo factível. Entretanto, a tendência favorável pode apresentar uma taxa pífia, que denote que o atingimento do valor do benchmark será improvável ou em um prazo muito distante. Este seria o caso de que, embora o indicador apresente uma tendência favorável, sejam tomadas ações para que as taxas de aumento ou redução sejam intensificadas, por programas que melhor direcionem o indicador para o atingimento da meta em prazo factível.

Semelhante a primeira situação, o caso em que o indicador apresenta valor próximo ou já coincidente com seu benchmark, mas uma tendência desfavorável nos últimos anos, identifica a necessidade de cautela e atenção ao indicador que já atingiu sua meta ou seu valor de referência. Faz-se necessário levar em conta as variações populacionais da cidade e a consequente alteração das demandas urbanas, que podem alterar a tendência de um indicador fazendo-o distanciar de benchmark. Outra circunstância identificada é a dos valores do indicador estarem próximos da meta, mas que ele não está acompanhado por programas e ações que adequadamente o direcionem ao seu melhor valor de referência. 
Por último, na situação em que o indicador apresenta tendência desfavorável e valor distante do seu benchmark, identifica-se a pior circunstância. Esta situação denota que a distância dos valores do indicador em relação ao benckmark tendem a aumentar cada vez mais, e que o atingimento do valor do benchmark será improvável ou em um prazo muito distante. Este seria o caso de priorização de ações para que a tendência do indicador seja revertida de desfavorável para favorável, acompanhada de intensificação das taxas de aumento ou redução, dependendo do indicador, para que direcionar adequadamente o indicador para o atingimento da meta em prazo factível.

Os indicadores e seus critérios de classificação servem para indicar onde há um problema e qual é a gravidade da situação, com o fim de priorizar a ação. Os indicadores não precisam identificar a problemática específica dentro do tema, nem oferecer soluções. Esse tipo de análise mais detalhada deve ser realizado em etapa mais adiante, em relação ao menor grupo de temas priorizados, como preparação para o desenvolvimento de soluções e intervenções de retrofit urbano.

Os dados obtidos durante a etapa de diagnóstico da cidade fornecem também uma linha de base para o sistema de monitoramento. $\mathrm{O}$ acompanhamento dos indicadores realizado ao longo do tempo constitui uma boa ferramenta interna de monitoramento administrativo e aumenta a transparência. Também pode representar uma importante via para que os cidadãos assumam um papel mais proativo para garantir a continuidade e melhoria dos programas, tornando os processos decisórios mais participativos (BID, 2013).

$\mathrm{Na}$ etapa de levantamento e identificação de referencial teórico, desenvolveu-se uma análise cruzada entre os indicadores de sustentabilidade urbana, selecionada a NBR ISO 37120:2017, e seus respectivos objetivos e metas, dentro da escolha de uso dos ODS Objetivos de Desenvolvimento Sustentável. Como informado anteriormente, os indicadores propostos para os ODS foram globalmente acordados em julho de 2017, definidos pela Comissão Estatística das Nações Unidas, e somam 232. A pesquisa bibliográfica realizada auxiliou neste processo de análise cruzada, e foram levados em conta as seguintes publicações:

- Os 100 indicadores da NBR ISO 37120:2017 (ABNT, 2017a) 
- Os indicadores do Programa Cidades Sustentáveis, gestão 2013-2016 (REDE NOSSA SÃO PAULO, 2012)

- Os indicadores do Programa Cidades Sustentáveis, gestão 2017-2020 (REDE NOSSA SÃO PAULO, 2016)

- Os indicadores das metas dos ODS previstos inicialmente para o Brasil (PNUD, 2015b)

- Os 232 indicadores das metas dos ODS acordados na Comissão Estatística (IAEGSDGs, 2018)

- Os indicadores do Índice ODS (SDSN, 2016)

- O Anexo C da revisão da ISO 37120:2018 (ISO, 2018b)

Assim, elaborou-se uma planilha com todos os dados cruzados, confrontando indicadores e metas, identificando muitas vezes mais de uma meta ODS para o mesmo indicador, e também mais de um indicador relacionado a várias metas ODS. Algumas metas ODS não podem traduzidas numericamente, cujo texto contém expressões tais como: "reduzir significativamente", "aumentar substancialmente", "dobrar a taxa global de melhoria da eficiência energética" (PNUD, 2015b), entre outros, mas que contribuem para auxiliar na decisão de definição de uma meta de longo prazo. Por outro lado, vários indicadores das Seções 6 - "Educação", 20 - "Esgotos" e 21 - "Água e Saneamento", da NBR ISO 37120:2017, trazem a respectiva meta ODS de proporcionar "acesso universal" (PNUD, 2015b) aos serviços, o que foi traduzido numericamente a $100 \%$ da população. Estas informações de relacionamento de indicadores e metas textuais dos ODS foram relacionadas e aparecem visualmente em uma tabela contida no dashboard proposto para o método. Os indicadores da NBR ISO 37120:2017 e suas respectivas metas ODS, podem ser observados no Apêndice B.

Algumas das principais referências teóricas utilizadas tese trazem compilações oriundas de diversas fontes. Ao mesmo tempo, quanto mais se aumenta o nível de detalhe da análise, torna-se mais difícil sustentar uma pauta idealizada e genérica de objetivos, principalmente do ponto de vista urbano, e da aplicabilidade na cidade real. O número de 100 indicadores da NBR ISO 37120:2017 pode ser utilizado para desenvolvimento genérico do método para retrofit urbano, e a qualquer momento pode-se incluir outros indicadores a que sejam 
atribuídas metas numéricas, quer seja pela gestão municipal, quer pela revisão e atualização das dinâmicas publicações sobre o tema de metas e indicadores ODS.

Cabe salientar a dificuldade em generalizar um método para 100 indicadores tão distintos, de temas tão diversos, com escala, precisão e fonte dos dados diferentes. Mas a intenção foi agrupá-los de forma visual e compartilhando os mesmos critérios de classificação, na intenção de priorizar áreas e soluções de retrofit urbano. $\mathrm{Na}$ análise de tendência, por exemplo, a Média Móvel Simples pode não ser ideal para todos os 100 indicadores. Porém, a análise deve levar em conta e reconhecer as diferenças entre indicadores, bem como considerá-los as influências de um indicador sobre outro, ou outros.

Para a identificação de fronteiras de eficiência, realizou-se um levantamento de valores recomendados na literatura para cada um dos 100 indicadores, levando em conta as publicações:

- Guia Metodológico dos ICES - Indicadores da Iniciativa Cidades Emergentes e Sustentáveis (BID, 2013)

- Os indicadores do Índice ODS (SDSN, 2016)

Além das publicações acima, os valores publicados para as 58 cidades já certificadas pela ISO 37120:2014 pelo WCCD foram levantados e auxiliaram na composição da fronteira de eficiência (WCCD, 2018).

Estes mesmos dados das 58 cidades certificadas foram utilizados no processo de benchmarking por clustering. Porém, primeiramente, foram utilizados para a análise por clustering os dados do SNIS - Sistema Nacional de Indicadores de Saneamento, que apresenta séries históricas de 2010 a 2016 de todos os 5570 municípios brasileiros. Assim, como o SNIS é fonte de dados de somente 10 indicadores dos 100 indicadores da NBR ISO 37120:2017, a etapa de clustering se resumiu a um exercício para estes 10 indicadores, relacionados aos temas de resíduos sólidos, esgotos e água. Foi realizada uma análise por clustering dos 10 indicadores para os munícipios brasileiros, e posteriormente uma análise similar de clustering para estes mesmos 10 indicadores para as 58 cidades certificadas pelo WCCD. 


\subsection{Principais Fontes de Dados de Indicadores Urbanos no Brasil}

Durante o processo de levantamento dos dados para pontuar a série histórica de 2010 a 2017 dos indicadores da NBR ISO 37120:2017, várias fontes de dados foram identificadas, nos âmbitos nacional, estadual e municipal. A busca partiu de dados administrativos, gerados no âmbito dos programas ou em outros cadastros oficiais, e paralelamente de estatísticas públicas, produzidas pelo IBGE - Instituto Brasileiro de Geografia e Estatística e outras instituições. Várias são as publicações e plataformas com dados para indicadores diversos, sejam ou não urbanos, constantes ou não na NBR ISO 37120:2017. O Quadro 14, a seguir, lista as principais fontes identificadas e consultadas.

Quadro 14: Fontes de dados consultadas

\begin{tabular}{|c|c|c|c|}
\hline Instituição & Site & Informações & Referência \\
\hline $\begin{array}{l}\text { ANATEL - Agência Nacional de } \\
\text { Telecomunicações }\end{array}$ & $\begin{array}{c}\text { https://cloud.anatel.gov.br/in } \\
\text { dex.php/s/TpaFAwSw7RPf } \\
\text { Ba8 }\end{array}$ & & $\begin{array}{l}\text { ANATEL } \\
(2018)\end{array}$ \\
\hline $\begin{array}{l}\text { ANEEL - Agência Nacional de } \\
\text { Energia Elétrica }\end{array}$ & $\begin{array}{l}\text { http://www.aneel.gov.br/indi } \\
\text { cadores-coletivos-de- } \\
\text { continuidade }\end{array}$ & & $\begin{array}{l}\text { ANEEL } \\
(2018)\end{array}$ \\
\hline BBC - Banco Central do Brasil & $\begin{array}{l}\text { http://www4.bcb.gov.br/pec/ } \\
\text { taxas/port/ptaxnpesq.asp?id= } \\
\text { txcotacao }\end{array}$ & $\begin{array}{l}\text { Cotações de moedas } \\
\text { estrangeiras }\end{array}$ & $\mathrm{BBC}(2018)$ \\
\hline $\begin{array}{l}\text { CETESB - Companhia Ambiental } \\
\text { do Estado de São Paulo - } \\
\text { QUALAR - Sistema de } \\
\text { Informações da Qualidade do Ar }\end{array}$ & $\begin{array}{l}\text { http://qualar.cetesb.sp.gov.br } \\
\text { /qualar/home.do }\end{array}$ & $\begin{array}{l}\text { QUALAR - Sistema de } \\
\text { Informações da } \\
\text { Qualidade do Ar }\end{array}$ & $\begin{array}{l}\text { CETESB } \\
(2017)\end{array}$ \\
\hline $\begin{array}{l}\text { DAESP - Departamento } \\
\text { Aeroviário do Estado de São } \\
\text { Paulo }\end{array}$ & http://www.daesp.sp.gov.br & Dados de aeroportos & $\begin{array}{l}\text { DAESP } \\
(2017)\end{array}$ \\
\hline $\begin{array}{l}\text { IBGE - Instituto Brasileiro de } \\
\text { Geografia e Estatística } \\
\text { @Cidades, Perfil dos Municípios } \\
\text { Brasileiros }\end{array}$ & https://cidades.ibge.gov.br/ & $\begin{array}{l}\text { Características } \\
\text { demográficas, habitação, } \\
\text { escolaridade, população } \\
\text { ocupada, renda, etc, com } \\
\text { dados agregados por } \\
\text { município e por setor } \\
\text { censitário }\end{array}$ & $\begin{array}{l}\text { IBGE } \\
(2018)\end{array}$ \\
\hline $\begin{array}{l}\text { INPI - Instituto Nacional da } \\
\text { Propriedade Industrial }\end{array}$ & $\begin{array}{c}\text { http://www.inpi.gov.br/estati } \\
\text { sticas }\end{array}$ & $\begin{array}{l}\text { Estatísticas, Anuário } \\
\text { Estatístico de } \\
\text { Propriedade Industrial }\end{array}$ & INPI (2018) \\
\hline $\begin{array}{l}\text { Ministério da Ciência, } \\
\text { Tecnologia, Inovações e } \\
\text { Comunicações }\end{array}$ & www.mctic.gov.br/ & $\begin{array}{l}\text { Dados do Setor de } \\
\text { Comunicações - } \\
\text { Informações } \\
\end{array}$ & $\begin{array}{l}\text { MCTIC } \\
(2018)\end{array}$ \\
\hline $\begin{array}{l}\text { Ministério da Educação INEP - } \\
\text { Instituto Nacional de Estudos e } \\
\text { Pesquisas Educacionais Anísio } \\
\text { Teixeira }\end{array}$ & http://portal.inep.gov.br/ & $\begin{array}{l}\text { Censo escolar: } \\
\text { estudantes, docentes, } \\
\text { equipamentos }\end{array}$ & INEP (2018) \\
\hline $\begin{array}{l}\text { Ministério da Saúde DATASUS - } \\
\text { Departamento de Informática do } \\
\text { SUS }\end{array}$ & $\begin{array}{c}\text { http://tabnet.datasus.gov.br/t } \\
\text { abdata/cadernos/cadernosma } \\
\text { p.htm } \\
\end{array}$ & $\begin{array}{l}\text { Óbitos, mortalidade, } \\
\text { equipamentos, } \\
\text { profissionais }\end{array}$ & $\begin{array}{l}\text { DATASUS } \\
\quad(2017)\end{array}$ \\
\hline
\end{tabular}




\begin{tabular}{||l|c|l|c||}
\hline \multicolumn{1}{|c|}{ Instituição } & \multicolumn{1}{c|}{ Site } & \multicolumn{1}{c||}{ Informações } & Referência \\
\hline \hline $\begin{array}{l}\text { Ministério das Cidades SNIS - } \\
\text { Sistema Nacional de Indicadores } \\
\text { de Saneamento }\end{array}$ & http://app3.cidades.gov.br/ & Série histórica & SNIS (2016) \\
\hline $\begin{array}{l}\text { Ministério do Desenvolvimento } \\
\text { Social e Combate à Fome - Plano } \\
\text { Brasil sem Miséria }\end{array}$ & http://aplicacoes.mds.gov.br & $\begin{array}{l}\text { Relatórios de } \\
\text { Informações Sociais }\end{array}$ & MDS (2017) \\
\hline $\begin{array}{l}\text { SEADE - Fundação Sistema } \\
\text { Estadual de Análise de Dados }\end{array}$ & $\begin{array}{c}\text { http://www.imp.seade.gov.br } \\
\text { /frontend/\#/tabelas }\end{array}$ & $\begin{array}{l}\text { IMP - Informações dos } \\
\text { Municípios Paulistas }\end{array}$ & $\begin{array}{c}\text { SEADE } \\
\text { (2018a) }\end{array}$ \\
\hline $\begin{array}{l}\text { SEADE - Fundação Sistema } \\
\text { Estadual de Análise de Dados }\end{array}$ & $\begin{array}{c}\text { http://produtos.seade.gov.br/ } \\
\text { produtos/projpop/ }\end{array}$ & $\begin{array}{l}\text { Projeções Populacionais } \\
\text { SEADE } \\
\text { (2018b) }\end{array}$ \\
\hline $\begin{array}{l}\text { Secretaria de Energia do Estado } \\
\text { de SP }\end{array}$ & $\begin{array}{c}\text { htta.//dadosenergeticos.ener } \\
\text { gianev//BiblioVirtual }\end{array}$ & $\begin{array}{l}\text { Anuário Estatístico de } \\
\text { Energéticos por } \\
\text { Município no Estado de } \\
\text { São Paulo }\end{array}$ & $\begin{array}{c}\text { PÃO } \\
\text { PALO } \\
(2017)\end{array}$ \\
\hline $\begin{array}{l}\text { Secretaria de Segurança Pública } \\
\text { do Estado de São Paulo }\end{array}$ & $\begin{array}{c}\text { http://www.ssp.sp.gov.br/Est } \\
\text { atistica/Pesquisa.aspx }\end{array}$ & $\begin{array}{l}\text { Dados Estatísticos do } \\
\text { Estado de São Paulo }\end{array}$ & $\begin{array}{c}\text { SSP/SP } \\
\text { (2018) }\end{array}$ \\
\hline TSE - Tribunal Superior Eleitoral & $\begin{array}{c}\text { http://www.tse.jus.br/eleicoe } \\
\text { s/estatisticas/ }\end{array}$ & Estatísticas eleitorais & TSE (2016) \\
\hline
\end{tabular}

Elaborado pela autora.

Como se observa no Quadro anterior, o Estado de São Paulo possui instituições de produção de indicadores, o que não pode ser extrapolado para o restante do país. Portanto, no Brasil, cautela deve ser tomada para a aquisição de dados para indicadores da NBR ISO 37120:2017 para municípios que não sejam do Estado de São Paulo.

A listagem do Quadro anterior não abrange algumas fontes que contém dados importantes de indicadores urbanos, mas que não correspondem diretamente a indicadores da NBR ISO 37120:2017, mas que são citados abaixo pois trazem informações importantes:

- Desenvolvidos pela EMPLASA - Empresa Paulista de Planejamento Metropolitano Emplasa, o $\quad$ SIM $\quad-\quad$ Sistema de Informações Municipais (http://www.sim.emplasa.sp.gov.br/mapa) e o SIMM-SP - Sistema de Informações Municipais e Metropolitanas do Estado de São Paulo permitem visão integrada do território com dados multidisciplinares de várias fontes

- Desenvolvida pelo IBGE - Instituto Brasileiro de Geografia e Estatística, a Pesquisa de Informações $\quad$ Básicas $\quad$ Municipais $\quad-\quad$ MUNIC (https://ww2.ibge.gov.br/home/estatistica/economia/perfilmunic/defaulttab1_perfil.s $\mathrm{htm})$ efetua, periodicamente, um levantamento pormenorizado de informações sobre a estrutura, a dinâmica e o funcionamento das instituições públicas municipais, por meio de questionários auto-avaliativos

- Publicada pelo IBGE, a Pesquisa Nacional por Amostra de Domicílios - PNAD (https://www.ibge.gov.br/estatisticas-novoportal/sociais/populacao/9171-pesquisa- 
nacional-por-amostra-de-domicilios-continua-mensal.html ) investiga anualmente, de forma permanente, características gerais da população, de educação, trabalho, rendimento e habitação, além de outras com periodicidade variável, de acordo com as necessidades de informação para o País, como as características sobre migração, fecundidade, nupcialidade, saúde, segurança alimentar, entre outros temas. O levantamento dessas estatísticas se dá nos níveis de divulgação - Brasil, Grandes Regiões, Unidades da Federação e nove Regiões Metropolitanas.

- Divulgados pelo Fórum Brasileiro de Segurança Pública (http://www.forumseguranca.org.br/), indicadores de criminalidade correspondentes a: Ocorrências letais; crimes contra a dignidade sexual; crimes patrimoniais, entre outros, são agregados por UF.

- Desenvolvido pelo Ministério do Trabalho, o PDET - Programa de Disseminação das Estatísticas do Trabalho (http://pdet.mte.gov.br/acesso-online-as-bases-dedados) apresenta dados de empregos, salários, admissões e demissões.

\subsection{Confiabilidade dos Dados Brutos}

A confiabilidade nos valores observados é outra propriedade importante para legitimar o uso do indicador. Na avaliação do nível de violência em uma comunidade, por exemplo, indicadores baseados nos registros de ocorrências policiais ou mesmo de mortalidade por causas violentas tendem a ser menos confiáveis - e menos válidos - que aqueles passíveis de serem obtidos a partir de pesquisas de vitimização, em que se questionam os indivíduos acerca de agravos sofridos em seu meio em determinado período (JANNUZZI, 2001).

No contexto da sociedade da informação, há disponibilidade de acesso a fontes de informação abundantes, atualizadas, precisas, objetivas e, em resumo, de qualidade. Ao mesmo tempo, toda esta informação necessita ser organizada, sistematizada e gerenciada de forma que este grande volume de dados não se torne uma situação de excesso e saturação, com consequências que acarretam em ineficiências de gestão. As possibilidades de gestão da informação são muitas, mas sua mera implementação não é uma solução para todos os problemas e não é garantia automática de sucesso. O planejamento urbano estratégico está geralmente em uma situação de volatilidade e custos dos erros, em termos de recursos 
públicos utilizados, e, portanto, necessita de estudo constante. Este fato dá peso à necessidade de sistematização das informações urbanas, de forma que o sistema seja abastecido com estudo regular, frequente e específico dos dados. Estes sistemas de informação incorporam indicadores, ferramentas e técnicas, e, com uma metodologia adequada, proporcionam melhor e mais rápido conhecimento, tanto sobre o ambiente quanto sobre os espaços urbanos relevantes (LUQUE-MARTÍNEZ; MUÑOZ-LEIVA, 2005).

Um número significativo de indicadores e dados foram e estão sendo desenvolvidos ao redor do mundo. Conforme as cidades crescem, a importância da tomada de decisão guiada por dados é fundamental para a comparação global. Muitas cidades estão tornando dados urbanos publicamente disponíveis, sem custo, como uma maneira de reforçar a transparência e facilitar novos usos e aplicações dos dados. Estas iniciativas recentes têm o potencial de transformar o envolvimento e o comprometimento dos cidadãos na governança da cidade. $\mathrm{O}$ fluxo crescente de dados urbanos abertos durante os últimos anos sugere que esta tendência irá continuar. Entretanto, vários desafios devem ser enfrentados para proporcionar que os dados sejam completamente aproveitados. Um deles é a falta de padronização de formatos de disponibilização, inclusive muitos deles não são passíveis de leitura de máquina (machine reading). Portanto, mecanismos e ferramentas são necessários para auxiliar os usuários a identificar ligações entre conjuntos de dados (BARBOSA et al, 2014).

A qualidade de uma grande quantidade dados disponíveis frequentemente não é satisfatória ou não é definida para os usos necessários. Portanto, é necessário avaliar a qualidade necessária, questionando o propósito de uso para os dados e a relevância dos dados para este uso. A qualidade dos dados pode ser melhorada pelo controle, por meio da prevenção e correção de erros, e pela confiança, abordagem que implica em filtrar e excluir dados com qualidade insuficiente (VEIGA et al., 2017).

Dados abertos, big data e infraestruturas de dados mais diversificadas têm contribuído para melhoria relativa na precisão, resolução e utilização de dados em avaliação e monitoramento de sustentabilidade urbana, em comparação a abordagens passadas. Os dados abertos possibilitam a exploração de informações com maior transparência e formas de comparação do que anteriormente. Big data possibilita a coleta de dados mais desagregados, ao passo que microdados e dados em tempo real são disponibilizados para cidades. Por 
exemplo, em mobilidade urbana, é gradualmente possível coletar e analisar extensa informação das viagens e temas correlatos, tais como: emissões de gases de efeito estufa, congestionamentos, etc. As novas infraestruturas de dados, por sua vez, possibilitam o levantamento de dados que não eram coletados antes ou que não existiam ainda (RAJAONSON; TANGUAY, 2017).

Uma restrição na implementação de indicadores urbanos é a frequente ausência de dados na escala da cidade, do município. Em alguns casos os limites territoriais exatos da cidade e da unidade administrativa podem não ser precisamente estabelecidos, e podem existir diferenças importantes entre cidades na responsabilidade pela coleta dos dados. Esta responsabilidade compartilhada entre os governos nacional e da administração local podem afetar bastante a variação e a qualidade dos dados (WESTFALL; DE VILLA; ASIAN DEVELOPMENT BANK, 2001).

No caso da ausência de dados específicos agregados para um determinado indicador, é possível calculá-lo empregando-se variáveis intermediárias, o que pode exigir certa criatividade e engenho (BID, 2013). Os indicadores da NBR ISO 37120:2017 são em base anual e, no método para retrofit urbano, são tomados na escala da cidade. Porém, há vários desafios nas escalas temporal e espacial dos indicadores. Alguns indicadores são nacionais ou estaduais e não estão disponíveis na desagregação de municípios, ao mesmo tempo que outros indicadores estão desagregados até a escala de setores censitários ou bairros. Do mesmo modo, alguns indicadores estão desagregados no tempo, em frequência diária ou mensal, e faz-se necessário agregá-los na base anual. A análise dos indicadores, enfim, pode ser realizada na escala temporal ou espacial na desagregação em que os valores são disponíveis, de forma a realizar uma análise mais direcionada e mitigando os possíveis erros de agregação.

O levantamento de valores dos indicadores é passível de dados incompletos, desatualizados e/ou incorretos. Convém que os dados sejam levantados e processados de uma maneira estatisticamente confiável sem grandes ou frequentes revisões. Convém que as séries temporais dos dados sejam publicadas em uma frequência razoável e disponibilizadas para os anos mais recentes. A qualidade dos dados deve representar a melhor medida disponível para um tema específico, proveniente de fontes oficiais nacionais ou internacionais, por exemplo, 
agências estatísticas nacionais ou organizações das Nações Unidas, ou outras internacionalmente reconhecidas (SDSN, 2016).

Na ciência da computação e nas áreas de TI - Tecnologia da Informação há a expressão Garbage in, garbage out (GIGO) que significa, literalmente, "lixo entra, lixo sai". Ela faz referência ao fato de que computadores operam utilizando processos de transformação lógica e, portanto, são capazes de processar sem questionar todos os tipos de dados, mesmo que eles não façam sentido algum para a solução do problema desejado (lixo entra) e, como consequência, geralmente produzem saída indesejada e sem sentido (lixo sai). Mesmo em um computador corretamente programado para processar uma massa de dados, erros introduzidos nele podem ser assimilados e até amplificados. Com isso, para o perfeito funcionamento de um sistema computacional é necessário que não somente suas funcionalidades estejam corretamente programadas, mas que os dados de entrada também sejam confiáveis (MATTOS, 1978).

Para elaboração do método para retrofit urbano foi muito importante a fazer a diferenciação do que são células vazias, ou seja, desprovidas de informação ou com dados faltantes, das células com valor igual a zero. Na programação do sistema, esta importante diferenciação matemática é fundamental, pois células vazias ou que não contém informação não podem ser entendidas como células de valor igual a zero ou nulo. $\mathrm{O}$ cálculo de qualquer tipo de média, ou máximos, ou mínimos, incluindo-se o próprio cálculo de Médias Móveis, podem incorrer em erros e equívocos se esta diferenciação não for estabelecida. Por exemplo, tomando-se o indicador de "mortes no trânsito", o fato de não se possuir a informação precisa de quantas mortes aconteceram em determinado ano é muito diferente do que assumir que esse número de mortes foi igual a zero sistematicamente na programação. Este é um detalhe importantíssimo e que propicia muitos equívocos de análise.

Claramente, a análise detalhada dos dados é tão importante quanto sua própria compilação. Este também é o caso da combinação de informações complementares de caráter qualitativo com os dados do indicador especifico. As mudanças ao longo do tempo, a implementação atual de projetos, os novos avanços e as informações específicas de cada área podem oferecer um panorama mais completo da cidade do que só as estatísticas. Os especialistas com experiência no país podem ser especialmente úteis para contextualizar os 
dados obtidos. Faz-se necessária uma análise subjetiva e qualitativa de indicadores, saindo da escala meramente numérica e matemática para abarcar também questões intangíveis que não são reveladas estatisticamente.

Uma prioridade da implementação dos ODS deve ser o investimento em fortalecimento da coleta de dados e da capacidade de tratamento estatístico em todos os países (SDSN, 2016). A qualidade dos dados para monitorar o progresso na direção dos ODS requer o levantamento, processamento, análise e disseminação de uma quantidade sem precedentes de dados e estatísticas nos âmbitos subnacional, nacional, regional e global, incluindo os dados provenientes de sistemas estatísticos oficiais e de fontes de dados novas e inovadoras. Muitos sistemas estatísticos nacionais ao redor do mundo enfrentam vários desafios nesta questão. Como resultado, informação precisa e adequada sobre determinados aspectos das populações são desconhecidos, e numerosos grupos e indivíduos permanecem "invisíveis", sobre os quais se tem pouco entendimento. Quando possível, convém que o monitoramento global seja baseado em dados comparáveis e padronizados, obtidos por meio de mecanismos de pesquisa adequadamente estabelecidos, no sistema estatístico internacional. Estes mecanismos podem ser melhorados pelo fortalecimento da coordenação entre as agências estatísticas e outras e/ou outras instituições nacionais. Além disto, faz-se necessário explorar novas fontes de dados, inclusive por meio de parcerias com a sociedade civil, o setor privado e a academia. A integração de informações geoespaciais e estatísticas será particularmente importante na produção de vários indicadores (UN-DESA, 2017b).

O uso de indicadores padronizados para cidades abre a possibilidade para que atores urbanos e cidadãos visualizem a situação da cidade no momento atual, pontuando seus indicadores em situação melhor ou pior, para que sejam priorizadas ações na direção de como a cidade estará no futuro. No caso dos valores dos indicadores, é importante mencionar que há vários números e dados disponíveis, em várias plataformas, mas sem uma análise mais aprofundada sobre os mesmos, para que estes dados gerem informações. Quando analisados, divergências são observadas, geralmente fruto de diferenças entre metodologias de mensuração existentes frente ao método descrito na NBR ISO 37120:2017. Porém, quanto mais os valores dos indicadores da NBR ISO 37120:2017 forem analisados, entendidos e assimilados pelos gestores municipais, pelos cidadãos e por todos os atores da gestão urbana, 
mais se buscará a confiabilidade e coerente levantamento dos números, e mais sua melhoria contínua. 


\section{ESTUDO DE CASO - SOROCABA-SP}

O município de Sorocaba-SP foi escolhido para estudo de caso por três motivos fundamentais:

- vários indicadores de sustentabilidade urbana estão disponíveis e abertos em outras plataformas, como a do Programa Cidades Sustentáveis, que contemplou Sorocaba com seu Prêmio Cidades Sustentáveis, com o primeiro lugar na categoria "Cidades Grandes", em 2014

- pela representatividade, por ser um município de grande porte, com uma população de 586.625 habitantes em 2010 e 659.871 estimado em 2018 (IBGE, 2018)

- proximidade com São Paulo, em que a pesquisa de doutorado é desenvolvida, sendo que Sorocaba localiza-se a $85 \mathrm{~km}$ de São Paulo - capital e a $87 \mathrm{~km}$ Campinas (IBGE, 2018), na região oeste do Estado de São Paulo

\subsection{Características da Região Administrativa de Sorocaba - RAS e da Região Metropolitana de Sorocaba - RMS}

A RAS - Região Administrativa de Sorocaba é uma das 8 regiões administrativas do Estado de São Paulo e está localizada na região Oeste do Estado (Figura 38). A RAS é formada por 77 municípios (Figura 39) distribuídos em 5 Regiões de Governo - RGs: Avaré, Botucatu, Itapetininga, Itapeva e Sorocaba, que juntas ocupam a maior área territorial entre as regiões paulistas: $41.077 \mathrm{~km}^{2}$ ou 16,5\% do território estadual (SÃO PAULO, 2012).

Recentemente, em 2014, foi criada a RMS - Região Metropolitana de Sorocaba, que compreende 27 municípios e uma área de 9.821,22 km² (IBGE, 2018), mapeada na Figura 40. De acordo com o censo de 2010 do IBGE - Instituto Brasileiro de Geografia e Estatística, a RMS correspondia a uma população de 1.871 .162 habitantes, ou seja, 4,2\% da população estadual, uma densidade de 175,82 hab $/ \mathrm{km}^{2}$ e um PIB - Produto Interno Bruto de R 47,4 bilhões, ou seja, 3,5\% do PIB estadual. O município com maior população é Sorocaba, com 586.625 habitantes no Censo 2010, e o município com menor população é Jumirim com 2.798 habitantes. Além de Sorocaba, outros municípios com mais de 100 mil habitantes se destacam: Itu (154.147 hab.), Itapetininga (144.377 hab.), Votorantim (108.809 hab.), Tatuí (107.326 hab.) e Salto (105.516 hab.). A taxa média anual de crescimento da população da 
RMS é $0,9 \%$, superior à do Estado de São Paulo, 0,63\%, para o período de 2010 a 2030 (EMPLASA, 2017).

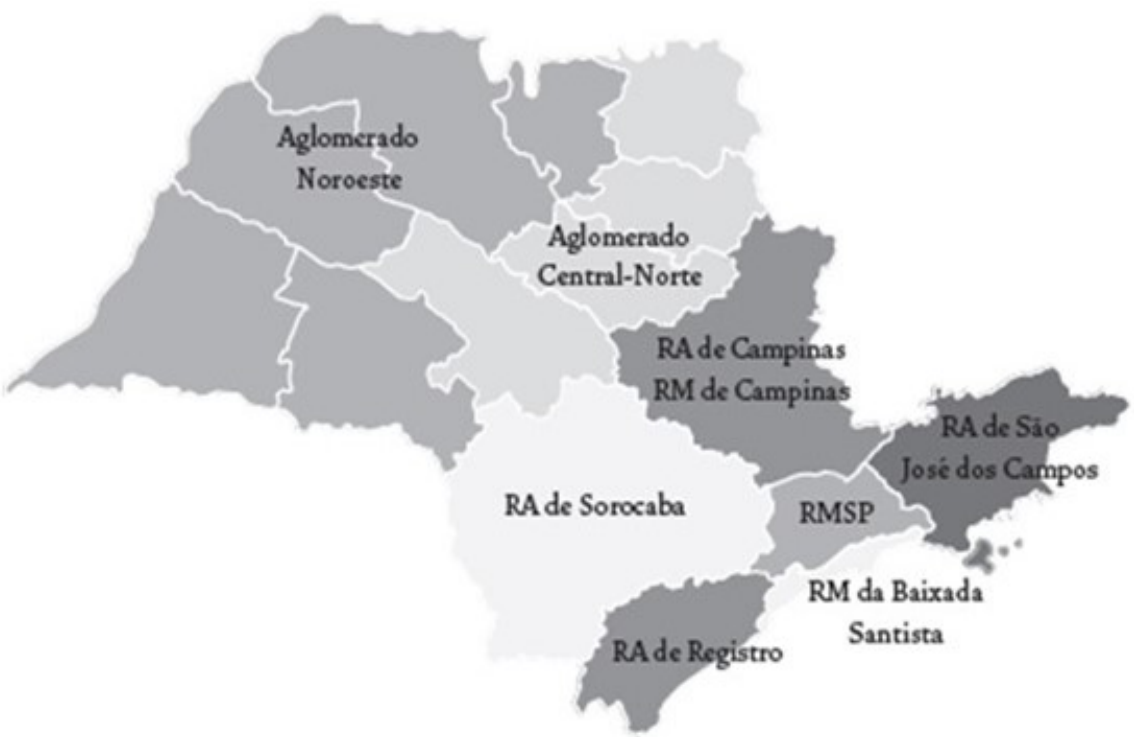

Figura 38: Localização da RAS - Região Administrativa de Sorocaba. Fonte: (SÃO PAULO, 2012).

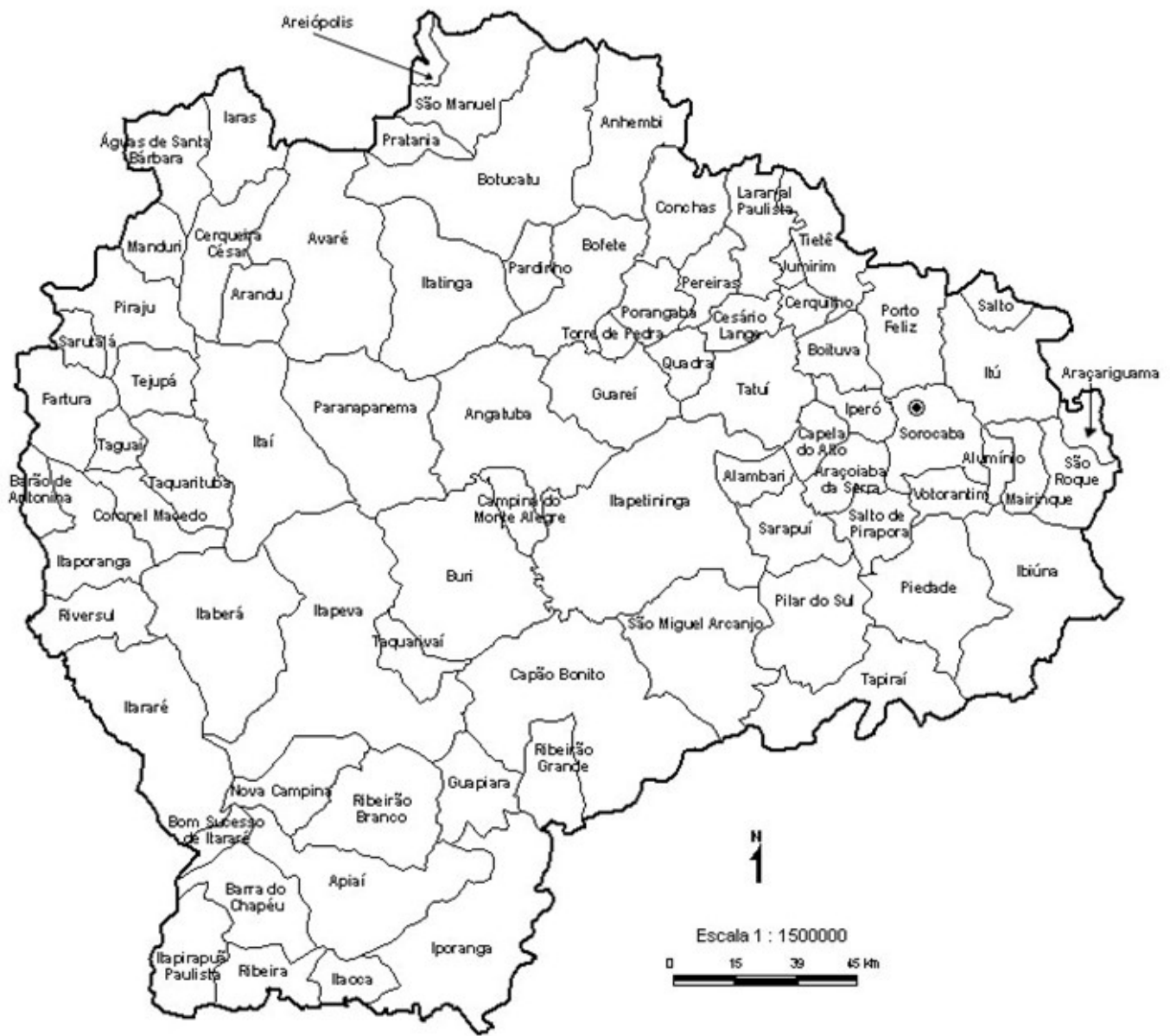

Figura 39: Os 77 municípios que compõem a RAS - Região Administrativa de Sorocaba. Fonte: (SÃO PAULO, 2012). 


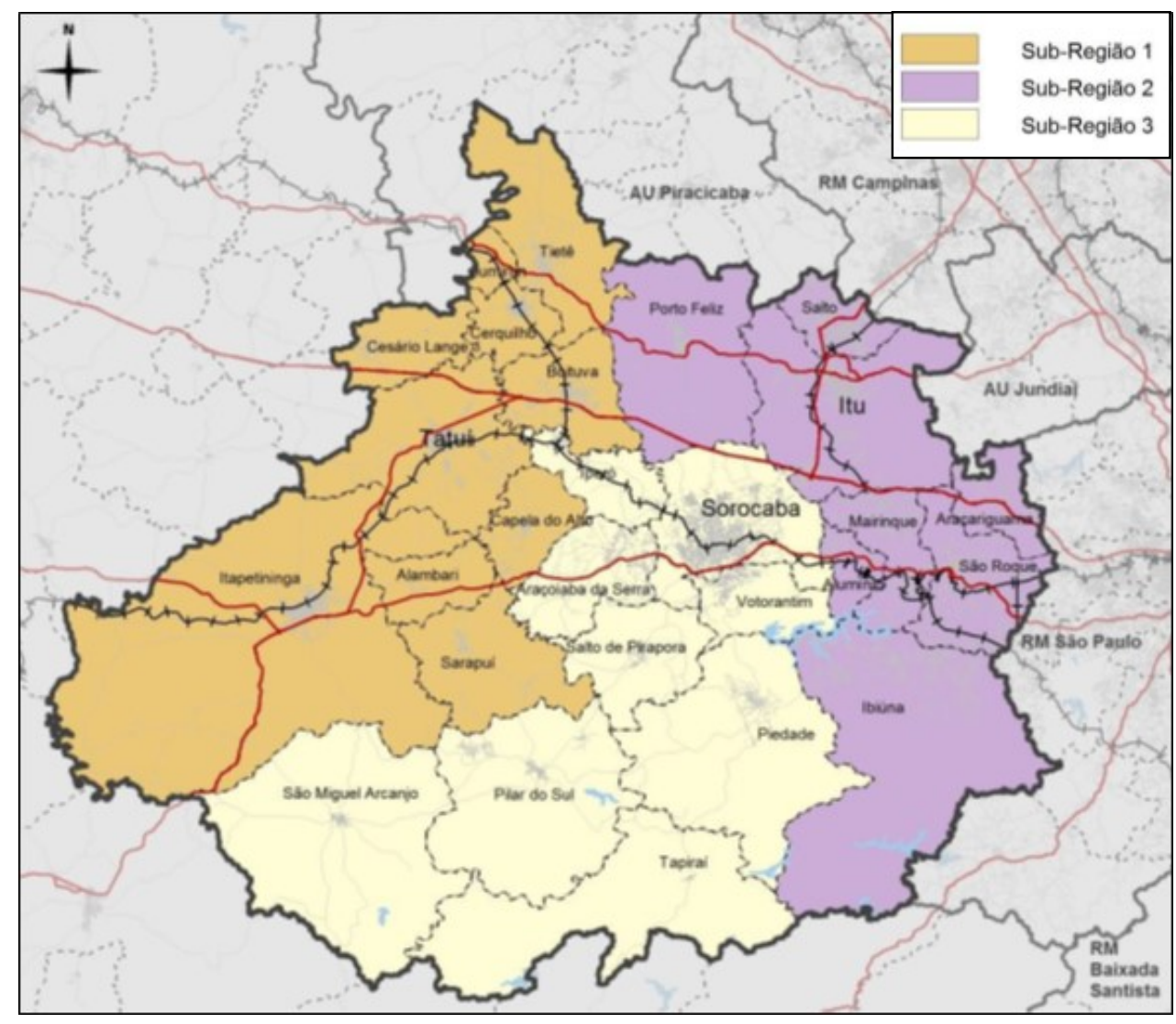

Figura 40: Os 27 municípios que compõem a RMS - Região Metropolitana de Sorocaba. Fonte: EMPLASA (2017).

Os empregos na RMS são fortemente concentrados, principalmente no município de Sorocaba, que responde sozinho por $37 \%$ dos empregos da região. Quando analisadas as disparidades entre os municípios, verifica-se que a maior renda média per capita, encontrada em Sorocaba, é mais de duas vezes superior à menor verificada no município de Tapiraí. A Região Metropolitana de Sorocaba apresenta atividades econômicas diversificadas, potencializadas pela grande disponibilidade de matérias-primas e recursos naturais no território. Os recursos de infraestrutura também são abundantes, como fornecimento de água, energia elétrica e gás natural, sendo que o Gasoduto Bolívia-Brasil atende nove municípios da região. A localização estratégica com fácil acesso aos maiores centros consumidores do Estado, São Paulo e Campinas, por rodovias bem estruturadas, atraiu grandes empresas dos mais variados segmentos e seus respectivos fornecedores, favorecendo o desenvolvimento industrial integrado e estimulando pesquisas aplicadas. A indústria de transformação da RMS vem aumentando sua representação no Estado, e ainda há capacidade de expansão física nas zonas industriais e incentivos municipais para a instalação de novas empresa (EMPLASA, 2017). 
A RMS conta, também, com crescente oferta de mão de obra qualificada, graças à presença de importantes instituições de ensino, escolas técnicas e centros de formação profissional, como Unesp, Uniso, Facens, Unip, Fatecs e Etecs (EMPLASA, 2017).

A agricultura na RMS é bastante diversificada, destacando-se a olericultura, a fruticultura e a viticultura, que abastecem a própria região e ainda as RMs de São Paulo e Campinas. Na mineração, o principal produto extraído na região é o calcário, representando $12,1 \%$ das reservas medidas do Estado (EMPLASA, 2017).

Os municípios com maior população e que apresentam atividades industriais e comerciais mais diversificadas são os que mais atraem movimentos pendulares. A comparação com os municípios receptores mostra a hegemonia de Sorocaba como organizadora do espaço metropolitano, e representa um grande polo de emprego e renda na região. As conexões principalmente rodoviárias entre os municípios principais da região, que também concentram os parques industriais, podem ser observadas na Figura 41, a seguir, que constata que os vetores de desenvolvimento industrial estão intimamente ligados com as estruturas urbana e rodoviária (EMPLASA, 2017).

A RMS está contida no bioma da Mata Atlântica e abriga quatro unidades de conservação de proteção integral municipais, todas no município de Sorocaba, a saber (EMPLASA, 2017):

- Parque Natural Municipal Corredores de Biodiversidade, criado em 2008, em decorrência da compensação ambiental pela instalação do pátio industrial da empresa Toyota do Brasil

- Parque Natural Municipal de Brigadeiro Tobias, criado em 2015, inserido na bacia do córrego Pirajibu-Mirim, atualmente utilizado para abastecimento público

- Estação Ecológica Mário Covas, criada em 2015, inserida no corredor de proteção e recuperação ambiental proposto no Plano Municipal de Conservação e Recuperação da Mata Atlântica (PMS, 2014a)

- Estação Ecológica Municipal do Pirajibu, criada em 2015 


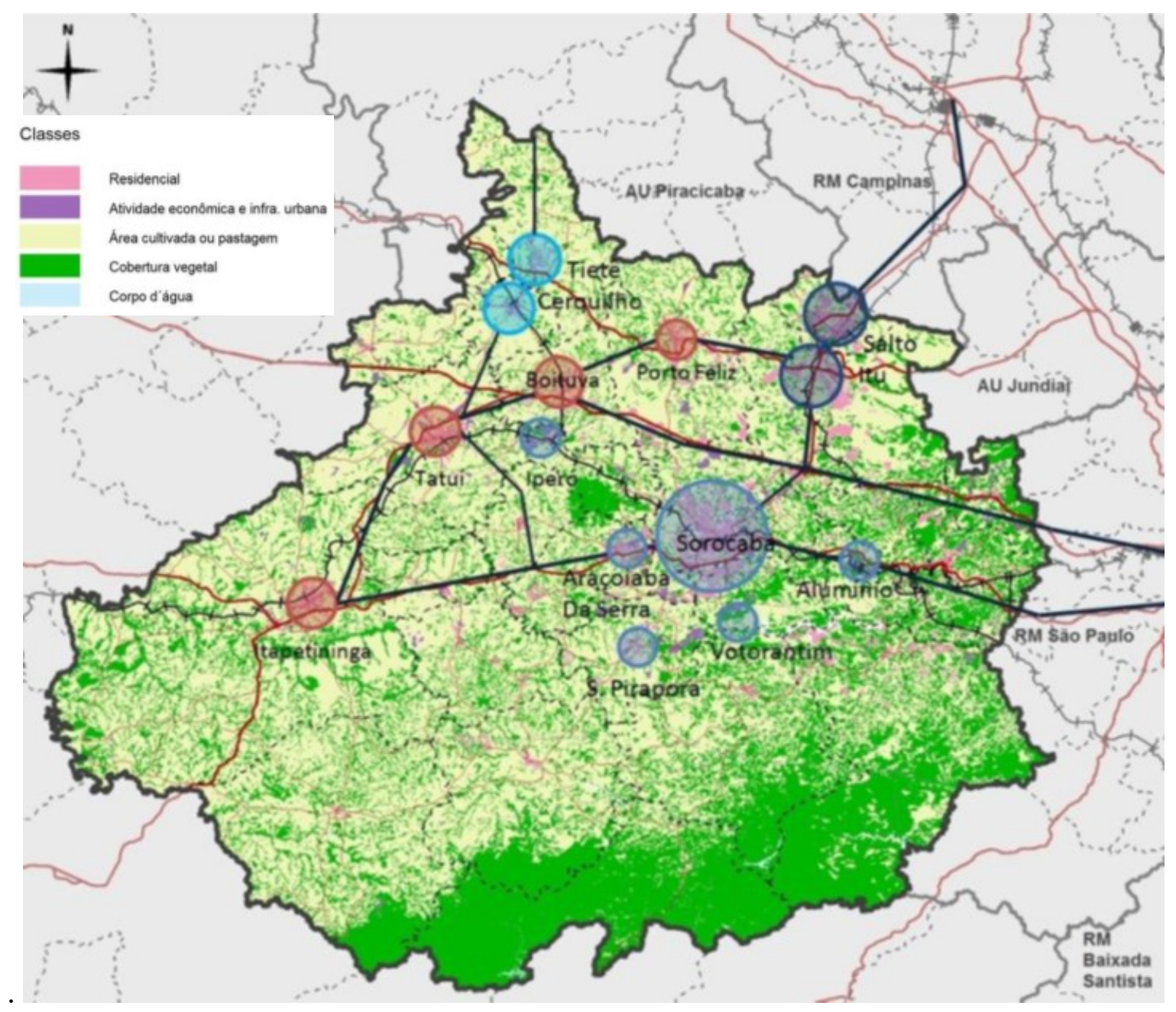

Figura 41: Uso do solo, estrutura urbana e conexões da RMS - Região Metropolitana de Sorocaba. Fonte: EMPLASA (2017).

A Região Metropolitana de Sorocaba tem extensa rede hidrográfica, com corpos d'água de importância regional, como os rios Tietê e Sorocaba, além dos rios Sarapuí, Tatuí, Sorocabuçu, Sorocamirim e Jurumirim. Os municípios da região estão inseridos na sua totalidade em três Unidades de Gerenciamento de Recursos Hídricos: Tietê/Sorocaba (UGRHI-10), Alto Paranapanema (UGRHI-14) e Ribeira de Iguape/Litoral Sul (UGRHI-11), A maioria dos municípios da RMS está integral ou parcialmente inserida na UGRHI-10, sendo o rio Tietê o responsável pela maior vazão. No entanto, por sua água ser de baixa qualidade, devido à poluição, não pode ser utilizada para abastecimento público, diminuindo significativamente a disponibilidade hídrica da região - que já se encontra em situação de déficit com muitos municípios. Os municípios de Sorocaba, Votorantim e São Roque estão em situação um pouco mais confortável pela presença do manancial de Itupararanga, que desempenha papel estratégico para o abastecimento público de água e geração de energia, o 
que reforça a necessidade de garantir sua proteção e destacá-la como área prioritária para conservação e preservação. A bacia hidrográfica formadora dessa represa, denominada Alto Sorocaba, é uma unidade de conservação de uso sustentável, a APA Itupararanga (EMPLASA, 2017).

Constata-se que, quanto ao processamento de resíduos sólidos na RMS, predominam os aterros sanitários. Os fluxos de disposição de resíduos sólidos urbanos na RMS podem ser observados na Figura 42, a seguir, que evidencia o papel do município de Sorocaba como o maior receptor de resíduos da região (EMPLASA, 2017).

Quanto aos leitos hospitalares, os municípios de Itu e Sorocaba apresentam número de leitos, por mil habitantes, próximo ao do Estado de São Paulo, que apresenta 2,14. Quanto aos equipamentos sociais de saúde, a maior concentração de hospitais e equipamentos diversos apresenta-se no município de Sorocaba, bem como maior número de equipamentos de atenção primária, do tipo UBS - Unidade Básica de Saúde (EMPLASA, 2017).

No tema de Segurança, verificando-se os dados absolutos de ocorrências policiais para a RMS, no período de 2001 a 2016, nota-se que os padrões de variação foram majoritariamente semelhantes entre a RMS e o Estado de São Paulo, embora reconhecendo possíveis incoerências por se tratarem de diferentes unidades territoriais. Nas categorias Homicídios Dolosos, Roubo e Furto houve paridade com as variações estaduais, conforme pontua o Quadro 15. Os homicídios diminuíram na RMS, a exemplo do que ocorreu no Estado, embora com um percentual menor: $53,1 \%$ contra $71,8 \%$. Os roubos aumentaram em 43,3\%, próximo ao aumento estadual de $47,2 \%$ e os furtos tiveram um acréscimo de 4,9\%, abaixo do incremento de 17,1\% observado no Estado, considerando os dados de 2001 e 2016 (EMPLASA, 2017).

As questões estratégicas ao desenvolvimento da RMS passam pelas questões de disparidades no território da RMS, com heterogênea distribuição espacial dos equipamentos urbanos, com concentração de equipamentos, emprego e renda no município de Sorocaba, quadro que acarreta distúrbios principalmente ligados aos deslocamentos de pessoas e bens, influindo na mobilidade urbana e na qualidade de vida da população. Os habitantes da RMS necessitam se deslocar diariamente, muitas vezes para outros municípios, para serem atendidos por serviços urbanos essenciais para melhoria da qualidade de. Isto ocorre, 
principalmente, pela existência, em alguns locais, de equipamentos de abrangência regional, com raio de atendimento que alcança vários municípios (EMPLASA, 2017).

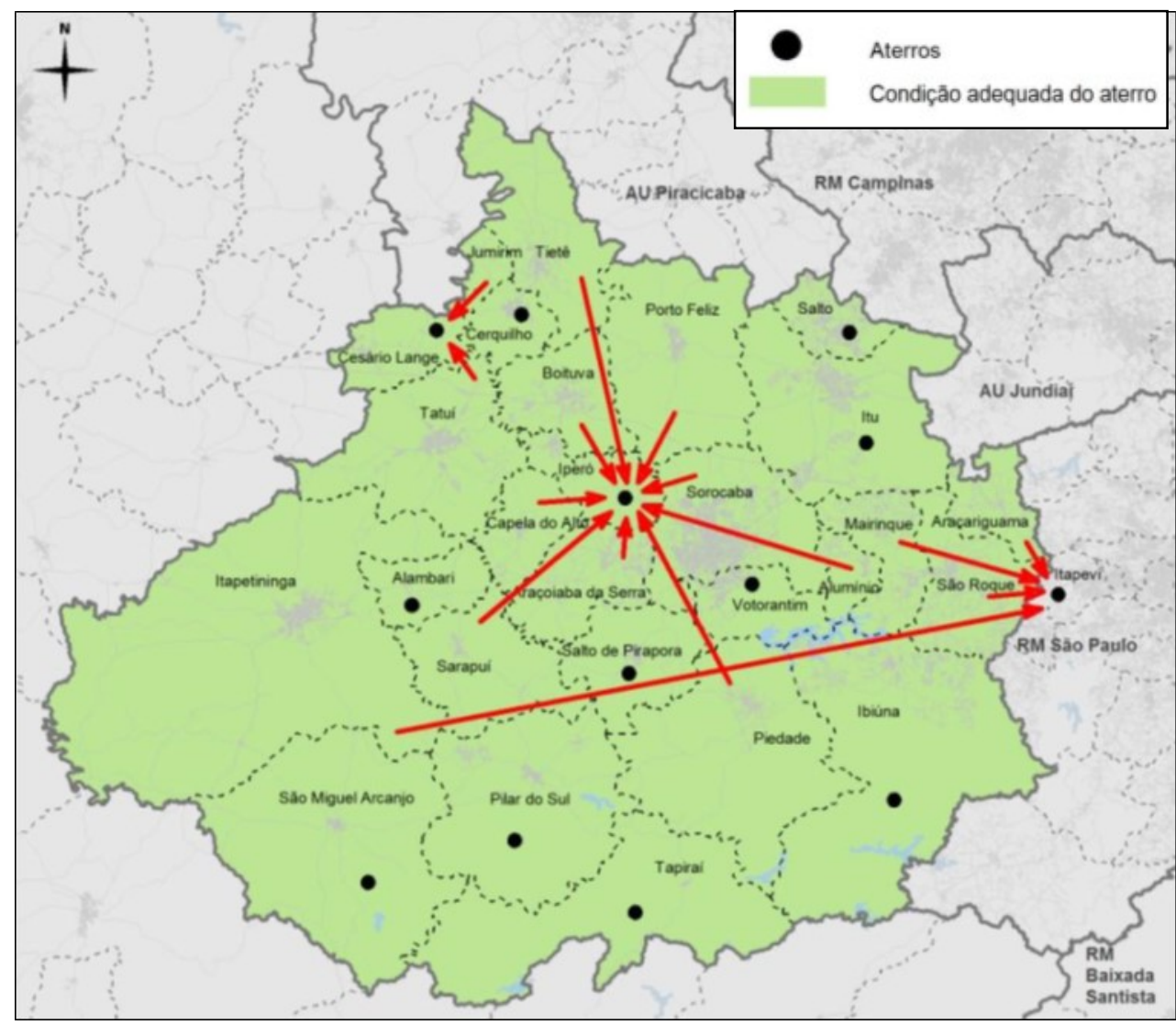

Figura 42: Disposição de resíduos sólidos urbanos na RMS - Região Metropolitana de Sorocaba. Fonte: EMPLASA (2017).

Quadro 15: Representação esquemática das ocorrências policiais na RMS - Região Metropolitana de Sorocaba e ESP - Estado de São Paulo, considerando os anos de 2001 e 2016. Fonte: EMPLASA (2017).

\begin{tabular}{|c|c|c|}
\hline Ocorrências & RMS & ESP \\
\hline \multicolumn{3}{|l|}{ Homicídos Dolosos } \\
\hline & $-53,1 \%$ & $-71,8 \%$ \\
\hline \multicolumn{3}{|l|}{ Roubos } \\
\hline & $+43,3 \%$ & $+47,2 \%$ \\
\hline \multirow[t]{2}{*}{ Furtos } & $\uparrow$ & $\uparrow$ \\
\hline & $+4,9 \%$ & $+17,1 \%$ \\
\hline \multirow[t]{2}{*}{ Furto e Roubo de Veículos } & $\uparrow$ & $\downarrow$ \\
\hline & $+12,0 \%$ & $-12,1 \%$ \\
\hline
\end{tabular}

(1) Homicídio Doloso inclui Homicídio Doloso por Acidente de Trânsito

(2) Roubos incluí Roubo Carga e Banco. 


\subsection{Características do Município de Sorocaba}

Historicamente, as primeiras construções da cidade de Sorocaba iniciaram-se por volta de 1599, marcadas pelo bandeirismo. A corrida do ouro do final do Século XVII no Brasil propiciou que os bandeirantes que buscavam ouro, prata e ferro, contribuíssem para o surgimento, ao longo de suas rotas, de vilas como Sorocaba, Itu e Curitiba. O povoado de Sorocaba iniciou-se pela construção da Antiga capela de Nossa Senhora da Ponte, fundada em 15 de agosto de 1654 (Figura 43) (MANFREDINI; GUANDIQUE; ROSA, 2015).

Sendo o território marcado por várias voçorocas, os índios que habitavam originalmente a região conheciam este fenômeno comum de erosão pelas enxurradas, dando origem ao nome do rio e do povoado. A palavra vem do tupi "soro" (rasgar) e "aba", significando "rasgão" ou “terra rasgada” (MANFREDINI; GUANDIQUE; ROSA, 2015) (LANÇAS, 2007).

A partir de 1732, intensifica-se o fluxo de tropeiros e o comércio de mulas (muares), e Sorocaba torna-se um marco obrigatório para os tropeiros devido a sua posição estratégica, uma feira onde os brasileiros de todos os estados reuniam-se para comercializar animais. A cultura do algodão desenvolveu-se grandemente, sendo inaugurada em 1875 a Estrada de Ferro Sorocabana com o objetivo de escoar a produção. A ferrovia (Figura 44) foi um dos fatores do desenvolvimento industrial, que teve início com a Real Fábrica de Ferro São João do Ipanema, financiada pela coroa de D. Pedro II. A cidade obteve grande desenvolvimento, com aumento expressivo de sua população e elevação à condição de município. A partir da queda das exportações do algodão, surgiram as primeiras indústrias têxteis, a fábrica de tecido Nossa Senhora da Ponte; em 1882, e outras que perduram em atividade até os anos 1970. Com a política desenvolvimentista do governo federal nos anos 1960, foi construída a Rodovia Castelo Branco, importante corredor viário até os dias atuais (LANÇAS, 2007). O processo de industrialização de Sorocaba passou por mudanças significativas, e hoje, a Concentração Urbana é um polo industrial consolidado, de porte médio, que conta com um setor de serviços produtivos e forte presença de indústrias dinâmicas e tradicionais (PEREIRA; LEMOS, 2004). 


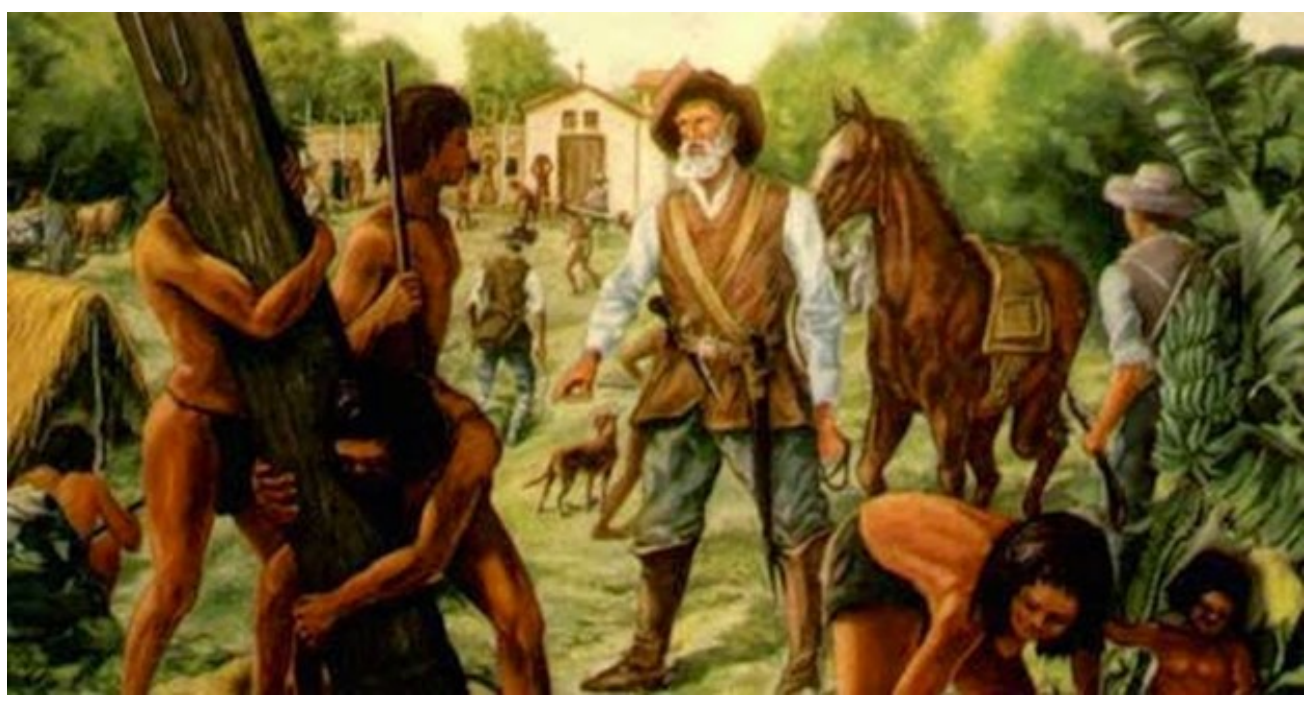

Figura 43: Fundação de Sorocaba - Quadro de Ettore Marangoni.

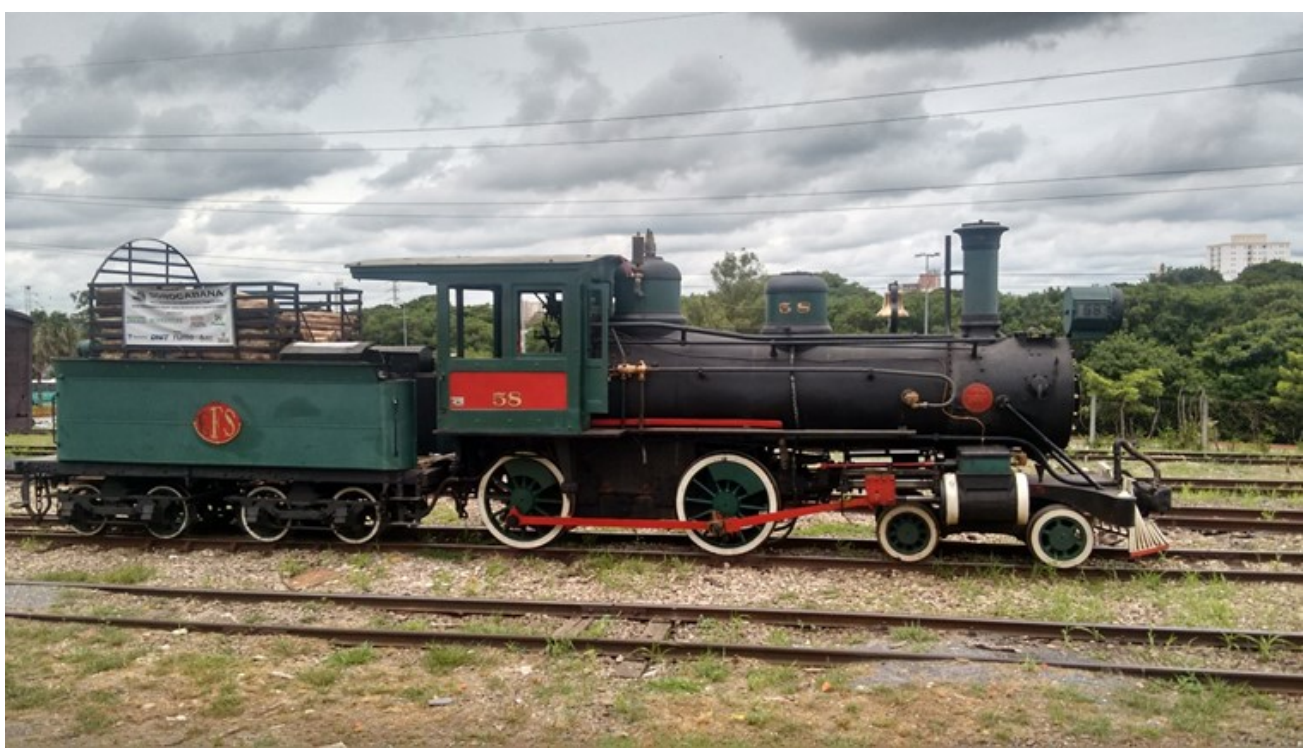

Figura 44: Locomotiva recuperada da EFS- Estrada de Ferro Sorocabana. Acervo da autora (fevereiro/2018).

Sorocaba se situa em um território explorado ao longo dos últimos 400 anos. Consideráveis transformações no uso do solo ocorreram principalmente nos últimos trinta anos, devido a crescente urbanização e a expansão da rede rodoviária (Figura 45). Nas últimas décadas observam-se alterações no padrão da cobertura do solo, causando uma perda de conectividade ecológica no âmbito local e regional. Atualmente, há centenas de remanescentes florestais dispersos na área de estudo, que permanecem protegidos por lei (SILVA DE SOUZA LIMA; MANCINI, 2017). Entre 1988 e 2011, alguns destes remanescentes florestais foram transformados em UCs - Unidades de Conservação, ou em área urbanizada (Figura 46). Enquanto aumentam os assentamentos nas áreas urbanizadas, as transformações nas UCs são na direção do restabelecimento das condições naturais 
(BORTOLETO et al., 2016). As tendências de uso do solo identificadas em Sorocaba são similares a outras regiões do Brasil.

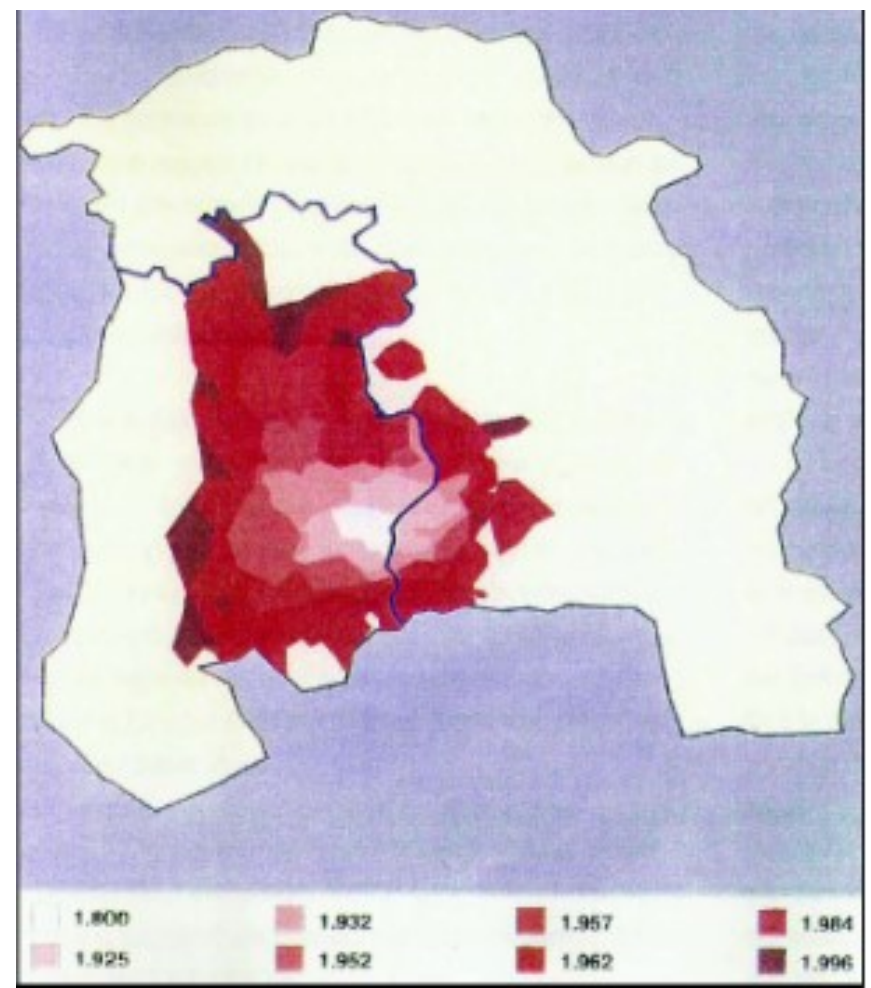

Figura 45: Evolução esquemática da mancha urbana de Sorocaba, de 1800 a 1996. Fonte: (PMS, WALM, 2011)
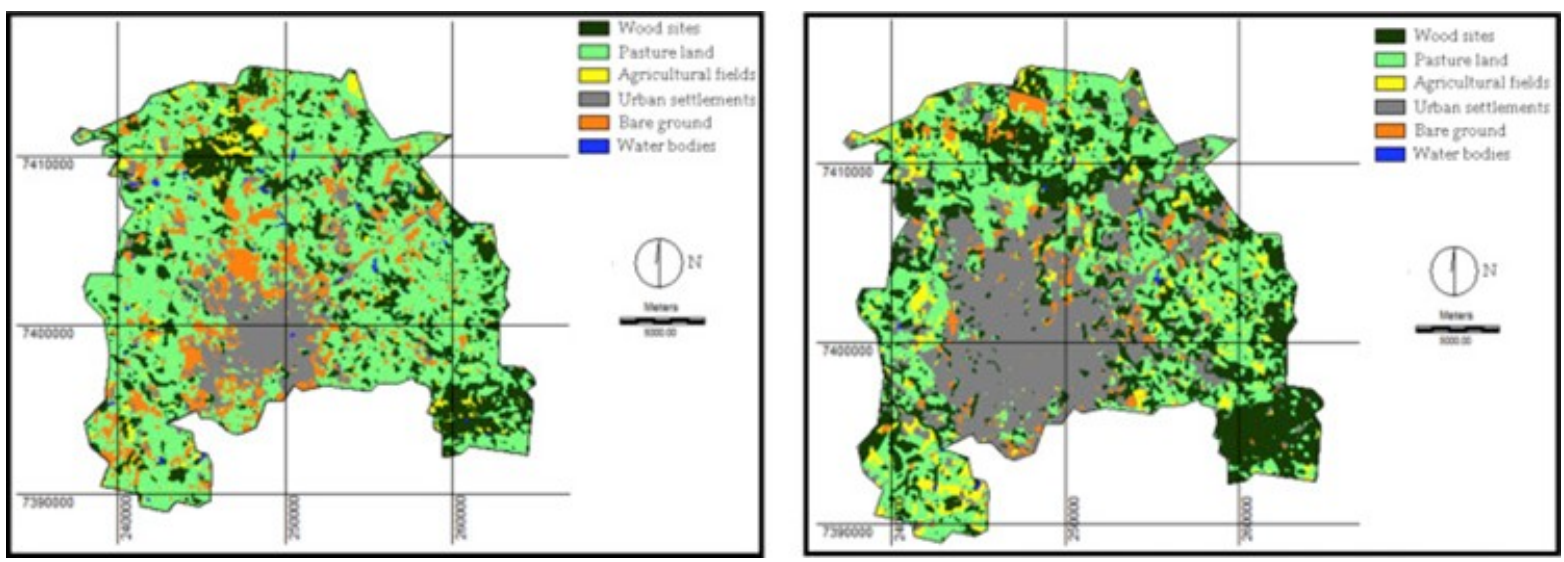

Figura 46: Mapas de uso do solo do território de Sorocaba a partir de imagens do satélite Landsat-5 em 1988 (esquerda) e 2011 (direita). Coordenadas geográficas no sistema UTM. Fonte: (BORTOLETO et al., 2016)

A evolução do uso do solo em Sorocaba também pode ser observada em pequeno vídeo disponível na web: https://earthengine.google.com/iframes/timelapse player embed.html $\# v=-$ 23.47743,-47.4667,11.016, latLng\&t=2.27. Um folheto destacando informações básicas do 
município, distribuído pelo IBGE por ocasião das eleições de 2016, pode ser observado no Anexo A. A evolução da ocupação urbana de Sorocaba a partir de 1950 e respectivos vetores de crescimento pode ser observada na Figura 47.

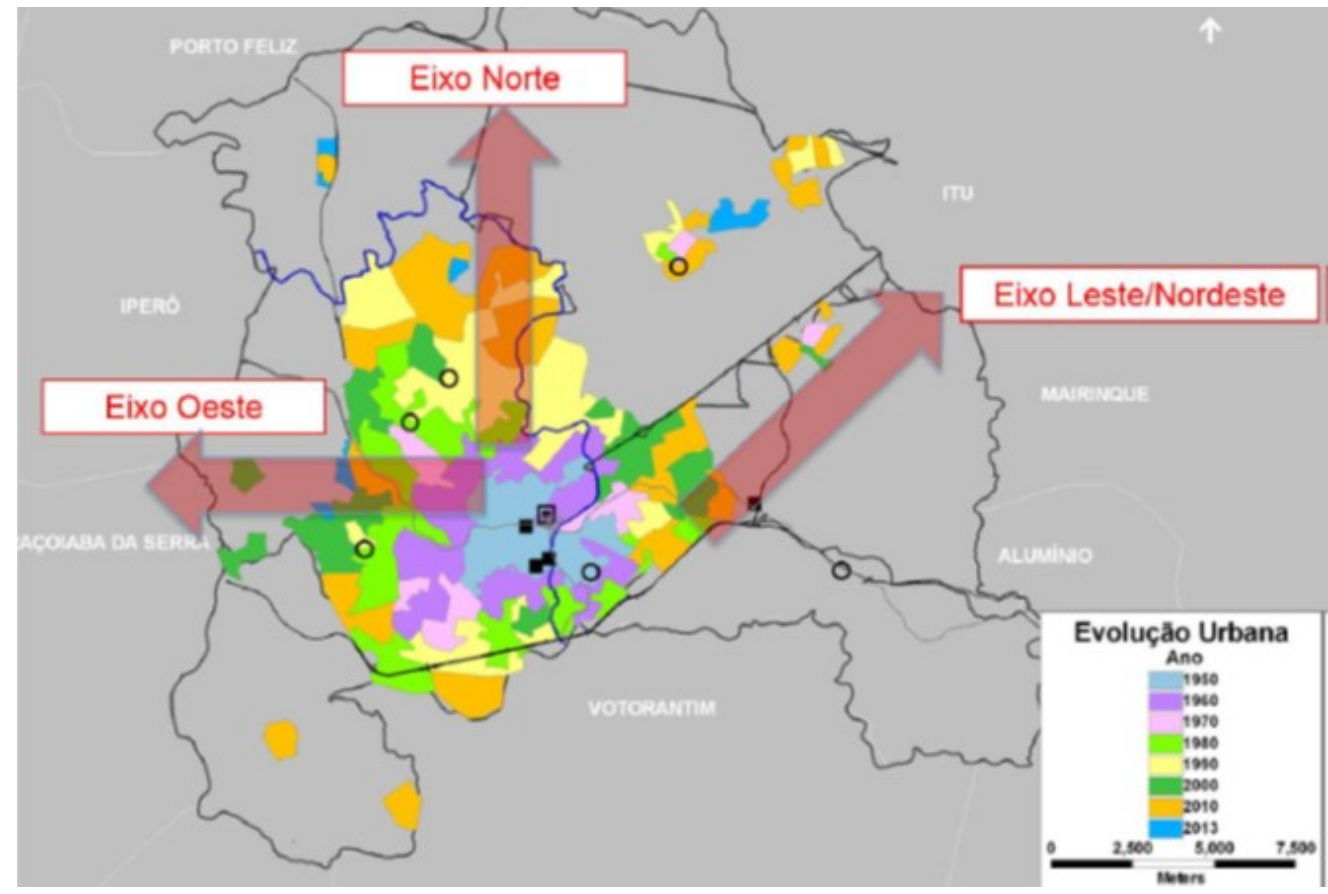

Figura 47: Evolução da Ocupação Urbana de Sorocaba a partir de 1950 e Vetores de Crescimento. Fonte: (URBES, 2014)

Segundo a EMPLASA - Empresa Paulista de Planejamento Metropolitano (2017), a taxa média anual de crescimento da população de Sorocaba prevista para o período de 2010 a 2030 é $0,95 \%$, com acréscimo de 114.946 habitantes à população do Censo 2010, perfazendo um total previsto de 701.571 habitantes em 2030 (Figura 48).

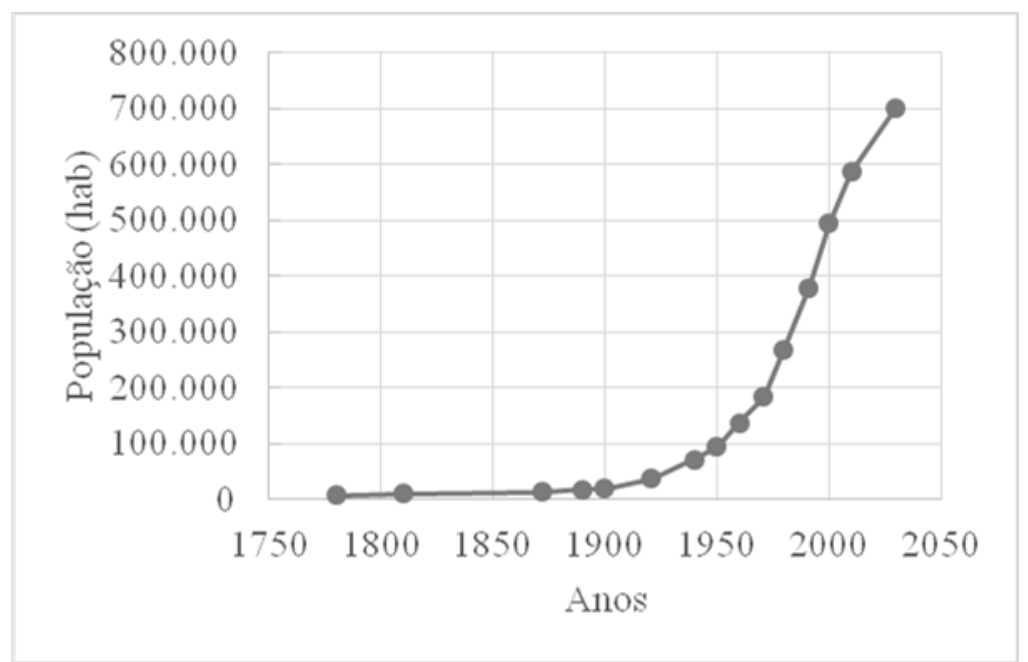

Figura 48: Evolução da população do Município de Sorocaba de 1780 a 2010, com previsão para 2030. Fonte: Elaborado pela autora a partir de dados do IBGE (IBGE, 2018), de Manfredini, Guandique e Rosa (2015) e previsão da EMPLASA (2017). 
Para simulação de aplicação do método de retrofit urbano, foram considerados os documentos com cenários futuros para o munícipio elencados no Quadro 16r.

Quadro 16: Documentos com cenários de futuro para o Município de Sorocaba.

\begin{tabular}{||l|c|c||}
\hline \multicolumn{1}{|c|}{ Documento } & Horizonte & Referência \\
\hline \hline Plano Diretor Ambiental & diagnóstico & (PMS: WALM, 2011) \\
\hline $\begin{array}{l}\text { Plano Municipal de Conservação e Recuperação da Mata } \\
\text { Atlântica }\end{array}$ & diagnóstico & (PMS, 2014a) \\
\hline Plano Diretor & 2025 & (PMS, 2014c) \\
\hline PPA - Plano Plurianual 2014-2017 & 2017 & (PMS, 2013b) \\
\hline PPA - Plano Plurianual 2018-2021 & 2021 & (PMS, 2017) \\
\hline $\begin{array}{l}\text { PLHIS - Plano Local de Habitação de Interesse Social } \\
\text { Plano de Mobilidade }\end{array}$ & $\begin{array}{c}\text { (PMS; INTEGRA, } \\
\text { 2011) }\end{array}$ \\
\hline $\begin{array}{l}\text { PMGIRS - Plano Municipal de Gestão Integrada de } \\
\text { Resíduos Sólidos }\end{array}$ & 2015 - 2050 & $\begin{array}{c}\text { (PASE; 2014b) } \\
\text { PROESPLAN 2016) }\end{array}$ \\
\hline Plano Diretor do Sistema de Esgotamento Sanitário & $2015-2050$ & $\begin{array}{c}\text { (SAAE; } \\
\text { PROESPLAN 2016) }\end{array}$ \\
\hline $\begin{array}{l}\text { Plano Diretor do Sistema de Abastecimento de Água } \\
\text { Inventário de Gases do Efeito Estufa do Município de } \\
\text { Sorocaba }\end{array}$ & & $\begin{array}{c}\text { PMS; IN NATURA, } \\
\text { 2014) }\end{array}$ \\
\hline Plano Municipal de Educação & 2020 & (PMS, 2015) \\
\hline Programa Municipal de Educação Ambiental & 2020 & (PMS, 2013a) \\
\hline Plano de Arborização Urbana & & \\
\hline \hline
\end{tabular}

Elaborado pela autora

As Figuras 49 e 50, a seguir, mapeiam a situação da rede de cobertura de abastecimento de água e de coleta de lixo no município de Sorocaba, respectivamente. A Figura 51, por sua vez, pondera o IPVS - Índice Paulista de Vulnerabilidade Social para o município. 


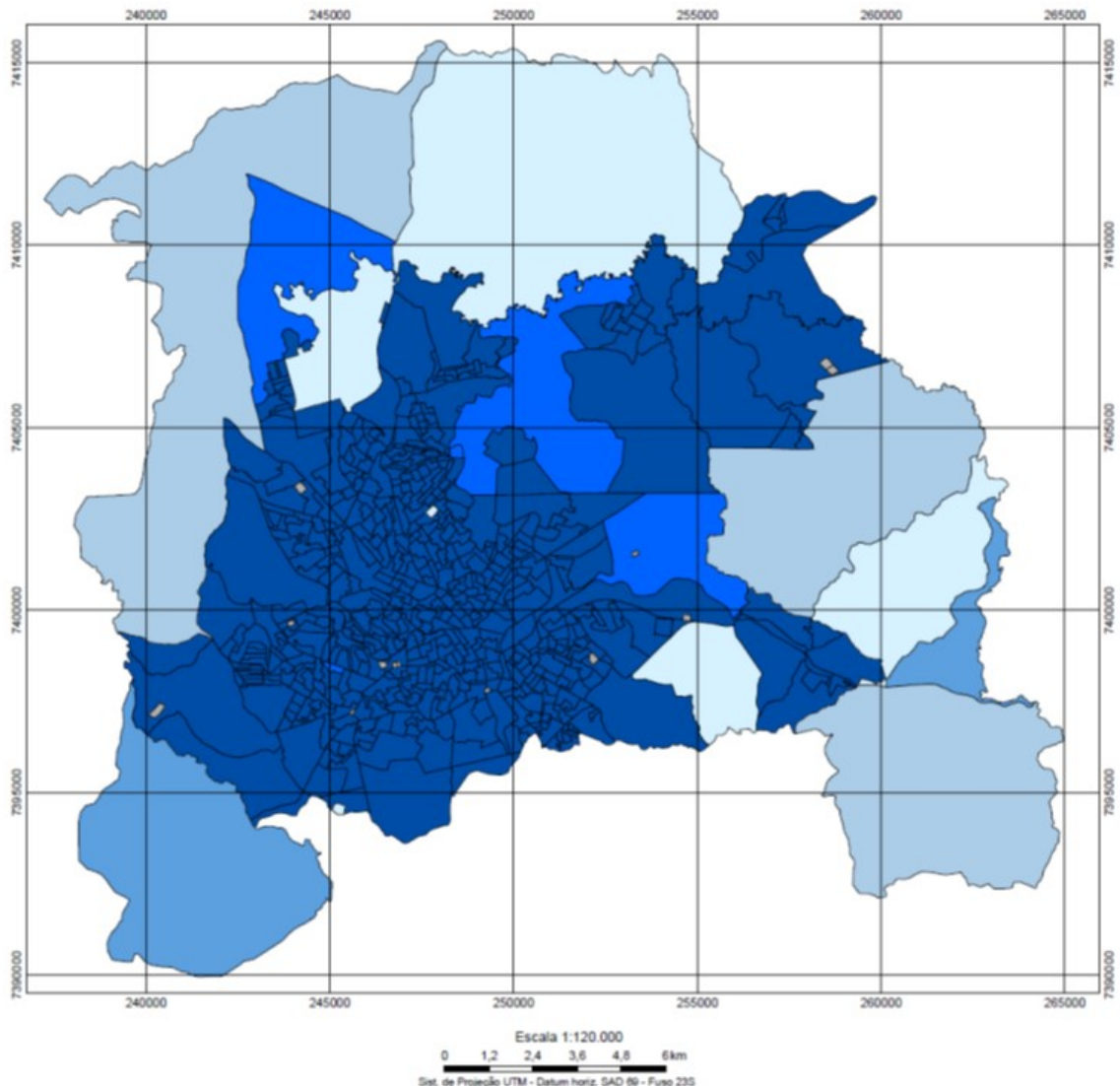

1

Domicilios particulares permanentes com abastecimento de água na rede geral (\%)

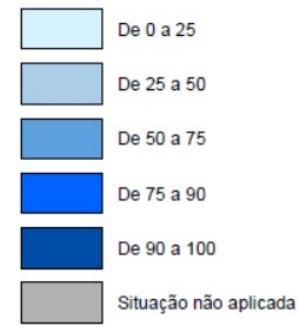

Figura 49: Cobertura da rede de abastecimento de água no município de Sorocaba. Fonte: (PMS, 2014c).
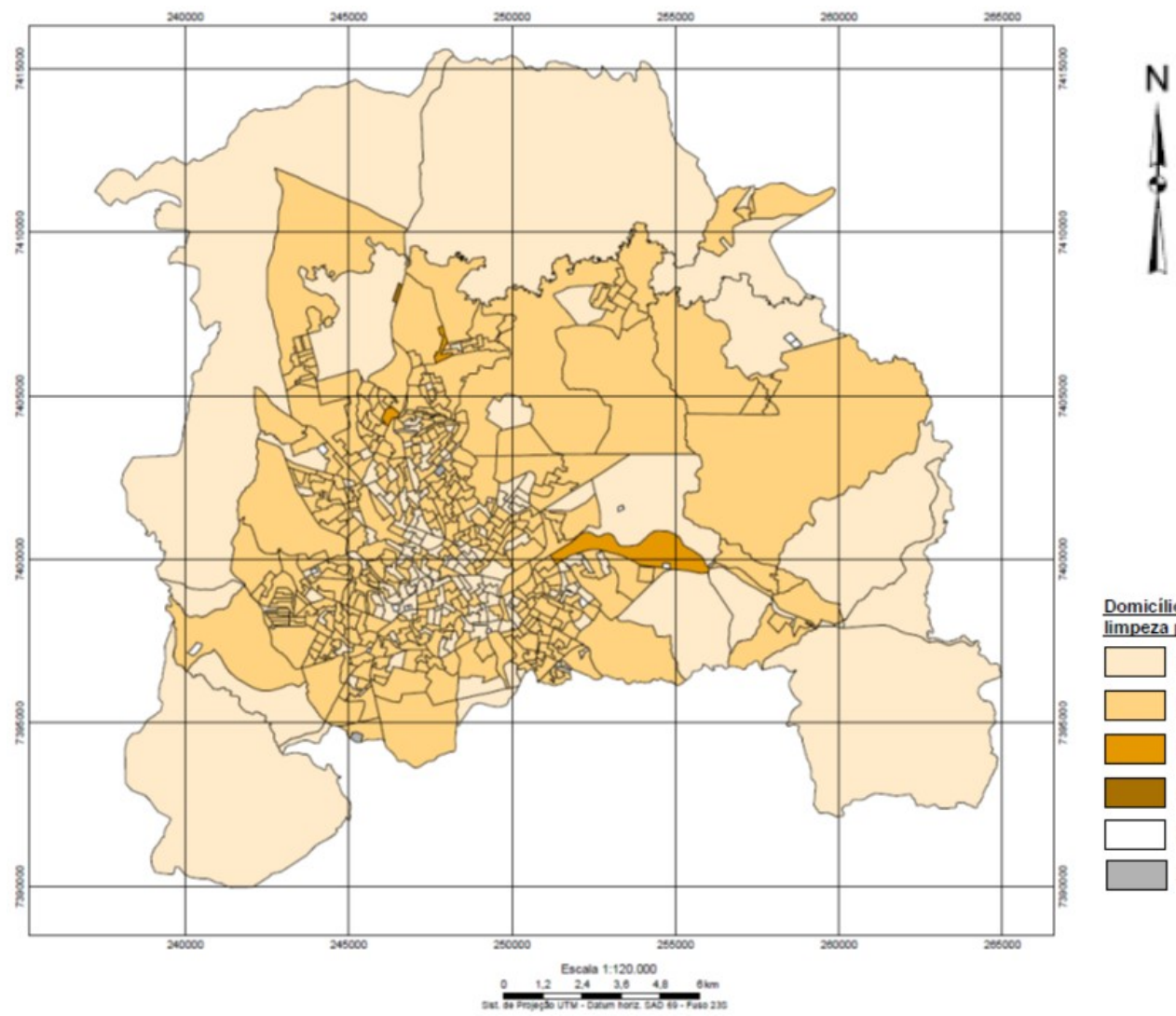

Domicilios com coleta de lixo pelo serviço de impeza pública

$\square$ Até 200 domicilios De 201 a 500 domicilios De 501 a 900 domicilios Acima de 901 domicilios Situação não encontrada Situação não aplicada

Figura 50: Cobertura da rede de coleta de lixo no município de Sorocaba. Fonte: (PMS, 2014c). 


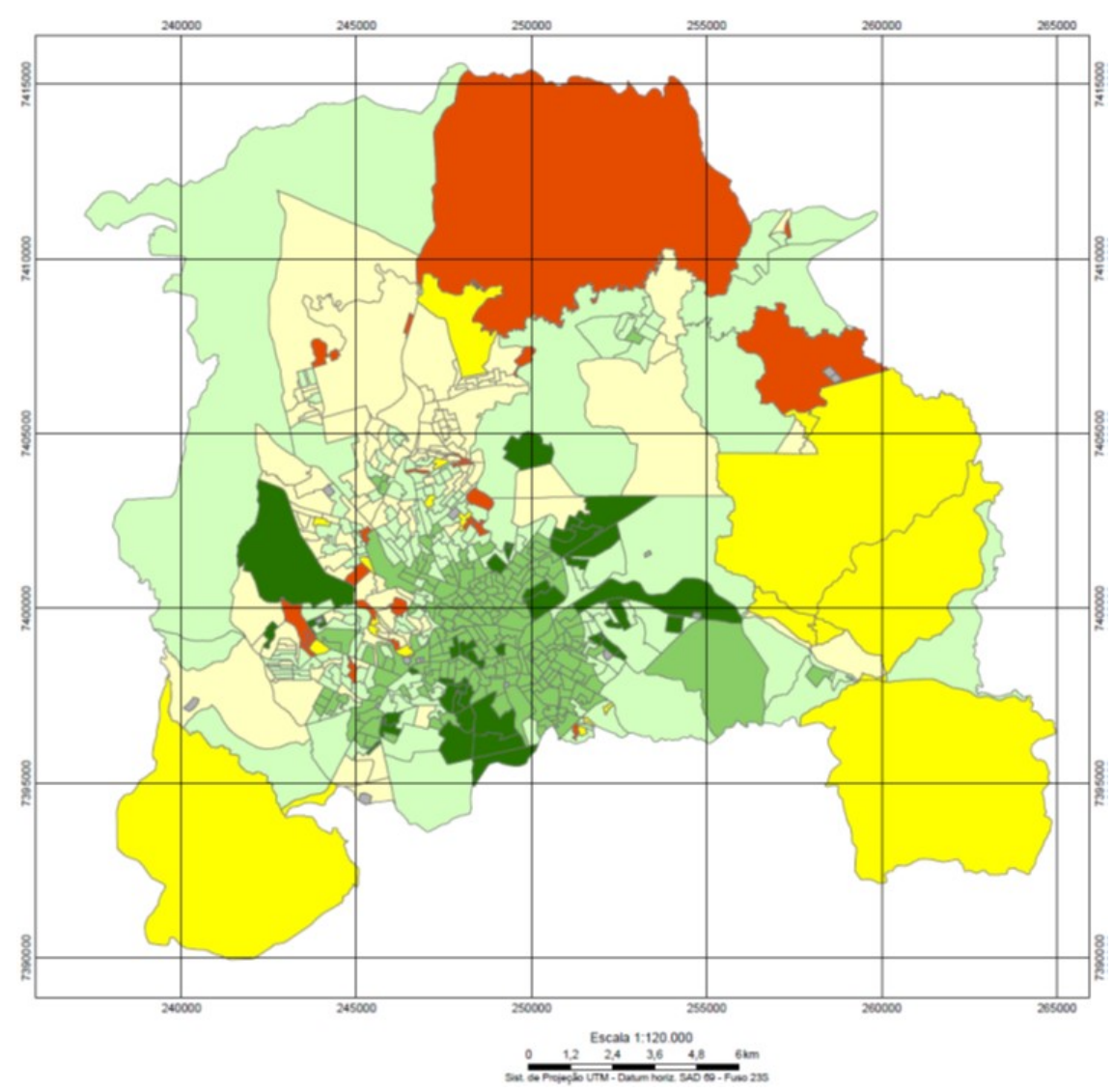

\begin{tabular}{|c|c|c|c|}
\hline \multirow{2}{*}{ Grupo } & \multicolumn{2}{|c|}{ Dimensöes } & \multirow{2}{*}{ IPVS } \\
\cline { 2 - 3 } & Socioeconômica & Ciclo de Vida Familiar & I \\
\hline $\mathbf{1}$ & Muito Alta & Idosas & Nenhuma Vulnerabilidade \\
\hline 2 & Média ou Alta & Familias Idosas & Vulnerabilidade Muito Baixa \\
\hline & Alta & Familias Jovens e Adultas & \\
\cline { 2 - 3 } 3 & Média & Familias Adultas & Vulnerabilidade Baixa \\
\hline 4 & Média & Familias Jovens & Vulnerabilidade Média \\
\hline 5 & Baixa & Familias Adultas e Idosas & Vulnerabilidade Alta \\
\hline 6 & Baixa & Familias Jovens & Vulnerabilidade Muito Alta \\
\hline
\end{tabular}

Figura 51: IPVS - Índice Paulista de Vulnerabilidade Social do município de Sorocaba. Fonte: (PMS, 2014c).

De acordo com o censo 2010 do IBGE, o município de Sorocaba era a $4^{\mathrm{a}}$ cidade mais populosa do interior do Estado de SP, excetuando cidades da RMSP - Região Metropolitana de São Paulo, apresentando um PIB de R\$ 15 bilhões, correspondente a 2,5\% do PIB do Estado de São Paulo e 0,8\% do PIB brasileiro (IBGE, 2018). A Figura 52 situa o município de Sorocaba na rede viária do Estado de São Paulo, mostrando que a cidade se localiza entre as rodovias Castelo Branco e Raposo Tavares. 
O município de Sorocaba apresentava em 2010 um IDH - Índice de Desenvolvimento Humano de 0,798 e uma densidade populacional média de $1.304 \mathrm{hab} / \mathrm{km}^{2}$ (IBGE, 2018), distribuída no seu território conforme ilustra a Figura 52.

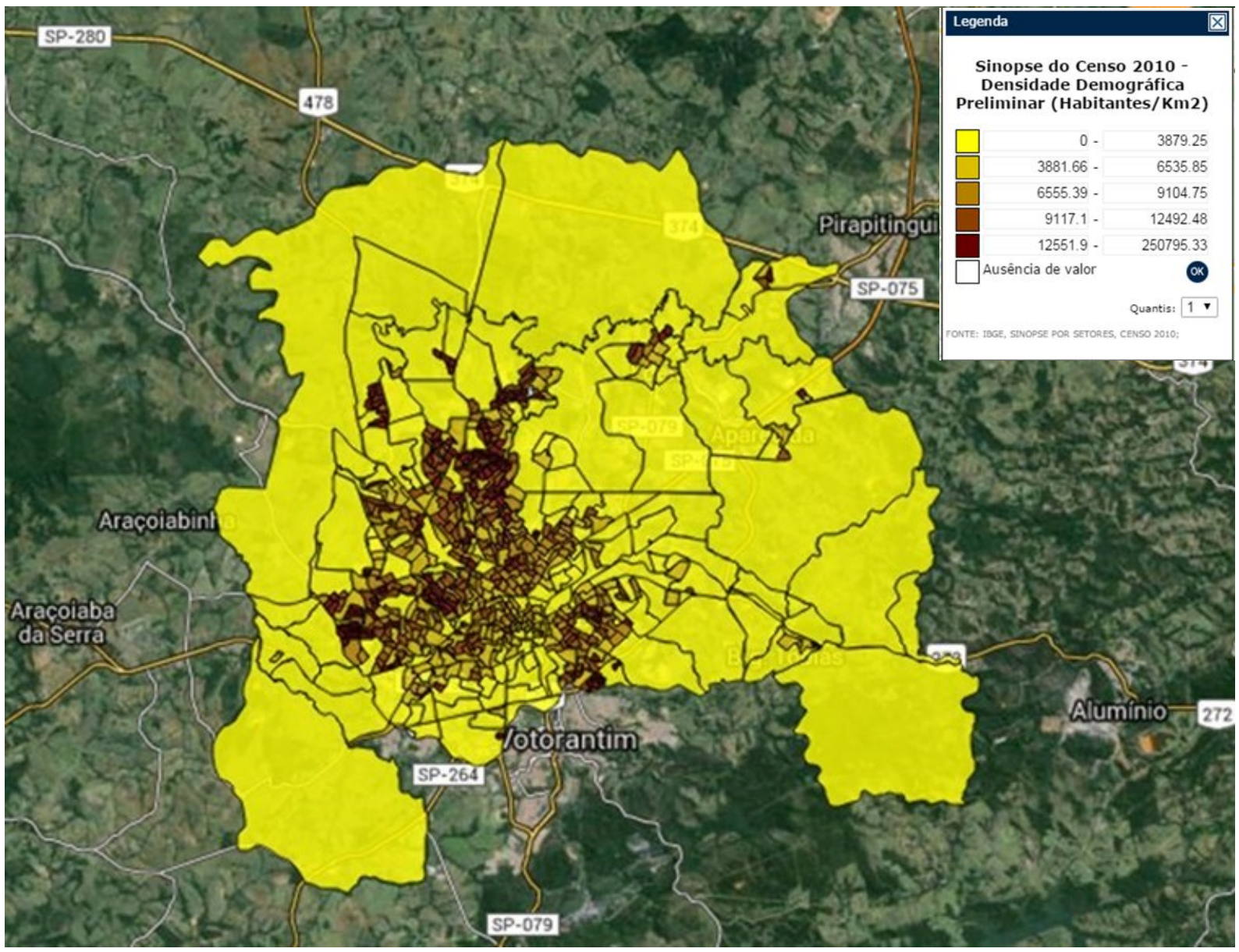

Figura 52: Densidades demográficas do município de Sorocaba. Fonte: IBGE (2010).

As maiores densidades de Sorocaba concentram-se na sua área urbana, central, conforme ilustram as vistas aéreas da Figura 53.

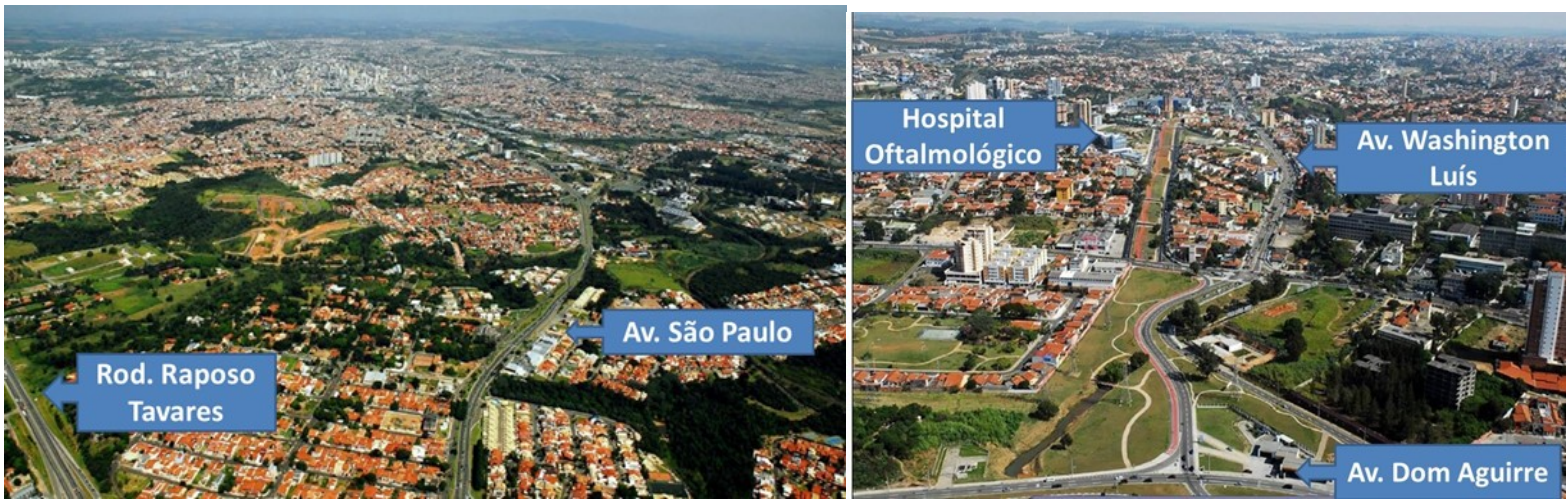

Figura 53: Vistas aéreas do município de Sorocaba. Fonte: Urbes (2014). 
Inaugurado em julho de 2012, o Parque Tecnológico de Sorocaba ocupa uma área construída $12.000 \mathrm{~m}^{2}$ (Figura 54), compreendendo start-ups, universidades, empresas, etc, de acordo com o conceito de "triple helix" para fomentar empresas, universidades e entidades públicas, para promover oportunidades de desenvolvimento e inclusão de novos talentos (PMS, 2017). O Parque Tecnológico de Sorocaba, ainda que não totalmente implementado, possui como foco os seguintes setores: metalomecânico, eletroeletrônico, automotivo, energias limpas e TIC - Tecnologias de Informação e Comunicação. Conta, também, com uma incubadora de empresas de base tecnológica e possui 22 instituições, entre setor público e privado, instaladas no parque (EMPLASA, 2017). O FIT - Instituto de Tecnologia, fundado em 2003, é uma organização nacional sem fins lucrativos, acreditada pelo MCTIC Ministério da Ciência, Tecnologia, Inovações e Comunicações. O FIT contribui para o desenvolvimento tecnológico com uma equipe técnica e multidisciplinar de pesquisa, apresentando um Centro para Sustentabilidade Ambiental, focado em Green IT e inovação tecnológica para promover o tratamento ambientalmente adequado de materiais industriais.

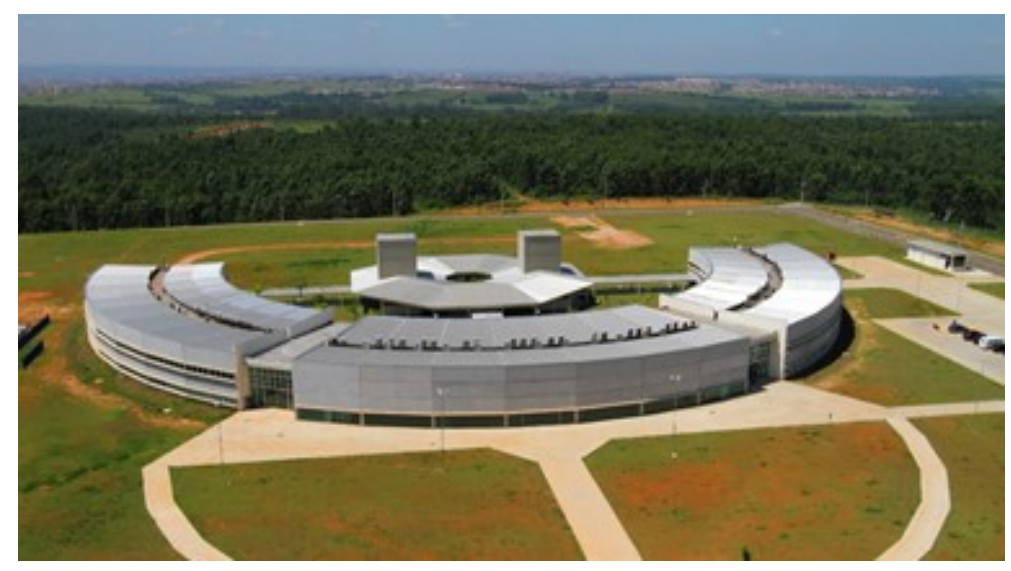

Figura 54: Parque Tecnológico de Sorocaba. Fonte: www.empts.com.br

O desenvolvimento atual das políticas públicas em Sorocaba é pautado por quatro eixos estratégicos, com diretrizes norteadoras para a execução de programas, na intenção de que Sorocaba seja uma (1) Cidade Humanizada, com (2) Infraestrutura Urbana e que tenha (3) Inclusão Social e Cidadania além de (4) Governança e Transparência (PMS, 2017). Os principais programas dos quatro eixos estratégicos podem ser observados na Figura 55. 
Objetivos Estratégicos

Resultados para os sorocabanos

\begin{tabular}{|c|c|c|c|}
\hline Cidade Viva e Bonita & \multirow{2}{*}{\multicolumn{2}{|c|}{$\begin{array}{l}\text { Cidade Modema e de } \\
\text { Oportunidades }\end{array}$}} & Cidade Humana e Educadora \\
\hline \multirow{3}{*}{$\begin{array}{l}\text { Ampliar as areas de proteçao ambiertal } e \\
\text { de recreaça e a oferta de evertos } \theta \text { de } \\
\text { equipamentos culturais e esportivos }\end{array}$} & & & \multirow{2}{*}{$\begin{array}{l}\text { Aprimorar o atendimento à saúde } \\
\text { incluindo de urgéncias e emergéncias }\end{array}$} \\
\hline & \multirow{2}{*}{\multicolumn{2}{|c|}{$\begin{array}{l}\text { Ampliar a oferta e qualificaçao dos } \\
\text { empregos }\end{array}$}} & \\
\hline & & & \multirow{2}{*}{$\begin{array}{l}\text { Ampliar as agoes de atençâo basica a } \\
\text { saude e a disponibilidade de leitos } \\
\text { hospitalares }\end{array}$} \\
\hline $\begin{array}{l}\text { Conservar o património histónco, cultural e } \\
\text { artistico }\end{array}$ & \multicolumn{2}{|c|}{ Universalizar o saneamento básico } & \\
\hline Promover a mobilidade urbana & \multicolumn{2}{|c|}{$\begin{array}{l}\text { Atrair investimentos de maior valor } \\
\text { agregado }\end{array}$} & $\begin{array}{l}\text { Ampliar o acesso e qualidade da } \\
\text { educagáo básica }\end{array}$ \\
\hline Modemizar e ampliar a luminaçá publica & \multirow{2}{*}{\multicolumn{2}{|c|}{$\begin{array}{l}\text { Implantar pol tica urbana e plano } \\
\text { estrategico de longo prazo }\end{array}$}} & Modernizaçào da Educaçåo Básica. \\
\hline \multirow{2}{*}{$\begin{array}{l}\text { Aprimorar a limpeza urbana e destinaçâo } \\
\text { dos residuos solidos }\end{array}$} & & & $\begin{array}{l}\text { capacitaçao e valonzaçao dos } \\
\text { educadores }\end{array}$ \\
\hline & \multicolumn{2}{|c|}{$\begin{array}{l}\text { Modernizar o sistema viário e transporte } \\
\text { urbano }\end{array}$} & \multirow{2}{*}{$\begin{array}{l}\text { Reduzir o deficit habitacional e } \\
\text { habitaçes irregulares }\end{array}$} \\
\hline $\begin{array}{l}\text { Manter limpo o rio Sorocaba e comegos e } \\
\text { eliminar pontos de alagamento }\end{array}$ & \multirow{2}{*}{\multicolumn{2}{|c|}{ Promover a qualificaçdo do trabalhador }} & \\
\hline \multirow{2}{*}{$\begin{array}{l}\text { Manter adequadamente o sistema viário } \\
\text { - pavimentaçáo e recapeamento }\end{array}$} & & & Reduzir vulnerabilidades sociais \\
\hline & \multicolumn{2}{|c|}{$\begin{array}{l}\text { Ampliar o acesso a intemet e serviços à } \\
\text { distancia }\end{array}$} & Reduzir indices de violéncia \\
\hline \multirow[t]{2}{*}{$\begin{array}{l}\text { Manter adequadamente os prédios } \\
\text { públicos }\end{array}$} & \multicolumn{2}{|c|}{$\begin{array}{l}\text { Universalizar o saneamento basico com } \\
\text { reduçáo de perdas de água }\end{array}$} & Ampliar as vagas em creches \\
\hline & & & $\begin{array}{l}\text { Aprimorar a segurança urbana, dos } \\
\text { propnos e das aç6es governamentais }\end{array}$ \\
\hline \multicolumn{4}{|c|}{ Cidade de Gestão Eficiente } \\
\hline \multicolumn{2}{|c|}{ Ampliar a arrecadaça e o nivel de investimento por habitante } & \multicolumn{2}{|c|}{ Ampliar os servicos via intemet para a sociedade } \\
\hline \multicolumn{2}{|c|}{ Aprimorar os serviços a populagâo e agilizar o atendimerto } & \multicolumn{2}{|c|}{$\begin{array}{l}\text { Implantar a gestáo estratégica para resultados e aprimorar a } \\
\text { geståo de projetos }\end{array}$} \\
\hline \multicolumn{2}{|c|}{$\begin{array}{l}\text { Aprimorar a de fesa do consumidor e dos interesses do } \\
\text { municipio }\end{array}$} & \multicolumn{2}{|c|}{$\begin{array}{l}\text { Ampliar e modernizar a estrutura de tecnologia da informaçáo } \\
\text { e comunicaçdo com foco na prestaçâo de serviços }\end{array}$} \\
\hline
\end{tabular}

Figura 55: Objetivos estratégicos de governo de Sorocaba, distribuídos em seus quatro principais eixos estratégicos. Fonte: PMS (2017).

Há programas que incluem o tema da sustentabilidade nos quatro eixos estratégicos, mas especificamente no eixo de Infraestrutura Urbana, a intenção é focar a mobilidade e o desenvolvimento urbano no sentido de otimização da infraestrutura existente que visa potencializar o aproveitamento do solo urbano ao longo da rede de transporte coletivo, bem como buscar a integração territorial das políticas públicas de transporte, habitação, emprego e equipamentos sociais, atrelada à sustentabilidade e ao desenvolvimento igualitário. Os objetivos traçados no modelo de estruturação urbana trazem os seguintes programas e projetos principais (PMS, 2017):

- Diminuir os vazios urbanos e estimular o crescimento horizontal da cidade.

- Modernizar e melhorar a mobilidade urbana com a implantação o BRT e VLT.

- Desenvolver a região metropolitana.

- Reestruturação e urbanização da área central.

- Eficiência no consumo de água e no uso da rede de esgoto. 
Alguns projetos urbanos do município de Sorocaba merecem destaque. Um deles é o IntegraBike, um sistema gratuito de empréstimo de bicicletas pela própria Prefeitura Municipal de Sorocaba, que conta com 25 estações e um total de 250 bicicletas, espalhados pela cidade. A cidade conta também com $126 \mathrm{~km}$ de ciclovias, conforme mapa da Figura 56. A Figura 57 traz imagens de uma das ciclovias da cidade e uma das estações de bicicletas.

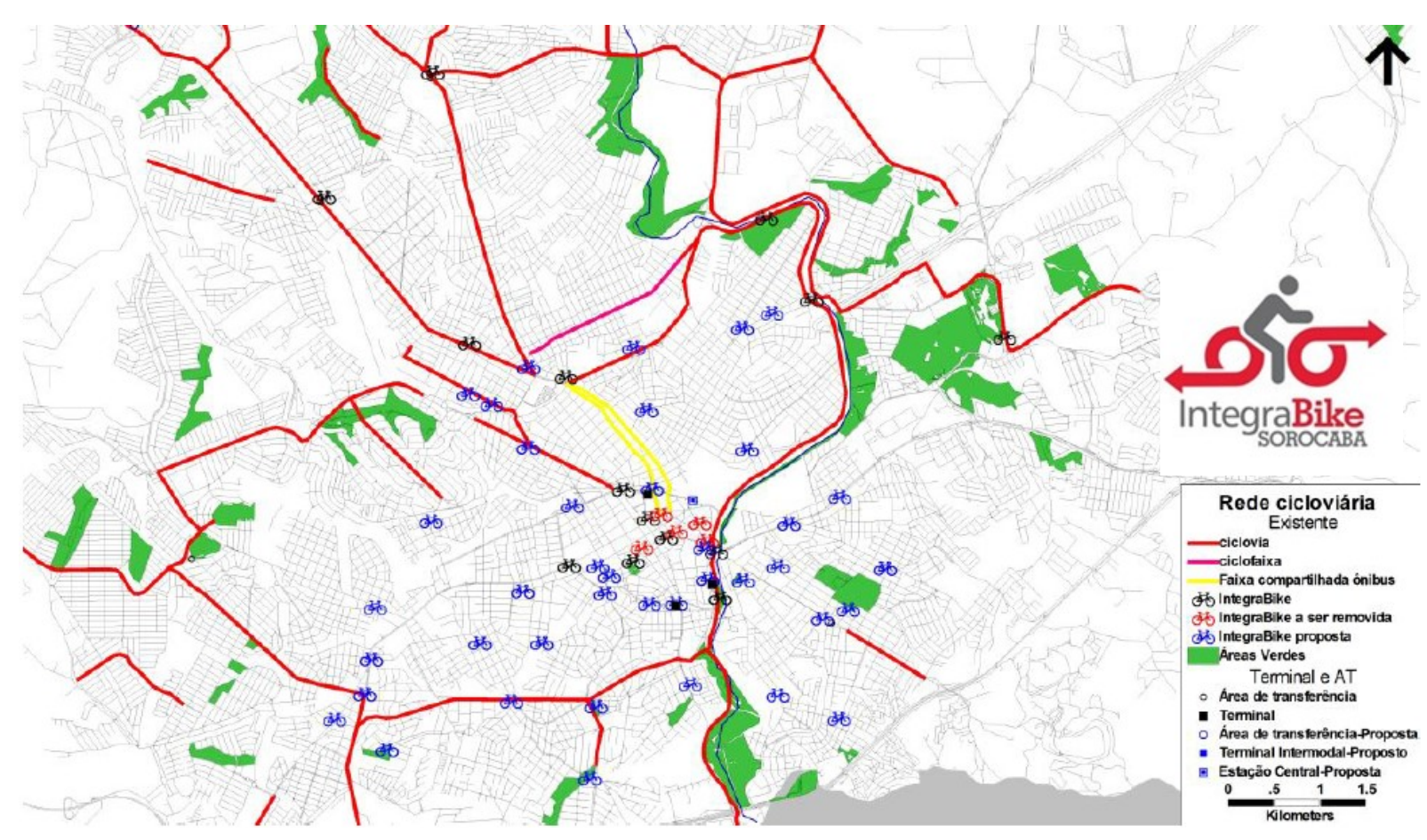

Figura 56: Mapa de ciclovias do município de Sorocaba (em vermelho). Fonte: Urbes (2014).

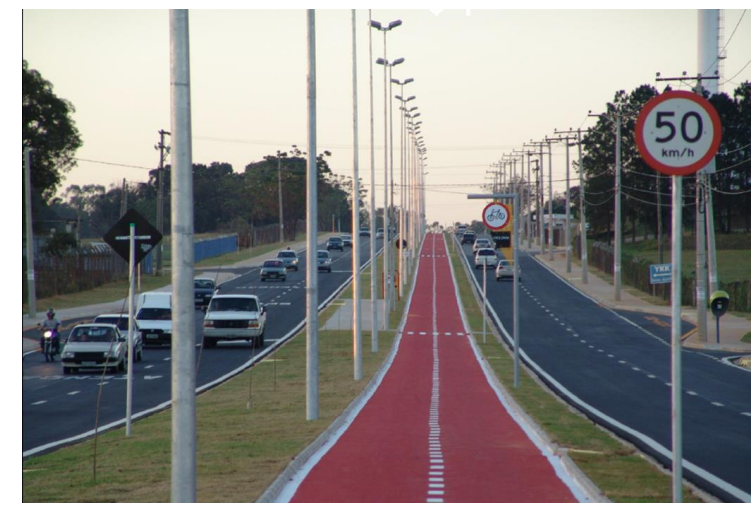

(a)

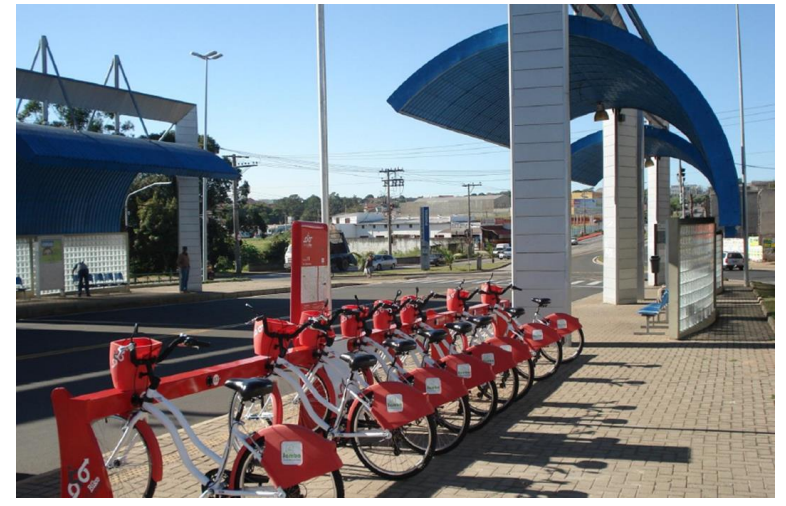

(b)

Figura 57: (a) Ciclovia da Av. Camilo Júlio e (b) Estação de bicicletas para empréstimo gratuito. Fonte: Urbes (2014). 
O segundo projeto de destaque é o Programa de Despoluição do Rio Sorocaba, que vem ocorrendo desde 2000, com R\$ 180 milhões investidos em 5 Estações de Tratamento de Esgoto, 17 estações elevatórias e 28 km de interceptores de esgoto. Em 2014, o município alcançou a meta de 100\% do esgoto tratado (REDE NOSSA SÃO PAULO, 2016). As Figuras 58 e 59 ilustram o Rio Sorocaba, onde diariamente pode-se observar pescadores ao longo de seu trecho urbano.

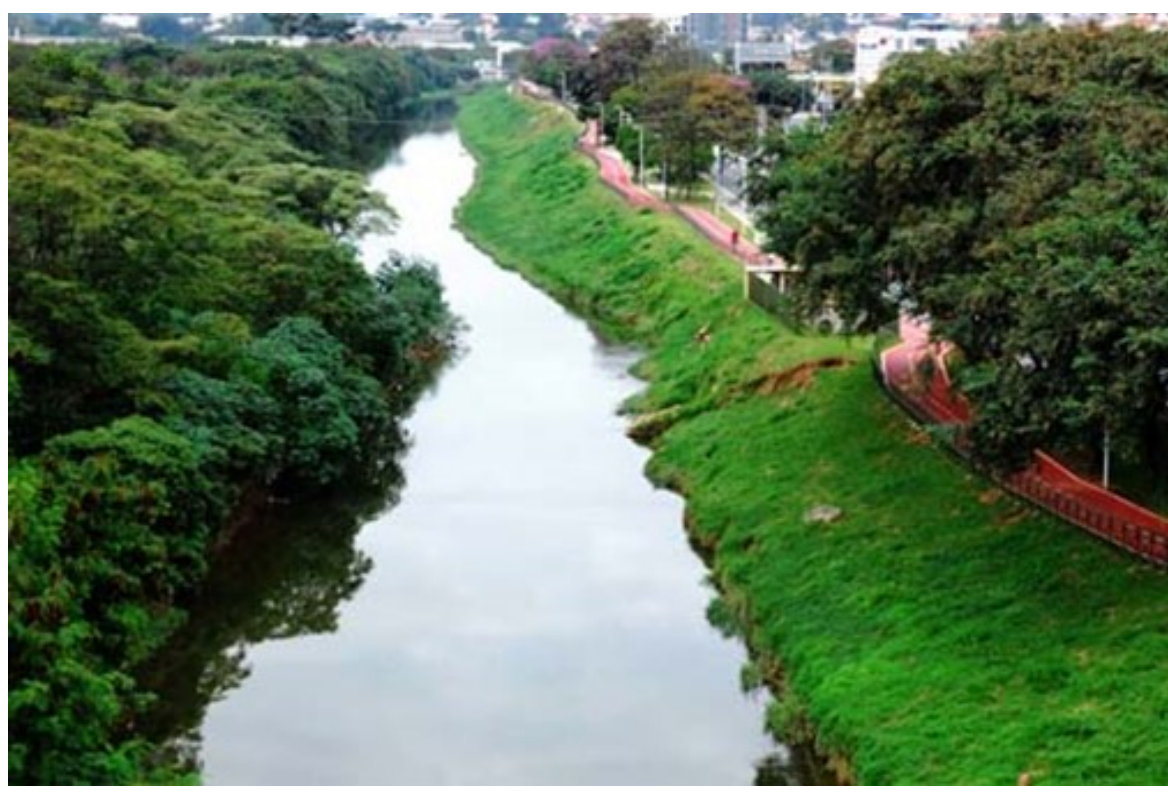

Figura 58: Vista aérea do trecho urbano do Rio Sorocaba. Fonte: Urbes (2014).

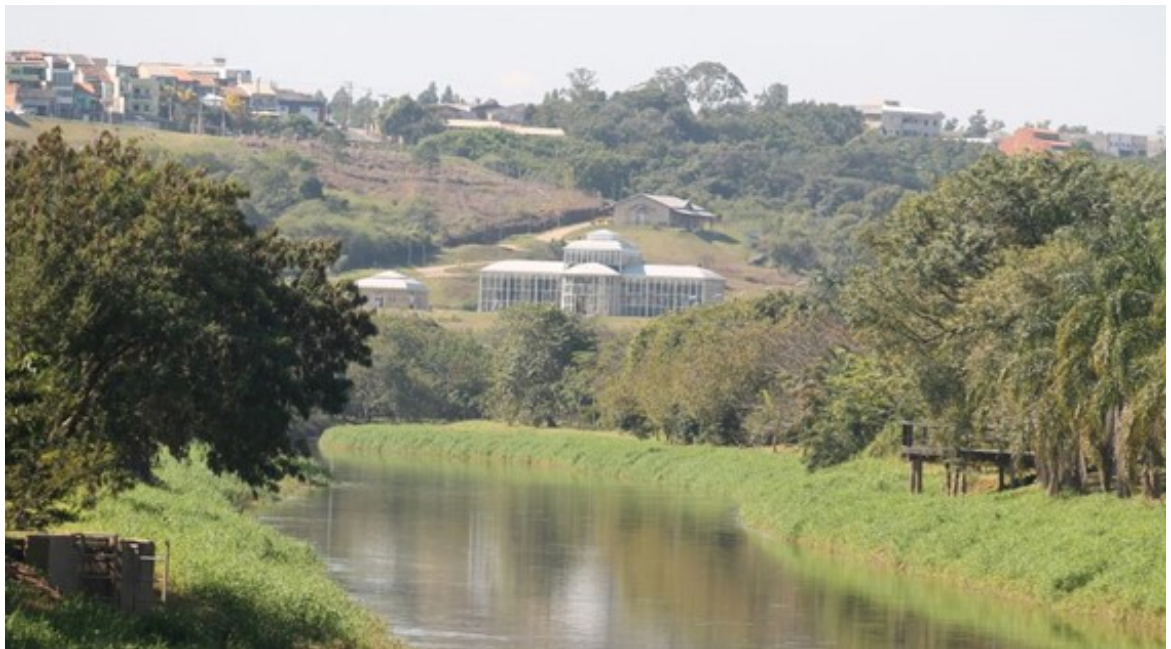

Figura 59: Rio Sorocaba e Jardim Botânico ao fundo.

Foto: Felipe Pinheiro. 
Sorocaba também é um dos dez municípios brasileiros participantes do Desafio das Cidades pelo Planeta, ou One Planet City Challenge - OPCC, em inglês. Criado pelo WWF World Wide Fund for Nature para ressaltar as soluções criativas desenvolvidas por governos locais em todo o mundo rumo a uma economia de baixo carbono, além de premiar e reconhecer as cidades que entregam os maiores esforços e resultados em áreas como construção sustentável, transporte e energia, o Desafio convida municípios a reportar suas ações climáticas ambiciosas e inovadoras. No biênio 2017/2018, 30 países participam do concurso. Sorocaba participa com uma série de iniciativas para reduzir as emissões de gases de efeito estufa. Os transportes movidos a propulsão humana ganham destaque com o IntegraBike.

Sorocaba também participa do Carbonn ${ }^{\circledR}$ Climate Registry, ou Registro Climático

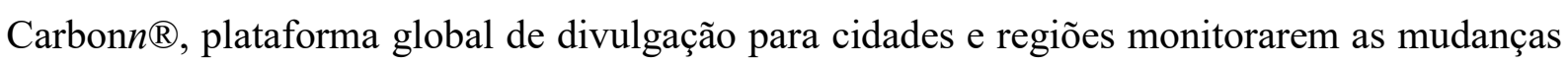
climáticas, criada para apoiar a transparência, responsabilidade e credibilidade. Trata-se da plataforma oficial do Desafio das Cidades e gerida pelo ICLEI - International Council for Local Environmental Initiatives, parceiro global do concurso. As ações divulgadas por Sorocaba compreendem a incorporação de carros híbridos à frota de táxis, incentivo ao uso de carros elétricos ou hidrogênio, expansão do plantio de árvores e a criação de novos parques e praças. Além disto, Sorocaba foi uma das oito cidades brasileiras selecionadas em 2013 pelo Urban-LEDS - Urban Low Emissions Development Strategy, ou Estratégia de Desenvolvimento Urbano de Baixo Carbono, implementado pelo ICLEI, em parceria com UN-Habitat.

Sorocaba apresenta a maior parte da população residindo em tipos intraurbanos com boas e médias condições de vida, sendo os mais relevantes os tipos C, D e E que, juntos, somam $85,5 \%$ da população do município. Os tipos $\mathrm{G}$ e $\mathrm{H}$ figuram em menor proporção, somando 13,3\%, e é interessante notar a ausência dos piores tipos I, J e K (IBGE, 2017).

\subsection{Diagnóstico de Sorocaba pela ABNT NBR ISO 37120:2017}

A metodologia para a coleta de informações relativas ao município de Sorocaba foi primeiramente uma revisão bibliográfica de dados secundários, provenientes de publicações de instituições tais como: IBGE - Instituto IBGE - Instituto Brasileiro de Geografia e 
Estatística, Fundação SEADE - Sistema Estadual de Análise de Dados, SNIS - Sistema Nacional de Indicadores de Saneamento, entre outras. Posteriormente, buscou-se dados primários, a partir de instituições tais como: Prefeitura de Sorocaba, concessionárias, entre outros. Para tal, foram realizadas as consultas, entrevistas e visitas técnicas relacionadas no Quadro 17.

Quadro 17: Consultas, entrevistas e visitas técnicas realizadas.

\begin{tabular}{|c|c|c|c|c|}
\hline Data & Instituição & Contato(s) & Local & Objetivo \\
\hline $14 / 05 / 2015$ & $\begin{array}{l}\text { Regional do Secovi - } \\
\text { Sindicato da Habitação } \\
\text { de SP, em Sorocaba e } \\
\text { Região }\end{array}$ & Flavio Amary & $\begin{array}{l}\text { R. Piauí, } 50 \\
\text { - Vila Santa } \\
\text { Terezinha }\end{array}$ & $\begin{array}{l}\text { Apoio e contatos para levantamento de } \\
\text { dados do município, bem como acesso à } \\
\text { plataforma GeoSecovi. }\end{array}$ \\
\hline $18 / 06 / 2015$ & $\begin{array}{l}\text { URBES - Empresa de } \\
\text { Desenvolvimento } \\
\text { Urbano e Social de } \\
\text { Sorocaba }\end{array}$ & $\begin{array}{l}\text { Eng. José } \\
\text { Carlos de } \\
\text { Almeida }\end{array}$ & $\begin{array}{l}\text { R. Pedro de } \\
\text { Oliveira } \\
\text { Neto, } 98\end{array}$ & $\begin{array}{l}\text { Levantamento de valores de indicadores } \\
\text { da Seção } 18 \text { - Transportes da ISO } \\
\text { 37120:2014. }\end{array}$ \\
\hline $23 / 07 / 2015$ & $\begin{array}{l}\text { SAAE - Serviço } \\
\text { Autônomo de Água e } \\
\text { Esgoto de Sorocaba }\end{array}$ & $\begin{array}{l}\text { Adhemar José } \\
\text { Spinelli Júnior }\end{array}$ & $\begin{array}{l}\text { Av. Pereira } \\
\text { da Silva, } \\
1285\end{array}$ & $\begin{array}{l}\text { Levantamento de valores de indicadores } \\
\text { das Seções } 20 \text { - Esgotos e } 21 \text { - Água e } \\
\text { Saneamento da ISO 37120:2014. }\end{array}$ \\
\hline $09 / 12 / 2015$ & $\begin{array}{l}\text { Prefeitura Municipal } \\
\text { de Sorocaba - } \\
\text { Secretaria de } \\
\text { Planejamento e Gestão }\end{array}$ & $\begin{array}{l}\text { Edsom Ortega } \\
\text { e Eduardo } \\
\text { Almeida }\end{array}$ & $\begin{array}{l}\text { Av. Eng } \\
\text { Carlos } \\
\text { Reinaldo } \\
\text { Mendes, } \\
3041 \text { - Alto } \\
\text { da Boa } \\
\text { Vista } \\
\end{array}$ & $\begin{array}{l}\text { Apresentação dos valores de indicadores } \\
\text { da ISO 37120:2014 levantados e apoio } \\
\text { para levantamento dos indicadores } \\
\text { faltantes. }\end{array}$ \\
\hline $23 / 10 / 2017$ & $\begin{array}{l}\text { Secretaria do Meio } \\
\text { Ambiente, Parques e } \\
\text { Jardins - SEMA }\end{array}$ & $\begin{array}{c}\text { Sara Regina de } \\
\text { Amorim }\end{array}$ & $\begin{array}{l}\text { Av. Rudolf } \\
\text { Dafferner, } \\
105 \text { - Alto } \\
\text { da Boa } \\
\text { Vista }\end{array}$ & $\begin{array}{l}\text { Apresentação dos valores de indicadores } \\
\text { da NBR ISO 37120:2017 levantados e } \\
\text { apoio para levantamento dos indicadores } \\
\text { faltantes. }\end{array}$ \\
\hline $13 / 11 / 2017$ & $\begin{array}{l}\text { Prefeitura Municipal } \\
\text { de Sorocaba - } \\
\text { Controladoria }\end{array}$ & $\begin{array}{l}\text { Mário Arruda } \\
\text { Mortara e } \\
\text { Renan } \\
\text { Rodrigues da } \\
\text { Silva }\end{array}$ & $\begin{array}{l}\text { Av. Eng } \\
\text { Carlos } \\
\text { Reinaldo } \\
\text { Mendes, } \\
3041 \text { - Alto } \\
\text { da Boa } \\
\text { Vista }\end{array}$ & $\begin{array}{l}\text { Apresentação dos valores de indicadores } \\
\text { da NBR ISO 37120:2017 levantados e } \\
\text { apoio para levantamento dos indicadores } \\
\text { faltantes. Levantamento de dados } \\
\text { disponíveis no SIG - Sistema de } \\
\text { Informações Gerenciais. }\end{array}$ \\
\hline
\end{tabular}

Elaborado pela autora.

Um dos importantes instrumentos de monitoramento dos indicadores em Sorocaba é o SIG - Sistema de Informações Gerenciais. O acesso aos valores divulgados nesta plataforma auxiliou o levantamento e a análise dos indicadores da NBR ISO 37120:2017. Realizando uma análise cruzada entre os indicadores monitorados pelo SIG/Sorocaba e os da NBR ISO 37120:2017, o resultado pontuou 18 indicadores da NBR ISO 37120:2017 que já são idênticos ou podem se basear, com algum cálculo ou correção matemática, em indicadores do 
SIG/Sorocaba. Além disto, há vários indicadores no SIG/Sorocaba que se mostram bastante interessantes ao monitoramento, e que poderiam ser sugeridos para a revisão da ISO 37120 .

Cada dado coletado foi registrado em uma planilha, tal qual o modelo de aplicação para a cidade de Toronto, uma das primeiras a divulgar seus indicadores no formato da ISO 37120:2014 (WCCD, 2014), citando a unidade de mensuração, a fonte dos dados, e alguns comentários. Optou-se pelo levantamento da série histórica de 2010 a 2017, uma vez que os dados do censo 2010 são disponibilizados para a maioria dos indicadores da NBR ISO 37120:2017, mas os demais anos também apresentam resultados, provenientes do próprio IBGE ou de monitoramentos e publicações setoriais, cujo registro é importante para posterior análise da evolução da série histórica. A Tabela 4 pontua os valores mais atuais dos indicadores essenciais (E) e de apoio (A) da NBR ISO 37120:2017 levantados para o município de Sorocaba, com ano correspondente. A planilha completa dos valores destes indicadores levantados na série histórica de 2010 a 2017 pode ser observada no Apêndice C, com respectivas fontes dos dados.

Tabela 4: Indicadores essenciais (E) e de apoio (A) da NBR ISO 37120:2017 levantados para Sorocaba.

\begin{tabular}{|c|c|c|c|c|}
\hline N. & \begin{tabular}{|l|} 
Ti- \\
po
\end{tabular} & Descrição & Valor & Ano \\
\hline \multicolumn{5}{|c|}{ Seção 5 - Economia } \\
\hline 5.1 & $\mathrm{E}$ & Taxa de desemprego da cidade & $8,10 \%$ & 2010 \\
\hline 5.2 & E & $\begin{array}{l}\text { Valor de avaliação de propriedades comerciais e industriais como uma } \\
\text { porcentagem do valor de avaliação total de todas as propriedades }\end{array}$ & - & - \\
\hline 5.3 & $\mathrm{E}$ & Porcentagem da população abaixo da linha de pobreza & $0,89 \%$ & 2010 \\
\hline 5.4 & $\mathrm{~A}$ & Porcentagem da população com emprego em tempo integral & $30,3 \%$ & 2015 \\
\hline 5.5 & A & Taxa de desemprego de jovens & $21 \%$ & 2012 \\
\hline 5.6 & A & Número de empresas por 100.000 habitantes & 3.868 empresas $/ 100.000 \mathrm{hab}$ & 2015 \\
\hline 5.7 & $\mathrm{~A}$ & Número de novas patentes por 100.000 habitantes por ano & 0,2 patentes $/ 100.000 \mathrm{hab}$ & 2012 \\
\hline \multicolumn{5}{|c|}{ Seção 6 - Educação } \\
\hline 6.1 & $\mathrm{E}$ & $\begin{array}{l}\text { Porcentagem da população feminina em idade escolar matriculada em } \\
\text { escolas }\end{array}$ & - & - \\
\hline 6.2 & E & $\begin{array}{l}\text { Porcentagem de estudantes com ensino primário completo: taxa de } \\
\text { sobrevivência }\end{array}$ & $12,1 \%$ & 2013 \\
\hline 6.3 & $\mathrm{E}$ & $\begin{array}{l}\text { Porcentagem de estudantes com ensino secundário completo: taxa de } \\
\text { sobrevivência }\end{array}$ & $25,7 \%$ & 2013 \\
\hline 6.4 & E & Relação estudante/professor no ensino primário & 20,1 estudantes/professor & 2016 \\
\hline 6.5 & A & $\begin{array}{l}\text { Porcentagem de população masculina em idade escolar matriculada em } \\
\text { escolas }\end{array}$ & - & - \\
\hline 6.6 & $\mathrm{~A}$ & Porcentagem de população em idade escolar matriculada em escolas & $91,4 \%$ & 2016 \\
\hline 6.7 & A & $\begin{array}{l}\text { Número de indivíduos com ensino superior completo por } 100.000 \\
\text { habitantes }\end{array}$ & 15,904 graduados/100.000 hab & 2017 \\
\hline \multicolumn{5}{|c|}{ Seção 7 - Energia } \\
\hline 7.1 & E & Uso de energia elétrica residencial total per capita (kWh/ano) & 982,4 kWh/hab.ano & 2016 \\
\hline 7.2 & $\mathrm{E}$ & $\begin{array}{l}\text { Porcentagem de habitantes da cidade com fornecimento regular de } \\
\text { energia elétrica }\end{array}$ & $99,7 \%$ & 2010 \\
\hline 7.3 & $\mathrm{E}$ & Consumo de energia de edifícios públicos por ano $\left(\mathrm{kWh} / \mathrm{m}^{2}\right)$ & - & - \\
\hline 7.4 & E & $\begin{array}{l}\text { Porcentagem da energia total proveniente de fontes renováveis, como } \\
\text { parte do consumo total de energia da cidade }\end{array}$ & - & - \\
\hline
\end{tabular}




\begin{tabular}{|c|c|c|c|c|}
\hline N. & \begin{tabular}{l|} 
Ti- \\
po
\end{tabular} & Descrição & Valor & Ano \\
\hline 7.5 & $\mathrm{~A}$ & Uso total de energia elétrica per capita (kWh/ano) & 3067,1 kWh/hab.ano & 2016 \\
\hline 7.6 & A & $\begin{array}{l}\text { Número médio de interrupções de energia elétrica por consumidor por } \\
\text { ano }\end{array}$ & 18,0 interrupções & 2016 \\
\hline 7.7 & $\mathrm{~A}$ & Duração média das interrupções de energia elétrica (em horas) & 56,6 horas & 2016 \\
\hline \multicolumn{5}{|c|}{ Seção 8-Meio Ambiente } \\
\hline 8.1 & $\mathrm{E}$ & Concentração de material particulado fino (PM 2.5) & 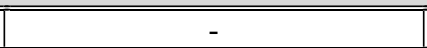 & 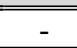 \\
\hline 8.2 & $\mathrm{E}$ & Concentração de material particulado (PM 10) & $24 \mu \mathrm{g} / \mathrm{m}^{3}$ & 2017 \\
\hline 8.3 & $\mathrm{E}$ & Emissão de gases de efeito de estufa medida em toneladas per capita & 1,83 ton/inhab & 2012 \\
\hline 8.4 & A & Concentração de $\mathrm{NO}_{2}$ (dióxido de nitrogênio) & $15 \mu \mathrm{g} / \mathrm{m}^{3}$ & 2017 \\
\hline 8.5 & A & Concentração de $\mathrm{SO}_{2}$ (dióxido de enxofre) & - & - \\
\hline 8.6 & $\mathrm{~A}$ & Concentração de $\mathrm{O}_{3}$ (ozônio) & $42 \mu \mathrm{g} / \mathrm{m}^{3}$ & 2017 \\
\hline 8.7 & $\mathrm{~A}$ & Poluição sonora & - & - \\
\hline 8.8 & $\mathrm{~A}$ & Variação percentual em número de espécies nativas & - & - \\
\hline \multicolumn{5}{|c|}{ Seção 9-Finanças } \\
\hline 9.1 & $\mathrm{E}$ & $\begin{array}{l}\text { Taxa de endividamento (expansão do serviço da dívida como uma } \\
\text { porcentagem da receita própria do município) }\end{array}$ & $2,79 \%$ & 2016 \\
\hline 9.2 & $\mathrm{~A}$ & Despesas de capital como porcentagem de despesas totais & $5,58 \%$ & 2016 \\
\hline 9.3 & A & Porcentagem da receita própria em função do total das receitas & $55,80 \%$ & 2016 \\
\hline 9.4 & $\mathrm{~A}$ & Porcentagem dos impostos recolhidos em função dos impostos cobrados & $87,63 \%$ & 2016 \\
\hline \multicolumn{5}{|c|}{ Seção 10 - Resposta a Incêndios e Emergências } \\
\hline 10.1 & $\mathrm{E}$ & Número de bombeiros por 100.000 habitantes & - & 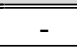 \\
\hline 10.2 & $\mathrm{E}$ & Número de mortes relacionadas a incêndios por 100.000 habitantes & 0,0 mortes $/ 100.000 \mathrm{hab}$ & 2017 \\
\hline 10.3 & $\mathrm{E}$ & $\begin{array}{l}\text { Número de mortes relacionadas a desastres naturais por } 100.000 \\
\text { habitantes }\end{array}$ & 0,0 mortes/100.000 hab & 2017 \\
\hline 10.4 & A & $\begin{array}{l}\text { Número de bombeiros voluntários e em tempo parcial por } 100.000 \\
\text { habitantes }\end{array}$ & - & - \\
\hline 10.5 & A & $\begin{array}{l}\text { Tempo de resposta dos serviços de emergência a partir do primeiro } \\
\text { chamado }\end{array}$ & - & - \\
\hline 10.6 & A & $\begin{array}{l}\text { Tempo de resposta do Corpo de Bombeiros a partir do primeiro } \\
\text { chamado }\end{array}$ & - & - \\
\hline \multicolumn{5}{|c|}{ Seção 11 - Governança } \\
\hline 11.1 & $\mathrm{E}$ & $\begin{array}{l}\text { Porcentagem de participação dos eleitores nas últimas eleições } \\
\text { municipais em função do total de eleitores aptos a votar }\end{array}$ & $80,5 \%$ & 2016 \\
\hline 11.2 & E & $\begin{array}{l}\text { Porcentagem de mulheres eleitas em função do número total de eleitos } \\
\text { na gestão da cidade }\end{array}$ & $13,6 \%$ & 2016 \\
\hline 11.3 & $\mathrm{~A}$ & Porcentagem de mulheres empregadas na gestão da cidade & $64,65 \%$ & 2012 \\
\hline 11.4 & A & $\begin{array}{l}\text { Número de condenações de servidores da cidade por corrupção e/ou } \\
\text { suborno por } 100.000 \text { habitantes }\end{array}$ & - & - \\
\hline 11.5 & A & $\begin{array}{l}\text { Representação de cidadãos: número de autoridades locais eleitas para o } \\
\text { cargo por } 100.000 \text { habitantes }\end{array}$ & - & - \\
\hline 11.6 & A & $\begin{array}{l}\text { Porcentagem de eleitores registrados em função da população com } \\
\text { idade para votar }\end{array}$ & $89,6 \%$ & 2016 \\
\hline \multicolumn{5}{|c|}{ Seção 12-Saúde } \\
\hline 12.1 & $\mathrm{E}$ & Expectativa média de vida & 75,6 anos & 2010 \\
\hline 12.2 & $\mathrm{E}$ & Número de leitos hospitalares por 100.000 habitantes & 220,5 leitos $/ 100.000 \mathrm{hab}$ & 2017 \\
\hline 12.3 & $\mathrm{E}$ & Número de médicos por 100.000 habitantes & 260,1 médicos/100.000 hab & 2017 \\
\hline 12.4 & $\mathrm{E}$ & $\begin{array}{l}\text { Taxa de mortalidade de crianças menores de cinco anos a cada } 1.000 \\
\text { nascidos vivos }\end{array}$ & $\begin{array}{l}11,56 \text { mortes } / 1000 \text { nascidos } \\
\text { vivos }\end{array}$ & 2016 \\
\hline 12.5 & A & $\begin{array}{l}\text { Número de pessoas da equipe de enfermagem e obstetrícia por } 100.000 \\
\text { habitantes }\end{array}$ & $\begin{array}{l}1.153,9 \text { enfermeiros/100.000 } \\
\text { hab }\end{array}$ & 2016 \\
\hline 12.6 & A & Número de profissionais de saúde mental por 100.000 habitantes & 163,5 profissionais/ $100.000 \mathrm{hab}$ & 2014 \\
\hline 12.7 & $\mathrm{~A}$ & Taxa de suicídio por 100.000 habitantes & $6,03 \%$ & 2016 \\
\hline \multicolumn{5}{|c|}{ Seção 13 - Recreação } \\
\hline 13.1 & A & $\begin{array}{l}\text { Área em metros quadrados de espaços públicos de recreação cobertos } \\
\text { per capita }\end{array}$ & - & - \\
\hline 13.2 & A & $\begin{array}{l}\text { Área em metros quadrados de espaços públicos de recreação ao ar livre } \\
\text { per capita }\end{array}$ & $2,61 \mathrm{~m}^{2} / \mathrm{hab}$ & 2017 \\
\hline \multicolumn{5}{|c|}{ Seção 14 - Segurança } \\
\hline 14.1 & E & Número de agentes de polícia por 100.000 habitantes & - & - \\
\hline 14.2 & $\mathrm{E}$ & Número de homicídios por 100.000 habitantes & 11,5 mortes/100.000 hab & 2012 \\
\hline
\end{tabular}




\begin{tabular}{|c|c|c|c|c|}
\hline N. & \begin{tabular}{l|} 
Ti- \\
po
\end{tabular} & Descrição & Valor & Ano \\
\hline 14.3 & $\mathrm{~A}$ & Crimes contra a propriedades por 100.000 habitantes & $1.946,9$ crimes $/ 100.000 \mathrm{hab}$ & 2017 \\
\hline 14.4 & $\mathrm{~A}$ & Tempo de resposta da polícia a partir do primeiro chamado & - & - \\
\hline 14.5 & $\mathrm{~A}$ & Taxa de crimes violentos por 100.000 habitantes & 284,8 crimes $/ 100.000 \mathrm{hab}$ & 2017 \\
\hline \multicolumn{5}{|c|}{ Seção 15 - Habitação } \\
\hline 15.1 & $\mathrm{E} \mathrm{E}$ & Porcentagem da população urbana morando em favelas & $0,5 \%$ & 2017 \\
\hline 15.2 & $\mathrm{~A}$ & Número de sem-teto por 100.000 habitantes & 86,7 pessoas/100.000 hab & 2017 \\
\hline 15.3 & $\mathrm{~A}$ & Porcentagem de moradias sem títulos de propriedade registrados & - & - \\
\hline \multicolumn{5}{|c|}{ Seção 16 - Resíduos Sólidos } \\
\hline 16.1 & $\mathrm{E} \mid \mathrm{l}$ & $\begin{array}{l}\text { Porcentagem da população urbana com coleta regular de lixo } \\
\text { (domiciliar) }\end{array}$ & $100 \%$ & 2016 \\
\hline 16.2 & $\mathrm{E}$ & Total de coleta de resíduos sólidos municipais per capita & 0,31 ton/hab.ano & 2016 \\
\hline 16.3 & $\mathrm{E}$ & Porcentagem de resíduos sólidos urbanos que são reciclados & $1,87 \%$ & 2016 \\
\hline 16.4 & $\mathrm{~A}$ & Porcentagem de resíduos sólidos urbanos dispostos em aterros sanitários & $97,0 \%$ & 2016 \\
\hline 16.5 & \begin{tabular}{l|l}
$\mathrm{A}$ & 1 \\
\end{tabular} & Porcentagem de resíduos sólidos urbanos descartados para incineração & $0,00 \%$ & 2016 \\
\hline 16.6 & A 1 & Porcentagem de resíduos sólidos urbanos queimados a céu aberto & $0,12 \%$ & 2010 \\
\hline 16.7 & $\mathrm{~A}$ & Porcentagem de resíduos sólidos urbanos dispostos a céu aberto & $0,00 \%$ & 2016 \\
\hline 16.8 & A 1 I & Porcentagem de resíduos sólidos urbanos dispostos por outros meios & $0,01 \%$ & 2010 \\
\hline 16.9 & $\mathrm{~A}$ & Geração de resíduos perigosos per capita & - & - \\
\hline $\mid 16.10$ & $\mathrm{~A} \mid \mathrm{I}$ & $\begin{array}{l}\text { Porcentagem da população urbana com coleta regular de lixo } \\
\text { (domiciliar) }\end{array}$ & - & - \\
\hline \multicolumn{5}{|c|}{ Seção 17 - Telecomunicações e Inovação } \\
\hline 17.1 & $\begin{array}{lll}\mathrm{E} & \mathrm{l} \\
\end{array}$ & Número de conexões de internet por 100.000 habitantes & $28,950,7$ conexões/100.000 hab & 2017 \\
\hline 17.2 & $\mathrm{E}$ & Número de conexões de telefone celular por 100.000 habitantes & - & - \\
\hline 17.3 & $\mathrm{~A}$ & Número de conexões de telefone fixo por 100.000 habitantes & $18,150,5$ conexões/100.000 hab & 2017 \\
\hline \multicolumn{5}{|c|}{ Seção 18 - Transporte } \\
\hline 18.1 & & $\begin{array}{l}\text { Quilômetros de sistema de transporte público de alta capacidade por } \\
100.000 \text { habitantes }\end{array}$ & $0 \mathrm{~km} / 100.000 \mathrm{hab}$ & 2017 \\
\hline 18.2 & $\mathrm{E}$ & $\begin{array}{l}\text { Quilômetros de sistema de transporte público de média capacidade por } \\
100.000 \text { habitantes }\end{array}$ & $2,2 \mathrm{~km} / 100.000 \mathrm{hab}$ & 2016 \\
\hline 18.3 & E & Número anual de viagens em transporte público per capita & 67,0 viagens/hab.ano & 2017 \\
\hline 18.4 & $\begin{array}{lll}\mathrm{E} & 1 \\
\end{array}$ & Número de automóveis privados per capita & 0,46 auto/hab & 2017 \\
\hline 18.5 & $\mathrm{~A}$ & $\begin{array}{l}\text { Porcentagem de passageiros que se deslocam para o trabalho de forma } \\
\text { alternativa ao automóvel privado }\end{array}$ & $57,6 \%$ & 2013 \\
\hline 18.6 & A 1 & Número de veículos motorizados de duas rodas per capita & 0,14 moto/hab & 2017 \\
\hline 18.7 & A & Quilômetros de ciclovias e ciclofaixas por 100.000 habitantes & $19,1 \mathrm{~km} / \mathrm{hab}$ & 2017 \\
\hline 18.8 & A 1 & Mortalidades de trânsito por 100.000 habitantes & 5,46 mortes/ $100.000 \mathrm{hab}$ & 2017 \\
\hline 18.9 & $\mathrm{~A} / \mathrm{C}$ & Conectividade aérea (no. de partidas de voos comerciais sem escalas) & 0 voos comerciais & 2017 \\
\hline \multicolumn{5}{|c|}{ Seção 19 - Planejamento Urbano } \\
\hline 19.1 & $\mathrm{E}$ & Áreas verdes (hectares) por 100.000 habitantes & $269,5 \mathrm{ha} / 100.000 \mathrm{hab}$ & 2016 \\
\hline 19.2 & $\mathrm{~A}$ & Número de árvores plantadas anualmente por 100.000 habitantes & 6.156 árvores/100.000 hab & 2016 \\
\hline 19.3 & $\mathrm{~A} \mid \mathrm{l}$ & $\begin{array}{l}\text { Porcentagem de área de assentamentos informais em função da área } \\
\text { total da cidade }\end{array}$ & - & - \\
\hline 19.4 & $\mathrm{~A} \mid \mathrm{I}$ & Relação empregos/habitação & 0,97 empregos/domicílio & 2015 \\
\hline \multicolumn{5}{|c|}{ Seção 20 - Esgotos } \\
\hline 20.1 & $\mathrm{E} \mid \mathrm{l}$ & $\begin{array}{l}\text { Porcentagem da população da cidade atendida por sistemas de coleta e } \\
\text { afastamento de esgoto }\end{array}$ & $97,1 \%$ & 2016 \\
\hline 20.2 & $\mathrm{E}$ & Porcentagem do esgoto da cidade que não recebeu qualquer tratamento & $9,2 \%$ & 2016 \\
\hline 20.3 & $\mathrm{E}$ & Porcentagem do esgoto da cidade que recebe tratamento primário & $100 \%$ & 2010 \\
\hline 20.4 & $\mathrm{E}$ & Porcentagem do esgoto da cidade que recebe tratamento secundário & $0 \%$ & 2010 \\
\hline 20.5 & $\mathrm{E}$ & Porcentagem do esgoto da cidade que recebe tratamento terciário & $0 \%$ & 2010 \\
\hline \multicolumn{5}{|c|}{ Seção 21 - Água e Saneamento } \\
\hline 21.1 & & $\begin{array}{l}\text { Porcentagem da população da cidade com serviço de abastecimento de } \\
\text { água potável }\end{array}$ & $99,5 \%$ & 2016 \\
\hline || 21.2 & $\mathrm{E}$ & $\begin{array}{l}\text { Porcentagem da população da cidade com acesso sustentável a uma } \\
\text { fonte de água adequada para consumo }\end{array}$ & $99,5 \%$ & 2016 \\
\hline || 21.3 & $\mathrm{E}$ & $\begin{array}{l}\text { Porcentagem da população da cidade com acesso a saneamento } \\
\text { melhorado }\end{array}$ & $97,1 \%(*)$ & 2016 \\
\hline 21.4 & \begin{tabular}{l|l}
$\mathrm{E}$ & $(\mathrm{n}$ \\
\end{tabular} & Consumo doméstico total de água per capita (litros/dia) & 150,8 litros/hab.dia & 2016 \\
\hline \begin{tabular}{||l|l|}
21.5 \\
\end{tabular} & $\mathrm{~A}$ & Consumo total de água per capita (litros/dia) & 181,3 litros/hab.dia & 2016 \\
\hline 21.6 & $\mathrm{~A} \mid \mathrm{T}$ & Valor médio anual de horas de interrupção do abastecimento de água & 0,01 horas/domicílio.ano & 2016 \\
\hline
\end{tabular}




\begin{tabular}{||c|c|c|c|c||}
\hline N. & $\begin{array}{l}\text { Ti- } \\
\text { po }\end{array}$ & \multicolumn{1}{|c|}{ Descrição } & Valor & Ano \\
\hline \hline & & por domićlio & & \\
\hline 21.7 & A & Porcentagem de perdas de água (água não faturada) & $41,0 \%(* *)$ & 2016 \\
\hline
\end{tabular}

Elaborada pela autora com base nas fontes citadas no item 5.7 do Capítulo 5 .

(*) O valor do indicador 21.3 se iguala ao indicador 20.1 pois o texto da NBR ISO 37120:2017 preconiza que "as instalações sanitárias melhoradas devem incluir (...) lançamento ou descarga para sistema de esgoto canalizado" (ABNT, 2017a, p. 69).

(**) O valor do indicador 21.7 foi levantado considerando perdas físicas pois o texto da NBR ISO 37120:2017 preconiza que "deve ser calculada como o volume de água fornecido menos o volume de água utilizado (numerador) dividido pelo volume total de água fornecido (denominador)" (ABNT, 2017a, p. 72).

Os indicadores de perfil da NBR ISO 37120:2017, por sua vez, estão listados na Tabela 5.

Tabela 5: Indicadores de Perfil da NBR ISO 37120:2017, levantados para Sorocaba ao ano de 2010.

\begin{tabular}{|c|c|}
\hline \multicolumn{2}{|c|}{ "Indicadores de Perfil - Sorocaba - Ano 2010} \\
\hline \multicolumn{2}{|l|}{ População } \\
\hline População total da cidade & 586.625 \\
\hline Densidade populacional (por quilômetro quadrado) & $1.304,18$ \\
\hline Porcentagem da população do país & $0,31 \%$ \\
\hline Porcentagem infantil da população (0-14 anos) & $21,06 \%$ \\
\hline Porcentagem jovem da população (15-24 anos) & $17,21 \%$ \\
\hline Porcentagem adulta da população (25-64 anos) & $54,32 \%$ \\
\hline Porcentagem idosa da população (+65 anos) & $7,41 \%$ \\
\hline Relação homem/mulher (número de homens por 100 mulheres) & 95,80 \\
\hline Variação populacional anual & $0,40 \%$ \\
\hline População não economicamente ativa & 280.807 \\
\hline Porcentagem da população que é estrangeira & $0,3 \%$ \\
\hline Porcentagem da população que são novos imigrantes & $7,0 \%$ \\
\hline Porcentagem de residentes que não são cidadãos (naturalizados) & $0,1 \%$ \\
\hline \multicolumn{2}{|l|}{ Habitação } \\
\hline Número total de domicílios & 201.136 \\
\hline Número total de domicílios ocupados (próprios ou alugados) & 178.871 \\
\hline Pessoas por domicílio & 3,26 \\
\hline Densidade de domicílios (por quilômetro quadrado) & 680,4 \\
\hline \multicolumn{2}{|l|}{ Economia } \\
\hline Renda familiar média (US\$/ano) & $13.304,59(*)$ \\
\hline \multicolumn{2}{|l|}{ Taxa anual de inflação baseada na média dos últimos 5 anos } \\
\hline \multicolumn{2}{|l|}{ Custo de vida } \\
\hline Distribuição de renda (Índice Gini) & 0,5290 \\
\hline PIB do país (US\$) & $2.208 .900(*)$ \\
\hline PIB per capita do país (US\$) & $11.224,15(*)$ \\
\hline PIB per capita da cidade (US\$) & $10.511,40(*)$ \\
\hline Porcentagem do PIB da cidade em função do PIB do país & 0,28 \\
\hline Variação da taxa de empregos baseada nos últimos 5 anos & \\
\hline
\end{tabular}




\begin{tabular}{|c|c|}
\hline \multicolumn{2}{|c|}{ Indicadores de Perfil - Sorocaba - Ano 2010} \\
\hline \multicolumn{2}{|l|}{ Governo } \\
\hline Tipo de administração (por exemplo: local, regional, estadual) & Local \\
\hline Orçamento operacional bruto (US\$) & $68.516 .020(*)$ \\
\hline Orçamento operacional bruto per capita (US\$) & $116,80(*)$ \\
\hline \multicolumn{2}{|l|}{ Orçamento de capital bruto (US\$) } \\
\hline \multicolumn{2}{|l|}{ Orçamento de capital bruto per capita (US\$) } \\
\hline \multicolumn{2}{|l|}{ Geografia e clima } \\
\hline Região & América do Sul \\
\hline Tipo de clima & Subtropical úmido \\
\hline Área territorial (quilômetros quadrados) & 449,80 \\
\hline Porcentagem de área não residencial (quilômetros quadrados) & $34 \%$ \\
\hline Número de espécies nativas & 22.039 \\
\hline Temperatura média anual (graus Celsius) & 21,29 \\
\hline Precipitação média anual de chuva $(\mathrm{mm})$ & 1224 \\
\hline Precipitação média anual de neve $(\mathrm{cm})$ & 0 \\
\hline
\end{tabular}

Elaborada pela autora com base nas fontes citadas no item 5.7 do Capítulo 5.

(*) Taxa de conversão considerada: 1 US\$ $=\mathrm{R} \$ 3,20$

Durante o processo de levantamento dos valores para os indicadores, iniciado em maio de 2015 e revisado para a finalização e publicação desta pesquisa, cabe enfatizar a notável atualização e modernização das plataformas digitais das fontes dos indicadores, citadas anteriormente. Os websites estão claramente mais amigáveis, os indicadores e números mais organizados e disponibilizados de forma a facilitar o acesso e a coleta dos mesmos, ainda que seja por um buscador automático.

O levantamento e obtenção dos valores dos indicadores da NBR ISO 37120:2017 para Sorocaba levou a algumas importantes considerações, a saber:

- Aproximadamente 30\% dos indicadores da NBR ISO 37120:2017 podem ser obtidos de fontes secundárias, tais como: IBGE, SEADE, SNIS, etc, ou seja, fontes e bases de dados comuns a todos os municípios brasileiros

- Aproximadamente $10 \%$ dos indicadores não possuem monitoramento e/ou medição, tais como: "valor de avaliação de propriedades comerciais e industriais como uma porcentagem do valor de avaliação total de todas as propriedades valor de avaliação", poluição sonora, concentração de material particulado fino (PM 2.5)

- Foram identificadas algumas divergências de método de levantamento entre indicadores da NBR ISO 37120:2017 e os métodos usuais e existentes. Por exemplo, para o indicador "horas de interrupção de abastecimento de água", a NBR ISO 
37120:2017 recomenda levantar todas as horas de interrupção, independente da duração total da interrupção, e o SNIS - Sistema Nacional de Indicadores de Sustentabilidade estabelece que interrupções de abastecimento de água sejam contabilizadas somente acima de 6 horas de interrupção.

Tomando por base os valores dos indicadores da ISO 37120:2014 para Toronto (WCCD, 2014), em relação a aplicação da norma em Sorocaba, é importante mencionar:

- A planilha de Toronto não apresenta um ano base para os dados, não unifica os dados para um ano somente, há dados do censo de 2011, mas também de 2009, $2012,2013$.

- Como em Toronto a escolaridade é obrigatória até os 18 anos e há universalização dos serviços de fornecimento de energia elétrica, água tratada e tratamento esgoto, vários indicadores são reportados como $100 \%$, refletindo o cumprimento de leis e metas.

- Toronto não apresenta concentração de material particulado (PM 10), pois é medida a de particulado fino (PM 2,5).

- Toronto também não apresenta dados de poluição sonora.

- A porcentagem de população vivendo em favelas é zero em Sorocaba e 1,95\% em Toronto, pois para esta última foi considerada a população vivendo em habitação ilegal ou superlotada, definida pela norma canadense como domicílio com mais de 2 pessoas por dormitório. 


\section{RESULTADOS}

\subsection{Simulação de Aplicação do Método para Retrofit Urbano em Sorocaba}

\subsubsection{Análise de Tendência}

Aplicando-se a análise de tendência por MMS - Média Móvel Simples, com comprimento de média $\mathrm{k}=3$ anos, para cada um dos indicadores da NBR ISO 37120:2017, foi possível elaborar um gráfico de tendência padrão para cada indicador, como no exemplo da Figura 60, para o indicador 8.2 - "Concentração de material particulado (PM 10)". Estes gráficos constam no dashboard desenvolvido em Power BI, cujos dados e resultados podem ser totalmente acessados em: https://bit.ly/2EDnZ4J.

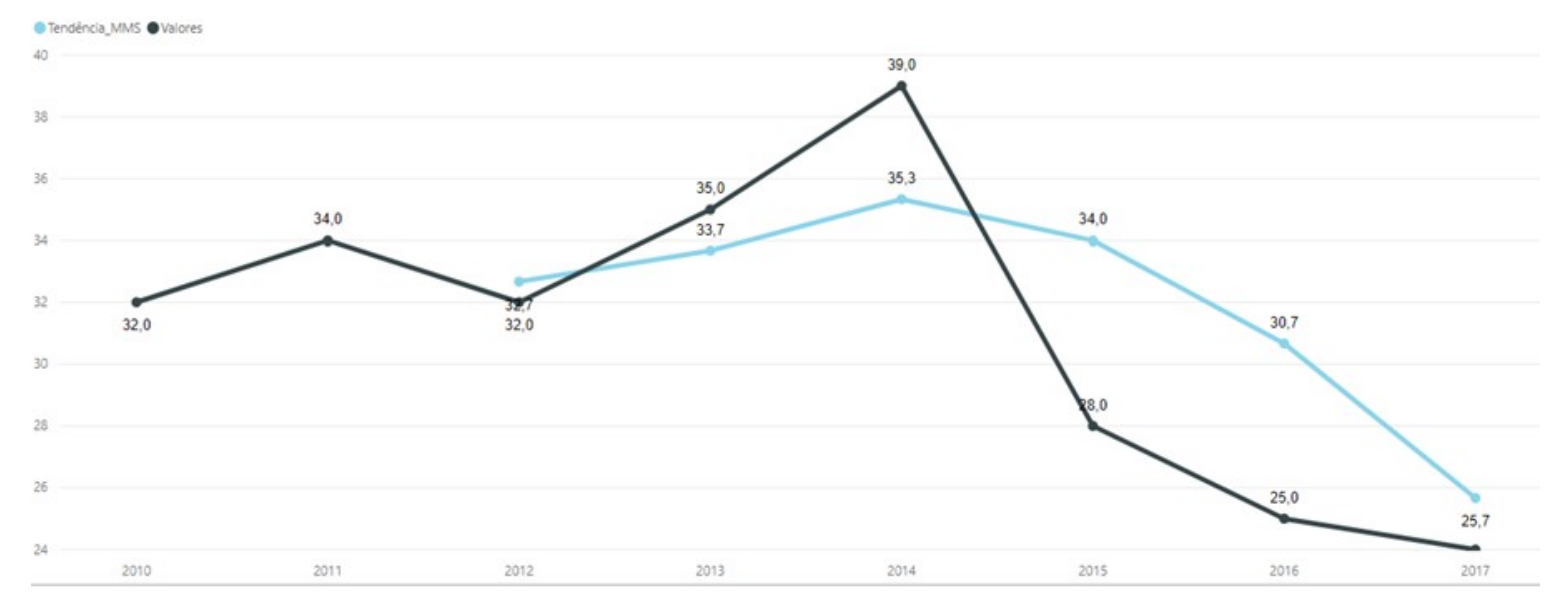

Figura 60: Gráfico de tendência padrão, exemplo para o indicador 8.2 - "Concentração de material particulado (PM 10)" com dados de Sorocaba.

Desconsiderando os 29 indicadores em que não foi possível encontrar dados, ou não há disponibilidade de dados para ao menos 3 anos, sejam consecutivos ou não, os demais 71 indicadores puderam ser classificados em termos de tendência, levando em conta a comparação entre o valor atual do indicador e sua média móvel calculada. Para Sorocaba, os resultados pontuam 29 indicadores em tendência favorável (verde), 15 estável (amarelo) e 27 em tendência desfavorável (vermelha). Os 71 indicadores correspondem a 35 essenciais e 36 de apoio. Dos 46 indicadores essenciais, dos quais 35 apresentam dados suficientes para análise de tendência em Sorocaba, são divididos entre 14 favoráveis, 11 estáveis e 10 
desfavoráveis. Dos 54 indicadores de apoio, reduzidos a 36 com dados suficientes para análise de tendência, os resultados pontuam 15 favoráveis, 4 estáveis e 17 desfavoráveis. A Figura 61 mostra estes resultados e também um exemplo de classificação de tendência dos indicadores de somente uma Seção da NBR ISO 37120:2017, no caso a Seção 21 - “Água e Saneamento”, possível nas opções de navegação do dashboard.

Todos os indicadores:

Indicadores Essenciais:

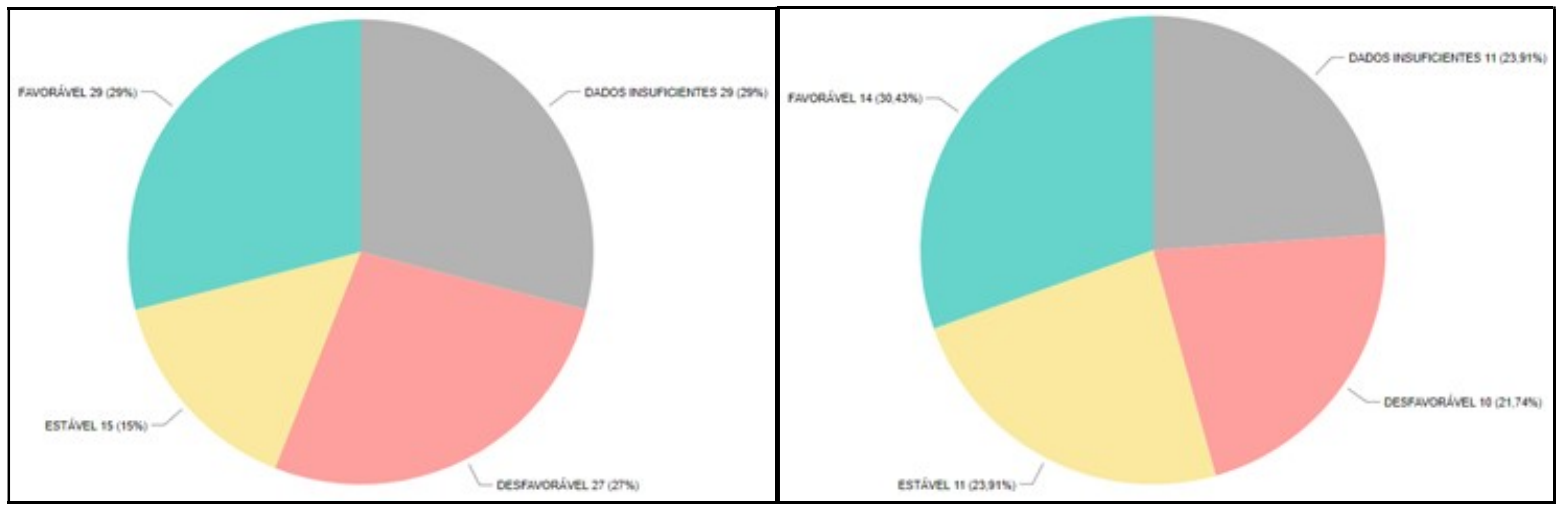

Indicadores de apoio:

Indicadores da Seção 21:

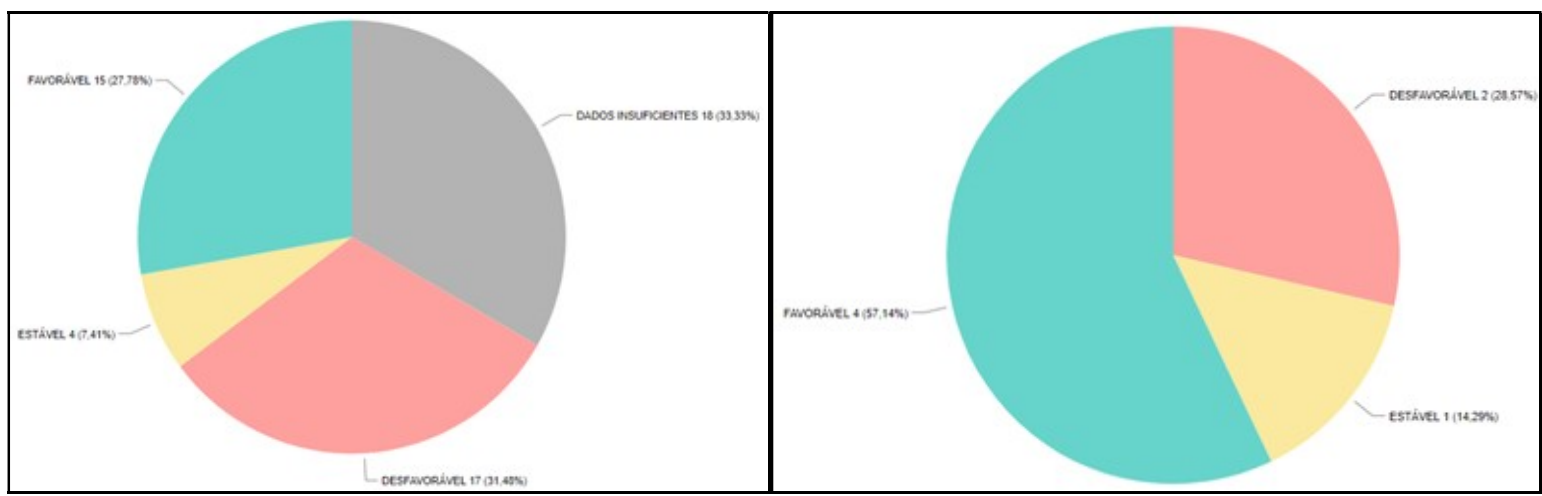

Figura 61: Resultados da classificação pela análise de tendência para os 100 indicadores da NBR ISO 37120:2017 com dados de Sorocaba.

\subsubsection{Fronteiras de Eficiência}

Conforme dito anteriormente, para a realização da etapa de benchmarking do método para retrofit urbano, a DEA foi utilizada neste estudo para definir as fronteiras de eficiência, ou seja, os melhores valores para os indicadores, que indicam a melhor unidade de desempenho atingida. 
Para tal, foi inicialmente realizada uma análise cruzada entre indicadores da ABNT NBR ISO 37120:2017 e as metas ODS (Apêndice B), que podem ser visualizadas em tabela contida no dashboard proposto para o método, individualmente para cada um dos 100 indicadores. As metas ODS identificadas já fornecem um primeiro valor para a fronteira de eficiência, principalmente no caso de serem passíveis de correspondência com um valor matemático.

Ao mesmo tempo, outras referências também foram levadas em consideração para pontuar melhores valores, tais como os provenientes de publicações de organizações internacionais, ou acordos internacionais, tais como OMS - Organização Mundial da Saúde, Nações Unidas, entre outros.

Também foram considerados os valores numéricos recomendados pelo BID - Banco Interamericano de Desenvolvimento (2013) e pelo SDSN - Sustainable Development Solutions Network (2016). Os dados provenientes de ambas fontes são divididos em escala de cores, também em matriz tricolor, indicando bom desempenho do indicador como verde, desempenho potencialmente problemático como amarelo e desempenho altamente problemático como vermelho.

$\mathrm{Na}$ ausência de indicadores levantados para a escala municipal, em contraponto com muitos dados na escala nacional encontrados na literatura, tomou-se também como referência de valores para os indicadores os publicados das 58 cidades certificadas pelo WCCD - World Council on City Data, dados de julho de 2018.

Desta forma, apresenta-se como resultado a Tabela 6, com as fronteiras de eficiência para os indicadores da NBR ISO 37120:2017. Estas informações também podem ser acessadas individualmente, para cada indicador, no dashboard proposto. 
Tabela 6: Fronteiras de eficiência para cada um dos indicadores da NBR ISO 37120:2017

\begin{tabular}{|c|c|c|c|c|c|c|c|c|}
\hline \multirow{2}{*}{$\begin{array}{c}\text { No. } \\
\text { Indi- } \\
\text { cador } \\
\end{array}$} & \multirow{2}{*}{ Referência } & \multirow{2}{*}{ Melhor } & \multirow{2}{*}{ Média } & \multirow{2}{*}{ Pior } & \multicolumn{2}{|c|}{ Brasil } & \multicolumn{2}{|c|}{ Referencial teórico } \\
\hline & & & & & Valor & Fonte & Valor & Fonte \\
\hline \multirow{3}{*}{5.1} & WCCD (2018) & 0,3 & 8,5 & 28,4 & & & & \\
\hline & BID (2013) & 7 & 9,5 & 12 & & & & \\
\hline & SDSN (2016) & 0,8 & 7,5 & 30,1 & 7,2 & $\begin{array}{l}\text { SDSN } \\
(2016)\end{array}$ & & \\
\hline 5.2 & WCCD (2018) & 70,7 & 27,5 & 1,0 & & & & \\
\hline \multirow{3}{*}{5.3} & WCCD (2018) & 0 & 15,2 & 50 & & & 0 & $\begin{array}{c}\text { Meta } 1.1 \\
\text { ODS }\end{array}$ \\
\hline & BID (2013) & 15,0 & 17,5 & 25 & & & & \\
\hline & SDSN (2016) & 0 & 7,35 & 68,7 & 4,9 & $\begin{array}{l}\text { SDSN } \\
(2016)\end{array}$ & & \\
\hline 5.4 & WCCD (2018) & 69 & 37,6 & 17,5 & & & & \\
\hline 5.5 & WCCD (2018) & 2,1 & 18,2 & 60,6 & & & & \\
\hline 5.6 & WCCD (2018) & 17.024 & 7127 & 226 & & & & \\
\hline \multirow{2}{*}{5.7} & WCCD (2018) & 516,7 & 58,8 & 0,0 & & & & \\
\hline & SDSN (2016) & 305,3 & 75 & 1,8 & & & & \\
\hline 6.1 & WCCD (2018) & 100 & 96,39 & 40,0 & & & 100 & $\begin{array}{c}\text { Meta } 4.1 \\
\text { ODS }\end{array}$ \\
\hline 6.2 & WCCD (2018) & 107,6 & 100 & 66,67 & & & 100 & $\begin{array}{c}\text { Meta } 4.1 \\
\text { ODS }\end{array}$ \\
\hline \multirow{2}{*}{6.3} & WCCD (2018) & 103,0 & 88 & 45 & & & 100 & $\begin{array}{c}\text { Meta } 4.1 \\
\text { ODS }\end{array}$ \\
\hline & SDSN (2016) & 100 & 77,5 & 0 & & & & \\
\hline \multirow{2}{*}{6.4} & WCCD (2018) & 11,2 & 17,54 & 66,48 & & & & \\
\hline & BID (2013) & 15,0 & 20,0 & 25,0 & & & & \\
\hline 6.5 & WCCD (2018) & 100 & 94,78 & 52,72 & & & 100 & $\begin{array}{c}\text { Meta } 4.1 \\
\text { ODS }\end{array}$ \\
\hline \multirow{2}{*}{6.6} & WCCD (2018) & 100 & 95,15 & 55,71 & & & 100 & $\begin{array}{c}\text { Meta } 4.1 \\
\text { ODS }\end{array}$ \\
\hline & BID (2013) & 98,0 & 96,5 & 95,0 & & & & \\
\hline 6.7 & WCCD (2018) & 40.034 & 27.858 & 464,3 & & & & \\
\hline 7.1 & WCCD (2018) & 127,49 & 2161,44 & 9300 & & & & \\
\hline \multirow{3}{*}{7.2} & WCCD (2018) & 100 & 96,7 & 57 & & & & \\
\hline & BID (2013) & 100 & 80 & 70 & & & 100 & $\begin{array}{c}\text { Meta } 7.1 \\
\text { ODS }\end{array}$ \\
\hline & SDSN (2016) & 100 & 79 & 9,8 & 99,5 & $\begin{array}{l}\text { SDSN } \\
(2016)\end{array}$ & & \\
\hline 7.3 & WCCD (2018) & 5,1 & 76,93 & 756,25 & & & & \\
\hline \multirow{3}{*}{7.4} & WCCD (2018) & 100 & 6 & 0 & & & & \\
\hline & BID (2013) & 50 & 35 & 20 & & & & \\
\hline & SDSN (2016) & 47 & 15 & 0,7 & & & & \\
\hline 7.5 & WCCD (2018) & 581,14 & $6.122,18$ & 25.153 & & & & \\
\hline
\end{tabular}




\begin{tabular}{|c|c|c|c|c|c|c|c|c|}
\hline \multirow{2}{*}{$\begin{array}{l}\text { No. } \\
\text { Indi- } \\
\text { cador }\end{array}$} & \multirow{2}{*}{ Referência } & \multirow{2}{*}{ Melhor } & \multirow{2}{*}{ Média } & \multirow{2}{*}{ Pior } & \multicolumn{2}{|c|}{ Brasil } & \multicolumn{2}{|c|}{ Referencial teórico } \\
\hline & & & & & Valor & Fonte & Valor & Fonte \\
\hline \multirow{2}{*}{7.6} & WCCD (2018) & 0,01 & 0,48 & 33,6 & & & 5 & $\begin{array}{l}\text { ANEEL } \\
(2018)\end{array}$ \\
\hline & BID (2013) & 10 & 11,5 & 13 & & & & \\
\hline \multirow{2}{*}{7.7} & WCCD (2018) & 0 & 1,02 & 76,31 & & & 5 & $\begin{array}{l}\text { ANEEL } \\
(2018)\end{array}$ \\
\hline & BID (2013) & 10,0 & 14,0 & 18,0 & & & & \\
\hline \multirow{2}{*}{8.1} & WCCD (2018) & 5,0 & 15,0 & 57,0 & & & 10 & $\begin{array}{l}\text { OMS } \\
(2006)\end{array}$ \\
\hline & SDSN (2016) & 0 & 15 & 48,4 & 16,5 & $\begin{array}{l}\text { SDSN } \\
(2016) \\
\end{array}$ & & \\
\hline \multirow{2}{*}{8.2} & WCCD (2018) & 11 & 24 & 166 & & & 20 & $\begin{array}{c}\text { OMS } \\
(2006)\end{array}$ \\
\hline & BID (2013) & 50 & 100 & 150 & & & & \\
\hline \multirow{3}{*}{8.3} & WCCD (2018) & 1,29 & 5,4 & 55,7 & & & & \\
\hline & BID (2013) & 5,0 & 7,5 & 10 & & & & \\
\hline & SDSN (2016) & 0 & 3,0 & 20,9 & 2,2 & $\begin{array}{l}\text { SDSN } \\
(2016)\end{array}$ & & \\
\hline 8.4 & WCCD (2018) & 4,58 & 27 & 110 & & & 40 & $\begin{array}{c}\text { OMS } \\
(2006)\end{array}$ \\
\hline 8.5 & WCCD (2018) & 0 & 3,7 & 63 & & & 20 & $\begin{array}{l}\text { OMS } \\
(2006)\end{array}$ \\
\hline 8.6 & WCCD (2018) & 0,06 & 44,28 & 81 & & & 100 & $\begin{array}{c}\text { OMS } \\
(2006)\end{array}$ \\
\hline 8.7 & WCCD (2018) & 4,22 & 38 & 100 & & & & \\
\hline 8.8 & WCCD (2018) & 0 & 0,32 & 2,78 & & & & \\
\hline \multirow{2}{*}{9.1} & WCCD (2018) & 0 & 7,52 & 86,63 & & & & \\
\hline & BID (2013) & 10,0 & 15,0 & 20 & & & & \\
\hline 9.2 & WCCD (2018) & 1,75 & 14,36 & 56,71 & & & & \\
\hline 9.3 & WCCD (2018) & 95,56 & 71,34 & 1,42 & & & & \\
\hline 9.4 & WCCD (2018) & 101,33 & 99,7 & 40 & & & & \\
\hline 10.1 & WCCD (2018) & 263,61 & 44,13 & 1,11 & & & & \\
\hline 10.2 & WCCD (2018) & 0 & 0,3 & 2,02 & & & & \\
\hline 10.3 & WCCD (2018) & 0 & 0 & 6,13 & & & & \\
\hline 10.4 & WCCD (2018) & 579,81 & 9,79 & 0 & & & & \\
\hline 10.5 & WCCD (2018) & 1,47 & 7,9 & 23,1 & & & & \\
\hline 10.6 & WCCD (2018) & 1 & 7,49 & 22,28 & & & & \\
\hline 11.1 & WCCD (2018) & 99,53 & 50 & 0,5 & & & & \\
\hline 11.2 & WCCD (2018) & 60 & 35,56 & 0 & & & & \\
\hline 11.3 & WCCD (2018) & 77,28 & 43 & 0,81 & & & & \\
\hline 11.4 & WCCD (2018) & 0 & 0,79 & 14,95 & & & & \\
\hline 11.5 & WCCD (2018) & 0,4 & 17,02 & 243,67 & & & & \\
\hline
\end{tabular}




\begin{tabular}{|c|c|c|c|c|c|c|c|c|}
\hline \multirow{2}{*}{$\begin{array}{c}\text { No. } \\
\text { Indi- } \\
\text { cador }\end{array}$} & \multirow{2}{*}{ Referência } & \multirow{2}{*}{ Melhor } & \multirow{2}{*}{ Média } & \multirow{2}{*}{ Pior } & \multicolumn{2}{|c|}{ Brasil } & \multicolumn{2}{|c|}{ Referencial teórico } \\
\hline & & & & & Valor & Fonte & Valor & Fonte \\
\hline 11.6 & WCCD (2018) & 100 & 98,2 & 3,7 & & & & \\
\hline \multirow{2}{*}{12.1} & WCCD (2018) & 86 & 79,76 & 54 & & & & \\
\hline & BID (2013) & 74 & 72 & 70 & & & & \\
\hline \multirow[b]{2}{*}{12.2} & WCCD (2018) & 997,67 & 301,64 & 0 & & & & \\
\hline & BID (2013) & 100 & 75 & 50 & & & 300 & $\begin{array}{l}\text { OMS } \\
(2006)\end{array}$ \\
\hline \multirow{3}{*}{12.3} & WCCD (2018) & $2.540,2$ & 279,3 & 11,6 & & & & \\
\hline & BID (2013) & 200 & 122,5 & 75 & & & & \\
\hline & SDSN (2016) & 630,0 & 200 & 0 & 190,0 & $\begin{array}{l}\text { SDSN } \\
(2016)\end{array}$ & & \\
\hline \multirow{3}{*}{12.4} & WCCD (2018) & 0 & 5 & 121 & & & 25 & $\begin{array}{c}\text { Meta } 3.1 \\
\text { ODS }\end{array}$ \\
\hline & BID (2013) & 20 & 10 & 30 & & & & \\
\hline & SDSN (2016) & 0 & 37,5 & 120,4 & 16,4 & $\begin{array}{l}\text { SDSN } \\
(2016) \\
\end{array}$ & & \\
\hline 12.5 & WCCD (2018) & 5.538 & 622 & 20 & & & & \\
\hline 12.6 & WCCD (2018) & $3.213,8$ & 31,05 & 0,27 & & & & \\
\hline 12.7 & WCCD (2018) & 0 & 8,4 & 42,11 & & & & \\
\hline 13.1 & WCCD (2018) & 10,41 & 1,04 & 0 & & & & \\
\hline \multirow{2}{*}{13.2} & WCCD (2018) & 469 & 62,57 & 0 & & & & \\
\hline & BID (2013) & 1 & 0,85 & 0,7 & & & & \\
\hline 14.1 & WCCD (2018) & $1.162,25$ & 196,55 & 9,22 & & & & \\
\hline \multirow{3}{*}{14.2} & WCCD (2018) & 0 & 2 & 63,0 & & & & \\
\hline & BID (2013) & 10 & 17,5 & 25 & & & & \\
\hline & SDSN (2016) & 0 & 2,25 & 39,9 & 25,2 & $\begin{array}{l}\text { SDSN } \\
(2016) \\
\end{array}$ & & \\
\hline \multirow{2}{*}{14.3} & WCCD (2018) & 0,08 & 1290 & $14.663,51$ & & & & \\
\hline & BID (2013) & 3.300 & 4.750 & 6.000 & & & & \\
\hline 14.4 & WCCD (2018) & 0,09 & 7,9 & 94,04 & & & & \\
\hline 14.5 & WCCD (2018) & 8,48 & 382 & $3.973,51$ & & & & \\
\hline \multirow{2}{*}{15.1} & WCCD (2018) & 0 & 0 & 40 & & & & \\
\hline & BID (2013) & 10 & 17,5 & 25 & & & & \\
\hline 15.2 & WCCD (2018) & 0 & 139,92 & 940 & & & & \\
\hline \multirow{2}{*}{15.3} & WCCD (2018) & 0 & 0,2 & 70 & & & & \\
\hline & BID (2013) & 20 & 25 & 30 & & & & \\
\hline \multirow{2}{*}{16.1} & WCCD (2018) & 100 & 96,2 & 19,7 & & & & \\
\hline & BID (2013) & 100 & 85 & 80 & & & & \\
\hline 16.2 & WCCD (2018) & 0,1 & 0,4 & 1,4 & & & & \\
\hline
\end{tabular}




\begin{tabular}{|c|c|c|c|c|c|c|c|c|}
\hline \multirow{2}{*}{$\begin{array}{c}\text { No. } \\
\text { Indi- } \\
\text { cador }\end{array}$} & \multirow{2}{*}{ Referência } & \multirow{2}{*}{ Melhor } & \multirow{2}{*}{ Média } & \multirow{2}{*}{ Pior } & \multicolumn{2}{|c|}{ Brasil } & \multicolumn{2}{|c|}{ Referencial teórico } \\
\hline & & & & & Valor & Fonte & Valor & Fonte \\
\hline & SDSN (2016) & 0,1 & 1,5 & 2,4 & 1,0 & $\begin{array}{l}\text { SDSN } \\
(2016)\end{array}$ & & \\
\hline 16.3 & WCCD (2018) & 90,3 & 30,3 & 0,0 & & & & \\
\hline 16.4 & WCCD (2018) & 100,0 & 50,2 & 0,0 & & & & \\
\hline 16.5 & WCCD (2018) & 93,0 & 14,1 & 0,0 & & & & \\
\hline 16.6 & WCCD (2018) & 0,0 & 2,2 & 100,0 & & & & \\
\hline 16.7 & WCCD (2018) & 0,0 & 2,6 & 94,1 & & & 0 & $\begin{array}{c}\text { Política } \\
\text { Nacional } \\
\text { de } \\
\text { Resíduos } \\
\text { Sólidos } \\
\end{array}$ \\
\hline 16.8 & WCCD (2018) & 0,0 & 2,7 & 34,9 & & & & \\
\hline 16.9 & WCCD (2018) & 0,0 & 0,1 & 3,7 & & & & \\
\hline 16.10 & WCCD (2018) & 100,0 & 4,8 & 0,0 & & & & \\
\hline \multirow{2}{*}{17.1} & WCCD (2018) & $120.317,0$ & $49.836,0$ & $3.013,0$ & & & 100.000 & $\begin{array}{c}\text { Meta 9.c } \\
\text { ODS }\end{array}$ \\
\hline & BID (2013) & $15.000,0$ & $11.000,0$ & $7.000,0$ & & & & \\
\hline \multirow{2}{*}{17.2} & WCCD (2018) & $276.321,0$ & $98.044,0$ & $22.423,0$ & & & 100.000 & $\begin{array}{c}\text { Meta 9.c } \\
\text { ODS }\end{array}$ \\
\hline & BID (2013) & $90.000,0$ & $75.000,0$ & 60.000 & & & & \\
\hline 17.3 & WCCD (2018) & $94.054,71$ & $41.703,34$ & 676,63 & & & & \\
\hline 18.1 & WCCD (2018) & 186,98 & 3,86 & 0 & & & & \\
\hline \multirow{2}{*}{18.2} & WCCD (2018) & 670,9 & 131,46 & 0,59 & & & & \\
\hline & BID (2013) & 40 & 25 & 10 & & & & \\
\hline 18.3 & WCCD (2018) & 563 & 89,75 & 0,01 & & & & \\
\hline \multirow{2}{*}{18.4} & WCCD (2018) & 0,01 & 0,38 & 0,92 & & & & \\
\hline & BID (2013) & 0,3 & 0,25 & 0,4 & & & & \\
\hline \multirow{2}{*}{18.5} & WCCD (2018) & 10,7 & 45,6 & 87,8 & & & & \\
\hline & BID (2013) & 50 & 57,5 & 65 & & & & \\
\hline 18.6 & WCCD (2018) & 0 & 0,03 & 0,68 & & & & \\
\hline \multirow{2}{*}{18.7} & WCCD (2018) & 226,7 & 19,1 & 0,0 & & & & \\
\hline & BID (2013) & 25,0 & 20,0 & 15 & & & & \\
\hline \multirow{3}{*}{18.8} & WCCD (2018) & 0,0 & 5,9 & 41,3 & & & & \\
\hline & BID (2013) & 10,0 & 15,0 & 20,0 & & & & \\
\hline & SDSN (2016) & 2,1 & 12,6 & 33,2 & 23,4 & $\begin{array}{l}\text { SDSN } \\
(2016) \\
\end{array}$ & & \\
\hline 18.9 & WCCD (2018) & 672092 & 118217 & 0 & & & & \\
\hline 19.1 & WCCD (2018) & 9174,1 & 376,23 & 0 & & & 120 & $\begin{array}{c}\text { OMS } \\
(2006)\end{array}$ \\
\hline 19.2 & WCCD (2018) & 22092,42 & 853,31 & 21 & & & & \\
\hline
\end{tabular}




\begin{tabular}{|c|c|c|c|c|c|c|c|c|}
\hline \multirow{2}{*}{$\begin{array}{l}\text { No. } \\
\text { Indi- } \\
\text { cador }\end{array}$} & \multirow{2}{*}{ Referência } & \multirow{2}{*}{ Melhor } & \multirow{2}{*}{ Média } & \multirow{2}{*}{ Pior } & \multicolumn{2}{|c|}{ Brasil } & \multicolumn{2}{|c|}{ Referencial teórico } \\
\hline & & & & & Valor & Fonte & Valor & Fonte \\
\hline 19.3 & WCCD (2018) & 0,0 & 2,1 & 23,5 & & & & \\
\hline \multirow{2}{*}{19.4} & WCCD (2018) & 7,22 & 1,26 & 0,64 & & & & \\
\hline & BID (2013) & 1,7 & 1,5 & 1,3 & & & & \\
\hline \multirow{2}{*}{20.1} & WCCD (2018) & 100 & 91,7 & 36,9 & & & 100 & $\begin{array}{c}\text { Meta } 6.2 \\
\text { ODS }\end{array}$ \\
\hline & BID (2013) & 75 & 67,5 & 60 & & & & \\
\hline 20.2 & WCCD (2018) & 0 & 11,9 & 100 & & & & \\
\hline \multirow{3}{*}{20.3} & WCCD (2018) & 100 & 82,1 & 0 & & & & \\
\hline & BID (2013) & 100 & 87,5 & 75 & & & & \\
\hline & SDSN (2016) & 100 & 32,5 & 0 & 10,9 & $\begin{array}{l}\text { SDSN } \\
(2016)\end{array}$ & & \\
\hline 20.4 & WCCD (2018) & 100 & 79,1 & 0 & & & & \\
\hline 20.5 & WCCD (2018) & 100 & 44,7 & 0 & & & & \\
\hline \multirow{2}{*}{21.1} & WCCD (2018) & 100 & 98,2 & 66,6 & & & 100 & $\begin{array}{c}\text { Meta } 6.1 \\
\text { ODS }\end{array}$ \\
\hline & SDSN (2016) & 100 & 86,5 & 6,1 & 97,7 & $\begin{array}{l}\text { SDSN } \\
(2016)\end{array}$ & & \\
\hline \multirow{2}{*}{21.2} & WCCD (2018) & 100 & 98,8 & 76 & & & 100 & $\begin{array}{c}\text { Meta } 6.1 \\
\text { ODS }\end{array}$ \\
\hline & SDSN (2016) & 100 & 89 & 50,8 & 98,1 & $\begin{array}{l}\text { SDSN } \\
(2016)\end{array}$ & & \\
\hline \multirow{2}{*}{21.3} & WCCD (2018) & 100 & 95,6 & 47 & & & 100 & $\begin{array}{c}\text { Meta } 6.1 \\
\text { ODS }\end{array}$ \\
\hline & SDSN (2016) & 100 & 85 & 12,1 & 82,8 & $\begin{array}{l}\text { SDSN } \\
(2016)\end{array}$ & & \\
\hline \multirow{2}{*}{21.4} & WCCD (2018) & 52 & 186,1 & 612 & & & & \\
\hline & BID (2013) & 120,00 & 160,00 & 250 & & & & \\
\hline 21.5 & WCCD (2018) & 96,5 & 266,1 & 696,3 & & & 110 & ONU \\
\hline 21.6 & WCCD (2018) & 0 & 67,3 & 89,62 & & & & \\
\hline \multirow{2}{*}{21.7} & WCCD (2018) & 2,6 & 18,7 & 67 & & & & \\
\hline & BID (2013) & 0 a 30 & 30 a 45 & $>45$ & & & & \\
\hline
\end{tabular}

Elaborada pela autora.

Cabe salientar que algumas discrepâncias entre adoção de um valor ou outro nas fronteiras de eficiência foram observadas nas diferentes publicações, muitas vezes fruto das divergências entre as escalas nacional e municipal, mas também por valores incoerentes, "fora da curva", de algumas cidades no portal de indicadores do WCCD, valores estes que foram desconsiderados. 
Para continuidade da simulação de aplicação do método para retrofit urbano, fez-se o exercício de adoção de metas para cada um dos indicadores, com base na tabela anterior, com a seguinte ordem de preferência da adoção do valor da meta:

- valor numérico da meta ODS (por exemplo, indicador "mortalidade infantil")

- valor numérico estipulado por legislação, recomendações e publicações de organizações nacionais, tais como Planos Nacionais, agências reguladoras, normas, entre outros

- valor numérico proveniente de publicações de organizações internacionais, ou acordos internacionais, tais como OMS - Organização Mundial da Saúde, Nações Unidas, entre outros

- valor do PPA - Plano Anual de Metas de Sorocaba, quando este representa um valor de melhor desempenho em relação às fronteiras de eficiência

- valor numérico recomendado pelo BID - Banco Interamericano de Desenvolvimento (2013), correspondente à meta melhor, verde

- valor numérico SDSN - Sustainable Development Solutions Network (2016) correspondente à meta melhor, $=100$

Todos os valores de metas adotadas para o exercício de simulação do método são relacionados na Tabela 7. Cabe salientar que se trata somente de um exercício, uma vez que o objetivo do método é auxiliar na definição de metas. Portanto, neste exercício, foram adotadas metas prioritariamente para os indicadores que apresentam tendência favorável. Porém, com a adoção de um valor ou outro para a meta, pode-se visualizar no dashboard a variação do comportamento futuro do indicador, combinando-se a análise de tendência e a meta proposta, de forma a contribuir para o objetivo do método.

Tabela 7: Metas adotadas para indicadores da NBR ISO 37120:2017

\begin{tabular}{||c|l|c|c|c||}
\hline \hline No. & \multicolumn{1}{|c|}{ Descrição } & $\begin{array}{c}\text { Meta } \\
\text { adotada }\end{array}$ & $\begin{array}{c}\text { Horizonte } \\
\text { da Meta }\end{array}$ & Fonte da Meta \\
\hline \hline 5.1 & Taxa de desemprego da cidade & $7,0 \%$ & - & Melhor - BID (2013) \\
\hline 5.3 & Porcentagem da população abaixo da linha de pobreza & $0 \%$ & 2030 & Meta 1.1 ODS \\
\hline 5.4 & $\begin{array}{l}\text { Porcentagem da população com emprego em tempo } \\
\text { integral }\end{array}$ & $69,0 \%$ & - & Melhor - WCCD (2018) \\
\hline \multirow{2}{*}{6.1} & $\begin{array}{l}\text { Porcentagem da população feminina em idade escolar } \\
\text { matriculada em escolas }\end{array}$ & $100 \%$ & 2030 & Meta 4.1 ODS \\
\cline { 2 - 5 } & & 2025 & $\begin{array}{c}\text { Metas 2 e 3 do Plano } \\
\text { Municipal de Educação } \\
\text { (PMS, 2015) }\end{array}$ \\
\hline
\end{tabular}




\begin{tabular}{|c|c|c|c|c|}
\hline No. & Descrição & $\begin{array}{c}\text { Meta } \\
\text { adotada }\end{array}$ & \begin{tabular}{|c|}
$\begin{array}{c}\text { Horizonte } \\
\text { da Meta }\end{array}$ \\
\end{tabular} & Fonte da Meta \\
\hline \multirow[b]{2}{*}{6.2} & \multirow[b]{2}{*}{$\begin{array}{l}\text { Porcentagem de estudantes com ensino primário } \\
\text { completo (taxa de sobrevivência) }\end{array}$} & \multirow[b]{2}{*}{$100 \%$} & 2030 & Meta 4.1 ODS \\
\hline & & & 2025 & $\begin{array}{l}\text { Meta } 2 \text { do Plano } \\
\text { Municipal de Educação } \\
\text { (PMS, 2015) }\end{array}$ \\
\hline \multirow[b]{2}{*}{6.3} & \multirow[b]{2}{*}{$\begin{array}{l}\text { Porcentagem de estudantes com ensino secundário } \\
\text { completo (taxa de sobrevivência) }\end{array}$} & \multirow[b]{2}{*}{$100 \%$} & 2030 & Meta 4.1 ODS \\
\hline & & & 2025 & $\begin{array}{l}\text { Meta } 3 \text { do Plano } \\
\text { Municipal de Educação } \\
\text { (PMS, 2015) }\end{array}$ \\
\hline 6.4 & Relação estudante/professor no ensino primário & 15,0 & - & Melhor - BID (2013) \\
\hline \multirow[b]{2}{*}{6.5} & \multirow[b]{2}{*}{$\begin{array}{l}\text { Porcentagem de população masculina em idade escolar } \\
\text { matriculada em escolas }\end{array}$} & \multirow[b]{2}{*}{$100 \%$} & 2030 & Meta 4.1 ODS \\
\hline & & & 2025 & $\begin{array}{l}\text { Metas } 2 \text { e } 3 \text { do Plano } \\
\text { Municipal de Educação } \\
\quad \text { (PMS, 2015) }\end{array}$ \\
\hline \multirow[b]{2}{*}{6.6} & \multirow[b]{2}{*}{$\begin{array}{l}\text { Porcentagem de população em idade escolar } \\
\text { matriculada em escolas }\end{array}$} & \multirow[b]{2}{*}{$100 \%$} & 2030 & Meta 4.1 ODS \\
\hline & & & 2025 & $\begin{array}{l}\text { Metas } 2 \text { e } 3 \text { do Plano } \\
\text { Municipal de Educação } \\
\text { (PMS, 2015) }\end{array}$ \\
\hline 6.7 & $\begin{array}{l}\text { Número de indivíduos com ensino superior completo } \\
\text { por } 100.000 \text { habitantes }\end{array}$ & 27.858 & - & Média - WCCD (2018) \\
\hline 7.1 & $\begin{array}{l}\text { Uso de energia elétrica residencial total per capita } \\
(\mathrm{kWh} / \mathrm{ano})\end{array}$ & $2.161,4$ & - & Média - WCCD (2018) \\
\hline 7.2 & $\begin{array}{l}\text { Porcentagem de habitantes da cidade com fornecimento } \\
\text { regular de energia elétrica }\end{array}$ & $100 \%$ & 2030 & Meta 7.1 ODS \\
\hline 7.4 & $\begin{array}{l}\text { Porcentagem da energia total proveniente de fontes } \\
\text { renováveis, como parte do consumo total de energia da } \\
\text { cidade }\end{array}$ & $50 \%$ & - & Melhor - BID (2013) \\
\hline 7.5 & Uso total de energia elétrica per capita (kWh/ano) & $6.122,18$ & - & Média - WCCD (2018) \\
\hline 7.6 & $\begin{array}{l}\text { Número médio de interrupções de energia elétrica por } \\
\text { consumidor por ano }\end{array}$ & 5 & 2018 & ANEEL (2018) \\
\hline 7.7 & $\begin{array}{l}\text { Duração média das interrupções de energia elétrica (em } \\
\text { horas) }\end{array}$ & 5 & 2018 & ANEEL (2018) \\
\hline 8.1 & Concentração de material particulado fino (PM 2.5) & 10 & - & OMS (2006) \\
\hline 8.2 & Concentração de material particulado (PM 10) & 20 & - & OMS (2006) \\
\hline 8.3 & $\begin{array}{l}\text { Emissão de gases de efeito estufa medida em toneladas } \\
\text { per capita }\end{array}$ & 5 & - & Melhor - BID (2013) \\
\hline 8.4 & Concentração de $\mathrm{NO}_{2}$ (dióxido de nitrogênio) & 40 & - & OMS (2006) \\
\hline 8.5 & Concentração de $\mathrm{SO}_{2}$ (dióxido de enxofre) & 20 & - & OMS (2006) \\
\hline 8.6 & Concentração de $\mathrm{O}_{3}$ (ozônio) & 100 & - & OMS (2006) \\
\hline 9.1 & $\begin{array}{l}\text { Taxa de endividamento (expansão do serviço da dívida } \\
\text { como uma porcentagem da receita própria do } \\
\text { município) }\end{array}$ & $10 \%$ & - & Melhor - BID (2013) \\
\hline 9.2 & $\begin{array}{l}\text { Despesas de capital como porcentagem de despesas } \\
\text { totais }\end{array}$ & $1,8 \%$ & - & Melhor - WCCD (2018) \\
\hline 9.3 & $\begin{array}{l}\text { Porcentagem da receita própria em função do total das } \\
\text { receitas }\end{array}$ & $95,6 \%$ & - & Melhor - WCCD (2018) \\
\hline 9.4 & $\begin{array}{l}\text { Porcentagem dos impostos recolhidos em função dos } \\
\text { impostos cobrados }\end{array}$ & $100 \%$ & - & Melhor - WCCD (2018) \\
\hline 10.2 & Número de mortes relacionadas a incêndios por & 0 & - & Melhor - WCCD (2018) \\
\hline
\end{tabular}




\begin{tabular}{|c|c|c|c|c|}
\hline No. & Descrição & $\begin{array}{c}\text { Meta } \\
\text { adotada }\end{array}$ & $\begin{array}{c}\text { Horizonte } \\
\text { da Meta }\end{array}$ & Fonte da Meta \\
\hline & 100.000 habitantes & & & \\
\hline 10.3 & $\begin{array}{l}\text { Número de mortes relacionadas a desastres naturais por } \\
100.000 \text { habitantes }\end{array}$ & 0 & - & Melhor - WCCD (2018) \\
\hline 11.1 & $\begin{array}{l}\text { Porcentagem de participação dos eleitores nas últimas } \\
\text { eleições municipais em função do total de eleitores } \\
\text { aptos a votar }\end{array}$ & 99,5 & - & Melhor - WCCD (2018) \\
\hline 11.2 & $\begin{array}{l}\text { Porcentagem de mulheres eleitas em função do número } \\
\text { total de eleitos na gestão da cidade }\end{array}$ & $36 \%$ & - & Média - WCCD (2018) \\
\hline 11.6 & $\begin{array}{l}\text { Porcentagem de eleitores registrados em função da } \\
\text { população com idade para votar }\end{array}$ & $100 \%$ & - & Melhor - WCCD (2018) \\
\hline 12.1 & Expectativa média de vida & 74 & - & Melhor - BID (2013) \\
\hline 12.2 & Número de leitos hospitalares por 100.000 habitantes & 300 & - & OMS (2006) \\
\hline 12.3 & Número de médicos por 100.000 habitantes & 630 & - & OMS (2006) \\
\hline 12.4 & $\begin{array}{l}\text { Taxa de mortalidade de crianças menores de cinco anos } \\
\text { a cada } 1.000 \text { nascidos vivos }\end{array}$ & 25 & 2030 & Meta 3.1 ODS \\
\hline 12.5 & $\begin{array}{l}\text { Número de pessoas da equipe de enfermagem e } \\
\text { obstetrícia por } 100.000 \text { habitantes }\end{array}$ & 5538 & - & Melhor - WCCD (2018) \\
\hline 12.6 & $\begin{array}{l}\text { Número de profissionais de saúde mental por } 100.000 \\
\text { habitantes }\end{array}$ & $3.213,8$ & - & Melhor - WCCD (2018) \\
\hline 12.7 & Taxa de suicídio por 100.000 habitantes & 0 & - & Melhor - WCCD (2018) \\
\hline 13.2 & $\begin{array}{l}\text { Área em metros quadrados de espaços públicos de } \\
\text { recreação ao ar livre per capita }\end{array}$ & 1 & - & Melhor - BID (2013) \\
\hline 14.2 & Número de homicídios por 100.000 habitantes & 1 & - & Melhor - BID (2013) \\
\hline 14.3 & Crimes contra a propriedades por 100.000 habitantes & 3.300 & - & Melhor - BID (2013) \\
\hline 14.5 & Taxa de crimes violentos por 100.000 habitantes & 8,5 & - & Melhor - WCCD (2018) \\
\hline 15.1 & Porcentagem da população urbana morando em favelas & $0 \%$ & - & Meta 11.1 ODS \\
\hline 15.2 & Número de sem-teto por 100.000 habitantes & $0 \%$ & - & Meta 11.1 ODS \\
\hline 15.3 & $\begin{array}{l}\text { Porcentagem de moradias sem títulos de propriedade } \\
\text { registrados }\end{array}$ & $20 \%$ & - & Melhor - BID (2013) \\
\hline 16.1 & $\begin{array}{l}\text { Porcentagem da população urbana com coleta regular } \\
\text { de lixo (domiciliar) }\end{array}$ & $100 \%$ & - & Melhor - BID (2013) \\
\hline 16.2 & $\begin{array}{l}\text { Total de coleta de resíduos sólidos municipais per } \\
\text { capita }\end{array}$ & 0,1 & - & Melhor - SDSN (2016) \\
\hline 16.3 & $\begin{array}{l}\text { Porcentagem de resíduos sólidos urbanos que são } \\
\text { reciclados }\end{array}$ & $10 \%$ & - & PPA 2018-2021 \\
\hline 16.4 & $\begin{array}{l}\text { Porcentagem de resíduos sólidos urbanos dispostos em } \\
\text { aterros sanitários }\end{array}$ & $100 \%$ & - & $\begin{array}{l}\text { Política Nacional de } \\
\text { Resíduos Sólidos }\end{array}$ \\
\hline 16.5 & $\begin{array}{l}\text { Porcentagem de resíduos sólidos urbanos descartados } \\
\text { para incineração }\end{array}$ & $0 \%$ & - & $\begin{array}{l}\text { Política Nacional de } \\
\text { Resíduos Sólidos }\end{array}$ \\
\hline 16.6 & $\begin{array}{l}\text { Porcentagem de resíduos sólidos urbanos queimados a } \\
\text { céu aberto }\end{array}$ & $0 \%$ & - & $\begin{array}{l}\text { Política Nacional de } \\
\text { Resíduos Sólidos }\end{array}$ \\
\hline 16.7 & $\begin{array}{l}\text { Porcentagem de resíduos sólidos urbanos dispostos a } \\
\text { céu aberto }\end{array}$ & $0 \%$ & - & $\begin{array}{l}\text { Política Nacional de } \\
\text { Resíduos Sólidos }\end{array}$ \\
\hline 16.8 & $\begin{array}{l}\text { Porcentagem de resíduos sólidos urbanos dispostos por } \\
\text { outros meios }\end{array}$ & $0 \%$ & - & $\begin{array}{c}\text { Política Nacional de } \\
\text { Resíduos Sólidos }\end{array}$ \\
\hline 17.1 & Número de conexões de internet por 100.000 habitantes & 100.000 & 2020 & Meta 9.c ODS \\
\hline 17.2 & $\begin{array}{l}\text { Número de conexões de telefone celular por } 100.000 \\
\text { habitantes }\end{array}$ & 100.000 & 2020 & Meta 9.c ODS \\
\hline
\end{tabular}




\begin{tabular}{|c|c|c|c|c|}
\hline No. & Descrição & $\begin{array}{c}\text { Meta } \\
\text { adotada } \\
\end{array}$ & $\begin{array}{c}\text { Horizonte } \\
\text { da Meta }\end{array}$ & Fonte da Meta \\
\hline 18.2 & $\begin{array}{l}\text { Quilômetros de sistema de transporte público de média } \\
\text { capacidade por } 100.000 \text { habitantes }\end{array}$ & 40 & - & Melhor - BID (2013) \\
\hline 18.3 & $\begin{array}{l}\text { Número anual de viagens em transporte público per } \\
\text { capita }\end{array}$ & 87 & 2021 & PPA 2018-2021 \\
\hline 18.4 & Número de automóveis privados per capita & 0,3 & - & Melhor - BID (2013) \\
\hline 18.5 & $\begin{array}{l}\text { Porcentagem de passageiros que se deslocam para o } \\
\text { trabalho de forma alternativa ao automóvel privado }\end{array}$ & $50 \%$ & - & Melhor - BID (2013) \\
\hline 18.6 & $\begin{array}{l}\text { Número de veículos motorizados de duas rodas per } \\
\text { capita }\end{array}$ & 0,1 & - & Média - WCCD (2018) \\
\hline 18.7 & $\begin{array}{l}\text { Quilômetros de ciclovias e ciclofaixas por } 100.000 \\
\text { habitantes }\end{array}$ & 25 & - & Melhor - BID (2013) \\
\hline 18.8 & Mortalidades de trânsito por 100.000 habitantes & 5 & 2021 & PPA 2018-2021 \\
\hline 19.1 & Áreas verdes (hectares) por 100.000 habitantes & 120 & - & OMS (2006) \\
\hline 19.2 & $\begin{array}{l}\text { Número de árvores plantadas anualmente por } 100.000 \\
\text { habitantes }\end{array}$ & 7.500 & 2020 & $\begin{array}{l}\text { Plano de Arborização } \\
\text { Urbana (PMS, 2013a) }\end{array}$ \\
\hline 19.4 & Relação empregos/habitação & 1,7 & - & Melhor - BID (2013) \\
\hline 20.1 & $\begin{array}{l}\text { Porcentagem da população da cidade atendida por } \\
\text { sistemas de coleta e afastamento de esgoto }\end{array}$ & $100 \%$ & 2030 & Meta 6.2 ODS \\
\hline 20.2 & $\begin{array}{l}\text { Porcentagem do esgoto da cidade que não recebeu } \\
\text { qualquer tratamento }\end{array}$ & $0 \%$ & - & Melhor - WCCD (2018) \\
\hline 20.3 & $\begin{array}{l}\text { Porcentagem do esgoto da cidade que recebe } \\
\text { tratamento primário }\end{array}$ & $100 \%$ & - & Melhor - BID (2013) \\
\hline 21.1 & $\begin{array}{l}\text { Porcentagem da população da cidade com serviço de } \\
\text { abastecimento de água potável }\end{array}$ & $100 \%$ & 2030 & Meta 6.1 ODS \\
\hline 21.2 & $\begin{array}{l}\text { Porcentagem da população da cidade com acesso } \\
\text { sustentável a uma fonte de água adequada para } \\
\text { consumo }\end{array}$ & $100 \%$ & 2030 & Meta 6.1 ODS \\
\hline 21.3 & $\begin{array}{l}\text { Porcentagem da população da cidade com acesso a } \\
\text { saneamento melhorado }\end{array}$ & $100 \%$ & 2030 & Meta 6.2 ODS \\
\hline 21.4 & Consumo doméstico total de água per capita (litros/dia) & 120 & - & Melhor - BID (2013) \\
\hline 21.5 & Consumo total de água per capita (litros/dia) & 120 & - & Melhor - BID (2013) \\
\hline 21.6 & $\begin{array}{l}\text { Valor médio anual de horas de interrupção do } \\
\text { abastecimento de água por domicílio }\end{array}$ & 0 & - & Melhor - WCCD (2018) \\
\hline 21.7 & Porcentagem de perdas de água (água não faturada) & $30 \%$ & - & Melhor - BID (2013) \\
\hline
\end{tabular}

Elaborada pela autora.

Para indicadores identificados com tendência favorável na análise de tendência do item 7.1.1, existindo uma meta numérica, pode-se calcular o prazo estimado para atingir a meta, dividindo-se a distância entre o valor atual do indicador e a meta respectiva, e dividindo-se pela taxa. Esta informação também consta no dashboard proposto.

A distância entre o valor numérico do indicador e sua respectiva meta não leva em conta aspectos futuros, importantes para o processo de retrofit urbano. O exemplo disto é o indicador 19.1 - "Porcentagem da população urbana morando em favelas", que em Sorocaba 
é zero e, portanto, já foi atingida a meta ODS 11.1. Com o crescimento populacional previsto para os próximos anos, este indicador pode mudar e a distância indicador-meta constituir novamente um parâmetro para acompanhamento. Há ainda questões intangíveis e imponderáveis, entre a distância indicador-meta, com o aumento populacional e o custo de novos projetos, por exemplo. A meta de longo prazo também pode ser mutável, e metas parciais poderão ser também definidas em consonância com o valor futuro.

\subsubsection{Clustering para Benchmarking de Cidades}

$\mathrm{Na}$ intenção de realizar um tratamento das várias dimensões e variáveis dos indicadores da NBR ISO 37120:2017, elaborou-se uma análise por clustering, a fim de analisar padrões ocultos em dados que podem não ser imediatamente óbvios apenas pela observação, e no sentido de verificar relações entre os indicadores.

\section{Dados do SNIS - Sistema Nacional de Indicadores de Saneamento}

$\mathrm{Na}$ ausência de dados completos dos 100 indicadores da NBR ISO 37120:2017 para várias cidades, ao menos não disponíveis para leitura de máquina, foram selecionados 10 indicadores, para compor um exercício de clustering, com dados disponíveis e passíveis de download do SNIS - Sistema Nacional de Indicadores de Saneamento, que apresenta séries históricas de 2010 a 2016 de todos os 5570 municípios brasileiros. Estes 10 indicadores são relacionados aos temas de resíduos sólidos, esgotos e água, conforme abaixo:

- Seção 16 - Resíduos Sólidos:

○ 16.1 - "Porcentagem da população urbana com coleta regular de lixo (domiciliar)", correspondente ao indicador do SNIS "IN016 - Taxa de cobertura do serviço de coleta de RDO em relação à população urbana"

○ 16.2 - "Total de coleta de resíduos sólidos municipais per capita", correspondente ao indicador do SNIS "IN021 - Massa coletada (RDO + RPU) per capita em relação à população urbana, $\mathrm{kg} / \mathrm{hab}$.dia, convertido em ton/hab.ano", convertido para ton/hab.ano 
○ 16.3 - "Porcentagem de resíduos sólidos urbanos que são reciclados", " "IN031 - Taxa de recuperação de materiais recicláveis (exceto matéria orgânica e rejeitos) em relação à quantidade total (RDO + RPU) coletada"

- Seção 20 - Esgotos:

○ 20.1 - "Porcentagem da população da cidade atendida por sistemas de coleta e afastamento de esgoto", correspondente ao indicador do SNIS "IN024 Índice de atendimento urbano de esgoto referido aos municípios atendidos com água"

○ 20.2 - "Porcentagem do esgoto da cidade que não recebeu qualquer tratamento", correspondente ao indicador do SNIS "IN016 - Índice de tratamento de esgoto", subtraído do total $100 \%$

- Seção 21 - Água e Saneamento:

○ 21.1 - "Porcentagem da população da cidade com serviço de abastecimento de água potável”, correspondente ao indicador do SNIS "IN023 - Índice de atendimento urbano de água"

○ 21.4 - "Consumo doméstico total de água per capita (litros/dia)", calculado com duas informações do SNIS, a saber "AG020 - Volume micromedido nas economias residenciais ativas de água", dado em $1.000 \mathrm{~m} 3 /$ ano e convertido em litros/dia, dividido por "AG001 - População total atendida com abastecimento de água”. Cabe ressalvar que o volume micromedido pode não corresponder à totalidade do consumo doméstico, tendo em vista os domicílios que não estão conectados à rede de distribuição, mas foi adotada esta informação na ausência de maiores dados sobre o indicador.

○ 21.5 - "Consumo total de água per capita (litros/dia)", correspondente ao indicador do SNIS "IN022 - Consumo médio per capita de água"

○ 21.6 - "Valor médio anual de horas de interrupção do abastecimento de água por domicílio", calculado com duas informações do SNIS, a saber "QD003 duração das paralisações (soma das paralisações maiores que 6 horas no ano)" dividido por “AG003 - Quantidade de economias ativas de água"

○ 21.7 - "Porcentagem de perdas de água (água não faturada)", correspondente ao indicador do SNIS "IN049_AE - Índice de perdas na distribuição". Foi adotado o índice de perdas físicas do SNIS (IN049_AE) e não o índice de perdas de faturamento (IN013_AE) pois o texto da NBR ISO 37120:2017 
tem mais aderência ao cálculo de perdas físicas de água na distribuição, apesar do enunciado do indicador 21.7 remeter à ideia de perdas de faturamento

O processo de clustering primeiramente desconsiderou as células vazias, e concatenou nomes de municípios a respectivos Estados, pois há municípios de mesmo nome em Estados diferentes, como por exemplo, Boa Vista de Roraima e Boa Vista da Paraíba. Posteriormente, para os indicadores com dados diferentes de porcentagem, foi realizada uma normalização de valores para a escala 0 a $100 \%$. Por fim, foi realizada uma análise por clustering do tipo Kmeans, por meio do Power BI, para os dados provenientes do SNIS, cujos resultados podem ser podem ser totalmente acessados em: https://bit.ly/2GvPdMA.

Cabe salientar que, para os fins do exercício de clustering realizado nesta pesquisa, o valor de $\mathrm{K}$ para obtenção dos clusters foi deixado no automático no sistema do Power BI, adotando-se o resultado gerado do número $\mathrm{K}$ de clusters em cada seção. Porém, para desenvolvimento e aperfeiçoamento desta análise, deve-se testar, validar e aferir o número de grupos, em cada seção, de modo a obter um valor de $\mathrm{K}$ adequado. Um número de clusters pode aparentemente ser satisfatório, mas um valor de $\mathrm{K}$ diferente pode propiciar um resultado inesperado, revelando um cluster anteriormente oculto (EVERITT, 2011).

Os resultados do clustering destes 10 indicadores são apresentados por seção, a seguir.

\section{Seção 16 - Resíduos Sólidos:}

A coleta de valores considerou alguns filtros:

- 16.1 - Não considerados 17.240 registros vazios das séries históricas.

- 16.2 - Não considerados 12.498 registros vazios das séries históricas e a normalização desprezou medidas menores que 2 ton/hab.ano duas medidas, de 8,38 e 8,41 ton/hab.ano, acima do padrão.

- 16.3 - A normalização desprezou duas medidas acima de $100 \%$, a saber: $116,58 \%$ e $251,25 \%$. 
Apesar de analisar séries históricas de 2010 a 2016, foi realizada a análise por clustering para 2016 com 1.400 municípios, sendo que 1.593 municípios não foram considerados pois não possuem registro para o ano de 2016.

Os resultados para a Seção 16 podem ser observados nas Figuras 62 e 63, a seguir.

Clusters S... • Cluster1 • Cluster2

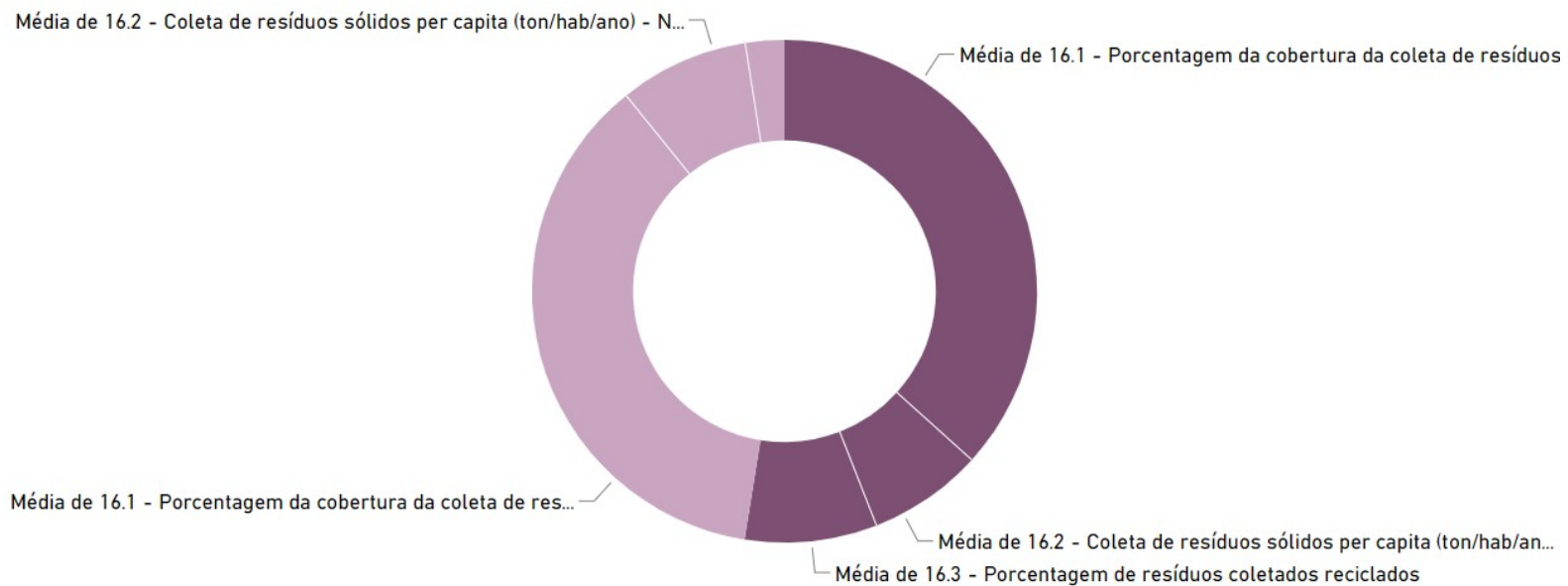

Figura 62: Médias dos indicadores dos clusters com dados do SNIS para a Seção 16 - Resíduos Sólidos

\begin{tabular}{|c|c|c|c|c|c|c|c|}
\hline $\begin{array}{l}\text { Custers } \\
\text { Seçäo } 16\end{array}$ & $\begin{array}{l}\text { Contagem } \\
\text { de } \\
\text { Município- } \\
\text { Estado }\end{array}$ & $\begin{array}{l}\text { Máximo de } \\
16.1 \text { - } \\
\text { Porcentagem } \\
\text { da cobertura } \\
\text { da coleta de } \\
\text { residuos }\end{array}$ & $\begin{array}{l}\text { Mínimo de } \\
16.1 \text { - } \\
\text { Porcentagem } \\
\text { da cobertura } \\
\text { da coleta de } \\
\text { residuos }\end{array}$ & $\begin{array}{l}\text { Máximo de } \\
16.2 \text { - Coleta } \\
\text { de resíduos } \\
\text { sólidos per } \\
\text { capita } \\
\text { (ton/hab/ano) } \\
\text { - Normalizado }\end{array}$ & $\begin{array}{l}\text { Mínimo de } \\
16.2 \text { - Coleta } \\
\text { de resíduos } \\
\text { sólidos per } \\
\text { capita } \\
\text { (ton/hab/ano) } \\
\text { - Normalizado }\end{array}$ & $\begin{array}{l}\text { Máximo de } \\
16.3 \text { - } \\
\text { Porcentagem } \\
\text { de resíduos } \\
\text { coletados } \\
\text { recidados }\end{array}$ & $\begin{array}{l}\text { Mínimo de } \\
16.3 \text { - } \\
\text { Porcentagem } \\
\text { de resíduos } \\
\text { coletados } \\
\text { recidados }\end{array}$ \\
\hline Cluster1 & 251 & 100,00 & 27,22 & 89,25 & 2,50 & 60,00 & 16,85 \\
\hline Cluster2 & 1149 & 100,00 & 16,36 & 96,75 & 2,50 & 18,11 & 0,00 \\
\hline
\end{tabular}

Figura 63: Detalhes dos clusters com dados do SNIS para a Seção 16 - Resíduos Sólidos

Sorocaba pertence ao Cluster 2 da Seção 16, que apresenta os seguintes valores médios:

- 16.1 - "Porcentagem da população urbana com coleta regular de lixo (domiciliar)" igual a $98,57 \%$, e Sorocaba apresenta $100 \%$

- 16.2 - "Total de coleta de resíduos sólidos municipais per capita" igual a 23,47\%. Como este é um valor normalizado, ele corresponde a 0,34 ton/hab.ano, e Sorocaba apresenta 0,31 ton/hab.ano

- $\quad 16.3$ - "Porcentagem de resíduos sólidos urbanos que são reciclados" igual a 5,2\%, e Sorocaba apresenta $1,87 \%$ 
Com estes resultados, é possível concluir que Sorocaba apresenta valores coerentes para os indicadores 16.1 e 16.2, porém necessita de melhoria para o indicador 16.3, aumentando a reciclagem de resíduos sólidos. Comparando com os valores de metas adotadas para os indicadores, de acordo com a Tabela 7, a meta para o indicador 16.3 é $10 \%$ no PPA - Plano Anual de Metas de Sorocaba, frente aos 5,2\% do Cluster 2, ou seja, a meta proposta é mais desafiadora que a situação de outros municípios de mesmas características.

\section{Seção 20 - Esgotos}

Da mesma maneira que a Seção 16, a coleta de valores considerou alguns filtros:

- 20.1 - Não considerados 23.529 registros vazios das séries históricas.

- 20.2 - Não considerados 255 registros vazios das séries históricas e desprezado um valor negativo (menor que zero).

Realizada a análise por clustering para 2016, com 2.493 municípios, sendo que 419 municípios não foram considerados pois não possuem registro para o ano de 2016.

Os resultados para a Seção 20 podem ser observados nas Figuras 64 e 65, a seguir. Como o clustering foi realizado para o ano de 2016 e são somente dois indicadores, é possível observar a evolução dos municípios ao longo da série histórica 2010 a 2016, conforme a sequência dos gráficos de dispersão da Figura 66, também a seguir, em que os eixos horizontal e vertical são os valores para os indicadores 20.1 e 20.2 , respectivamente, e as bolhas são as cidades consideradas, cujo tamanho denota sua população.

Sorocaba pertence ao Cluster 1 da Seção 20, que apresenta os seguintes valores médios:

- 20.1 - "Porcentagem da população da cidade atendida por sistemas de coleta e afastamento de esgoto" igual a $86,85 \%$, e Sorocaba apresenta $97,1 \%$

- 20.2 - "Porcentagem do esgoto da cidade que não recebeu qualquer tratamento", igual a $9,44 \%$, e Sorocaba apresenta $9,2 \%$ 


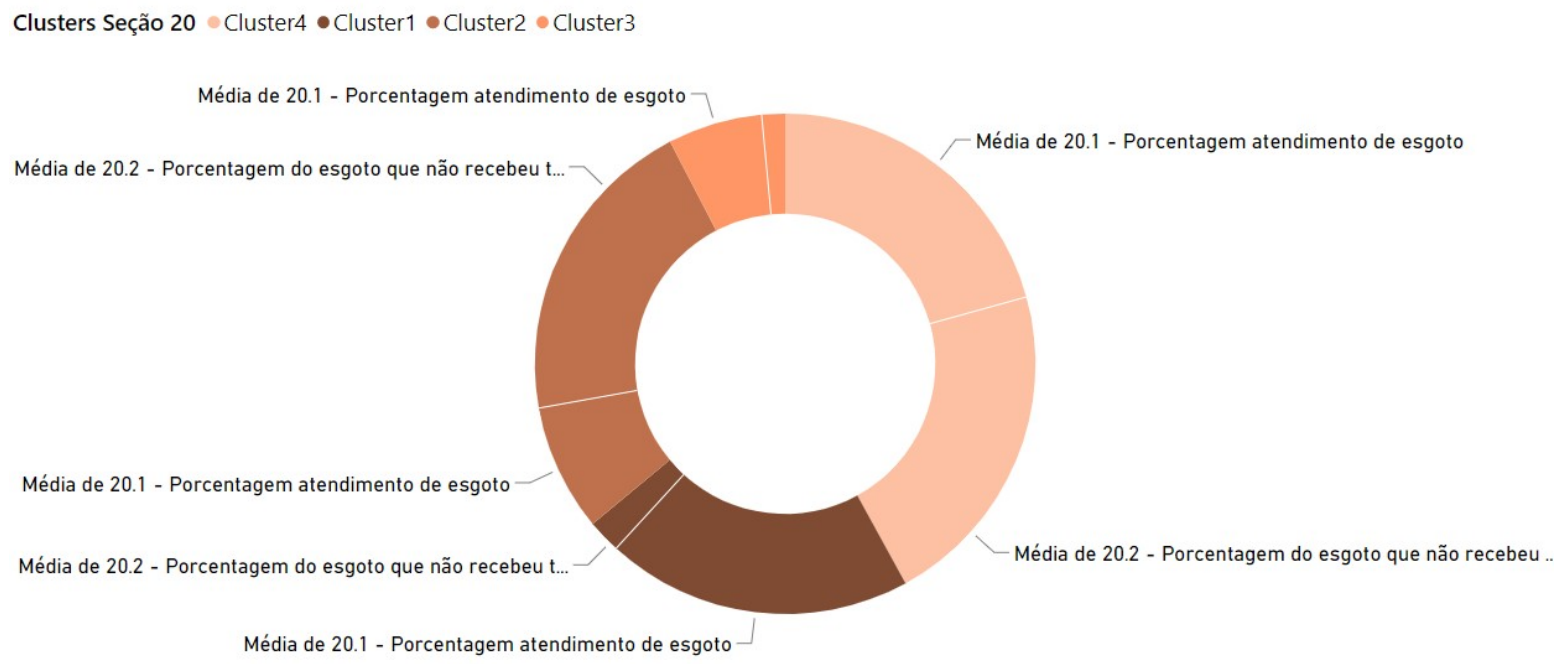

Figura 64: Médias dos indicadores dos clusters com dados do SNIS para a Seção 20 - Esgotos

\begin{tabular}{|c|c|c|c|c|c|}
\hline $\begin{array}{l}\text { Custers } \\
\text { Seçäo } 20\end{array}$ & $\begin{array}{l}\text { Contagem de } \\
\text { Município- } \\
\text { Estado }\end{array}$ & $\begin{array}{l}\text { Máximo de } \\
20.1 \text { - } \\
\text { Porcentagem } \\
\text { atendimento } \\
\text { de esgoto }\end{array}$ & $\begin{array}{l}\text { Mínimo de } \\
20.1 \text { - } \\
\text { Porcentagem } \\
\text { atendimento } \\
\text { de esgoto }\end{array}$ & $\begin{array}{l}\text { Máximo de } \\
20.2 \text { - } \\
\text { Porcentagem } \\
\text { do esgoto } \\
\text { que näo } \\
\text { recebeu } \\
\text { tratamento }\end{array}$ & $\begin{array}{l}\text { Mínimo de } \\
20.2 \text { - } \\
\text { Porcentagem } \\
\text { do esgoto } \\
\text { que näo } \\
\text { recebeu } \\
\text { tratamento }\end{array}$ \\
\hline Cluster1 & 1006 & 100,00 & 59,17 & 50,00 & 0,00 \\
\hline Cluster2 & 193 & 60,64 & 0,00 & 100,00 & 50,00 \\
\hline Cluster3 & 627 & 58,54 & 0,00 & 47,50 & 0,00 \\
\hline Cluster4 & 667 & 100,00 & 60,64 & 100,00 & 50,00 \\
\hline
\end{tabular}

Figura 65: Detalhes dos clusters com dados do SNIS para a Seção 20 - Esgotos

Com estes resultados, é possível concluir que Sorocaba apresenta valor melhor que a média do Cluster 1 para o indicador 20.1, porém necessita de melhoria para o indicador 20.2, aumentando a porcentagem de esgotos tratados. Comparando com os valores de metas adotadas para os indicadores, de acordo com a Tabela 7, a meta para o indicador 20.1 é 100\%, que é o valor máximo para o Cluster 1 da Seção 20, e para o indicador 20.2 é $0 \%$, também o mínimo e melhor valor do Cluster 1. 

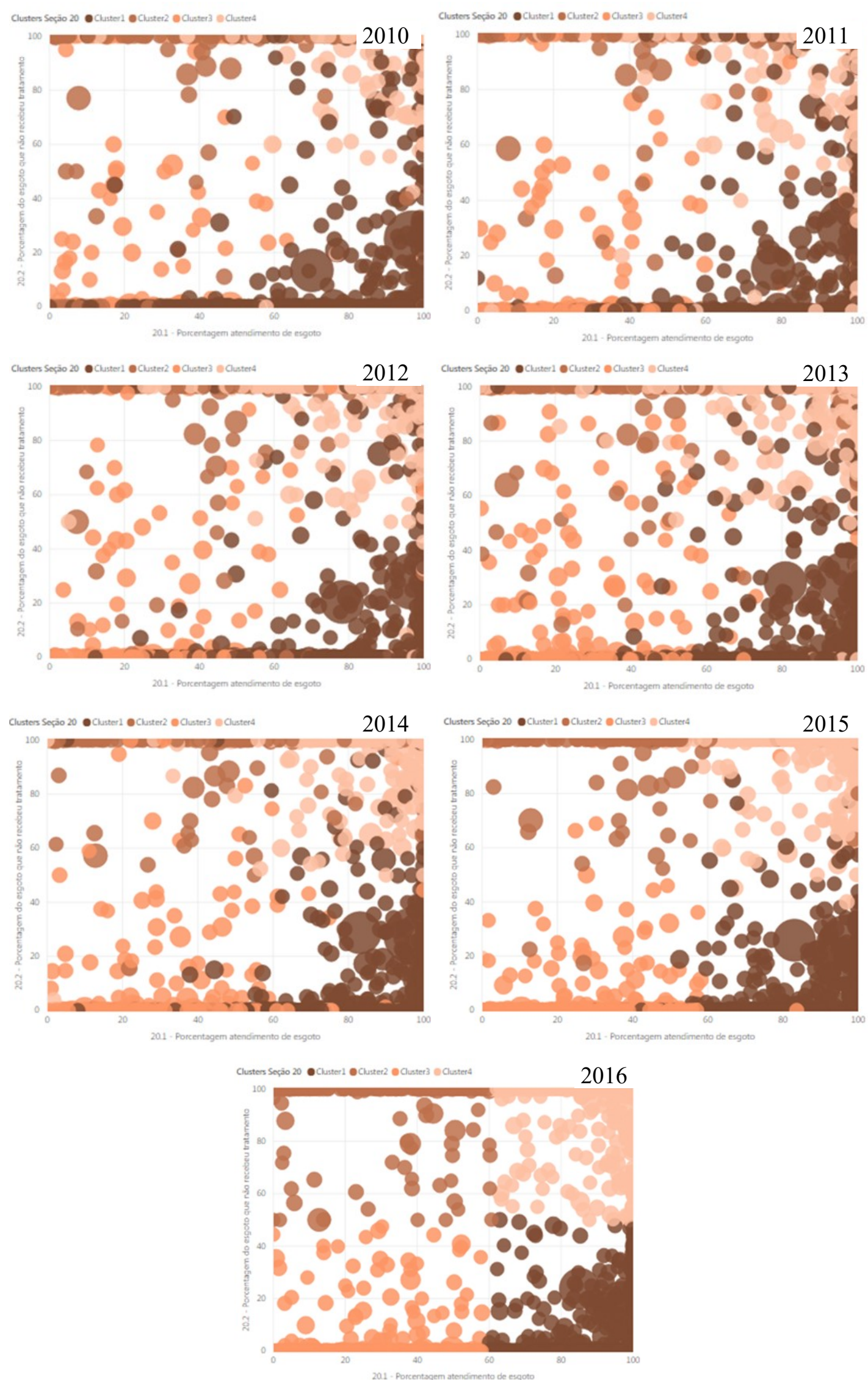

Figura 66: Evolução dos clusters com dados do SNIS para a Seção 20 - Esgotos, ao longo da série histórica 2010 a 2016 


\section{Seção 21 - Água e Saneamento}

Os filtros considerados para a Seção 21 foram:

- 21.1 - Não considerados 3.707 registros vazios das séries históricas. Não consideradas também as células iguais a 0 , além das vazias, por conta de existirem dados diferentes de zero de consumo, ou seja, desconsiderados mais 94 registros.

- 21.4 - Não considerados 4.508 registros vazios das séries históricas. Não consideradas também as células iguais a 0 , além das vazias, por conta de existirem dados diferentes de zero de distribuição, ou seja, desconsiderados mais 8 registros. A normalização desprezou valores abaixo de 0,10 e acima de 300 litros/hab.dia, o que excluiu vários registros superiores, chegando até a surpreendentes 1515,98 litros/hab.dia.

- 21.6 - Não considerados 5.289 registros, pela de ausência de informação do número de domicílios.

- 21.7 - Não considerados 101 registros vazios das séries históricas. Não considerados também valores menores do que zero (perdas negativas), ou seja, desconsiderados mais 51 registros, e não considerados valores iguais a zero, desconsiderados mais 302 registros

Realizada a análise por clustering para 2016, com 3.865 municípios, sendo que 419 municípios não foram considerados pois não possuem registro para o ano de 2016.

Os resultados para a Seção 21 podem ser observados nas Figuras 67 e 68, a seguir.

Sorocaba pertence ao Cluster 2 da Seção 21, que apresenta os seguintes valores médios:

- 21.1 - "Porcentagem da população da cidade com serviço de abastecimento de água potável” igual a $89,03 \%$, e Sorocaba apresenta $99,5 \%$

- 21.4 - "Consumo doméstico total de água per capita (litros/dia)" igual a 20,33\%. Como este é um valor normalizado, ele corresponde a 60,7 litros/hab.dia, e Sorocaba apresenta 150,8 litros/hab.dia.

- 21.5 - "Consumo total de água per capita (litros/dia)" igual a 24,09\%. Como este é um valor normalizado, ele corresponde a 106,8 litros/hab.dia, e Sorocaba apresenta 181,3 litros/hab.dia. 
- 21.6 - "Valor médio anual de horas de interrupção do abastecimento de água por domicílio" igual a $0,33 \%$. Como este é um valor normalizado, ele corresponde a 0,07 horas/domicílio, e Sorocaba apresenta 0,01 horas/domicílio.

- 21.7 - "Porcentagem de perdas de água (água não faturada)" igual a 48,41\%, e Sorocaba apresenta $41 \%$.

Clusters Seção $21 \bullet$ Cluster $2 \bullet$ Cluster1

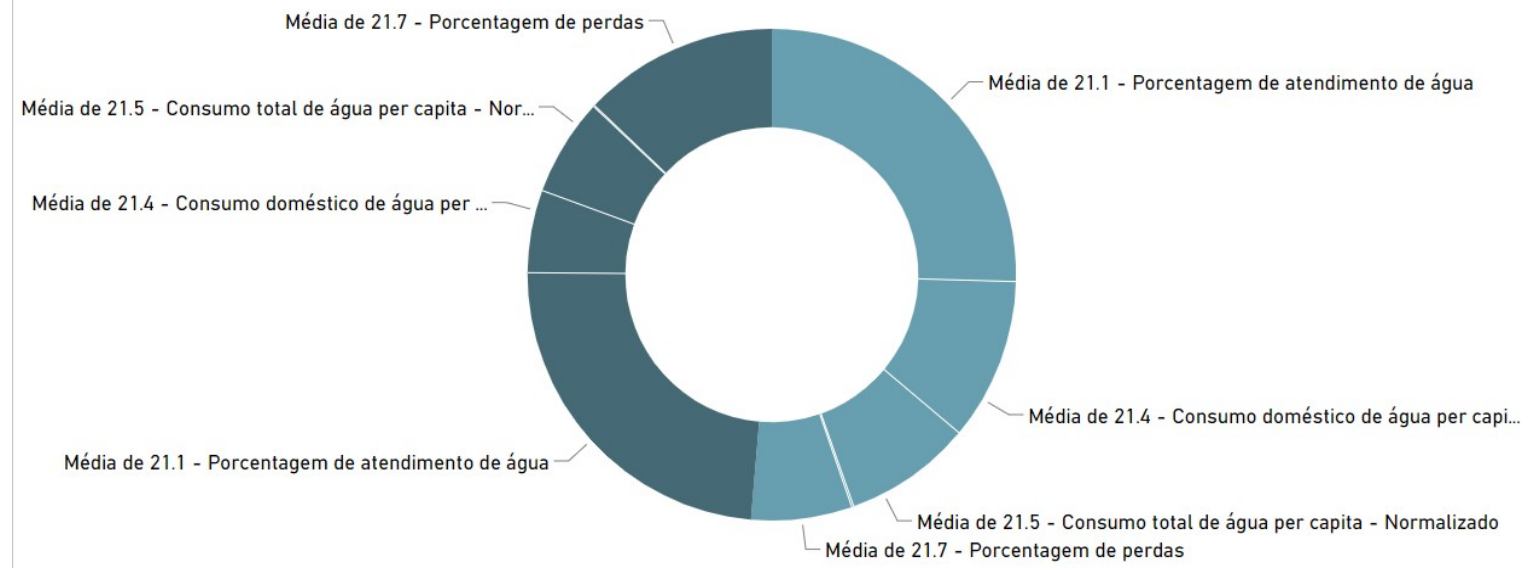

Figura 67: Médias dos indicadores dos clusters com dados do SNIS para a Seção 21 - Água e Saneamento

\begin{tabular}{|c|c|c|c|c|c|c|c|c|c|c|c|}
\hline $\begin{array}{l}\text { Custers } \\
\text { Seçäo } \\
21\end{array}$ & $\begin{array}{l}\text { Contagem } \\
\text { de } \\
\text { Município- } \\
\text { Estado }\end{array}$ & $\begin{array}{l}\text { Máximo } \\
\text { de 21.1 - } \\
\text { Porcenta } \\
\text { gem de } \\
\text { atendime } \\
\text { nto de } \\
\text { água }\end{array}$ & $\begin{array}{l}\text { Mínimo } \\
\text { de } 21.1 \text { - } \\
\text { Porcenta } \\
\text { gem de } \\
\text { atendim } \\
\text { ento de } \\
\text { água }\end{array}$ & $\begin{array}{l}\text { Máximo de } \\
21.4 \text { - } \\
\text { Consumo } \\
\text { doméstico } \\
\text { de água per } \\
\text { Capita - } \\
\text { Normalizado }\end{array}$ & $\begin{array}{l}\text { Mínimo de } \\
21.4 \text { - } \\
\text { Consumo } \\
\text { doméstico } \\
\text { de água per } \\
\text { capita - } \\
\text { Normalizado }\end{array}$ & $\begin{array}{l}\text { Máximo de } \\
21.5 \text { - } \\
\text { Consumo } \\
\text { total de } \\
\text { água per } \\
\text { Capita - } \\
\text { Normalizado }\end{array}$ & $\begin{array}{l}\text { Mínimo de } \\
21.5 \text { - } \\
\text { Consumo } \\
\text { total de } \\
\text { água per } \\
\text { capita - } \\
\text { Normalizado }\end{array}$ & $\begin{array}{l}\text { Máximo } \\
\text { de } 21.6 \text { - } \\
\text { Horas de } \\
\text { interrup } \\
\text { çä - } \\
\text { Normali } \\
\text { zado }\end{array}$ & $\begin{array}{l}\text { Mínimo } \\
\text { de 21.6 - } \\
\text { Horas de } \\
\text { interrup } \\
\text { çäo- } \\
\text { Normali } \\
\text { zado }\end{array}$ & $\begin{array}{l}\text { Máximo } \\
\text { de } 21.7 \text { - } \\
\text { Porcenta } \\
\text { gem de } \\
\text { perdas }\end{array}$ & $\begin{array}{l}\text { Mínimo } \\
\text { de } 21.7 \text { - } \\
\text { Porcenta } \\
\text { gem de } \\
\text { perdas }\end{array}$ \\
\hline Cluster1 & 1294 & 100,00 & 0,70 & 56,80 & 0,02 & 79,10 & 0,77 & 52,12 & 0,00 & 90,35 & 7,51 \\
\hline Cluster2 & 2571 & 100,00 & 20,30 & 99,28 & 1,39 & 100,00 & 2,10 & 100,00 & 0,00 & 93,75 & 0,01 \\
\hline
\end{tabular}

Figura 68: Detalhes dos clusters com dados do SNIS para a Seção 21 - Água e Saneamento

Com estes resultados, é possível concluir que Sorocaba apresenta valores melhores para indicadores 21.1, 21.6 e 21.7, porém necessita de melhoria para os indicadores de consumo 21.4 e 21.5. Comparando com os valores de metas adotadas para os indicadores, de acordo com a Tabela 7, a meta para o indicador 21.1 é $100 \%$ de cobertura e para o indicador 21.6 é 0 (zero) horas/domicílio, o que está coerente com os valores máximo e mínimo, respectivamente, do Cluster 2. Para os demais indicadores, porém, notam-se divergências em relação às metas e recomendações da Tabela 7 , necessitando uma análise mais profunda dos dados brutos do SNIS para estes indicadores. 


\section{Dados do WCCD - World Council on City Data}

Com os mesmos 10 indicadores selecionados para realizar uma análise por clustering dos para os munícipios brasileiros, foram levantados dados das 58 cidades certificadas pelo WCCD, coletados até julho de 2018. Cabe informar que os dados disponibilizados pelo WCCD não são passíveis de leitura de máquina ou de download, sendo necessário coletá-los visual e manualmente a partir de http://open.dataforcities.org. Por ausência de uma série histórica e de dados consolidados para todas as cidades em um único ano, foram coletados os valores mais atuais para os indicadores, independente da data. Há uma variação de dados de 2009 a 2016, o que pode gerar uma distorção, tendo em vista a comparação de dados de um ano para uma cidade e de outro ano para outra.

Similarmente ao processo de clustering para os dados do SNIS, também foram desconsideradas as células vazias. Isto resultou na análise do seguinte número de cidades, para cada Seção:

- Seção 16, consideradas 50 cidades

- Seção 20, consideradas 51 cidades

- Seção 21, consideradas 27 cidades. Buenos Aires foi desconsiderada por apresentar valores inconsistentes para o indicador 21.5, valor de 1006,2 litros/hab.dia, e 21.6, valor de 2258,6 horas/ano.domicílio.

Da mesma forma que o exercício de clustering com dados do SNIS, cabe salientar que o valor de $\mathrm{K}$ para obtenção dos clusters foi deixado no automático no sistema do Power BI, adotando-se o resultado gerado do número K de clusters em cada seção. Novamente, para desenvolvimento e aperfeiçoamento desta análise, deve-se testar, validar e aferir o número de grupos, em cada seção, de modo a obter um valor de K adequado (EVERITT, 2011).

Posteriormente, para os indicadores com dados diferentes de porcentagem, foi realizada uma normalização de valores para a escala 0 a 100\%. Por fim, foi realizada uma análise por clustering do tipo K-means, por meio do Power BI, para os dados provenientes do WCCD, cujos resultados podem ser podem ser totalmente acessados em: https://bit.ly/2LpHXke.

Os resultados do clustering destes 10 indicadores são apresentados por seção, a seguir. 


\section{Seção 16 - Resíduos Sólidos:}

Os resultados para a Seção 16 podem ser observados nas Figuras 69 e 70, a seguir.

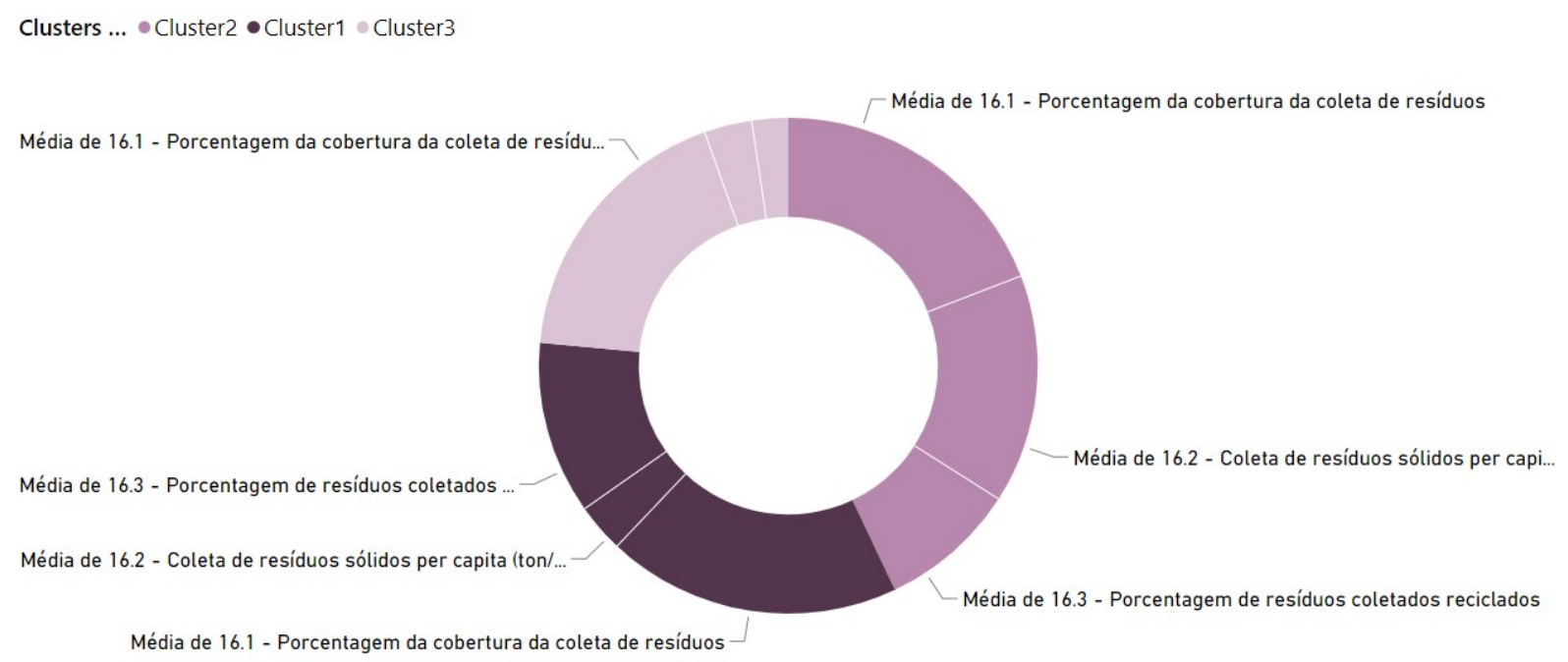

Figura 69: Médias dos indicadores dos clusters com dados do WCCD para a Seção 16 - Resíduos Sólidos

\begin{tabular}{|c|c|c|c|c|c|c|c|}
\hline $\begin{array}{l}\text { Custers } \\
\text { Seçäo } 16\end{array}$ & $\begin{array}{l}\text { Máximo de } \\
16.1 \text { - } \\
\text { Porcentagem } \\
\text { da cobertura } \\
\text { da coleta de } \\
\text { resíduos } \\
\end{array}$ & $\begin{array}{l}\text { Mínimo de } \\
16.1 \text { - } \\
\text { Porcentagem } \\
\text { da cobertura } \\
\text { da coleta de } \\
\text { residuos }\end{array}$ & $\begin{array}{l}\text { Máximo de } \\
16.2 \text { - Coleta } \\
\text { de residuos } \\
\text { sólidos per } \\
\text { capita } \\
\text { (ton/hab/ano) } \\
\text { - Normalirado }\end{array}$ & $\begin{array}{l}\text { Mínimo de } \\
16.2 \text { - Coleta } \\
\text { de residuos } \\
\text { s6́lidos per } \\
\text { capita } \\
\text { (ton/hab/ano) } \\
\text { - Normalrado }\end{array}$ & $\begin{array}{l}\text { Máximo de } \\
16.3 \text { - } \\
\text { Porcentagem } \\
\text { de residuos } \\
\text { coletados } \\
\text { reciclados }\end{array}$ & $\begin{array}{l}\text { Mínimo de } \\
16.3 \text { - } \\
\text { Porcentagem } \\
\text { de residuos } \\
\text { coletados } \\
\text { reciclados }\end{array}$ & $\begin{array}{l}\text { Contagem } \\
\text { de Cidade }\end{array}$ \\
\hline Cluster1 & 100,00 & 98,00 & 29,94 & 1,91 & 90,32 & 36,50 & 17 \\
\hline Cluster2 & 100,00 & 100,00 & 100,00 & 53,50 & 98,64 & 1,76 & 5 \\
\hline Cluster3 & 100,00 & 19,56 & 36,94 & 0,00 & 30,56 & 0,00 & 29 \\
\hline
\end{tabular}

Figura 70: Detalhes dos clusters com dados do WCCD para a Seção 16 - Resíduos Sólidos

Sorocaba pertence ao Cluster 3 da Seção 16, que apresenta os seguintes valores médios:

- 16.1 - "Porcentagem da população urbana com coleta regular de lixo (domiciliar)" igual a $94,59 \%$, e Sorocaba apresenta $100 \%$

- 16.2 - "Total de coleta de resíduos sólidos municipais per capita” igual a 16,21\%. Como este é um valor normalizado, ele corresponde a 0,36 ton/hab.ano, e Sorocaba apresenta 0,31 ton/hab.ano

- 16.3 - "Porcentagem de resíduos sólidos urbanos que são reciclados" igual a $12,32 \%$, e Sorocaba apresenta $1,87 \%$ 
Com estes resultados, é possível concluir que Sorocaba novamente apresenta valores coerentes para os indicadores 16.1 e 16.2, porém necessita de melhoria para o indicador 16.3, aumentando a reciclagem de resíduos sólidos. Comparando com os valores de metas adotadas para os indicadores, de acordo com a Tabela 7, a meta para o indicador 16.3 é $10 \%$ no PPA de Sorocaba, frente aos $12,32 \%$ do Cluster 3 e aos 5,2\% do Cluster 2 da Seção 16 com dados do SNIS, ou seja, a meta proposta é mais desafiadora em comparação com municípios brasileiros de mesmas características, mas a meta é mais conservadora no âmbito internacional.

\section{Seção 20 - Esgotos}

Os resultados para a Seção 20 podem ser observados nas Figuras 71 e 72, a seguir.

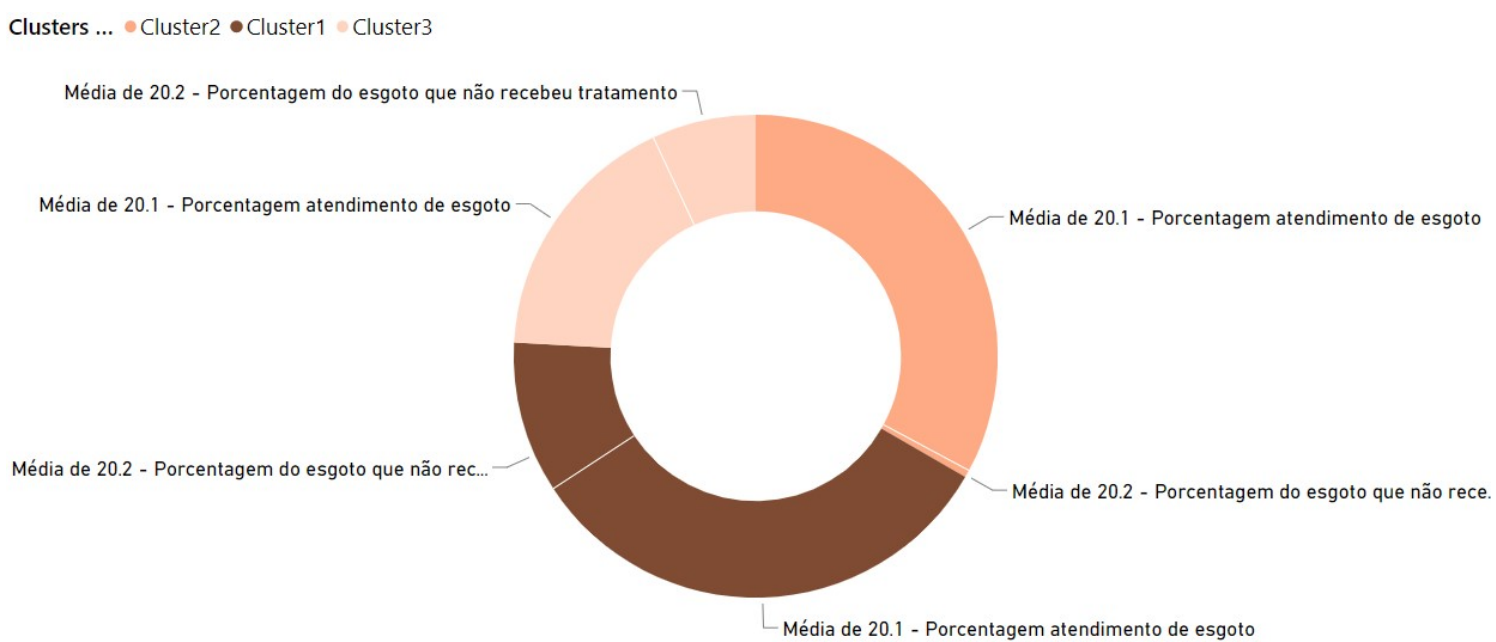

Figura 71: Médias dos indicadores dos clusters com dados do WCCD para a Seção 20 - Esgotos

\begin{tabular}{|c|c|c|c|c|c|}
\hline $\begin{array}{l}\text { Custers } \\
\text { Seçäo } 20\end{array}$ & $\begin{array}{l}\text { Máximo de } 20.1 \\
\text { - Porcentagem } \\
\text { atendimento de } \\
\text { esgoto }\end{array}$ & $\begin{array}{l}\text { Mínimo de } 20.1 \\
\text { - Porcentagem } \\
\text { atendimento de } \\
\text { esgoto }\end{array}$ & $\begin{array}{l}\text { Máximo de } 20.2 \text { - } \\
\text { Porcentagem do } \\
\text { esgoto que näo } \\
\text { recebeu } \\
\text { tratamento }\end{array}$ & $\begin{array}{l}\text { Mínimo de } 20.2 \text { - } \\
\text { Porcentagem do } \\
\text { esgoto que não } \\
\text { recebeu } \\
\text { tratamento }\end{array}$ & $\begin{array}{l}\text { Contagem } \\
\text { de Cidade }\end{array}$ \\
\hline Cluster1 & 100,00 & 84,00 & 89,90 & 0,00 & 8 \\
\hline Cluster2 & 100,00 & 80,65 & 25,00 & 0,00 & 39 \\
\hline Cluster3 & 68,00 & 36,92 & 100,00 & 0,00 & 5 \\
\hline
\end{tabular}

Figura 72: Detalhes dos clusters com dados do WCCD para a Seção 20 - Esgotos 
Sorocaba pertence ao Cluster 2 da Seção 20, que apresenta os seguintes valores médios:

- 20.1 - "Porcentagem da população da cidade atendida por sistemas de coleta e afastamento de esgoto" igual a 96,12\%, e Sorocaba apresenta 97,1\%

- 20.2 - "Porcentagem do esgoto da cidade que não recebeu qualquer tratamento", igual a $1,42 \%$, e Sorocaba apresenta $9,2 \%$

Com estes resultados, é possível concluir que Sorocaba apresenta valores adequados para ambos indicadores. Comparando com os valores de metas adotadas para os indicadores, de acordo com a Tabela 7, a meta para o indicador 20.1 é $100 \%$, que é o valor máximo para o Cluster 2 da Seção 20, e para o indicador 20.2 é 0\%, também o mínimo e melhor valor do Cluster 1.

\section{Seção 21 - Água e Saneamento}

Os resultados para a Seção 21 podem ser observados nas Figuras 73 e 74, a seguir.

Sorocaba pertence ao Cluster 1 da Seção 21, que apresenta os seguintes valores médios:

- 21.1 - "Porcentagem da população da cidade com serviço de abastecimento de água potável" igual a 99,65\%, e Sorocaba apresenta 99,5\%

- 21.4 - "Consumo doméstico total de água per capita (litros/dia)" igual a 31,81\%. Como este é um valor normalizado, ele corresponde a 150,8 litros/hab.dia, exatamente o valor apresentado em Sorocaba

- 21.5 - "Consumo total de água per capita (litros/dia)" igual a 38,07\%. Como este é um indicador normalizado, ele corresponde a 255,8 litros/hab.dia, e Sorocaba apresenta 181,3 litros/hab.dia

- 21.6 - "Valor médio anual de horas de interrupção do abastecimento de água por domicílio" igual a 1,55\%. Como este é um indicador normalizado, ele corresponde a 1,2 horas, e Sorocaba apresenta 0,01 horas

- 21.7 - "Porcentagem de perdas de água (água não faturada)" igual a 22,78\%, e Sorocaba apresenta o valor de $41 \%$ 


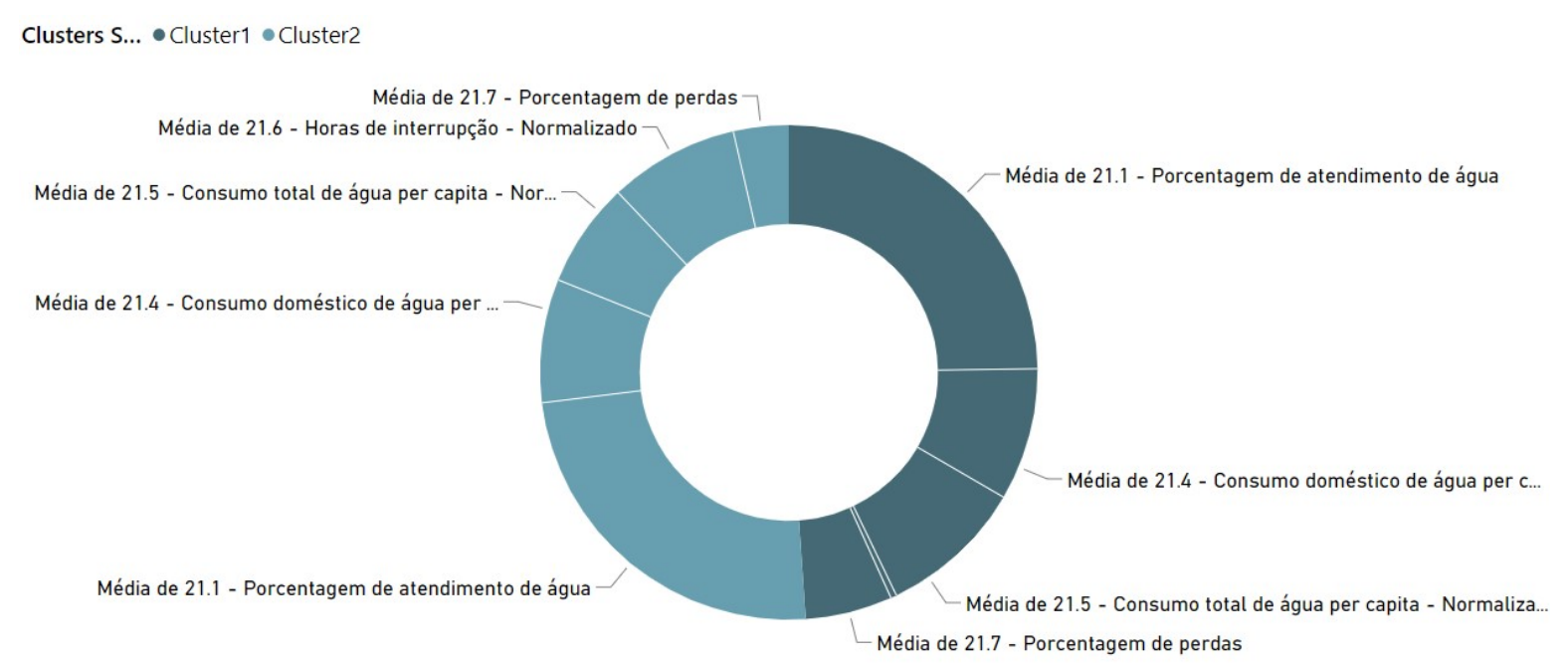

Figura 73: Médias dos indicadores dos clusters com dados do WCCD para a Seção 21 - Água e Saneamento

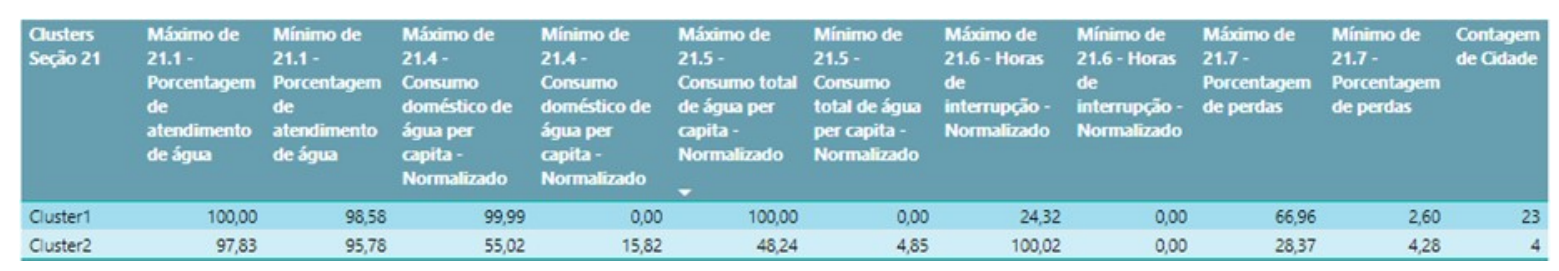

Figura 74: Detalhes dos clusters com dados do WCCD para a Seção 21 - Água e Saneamento

Com estes resultados, é possível concluir que Sorocaba apresenta valores coerentes para os indicadores 21.1 e 21.2, valor muito melhor para o indicador 21.6, porém necessita de melhoria para os indicadores 21.5 e 21.7 , reduzindo o consumo total de água e combatendo as perdas. Cabe lembrar que o indicador 21.6, quando levantado pelos valores do SNIS para Sorocaba, apresenta uma divergência de método, pois pelo SNIS são computadas somente interrupções de mais de 6 horas, e os números do WCCD consideram a metodologia da ISO 37120:2014, de somar todas as horas de todas as interrupções, independente da magnitude. Comparando com os valores de metas adotadas para os indicadores, de acordo com a Tabela 7, as metas das fronteiras de eficiência estão mais próximas dos valores médios do Cluster 1 do que dos valores melhores, máximo para alguns indicadores e mínimo para outros.

\section{Seções 16, 20 e 21}

Diferentemente dos dados do SNIS, para muitos municípios e com o registro de 7 anos de série histórica, foi possível agregar os 10 indicadores e realizar uma análise por clustering para as 3 Seções ao mesmo tempo. Esta análise simultânea para os 10 indicadores das Seções 
16, 20 e 21 resultou em 3 clusters, que somam 26 cidades conforme Tabela 8, agregadas conforme ilustra a Figura 75.

Tabela 8: Clusters com dados do WCCD para as Seções 16, 20 e 21

\begin{tabular}{||c|c||}
\hline Clusters & Número de cidades \\
\hline \hline Cluster 1 & 7 \\
\hline Cluster 2 & 15 \\
\hline Cluster 3 & 4 \\
\hline Total & 26 \\
\hline
\end{tabular}

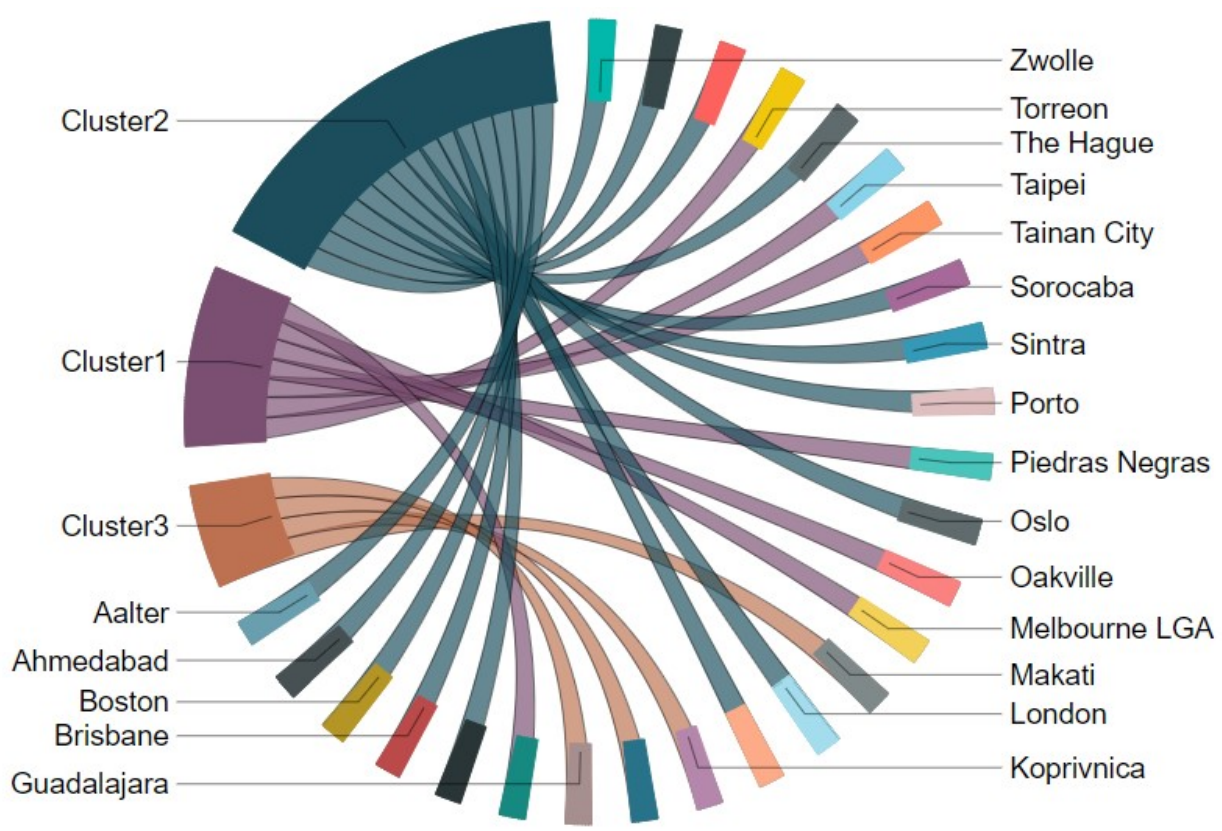

Figura 75: As 26 cidades agregadas nos 3 clusters com dados do WCCD para as Seções 16, 20 e 21

Os detalhes de cada um dos 3 clusters para os indicadores de cada Seção podem ser observados nas Figuras 76, 77 e 78, a seguir.

\begin{tabular}{|c|c|c|c|c|c|c|}
\hline Custers & $\begin{array}{l}\text { Máximo de } \\
16.1 \text { - } \\
\text { Porcentagem } \\
\text { da cobertura } \\
\text { da coleta de } \\
\text { residuos }\end{array}$ & $\begin{array}{l}\text { Mínimo de } \\
\text { 16.1 - } \\
\text { Porcentagem } \\
\text { da cobertura } \\
\text { da coleta de } \\
\text { residuos }\end{array}$ & $\begin{array}{l}\text { Máximo de } \\
16.2 \text { - Coleta } \\
\text { de residuos } \\
\text { sólidos per } \\
\text { capita } \\
\text { (ton/hab/ano) } \\
\text { - Normalirado }\end{array}$ & $\begin{array}{l}\text { Mínimo de } \\
16.2 \text { - Coleta } \\
\text { de resíduos } \\
\text { sólidos per } \\
\text { capita } \\
\text { (ton/hab/ano) } \\
\text { - Normalizado }\end{array}$ & $\begin{array}{l}\text { Máximo de } \\
\text { 16.3 - } \\
\text { Porcentagem } \\
\text { de resíduos } \\
\text { coletados } \\
\text { reciclados }\end{array}$ & $\begin{array}{l}\text { Mínimo de } \\
16.3 \text { - } \\
\text { Porcentagem } \\
\text { de residuos } \\
\text { coletados } \\
\text { recidados } \\
\end{array}$ \\
\hline Cluster1 & 100,00 & 98,77 & 80,25 & 3,18 & 98,64 & 16,43 \\
\hline Cluster2 & 100,00 & 98,00 & 33,76 & 1,91 & 81,33 & 0,00 \\
\hline Cluster3 & 100,00 & 88,40 & 17,83 & 9,55 & 26,85 & 0,00 \\
\hline
\end{tabular}

Figura 76: Detalhes dos clusters com dados do WCCD para as Seções 16, 20 e 21, para indicadores da Seção 16 


\begin{tabular}{|lrrrrr|}
\hline Custers & $\begin{array}{l}\text { Máximo de 20.1 } \\
\text { - Porcentagem } \\
\text { atendimento de } \\
\text { esgoto }\end{array}$ & $\begin{array}{l}\text { Mínimo de 20.1 } \\
\text { - Porcentagem } \\
\text { atendimento de } \\
\text { esgoto }\end{array}$ & $\begin{array}{l}\text { Máximo de 20.2 - } \\
\text { Porcentagem do } \\
\text { esgoto que não } \\
\text { recebeu } \\
\text { tratamento }\end{array}$ & $\begin{array}{l}\text { Mínimo de 20.2 - } \\
\begin{array}{l}\text { Porcentagem do } \\
\text { esgoto que não } \\
\text { recebeu } \\
\text { tratamento }\end{array}\end{array}$ \\
\hline Cluster1 & 100,00 & 36,92 & 4,02 & 0,00 \\
\hline Cluster2 & 100,00 & 80,65 & 25,00 & 0,00 \\
\hline Cluster3 & 97,16 & 39,81 & 100,00 & 0,00 \\
\hline
\end{tabular}

Figura 77: Detalhes dos clusters com dados do WCCD para as Seções 16, 20 e 21, para indicadores da Seção 20

\begin{tabular}{|c|c|c|c|c|c|c|c|c|c|c|}
\hline Custers & $\begin{array}{l}\text { Máximo de } \\
21.1 \text { - } \\
\text { Porcentagem } \\
\text { de } \\
\text { atendimento } \\
\text { de água }\end{array}$ & $\begin{array}{l}\text { Mínimo de } \\
21.1 \text { - } \\
\text { Porcentagem } \\
\text { de } \\
\text { atendimento } \\
\text { de água }\end{array}$ & $\begin{array}{l}\text { Máximo de } \\
21.4 \text { - } \\
\text { Consumo } \\
\text { doméstico de } \\
\text { água per } \\
\text { capita - } \\
\text { Normalizado }\end{array}$ & $\begin{array}{l}\text { Mínimo de } \\
21.4 \text { - } \\
\text { Consumo } \\
\text { doméstico de } \\
\text { água per } \\
\text { capita - } \\
\text { Normalizado }\end{array}$ & $\begin{array}{l}\text { Máximo de } \\
21.5 \text { - } \\
\text { Consumo total } \\
\text { de água per } \\
\text { capita - } \\
\text { Normalizado } \\
\text { - }\end{array}$ & $\begin{array}{l}\text { Mínimo de } \\
21.5 \text { - } \\
\text { Consumo } \\
\text { total de água } \\
\text { per capita - } \\
\text { Normalizado }\end{array}$ & $\begin{array}{l}\text { Máximo de } \\
21.6 \text { - Horas } \\
\text { de } \\
\text { internupçāo - } \\
\text { Normalizado }\end{array}$ & $\begin{array}{l}\text { Mínimo de } \\
21.6 \text { - Horas } \\
\text { de } \\
\text { internupçäo- } \\
\text { Normalizado }\end{array}$ & $\begin{array}{l}\text { Máximo de } \\
21.7 \text { - } \\
\text { Porcentagem } \\
\text { de perdas }\end{array}$ & $\begin{array}{l}\text { Mínimo de } \\
21.7 \text { - } \\
\text { Porcentagem } \\
\text { de perdas }\end{array}$ \\
\hline Cluster1 & 100,00 & 98,58 & 99,99 & 26,24 & 100,00 & 25,08 & 24,32 & 0,00 & 54,88 & 7,43 \\
\hline Cluster2 & 100,00 & 98,71 & 39,48 & 0,00 & 55,68 & 0,00 & 1,17 & 0,00 & 66,96 & 2,60 \\
\hline
\end{tabular}

Figura 78: Detalhes dos clusters com dados do WCCD para as Seções 16, 20 e 21, para indicadores da Seção 21

Sorocaba pertence ao Cluster 2, que apresenta as médias para os indicadores conforme Figura 79.

\begin{tabular}{|c|c|c|c|c|c|c|c|c|c|c|}
\hline Clusters & $\begin{array}{l}\text { Média de } 16.1 \text { - } \\
\text { Porcentagem da } \\
\text { cobertura da } \\
\text { coleta de } \\
\text { resíduos }\end{array}$ & $\begin{array}{l}\text { Média de } 16.2 \text { - } \\
\text { Coleta de } \\
\text { resíduos sólidos } \\
\text { per capita } \\
\text { (ton/hab/ano) - } \\
\text { Normalizado }\end{array}$ & $\begin{array}{l}\text { Média de } 16.3 \text { - } \\
\text { Porcentagem de } \\
\text { resíduos } \\
\text { coletados } \\
\text { reciclados }\end{array}$ & $\begin{array}{l}\text { Média de } 20.1 \text { - } \\
\text { Porcentagem } \\
\text { atendimento de } \\
\text { esgoto }\end{array}$ & $\begin{array}{l}\text { Média de } 20.2 \text { - } \\
\text { Porcentagem do } \\
\text { esgoto que não } \\
\text { recebeu } \\
\text { tratamento }\end{array}$ & $\begin{array}{l}\text { Média de } 21.1 \text { - } \\
\text { Porcentagem de } \\
\text { atendimento de } \\
\text { água }\end{array}$ & $\begin{array}{l}\text { Média de } 21.4 \text { - } \\
\text { Consumo } \\
\text { doméstico de } \\
\text { água per capita } \\
\text { - Normalizado }\end{array}$ & $\begin{array}{l}\text { Média de } 21.5 \text { - } \\
\text { Consumo total } \\
\text { de água per } \\
\text { capita - } \\
\text { Normalizado }\end{array}$ & $\begin{array}{l}\text { Média de } 21.6 \text { - } \\
\text { Horas de } \\
\text { interrupção- } \\
\text { Normalizado }\end{array}$ & $\begin{array}{l}\text { Média de } 21.7 \text { - } \\
\text { Porcentagem } \\
\text { de perdas }\end{array}$ \\
\hline Cluster1 & 99,82 & 31,57 & 49,08 & 87,56 & 0,57 & 99,46 & 60,45 & 65,87 & 4,52 & 17,01 \\
\hline Cluster2 & 99,60 & 17,07 & 31,89 & 96,92 & 3,37 & 99,71 & 23,94 & 26,59 & 0,26 & 26,55 \\
\hline Cluster3 & 95,74 & 13,06 & 8,42 & 67,47 & 30,25 & 97,05 & 32,47 & 27,58 & 34,03 & 14,43 \\
\hline Total & 99,07 & 20,36 & 32,91 & 89,87 & 6,75 & 99,23 & 35,08 & 37,32 & 6,61 & 22,12 \\
\hline
\end{tabular}

Figura 79: Médias dos indicadores dos clusters com dados do WCCD para as Seções 16, 20 e 21

Os valores médios, mínimos e máximos do Cluster 2 para as 3 Seções simultaneamente, quando comparados com a situação de Sorocaba, não diferem muito dos valores analisados no clustering por Seção. Isto se explica pela natureza dos 10 indicadores selecionados, todos referentes a aspectos de saneamento ambiental. Talvez o comportamento do clustering entre seções pontue questões distintas se inseridos indicadores de economia ou governança, por exemplo. 


\subsection{Resultado da Aplicação do Método para Retrofit Urbano em Sorocaba}

Conforme informado anteriormente, o dashboard final para o método para retrofit urbano, desenvolvido em Power BI, apresenta os dados e resultados podem ser totalmente acessados em: https://bit.ly/2EDnZ4J.

Desconsiderando os 29 indicadores em que não foi possível encontrar dados, ou não há disponibilidade de dados para ao menos 3 anos para a análise de tendência, para Sorocaba, a simulação pontua 33 indicadores com resultado bom boa (verde), 34 médio (amarelo) e 4 com resultado ruim (vermelho). Os 71 indicadores correspondem a 35 essenciais e 36 de apoio. Dos 46 indicadores essenciais, dos quais 35 apresentam dados suficientes para análise em Sorocaba, são divididos entre 20 com resultado bom, 14 médio e 1 ruim. Dos 54 indicadores de apoio, reduzidos a 36 com dados suficientes para análise, o resultado é bom para 13 indicadores, médio para 20 e ruim para 3. A Figura 80 mostra estes resultados e também um exemplo de classificação final dos indicadores de somente uma Seção da NBR ISO 37120:2017, no caso novamente a Seção 21 - “Água e Saneamento”, possível nas opções de navegação do dashboard. 
Todos os indicadores:

Indicadores Essenciais:

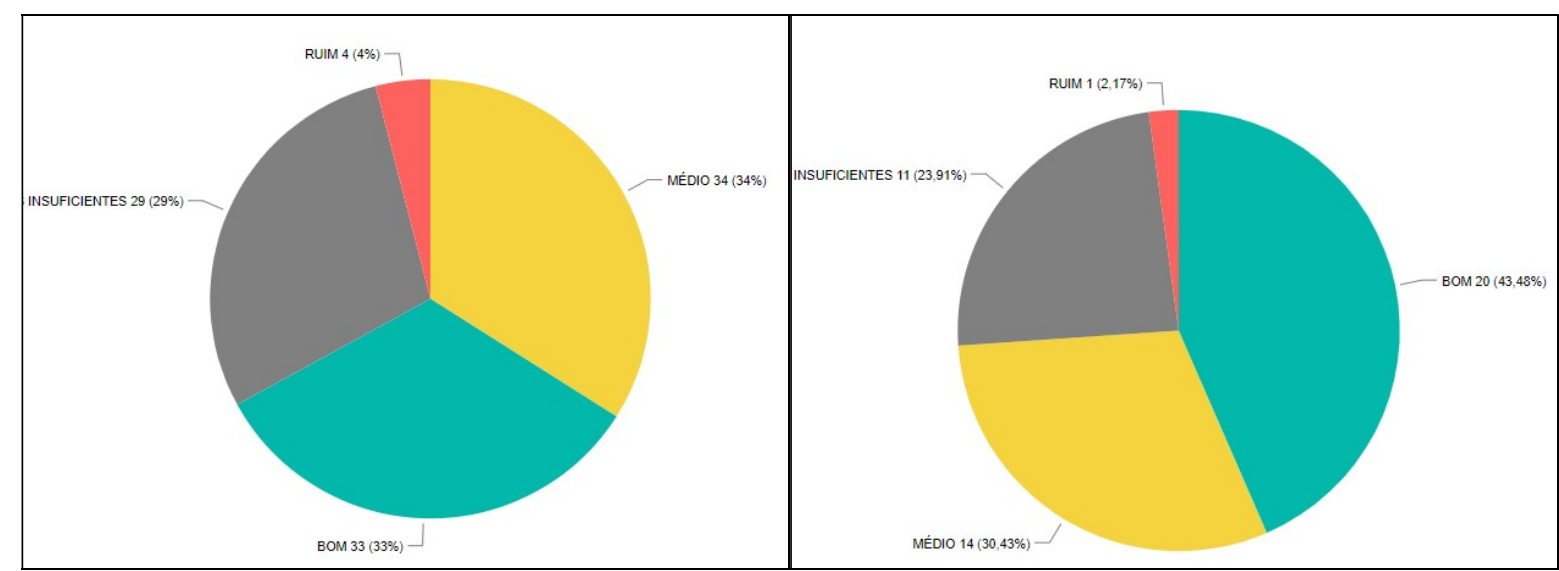

Indicadores de apoio:

Indicadores da Seção 21:

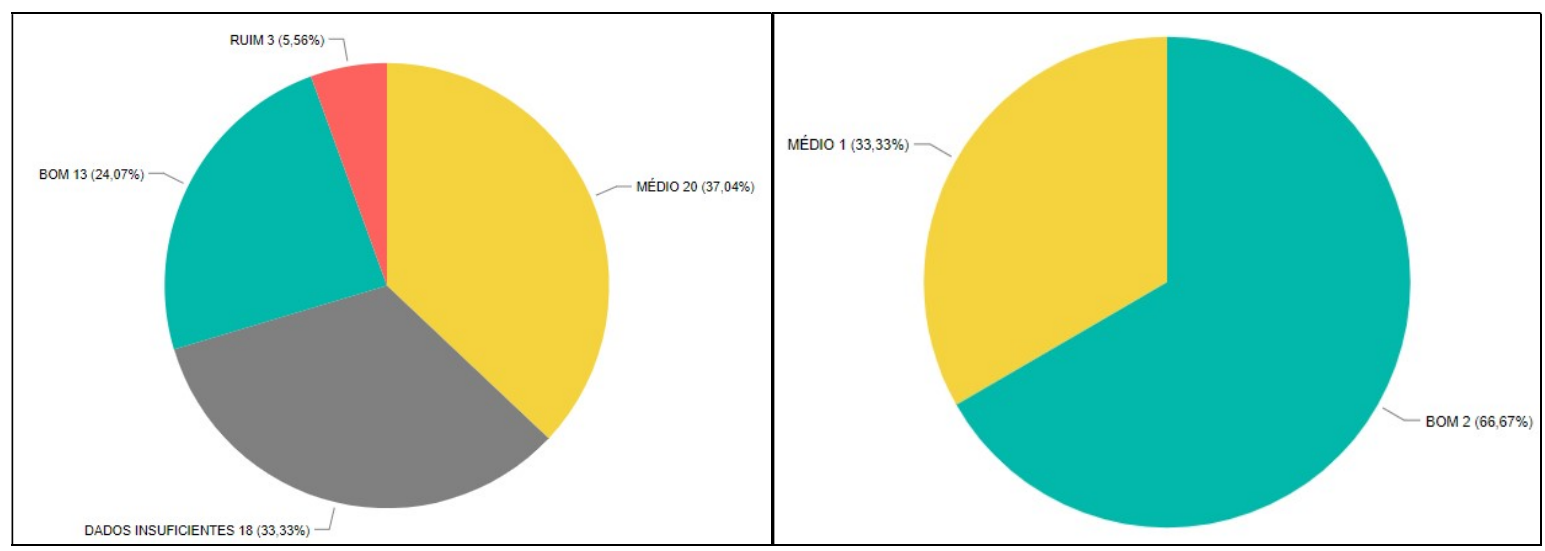

Figura 80: Resultados da classificação final do método para retrofit urbano para os 100 indicadores da NBR ISO 37120:2017 com dados de Sorocaba.

O dashboard final pode ser observado nas Figuras 81, 82, 83, 84 e 85, a seguir, que exemplificam as várias situações em que a classificação de tendência e a classificação final dos indicadores podem se apresentar. 


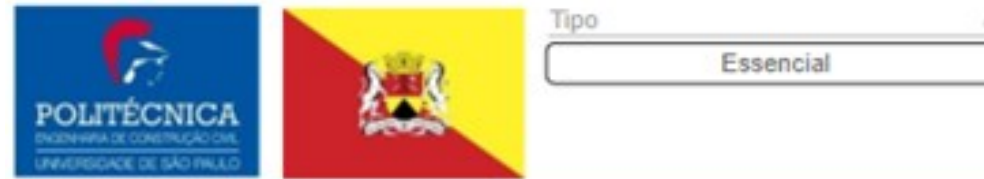

Seçẫo Tema

$\square 6.6$ - Porcentagem de populaç̧̄o em idade escolar matriculada em escolas

ㅁ. 6.7 - Número de indivíduos com ensino superior completo por 100,000 habitantes

口 07 - Energia

7.1 - Uso de energia elëtrica residencial total per capita (kWh/ano)

- 7.2 . Porcentagem de habitantes da cidade com fornecimento regular de energia eli

$\square 7.3$ - Consumo de energia de edifícios públicos por ano (kWh/m2)

$\square 7.4$ - Porcentagem da energia total proveniente de fontes renováveis, como parte di

ㅁ 7.5 - Uso total de energia eiétrica per capita (kWh/ano)

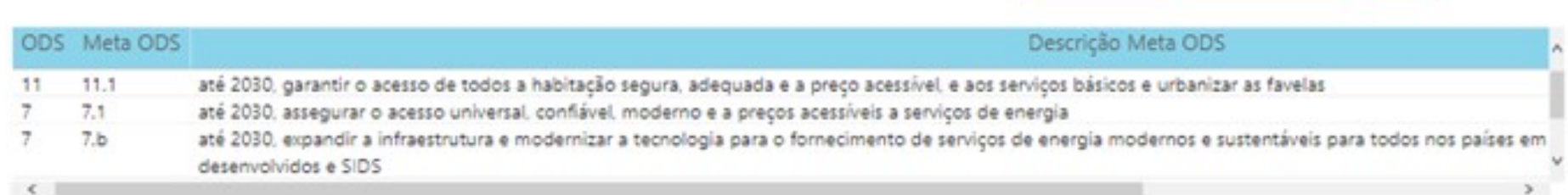

$<$ desetivalvidos esios

- Tandencia,MMS $\bullet$ valores

1000

(1000

99.9

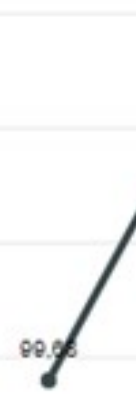

2010

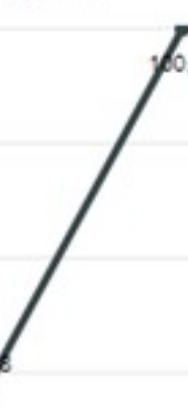

100,00
wCeD (2018)
Média Bras

SDSN (2016)

99,50

Melhores Práticas

\author{
BID (2013) \\ SDSN (2016) \\ 2013)
}

100.0

80.0

70.0

100,0

9.0

100.0

96.7

57.0

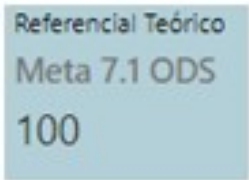

Tendência

Unidade

$\%$

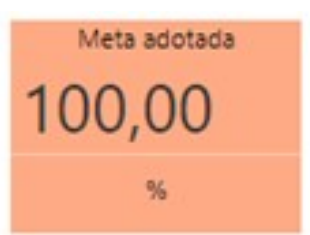

Estimativa

(Vazio)

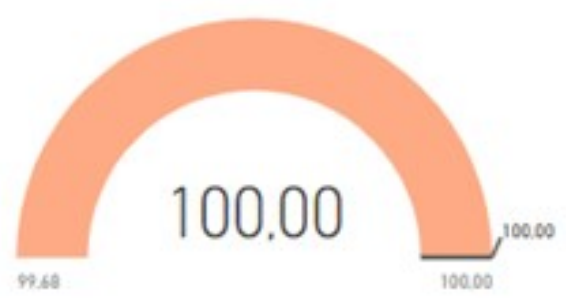

Resultado Fina

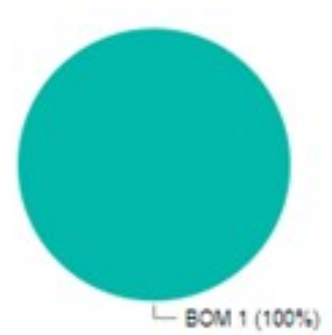

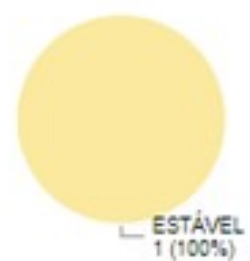

Figura 81: Dashboard para o indicador 7.2 - "Porcentagem de habitantes da cidade com fornecimento regular de energia elétrica", exemplo de tendência estável. 


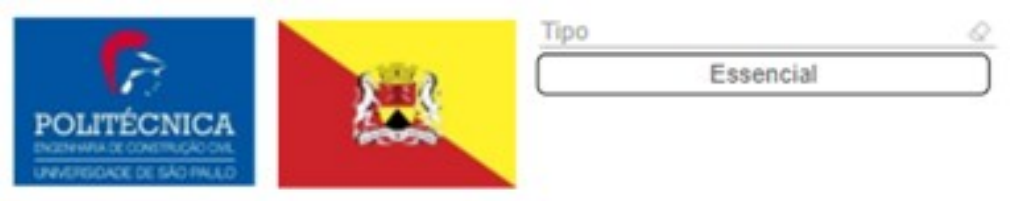

Seçằ Tema

口 08 - Meio Ambiente

$\square 8.1$. Concentração de material particulado fino (PM 2.5)

- 8.2 - Concentraçäo de material particulado (PM 10)

$\square 8.3$ - Emissão de gases de efeito de estufa medida em toneladas per capita

ㅁ.4. - Concentração de $\mathrm{NO} 2$ (dióxido de nitrogènio)

$\square 8.5$. Concentração de $\mathrm{SO} 2$ (dióxido de enxofre)

ㅁ 8.6 - Concentração de $\mathrm{O} 3$ (ozônio)

ㅁ 8.7 - Poluiçăo sonora

\section{ODS Meta ODS}

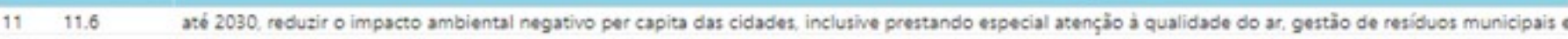
3.92030 .edusir substancialmente o número de mortes e doenças por produtos quimicos perigosos contaminaça e poluiça do are bigua do solo

- Tendincia MMMS • valoces

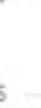

35

30

25

20
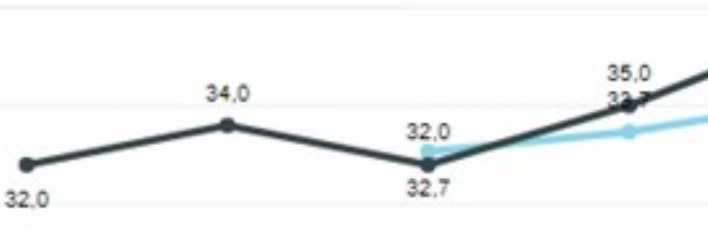

32,7

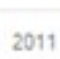

2012

2013

BID (2013)

50.0

100.0

150.0

WCCD (2018)

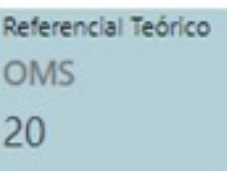

Média Bras
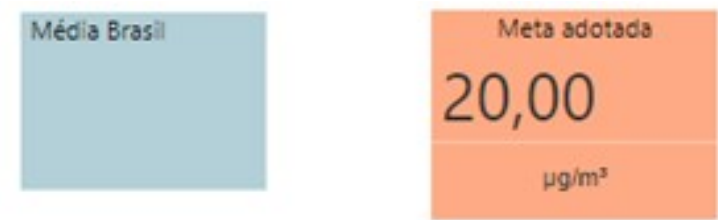

2021

Melhores Práticas

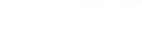

\section{Descrição Meta ODS}

66.0

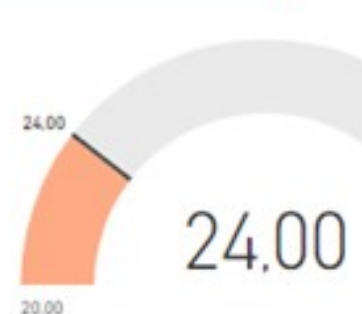

Resultado Final

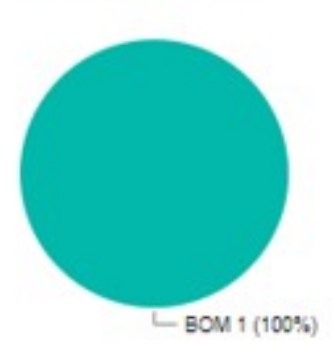

Tendência
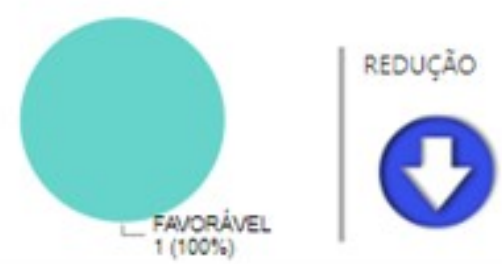

Figura 82: Dashboard para o indicador 8.2 - "Concentração de material particulado (PM 10)", exemplo de tendência favorável e resultado final bom. 


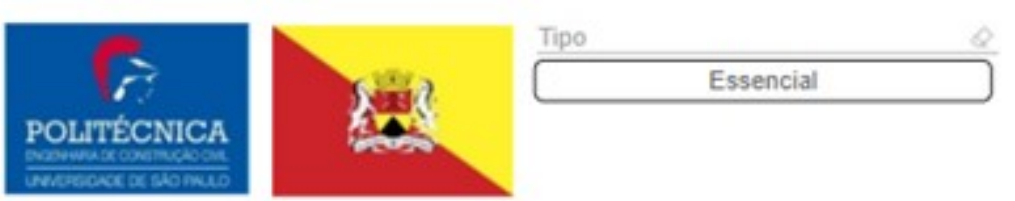

Seção Tema.

$\square 16.8$ - Porcentagem de resíduos sólidos urbanos dispostos por outros meios

ㅁ 16.9 - Geração de resíduos perigosos per capita

口 17 - Telecomunicaçòes e Inovação

- 17.1 - Número de conexões de internet por 100,000 habitantes

$\square 17.2$ - Número de conexões de telefone celular por 100.000 habitantes

ㅁ 17.3 - Número de conexões de telefone fixo por 100.000 habitantes

4ㅁ 18 - Transporte

$\square 18.1$ - Quilòmetros de sistema de transporte público de alta capacidade por 100.00

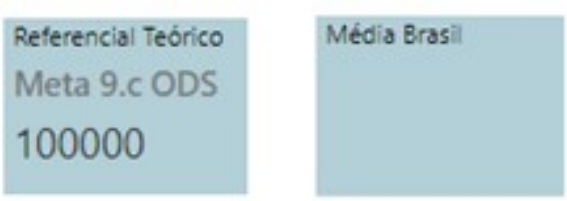

Melhores Práticas

WCCD (2018)

153980.0

49836,0

BID (2013)
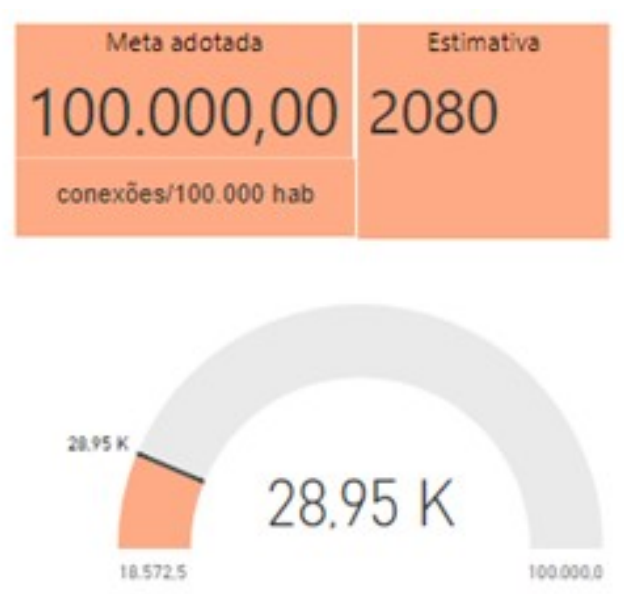

Resultado Final

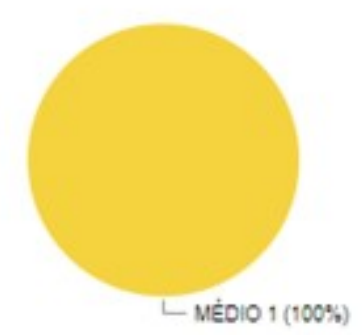

Tendência

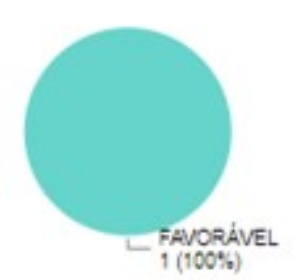

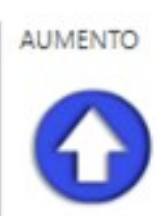

Unidade

conexōes/100.000 hab

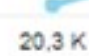

2012

2013

2014

2015

2016

2017

Figura 83: Dashboard para o indicador 17.1 - "Número de conexões de internet por 100.000 habitantes", exemplo de tendência favorável e resultado final médio. 


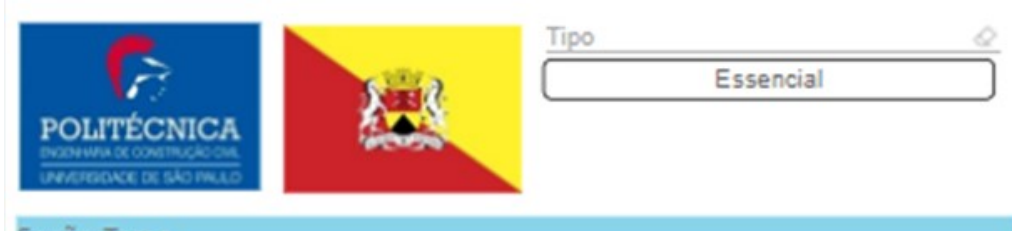

\section{Seção Tema}

口 12 - Saúde

$\square 12.1$ - Expectativa média de vida

12.2 - Número de leitos hospitalares por 100.000 habitantes

ㅁ 12.3 - Número de médicos por 100.000 habitantes

ㅁ 12.4 - Taxa de mortalidade de crianças menores de cinco anos a cada 1.000 nascido

$\square 12.5$ - Número de pessoas da equipe de enfermagem e obstetrícia por 100.000 habi

ㅁ 12.6 - Número de profissionais de saúde mental por 100.000 habitantes

ㅁ 12.7 - Taxa de suicídio por 100.000 habitantes
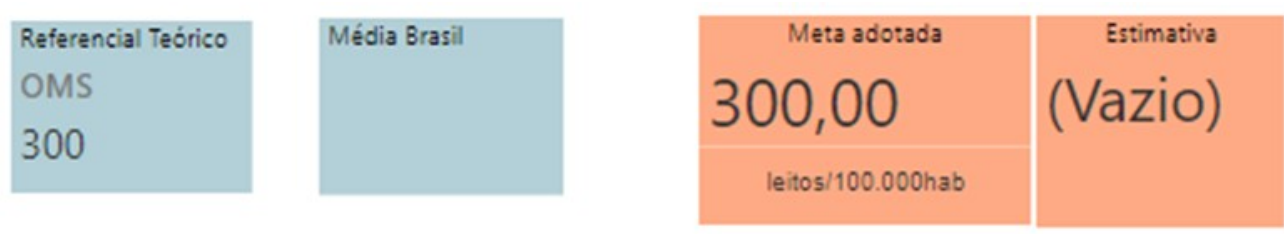

Melhores Práticas

WCCD (2018)

997.7

301.6

BID (2013)

\section{(1)}

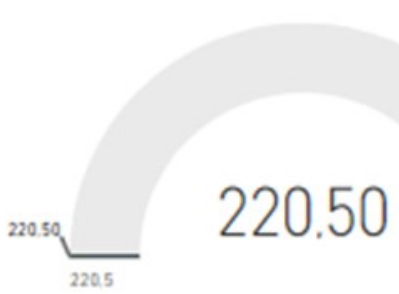

Resultado Final

Descriçăo Meta ODS

até 2030. garantir o acesso de todos a habitaçào segura, adequada e a preço acessivel e aos serviços básicos e urbanizar as favelas ate 2030, reduzir em um terço a mortalidade prematura por doenças năo transmissiveis (DNTs) via prevençäo e tratamento, e promover a saúde mental e ob reforçar a prevenção e o tratamento do abuso de substảncias. incluindo 0 abuso de drogas entorpecentes e uso nocivo do álcool

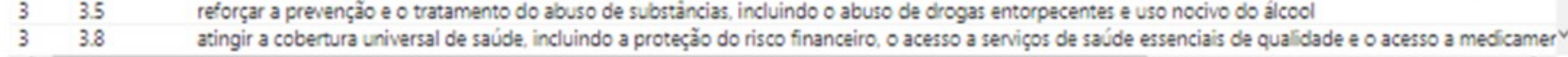

- Tendéncia MMS $\bullet$ Valiares

440

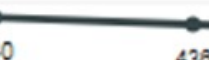

418

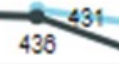

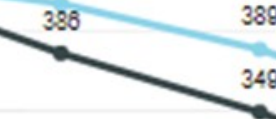

\section{8

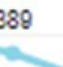

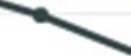

345

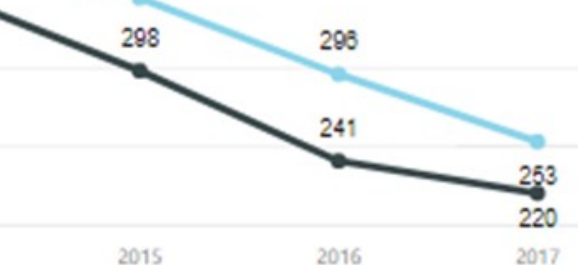

2017
Unidade leitos $/ 100.000 \mathrm{hab}$
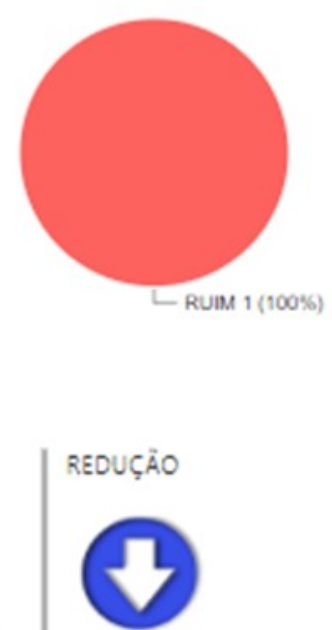

2010

2011

201.

2013

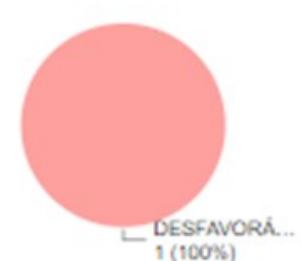

Figura 84: Dashboard para o indicador 12.2 - "Número de leitos hospitalares por 100.000 habitantes", exemplo de tendência desfavorável e resultado final ruim. 


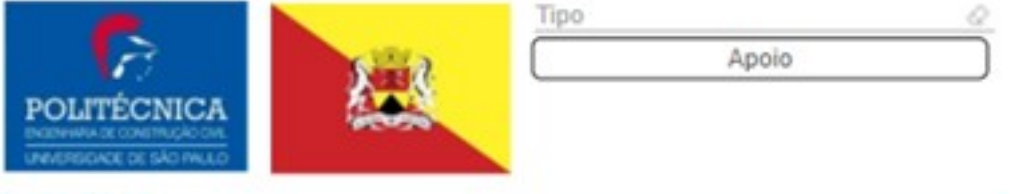

Seçăo Tema

$\square 21.3$ - Porcentagem da populaç̋o da cidade com acesso a saneamento melhorado

口 21.4 - Consumo doméstico total de água per capita (litros/dia)

21.5 - Consumo total de áqua per capita (litros/dia)

$\square 21.6$ - Valor médio anual de horas de interrupção do abastecimento de água por do

- 21.7 - Porcentagem de perdas de água (água näo faturada)

$\triangle \square$ B . Perfil

… Número total de domicilios ocupados (próprios ou alugados)

ㅁ 10.5 - Orçamento operacional bruto per capita (USD)
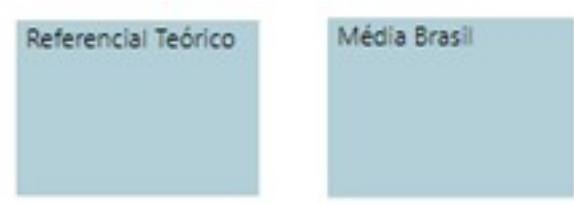

Melhores Práticas

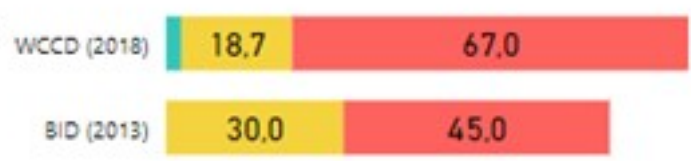
Descriçăo Meta ODS
ODS Meta ODS alteraçäes climáticas, a resilièncis a desastres; e deservolver e implementar, de acordo com o "Sendai Framework' para a reduę̧o do risco de desastres 2015 todos os nivetis
1212.2 até 2030 , alcançar gestro sustentavel e uso eficiente dos recursos naturais
6 até 2030. alcançar o acesso universal e equitativo à água potável segura e acessivel para todos

\section{Tendincia JuM $\bullet$ valores}

38
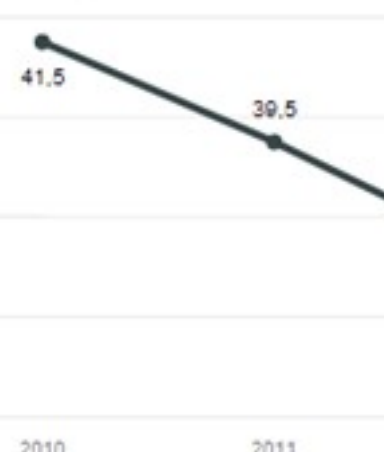

2010

2011

2012

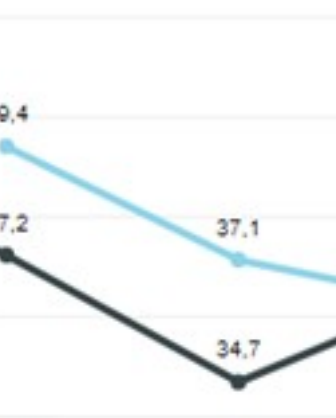

2013

:015

2016
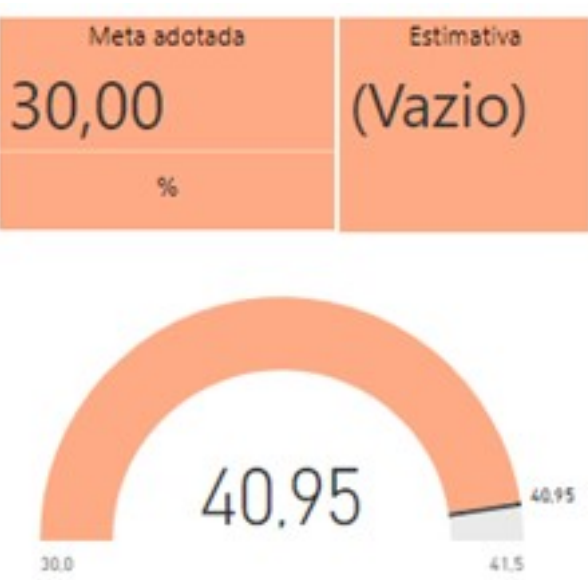

Resultado Final

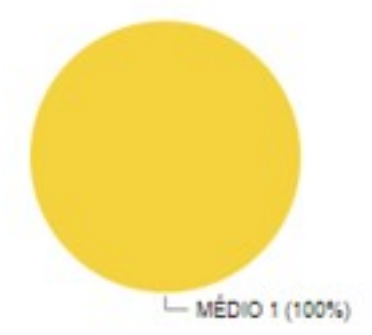

Tendência

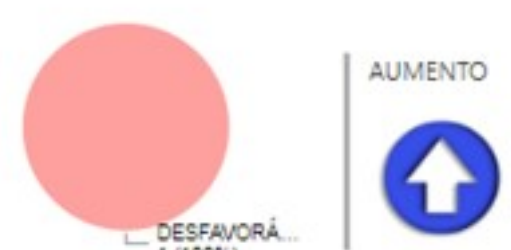

Figura 85: Dashboard para o indicador 21.7 - "Porcentagem de perdas de água (água não faturada)", exemplo de tendência desfavorável e resultado final médio. 
A Tabela 9 resume o resultado da análise de tendência e da classificação final de cada um dos 100 indicadores, fruto da simulação de aplicação do método para retrofit urbano em Sorocaba.

Tabela 9: Resultado final da simulação de aplicação do método para retrofit urbano em Sorocaba.

$(\mathrm{E}=$ Essencial, $\mathrm{A}=$ de Apoio, INSUF = Dados Insuficientes, FAV = Favorável, DESFAV $=$ Desfavorável, EST $=$ Estável

\begin{tabular}{|c|c|c|c|c|c|c|}
\hline No. & $\begin{array}{l}\mathbf{T} \\
\mathbf{i} \\
\mathbf{p} \\
\mathbf{0}\end{array}$ & Descrição & $\begin{array}{l}\text { Tendên- } \\
\text { cia }\end{array}$ & Meta & $\begin{array}{c}\text { Estima- } \\
\text { tiva para } \\
\text { atingir } \\
\text { meta }\end{array}$ & $\begin{array}{l}\text { Resul- } \\
\text { tado } \\
\text { Final }\end{array}$ \\
\hline 5.1 & $\mathrm{E}$ & Taxa de desemprego da cidade & DESFAV & 7 & & MÉDIO \\
\hline 5.2 & $\mathrm{E}$ & $\begin{array}{l}\text { Valor de avaliação de propriedades comerciais e } \\
\text { industriais como uma porcentagem do valor de } \\
\text { avaliação total de todas as propriedades }\end{array}$ & INSUF & & & INSUF \\
\hline 5.3 & $\mathrm{E}$ & $\begin{array}{l}\text { Porcentagem da população abaixo da linha de } \\
\text { pobreza }\end{array}$ & INSUF & 0 & & INSUF \\
\hline 5.4 & A & $\begin{array}{l}\text { Porcentagem da população com emprego em } \\
\text { tempo integral }\end{array}$ & FAV & 69 & 2027 & MÉDIO \\
\hline 5.5 & A & Taxa de desemprego de jovens & INSUF & & & INSUF \\
\hline 5.6 & A & Número de empresas por 100.000 habitantes & DESFAV & & & RUIM \\
\hline 5.7 & A & $\begin{array}{l}\text { Número de novas patentes por } 100.000 \text { habitantes } \\
\text { por ano }\end{array}$ & DESFAV & & & RUIM \\
\hline 6.1 & $\mathrm{E}$ & $\begin{array}{l}\text { Porcentagem da população feminina em idade } \\
\text { escolar matriculada em escolas }\end{array}$ & DESFAV & 100 & & MÉDIO \\
\hline 6.2 & $\mathrm{E}$ & $\begin{array}{l}\text { Porcentagem de estudantes com ensino primário } \\
\text { completo: taxa de sobrevivência }\end{array}$ & INSUF & 100 & & INSUF \\
\hline 6.3 & E & $\begin{array}{l}\text { Porcentagem de estudantes com ensino secundário } \\
\text { completo: taxa de sobrevivência }\end{array}$ & INSUF & 100 & & INSUF \\
\hline 6.4 & $\mathrm{E}$ & Relação estudante/professor no ensino primário & DESFAV & 15 & & MÉDIO \\
\hline 6.5 & A & $\begin{array}{l}\text { Porcentagem de população masculina em idade } \\
\text { escolar matriculada em escolas }\end{array}$ & DESFAV & 100 & & MÉDIO \\
\hline 6.6 & A & $\begin{array}{l}\text { Porcentagem de população em idade escolar } \\
\text { matriculada em escolas }\end{array}$ & DESFAV & 100 & & MÉDIO \\
\hline 6.7 & A & $\begin{array}{l}\text { Número de indivíduos com ensino superior } \\
\text { completo por } 100.000 \text { habitantes }\end{array}$ & FAV & 27.858 & 2030 & BOM \\
\hline 7.1 & $\mathrm{E}$ & $\begin{array}{l}\text { Uso de energia elétrica residencial total per capita } \\
(\mathrm{kWh} / \mathrm{ano})\end{array}$ & FAV & 2.161 & Já atingida & BOM \\
\hline 7.2 & $\mathrm{E}$ & $\begin{array}{l}\text { Porcentagem de habitantes da cidade com } \\
\text { fornecimento regular de energia elétrica }\end{array}$ & EST & 100 & Já atingida & $\mathrm{BOM}$ \\
\hline 7.3 & $\mathrm{E}$ & $\begin{array}{l}\text { Consumo de energia de edifícios públicos por ano } \\
\left(\mathrm{kWh} / \mathrm{m}^{2}\right)\end{array}$ & INSUF & & & INSUF \\
\hline 7.4 & $\mathrm{E}$ & $\begin{array}{l}\text { Porcentagem da energia total proveniente de fontes } \\
\text { renováveis, como parte do consumo total de } \\
\text { energia da cidade }\end{array}$ & INSUF & 50 & & INSUF \\
\hline 7.5 & A & Uso total de energia elétrica per capita (kWh/ano) & FAV & 6.122 & Já atingida & BOM \\
\hline 7.6 & A & $\begin{array}{l}\text { Número médio de interrupções de energia elétrica } \\
\text { por consumidor por ano }\end{array}$ & DESFAV & 5 & & MÉDIO \\
\hline 7.7 & A & $\begin{array}{l}\text { Duração média das interrupções de energia elétrica } \\
\text { (em horas) }\end{array}$ & DESFAV & 5 & & RUIM \\
\hline 8.1 & $\mathrm{E}$ & $\begin{array}{l}\text { Concentração de material particulado fino (PM } \\
2.5)\end{array}$ & INSUF & 10 & & INSUF \\
\hline 8.2 & E & Concentração de material particulado (PM 10) & FAV & 20 & 2021 & BOM \\
\hline 8.3 & $E$ & $\begin{array}{l}\text { Emissão de gases de efeito de estufa medida em } \\
\text { toneladas per capita }\end{array}$ & DESFAV & 5 & & MÉDIO \\
\hline
\end{tabular}




\begin{tabular}{|c|c|c|c|c|c|c|}
\hline No. & \begin{tabular}{|l|}
$\mathbf{T}$ \\
$\mathbf{i}$ \\
$\mathbf{p}$ \\
$\mathbf{0}$ \\
\end{tabular} & Descrição & $\begin{array}{l}\text { Tendên- } \\
\text { cia }\end{array}$ & Meta & $\begin{array}{c}\text { Estima- } \\
\text { tiva para } \\
\text { atingir } \\
\text { meta } \\
\end{array}$ & $\begin{array}{c}\text { Resul- } \\
\text { tado } \\
\text { Final }\end{array}$ \\
\hline 8.4 & $\mathrm{~A}$ & Concentração de $\mathrm{NO}_{2}$ (dióxido de nitrogênio) & FAV & 40 & Já atingida & $\mathrm{BOM}$ \\
\hline 8.5 & A & Concentração de $\mathrm{SO}_{2}$ (dióxido de enxofre) & INSUF & 20 & & INSUF \\
\hline 8.6 & A & Concentração de $\mathrm{O}_{3}$ (ozônio) & DESFAV & 100 & & MÉDIO \\
\hline 8.7 & A & Poluição sonora & INSUF & & & INSUF \\
\hline 8.8 & A & $\begin{array}{l}\text { Variação percentual em número de espécies } \\
\text { nativas }\end{array}$ & INSUF & & & INSUF \\
\hline 9.1 & $\mathrm{E}$ & $\begin{array}{l}\text { Taxa de endividamento (expansão do serviço da } \\
\text { dívida como uma porcentagem da receita própria } \\
\text { do município) }\end{array}$ & FAV & 10 & Já atingida & BOM \\
\hline 9.2 & A & $\begin{array}{l}\text { Despesas de capital como porcentagem de } \\
\text { despesas totais }\end{array}$ & FAV & 1,8 & 2142 & MÉDIO \\
\hline 9.3 & A & $\begin{array}{l}\text { Porcentagem da receita própria em função do total } \\
\text { das receitas }\end{array}$ & FAV & 95,6 & 2052 & MÉDIO \\
\hline 9.4 & A & $\begin{array}{l}\text { Porcentagem dos impostos recolhidos em função } \\
\text { dos impostos cobrados }\end{array}$ & DESFAV & 100 & & MÉDIO \\
\hline 10.1 & $\mathrm{E}$ & Número de bombeiros por 100.000 habitantes & INSUF & & & INSUF \\
\hline 10.2 & $\mathrm{E}$ & $\begin{array}{l}\text { Número de mortes relacionadas a incêndios por } \\
100.000 \text { habitantes }\end{array}$ & EST & 0 & & BOM \\
\hline 10.3 & $\mathrm{E}$ & $\begin{array}{l}\text { Número de mortes relacionadas a desastres } \\
\text { naturais por } 100.000 \text { habitantes }\end{array}$ & EST & 0 & & BOM \\
\hline 10.4 & A & $\begin{array}{l}\text { Número de bombeiros voluntários e em tempo } \\
\text { parcial por } 100.000 \text { habitantes }\end{array}$ & INSUF & & & INSUF \\
\hline 10.5 & $\mathrm{~A}$ & $\begin{array}{l}\text { Tempo de resposta dos serviços de emergência a } \\
\text { partir do primeiro chamado }\end{array}$ & INSUF & & & INSUF \\
\hline 10.6 & A & $\begin{array}{l}\text { Tempo de resposta do Corpo de Bombeiros a partir } \\
\text { do primeiro chamado }\end{array}$ & INSUF & & & INSUF \\
\hline 11.1 & $\mathrm{E}$ & $\begin{array}{l}\text { Porcentagem de participação dos eleitores nas } \\
\text { últimas eleições municipais em função do total de } \\
\text { eleitores aptos a votar }\end{array}$ & DESFAV & 99,5 & & MÉDIO \\
\hline 11.2 & $\mathrm{E}$ & $\begin{array}{l}\text { Porcentagem de mulheres eleitas em função do } \\
\text { número total de eleitos na gestão da cidade }\end{array}$ & FAV & 36 & & MÉDIO \\
\hline 11.3 & $\mathrm{~A}$ & $\begin{array}{l}\text { Porcentagem de mulheres empregadas na gestão da } \\
\text { cidade }\end{array}$ & INSUF & & & INSUF \\
\hline 11.4 & A & $\begin{array}{l}\text { Número de condenações de servidores da cidade } \\
\text { por corrupção e/ou suborno por } 100.000 \text { habitantes }\end{array}$ & INSUF & & & INSUF \\
\hline 11.5 & $\mathrm{~A}$ & $\begin{array}{l}\text { Representação de cidadãos: número de autoridades } \\
\text { locais eleitas para o cargo por } 100.000 \text { habitantes }\end{array}$ & INSUF & & & INSUF \\
\hline 11.6 & A & $\begin{array}{l}\text { Porcentagem de eleitores registrados em função da } \\
\text { população com idade para votar }\end{array}$ & DESFAV & 100 & & MÉDIO \\
\hline 12.1 & $\mathrm{E}$ & Expectativa média de vida & EST & 74 & 2021 & BOM \\
\hline 12.2 & $\mathrm{E}$ & $\begin{array}{l}\text { Número de leitos hospitalares por } 100.000 \\
\text { habitantes }\end{array}$ & DESFAV & 300 & & RUIM \\
\hline 12.3 & $\mathrm{E}$ & Número de médicos por 100.000 habitantes & FAV & 630 & 2083 & MÉDIO \\
\hline 12.4 & $\mathrm{E}$ & $\begin{array}{l}\text { Taxa de mortalidade de crianças menores de cinco } \\
\text { anos a cada } 1.000 \text { nascidos vivos }\end{array}$ & FAV & 10 & Já atingida & BOM \\
\hline 12.5 & $\mathrm{~A}$ & $\begin{array}{l}\text { Número de pessoas da equipe de enfermagem e } \\
\text { obstetrícia por } 100.000 \text { habitantes }\end{array}$ & FAV & 5538 & 2153 & MÉDIO \\
\hline 12.6 & A & $\begin{array}{l}\text { Número de profissionais de saúde mental por } \\
100.000 \text { habitantes }\end{array}$ & FAV & 3213,8 & 2422 & MÉDIO \\
\hline 12.7 & $\mathrm{~A}$ & Taxa de suicídio por 100.000 habitantes & DESFAV & 0 & & MÉDIO \\
\hline 13.1 & $\mathrm{~A}$ & $\begin{array}{l}\text { Área em metros quadrados de espaços públicos de } \\
\text { recreação cobertos per capita }\end{array}$ & INSUF & & & INSUF \\
\hline
\end{tabular}




\begin{tabular}{|c|c|c|c|c|c|c|}
\hline No. & \begin{tabular}{|l|}
$\mathbf{T}$ \\
$\mathbf{i}$ \\
$\mathbf{p}$ \\
$\mathbf{0}$
\end{tabular} & Descrição & $\begin{array}{l}\text { Tendên- } \\
\text { cia }\end{array}$ & Meta & $\begin{array}{c}\text { Estima- } \\
\text { tiva para } \\
\text { atingir } \\
\text { meta }\end{array}$ & $\begin{array}{l}\text { Resul- } \\
\text { tado } \\
\text { Final }\end{array}$ \\
\hline 13.2 & A & $\begin{array}{l}\text { Área em metros quadrados de espaços públicos de } \\
\text { recreação ao ar livre per capita }\end{array}$ & DESFAV & 1 & & MÉDIO \\
\hline 14.1 & $\mathrm{E}$ & $\begin{array}{l}\text { Número de agentes de polícia por } 100.000 \\
\text { habitantes }\end{array}$ & INSUF & & & INSUF \\
\hline 14.2 & $\mathrm{E}$ & Número de homicídios por 100.000 habitantes & FAV & 10 & 2013 & BOM \\
\hline 14.3 & A & $\begin{array}{l}\text { Crimes contra a propriedades por } 100.000 \\
\text { habitantes }\end{array}$ & FAV & 3300 & Já atingida & BOM \\
\hline 14.4 & A & $\begin{array}{l}\text { Tempo de resposta da polícia a partir do primeiro } \\
\text { chamado }\end{array}$ & INSUF & & & INSUF \\
\hline 14.5 & A & Taxa de crimes violentos por 100.000 habitantes & FAV & 8,5 & 2024 & BOM \\
\hline 15.1 & $\mathrm{E}$ & $\begin{array}{l}\text { Porcentagem da população urbana morando em } \\
\text { favelas }\end{array}$ & DESFAV & 0 & & MÉDIO \\
\hline 15.2 & $\mathrm{~A}$ & Número de sem-teto por 100.000 habitantes & INSUF & 0 & & INSUF \\
\hline 15.3 & A & $\begin{array}{l}\text { Porcentagem de moradias sem títulos de } \\
\text { propriedade registrados }\end{array}$ & INSUF & 20 & & INSUF \\
\hline 16.1 & $\mathrm{E}$ & $\begin{array}{l}\text { Porcentagem da população urbana com coleta } \\
\text { regular de lixo (domiciliar) }\end{array}$ & EST & 100 & & BOM \\
\hline 16.2 & $\mathrm{E}$ & $\begin{array}{l}\text { Total de coleta de resíduos sólidos municipais per } \\
\text { capita }\end{array}$ & FAV & 0,1 & 2024 & $\mathrm{BOM}$ \\
\hline 16.3 & $\mathrm{E}$ & $\begin{array}{l}\text { Porcentagem de resíduos sólidos urbanos que são } \\
\text { reciclados }\end{array}$ & FAV & 10 & 2090 & MÉDIO \\
\hline 16.4 & A & $\begin{array}{l}\text { Porcentagem de resíduos sólidos urbanos dispostos } \\
\text { em aterros sanitários }\end{array}$ & DESFAV & 100 & & MÉDIO \\
\hline 16.5 & A & $\begin{array}{l}\text { Porcentagem de resíduos sólidos urbanos } \\
\text { descartados para incineração }\end{array}$ & EST & 0 & & BOM \\
\hline 16.6 & A & $\begin{array}{l}\text { Porcentagem de resíduos sólidos urbanos } \\
\text { queimados a céu aberto }\end{array}$ & EST & 0 & & BOM \\
\hline 16.7 & A & $\begin{array}{l}\text { Porcentagem de resíduos sólidos urbanos dispostos } \\
\text { a céu aberto }\end{array}$ & EST & 0 & & BOM \\
\hline 16.8 & A & $\begin{array}{l}\text { Porcentagem de resíduos sólidos urbanos dispostos } \\
\text { por outros meios }\end{array}$ & DESFAV & 0 & & MÉDIO \\
\hline 16.9 & $\mathrm{~A}$ & Geração de resíduos perigosos per capita & INSUF & 0 & & INSUF \\
\hline 16.10 & A & $\begin{array}{l}\text { Porcentagem de resíduos urbanos perigosos que } \\
\text { são reciclados }\end{array}$ & INSUF & & & INSUF \\
\hline 17.1 & $\mathrm{E}$ & $\begin{array}{l}\text { Número de conexões de internet por } 100.000 \\
\text { habitantes }\end{array}$ & FAV & 100.000 & 2080 & MÉDIO \\
\hline 17.2 & $\mathrm{E}$ & $\begin{array}{l}\text { Número de conexões de telefone celular por } \\
100.000 \text { habitantes }\end{array}$ & INSUF & 100.000 & & INSUF \\
\hline 17.3 & A & $\begin{array}{l}\text { Número de conexões de telefone fixo por } 100.000 \\
\text { habitantes }\end{array}$ & DESFAV & & & MÉDIO \\
\hline 18.1 & $\mathrm{E}$ & $\begin{array}{l}\text { Quilômetros de sistema de transporte público de } \\
\text { alta capacidade por } 100.000 \text { habitantes }\end{array}$ & EST & & & MÉDIO \\
\hline 18.2 & $\mathrm{E}$ & $\begin{array}{l}\text { Quilômetros de sistema de transporte público de } \\
\text { média capacidade por } 100.000 \text { habitantes }\end{array}$ & FAV & 40 & 2051 & $\mathrm{BOM}$ \\
\hline 18.3 & $\mathrm{E}$ & $\begin{array}{l}\text { Número anual de viagens em transporte público } \\
\text { per capita }\end{array}$ & DESFAV & 87 & & MÉDIO \\
\hline 18.4 & $\mathrm{E}$ & Número de automóveis privados per capita & DESFAV & 0,3 & & MÉDIO \\
\hline 18.5 & $\mathrm{~A}$ & $\begin{array}{l}\text { Porcentagem de passageiros que se deslocam para } \\
\text { o trabalho de forma alternativa ao automóvel } \\
\text { privado }\end{array}$ & INSUF & 50 & & INSUF \\
\hline 18.6 & A & $\begin{array}{l}\text { Número de veículos motorizados de duas rodas per } \\
\text { capita }\end{array}$ & DESFAV & 0,1 & Já atingida & MÉDIO \\
\hline 18.7 & A & $\begin{array}{l}\text { Quilômetros de ciclovias e ciclofaixas por } 100.000 \\
\text { habitantes }\end{array}$ & FAV & 25 & 2021 & BOM \\
\hline
\end{tabular}




\begin{tabular}{|c|c|c|c|c|c|c|}
\hline No. & \begin{tabular}{|l|}
$\mathbf{T}$ \\
$\mathbf{i}$ \\
$\mathbf{p}$ \\
$\mathbf{o}$ \\
\end{tabular} & Descrição & $\begin{array}{l}\text { Tendên- } \\
\text { cia }\end{array}$ & Meta & $\begin{array}{c}\text { Estima- } \\
\text { tiva para } \\
\text { atingir } \\
\text { meta } \\
\end{array}$ & $\begin{array}{l}\text { Resul- } \\
\text { tado } \\
\text { Final }\end{array}$ \\
\hline 18.8 & $\mathrm{~A}$ & Mortalidades de trânsito por 100.000 habitantes & FAV & 5 & 2018 & $\mathrm{BOM}$ \\
\hline 18.9 & A & $\begin{array}{l}\text { Conectividade aérea (número de partidas de voos } \\
\text { comerciais sem escalas) }\end{array}$ & EST & & & MÉDIO \\
\hline 19.1 & $\mathrm{E}$ & Áreas verdes (hectares) por 100.000 habitantes & INSUF & 120 & & INSUF \\
\hline 19.2 & A & $\begin{array}{l}\text { Número de árvores plantadas anualmente por } \\
100.000 \text { habitantes }\end{array}$ & DESFAV & 7500 & & MÉDIO \\
\hline 19.3 & A & $\begin{array}{l}\text { Porcentagem de área de assentamentos informais } \\
\text { em função da área total da cidade }\end{array}$ & INSUF & & & INSUF \\
\hline 19.4 & A & Relação empregos/habitação & FAV & 1,7 & 2023 & BOM \\
\hline 20.1 & $\mathrm{E}$ & $\begin{array}{l}\text { Porcentagem da população da cidade atendida por } \\
\text { sistemas de coleta e afastamento de esgoto }\end{array}$ & EST & 100 & & BOM \\
\hline 20.2 & $\mathrm{E}$ & $\begin{array}{l}\text { Porcentagem do esgoto da cidade que não recebeu } \\
\text { qualquer tratamento }\end{array}$ & FAV & 0 & 2029 & BOM \\
\hline 20.3 & $\mathrm{E}$ & $\begin{array}{l}\text { Porcentagem do esgoto da cidade que recebe } \\
\text { tratamento primário }\end{array}$ & EST & 100 & & BOM \\
\hline 20.4 & $\mathrm{E}$ & $\begin{array}{l}\text { Porcentagem do esgoto da cidade que recebe } \\
\text { tratamento secundário }\end{array}$ & EST & & & BOM \\
\hline 20.5 & $\mathrm{E}$ & $\begin{array}{l}\text { Porcentagem do esgoto da cidade que recebe } \\
\text { tratamento terciário }\end{array}$ & EST & & & BOM \\
\hline 21.1 & $\mathrm{E}$ & $\begin{array}{l}\text { Porcentagem da população da cidade com serviço } \\
\text { de abastecimento de água potável }\end{array}$ & FAV & 100 & 2017 & BOM \\
\hline 21.2 & $\mathrm{E}$ & $\begin{array}{l}\text { Porcentagem da população da cidade com acesso } \\
\text { sustentável a uma fonte de água adequada para } \\
\text { consumo }\end{array}$ & FAV & 100 & 2017 & BOM \\
\hline 21.3 & $\mathrm{E}$ & $\begin{array}{l}\text { Porcentagem da população da cidade com acesso a } \\
\text { saneamento melhorado }\end{array}$ & EST & 100 & & BOM \\
\hline 21.4 & $\mathrm{E}$ & $\begin{array}{l}\text { Consumo doméstico total de água per capita } \\
\text { (litros/dia) }\end{array}$ & DESFAV & 120 & & MÉDIO \\
\hline 21.5 & A & Consumo total de água per capita (litros/dia) & FAV & 120 & 2030 & BOM \\
\hline 21.6 & A & $\begin{array}{l}\text { Valor médio anual de horas de interrupção do } \\
\text { abastecimento de água por domicílio }\end{array}$ & FAV & 0 & & BOM \\
\hline 21.7 & $\mathrm{~A}$ & $\begin{array}{l}\text { Porcentagem de perdas de água (água não } \\
\text { faturada) }\end{array}$ & DESFAV & 30 & & MÉDIO \\
\hline
\end{tabular}

Elaborada pela autora.

\subsection{Análise e Discussão}

A seguir serão discutidas individualmente as Seções da NBR ISO 37120:2017, e por fim uma discussão mais ampla sobre a análise e resultados obtidos.

\section{Seção 5 - Economia}

Alguns indicadores da seção não podem ser influenciados, ao menos não diretamente, pelas intervenções de atores locais. Portanto, como dito anteriormente, metas não podem ser definidas para estes indicadores no nível do distrito (LÜTZKENDORF; BALOUKTSI, 2017). 
De fato, a influência sobre o indicador 5.1 - "Taxa de desemprego da cidade" não é da jurisdição do município, nem do Estado. Porém, a tendência da taxa de desemprego pode indicar antecipadamente problemas futuros. Neste caso, atores locais podem desenvolver estratégias para lidar com as consequências. Entretanto, não há esta informação frequente sobre a taxa de desemprego na escala municipal. Tem-se dados de emprego e pessoas empregadas, mas não da PEA - População Economicamente Ativa, para cálculo e obtenção da taxa. A mesma ausência ocorre para o indicador 5.5 - "Taxa de desemprego de jovens", pois não há dados de PEA do município desagregada por faixa etária, ou gênero. Mesmo a fundação SEADE, do Estado de São Paulo, elabora este indicador para a RMSP - Região Metropolitana de São Paulo.

O indicador 5.2 - "Valor de avaliação de propriedades comerciais e industriais como uma porcentagem do valor de avaliação total de todas as propriedades" é de difícil obtenção, e $14 \%$ das cidades certificadas pelo WCCD não apresentaram este valor.

Quanto ao indicador 5.3 - "Porcentagem da população abaixo da linha de pobreza", pode-se tomar o Cadastro Único do MDS - Ministério de Desenvolvimento Social, mas alguns indivíduos cadastrados são atendidos e alguns não estão cadastrados. As faixas de renda do MDS não coincidem com as várias definições de linha de pobreza, sendo adotada a proporção de habitantes com renda domiciliar per capita abaixo de $\mathrm{R} \$ 77,00 /$ mês, valor levantado somente no Censo 2010. A NBR 37120:2017 fala em US\$ 1,25/dia, o Banco Mundial em US\$ 5,50/dia, o SDSN (2016) em US\$ 1,90/dia. Seja qual for a linha de corte monetária, entretanto, a análise de tendência, mantida a mesma definição de renda, pode evidenciar se a pobreza extrema está aumentando ou não.

O número de empresas atuantes levantado no IBGE Cidades (IBGE, 2018), que tem por fonte o Cadastro Central de Empresas, foi utilizado para compor o indicador 5.6 - "Número de empresas por 100.000 habitantes". Porém, a Prefeitura de Sorocaba utiliza como fonte o cadastro de empresas da Secretaria da Fazenda, que informa que no início do mês de setembro de 2017 o número total de empresas era de 56.071, contra o valor de 24.454 empresas atuantes do IBGE em 2016. Na JUSCESP o número é superior, o total de empresas é de 91.094 em 2017. 


\section{Seção 6 - Educação}

Para os indicadores 6.1 "Porcentagem da população feminina em idade escolar matriculada em escolas" e 6.5 "Porcentagem de população masculina em idade escolar matriculada em escolas" Nas Sinopses Estatísticas do INEP - "Instituto Nacional de Estudos e Pesquisas Educacionais Anísio Teixeira" há várias informações do Censo Escolar relativas às matrículas na escala municipal, a partir do ano de 2010, inclusive divididas por tipo de instituição (pública federal, estadual ou municipal, ou privada). Para o indicador 6.1 "Porcentagem da população feminina em idade escolar matriculada em escolas", as matrículas da parcela feminina foram somadas das planilhas do Ensino Fundamental - Anos Iniciais e Finais, Ensino Médio e Educação Profissional. A população em idade escolar foi obtida no SEADE-IMP, somando as faixas de 4 a 17 anos ( $1^{\circ}$ ano fundamental ao $3^{\circ}$ do médio). A divisão entre população feminina e masculina foi calculada a partir da razão de sexo, também obtida no SEADE-IMP.

Os indicadores 6.2 - "Porcentagem de estudantes com ensino primário completo (taxa de sobrevivência)" e 6.3 "Porcentagem de estudantes com ensino secundário completo (taxa de sobrevivência)" correspondem aos concluintes do último ano da respectiva etapa de ensino, sobre aqueles que inicialmente se matricularam. Apesar de existirem várias informações relativas às matrículas na escala municipal no site do INEP, não há informações sobre concluintes. Há informações sobre concluintes no SEADE-IMP, mas somente de 2009 a 2013, o que demandariam matriculados no $1^{\circ}$ ano do Ensino Fundamental de 2001 a 2004, e não há esta informação desagregada por município para estes anos.

O SIG - Sistema de Informações Gerenciais de Sorocaba monitora somente o número de alunos atendidos na rede municipal, dividindo em Fundamental I, II e Médio. Frequência mensal, e a meta refere-se ao número de alunos atendidos.

\section{Seção 7 - Energia}

A meta para o indicador 7.1 - "Uso de energia elétrica residencial total per capita (kWh/ano)" foi adotada como 2.161,4 kWh/hab.ano, que é o valor médio levantado entre as cidades certificadas pelo WCCD. O menor valor é 127,49 kWh/hab.ano de Amman, ou Amã, 
que é a capital e a maior cidade da Jordânia. Para este indicador, a tendência favorável é a de redução, mas um valor muito reduzido, apesar de associado a alta eficiência energética, pode esconder um baixo consumo devido à escassez de bens nas residências, como eletrodomésticos e climatizadores, por exemplo.

Tanto o indicador 7.3 - "Consumo de energia de edifícios públicos por ano $\left(\mathrm{kWh} / \mathrm{m}^{2}\right)$ " quanto o 7.4 - "Porcentagem da energia total proveniente de fontes renováveis, como parte do consumo total de energia da cidade" são de difícil obtenção.

No caso dos indicadores 7.6 - "Número médio de interrupções de energia elétrica por consumidor por ano" e 7.7 - "Duração média das interrupções de energia elétrica (em horas)" foram considerados a FEC - Frequência Equivalente de Interrupção por Consumidor e a DEC - Duração Equivalente de Interrupção por Consumidor, respectivamente, que caracterizam a continuidade dos serviços de fornecimento de energia elétrica no Brasil. A FEC apresenta o número de interrupções que cada consumidor sofreu, em média, ao passo que a DEC mostra o intervalo de tempo que cada consumidor, em média, ficou sem energia elétrica, ambas considerando interrupções iguais ou superiores a três minutos. A ANEEL estipula os limites destes indicadores individuais de continuidade por município, apresentando os valores por subdivisões das distribuidoras, que podem ter abrangência variada.

\section{Seção 8 - Meio Ambiente}

A CETESB - Companhia Ambiental do Estado de São Paulo uma rede automática de monitoramento da qualidade do ar, com estações medidoras na Região Metropolitana de São Paulo e no interior e litoral do Estado. Esta rede, registra ininterruptamente as concentrações dos poluentes na atmosfera, os dados são processados com base nas médias estabelecidas por padrões legais e disponibilizados de hora em hora na internet. Porém, para o indicador 8.1 "Concentração de material particulado fino (PM 2.5)", as estações para monitoramento de qualidade do ar da CETESB em Sorocaba não medem as concentrações de PM2,5. Além disto, o monitoramento da CETESB é um exemplo do que é monitorado por um Estado do Brasil, diferentemente de outras localidades do país. 
Os indicadores 8.7 - "Poluição sonora" e 8.8 - "Variação percentual em número de espécies nativas" de difícil obtenção

\section{Seção 9 - Finanças}

Na versão brasileira NBR ISO 37120:2017, o indicador 9.4 - "Tax collected as a percentage of tax billed" por "Porcentagem dos impostos recolhidos em função dos impostos cobrados". Mas como se trata do termo "tax", cabe tanto "imposto" como "tributo", porém os impostos compõem os tributos, e nestes estão as taxas e contribuições de melhorias. A Controladoria de Sorocaba entende que este indicador se refere aos Impostos Municipais.

Na versão brasileira NBR ISO 37120:2017 o indicador de perfil "gross operating budget" foi adotado como "orçamento operacional bruto". Mas a Controladoria de Sorocaba entende que este valor corresponde a $\mathrm{RCL}=$ Receita Corrente Líquida. A RCL corresponde à receita contínua. A parcela maior das $\mathrm{DCL}=$ Despesa Corrente Líquida é relativa ao pagamento de pessoal, tanto ativo quanto inativo. A curva de crescimento da despesa com pessoal é maior que a curva de crescimento da receita. Em Sorocaba, o crescimento da despesa com pessoal, sem considerar os reajustes por perda de poder de compra, é vegetativo, da ordem de 3 a 3,5\% ao ano. Esta mesma situação é recorrente em vários municípios e Estados do país.

\section{Seção 10 - Resposta a Incêndios e Emergências}

Os indicadores 10.1 "Número de bombeiros por 100.000 habitantes" e 10.6 "Tempo de resposta do Corpo de Bombeiros a partir do primeiro chamado" foram solicitados oficialmente ao Corpo de Bombeiros em Sorocaba em janeiro/2018, depois solicitados diretamente ao Corpo de Bombeiros do Estado de São Paulo. Foi obtida resposta oficial em agosto/2018 de que não há estes dados consolidados. 


\section{Seção 11 - Governança}

Tanto o indicador 11.4 "Número de condenações de servidores da cidade por corrupção e/ou suborno por 100.000 habitantes" quanto o 11.5 "Representação de cidadãos: número de autoridades locais eleitas para o cargo por 100.000 habitantes" de difícil obtenção

Os resultados para os indicadores 11.2 - "Porcentagem de mulheres eleitas em função do número total de eleitos na gestão da cidade" e 11.3 - "Porcentagem de mulheres empregadas na gestão da cidade" refletem a desigualdade de gênero na política brasileira, em que, apesar de serem maioria $(51,7 \%)$ da população, as mulheres são somente $44,27 \%$ dos filiados a partidos. Na composição atual do Congresso, 10,94\% dos parlamentares são mulheres, frente a média mundial de 23,5\%. Nas eleições de 2016, menos de $12 \%$ dos municípios elegeram prefeitas. (RIOS; PEREIRA; RANGEL, 2017)

\section{Seção 12 - Saúde}

Quanto ao indicador 12.2 - "Número de leitos hospitalares por 100.000 habitantes", o SIG/Sorocaba monitora por 100 habitantes desde 2014, com frequência quadrimestral. Porém, a meta do SIG/Sorocaba era de 4,31/1.000hab em 2017, e uma meta para este indicador não consta no PPA - Plano Anual de Metas de Sorocaba 2018-2021. Segundo a OMS (2006), o recomendável é 2,5 a 3 por 1.000 habitantes, o que corresponderia a 250 leitos para 100.000 habitantes.

Há indicadores idênticos para 12.4 "Taxa de mortalidade de crianças menores de cinco anos a cada 1.000 nascidos vivos" e 12.7 "Taxa de suicídio por 100.000 habitantes" monitorados pelo SEADE-IMP, mas considerando as estimativas populacionais do SEADE, que divergem das estimativas do IBGE. No DATASUS - Sistema de Informática do Sistema Único de Saúde (SUS) há óbitos infantis de vários tipos, mas não foi localizada a taxa consolidada. Como comentado Para o indicador 12.4, a meta do PPA 2018-2021 é de 9,99 para cada 1.000 nascidos vivos, mais exigente do que a Meta 3.1 ODS, que é reduzir "para pelo menos 25 por 1.000 nascidos vivos" 
Quanto aos indicadores relacionados a profissionais de saúde, o SEADE considera aqueles registrados nos conselhos regionais do Estado de São Paulo, e o DATASUS segundo a CBO - Classificação Brasileira de Ocupações, evidenciando uma pequena divergência. Quanto ao indicador 12.6 - "Número de profissionais de saúde mental por 100.000 habitantes", o SIG/Sorocaba monitora desde 2014, com frequência quadrimestral, a "taxa de cobertura de Centro de Atenção Psicossocial", com meta de 2,14/100.000hab em 2017, valor de difícil correspondência com o indicador 12.6.

\section{Seção 13 - Recreação}

O indicador 13.1 - "Área em metros quadrados de espaços públicos de recreação cobertos per capita" é difícil obtenção. O SIG/Sorocaba monitora desde 2014, com frequência semestral, "equipamentos esportivos" em unidades por 10.000 habitantes, com meta de 1,6 em 2017, no PPA 2018-2021 consta somente meta financeira (em R\$), valor de difícil correspondência com o indicador 13.1 .

Quanto ao indicador 13.2 - “Área em metros quadrados de espaços públicos de recreação ao ar livre per capita", o SIG/Sorocaba monitora desde 2014, com frequência semestral, "parques abertos mantidos" em $\mathrm{m}^{2}$, que foi utilizado como fonte deste indicador. Porém, há uma meta de $1.725 .000 \mathrm{~m}^{2}$ em 2017, e no PPA 2018-2021 consta somente meta financeira (em R\$), valor de difícil correspondência com o indicador 13.2.

\section{Seção 14 - Segurança}

Os indicadores 14.1 "Número de agentes de polícia por 100.000 habitantes" e 14.4 “Tempo de resposta da polícia a partir do primeiro chamado" são de difícil obtenção.

Quanto ao indicador 14.3 - "Crimes contra a propriedades por 100.000 habitantes", o SIG/Sorocaba monitora desde 2014, com frequência mensal, com meta de 2019 em 2017, e no PPA 2018-2021 consta somente meta financeira (em R\$), valor de difícil correspondência com o indicador 14.3.

A SSP/SP - Secretaria de Segurança Pública do Estado de São Paulo monitora e divulga vários indicadores interessantes, a saber: ocorrências de porte, de tráfico e de apreensão de entorpecentes, ocorrências de porte ilegal de arma, número de armas de fogo apreendidas, 
número de flagrantes lavrados, número de infratores apreendidos em flagrante e por mandado, número de pessoas presas em flagrante e por mandado, número de prisões efetuadas, número de veículos recuperados, total de inquéritos policiais instaurados.

\section{Seção 15 - Habitação}

O censo IBGE 2010 e outras fontes indicam que não há favelas em Sorocaba, em relação ao indicador 15.1 - "Porcentagem da população urbana morando em favelas". Porém, o PPA 2018-2021 cita que no ano base 2017 há 3.500 habitantes em aglomerados subnormais, seguida de uma meta de 1.500 habitantes para 2021, o que corresponde a $0,5 \%$ e $0,2 \%$ da população prevista, respectivamente.

Quanto ao indicador 15.3 - "Porcentagem de moradias sem títulos de propriedade registrados", o SIG/Sorocaba monitora desde 2015, com frequência trimestral, o indicador "Títulos de Imóveis (Regularização Fundiária)", com meta de 2000 novas matrículas no PPA 2018-2021., valor de difícil correspondência com o indicador 15.3.

\section{Seção 16 - Resíduos Sólidos}

Os indicadores 16.1 - "Porcentagem da população urbana com coleta regular de lixo (domiciliar)" e 16.2 - "Total de coleta de resíduos sólidos municipais per capita" tem uma correlação interessante. A cidade de Jamshedpur, na Índia, apresenta 0,12 ton/hab.ano para o 16.2, um dos melhores valores entre as cidades certificadas pelo WCCD. Porém, se analisado o indicador 16.1, Jamshedpur apresenta $88 \%$ de porcentagem da população com coleta regular de lixo. Pode-se intuir que os resíduos municipais per capita calculados apresentam um valor baixo porque não leva em consideração o potencial de coleta na totalidade da população. Sorocaba, por sua vez, apresenta para 16.2 o valor de 0,31 ton/hab.ano em 2016, com tendência de redução, ao passo que o indicador 16.1 está estável em 100\%. Ou seja, de posse do volume de todos os resíduos domiciliares coletados, é possível calcular um valor per capita que reflete a real geração de resíduos.

Quanto ao indicador 16.3 - "Porcentagem de resíduos sólidos urbanos que são reciclados", o SIG/Sorocaba monitora desde 2014, com frequência mensal, o indicador 
"resíduos recicláveis coletados e destinados", com meta de 10\% no PPA 2018-2021. Para este indicador, podem ser utilizados dados de logística reversa, conforme estabelecido na Política Nacional de Resíduos Sólidos (BRASIL, 2010) e, em São Paulo, na Política Estadual de Resíduos Sólidos (SÃO PAULO, 2006b). A logística reversa é um dos instrumentos para aplicação da RCCVP - Responsabilidade Compartilhada pelo Ciclo de Vida do Produto.

O indicador 16.4- "Porcentagem de resíduos sólidos urbanos dispostos em aterros sanitários" é monitorado pelo SIG/Sorocaba desde 2014, com frequência mensal, o indicador "resíduos coletados e transportados". Entretanto, no PPA 2018-2021 consta somente meta financeira (em R\$), valor de difícil correspondência com o indicador 16.4.

\section{Seção 17 - Telecomunicações e Inovação}

O indicador 17.1 - "Número de conexões de internet por 100.000 habitantes" é meramente quantitativo, mas pode ser analisado também do ponto de vista qualitativo, com informações sobre as características das conexões, bem como a estabilidade do sistema de internet, em paralelo aos indicadores da Seção 7 que refletem a continuidade fornecimento de energia.

Quanto ao indicador 17.2 - "Número de conexões de telefone celular por 100.000 habitantes", tanto a ANATEL - Agência Nacional de Telecomunicações quanto o MCTIC Ministério da Ciência, Tecnologia, Inovações e Comunicações agregam os dados por unidade da federação ou número DDD, não disponibilizando os valores por município. O censo 2010 IBGE traz o valor de domicílios com telefone celular, o que não representa a quantidade de celulares por habitantes.

\section{Seção 18 - Transporte}

Para o indicador 18.2 - "Quilômetros de sistema de transporte público de média capacidade por 100.000 habitantes" há no PPA 2018-2021 uma meta prevista 40,5 km, referente à implantação de BRT - Bus Rapid Transit e BRS - Bus Rapid Service no PPA 2018-2021. O Projeto do BRT em Sorocaba é um principais programas e projetos da cidade, uma concessão de 20 anos com obras previstas para início em setembro de 2018, que 
consistem em 65,4 km de vias, três terminais integrados, quatro estações de integração, 96 abrigos e uma garagem, além da aquisição de 125 ônibus, sendo 41 articulados, todos com arcondicionado. Serão investidos R\$ 384 milhões em obras de infraestrutura, projetos, desapropriações, material rodante e ITS - Intelligent Transportation System, ou Sistemas Inteligentes de Transporte. Dos R\$ 384 milhões, R\$ 133 milhões são provenientes da Prefeitura de Sorocaba, R\$ 127 milhões do Governo Federal e o restante de responsabilidade da iniciativa privada.

Quanto ao indicador 18.3- "Número anual de viagens em transporte público per capita", o SIG/Sorocaba monitora desde 2015, com frequência mensal, o indicador "passageiros transportados", com meta de 4.800.000/mês no PPA 2018-2021. Este valor foi convertido para viagens/hab.ano utilizando a população prevista para 2021, para compor a fronteira de eficiência e a própria meta adotada.

A fronteira de eficiência para o indicador 18.5 - "Porcentagem de passageiros que se deslocam para o trabalho de forma alternativa ao automóvel privado" indica 50\% (BID, 2013), mas há uma meta de 59,3\% no PDTUM - Plano Diretor de Transporte Urbano e Mobilidade (URBES, 2015), na Tabela 21 - Divisão modal proposta para 2027.

Quanto ao indicador 18.7 - "Quilômetros de ciclovias e ciclofaixas por 100.000 habitantes", o SIG/Sorocaba monitora desde 2014, com frequência mensal, os indicadores "ciclovias implantadas" (novas) e "ciclovias mantidas" (existentes), com meta de 4,7\% no PPA 2018-2021. Também monitora "integração dos usuários do IntegraBike com o transporte coletivo" e "viagens no sistema IntegraBike", valor de difícil correspondência com o indicador 18.7 .

O SIG/Sorocaba monitora desde 2014, com frequência mensal, o indicador "índice de acidentes de trânsito com vítimas fatais (óbitos) por 100 mil habitantes", que corresponde ao indicador 18.8 - "Mortes de trânsito por 100.000 habitantes", com meta de 5 óbitos/100.000hab no PPA 2018-2021. 


\section{Seção 19 - Planejamento Urbano}

O indicador 19.1 - “Áreas verdes (hectares) por 100.000 habitantes" reflete uma questão de definição destas áreas verdes, uma vez que não são especificados os tipos diferentes de áreas verdes, tais como: parques, loteamentos, áreas de lazer, instalações desportivas, etc. $\mathrm{O}$ SIG/Sorocaba monitora desde 2014, com frequência anual, o indicador "cobertura vegetal por habitante", em $\mathrm{m}^{2} / \mathrm{hab}$, com meta de $100 \mathrm{~m}^{2} / \mathrm{hab}$ no PPA 2018-2021, referente às áreas de fragmentos florestais e não considerando somente os "parques naturais e seminaturais e demais espaços abertos" (ABNT, 2017a, p. 60). A Organização Mundial de Saúde (OMS, 2006) recomenda um mínimo de $12 \mathrm{~m}^{2}$ de área verde por habitante, valor convertido para hectares/100.000 hab.

O SIG/Sorocaba monitora desde 2014, com frequência mensal, o indicador "mudas plantadas", correspondente ao indicador 19.2 - "Número de árvores plantadas anualmente por 100.000 habitantes", com meta de 50.000 mudas por ano no Plano de Arborização Urbana (PMS, 2013a). Este valor convertido para mudas/100.000 hab com a população prevista para 2020.

O indicador 19.3 - "Porcentagem de área de assentamentos informais em função da área total da cidade" é de difícil obtenção. Porém, o SIG/Sorocaba monitora desde 2015, com frequência trimestral, o indicador "Títulos de Imóveis (Regularização Fundiária)", com meta de 2000 novas matrículas no PPA 2018-2021, valor de difícil correspondência com o indicador 19.3.

O indicador 19.4 - "Relação empregos/habitação" reflete uma proporção que, se equilibrada, influencia nos deslocamentos das pessoas e, consequentemente, na mobilidade urbana. A tendência favorável foi considerada como de aumento, mas valores muito altos também não são adequados, pois podem significar distritos essencialmente comerciais ou industriais. Este seria o caso de existir uma meta com limite superior e inferior, como recomenda o BID (2013). 


\section{Seção 20 - Esgotos}

Quanto ao indicador 20.1 - "Porcentagem da população da cidade atendida por sistemas de coleta e afastamento de esgoto", o SIG/Sorocaba monitora desde 2014, com frequência semestral, o indicador "cobertura do afastamento de esgoto". No PPA 2018-2021 consta somente uma meta de ampliação da rede coletora e coletores tronco em 1.365,47 km, valor de difícil correspondência com o indicador 20.1.

O SIG/Sorocaba monitora desde 2014, com frequência semestral, o indicador "cobertura do tratamento de esgoto", com meta de 97\% no PPA 2018-2021, correspondente ao inverso do indicador 20.2 - "Porcentagem do esgoto da cidade que não recebeu qualquer tratamento". Novamente, este é um indicador quantitativo, que não leva em consideração a qualidade do tratamento aplicado. O ICTEM - Indicador de Coleta e Tratabilidade de Esgoto da População Urbana de Município é um indicador desenvolvido pela CETESB - Companhia Ambiental do Estado de São Paulo, com o objetivo de verificar as condições de operação de um sistema público de tratamento de esgotos. Esse indicador leva em consideração a efetiva remoção da carga orgânica dos esgotos domésticos, observando também outros elementos que compõem um sistema de tratamento de esgotos, como a coleta, o afastamento e o tratamento. Considera, ainda, o atendimento à legislação quanto à eficiência de remoção da carga orgânica e a conformidade com os padrões de qualidade do corpo receptor dos efluentes. Em 2015, o valor do ICTEM para Sorocaba correspondia a 9,85, a eficiência do tratamento de esgoto era de 90,35\%, a Carga Poluidora Potencial era de $34.471 \mathrm{~kg}$ DBO/dia e Carga Poluidora Remanescente era de $6.483 \mathrm{~kg}$ DBO/dia (EMPLASA, 2017). Cabe citar que a revisão da Norma ISO 37120:2018 (ISO, 2018b) prevê um indicador referente à taxa de conformidade do tratamento do esgoto.

\section{Seção 21 - Água e Saneamento}

Quanto ao indicador 21.1 - "Porcentagem da população da cidade com serviço de abastecimento de água potável”, o SIG/Sorocaba monitora desde 2014, com frequência semestral, o indicador "cobertura para abastecimento de água", com meta de 97\% no PPA 2018-2021. No PPA 2018-2021 consta também uma meta de ampliação de redes e adutoras de 
água tratada em $1.975,02 \mathrm{~km}$, e uma ampliação na capacidade de tratamento de 750 litros/segundo. Este indicador se refere somente ao abastecimento de água por tubulação, ou seja, pela rede de abastecimento, ao passo que o indicador 21.2 - "Porcentagem da população da cidade com acesso sustentável a uma fonte de água adequada para consumo" inclui outros tipos de fornecimento, como fontes públicas, nascentes, poços, entre outros. Novamente, estes são indicadores quantitativos, que não leva em consideração a qualidade da água fornecida. Cabe citar que a revisão da Norma ISO 37120:2018 (ISO, 2018b) prevê um indicador referente à taxa de conformidade da qualidade e potabilidade da água.

Tanto para o indicador 21.4 - "Consumo doméstico total de água per capita (litros/dia)" quanto para o indicador 21.5 - "Consumo total de água per capita (litros/dia)", a NBR ISO 37120:2017 define que a população urbana a ser considerada na divisão é a população urbana total, ao passo que a definição do SNIS - Sistema Nacional de Informações sobre Saneamento considera somente a população atendida com abastecimento de água. Os valores podem divergir, uma vez que pode existir uma parcela da população não atendida. Além disto, cabe o mesmo comentário de outros indicadores de consumo, como o 7.1 - "Uso de energia elétrica residencial total per capita (kWh/ano)". Para os indicadores 21.4 e 21.5, a tendência favorável é a de redução, mas um valor muito reduzido pode esconder um baixo consumo devido à escassez de água.

Quanto ao indicador 21.7 - "Porcentagem de perdas de água (água não faturada)", o SIG/Sorocaba monitora desde 2014, com frequência semestral, o indicador "perda de água tratada", com meta de 30\% no PPA 2018-2021.

\section{Alguns aspectos gerais}

Um problema que emerge em comparações baseadas em indicadores corresponde à invalidação da comparação devido a inconsistências dos dados utilizados ou obtidos. A exemplo do trabalho de Wang e Fox (2017), a análise buscou identificar inconsistências nos dados não só da cidade de Sorocaba, estudo de caso, mas também outras cidades utilizadas no benchmarking. Especificamente, foram realizadas:

- Análise de consistência de definição: avaliando se os dados utilizados geram um indicador da cidade coerente com a definição dada pela NBR ISO 37120:2017 
- Análise de consistência transversal: avalia se os indicadores publicados por uma ou mais cidades são coerentes entre si

- Análise de consistência longitudinal: avalia se um indicador publicado por uma cidade é coerente ao longo de diferentes períodos do tempo

As fontes de dados de indicadores são difusas e o estudo de caso em uma cidade do Estado de São Paulo evidenciou a disponibilidade de dados em bases estaduais. Fazem-se necessárias fontes consistentes de dados nacionais, nomeadamente o IBGE, o SNIS e o DATASUS são bons exemplos. As fontes de dados do Estado de São Paulo, particularmente, são também bons exemplos, especialmente o SEADE, a SSP-SP, a CETESB, a EMPLASA, entre outros.

O levantamento de valores para os indicadores, confrontados com indicadores já monitorados, tanto efetivamente nas cidades e sistemas de gestão quanto em publicações de pesquisas, levantou a questão da existência de indicadores para medir esforço, em contraponto a indicadores para medir resultados. Indicadores para cobertura de coleta de resíduos, de esgotos, ou de abastecimento de água, por exemplo, em alguns sistemas são abordados como quilômetros de redes a serem implantados, o que reflete um esforço, mas não necessariamente um efetivo resultado de saneamento. Se a velocidade de construção de redes não acompanhar o crescimento populacional, a universalização prevista nos ODS - Objetivos de Desenvolvimento Sustentável se torna cada vez mais distante.

A questão da universalização de serviços urbanos demanda um acesso suficiente e pleno a todas as capacidades instaladas, sendo possível análise por meio de um raciocínio topológico do fluxo de redes diante dos desafios das metrópoles para regulação dos custos crescentes e deseconomias de escalas em consequência do crescimento desordenado. Porém, os antigos conceitos subjacentes de universalidade/cobertura aplicados à infraestrutura nas avaliações de pobreza urbana são hoje claramente insuficientes para representar a complexidade do contexto. Se estes conceitos seguirem utilizados da mesma forma, as avaliações refletirão a imprecisão destas representações (TOLEDO, 2014). O modelo de universalização moderno tem por objetivo "evidenciar as ações e omissões intoleráveis ao alcance de um modo de vida sustentável para as presentes e futuras gerações e que, muitas vezes, não estão evidentes ao cidadão, além de mandatoriamente propor soluções inovadoras" (GUIMARÃES, 2015). Outra questão a observar no processo de universalização é que, 
quanto mais próximo um serviço está da meta de $100 \%$, as ampliações se tornam mais complexas e onerosas, sejam pelos custos incrementais, sejam pelas necessidades de inovações tecnológicas. Na análise da relação de custo/benefício marginal, frente ao aumento do nível de uma atividade, no caso de serviço urbano, percebe-se uma tendência inexorável a obter benefícios cada vez menores.

É importante conhecer os potenciais efeitos contrários dos valores de alguns indicadores, sejam positivos ou negativos, na análise de resultados. Por exemplo, embora o uso de madeira para aquecimento possa contribuir para a conservação de recursos não renováveis, também leva a um aumento de emissões de material particulado e, consequentemente, a deterioração da qualidade do ar. É evidente a necessidade de um sistema abrangente de indicadores, elaborado sobre cadeias de causa e efeito, capaz de mapear efeitos colaterais, relações inversas (trade-offs) ou conflitos entre metas (LÜTZKENDORF; BALOUKTSI, 2017).

O exercício da análise por clustering mostrou que é possível levar em consideração vários indicadores distintos em uma mesma análise, o que pode proporcionar uma melhor compreensão das relações entre indicadores. Os resultados indicam que uma cidade pode comparar seu desempenho entre cidades agrupadas em função de indicadores semelhantes, detectando melhores práticas em cidades similares, ou ainda buscar uma meta de mudar sua situação de um grupo para outro, que apresente benchmarks e metas mais desafiadoras.

Evidenciam-se, também, questões de escala de análise, tanto de indicadores quanto de metas. Quando analisados comparativamente, a escala da cidade possui valores e métricas muitas vezes diferenciados do fórum internacional, que, por sua vez, não leva em consideração as especificidades da gestão local, ou mesmo da gestão da federação, para cada caso ou contexto. Entretanto, de um modo geral, é possível analisar os valores comparativamente, sempre levando em conta que divergências podem indicar aspectos locais que também devem ser considerados. Na elaboração das fronteiras de eficiência e no benchmarking em si, devem ser levadas em consideração estas inconsistências, na intenção de minimizá-las ou mitigá-las.

Os existentes painéis visuais (dashboards) para cidades são diferentes, interessantes, sofisticados, provenientes de diversos fornecedores. No entanto, poucos deles são de fato 
utilizados para tomar melhores decisões ou para melhorar os serviços públicos. Muitas informações e dados isoladamente não conduzem à cidade sustentável, ou ainda, à cidade inteligente. Faz-se necessário aliar o desenvolvimento das tecnologias e dos serviços à resposta de problemas da cidade, dos cidadãos. É de suma importância que o processo participativo seja o centro da revolução digital. Por outro lado, dashboards auxiliam a visualização e a compreensão mais clara das questões, oferecendo um grande potencial para fomentar os próprios processos participativos.

A análise dos 100 indicadores da NBR ISO 37120:2017 baseada nos dados atuais do desenvolvimento urbano de Sorocaba reflete o progresso resultante das recentes intervenções na sustentabilidade urbana, tais como: o tratamento de esgoto e consequente despoluição do rio Sorocaba, a implantação de ciclovias e disponibilização gratuita de bicicletas para empréstimo, conservação da biodiversidade, entre outros. Como citado anteriormente, a sustentabilidade está presente nos temas da cidade de Sorocaba, que é um dos dez municípios brasileiros participantes do OPCC - One Planet City Challenge criado pelo WWF - World Wide Fund for Nature, e uma das oito cidades brasileiras selecionadas em 2013 pelo UrbanLEDS - Urban Low Emissions Development Strategy, ou Estratégia de Desenvolvimento Urbano de Baixo Carbono, implementado pelo ICLEI - Local Governments for Sustainability, em parceria com UN-Habitat. Fazem parte dos programas e projetos principais da cidade, conforme pontuado na página 168: diminuir os vazios urbanos e estimular o crescimento horizontal da cidade, modernizar e melhorar a mobilidade urbana com a implantação o BRT e VLT, desenvolver a região metropolitana, reestruturação e urbanização da área central e a eficiência no consumo de água e no uso da rede de esgoto. Estes programas consistem em ações de intervenção para a transição da cidade atual e seu cenário futuro, compreendendo várias intervenções de retrofit urbano, que podem ser priorizadas pelo método proposto.

Cabe citar que o estudo de caso proporcionou um embasamento prático, de maneira que o volume de inúmeros dados coletados serviu como insumo do método proposto, que foi sendo elaborado e desenvolvido sobre os valores numéricos, de forma a minimizar inconsistências. O exercício de definição de metas resultou em uma classificação dos indicadores, de forma a identificar temas da cidade com potencial de melhoria, em que novas metas podem ser arbitradas, de acordo com as intervenções necessárias e prioritárias de retrofit urbano que potencialmente alterariam a classificação dos indicadores "médios" e "ruins". A integração dos 100 indicadores em um único dashboard proporciona a visualização 
abrangente das potenciais melhorias, nos diversos temas da NBR ISO 37120:2017. Desta forma, o tomador de decisão pode priorizar entre prover mais leitos hospitalares (construir um novo hospital), mais ciclovias, mais redes de abastecimento de água e de coleta de esgoto, ou todas as ações integradas, por exemplo, atribuindo valores numéricos para monitorar os indicadores relacionados.

Os indicadores da NBR ISO 37120:2017 fornecem um potencial de compreensão mais claro e holístico pela sociedade sobre a urbanização e tópicos de sustentabilidade relacionados. Porém, indicadores figuram como um meio efetivo de capturar, monitorar e direcionar várias situações e problemas. Exigências sobre dados significativos surgem quando os indicadores são monitorados e levam ao desenvolvimento urbano sustentável. Uma vez que municípios, distritos, bairros e comunidades enfrentam circunstâncias distintas, com diferentes prioridades e pretensões, é evidente que há múltiplos caminhos que levam ao desenvolvimento urbano sustentável. Há um grande desafio na criação de capacidade de gestão nos municípios brasileiros, no levantamento, acompanhamento e monitoramento de indicadores. 


\section{CONSIDERAÇÕES FINAIS}

\section{Retrofit Urbano}

A dimensão quantitativa para a expansão urbana futura é de suma importância, pois provê a informação necessária para uma discussão integrada de planos e políticas para gestão da expansão urbana, seja para a reverter, conter, guiar, ou simplesmente permitir que ela ocorra. A disponibilidade de informação confiável quanto a área territorial necessária para acomodar a população crescente de muitas cidades nos países em desenvolvimento é claramente necessária para instrumentar uma tomada de decisão no momento atual.

Vários autores defendem o conceito de cidade compacta, que se caracteriza por evitar expansão sobre as áreas rurais e áreas de preservação ambiental, por aumentar o desempenho da energia, reduzir o nível de poluição e o consumo de recursos, e apresentar predominância de transporte coletivo eficiente. Por outro lado, Neuman (2005) afirma que há um paradoxo da cidade compacta, que se refere à relação inversa da sustentabilidade das cidades e de sua habitabilidade. Para uma cidade ser sustentável, funcionalidades e população devem ser concentrar em densidades maiores. Contudo, para uma cidade ser habitável, funcionalidades e população devem se dispersar em densidades mais baixas. Deve-se ter cautela em aceitar alegações de que a habitabilidade é maior em uma forma de assentamento humano do que em outra, pois habitabilidade não é somente uma questão de forma urbana, mas também uma questão de preferência pessoal. Como um resultado combinado destes fatores, duas tendências contraditórias, forma urbana compacta e forma urbana dispersa ou espraiada (sprawling), resultam de políticas e investimentos também contraditórios.

Contudo, continuam a ocorrer ambas formas de expansão urbana, dispersa e compacta. Dispersão e segregação da população e de atividades perduram enquanto habitantes e proprietários de empresas buscam uma maior qualidade de vida e lucros maiores fora da cidade. Entretanto, relocação para o centro da cidade e reinvestimento no mesmo, também ocorrem assim que cidadãos, visitantes e empresas buscam benefícios para a cidade. Muitas cidades como Philadelphia, Baltimore, Cleveland e Detroit têm bairros residenciais compactos, habitáveis e vitais, em áreas que estiveram vazias por anos, senão décadas. Isso 
ocorreu mesmo quando suas áreas metropolitanas cresceram em população e território (NEUMAN, 2005).

Deakin, Campbell e Reid (2012) afirmam que a literatura atual disponível sobre retrofit é seletiva, oferecendo somente uma parte do conhecimento no assunto e insuficientemente abrangente para oferecer uma solução integrada. As razões podem ser tanto o foco exclusivo em urbanização recente, quanto as publicações relativas a renovação e reurbanização se concentrarem em reduções de consumo de energia.

O retrofit urbano consiste em um dos maiores desafios para planejadores urbanos e tomadores de decisão, na intenção de gerenciar as transições urbanas estratégicas. É importante que gestores compreendam as implicações de inovações disruptivas em setores urbanos essenciais, como energia, antes de proceder com transições substanciais. A gestão da transição requer governança responsiva, com uma abordagem urbana integrada e antecipativa, para atores urbanos se comprometerem em explorar a estruturação de processos sociais e técnicos de retrofit urbano, em meio a uma variedade de escalas e domínios (DIXON et al., 2014) (EAMES et al., 2018). Convém que o retrofit urbano também seja um processo solidamente fundamentado na cultura local, na distribuição igualitária dos serviços urbanos, aderência aos princípios de gestão democrática e regeneração de valores e práticas sociais (BOUSSAA, 2015). É fundamental o alinhamento entre as dimensões técnica e social do retrofit urbano, para que ele se concretize, e convém considerar as subjetividades das intervenções. Nas cidades da Austrália, por exemplo, em todas as escalas, mas particularmente na escala local, há um dinâmico conjunto de instituições e mecanismos para promover condutas de implantação de retrofit. Entretanto, há menos evidência da capacidade de gestão destas tecnologias para implementação efetiva do retrofit. Mais trabalhos significativos, tanto na pesquisa quanto na política, são necessários para fomentar sistemas sociais, técnicos e políticos indispensáveis para um retrofit mais abrangente da cidade (DOWLING; MCGUIRK; BULKELEY, 2014).

\section{Retrofit Urbano Sustentável}

Sustentabilidade é essencialmente um conceito integrado. Enquanto diversos métodos e ferramentas diferentes estão disponíveis para integração, nenhum componente do processo, 
considerado isoladamente, provavelmente será suficiente. Ao contrário, vários componentes são necessários para assegurar que a integração está completamente incorporada no processo de análise, não permitindo contínua ou renovada negligência de considerações tradicionalmente subvalorizadas, incluindo a proteção de sistemas ecológicos, redução de desigualdades e respeito pela incerteza (GIBSON, 2006).

Os processos existentes de planejamento urbano integrado evidenciam que são meios bem-sucedidos de implementação de projetos de larga escala sobre a infraestrutura urbana. Entretanto, o crescente interesse em promover cidades mais sustentáveis tem direcionado a questões sobre como estes processos são capazes de atingir a transformação requerida frente às mudanças climáticas e o desenvolvimento sustentável. Para melhoria do desempenho e sustentabilidade nas cidades, os indicadores e metas devem ser intensamente integrados com o planejamento estratégico da cidade e os processos de implementação (GIBBERD, 2017). Fazem-se necessárias pesquisas adicionais para determinar aspectos de comparação de cidades e para encontrar métodos que conectem indicadores de sustentabilidade urbana à tomada de decisão do poder público, na intenção de atingir as metas de sustentabilidade (DENG et al., 2017).

O retrofit urbano, compreendendo a renovação urbana e a recuperação de áreas degradadas, consiste também em resultado da aplicação dos conceitos de sustentabilidade, no sentido de monitorar a expansão urbana. Muitas cidades passaram por processo de mau uso, abandono e esvaziamento de áreas pela redução da função industrial, áreas essas geralmente localizadas ao longo das principais vias de transporte e ao longo de rios e canais. A intenção de recuperar e dar novos usos a estas áreas apresenta grande vantagem frente a criar novas urbanizações e infraestruturas.

\section{Padronização de Indicadores Urbanos}

Há uma lógica por trás da padronização e codificação de informações e conhecimento sobre desenvolvimento urbano, que permite compartilhar lições aprendidas, estimular a inovação e melhorar o benchmarking. Ao mesmo tempo, porém, aumenta o risco de descontextualização e desvalorização das realidades urbanas intrinsicamente locais e sociais. Além disto, os interesses que direcionam a abordagem de padronização de dados urbanos também devem ser analisados (CAPROTTI et al., 2017). 
A convergência global de padrões para indicadores urbanos, dados abertos de cidades e a internet fornece uma oportunidade singular para municípios e pesquisadores analisarem e compararem o desempenho de cidades. Infelizmente, cada indicador depende de dados primários, muitos dos quais não estão publicados e não há padrões para a divulgação de indicadores na internet (FOX; PETTIT, 2015) (FOX, 2015). Novas fontes de dados e tecnologias para coleta de dados e para integração de diversas fontes de dados necessitam ser exploradas, inclusive por meio de parcerias entre a sociedade civil, o setor privado e a academia. A integração de informação geoespacial e dados estatísticos será particularmente importante na produção de determinados indicadores (UN-DESA, 2017b).

Em contraponto, métricas adotadas pelos órgãos internacionais são passíveis de discussão mais aprofundada, pois denotam questões políticas e apresentam algumas metas difíceis ou mesmo inatingíveis, sem uma explicação de como foram calculadas. Os governos locais, por sua vez, lidam com limitações de participação na decisão de alguns temas, pois são relativos a competências extra local ou regional. Neste contexto, a gestão municipal pode desempenhar o papel de participação de agenda política regional ou nacional, através de fóruns específicos, obtendo direcionamentos para metas específicas além da competência local. Neste sentido, o benchmarking por meio de clustering pode ser uma alternativa de avaliar como a cidade pode buscar não só os melhores valores de desempenho no próprio grupo a que pertence, mas também considerando outros clusters, ou a região e/ou Estado em que os clusters estão contidos.

Embora sejam evidentes os benefícios decorrentes da utilização de métricas padronizadas, a norma ISO 37120:2104 não é perfeita e necessita de ajustes iniciais e regulares para assegurar a eficiência da coleta de dados a partir de indicadores existentes para os padronizados (DENG et al., 2017). Entretanto, no longo prazo, a padronização permitirá o diagnóstico de problemas e causas, e a identificação de áreas potenciais que poderiam se beneficiar com uma boa governança e com respostas e decisões baseadas em indicadores. A NBR ISO 37120:2017 permite que cidades possam monitorar o sucesso e o impacto de intervenções, projetos urbanos atuais e futuros, infraestruturas, políticas, disposição final de resíduos, poluição e acesso a serviços pelos cidadãos, entre outros. Assim, os planejadores, políticos e gestores urbanos podem monitorar os impactos socioeconômicos e ambientais de ações e intervenções de retrofit urbano. 
A NBR ISO 37120:2017 compreende uma abordagem "top-down". Portanto, critérios adicionais e respectivos indicadores podem ser elaborados e aceitos por meio de um processo participativo, em abordagem "bottom-up", concebido em um distrito ou comunidade com grupos de atores urbanos (LÜTZKENDORF; BALOUKTSI, 2017). Para municípios interessados, a combinação de dados transversais pode revelar situações inter-relacionadas. Uma cidade pode decidir, por exemplo, promover esforços colaborativos para traçar uma nova política urbana local e monitorar os resultados das soluções e intervenções por meio do método para retrofit urbano. Assim, podem ser identificadas ações antecipadas e fomentadas capacidades para auxiliar gestores a formular soluções mais específicas e efetivas.

O uso de indicadores pode ser restringido, entretanto, pela ausência de interesse e apoio político, limitando seu potencial em mudar políticas de desenvolvimento urbano sustentável no médio e longo prazos (MORENO PIRES; FIDÉLIS; RAMOS, 2014). Os mecanismos tradicionais de elaboração de políticas públicas e legislação geralmente não são equivalentes à tarefa de solucionar os desafios atuais enfrentados pelas cidades. Além disto, o discurso de cidades sustentáveis e/ou inteligentes é algumas vezes adotado por prefeituras e instituições públicas simplesmente para fins eleitorais (MARSAL-LLACUNA; SEGAL, 2017). Por outro lado, indicadores urbanos significativos, inequívocos e bem orientados, que possam atender as necessidades atuais e futuras dos cidadãos, são componentes vitais para o debate público municipal sobre o futuro da cidade e o comprometimento da sociedade.

A tomada de decisão envolve questões sociopolíticas e condicionalidades relativas aos impactos de visões diferentes de técnicos e tomadores de decisão, muitas vezes conflitantes. Aspectos políticos e institucionais, intangíveis e imensuráveis numericamente por indicadores, influenciam as tomadas de decisão e a definição de metas futuras. Além disto, a descontinuidade de gestão municipal e as mudanças de governos influenciam diretamente na condução e manutenção das metas, e constituem um componente sociopolítico institucional da maior gravidade.

Teoricamente, os dashboards são aptos a traduzir as complexidades das cidades em informações racionais, detalhadas e ordenadas sistematicamente. Porém, atenção especial deve ser dada à questão da disponibilidade de dados, à seleção das fontes de informação, e se os indicadores são fáceis de medir ou calcular, bem como fornecer informações confiáveis que podem ser compreendidas por não especialistas. Além disto, os dashboards de 
indicadores urbanos dependem de dados disponíveis, acessíveis, de reconhecida qualidade e frequentemente atualizados, e que podem ser obtidos de uma maneira econômica (LÜTZKENDORF; BALOUKTSI, 2017). Sistemas de informação podem impactar os cidadãos em termos de satisfação, percepção de utilidade, participação, produtividade e confiança em decisões tomadas. Eles podem também ter um impacto na economia das cidades em termos de benefícios econômicos, poder de atração, mercado de ações, redução de custos, etc (LUQUE-MARTÍNEZ; MUÑOZ-LEIVA, 2005). Os dashboards podem ser utilizados por diferentes atores urbanos, tais como: políticos, gestores de projetos, cidadãos comuns, e outros, para propósitos diversos e em diferentes contextos, utilizando plataformas distintas como websites ou dispositivos móveis. O dashboard proposto, resultado do método para retrofit urbano, indica a situação atual da cidade e após as ações de retrofit urbano, por meio de indicadores e metas, com uma estratégia adequada de comunicação, voltada também à comunidade local. A expectativa é de que o dashboard seja utilizado conceitualmente para fomentar discussões sobre a situação do desenvolvimento urbano local sustentável e as tendências futuras, na direção dos cenários futuros pretendidos.

As limitações e dificuldades relativas ao uso de indicadores padronizados e as metas dos ODS - Objetivos de Desenvolvimento Sustentável incluem a pouca disponibilidade de dados abertos, padronizados e comparáveis. Em muitas cidades isto é resultado da grande informalidade, especialmente na África e na Ásia, o que significa ausência de vários processos e dinâmicas nas pesquisas de domicílios em que as estatísticas nacionais estão fundamentadas. Outro problema é que estes dados enviesados são frequentemente gerados por indicadores que levam em conta aspectos formais estão em detrimento do vasto setor informal que existe em muitas cidades (KLOPP; PETRETTA, 2017). Assim, são negligenciados dados precisos e atualizados sobre alguns aspectos das vidas das pessoas, vários grupos e indivíduos permanecem “invisíveis" e muitos desafios da urbanização permanecem insuficientemente compreendidos (UN-DESA, 2017b). As agências e redes de estatísticas nacionais, e outras instituições relevantes, necessitam de melhoria na direção de corrigir estas deficiências. Ao mesmo tempo, os países devem criar sólidos mecanismos de comunicação destinados a agregar dados nacionais comparáveis e padronizados, no sistema estatístico internacional. Para suprir as lacunas nos dados, convém que os países adotem normas estabelecidas internacionalmente, ao passo que a comunidade estatística internacional deve se empenhar em desenvolver parcerias e outros atores urbanos devem buscar a redução da informalidade. 


\section{Método para Retrofit Urbano}

A despeito da complexidade de abordagens mais abrangentes e integradas, a aplicação da método para retrofit urbano, proposto nesta tese, permite constituir uma importante base de informação para apoio à decisão, proporcionando visão mais completa e global do diagnóstico atual e das metas de futuro existentes, proporcionando tomadas de decisão mais conscientes, no que diz respeito a identificação das prioridades das intervenções de retrofit urbano, possibilitando o desenvolvimento de planos de ação de longo prazo.

O método para retrofit urbano evidencia que os indicadores da NBR ISO 37120:2017 e os ODS podem ser aplicados e integrados aos processos de planejamento urbano, por meio de análise de tendência, levantamento de valores de melhor desempenho de cidades (city benchmarking) e cenários futuros baseados na definição clara de metas de longo prazo. $\mathrm{O}$ PPA - Plano PluriAnual, ou Plano de Metas municipal, elaborado por algumas cidades brasileiras, revela um plano de ação relacionado a metas numéricas e prazos definidos para o período de uma gestão municipal, quatro anos.

A busca para a melhoria contínua de vários indicadores da Norma deveria fazer parte do planejamento orçamentário dos municípios, principalmente frente a preocupação do atendimento da Agenda 2030 e das metas dos ODS. Os recursos devem ser priorizados no sentido de reduzir a mortalidade infantil e o número de mortes no trânsito, por exemplo. Projetos e programas devem ser fomentados para aumentar a porcentagem da população atendida por coleta e afastamento de esgoto, a porcentagem da população com abastecimento de água potável, a porcentagem dos resíduos sólidos domiciliares coletados, entre outros.

Buscou-se a proposição de um método fundamentado na abordagem sistêmica da engenharia urbana, com mais ênfase em medições e valores numéricos, quantitativos, como forma de redução da subjetividade. $\mathrm{Na}$ intenção de propor um dashboard para auxílio da tomada de decisão, especificamente para a definição de metas de longo prazo, o método resultante compôs uma ferramenta de governança, de informação, para acompanhamento e identificação de potencial de mitigação de problemas futuros. O dashboard evidencia a aplicabilidade do método, proporcionando um ponto de vista do passado (com a análise de tendência), do presente (com o benchmarking e identificação de valores de melhor 
desempenho de cidades) e do futuro (com a avaliação das distâncias entre indicadores atuais e metas futuras).

A flexibilidade e a abordagem dinâmica do dashboard proporcionam uma inovação, no sentido de apresentar funcionalidades que podem ser adaptadas para futuras utilizações e necessidades dos gestores e usuários. A ferramenta apresenta um potencial pedagógico para o gestor, como um instrumento de aprendizado sobre valores numéricos de metas e indicadores, mas também propiciando uma análise da natureza material do indicador, estimulando a abrangência de indicadores na parametrização das metas e de resultados. Desta forma, a definição das metas proporciona valores numéricos com maior consistência e adequação aos contextos urbanos.

\section{Continuidade da Pesquisa}

Cabe informar que o Programa Município Verde Azul, da Secretaria de Meio Ambiente do Estado de São Paulo, estimulou que os municípios participantes do Programa realizassem o levantamento de parte dos indicadores da NBR ISO 37120 no ciclo de 2017, o que auxiliou o processo de divulgação da Norma e também a conscientização do uso de indicadores para cidades sustentáveis. Fruto desta iniciativa, foi formalizado em janeiro de 2018 um protocolo de intenções entre a Secretaria de Meio Ambiente e a USP.

Conforme citado anteriormente, a norma ISO 37120:2014 foi revisada, cancelada e substituída pela ISO 37120:2018. A ABNT/CEE-268 - Comissão de Estudo Especial de Desenvolvimento Sustentável em Comunidades já iniciou os trabalhos de adoção da revisão da norma, o que irá gerar uma versão atualizada da NBR ISO 37120:2017. No processo de revisão desta norma pelo comitê da ISO, é importante informar a que a participação brasileira encaminhou 23 comentários à versão DIS - Draft International Standard da norma, em 10.08.17, sendo que 20 foram aceitos e 3 rejeitados. A Tabela 10, a seguir, resume a alteração entre a quantidade de indicadores e de Seções/Temas entre a ISO 37120:2014 e a ISO 37120:2018.

Portanto, para continuidade desta pesquisa, a atualização do método para retrofit urbano, análises e dashboard para a nova versão da norma será importante. Além disto, pode-se ampliar a análise de benchmarking levando-se em consideração outras fontes de dados, como 
os indicadores das cidades signatárias do Programa Cidades Sustentáveis. É interessante, caso os dados estejam disponíveis, adotar mais indicadores para a análise por clustering. Outras publicações, como o "Atlas 2017 de Objetivos de Desenvolvimento Sustentável” (WORLD BANK, 2017) podem ser consideradas para compor as fronteiras de eficiência. Além disto, outras cidades podem ser utilizadas como casos de estudo, selecionado outras unidades da federação, para comparar as fontes dos dados, principalmente as estaduais. Desta forma, é possível criar novos dashboards e novas bases de comparação brasileiras.

Tabela 10: Comparativo de indicadores da ISO 37120:2014 e da sua revisão de 2018.

$(\mathrm{E}=$ Essencial, $\mathrm{A}=$ de Apoio, $\mathrm{P}=$ de Perfil, alterações entre as versões em azul)

\begin{tabular}{|c|c|c|c|c|c|c|c|c|c|c|}
\hline \multicolumn{5}{|c|}{ ISO 37120:2014 } & \multicolumn{6}{|c|}{ ISO 37120:20184 } \\
\hline \multicolumn{2}{|c|}{ Seção - Tema } & \multirow{2}{*}{$\begin{array}{l}\mathbf{E} \\
3 \\
\end{array}$} & \multirow{2}{*}{$\begin{array}{l}\text { A } \\
4\end{array}$} & \multirow{2}{*}{$\begin{array}{c}\begin{array}{c}\text { Sub- } \\
\text { total }\end{array} \\
7\end{array}$} & \multicolumn{2}{|r|}{ Seção - Tema } & \multirow{2}{*}{$\frac{\mathbf{E}}{1}$} & \multirow{2}{*}{$\begin{array}{c}\mathbf{A} \\
7\end{array}$} & \multirow{2}{*}{$\begin{array}{l}\mathbf{P} \\
3\end{array}$} & \multirow{2}{*}{$\begin{array}{c}\begin{array}{c}\text { Sub- } \\
\text { total }\end{array} \\
11\end{array}$} \\
\hline 5 & Economia & & & & 5 & Economia & & & & \\
\hline 6 & Educação & 4 & 3 & 7 & 6 & Educação & 4 & 2 & 0 & 6 \\
\hline 7 & Energia & 4 & 3 & 7 & 7 & Energia & 5 & 2 & 2 & 9 \\
\hline 8 & Meio Ambiente & 3 & 5 & 8 & 8 & Meio Ambiente & 3 & 6 & 0 & 9 \\
\hline 9 & Finanças & 1 & 3 & 4 & 9 & Finanças & 2 & 2 & 2 & 6 \\
\hline 10 & $\begin{array}{l}\text { Resposta a Incêndio e } \\
\text { emergências }\end{array}$ & 3 & 3 & 6 & & & & & & \\
\hline 11 & Governança & 2 & 4 & 6 & 10 & Governança & 1 & 3 & 0 & 4 \\
\hline \multirow[t]{3}{*}{12} & Saúde & 4 & 3 & 7 & 11 & Saúde & 4 & 2 & 0 & 6 \\
\hline & & & & & 12 & Habitação & 2 & 2 & 6 & 10 \\
\hline & & & & & 13 & População e condições sociais & 1 & 2 & 6 & 9 \\
\hline 13 & Recreação & 0 & 2 & 2 & 14 & Recreação & 0 & 2 & 0 & 2 \\
\hline 14 & Segurança & 2 & 3 & 5 & 15 & Segurança & 5 & 5 & 0 & 10 \\
\hline 15 & Habitação & 1 & 2 & 3 & & & & & & \\
\hline \multirow[t]{2}{*}{16} & Resíduos Sólidos & 3 & 7 & 10 & 16 & Resíduos Sólidos & 5 & 5 & 0 & 10 \\
\hline & & & & & 17 & Esporte e Cultura & 1 & 2 & 0 & 3 \\
\hline 17 & $\begin{array}{l}\text { Telecomunicações e } \\
\text { inovação }\end{array}$ & 2 & 1 & 3 & 18 & Telecomunicações e inovação & 0 & 2 & 0 & 2 \\
\hline \multirow[t]{2}{*}{18} & Transporte & 4 & 5 & 9 & 19 & Transporte & 2 & 5 & 2 & 9 \\
\hline & & & & & 20 & $\begin{array}{l}\text { Agricultura Urbana/Local e } \\
\text { Segurança Alimentar }\end{array}$ & 1 & 3 & 0 & 4 \\
\hline 19 & Planejamento Urbano & 1 & 3 & 4 & 20 & Planejamento Urbano & 1 & 3 & 3 & 7 \\
\hline 20 & Esgotos & 5 & 0 & 5 & 21 & Esgotos & 3 & 1 & 0 & 4 \\
\hline \multirow[t]{4}{*}{21} & Água e Saneamento & 4 & 3 & 7 & 23 & Água e Saneamento & 4 & 3 & 0 & 7 \\
\hline & Sub-total & 46 & 54 & 100 & & Sub-total & 45 & 59 & 24 & 128 \\
\hline & Perfil & & & 39 & Per & il adicionais & & & & 16 \\
\hline & Total & & & 139 & & Total & & & & 144 \\
\hline
\end{tabular}

Elaborada pela autora. 
O acréscimo de 5 indicadores aos existentes na versão original da ISO 37120, de 2014, traz o questionamento sobre a necessidade de tantos indicadores, ou sobre qual seria o número ideal para monitoramento. Partindo do pressuposto que a participação da comunidade é necessária para a tomada de decisão da meta a ser adotada, a ferramenta do dashboard pode ser aferida em função dos usuários, adaptando-se as funcionalidades de acordo com o preparo dos usuários para utilização da ferramenta. Assim, é importante avaliar a aplicabilidade futura do método para retrofit urbano, na utilização efetiva e prática do dashboard, e nas possibilidades de adaptá-lo.

Conforme informado anteriormente, na análise de tendência foi adotada a Média Móvel Simples com o comprimento da média $(k)$ como 3 anos, pois muitos dados dos indicadores não estão disponíveis em período de tempo maior, para a cidade de Sorocaba. Porém, para aprimoramento do método, pode-se posteriormente testar, aferir e validar o valor de $k$, inclusive independentemente para cada indicador, valendo-se da flexibilidade e adaptabilidade do dashboard. Como a gestão municipal tem duração de 4 anos, uma primeira sugestão seria adotar $k$ como 4 anos. Porém, variações temporais distintas podem ocorrer para cada indicador individualmente, portanto é possível que outros meios de análise de tendência sejam mais adequados para alguns indicadores, e menos para outros. O dashboard permite que outras formulações para análise de tendência sejam adotadas para indicadores, individualmente, de acordo com a melhor adequação.

A questão do retrofit urbano com vistas a certificação tem atraído a atenção das políticas urbanas internacionalmente, e o debate científico neste campo tem se desenvolvido sob uma ótica multidisciplinar, envolvendo diversos tipos de pesquisas, de profissionais e organizações. De fato, faz-se necessária uma compreensão holística das demandas urbanas, a fim de implementar o retrofit urbano de forma mais ampla, para melhor proporcionar a transição para o cenário visualizado a longo prazo. A pesquisa buscou aproximar a academia das discussões com a vida pública e cotidiana, trazendo uma contribuição multidisciplinar e multipropósito, possibilitando discussões com outras áreas do conhecimento. 


\section{REFERÊNCIAS}

ABNT - ASSOCIAÇÃO BRASILEIRA DE NORMAS TÉCNICAS. NBR 15575:2013 Edificações Habitacionais - Desempenho, 2013.

ABNT - ASSOCIAÇÃO BRASILEIRA DE NORMAS TÉCNICAS. NBR 16280:2015 Reforma em edificações - Sistema de gestão de reformas - Requisitos, 2015.

ABNT - ASSOCIAÇÃO BRASILEIRA DE NORMAS TÉCNICAS. ABNT NBR ISO 37120:2017 - Desenvolvimento sustentável de comunidades - Indicadores para serviços urbanos e qualidade de vida, 18 jan. 2017a.

ABNT - ASSOCIAÇÃO BRASILEIRA DE NORMAS TÉCNICAS. ABNT NBR ISO 37100:2017 - Desenvolvimento sustentável de comunidades - Vocabulário, 23 ago. 2017b.

ABNT - ASSOCIAÇÃO BRASILEIRA DE NORMAS TÉCNICAS. ABNT NBR ISO 37101:2017 - Desenvolvimento sustentável de comunidades - Sistema de gestão para desenvolvimento sustentável - Requisitos com orientações para uso, 23 ago. 2017c.

AFONSO, R. A.; DO NASCIMENTO, C. H.; GARCIA, V. C.; ÁlVARO, A. Smartcluster: Utilizando dados publicos para agrupar cidades inteligentes por dominios. In: XI Simposio Brasileiro de Sistemas de Informacao (SBSI), Anais...2015a. Disponível em:

$<$ https://www.researchgate.net/profile/Vinicius_Garcia/publication/280161476_SmartCluster _Utilizando_Dados_Publicos_para_Agrupar_Cidades_Inteligentes_por_Dominios_Alternativ e_Title_SmartCluster_Using_Public_Data_to_Group_Smart_Cities_by_Domains//inks/55ad5 dfd08aee079921e238c.pdf>. Acesso em: 13 set. 2017.

AFONSO, R. A.; DOS SANTOS BRITO, K.; DO NASCIMENTO, C. H.; GARCIA, V. C.; ÁLVARO, A. Brazilian smart cities: using a maturity model to measure and compare inequality in cities. In: Anais...ACM Press, 2015b. Disponível em:

$<$ http://dl.acm.org/citation.cfm?doid=2757401.2757426>. Acesso em: 13 set. 2017.

AHVENNIEMI, H.; HUOVILA, A.; PINTO-SEPPÄ, I.; AIRAKSINEN, M. What Are the Differences between Sustainable and Smart Cities? Cities, v. 60, p. 234-245, fev. 2017.

AILA - AUSTRALIAN INSTITUTE OF LANDSCAPE ARCHITECTS. Retrofitting Urban Environments: National Policy Statement., nov. 2010. Disponível em:

$<$ http://members.aila.org.au/imis_prod/documents/AILA/Advocacy/National\%20Policy\%20S tatements/Retrofitting\%20Urban\%20Environments.pdf>. Acesso em: 19 maio. 2016.

ALONSO, A.; MONZÓN, A.; CASCAJO, R. Comparative Analysis of Passenger Transport Sustainability in European Cities. Ecological Indicators, v. 48, p. 578-592, jan. 2015.

AMIRTAHMASEBI, R.; ORLOFF, M.; WAHBA, S.; ALTMAN, A. Regenerating Urban Land: A Practitioner's Guide to Leveraging Private Investment. The World Bank, 2016.

ANATEL - AGÊNCIA NACIONAL DE TELECOMUNICAÇÕES. Arquivos Anatel.

Disponível em: <https://cloud.anatel.gov.br/index.php/s/TpaFAwSw7RPfBa8 $>$. Acesso em: 20 mar. 2018. 
ANEEL - AGÊNCIA NACIONAL DE ENERGIA ELÉTRICA. Indicadores Coletivo de Continuidade. Disponível em: $<$ http://www.aneel.gov.br/indicadores-coletivos-decontinuidade>. Acesso em: 20 mar. 2018.

ANGEL, S.; PARENT, J.; CIVCO, D. L.; BLEI, A.; POTERE, D. The dimensions of global urban expansion: Estimates and projections for all countries, 2000-2050. Progress in Planning, v. 75, n. 2, p. 53-107, 2011.

ANGELIDOU, M. Smart Cities: A Conjuncture of Four Forces. Cities, v. 47, p. 95-106, set. 2015.

ANTHOPOULOS, L. Smart Utopia VS Smart Reality: Learning by Experience from 10 Smart City Cases. Cities, v. 63, p. 128-148, mar. 2017.

ASMUSSEN, M. W. Entendendo o jargão hoteleiro: conceitos e terminologia básicos do ramo hoteleiro. In: Real State: Economia \& Mercados. [s.l: s.n.]2p. 34 a 37.

ÅSTEBØL, S. O.; HVITVED-JACOBSEN, T.; SIMONSEN, Ø. Sustainable stormwater management at Fornebu - from an airport to an industrial and residential area of the city of Oslo, Norway. Highway and Urban Pollution, v. 334-335, p. 239-249, 1 dez. 2004.

BAI, X.; DAWSON, R. J.; ÜRGE-VORSATZ, D.; DELGADO, G. C.; SALISU BARAU, A.; DHAKAL, S.; DODMAN, D.; LEONARDSEN, L.; MASSON-DELMOTTE, V.; ROBERTS, D. C.; SCHULTZ, S. Six research priorities for cities and climate change. Nature, v. 555, n. 7694, p. 23-25, 1 mar. 2018.

BARNS, S. Smart Cities and Urban Data Platforms: Designing Interfaces for Smart Governance. City, Culture and Society, nov. 2017. Disponível em:

$<$ http://linkinghub.elsevier.com/retrieve/pii/S1877916617302047>. Acesso em: 8 jan. 2018.

BBC - BANCO CENTRAL DO BRASIL. Cotações e boletins. Disponível em: $<$ http://www4.bcb.gov.br/pec/taxas/port/ptaxnpesq.asp?id=txcotacao $>$. Acesso em: $14 \mathrm{mar}$. 2018.

BELSKY, E. S. Planejamento para o Desenvolvimento Urbano Inclusivo e Sustentável. In: Estado do mundo 2012: rumo à prosperidade sustentável. Salvador: Universidade Livre da Mata Atlântica, 2012. p. 288.

BID - BANCO INTERAMERICANO DE DESENVOLVIMENTO. ICES - Indicadores da Iniciativa Cidades Emergentes e Sustentáveis - Guia metodológico - Anexo 2, 2013. Disponível em: $<$ http://transparencia.joaopessoa.pb.gov.br/wp-content/uploads/2015/01/GuiaMetodol\%C3\%B3gico-Anexo-2.pdf>. Acesso em: 29 mar. 2017.

BIRCH, E. L.; LYNCH, A. Mensuração de Desenvolvimento Urbano Sustentável nos Estados Unidos. In: Estado do mundo 2012: rumo à prosperidade sustentável. Salvador: Universidade Livre da Mata Atlântica, 2012. p. 288.

BISCHOF, S.; HARTH, A.; KÄMPGEN, B.; POLLERES, A.; SCHNEIDER, P. Enriching Integrated Statistical Open City Data by Combining Equational Knowledge and Missing Value Imputation. Web Semantics: Science, Services and Agents on the World Wide Web, out. 2017. Disponível em: $<$ http://linkinghub.elsevier.com/retrieve/pii/S1570826817300355>. Acesso em: 8 jan. 2018. 
BOND, A.; MORRISON-SAUNDERS, A.; POPE, J. Sustainability Assessment: The State of the Art. Impact Assessment and Project Appraisal, v. 30, n. 1, p. 53-62, mar. 2012.

BORTOLETO, L. A.; FIGUEIRA, C. J. M.; DUNNING, J. B.; RODGERS, J.; DA SILVA, A. M. Suitability Index for Restoration in Landscapes: An Alternative Proposal for Restoration Projects. Ecological Indicators, v. 60, p. 724-735, jan. 2016.

BOUSSAA, D. Souk Waqif, a Case of Urban Regeneration and Sustainability in Doha's Vanishing Urban Heritage, Qatar. v. 8, p. 13, 2015.

BRASIL. Lei $\mathrm{N}^{0}$ 12.305, de 2 de Agosto de 2010. Institui a Política Nacional de Resíduos Sólidos; altera a Lei $\mathrm{n}^{\circ}$ 9.605, de 12 de fevereiro de 1998; e dá outras providências. 2010.

BUILDING TECHNOLOGY INC. Smart Codes in Your Community: A Guide to Building Rehabilitation Codes, ago. 2001. Disponível em: $<$ https://www.huduser.gov/Publications/pdf/smartcodes.pdf $>$. Acesso em: 1 out. 2016.

CAPROTTI, F.; COWLEY, R.; DATTA, A.; BROTO, V. C.; GAO, E.; GEORGESON, L.; HERRICK, C.; ODENDAAL, N.; JOSS, S. The New Urban Agenda: Key Opportunities and Challenges for Policy and Practice. Urban Research \& Practice, v. 10, n. 3, p. 367-378, 3 jul. 2017.

CARMON, N. Three generations of urban renewal policies: analysis and policy implications. Geoforum, v. 30, n. 2, p. 145-158, 1999.

CARVALHO, L. Smart Cities from Scratch? A Socio-Technical Perspective. Cambridge Journal of Regions, Economy and Society, v. 8, n. 1, p. 43-60, mar. 2015.

CASTRO, S. H. R. de; CARVALHO, M. G. de. Indicador de efetividade da gestão municipal: contribuição dos tribunais de contas para a melhoria da gestão pública. Revista Técnica dos Tribunais de Contas - RTTC, p. 235-249, dez. 2016.

CBCS - CONSELHO BRASILEIRO DE CONSTRUÇÃO SUSTENTÁVEL; ASBEA ASSOCIAÇÃO BRASILEIRA DOS ESCRITÓRIOS DE ARQUITETURA. Retrofit:

Requalificação de edifícios e espaços construídos, ago. 2013. Disponível em:

$<$ www.cbcs.org.br/_5dotSystem/userFiles/comite-

tematico/projetos/CBCS_CTProjeto_Retrofit_folder.pdf>. Acesso em: 22 mar. 2014.

CBIC - CÂMARA BRASILEIRA DA INDÚSTRIA DA CONSTRUÇÃO. O desafio de pensar o futuro das cidades, 2012. Disponível em:

$<$ http://www.cbic.org.br/sites/default/files/LIVRO\%20BAIXA\%20RES.pdf>. Acesso em: 10 ago. 2012.

CBIC - CÂMARA BRASILEIRA DA INDÚSTRIA DA CONSTRUÇÃO. Por uma Nova Cultura Urbana: Caderno de Referência, mar. 2017. Disponível em:

$<$ http://www.cbic.org.br/sites/default/files/LIVRO\%20BAIXA\%20RES.pdf $>$. Acesso em: 4 ago. 2017.

CEDANO, K.; MARTINEZ, M. Consensus indicators of sustainability for urban infrastructure. In: Sustainable Systems and Technology (ISSST), 2010 IEEE International Symposium on, Anais...IEEE, 2010. Disponível em:

$<$ http://ieeexplore.ieee.org/xpls/abs_all.jsp?arnumber=5507705>. Acesso em: 19 maio. 2016. 
CETESB - COMPANHIA AMBIENTAL DO ESTADO DE SÃO PAULO. QUALAR Sistema de Informações da Qualidade do Ar. Disponível em:

$<$ http://qualar.cetesb.sp.gov.br/qualar/home.do>. Acesso em: 20 mar. 2018.

CHARNES, A.; COOPER, W. W.; RHODES, E. Measuring the efficiency of decision making units. European journal of operational research, v. 2, n. 6, p. 429-444, 1978.

CITY OF SYDNEY. Sustainable Sydney 2030 - Community Strategic Plan 2017- 2021, 2016. Disponível em: <http://www.cityofsydney.nsw.gov.au/vision/sustainable-sydney2030>. Acesso em: 20 maio. 2018.

CNM - CONFEDERAÇÃO NACIONAL DE MUNICÍPIOS. Guia para Localização dos Objetivos de Desenvolvimento Sustentável nos Municípios Brasileiros: o que os gestores municipais precisam saber, 2016. Disponível em:

$<$ http://www.cnm.org.br/cms/biblioteca_antiga/ODS-

Objetivos_de_Desenvolvimento_Sustentavel_nos_Municipios_Brasileiros.pdf $>$. Acesso em: 27 mar. 2017.

CORRÊA, F. R.; SANTOS, E. T. Na direção de uma Modelagem da Informação da Cidade (CIM). Blucher Engineering Proceedings, v. 2, n. 2, p. 344-357, 2015.

CRUZ, N. F. da; MARQUES, R. C. Scorecards for Sustainable Local Governments. Cities, v. 39, p. 165-170, ago. 2014.

DAESP - DEPARTAMENTO AEROVIÁRIO DO ESTADO DE SÃO PAULO. Aeroporto de Sorocaba. Disponível em: $<$ http://www.daesp.sp.gov.br/aeroporto-detalhe/?id=893>. Acesso em: 20 mar. 2018.

DATASUS - DEPARTAMENTO DE INFORMÁTICA DO SUS. Cadernos de Informação de Saúde. Disponível em: <http://tabnet.datasus.gov.br/tabdata/cadernos/cadernosmap.htm>. Acesso em: 20 mar. 2018.

DEAKIN, M.; AL WAER, H. From Intelligent to Smart Cities. Intelligent Buildings International, v. 3, n. 3, p. 140-152, jul. 2011.

DEAKIN, M.; CAMPBELL, F.; REID, A. The Mass-Retrofitting of an Energy Efficient-Low Carbon Zone: Baselining the Urban Regeneration Strategy, Vision, Masterplan and Redevelopment Scheme. Energy Policy, v. 45, p. 187-200, jun. 2012.

DENG, D.; LIU, S.; WALLIS, L.; DUNCAN, E.; MCMANUS, P. Urban Sustainability Indicators: How Do Australian City Decision Makers Perceive and Use Global Reporting Standards? Australian Geographer, v. 48, n. 3, p. 401-416, 3 jul. 2017.

DEVECCHI, A. M. Reformar não é construir. A reabilitação de edifícios verticais: novas formas de morar em São Paulo no século XXI. 2010. Faculdade de Arquitetura e Urbanismo da Universidade de São Paulo, São Paulo, SP, Brasil, 2010.

DIXON, T. Commercial Property Retrofitting: What Does "Retrofit" Mean, and How Can We Scale up Action in the UK Sector? Journal of Property Investment \& Finance, v. 32, n. 4, p. 443-452, jul. 2014. 
DIXON, T.; EAMES, M. Scaling up: The Challenges of Urban Retrofit. Building Research \& Information, v. 41, n. 5, p. 499-503, out. 2013.

DIXON, T.; EAMES, M.; HUNT, M.; LANNON, S. Urban Retrofitting for Sustainability Mapping the Transition to 2050. Florence: Taylor and Francis, 2014.

DIXON, T.; LANNON, S.; EAMES, M. Reflections on Disruptive Energy Innovation in Urban Retrofitting: Methodology, Practice and Policy. Energy Research \& Social Science, nov. 2017. Disponível em:

$<$ http://linkinghub.elsevier.com/retrieve/pii/S2214629617303365>. Acesso em: 8 jan. 2018.

DO VALE, M. S. DIRETRIZES PARA RACIONALIZAÇÃO E ATUALIZAÇÃO DAS EDIFICAÇÕES: Segundo o conceito da qualidade e sobre a ótica do Retrofit. 2006. Universidade Federal do Rio de Janeiro, 2006.

DOWLING, R.; MCGUIRK, P.; BULKELEY, H. Retrofitting cities: Local governance in Sydney, Australia. Cities, v. 38, p. 18-24, 2014.

DROKE, C. Moving averages simplified / by Clif Droke. Columbia, MD.: Marketplace Books, 2001.

EAMES, M.; DIXON, T. Visioning retrofit futures. Evaluation, 2013. Disponível em: $<$ http://www.retrofit2050.org.uk/sites/default/files/resources/WP20121.pdf $>$. Acesso em: 19 maio. 2016.

EAMES, M.; DIXON, T.; HUNT, M.; LANNON, S. Retrofitting cities for tomorrow's world. John Wiley \& Sons, 2017.

EAMES, M.; DIXON, T.; MAY, T.; HUNT, M. City Futures: Exploring Urban Retrofit and Sustainable Transitions. Building Research \& Information, v. 41, n. 5, p. 504-516, out. 2013a.

EAMES, M.; EGMOSE, J. Community Foresight for Urban Sustainability: Insights from the Citizens Science for Sustainability (SuScit) Project. Technological Forecasting and Social Change, v. 78, n. 5, p. 769-784, jun. 2011.

EAMES, M.; HUNT, M.; DIXON, T.; BRITNELL, J. Retrofit city futures: visions for urban sustainability. Report for the Retrofit 2050. 2013b. Disponível em:

$<$ http://orca.cf.ac.uk/56912/1/retrofit2050\%20visions\%20report.pdf $>$. Acesso em: 19 maio. 2016.

EAMES, M.; MARVIN, S.; HODSON, M.; DIXON, T. J.; GUTHRIE, P.; LANNON, S. Briefing: Re-Engineering the City 2020-2050 - Urban Foresight and Transition Management. Proceedings of the Institution of Civil Engineers: Urban Design and Planning, v. 167, n. 1, p. 1-4, 2014.

EMPLASA - EMPRESA PAULISTA DE PLANEJAMENTO. Plano de Ação da Macrometrópole Paulista 2013-2040: cenários e desafios da macrometrópole. 2014.

EMPLASA - EMPRESA PAULISTA DE PLANEJAMENTO METROPOLITANO. PDUI Plano de Desenvolvimento Urbano Integrado da RMS - Região Metropolitana de 
Sorocaba: Panorama Regional, jun. 2017. Disponível em:

$<$ https://www.pdui.sp.gov.br/sorocaba/>. Acesso em: 23 ago. 2017.

ESCOLA DA CIDADE; INSTITUTO ARAPYAÚ; INSTITUTO ETHOS; INSTITUTO SOCIOAMBIENTAL; REDE NOSSA SÃO PAULO. São Paulo 2022: Ideias, Diretrizes, Indicadores e Metas para os Próximos 10 Anos da Cidade, nov. 2011. .

EUROPEAN COMMISSION; DIRECTORATE-GENERAL FOR THE ENVIRONMENT; UNIVERSITY OF THE WEST OF ENGLAND (UWE); SCIENCE COMMUNICATION UNIT. Indicators for sustainable cities. Luxembourg: Publications Office, 2015.

EUROSTAT - STATISTICAL OFFICE OF THE EUROPEAN COMMUNITIES. Sustainable development in the European Union: a statistical glance from the viewpoint of the UN Sustainable Development Goals. 2016.

EVERITT, B. (ed.). Cluster analysis. 5th ed ed. Chichester, West Sussex, U.K: Wiley, 2011.

FERRANTE, A.; SEMPRINI, G. Building Energy Retrofitting in Urban Areas. Procedia Engineering, v. 21, p. 968-975, 2011.

FERRARIN, F. P. Requalificação de waterfronts e sustentabilidade ambiental: a operação urbana da Região do Porto no Rio de Janeiro. 2016. Escola Politécnica da Universidade de São Paulo, São Paulo, 2016.

FIESP - FEDERAÇÃO DAS INDÚSTRIAS DO ESTADO DE SÃO PAULO. Brasil 2022: Planejar, Construir, Crescer, 3 set. 2015. Disponível em:

$<$ http://az545403.vo.msecnd.net/observatoriodaconstrucao/2016/05/11-CB-Portugues.pdf $>$. Acesso em: 14 jul. 2016.

FOX, M. S. The Role of Ontologies in Publishing and Analyzing City Indicators. Computers, Environment and Urban Systems, v. 54, p. 266-279, nov. 2015.

FOX, M. S.; PETTIT, C. J. On the completeness of open city data for measuring city indicators. In: Piscataway, NJ. Anais... In: 2015 IEEE FIRST INTERNATIONAL SMART CITIES CONFERENCE (ISC2 2015): GUADALAJARA, MEXICO, 25-28 OCTOBER 2015. Piscataway, NJ: IEEE, 2015.

FRANCISCO, E. de R. Webinar Big Data e Inteligência Geográfica, 8 dez. 2014. Disponível em: <http://conteudo.geoeduc.com/webinar-big-data-mitos $>$. Acesso em: 2 dez. 2015.

GIBBERD, J. Strengthening Sustainability Planning: The City Capability Framework. Procedia Engineering, v. 198, p. 200-211, 2017.

GIBSON, R. B. Beyond the pillars: sustainability assessment as a framework for effective integration of social, economic and ecological considerations in significant decision-making. Journal of Environmental Assessment Policy and Management, v. 8, n. 03, p. 259-280, 2006.

GINDROZ, B. ISO/TC 268 - Sustainable Development in Communities. In: IOT WEEK. , 2017. . 
GOMES, A. S. S. Retrofit de Fachadas de Edifícios à luz da ABNT NBR 15575. 2015. Escola Politécnica da Universidade de São Paulo, São Paulo, 2015.

GONÇALVES, J. C. S.; DUARTE, D. H. S. Arquitetura sustentável: uma integração entre ambiente, projeto e tecnologia em experiências de pesquisa, prática e ensino. Ambiente construído, v. 6, n. 4, p. 51-81, 2006.

GRAAF, R. de. Adaptive urban development -A symbiosis between cities on land and water in the 21st century. Rotterdam: Rotterdam University Press, 2012.

GUIMARÃES, E. F. Modelo inclusivo para a universalização do saneamento básico em áreas de vulnerabilidade social. 2015. Escola de Engenharia de São Carlos da Universidade de São Paulo, São Paulo, SP, Brasil, 2015.

HACKING, T.; GUTHRIE, P. A Framework for Clarifying the Meaning of Triple BottomLine, Integrated, and Sustainability Assessment. Environmental Impact Assessment Review, v. 28, n. 2-3, p. 73-89, fev. 2008.

HOLDEN, M. Sustainability Indicator Systems within Urban Governance: Usability Analysis of Sustainability Indicator Systems as Boundary Objects. Ecological Indicators, v. 32, p. 8996, set. 2013.

IAEG-SDGS - INTER-AGENCY AND EXPERT GROUP ON SDG INDICATORS. Global indicator framework for the Sustainable Development Goals and targets of the 2030 Agenda for Sustainable Development, 11 maio 2018. . Disponível em:

$<$ https://unstats.un.org/sdgs/indicators/Global\%20Indicator\%20Framework\%20after\%20refin ement_Eng.pdf $>$. Acesso em: 11 maio. 2018.

IBAM - INSTITUTO BRASILEIRO DE ADMINISTRAÇÃO MUNICIPAL; MCTIC MINISTÉRIO DA CIÊNCIA, TECNOLOGIA, INOVAÇÕES E COMUNICAÇÕES. Políticas públicas para cidades sustentáveis: integração intersetorial, federativa e territorial. 2016.

IBGE - INSTITUTO BRASILEIRO DE GEOGRAFIA E ESTATÍSTICA. Sinopse por Setores do Censo 2010. Disponível em: $<$ https://censo2010.ibge.gov.br/sinopseporsetores/>. Acesso em: 20 maio. 2018.

IBGE - INSTITUTO BRASILEIRO DE GEOGRAFIA E ESTATÍSTICA. Síntese de Indicadores Sociais: uma análise das condições de vida da população brasileira 2013, 2013. Disponível em: < http://biblioteca.ibge.gov.br/visualizacao/livros/liv66777.pdf>.

IBGE - INSTITUTO BRASILEIRO DE GEOGRAFIA E ESTATÍSTICA. Mudança demográfica no Brasil no início do século XXI: subsídios para as projeções da população. 2015 .

IBGE - INSTITUTO BRASILEIRO DE GEOGRAFIA E ESTATÍSTICA. Tipologia intraurbana: espaços de diferenciação socioeconômica nas concentrações urbanas do Brasil. 2017.

IBGE - INSTITUTO BRASILEIRO DE GEOGRAFIA E ESTATÍSTICA. Informações sobre os municípios brasileiros - Sorocaba. Disponível em:

$<$ https://cidades.ibge.gov.br/brasil/sp/sorocaba/panorama>. Acesso em: 15 dez. 2017. 
INEP - INSTITUTO NACIONAL DE ESTUDOS E PESQUISAS EDUCACIONAIS ANÍSIO TEIXEIRA. Sinopses Estatísticas da Educação Básica. Disponível em: $<$ http://portal.inep.gov.br/web/guest/sinopses-estatisticas-da-educacao-basica $>$. Acesso em: 20 mar. 2018.

INPI - INSTITUTO NACIONAL DA PROPRIEDADE INDUSTRIAL. Estatísticas. Disponível em: $<$ http://www.inpi.gov.br/sobre/estatisticas/estatisticas $>$. Acesso em: 20 mar. 2018.

INPI - INSTITUTO NACIONAL DE PROPRIEDADE INDUSTRIAL. Anuário Estatístico de Propriedade Industrial: 2000-2012, 2013. Disponível em:

$<\mathrm{http}$ //www.inpi.gov.br/estatisticas>. Acesso em: 15 set. 2015.

IPCC - INTERGOVERNMENTAL PANEL ON CLIMATE CHANGE. Climate Change 2014: Mitigation of Climate Change. Contribution of Working Group III to the Fifth Assessment Report of the Intergovernmental Panel on Climate Change.Cambridge University Press, , 2014. . Disponível em: $<$ http://pure.iiasa.ac.at/11114/>. Acesso em: 12 jul. 2016.

IPEA - INSTITUTO DE PESQUISA; ASSECOR - ASSOCIAÇÃO NACIONAL DOS SERVIDORES DA CARREIRA. Brasil 2035: cenários para o desenvolvimento, 2017. Disponível em: <http://www.ipea.gov.br>. Acesso em: 20 jun. 2016.

ISO - INTERNATIONAL ORGANIZATION FOR STANDARDIZATION. Business Plan: ISO/TC 268 - Sustainable Development in Communities, 14 nov. 2013. Disponível em: $<\mathrm{http}$ //isotc.iso.org/livelink/livelink/fetch/2000/2122/687806/ISO_TC_268_Sustainable_de velopment_in_communities_.pdf?nodeid=16488152\&vernum $=-2>$. Acesso em: 20 ago. 2015.

ISO - INTERNATIONAL ORGANIZATION FOR STANDARDIZATION. ISO 37120:2014 -Sustainable development in communities - Indicators for City Services and Quality of Life, 15 maio 2014.

ISO - INTERNATIONAL ORGANIZATION FOR STANDARDIZATION. ISO 37101:2016 -Sustainable development in communities - Management system for sustainable development - Requirements with guidance for use, 7 nov. $2016 \mathrm{a}$.

ISO - INTERNATIONAL ORGANIZATION FOR STANDARDIZATION. ISO 37100:2016 -Sustainable development in communities - Vocabulary, dez. $2016 \mathrm{~b}$.

ISO - INTERNATIONAL ORGANIZATION FOR STANDARDIZATION. ISO/DIS 37122 -Sustainable development in communities - Indicators for Smart Cities (Draft International Standard), jun. 2018a.

ISO - INTERNATIONAL ORGANIZATION FOR STANDARDIZATION. ISO 37120:2018 -Sustainable development in communities - Indicators for City Services and Quality of Life, jul. $2018 b$.

JAMES CORNER FIELD OPERATIONS; DILLER SCOFIDIO + RENFRO (ed.). The High Line: foreseen, unforeseen. London; New York, N.Y: Phaidon, 2015. 
JANNUZZI, P. de M. Indicadores sociais no Brasil: conceitos, fontes de dados e aplicações para formulação e avaliação de políticas públicas, elaboração de estudos socioeconômicos. Campinas, SP: Alínea Editora, 2001.

KARVONEN, A. Towards Systemic Domestic Retrofit: A Social Practices Approach. Building Research \& Information, v. 41, n. 5, p. 563-574, out. 2013.

KEIRSTEAD, J.; CALDERON, C. Capturing Spatial Effects, Technology Interactions, and Uncertainty in Urban Energy and Carbon Models: Retrofitting Newcastle as a Case-Study. Energy Policy, v. 46, p. 253-267, jul. 2012.

KITCHIN, R. Big Data and Human Geography: Opportunities, Challenges and Risks. Dialogues in Human Geography, v. 79, n. 1, p. 1-14, 2013.

KITCHIN, R. The Real-Time City? Big Data and Smart Urbanism. GeoJournal, v. 79, n. 1, p. 1-14, fev. 2014.

KITCHIN, R.; MAALSEN, S.; MCARDLE, G. The Praxis and Politics of Building Urban Dashboards. Geoforum, v. 77, p. 93-101, dez. 2016.

KLOECKL, K.; SENN, O.; RATTI, C. Enabling the Real-Time City: LIVE Singapore! Journal of Urban Technology, v. 19, n. 2, p. 89-112, abr. 2012.

KLOPP, J. M.; PETRETTA, D. L. The Urban Sustainable Development Goal: Indicators, Complexity and the Politics of Measuring Cities. Cities, v. 63, p. 92-97, mar. 2017.

KÜHL, F. M.; NEGREIROS, I.; ABIKO, A. Análise de Indicadores de Sustentabilidade Urbana Relevantes ao Retrofit Urbano. In: Anales de Trabajos Extendidos y Resumenes [do] IV Workshop Interdisciplinario de Investigación e Indicadores de Sustentabilidad = Anais de Trabalhos Extendidos e Resumos [do] IV Workshop Interdisciplinar de Pesquisa em Indicadores de Sustentabilidade $=$ Proceedings - Abstracts and Extended Papers [of] IV Interdisciplinary Workshop on Research and Sustainability Indicators, Concepción, Chile. Anais... In: WIPIS 2015. Concepción, Chile: UDEC/USP/UP, 2015. Disponível em: $<$ http://www.eula.cl/doc/Anais_WIPIS\%202015_com\%20ISBN.pdf $>$.

LAI, L. W. C.; CHAU, K. W.; CHEUNG, P. A. C. W. Urban Renewal and Redevelopment: Social Justice and Property Rights with Reference to Hong Kong's Constitutional Capitalism. Cities, jan. 2018. Disponível em:

$<$ http://linkinghub.elsevier.com/retrieve/pii/S0264275117306686>. Acesso em: 8 jan. 2018.

LANÇAS, S. Y. S. Espaços públicos abertos e infraestrutura verde para Sorocaba/SP. 2007. Faculdade de Arquitetura e Urbanismo da Universidade de São Paulo, São Paulo, 2007.

LATOUCHE, S. Pequeno Tratado do Decrescimento Sereno. Martins Fontes, 2009.

LEITE, C. Indicadores de Desenvolvimento Urbano Sustentável. In: São Paulo: em busca da sustentabilidade. São Paulo, SP, Brasil: EDUSP: PINI, 2012. p. 54-69.

LESTER, T. W. Dedicating New Real Estate Transfer Taxes for Energy Efficiency: A Revenue Option for Scaling up Green Retrofit Programs. Energy Policy, v. 62, p. 809-820, nov. 2013. 
LIVING CITIES. Scaling Up Building Energy Retrofitting in U.S. Cities., 2010.

Disponível em: $<$ https://www.livingcities.org/resources/19-scaling-up-building-energyretrofitting-in-u-s-cities-a-resource-guide-for-local-leaders>. Acesso em: 16 out. 2013.

LO STORTO, C. The Trade-off between Cost Efficiency and Public Service Quality: A NonParametric Frontier Analysis of Italian Major Municipalities. Cities, v. 51, p. 52-63, jan. 2016.

LOUETTE, A. Indicadores de Nações: uma Contribuição ao Diálogo da

Sustentabilidade. 1a. ed. São Paulo, SP, Brasil: WHH - Willis Harman House, 2007.

LUQUE-MARTÍNEZ, T.; MUÑOZ-LEIVA, F. City Benchmarking: A Methodological Proposal Referring Specifically to Granada. Cities, v. 22, n. 6, p. 411-423, dez. 2005.

LÜTZKENDORF, T.; BALOUKTSI, M. Assessing a Sustainable Urban Development: Typology of Indicators and Sources of Information. Procedia Environmental Sciences, v. 38, p. 546-553, 2017.

MALHEIROS, T. F.; COUTINHO, S. M. V.; JR, A. Desafios do uso de indicadores na avaliação da sustentabilidade. In: Indicadores de sustentabilidade e gestão ambiental. Barueri: Manole, 2012. p. 1-29.

MANFREDINI, F. N.; GUANDIQUE, E. G.; ROSA, A. H. A história ambiental de Sorocaba. Sorocaba: Unesp - Câmpus Experimental de Sorocaba, 2015.

MAOH, H.; KANAROGLOU, P. A tool for evaluating urban sustainability via Integrated Transportation and Land Use Simulation Models. Urban Environment, v. 3, p. 28-46, 2009.

MARCHESIN, M. M. Proposta de estrutura para o gerenciamento de projetos de revitalização urbana: estudo aplicado na cidade de São Paulo. 2015. Escola Politécnica da Universidade de São Paulo, São Paulo, SP, Brasil, 2015.

MARKER, A. Manual: Revitalização de áreas degradadas e contaminadas (brownfields) na América Latina. São Paulo: ICLEI - Governos Locais pela Sustentabilidade / Secretariado para América do Sul (SAMS), 2013.

MARQUES DE JESUS, C. R. Análise de custos para reabilitação de edifícios para habitação. 2008. Escola Politécnica da Universidade de São Paulo, São Paulo, SP, Brasil, 2008.

MARSAL-LLACUNA, M.-L. Building Universal Socio-Cultural Indicators for Standardizing the Safeguarding of Citizens? Rights in Smart Cities. Social Indicators Research, v. 130, n. 2, p. 563-579, jan. 2017.

MARSAL-LLACUNA, M.-L.; SEGAL, M. E. The Intelligenter Method (II) for "Smarter" Urban Policy-Making and Regulation Drafting. Cities, v. 61, p. 83-95, jan. 2017.

MASOTTI, C.; FERRANTE, A.; BOIARDI, L.; FABBRI, C. Self-Help Retrofitting Technologies for Low-Cost Housing Construction. The Case Study of Vila Novo Ouro Preto, Brasil. Procedia Engineering, v. 21, p. 625-632, 2011. 
MATTOS, A. C. M. O impacto do computador na empresa. Revista de Administração de Empresas, v. 18, n. 4, p. 53-58, dez. 1978.

MCARTHUR, J. J.; JOFEH, C. G. H. Portfolio Retrofit Evaluation: A Methodology for Optimizing a Large Number of Building Retrofits to Achieve Triple-Bottom-Line Objectives. Sustainable Cities and Society, mar. 2016. Disponível em:

$<$ http://linkinghub.elsevier.com/retrieve/pii/S2210670716300427>. Acesso em: 12 jul. 2016.

MCTIC - MINISTÉRIO DA CIÊNCIA, TECNOLOGIA, INOVAÇÕES E COMUNICAÇÕES. Dados do Setor de Comunicações - Informações. Disponível em: $<$ http://sistema.mc.gov.br/DSCOM/view/Informacoes.php>. Acesso em: 20 mar. 2018.

MDS - MINISTÉRIO DO DESENVOLVIMENTO SOCIAL. Plano Brasil sem Miséria. Disponível em:

$<$ http://aplicacoes.mds.gov.br/sagirmps/ferramentas/nucleo/grupo.php?id_grupo=69>. Acesso em: 20 mar. 2018.

MEIRELLES, J. L. J. S. A renovação de escritórios comerciais com vistas ao seu reposicionamento de mercado: o caso do Conjunto Nacional em São Paulo. 2007. Escola Politécnica da Universidade de São Paulo, São Paulo, 2007.

MORENO PIRES, S.; FIDÉLIS, T.; RAMOS, T. B. Measuring and Comparing Local Sustainable Development through Common Indicators: Constraints and Achievements in Practice. Cities, v. 39, p. 1-9, ago. 2014.

MORETTIN, P. A.; TOLOI, C. M. de C. Análise de séries temporais. São Paulo: Edgard Blucher, 2008.

NEUMAN, M. The Compact City Fallacy. Journal of Planning Education and Research, v. 25, n. 1 , p. 11-26, 1 set. 2005.

NEW YORK CITY. PlanNYC - A greener, greater New York, 2011. Disponível em: $<$ http://www.nyc.gov/html/planyc/downloads/pdf/publications/planyc_2011_planyc_full_repo rt.pdf>. Acesso em: 11 nov. 2013.

NEWTON, P. W. Regenerating Cities: Technological and Design Innovation for Australian Suburbs. Building Research \& Information, v. 41, n. 5, p. 575-588, out. 2013.

NOBRE, C. A.; YOUNG, A. F.; SALDIVA, P.; MARENGO, J. A.; NOBRE, A. D.; ALVES JR., S.; SILVA, G. C. M. da; LOMBARDO, M. Vulnerabilidades das Megacidades Brasileiras às Mudanças Climáticas: Região Metropolitana de São PauloUNESP-Rio Claro, , 2010. . Disponível em:

$<$ http://www.doma.observandosaopaulo.org/uploads/artigos/megacidades.pdf $>$. Acesso em: 16 jun. 2010.

NOIVA, K.; FERNÁNDEZ, J. E.; WESCOAT, J. L. Cluster Analysis of Urban Water Supply and Demand: Toward Large-Scale Comparative Sustainability Planning. Sustainable Cities and Society, v. 27, p. 484-496, nov. 2016.

NOVOTNY, V. Water-Energy Nexus: Retrofitting Urban Areas to Achieve Zero Pollution. Building Research \& Information, v. 41, n. 5, p. 589-604, out. 2013. 
NRDC - NATURAL RESOURCES DEFENSE (US). A Citizen's Guide to LEED for Neighborhood Development: How to Tell if Development is Smart and Green, 2011. . Disponível em: <https://www.nrdc.org/sites/default/files/citizens_guide_LEED-ND.pdf>. Acesso em: 17 out. 2013.

OMS - ORGANIZAÇÃO MUNDIAL DE SAÚDE. WHO Air quality guidelines for particulate matter, ozone, nitrogen dioxide and sulfur dioxide - Global update 2005 Summary of risk assessment, 2006. Disponível em:

$<$ http://apps.who.int/iris/bitstream/handle/10665/69477/WHO_SDE_PHE_OEH_06.02_eng.p df;jsessionid=77FCDA66FD094BC623862D53AE09994F? sequence=1>. Acesso em: 3 jan. 2018.

PAUL, A.; SEN, J. Livability Assessment within a Metropolis Based on the Impact of Integrated Urban Geographic Factors (IUGFs) on Clustering Urban Centers of Kolkata. Cities, dez. 2017. Disponível em: $<$ http://linkinghub.elsevier.com/retrieve/pii/S0264275117306741>. Acesso em: 8 jan. 2018.

PCS - PROGRAMA CIDADES SUSTENTÁVEIS. Sorocaba. Disponível em: $<$ http://20132016.indicadores.cidadessustentaveis.org.br/br/SP/sorocaba/>. Acesso em: 20 mar. 2018.

PHILIPS LIGHTING RESEARCH. Future of cities: scenarios that show how people may experience cities in 2035, dez. 2017. Disponível em:

$<$ http://www.lighting.philips.com/main/inspiration/smart-cities/smart-city-trends/cityscenarios?origin=1_global_en_smartcities_wccd_city_scenarios_70124000000wusr $>$.

PMS - PREFEITURA MUNICIPAL DE SOROCABA. Lei No 10.521 , de 17 de Julho de 2013. Dispõe sobre a instituição do Plano de Arborização Urbana de Sorocaba e dá outras providências. 17 jul. 2013 a.

PMS - PREFEITURA MUNICIPAL DE SOROCABA. Lei N ${ }^{\circ} 10.620$, de 14 de Novembro de 2013. Estabelece o Plano Plurianual do Município para o quadriênio 2014 - 2017, define as metas e prioridades da administração pública municipal para o exercício de 2014. . 14 nov. 2013 b.

PMS - PREFEITURA MUNICIPAL DE SOROCABA. Plano Municipal de Conservação e Recuperação da Mata Atlântica, 2014a. Disponível em: <https://www.sosma.org.br/wpcontent/uploads/2014/04/pmma-sorocaba-bx.pdf>. Acesso em: 4 jul. 2017.

PMS - PREFEITURA MUNICIPAL DE SOROCABA. PMGIRS - Plano Municipal de Gestão Integrada de Resíduos Sólidos do Município de Sorocaba - SP - Relatório R 3, jul. 2014b. Disponível em:

$<$ http://www.meioambientesorocaba.com.br/sema/UserFiles/file/Residuos\%202014/Relat\%C 3\%B3rio\%20R-3\%20PMGIRS.pdf>. Acesso em: 12 out. 2015.

PMS - PREFEITURA MUNICIPAL DE SOROCABA. Lei No 11.022, de 16 de Dezembro de 2014. Dispõe sobre a revisão do Plano Diretor de desenvolvimento físico territorial do município de Sorocaba e dá outras providências. 16 dez. 2014 c.

PMS - PREFEITURA MUNICIPAL DE SOROCABA. Lei No 11.133, de 25 de Junho de 2015. Aprova o Plano Municipal de Educação de Sorocaba. 25 jun. 2015. 
PMS - PREFEITURA MUNICIPAL DE SOROCABA. Lei N ${ }^{0} 11.619$, de 30 de Novembro de 2017. Estabelece o Plano Plurianual do Município para o quadriênio 2018 - 2021, define as metas e prioridades da administração pública municipal para o exercício de 2018 e dá outras providências. 14 dez. 2017.

PMS - PREFEITURA MUNICIPAL DE SOROCABA; IN NATURA TECNOLOGIA E SOLUÇÕES AMBIENTAIS LTDA - ME. Inventário de Gases do Efeito Estufa do Município de Sorocaba - Relatório Final 2002 - 2012, 2014. . Disponível em: $<$ http://meioambiente.sorocaba.sp.gov.br/gestaoambiental/wpcontent/uploads/sites/4/2015/12/inventario-de-gases-do-efeito-estufa-do-municipio-desorocaba.pdf $>$. Acesso em: 4 jan. 2017.

PMS - PREFEITURA MUNICIPAL DE SOROCABA; INTEGRA SOCIEDADE COOPERATIVA. PLHIS - Plano Local de Habitação de Interesse Social de Sorocaba, maio 2011. Disponível em: <http://habitacao.sorocaba.sp.gov.br/wpcontent/uploads/2016/10/plano-local-de-habitacao-de-interesse-social-de-sorocaba.pdf $>$. Acesso em: 1 jun. 2017.

PMS - PREFEITURA MUNICIPAL DE SOROCABA; WALM - ENEGENHARIA E TECNOLOGIA AMBIENTAL LTDA. Plano Diretor Ambiental de Sorocaba, dez. 2011. Disponível em: $<$ http://meioambiente.sorocaba.sp.gov.br/gestaoambiental/wpcontent/uploads/sites/4/2015/12/pda-finalvoli.pdf>. Acesso em: 4 jul. 2017.

PMSP - PREFEITURA MUNICIPAL DE SÃO PAULO. Plano Municipal de Saneamento Básico - PMSB, 2010a.

PMSP - PREFEITURA MUNICIPAL DE SÃO PAULO. Plano Municipal de Habitação 2009-2024, set. 2010 b.

PMSP - PREFEITURA MUNICIPAL DE SÃO PAULO. SP 2040: a cidade que queremos. SMDU, 2012a. . Disponível em: <http:/www.habisp.inf.br/theke/documentos/outros/sp2040acidadequequeremos/>. Acesso em: 3 out. 2013.

PMSP - PREFEITURA MUNICIPAL DE SÃO PAULO. Manual de Drenagem e Manejo de Águas Pluviais de São Paulo, 2012 b.

PNUD - PROGRAMA DAS NAÇÕES UNIDAS PARA O DESENVOLVIMENTO. Transformando Nosso Mundo: A Agenda 2030 para o Desenvolvimento Sustentável, 2015a. Disponível em: <www.pnud.org.br/Docs/Agenda2030completo_PtBR.pdf>.

PNUD - PROGRAMA DAS NAÇÕES UNIDAS PARA O DESENVOLVIMENTO. Acompanhando a agenda 2030 para o desenvolvimento sustentável: subsídios iniciais do Sistema das Nações Unidas no Brasil sobre a identificação de indicadores nacionais referentes aos objetivos de desenvolvimento sustentável/Programa das Nações Unidas para o Desenvolvimento. Brasília: PNUD, 2015b.

PRÉFECTURE DE PARIS. Évaluation du contrat urbain de cohésion sociale de Paris 2007 - 2010: Rapport de synthèse., set. 2010. Disponível em:

$<$ http://www.paris.fr/politiques/vie-de-quartier/evaluation-du-contrat-urbain-de-cohesionsociale-2007-2010/rub_6144_stand_95378_port_13817>. Acesso em: 14 maio. 2014. 
RAJAONSON, J.; TANGUAY, G. A. A Sensitivity Analysis to Methodological Variation in Indicator-Based Urban Sustainability Assessment: A Quebec Case Study. Ecological Indicators, v. 83, p. 122-131, dez. 2017.

REDE NOSSA SÃO PAULO. Programa Cidades Sustentáveis - Metas de Sustentabilidade para os Municípios Brasileiros (Indicadores e Referências), 2012. Disponível em: $<$ http://www.cidadessustentaveis.org.br/downloads/publicacoes/publicacaometas-de-sustentabilidade-municipios-brasileiros.pdf>. Acesso em: 3 out. 2013.

REDE NOSSA SÃO PAULO. Programa Cidades Sustentáveis - Guia GPS - Gestão Pública Sustentável, 2016. Disponível em:

$<$ www.cidadessustentaveis.org.br/arquivos/gestão-pública-sustentável.pdf>. Acesso em: 7 dez. 2016.

RIOS, F.; PEREIRA, A. C.; RANGEL, P. Paradoxo da igualdade: gênero, raça e democracia. Ciência e Cultura, v. 69, n. 1, p. 39-44, 2017.

RODERS, A. R. P.; POST, J.; AGUIAR, J.; ERKELENS, P. A.; TECHNISCHE UNIVERSITEIT EINDHOVEN; FACULTEIT BOUWKUNDE. Re-architecture: lifespan rehabilitation of built heritage. Book I, Book I,. Eindhoven: Technische Universiteit Eindhoven, Faculteit Bouwkunde, 2007.

SAAE - SERVIÇO AUTÔNOMO DE ÁGUA E ESGOTO; PROESPLAN ENGENHARIA. Plano Diretor do Sistema de Esgotamento Sanitário, mar. 2016. Disponível em: $<$ http://www.camarasorocaba.sp.gov.br/sitecamara/saaeplanodiretor/esgoto/PlanoDiretordoSE SdeSorocabaVolumeI.pdf $>$. Acesso em: 8 jul. 2016.

SAATY, T. L. Decision making with the analytic hierarchy process. International journal of services sciences, v. 1, n. 1, p. 83-98, 2008.

SABESP - COMPANHIA DE SANEAMENTO BÁSICO DO ESTADO DE SÃO PAULO. Plano Diretor de Abastecimento de Água da Região Metropolitana de São Paulo PDAA, 2006.

SABESP - COMPANHIA DE SANEAMENTO BÁSICO DO ESTADO DE SÃO PAULO. Plano Diretor de Esgotos da Região Metropolitana de São Paulo - PDE - Relatório Síntese, 2010.

SÃO PAULO (ESTADO). Plano Integrado de Transportes Urbanos - PITU 2025, 2006 a. Disponível em:

$<$ http://www.stm.sp.gov.br/images/stories/Pitus/Pitu2025/Pdf/Pitu_2025_01.pdf $>$. Acesso em: 20 abr. 2014.

SÃO PAULO (ESTADO). Lei Estadual No 12.300, de 16 de Março de 2006. Institui a Política Estadual de Resíduos Sólidos e define princípios e diretrizes. 2006 b.

SÃO PAUlO (ESTADO). Matriz energética do Estado de São Paulo - 2035, mar. 2011. Disponível em: $<$ http://www.energia.sp.gov.br/arquivos/matriz-energetica-relatoriofinal.pdf>. Acesso em: 28 ago. 2014.

SÃO PAUlO (ESTADO). Caracterização Socieconômica de São Paulo - Região Administrativa de SorocabaSecretaria de Planejamento e Desenvolvimento Regional, 2012. 
SÃO PAULO (ESTADO). Anuário Estatístico de Energéticos por Município no Estado de São Paulo 2017 - Ano base 2016Secretaria de Energia do Estado de SP, 2017. Disponível em:

$<$ http://dadosenergeticos.energia.sp.gov.br/portalcev2/intranet/BiblioVirtual/diversos/anuario _energetico_municipio.pdf $>$.

SÃO PAULO (MUNICÍPIO). Projeto de Lei 01-00466/2015: Aprova o Código de Obras e Edificações do Município de São Paulo, 2015.

SDSN - SUSTAINABLE DEVELOPMENT SOLUTIONS NETWORK. SDG Index \& Dashboards - Global Report, jul. 2016. Disponível em: $<$ http://sdgindex.org/download/>.

SEADE - FUNDAÇÃO SISTEMA ESTADUAL DE ANÁLISE DE DADOS. IMP Informações dos Municípios Paulistas. Disponível em:

$<$ http://www.imp.seade.gov.br/frontend/\#/tabelas>. Acesso em: 20 mar. 2018a.

SEADE - FUNDAÇÃO SISTEMA ESTADUAL DE ANÁLISE DE DADOS. Projeções

Populacionais. Disponível em: $<\mathrm{http} / /$ produtos.seade.gov.br/produtos/projpop/>. Acesso em: 20 mar. 2018 b.

SENA, F. B.; NEGREIROS, I.; ABIKO, A. Análise da implementação de indicadores de sustentabilidade urbana estabelecidos em Normas internacionais e sua adequação a realidade brasileira. In: São Paulo. Anais... In: $25^{\circ}$ SIMPÓSIO INTERNACIONAL DE INICIAÇÃO CIENTÍFICA E TECNOLÓGICA DA USP 2017. São Paulo: 2017.

SIEMENS AG. The Green City Index: A summary of the Green City Index research series, 2012. Disponível em:

$<\mathrm{http}$ //www.siemens.com/entry/cc/features/greencityindex_international/all/en/pdf/gci_report _summary.pdf>. Acesso em: 10 jul. 2013.

SILVA DE SOUZA LIMA, N.; MANCINI, S. D. Integration of Informal Recycling Sector in Brazil and the Case of Sorocaba City. Waste Management \& Research, v. 35, n. 7, p. 721729, jul. 2017.

SNIS - SISTEMA NACIONAL DE INDICADORES DE SANEAMENTO. SNIS - Série Histórica. Disponível em:

$<$ http://app3.cidades.gov.br/serieHistorica/\%20\%e2\%80\%93\%20Munic\%c3\%adpios\%20\%e2 $\% 80 \% 93 \% 20$ Informa $\%$ c3\%a $7 \%$ c3\%b5es $\% 20 \mathrm{e} \% 20$ indicadores $\% 20$ municipais $\% 20$ consolida dos>. Acesso em: 14 mar. 2018.

SSP/SP - SECRETARIA DE SEGURANÇA PÚBLICA DO ESTADO DE SÃO PAULO. Dados Estatísticos do Estado de São Paulo. Disponível em:

$<$ http://www.ssp.sp.gov.br/Estatistica/Pesquisa.aspx>. Acesso em: 20 mar. 2018.

STEINER, F. Landscape Ecological Urbanism: Origins and Trajectories. Landscape and Urban Planning, v. 100, n. 4, p. 333-337, abr. 2011.

STEVENSON, A.; PEARSALL, J. (ed.). Oxford dictionary of English. 3. ed ed. Oxford: Oxford Univ. Press, 2010. 
TALEN, E.; ALLEN, E.; BOSSE, A.; AHMANN, J.; KOSCHINSKY, J.; WENTZ, E.; ANSELIN, L. LEED-ND as an urban metric. Landscape and Urban Planning, v. 119, p. 20-34, nov. 2013.

TOLEDO, R. Notas de Aula da Disciplina AUT-5818: Tecnologia e Gestão da Infraestrutura, 8 maio 2014.

TRÉGUER, L.; NEGREIROS, I.; ABIKO, A. The Agua Branca Urban Retrofit Project in São Paulo: comparative analysis to Paris Nord-Est Project. In: Proceedings of the CIB Word Building Conference Tampere, 2016, Tampere. Anais... In: CIB 2016. Tampere: 2016.

TSE - TRIBUNAL SUPERIOR ELEITORAL. Estatísticas eleitorais 2016. Disponível em: $<$ http://www.tse.jus.br/eleicoes/estatisticas/estatisticas-eleitorais-2016/eleicoes-2016>. Acesso em: 20 mar. 2018.

UN- HABITAT - UNITED NATIONS HUMAN SETTLEMENTS PROGRAMME; UNEP UNITED NATIONS ENVIRONMENT PROGRAMME. The Sustainable Cities Programme in the Philippines, 1998-2007: addressing poverty, gender inequality, and environmental degradation. Nairobi: UN-HABITAT: UNEP, 2009.

UN-DESA - DEPARTMENT OF ECONOMIC AND SOCIAL AFFAIRS. World Population Prospects - Population Division - United Nations. Disponível em: $<$ https://esa.un.org/unpd/wpp/Graphs/Probabilistic/POP/TOT/>. Acesso em: 26 jul. 2018a.

UN-DESA - DEPARTMENT OF ECONOMIC AND SOCIAL AFFAIRS. Sustainable Development Goals Report 2017. New York, NY: United Nations, $2017 \mathrm{~b}$.

UN-HABITAT (ed.). State of Latin American and Caribbean cities 2012: towards a new urban transition. Nairobi: UN-HABITAT, 2012.

UN-HABITAT - UNITED NATIONS HUMAN SETTLEMENTS PROGRAMME. World Cities Report 2016 - Urbanization and Development: Emerging Futures, 2016. Disponível em: <http:/wcr.unhabitat.org/wp-content/uploads/sites/16/2016/05/WCR\%20Full-Report-2016.pdf $>$. Acesso em: 13 jul. 2016.

UNITED NATIONS. World urbanization prospects: the 2014 revision: highlights. 2014. UNITED NATIONS. 2018 Revision of World Urbanization Prospects. 2018.

URBES - EMPRESA DE DESENVOLVIMENTO URBANO E SOCIAL DE SOROCABA. PDTUM - Plano Diretor de Transporte Urbano e Mobilidade, 2014 Disponível em: $<$ http://www.urbes.com.br/uploads2/PDTUM_CAMARA_SITE.pdf $>$. Acesso em: 10 dez. 2015 .

URBES - EMPRESA DE DESENVOLVIMENTO URBANO E SOCIAL DE SOROCABA. Evolução da frota. Disponível em: $<$ http://187.32.155.17:8282/SICAT/graficos/graficosite.php?reg=4>. Acesso em: 14 mar. 2018a.

URBES - EMPRESA DE DESENVOLVIMENTO URBANO E SOCIAL DE SOROCABA. Passageiros transportados. Disponível em: $<$ https://www.urbes.com.br/passageirostransportados $>$. Acesso em: 14 mar. 2018b. 
USGBC - UNITED STATES GREEN BUILDING COUNCIL. A local government guide to LEED for neigborhood development. 2011. Disponível em:

$<$ http://elibrary.kiu.ac.ug:8080/jspui/handle/1/1484>. Acesso em: 19 maio. 2016.

VEIGA, A. K.; SARAIVA, A. M.; CHAPMAN, A. D.; MORRIS, P. J.; GENDREAU, C.; SCHIGEL, D.; ROBERTSON, T. J. A Conceptual Framework for Quality Assessment and Management of Biodiversity Data. PLOS ONE, v. 12, n. 6, p. e0178731, 28 jun. 2017.

VEIGA, J. E. da. O cumprimento das metas de desenvolvimento sustentável, segundo colunista, 14 jul. 2016. Disponível em: $<$ http://jornal.usp.br/atualidades/universitarios-naoacreditam-no-cumprimento-das-metas-de-desenvolvimento-sustentavel-segundo-colunista/ $>$. Acesso em: 14 jul. 2016.

WANG, X.; LI, Z.; MENG, H.; WU, J. Identification of Key Energy Efficiency Drivers through Global City Benchmarking: A Data Driven Approach. Applied Energy, v. 190, p. 18-28, mar. 2017.

WANG, Y.; FOX, M. S. Consistency Analysis of City Indicator Data. In: Planning support science for smarter urban futures. Lecture Notes in Geoinformation and Cartography. New York, NY: Springer Berlin Heidelberg, 2017. p. 355-369.

WBCSD - WORLD BUSINESS COUNCIL FOR SUSTAINABLE DEVELOPMENT (ed.). Vision 2050 - the new agenda for business. Conches-Geneva: WBCSD, 2010.

WCCD - WORLD COUNCIL ON CITY DATA. Toronto's 2013 Results under ISO 37120 - Indicators of City Service Delivery and Quality of Life, 2014. Disponível em:

$<$ https://www1.toronto.ca/City\%20Of\%20Toronto/City\%20Managers\%20Office/Toronto\%20 Progress\%20Portal/ISO\%2037120/Final\%20-\%20Summary\%20of\%20Toronto's\%20WCCD\%20ISO\%2037120\%20Results-6\%20.pdf>. Acesso em: 25 mar. 2015.

WCCD - WORLD COUNCIL ON CITY DATA. Data Cities Portal. Disponível em: $<$ http://open.dataforcities.org/>. Acesso em: 27 jul. 2018.

W/E CONSULTANTS. Sustainable Roof Extension Retrofit for High-Rise Social Housing in Europe - SuRE-Fit - Study of the potential for roof-top extension retrofit for energy efficiency in social housing, nov. 2007.

WESTFALL, M.; DE VILLA, V. A.; ASIAN DEVELOPMENT BANK (ed.). Urban indicators for managing cities: cities data book. Manila, Philippines: Asian Development Bank, 2001.

WILLIAMS, K.; GUPTA, R.; HOPKINS, D.; GREGG, M.; PAYNE, C.; JOYNT, J. L. R.; SMITH, I.; BATES-BRKLJAC, N. Retrofitting England's Suburbs to Adapt to Climate Change. Building Research \& Information, v. 41, n. 5, p. 517-531, out. 2013.

WORLD BANK. Community Driven Development in Urban Upgrading, jul. 2004. Disponível em: < http://siteresources.worldbank.org/INTUSU/Resources/cdd-urbanupgrading.pdf $>$. Acesso em: 10 jul. 2016.

WORLD BANK. Atlas of Sustainable Development Goals 2017: From World Development Indicators. The World Bank, 2017. 
WWI - WORLDWATCH INSTITUTE; UNIVERSIDADE LIVRE DA MATA ATLÂNTICA. Estado do mundo 2012: rumo à prosperidade sustentável. 2012.

YIN, R. K. Estudo de caso: planejamento e métodos. Porto Alegre (RS): Bookman, 2010.

ZDRAVESKI, V.; MISHEV, K.; TRAJANOV, D.; KOCAREV, L. ISO-Standardized Smart City Platform Architecture and Dashboard. IEEE Pervasive Computing, v. 16, n. 2, p. 3543, 2017. 


\section{APÊNDICES}

\section{Apêndice A - Sistemas de indicadores de sustentabilidade urbana analisados}

Tabela A.1: Sistemas de indicadores de sustentabilidade urbana analisados

Indicadores

$\mathrm{IDH}+\mathrm{IPH}+\mathrm{IDG}+\mathrm{MPG}$ (Índice

Desenv. Humano + Índice Pobreza

1 Humana + Índice Desenv. ajustado ao

Gênero + Medida Participação segundo o Gênero)

2

BIP 40 - Baromêtre des Inegalités et de la Pauvreté

BCN - Balanço Contábil das Nações

Calvert-Henderson Quality of Life Indicators

5

6

7

8 Índice DNA Brasil

EF - Ecological Footprint EPI - Environmental Performance Index

ESI - Environmental Sustainability Index

EVI - Environmental Vulnerability Index

GPI - Genuine Progress Indicator GSI - World Bank’s Genuine Saving Indicator

IDS - Indicadores de Desenvolvimento Sustentável IBGE

IEWB - Index of Economic Wellbeing IPRS - Índice Paulista de Responsabilidade Social IPVS - Índice Paulista de Vulnerabilidade Social

Isew - Index of Sustainable Economic Welfare

ISH - Index Social Health

LPI - Living Planet Index

WN - The Well-being of Nations

GEO - Global Environment Outlook
Origem

PNUD - Programa das Nações

Unidas para o Desenvolvimento

UNDP - United Nations

Development Programme

Réseau d'alerte sur les inegalites et de la pauvrete

FEA, PROCAM e IPEN/USP

Inst. Pesquisas Civilização Yoko (IPCY)

$$
\begin{gathered}
\text { Calvert Group } \\
\text { Instituto DNA Brasil } \\
\text { NEPP -Unicamp }
\end{gathered}
$$

University of British Columbia

Universidade de Yale e

Universidade de Columbia

Universidade de Yale e

Universidade de Columbia

SOPAC - Comissão de Geociência

Aplicada do Pacífico Sul PNUMA

Redefining Progress

$$
\text { World Bank }
$$

IBGE - Instituto Brasileiro de

Geografia e Estatística

Centre for the Study of Living Standards

Fundação Seade

Fundação Seade

Friends of the Earth CES / NEF

Institute for Innovation in Social Policy

WWF - World Wildlife Fund

IDRC - International Research Centre

IUCN - World Conservation Union UNEP

$\begin{array}{cc}\text { País } & \text { Ano } \\ & \text { A } \\ \text { partir } \\ \text { de } \\ 1990 \\ & \\ \text { França } & 2002 \\ & \\ \text { Brasil } & \end{array}$

EUA

2000

Brasil

2004

EUA

1993

EUA

1996

EUA

Nova Zelândia, Noruega, Irlanda, Itália.

EUA

1996

EUA

Brasil

2002

Canadá

1998

Brasil

2002

Brasil

Reino Unido

EUA
Suíça
Canadá

Internacional 
Tabela A.1: Sistemas de indicadores de sustentabilidade urbana analisados (continuação 1)

$$
\text { Indicadores }
$$

21

48 Sustainable Cities (RFSC)/ Sustainable GRI - Global Report Iniciative World Development Indicators Sustainable Development Indicators Quality of Life Indicators

Sustainable Development Indicators for Sweden

The Barcelona Agenda 21 Indicators City of Winnipeg Quality of Life Indicators

IQVU - Índice de Qualidade de Vida Urbana

Sistema de Indicadores de Desarollo Sustentable en Republica Argentina Green City Index Vancouver's Vital Signs Conj. de Indicadores de Sustentabilidade - Empreendimentos HPI - Happy Planet Index

Changsha, Zhuzhou, Xiangtan, Twooriented Society

Sino-Singapore Guangzhou Knowledge City

Sino-Singapore Tianjin Eco-city project

Eco-Garden City of MoHURD in China

$$
\text { Eco-city of MEP in China }
$$

\section{Tangshan Caofeidian Eco-city}

\section{Origem \\ CSD - Commission on Sustainable Development - United Nations European Environmental Agency OECD - Organization for Economic Co-operation and Development \\ INEGI - Instituto Nacional Estadistica y Geografia / INE - Inst. Nacional Ecologia}

Environment Canada

United Nations Statistical Division United Nations

\section{city project \\ CONCERTO}$$
\text { World Bank }
$$

European Environmental Agency UK Goverment

Swedish Environmental Protection

$$
\text { Agency }
$$

Barcelona Goverment

Winnipeg Goverment

Belo Horizonte - MG

Ministerio de Salud y Ambiente

EIU - Economist Intelligence Unit in cooperation with Siemens Vancouver Foundation

CBCS - Conselho Brasileiro de Construção Sustentável

NEF - New Economics Foundation

$$
\text { Vanion Group }
$$

Hunan University e Governo Chinês

Sino-Singapure Guangzhou Knowledge City Investment and Development Co.

Governos da China e de Singapura

MoHURD - Ministry of Housing and Urban and Rural Development MEP - Ministry of Environment Protection

MoHURD - Ministry of Housing and Urban and Rural Development e SMESUD - Swedish Ministry of Environment on Sustainable Urban Development

EU - European Union

RFSC - Reference Framework for Sustainable Cities
País

Internacional

Europa

Internacional

México

Canadá

2003

Internacional

Internacional

2006

EUA

Europa

Reino Unido

Suécia

Espanha

Canadá

Brasil

Argentina

Alemanha

2010

Canadá

2006

Brasil

Reino Unido

1986

China

China

China e Singapura

China e Singapura

China

China

China e Suécia

Europa

Europa 
Tabela A.1: Sistemas de indicadores de sustentabilidade urbana analisados (continuação 2).

Indicadores

49

51 Surabaya Urban Development Project

52

53 Yokohama Smart City Project

54 The Multimedia Super Corridor (MSC)

Project

55

56

57 Smart Grid Research Development and Demonstration Assessment: California

58

59 Comprehensive Urban Development Program in Hanoi Capital City

60

61

62

63

64

65

66
Origem

Vienna University of Technology,

Delft University of Technology e Department of Geography at University of Ljubljana

Kenya Electricity Generating Co.,

Ltd., United Nations University e Geothermal Development Company

World Bank e JICA - Japan

International Cooperation Agency

Enel - Ente Nazionale per l'energia Elettrica

City of Yokohama

Governo da Malásia

Moscow International Portal

Masdar Corporate

California Energy Comission

Sustainable Dubuque

World Bank

SOCIB - Balearic Islands Coastal Observing and Forecasting System

Global Cities Institute

PAHO - Pan American Health Organization

GPCB - Global Partnership on Cities and Biodiversity

Sustainable Society Foundation

Prefeitura de São Paulo

International Organization for Standardization
País

Áustria, Eslovênia

e Holanda

Islândia

Indonésia

Itália

Japão

Malásia

Russia

Emirados Árabes

Unidos

EUA

EUA

Vietnã

Espanha

América

Internacional

Holanda

Brasil

2015

Internacional

Ano 


\section{Apêndice B - Indicadores da NBR ISO 37120:2017 e suas respectivas metas ODS}

Resultado de análise comparativa cruzada entre:

- Os 100 indicadores da NBR ISO 37120:2017 (ABNT, 2017a)

- Os indicadores do Programa Cidades Sustentáveis, gestão 2013-2016 (REDE NOSSA SÃO PAULO, 2012)

- Os indicadores do Programa Cidades Sustentáveis, gestão 2017-2020 (REDE NOSSA SÃO PAULO, 2016)

- Os indicadores das metas dos ODS previstos inicialmente para o Brasil (PNUD, 2015b)

- Os 232 indicadores das metas dos ODS acordados na Comissão Estatística (IAEGSDGs, 2018)

- Os indicadores do Índice ODS (SDSN, 2016)

- O Anexo C da revisão da ISO 37120:2018 (ISO, 2018b) 


\begin{tabular}{|c|c|c|c|c|c|c|c|}
\hline Tema & Seção & No. & Tipo & Descrição & ODS & $\begin{array}{l}\text { Meta } \\
\text { ODS }\end{array}$ & Descrição Meta ODS \\
\hline Economia & 05 & 5.1 & Essencial & Taxa de desemprego da cidade & 8 & 8.5 & $\begin{array}{l}\text { até 2030, alcançar o emprego pleno e produtivo e trabalho decente todas as mulheres e homens, inclusive para os jovens e as } \\
\text { pessoas com deficiência, e remuneração igual para trabalho de igual valor }\end{array}$ \\
\hline Economia & 05 & 5.2 & Essencial & $\begin{array}{l}\text { Valor de avaliação de propriedades } \\
\text { comerciais e industriais como uma } \\
\text { porcentagem do valor de avaliação } \\
\text { total de todas as propriedades }\end{array}$ & 1 & 1.a & $\begin{array}{l}\text { garantir uma mobilização significativa de recursos a partir de uma variedade de fontes, inclusive por meio do reforço da cooperação } \\
\text { para o desenvolvimento, para proporcionar meios adequados e previsíveis para que os países em desenvolvimento, em particular } \\
\text { os paises menos desenvolvidos (LCDs), implementem programas e políticas para acabar com a pobreza em todas as suas } \\
\text { dimensões }\end{array}$ \\
\hline Economia & 05 & 5.3 & Essencial & $\begin{array}{l}\text { Porcentagem da população abaixo } \\
\text { da linha de pobreza }\end{array}$ & 1 & 1.2 & $\begin{array}{l}\text { até } 2030 \text {, reduzir pelo menos à metade a proporção de homens, mulheres e crianças, de todas as idades, que vivem na pobreza, } \\
\text { em todas as suas dimensões, de acordo com as definições nacionais }\end{array}$ \\
\hline Economia & 05 & 5.3 & Essencial & $\begin{array}{l}\text { Porcentagem da população abaixo } \\
\text { da linha de pobreza }\end{array}$ & 1 & 1.4 & $\begin{array}{l}\text { até } 2030 \text {, garantir que todos os homens e mulheres, particularmente os pobres e vulneráveis, tenham direitos iguais aos recursos } \\
\text { econômicos, bem como o acesso a serviços básicos, propriedade e controle sobre a terra e outras formas de propriedade, herança, } \\
\text { recursos naturais, novas tecnologias apropriadas e serviços financeiros, incluindo microfinanças }\end{array}$ \\
\hline Economia & 05 & 5.3 & Essencial & $\begin{array}{l}\text { Porcentagem da população abaixo } \\
\text { da linha de pobreza }\end{array}$ & 10 & 10.1 & $\begin{array}{l}\text { até 2030, progressivamente alcançar e sustentar o crescimento da renda dos } 40 \% \text { da população mais pobre a uma taxa maior que a } \\
\text { média nacional }\end{array}$ \\
\hline Economia & 05 & 5.3 & Essencial & $\begin{array}{l}\text { Porcentagem da população abaixo } \\
\text { da linha de pobreza }\end{array}$ & 10 & 10.2 & $\begin{array}{l}\text { até 2030, empoderar e promover a inclusão social, econômica e política de todos, independentemente da idade, gênero, deficiência, } \\
\text { raça, etnia, origem, religião, condição econômica ou outra }\end{array}$ \\
\hline Economia & 05 & 5.3 & Essencial & $\begin{array}{l}\text { Porcentagem da população abaixo } \\
\text { da linha de pobreza }\end{array}$ & 1 & 1.1 & $\begin{array}{l}\text { até } 2030 \text {, erradicar a pobreza extrema para todas as pessoas em todos os lugares, atualmente medida como pessoas vivendo com } \\
\text { menos de US } 1,90 \text { por dia }\end{array}$ \\
\hline Economia & 05 & 5.4 & Apoio & $\begin{array}{l}\text { Porcentagem da população com } \\
\text { emprego em tempo integral }\end{array}$ & 1 & 1.4 & $\begin{array}{l}\text { até } 2030 \text {, garantir que todos os homens e mulheres, particularmente os pobres e vulneráveis, tenham direitos iguais aos recursos } \\
\text { econômicos, bem como o acesso a serviços básicos, propriedade e controle sobre a terra e outras formas de propriedade, herança, } \\
\text { recursos naturais, novas tecnologias apropriadas e serviços financeiros, incluindo microfinanças }\end{array}$ \\
\hline Economia & 05 & 5.4 & Apoio & $\begin{array}{l}\text { Porcentagem da população com } \\
\text { emprego em tempo integral }\end{array}$ & 8 & 8.5 & $\begin{array}{l}\text { até 2030, alcançar o emprego pleno e produtivo e trabalho decente todas as mulheres e homens, inclusive para os jovens e as } \\
\text { pessoas com deficiência, e remuneração igual para trabalho de igual valor }\end{array}$ \\
\hline Economia & 05 & 5.5 & Apoio & Taxa de desemprego de jovens & 1 & 1.4 & $\begin{array}{l}\text { até } 2030 \text {, garantir que todos os homens e mulheres, particularmente os pobres e vulneráveis, tenham direitos iguais aos recursos } \\
\text { econômicos, bem como o acesso a serviços básicos, propriedade e controle sobre a terra e outras formas de propriedade, herança, } \\
\text { recursos naturais, novas tecnologias apropriadas e serviços financeiros, incluindo microfinanças }\end{array}$ \\
\hline Economia & 05 & 5.5 & Apoio & Taxa de desemprego de jovens & 4 & 4.4 & $\begin{array}{l}\text { até 2030, aumentar substancialmente o número de jovens e adultos que tenham habilidades relevantes, inclusive competências } \\
\text { técnicas e profissionais, para emprego, trabalho decente e empreendedorismo }\end{array}$ \\
\hline Economia & 05 & 5.5 & Apoio & Taxa de desemprego de jovens & 8 & 8.5 & $\begin{array}{l}\text { até 2030, alcançar o emprego pleno e produtivo e trabalho decente todas as mulheres e homens, inclusive para os jovens e as } \\
\text { pessoas com deficiência, e remuneração igual para trabalho de igual valor }\end{array}$ \\
\hline Economia & 05 & 5.5 & Apoio & Taxa de desemprego de jovens & 8 & 8.6 & até 2020, reduzir substancialmente a proporção de jovens sem emprego, educação ou formação \\
\hline Economia & 05 & 5.5 & Apoio & Taxa de desemprego de jovens & 8 & 8.b & $\begin{array}{l}\text { até 2020, desenvolver e operacionalizar uma estratégia global para o emprego dos jovens e implementar o Pacto Mundial para o } \\
\text { Emprego da OIT }\end{array}$ \\
\hline Economia & 05 & 5.5 & Apoio & Taxa de desemprego de jovens & 10 & 10.2 & $\begin{array}{l}\text { até } 2030 \text {, empoderar e promover a inclusão social, econômica e política de todos, independentemente da idade, gênero, deficiência, } \\
\text { raça, etnia, origem, religião, condição econômica ou outra }\end{array}$ \\
\hline Economia & 05 & 5.6 & Apoio & $\begin{array}{l}\text { Número de empresas por } 100.000 \\
\text { habitantes }\end{array}$ & 8 & 8.3 & $\begin{array}{l}\text { promover políticas orientadas para o desenvolvimento, que apoiem as atividades produtivas, geração de emprego decente, } \\
\text { empreendedorismo, criatividade e inovação, e incentivar a formalização e o crescimento das micro, pequenas e médias empresas, } \\
\text { inclusive por meio do acesso a serviços financeiros }\end{array}$ \\
\hline Economia & 05 & 5.6 & Apoio & $\begin{array}{l}\text { Número de empresas por } 100.000 \\
\text { habitantes }\end{array}$ & 9 & 9.2 & $\begin{array}{l}\text { promover a industrialização inclusiva e sustentável e, até 2030, aumentar significativamente a participação da indústria no setor de } \\
\text { emprego e no PIB, de acordo com as circunstâncias nacionais, e dobrar sua participação nos países menos desenvolvidos }\end{array}$ \\
\hline
\end{tabular}




\begin{tabular}{|c|c|c|c|c|c|c|c|}
\hline Tema & Seção & No. & Tipo & Descrição & ODS & $\begin{array}{l}\text { Meta } \\
\text { ODS }\end{array}$ & Descrição Meta ODS \\
\hline Economia & 05 & 5.7 & Apoio & $\begin{array}{l}\text { Número de novas patentes por } \\
100.000 \text { habitantes por ano }\end{array}$ & 8 & 8.1 & $\begin{array}{l}\text { sustentar o crescimento econômico per capita, de acordo com as circunstâncias nacionais e, em particular, pelo menos um } \\
\text { crescimento anual de } 7 \% \text { do PIB nos paises menos desenvolvidos }\end{array}$ \\
\hline Economia & 05 & 5.7 & Apoio & $\begin{array}{l}\text { Número de novas patentes por } \\
100.000 \text { habitantes por ano }\end{array}$ & 8 & 8.2 & $\begin{array}{l}\text { atingir níveis mais elevados de produtividade das economias, por meio da diversificação, modernização tecnológica e inovação, } \\
\text { inclusive por meio de um foco em setores de alto valor agregado e intensivos em mão-de-obra }\end{array}$ \\
\hline Economia & 05 & 5.7 & Apoio & $\begin{array}{l}\text { Número de novas patentes por } \\
100.000 \text { habitantes por ano }\end{array}$ & 9 & 9.5 & $\begin{array}{l}\text { fortalecer a pesquisa cientifica, melhorar as capacidades tecnológicas de setores industriais em todos os países, particularmente } \\
\text { nos países em desenvolvimento, inclusive, até } 2030 \text {, incentivando a inovação e aumentando substancialmente o número de } \\
\text { trabalhadores de pesquisa e desenvolvimento por milhão de pessoas e os gastos público e privado em pesquisa e desenvolvimento }\end{array}$ \\
\hline Educação & 06 & 6.1 & Essencial & $\begin{array}{l}\text { Porcentagem da população } \\
\text { feminina em idade escolar } \\
\text { matriculada em escolas }\end{array}$ & 3 & 3.7 & $\begin{array}{l}\text { até } 2030 \text {, assegurar o acesso universal aos serviços de saúde sexual e reprodutiva, incluindo o planejamento familiar, informação e } \\
\text { educação, bem como a integração da saúde reprodutiva em estratégias e programas nacionais }\end{array}$ \\
\hline Educação & 06 & 6.1 & Essencial & $\begin{array}{l}\text { Porcentagem da população } \\
\text { feminina em idade escolar } \\
\text { matriculada em escolas }\end{array}$ & 4 & 4.1 & $\begin{array}{l}\text { até } 2030 \text {, garantir que todas as meninas e meninos completem o ensino primário e secundário livre, equitativo e de qualidade, que } \\
\text { conduza a resultados de aprendizagem relevantes e eficazes }\end{array}$ \\
\hline Educação & 06 & 6.1 & Essencial & $\begin{array}{l}\text { Porcentagem da população } \\
\text { feminina em idade escolar } \\
\text { matriculada em escolas }\end{array}$ & 4 & 4.3 & $\begin{array}{l}\text { até } 2030 \text {, assegurar a igualdade de acesso para todos os homens e mulheres à educação técnica, profissional e superior de } \\
\text { qualidade, a preços acessíveis, incluindo universidade }\end{array}$ \\
\hline Educação & 06 & 6.1 & Essencial & $\begin{array}{l}\text { Porcentagem da população } \\
\text { feminina em idade escolar } \\
\text { matriculada em escolas }\end{array}$ & 4 & 4.5 & $\begin{array}{l}\text { até } 2030 \text {, eliminar as disparidades de gênero na educação e garantir a igualdade de acesso a todos os níveis de educação e } \\
\text { formação profissional para os mais vulneráveis, incluindo as pessoas com deficiência, povos indígenas e as crianças em situação } \\
\text { de vulnerabilidade }\end{array}$ \\
\hline Educação & 06 & 6.1 & Essencial & $\begin{array}{l}\text { Porcentagem da população } \\
\text { feminina em idade escolar } \\
\text { matriculada em escolas }\end{array}$ & 5 & 5.1 & acabar com todas as formas de discriminação contra todas as mulheres e meninas em toda parte \\
\hline Educação & 06 & 6.1 & Essencial & $\begin{array}{l}\text { Porcentagem da população } \\
\text { feminina em idade escolar } \\
\text { matriculada em escolas }\end{array}$ & 5 & 5.6 & $\begin{array}{l}\text { assegurar o acesso universal à saúde sexual e reprodutiva e os direitos reprodutivos, como acordado em conformidade com o } \\
\text { Programa de Ação da CIPD e da Plataforma de Ação de Pequim e os documentos resultantes de suas conferências de revisão }\end{array}$ \\
\hline Educação & 06 & 6.1 & Essencial & $\begin{array}{l}\text { Porcentagem da população } \\
\text { feminina em idade escolar } \\
\text { matriculada em escolas }\end{array}$ & 5 & 5.c & $\begin{array}{l}\text { adotar e fortalecer políticas sólidas e legislação exequível para a promoção da igualdade de gênero e o empoderamento de todas as } \\
\text { mulheres e meninas, em todos os niveis }\end{array}$ \\
\hline Educação & 06 & 6.1 & Essencial & $\begin{array}{l}\text { Porcentagem da população } \\
\text { feminina em idade escolar } \\
\text { matriculada em escolas }\end{array}$ & 10 & 10.2 & $\begin{array}{l}\text { até } 2030 \text {, empoderar e promover a inclusão social, econômica e política de todos, independentemente da idade, gênero, deficiência, } \\
\text { raça, etnia, origem, religião, condição econômica ou outra }\end{array}$ \\
\hline Educação & 06 & 6.1 & Essencial & $\begin{array}{l}\text { Porcentagem da população } \\
\text { feminina em idade escolar } \\
\text { matriculada em escolas }\end{array}$ & 11 & 11.1 & $\begin{array}{l}\text { até } 2030 \text {, garantir o acesso de todos a habitação segura, adequada e a preço acessível, e aos serviços básicos e urbanizar as } \\
\text { favelas }\end{array}$ \\
\hline Educação & 06 & 6.2 & Essencial & $\begin{array}{l}\text { Porcentagem de estudantes com } \\
\text { ensino primário completo: taxa de } \\
\text { sobrevivência }\end{array}$ & 4 & 4.5 & $\begin{array}{l}\text { até } 2030 \text {, eliminar as disparidades de gênero na educação e garantir a igualdade de acesso a todos os níveis de educação e } \\
\text { formação profissional para os mais vulneráveis, incluindo as pessoas com deficiência, povos indígenas e as crianças em situação } \\
\text { de vulnerabilidade }\end{array}$ \\
\hline Educação & 06 & 6.2 & Essencial & $\begin{array}{l}\text { Porcentagem de estudantes com } \\
\text { ensino primário completo: taxa de } \\
\text { sobrevivência }\end{array}$ & 4 & 4.6 & $\begin{array}{l}\text { até 2030, garantir que todos os jovens e uma substancial proporção dos adultos, homens e mulheres, estejam alfabetizados e } \\
\text { tenham adquirido o conhecimento básico de matemática }\end{array}$ \\
\hline Educação & 06 & 6.2 & Essencial & $\begin{array}{l}\text { Porcentagem de estudantes com } \\
\text { ensino primário completo: taxa de } \\
\text { sobrevivência }\end{array}$ & 10 & 10.2 & $\begin{array}{l}\text { até } 2030 \text {, empoderar e promover a inclusão social, econômica e política de todos, independentemente da idade, gênero, deficiência, } \\
\text { raça, etnia, origem, religião, condição econômica ou outra }\end{array}$ \\
\hline
\end{tabular}




\begin{tabular}{|c|c|c|c|c|c|c|c|}
\hline Tema & Seção & No. & Tipo & Descrição & ODS & $\begin{array}{l}\text { Meta } \\
\text { ODS }\end{array}$ & Descrição Meta ODS \\
\hline Educação & 06 & 6.2 & Essencial & $\begin{array}{l}\text { Porcentagem de estudantes com } \\
\text { ensino primário completo: taxa de } \\
\text { sobrevivência }\end{array}$ & 4 & 4.1 & $\begin{array}{l}\text { até } 2030 \text {, garantir que todas as meninas e meninos completem o ensino primário e secundário livre, equitativo e de qualidade, que } \\
\text { conduza a resultados de aprendizagem relevantes e eficazes }\end{array}$ \\
\hline Educação & 06 & 6.3 & Essencial & $\begin{array}{l}\text { Porcentagem de estudantes com } \\
\text { ensino secundário completo: taxa } \\
\text { de sobrevivência }\end{array}$ & 4 & 4.1 & $\begin{array}{l}\text { até } 2030 \text {, garantir que todas as meninas e meninos completem o ensino primário e secundário livre, equitativo e de qualidade, que } \\
\text { conduza a resultados de aprendizagem relevantes e eficazes }\end{array}$ \\
\hline Educação & 06 & 6.3 & Essencial & $\begin{array}{l}\text { Porcentagem de estudantes com } \\
\text { ensino secundário completo: taxa } \\
\text { de sobrevivência }\end{array}$ & 4 & 4.3 & $\begin{array}{l}\text { até } 2030 \text {, assegurar a igualdade de acesso para todos os homens e mulheres à educação técnica, profissional e superior de } \\
\text { qualidade, a preços acessíveis, incluindo universidade }\end{array}$ \\
\hline Educação & 06 & 6.3 & Essencial & $\begin{array}{l}\text { Porcentagem de estudantes com } \\
\text { ensino secundário completo: taxa } \\
\text { de sobrevivência }\end{array}$ & 4 & 4.4 & $\begin{array}{l}\text { até 2030, aumentar substancialmente o número de jovens e adultos que tenham habilidades relevantes, inclusive competências } \\
\text { técnicas e profissionais, para emprego, trabalho decente e empreendedorismo }\end{array}$ \\
\hline Educação & 06 & 6.3 & Essencial & $\begin{array}{l}\text { Porcentagem de estudantes com } \\
\text { ensino secundário completo: taxa } \\
\text { de sobrevivência }\end{array}$ & 4 & 4.6 & $\begin{array}{l}\text { até } 2030 \text {, garantir que todos os jovens e uma substancial proporção dos adultos, homens e mulheres, estejam alfabetizados e } \\
\text { tenham adquirido o conhecimento básico de matemática }\end{array}$ \\
\hline Educação & 06 & 6.3 & Essencial & $\begin{array}{l}\text { Porcentagem de estudantes com } \\
\text { ensino secundário completo: taxa } \\
\text { de sobrevivência }\end{array}$ & 8 & 8.6 & até 2020, reduzir substancialmente a proporção de jovens sem emprego, educação ou formação \\
\hline Educação & 06 & 6.3 & Essencial & $\begin{array}{l}\text { Porcentagem de estudantes com } \\
\text { ensino secundário completo: taxa } \\
\text { de sobrevivência }\end{array}$ & 10 & 10.2 & $\begin{array}{l}\text { até } 2030 \text {, empoderar e promover a inclusão social, econômica e política de todos, independentemente da idade, gênero, deficiência, } \\
\text { raça, etnia, origem, religião, condição econômica ou outra }\end{array}$ \\
\hline Educação & 06 & 6.3 & Essencial & $\begin{array}{l}\text { Porcentagem de estudantes com } \\
\text { ensino secundário completo: taxa } \\
\text { de sobrevivência }\end{array}$ & 4 & 4.5 & $\begin{array}{l}\text { até } 2030 \text {, eliminar as disparidades de gênero na educação e garantir a igualdade de acesso a todos os níveis de educação e } \\
\text { formação profissional para os mais vulneráveis, incluindo as pessoas com deficiência, povos indígenas e as crianças em situação } \\
\text { de vulnerabilidade }\end{array}$ \\
\hline Educação & 06 & 6.4 & Essencial & $\begin{array}{l}\text { Relação estudante/professor no } \\
\text { ensino primário }\end{array}$ & 4 & 4.c & $\begin{array}{l}\text { até 2030, aumentar substancialmente o contingente de professores qualificados, inclusive por meio da cooperação internacional } \\
\text { para a formação de professores, nos países em desenvolvimento, especialmente os paises menos desenvolvidos e pequenos } \\
\text { estados insulares em desenvolvimento }\end{array}$ \\
\hline Educação & 06 & 6.4 & Essencial & $\begin{array}{l}\text { Relação estudante/professor no } \\
\text { ensino primário }\end{array}$ & 4 & 4.1 & $\begin{array}{l}\text { até } 2030 \text {, garantir que todas as meninas e meninos completem o ensino primário e secundário livre, equitativo e de qualidade, que } \\
\text { conduza a resultados de aprendizagem relevantes e eficazes }\end{array}$ \\
\hline Educação & 06 & 6.5 & Apoio & $\begin{array}{l}\text { Porcentagem de população } \\
\text { masculina em idade escolar } \\
\text { matriculada em escolas }\end{array}$ & 4 & 4.3 & $\begin{array}{l}\text { até } 2030 \text {, assegurar a igualdade de acesso para todos os homens e mulheres à educação técnica, profissional e superior de } \\
\text { qualidade, a preços acessíveis, incluindo universidade }\end{array}$ \\
\hline Educação & 06 & 6.5 & Apoio & $\begin{array}{l}\text { Porcentagem de população } \\
\text { masculina em idade escolar } \\
\text { matriculada em escolas }\end{array}$ & 4 & 4.1 & $\begin{array}{l}\text { até } 2030 \text {, garantir que todas as meninas e meninos completem o ensino primário e secundário livre, equitativo e de qualidade, que } \\
\text { conduza a resultados de aprendizagem relevantes e eficazes }\end{array}$ \\
\hline Educação & 06 & 6.5 & Apoio & $\begin{array}{l}\text { Porcentagem de população } \\
\text { masculina em idade escolar } \\
\text { matriculada em escolas }\end{array}$ & 4 & 4.3 & $\begin{array}{l}\text { até } 2030 \text {, assegurar a igualdade de acesso para todos os homens e mulheres à educação técnica, profissional e superior de } \\
\text { qualidade, a preços acessíveis, incluindo universidade }\end{array}$ \\
\hline
\end{tabular}




\begin{tabular}{|c|c|c|c|c|c|c|c|}
\hline Tema & Seção & No. & Tipo & Descrição & ODS & $\begin{array}{l}\text { Meta } \\
\text { ODS }\end{array}$ & Descrição Meta ODS \\
\hline Educação & 06 & 6.5 & Apoio & $\begin{array}{l}\text { Porcentagem de população } \\
\text { masculina em idade escolar } \\
\text { matriculada em escolas }\end{array}$ & 4 & 4.5 & $\begin{array}{l}\text { até } 2030 \text {, eliminar as disparidades de gênero na educação e garantir a igualdade de acesso a todos os niveis de educação e } \\
\text { formação profissional para os mais vulneráveis, incluindo as pessoas com deficiência, povos indígenas e as crianças em situação } \\
\text { de vulnerabilidade }\end{array}$ \\
\hline Educação & 06 & 6.5 & Apoio & $\begin{array}{l}\text { Porcentagem de população } \\
\text { masculina em idade escolar } \\
\text { matriculada em escolas }\end{array}$ & 10 & 10.2 & $\begin{array}{l}\text { até } 2030 \text {, empoderar e promover a inclusão social, econômica e política de todos, independentemente da idade, gênero, deficiência, } \\
\text { raça, etnia, origem, religião, condição econômica ou outra }\end{array}$ \\
\hline Educação & 06 & 6.5 & Apoio & $\begin{array}{l}\text { Porcentagem de população } \\
\text { masculina em idade escolar } \\
\text { matriculada em escolas }\end{array}$ & 11 & 11.1 & $\begin{array}{l}\text { até 2030, garantir o acesso de todos a habitação segura, adequada e a preço acessível, e aos serviços básicos e urbanizar as } \\
\text { favelas }\end{array}$ \\
\hline Educação & 06 & 6.6 & Apoio & $\begin{array}{l}\text { Porcentagem de população em } \\
\text { idade escolar matriculada em } \\
\text { escolas }\end{array}$ & 4 & 4.1 & $\begin{array}{l}\text { até } 2030 \text {, garantir que todas as meninas e meninos completem o ensino primário e secundário livre, equitativo e de qualidade, que } \\
\text { conduza a resultados de aprendizagem relevantes e eficazes }\end{array}$ \\
\hline Educação & 06 & 6.6 & Apoio & $\begin{array}{l}\text { Porcentagem de população em } \\
\text { idade escolar matriculada em } \\
\text { escolas }\end{array}$ & 4 & 4.5 & $\begin{array}{l}\text { até } 2030 \text {, eliminar as disparidades de gênero na educação e garantir a igualdade de acesso a todos os niveis de educação e } \\
\text { formação profissional para os mais vulneráveis, incluindo as pessoas com deficiência, povos indígenas e as crianças em situação } \\
\text { de vulnerabilidade }\end{array}$ \\
\hline Educação & 06 & 6.6 & Apoio & $\begin{array}{l}\text { Porcentagem de população em } \\
\text { idade escolar matriculada em } \\
\text { escolas }\end{array}$ & 10 & 10.2 & $\begin{array}{l}\text { até } 2030 \text {, empoderar e promover a inclusão social, econômica e política de todos, independentemente da idade, gênero, deficiência, } \\
\text { raça, etnia, origem, religião, condição econômica ou outra }\end{array}$ \\
\hline Educação & 06 & 6.6 & Apoio & $\begin{array}{l}\text { Porcentagem de população em } \\
\text { idade escolar matriculada em } \\
\text { escolas }\end{array}$ & 11 & 11.1 & $\begin{array}{l}\text { até 2030, garantir o acesso de todos a habitação segura, adequada e a preço acessivel, e aos serviços básicos e urbanizar as } \\
\text { favelas }\end{array}$ \\
\hline Educação & 06 & 6.7 & Apoio & $\begin{array}{l}\text { Número de indivíduos com ensino } \\
\text { superior completo por } 100.000 \\
\text { habitantes }\end{array}$ & 4 & 4.3 & $\begin{array}{l}\text { até } 2030 \text {, assegurar a igualdade de acesso para todos os homens e mulheres à educação técnica, profissional e superior de } \\
\text { qualidade, a preços acessiveis, incluindo universidade }\end{array}$ \\
\hline Educação & 06 & 6.7 & Apoio & $\begin{array}{l}\text { Número de indivíduos com ensino } \\
\text { superior completo por } 100.000 \\
\text { habitantes }\end{array}$ & 4 & 4.4 & $\begin{array}{l}\text { até } 2030 \text {, aumentar substancialmente o número de jovens e adultos que tenham habilidades relevantes, inclusive competências } \\
\text { técnicas e profissionais, para emprego, trabalho decente e empreendedorismo }\end{array}$ \\
\hline Educação & 06 & 6.7 & Apoio & $\begin{array}{l}\text { Número de indivíduos com ensino } \\
\text { superior completo por } 100.000 \\
\text { habitantes }\end{array}$ & 4 & 4.5 & $\begin{array}{l}\text { até 2030, eliminar as disparidades de gênero na educação e garantir a igualdade de acesso a todos os niveis de educação e } \\
\text { formação profissional para os mais vulneráveis, incluindo as pessoas com deficiência, povos indígenas e as crianças em situação } \\
\text { de vulnerabilidade }\end{array}$ \\
\hline Educação & 06 & 6.7 & Apoio & $\begin{array}{l}\text { Número de indivíduos com ensino } \\
\text { superior completo por } 100.000 \\
\text { habitantes }\end{array}$ & 8 & 8.6 & até 2020 , reduzir substancialmente a proporção de jovens sem emprego, educação ou formação \\
\hline Educação & 06 & 6.7 & Apoio & $\begin{array}{l}\text { Número de indivíduos com ensino } \\
\text { superior completo por } 100.000 \\
\text { habitantes }\end{array}$ & 9 & 9.5 & $\begin{array}{l}\text { fortalecer a pesquisa científica, melhorar as capacidades tecnológicas de setores industriais em todos os países, particularmente os } \\
\text { paises em desenvolvimento, inclusive, até } 2030 \text {, incentivando a inovação e aumentando substancialmente o número de } \\
\text { trabalhadores de P\&D por milhão de pessoas e os gastos público e privado em P\&D }\end{array}$ \\
\hline Educação & 06 & 6.7 & Apoio & $\begin{array}{l}\text { Número de indivíduos com ensino } \\
\text { superior completo por } 100.000 \\
\text { habitantes }\end{array}$ & 10 & 10.2 & $\begin{array}{l}\text { até } 2030 \text {, empoderar e promover a inclusão social, econômica e política de todos, independentemente da idade, gênero, deficiência, } \\
\text { raça, etnia, origem, religião, condição econômica ou outra }\end{array}$ \\
\hline Energia & 07 & 7.1 & Essencial & $\begin{array}{l}\text { Uso de energia elétrica residencial } \\
\text { total per capita }(\mathrm{kWh} / \mathrm{ano})\end{array}$ & 7 & 7.3 & dobrar a taxa global de melhoria da eficiência energética até 2030 \\
\hline Energia & 07 & 7.1 & Essencial & $\begin{array}{l}\text { Uso de energia elétrica residencial } \\
\text { total per capita (kWh/ano) }\end{array}$ & 12 & 12.2 & até 2030, alcançar gestão sustentável e uso eficiente dos recursos naturais \\
\hline
\end{tabular}




\begin{tabular}{|c|c|c|c|c|c|c|c|}
\hline Tema & Seção & No. & Tipo & Descrição & ODS & $\begin{array}{l}\text { Meta } \\
\text { ODS }\end{array}$ & Descrição Meta ODS \\
\hline Energia & 07 & 7.2 & Essencial & $\begin{array}{l}\text { Porcentagem de habitantes da } \\
\text { cidade com fornecimento regular de } \\
\text { energia elétrica }\end{array}$ & 7 & 7.1 & até 2030, assegurar o acesso universal, confiável, moderno e a preços acessíveis a serviços de energia \\
\hline Energia & 07 & 7.2 & Essencial & $\begin{array}{l}\text { Porcentagem de habitantes da } \\
\text { cidade com fornecimento regular de } \\
\text { energia elétrica }\end{array}$ & 7 & 7.b & $\begin{array}{l}\text { até } 2030 \text {, expandir a infraestrutura e modernizar a tecnologia para o fornecimento de serviços de energia modernos e sustentáveis } \\
\text { para todos nos países em desenvolvimento, particularmente nos países menos desenvolvidos e SIDS }\end{array}$ \\
\hline Energia & 07 & 7.2 & Essencial & $\begin{array}{l}\text { Porcentagem de habitantes da } \\
\text { cidade com fornecimento regular de } \\
\text { energia elétrica }\end{array}$ & 9 & 9.1 & $\begin{array}{l}\text { desenvolver infraestrutura de qualidade, confiável, sustentável e resiliente, incluindo infraestrutura regional e transfronteiriça, para } \\
\text { apoiar o desenvolvimento econômico e o bem-estar humano, com foco no acesso equitativo e a preços acessíveis para todos }\end{array}$ \\
\hline Energia & 07 & 7.2 & Essencial & $\begin{array}{l}\text { Porcentagem de habitantes da } \\
\text { cidade com fornecimento regular de } \\
\text { energia elétrica }\end{array}$ & 11 & 11.1 & $\begin{array}{l}\text { até } 2030 \text {, garantir o acesso de todos a habitação segura, adequada e a preço acessível, e aos serviços básicos e urbanizar as } \\
\text { favelas }\end{array}$ \\
\hline Energia & 07 & 7.3 & Essencial & $\begin{array}{l}\text { Consumo de energia de edifícios } \\
\text { públicos por ano }\left(\mathrm{kWh} / \mathrm{m}^{2}\right)\end{array}$ & 7 & 7.3 & dobrar a taxa global de melhoria da eficiência energética até 2030 \\
\hline Energia & 07 & 7.4 & Essencial & $\begin{array}{l}\text { Porcentagem da energia total } \\
\text { proveniente de fontes renováveis, } \\
\text { como parte do consumo total de } \\
\text { energia da cidade }\end{array}$ & 7 & 7.2 & até 2030 , aumentar substancialmente a participação de energias renováveis na matriz energética global \\
\hline Energia & 07 & 7.4 & Essencial & $\begin{array}{l}\text { Porcentagem da energia total } \\
\text { proveniente de fontes renováveis, } \\
\text { como parte do consumo total de } \\
\text { energia da cidade }\end{array}$ & 7 & 7.3 & dobrar a taxa global de melhoria da eficiência energética até 2030 \\
\hline Energia & 07 & 7.4 & Essencial & $\begin{array}{l}\text { Porcentagem da energia total } \\
\text { proveniente de fontes renováveis, } \\
\text { como parte do consumo total de } \\
\text { energia da cidade }\end{array}$ & 7 & 7.b & $\begin{array}{l}\text { até 2030, expandir a infraestrutura e modernizar a tecnologia para o fornecimento de serviços de energia modernos e sustentáveis } \\
\text { para todos nos paises em desenvolvimento, particularmente nos paises menos desenvolvidos e SIDS }\end{array}$ \\
\hline Energia & 07 & 7.4 & Essencial & $\begin{array}{l}\text { Porcentagem da energia total } \\
\text { proveniente de fontes renováveis, } \\
\text { como parte do consumo total de } \\
\text { energia da cidade }\end{array}$ & 9 & 9.4 & $\begin{array}{l}\text { até } 2030 \text {, modernizar a infraestrutura e reabilitar as indústrias para torná-las sustentáveis, com eficiência no uso de recursos } \\
\text { aumentada e maior adoção de tecnologias e processos industriais limpos e ambientalmente corretos; com todos os países atuando } \\
\text { de acordo com suas respectivas capacidades }\end{array}$ \\
\hline Energia & 07 & 7.4 & Essencial & $\begin{array}{l}\text { Porcentagem da energia total } \\
\text { proveniente de fontes renováveis, } \\
\text { como parte do consumo total de } \\
\text { energia da cidade }\end{array}$ & 7 & 7.1 & até 2030, assegurar o acesso universal, confiável, moderno e a preços acessiveis a serviços de energia \\
\hline Energia & 07 & 7.5 & Apoio & $\begin{array}{l}\text { Uso total de energia elétrica per } \\
\text { capita (kWh/ano) }\end{array}$ & 12 & 12.2 & até 2030 , alcançar gestão sustentável e uso eficiente dos recursos naturais \\
\hline Energia & 07 & 7.5 & Apoio & $\begin{array}{l}\text { Uso total de energia elétrica per } \\
\text { capita (kWh/ano) }\end{array}$ & 7 & 7.3 & dobrar a taxa global de melhoria da eficiência energética até 2030 \\
\hline
\end{tabular}




\begin{tabular}{|c|c|c|c|c|c|c|c|}
\hline Tema & Seção & No. & Tipo & Descrição & ODS & $\begin{array}{l}\text { Meta } \\
\text { ODS }\end{array}$ & Descrição Meta ODS \\
\hline Energia & 07 & 7.5 & Apoio & $\begin{array}{l}\text { Uso total de energia elétrica per } \\
\text { capita (kWh/ano) }\end{array}$ & 9 & 9.4 & $\begin{array}{l}\text { até 2030, modernizar a infraestrutura e reabilitar as indústrias para torná-las sustentáveis, com eficiência no uso de recursos } \\
\text { aumentada e maior adoção de tecnologias e processos industriais limpos e ambientalmente corretos; com todos os países atuando } \\
\text { de acordo com suas respectivas capacidades }\end{array}$ \\
\hline Energia & 07 & 7.6 & Apoio & $\begin{array}{l}\text { Número médio de interrupções de } \\
\text { energia elétrica por consumidor por } \\
\text { ano }\end{array}$ & 7 & 7.1 & até 2030 , assegurar o acesso universal, confiável, moderno e a preços acessiveis a serviços de energia \\
\hline Energia & 07 & 7.6 & Apoio & $\begin{array}{l}\text { Número médio de interrupções de } \\
\text { energia elétrica por consumidor por } \\
\text { ano }\end{array}$ & 9 & 9.1 & $\begin{array}{l}\text { desenvolver infraestrutura de qualidade, confiável, sustentável e resiliente, incluindo infraestrutura regional e transfronteiriça, para } \\
\text { apoiar o desenvolvimento econômico e o bem-estar humano, com foco no acesso equitativo e a preços acessíveis para todos }\end{array}$ \\
\hline Energia & 07 & 7.7 & Apoio & $\begin{array}{l}\text { Duração média das interrupções de } \\
\text { energia elétrica (em horas) }\end{array}$ & 9 & 9.1 & $\begin{array}{l}\text { desenvolver infraestrutura de qualidade, confiável, sustentável e resiliente, incluindo infraestrutura regional e transfronteiriça, para } \\
\text { apoiar o desenvolvimento econômico e o bem-estar humano, com foco no acesso equitativo e a preços acessíveis para todos }\end{array}$ \\
\hline Energia & 07 & 7.7 & Apoio & $\begin{array}{l}\text { Duração média das interrupções de } \\
\text { energia elétrica (em horas) }\end{array}$ & 7 & 7.1 & até 2030, assegurar o acesso universal, confiável, moderno e a preços acessíveis a serviços de energia \\
\hline Meio Ambiente & 08 & 8.1 & Essencial & $\begin{array}{l}\text { Concentração de material } \\
\text { particulado fino (PM 2.5) }\end{array}$ & 11 & 11.6 & $\begin{array}{l}\text { até 2030, reduzir o impacto ambiental negativo per capita das cidades, inclusive prestando especial atenção à qualidade do ar, } \\
\text { gestão de resíduos municipais e outros }\end{array}$ \\
\hline Meio Ambiente & 08 & 8.1 & Essencial & $\begin{array}{l}\text { Concentração de material } \\
\text { particulado fino (PM 2.5) }\end{array}$ & 3 & 3.9 & $\begin{array}{l}\text { até 2030, reduzir substancialmente o número de mortes e doenças por produtos químicos perigosos, contaminação e poluição do ar } \\
\text { e água do solo }\end{array}$ \\
\hline Meio Ambiente & 08 & 8.2 & Essencial & $\begin{array}{l}\text { Concentração de material } \\
\text { particulado (PM 10) }\end{array}$ & 3 & 3.9 & $\begin{array}{l}\text { até 2030, reduzir substancialmente o número de mortes e doenças por produtos químicos perigosos, contaminação e poluição do ar } \\
\text { e água do solo }\end{array}$ \\
\hline Meio Ambiente & 08 & 8.2 & Essencial & $\begin{array}{l}\text { Concentração de material } \\
\text { particulado (PM 10) }\end{array}$ & 11 & 11.6 & $\begin{array}{l}\text { até 2030, reduzir o impacto ambiental negativo per capita das cidades, inclusive prestando especial atenção à qualidade do ar, } \\
\text { gestão de resíduos municipais e outros }\end{array}$ \\
\hline Meio Ambiente & 08 & 8.3 & Essencial & $\begin{array}{l}\text { Emissão de gases de efeito de } \\
\text { estufa medida em toneladas per } \\
\text { capita }\end{array}$ & 9 & 9.4 & $\begin{array}{l}\text { até 2030, modernizar a infraestrutura e reabilitar as indústrias para torná-las sustentáveis, com eficiência no uso de recursos } \\
\text { aumentada e maior adoção de tecnologias e processos industriais limpos e ambientalmente corretos; com todos os paises atuando } \\
\text { de acordo com suas respectivas capacidades }\end{array}$ \\
\hline Meio Ambiente & 08 & 8.3 & Essencial & $\begin{array}{l}\text { Emissão de gases de efeito de } \\
\text { estufa medida em toneladas per } \\
\text { capita }\end{array}$ & 11 & 11.6 & $\begin{array}{l}\text { até } 2030 \text {, reduzir o impacto ambiental negativo per capita das cidades, inclusive prestando especial atenção à qualidade do ar, } \\
\text { gestão de resíduos municipais e outros }\end{array}$ \\
\hline Meio Ambiente & 08 & 8.3 & Essencial & $\begin{array}{l}\text { Emissão de gases de efeito de } \\
\text { estufa medida em toneladas per } \\
\text { capita }\end{array}$ & 12 & 12.2 & até 2030 , alcançar gestão sustentável e uso eficiente dos recursos naturais \\
\hline Meio Ambiente & 08 & 8.3 & Essencial & $\begin{array}{l}\text { Emissão de gases de efeito de } \\
\text { estufa medida em toneladas per } \\
\text { capita }\end{array}$ & 13 & 13.2 & integrar medidas da mudança do clima nas políticas, estratégias e planejamentos nacionais \\
\hline Meio Ambiente & 08 & 8.3 & Essencial & $\begin{array}{l}\text { Emissão de gases de efeito de } \\
\text { estufa medida em toneladas per } \\
\text { capita }\end{array}$ & 9 & 9.1 & $\begin{array}{l}\text { desenvolver infraestrutura de qualidade, confiável, sustentável e resiliente, incluindo infraestrutura regional e transfronteiriça, para } \\
\text { apoiar o desenvolvimento econômico e o bem-estar humano, com foco no acesso equitativo e a preços acessíveis para todos }\end{array}$ \\
\hline Meio Ambiente & 08 & 8.4 & Apoio & $\begin{array}{l}\text { Concentração de } \mathrm{NO}_{2} \text { (dióxido de } \\
\text { nitrogênio) }\end{array}$ & 3 & 3.9 & $\begin{array}{l}\text { até 2030, reduzir substancialmente o número de mortes e doenças por produtos químicos perigosos, contaminação e poluição do ar } \\
\text { e água do solo }\end{array}$ \\
\hline Meio Ambiente & 08 & 8.4 & Apoio & $\begin{array}{l}\text { Concentração de } \mathrm{NO}_{2} \text { (dióxido de } \\
\text { nitrogênio) }\end{array}$ & 11 & 11.6 & $\begin{array}{l}\text { até 2030, reduzir o impacto ambiental negativo per capita das cidades, inclusive prestando especial atenção à qualidade do ar, } \\
\text { gestão de resíduos municipais e outros }\end{array}$ \\
\hline Meio Ambiente & 08 & 8.5 & Apoio & $\begin{array}{l}\text { Concentração de } \mathrm{SO}_{2} \text { (dióxido de } \\
\text { enxofre) }\end{array}$ & 11 & 11.6 & $\begin{array}{l}\text { até 2030, reduzir o impacto ambiental negativo per capita das cidades, inclusive prestando especial atenção à qualidade do ar, } \\
\text { gestão de resíduos municipais e outros }\end{array}$ \\
\hline Meio Ambiente & 08 & 8.5 & Apoio & $\begin{array}{l}\text { Concentração de } \mathrm{SO}_{2} \text { (dióxido de } \\
\text { enxofre) }\end{array}$ & 3 & 3.9 & $\begin{array}{l}\text { até 2030, reduzir substancialmente o número de mortes e doenças por produtos químicos perigosos, contaminação e poluição do ar } \\
\text { e água do solo }\end{array}$ \\
\hline
\end{tabular}




\begin{tabular}{|c|c|c|c|c|c|c|c|}
\hline Tema & Seção & No. & Tipo & Descrição & ODS & $\begin{array}{l}\text { Meta } \\
\text { ODS }\end{array}$ & Descrição Meta ODS \\
\hline Meio Ambiente & 08 & 8.6 & Apoio & Concentração de $\mathrm{O}_{3}$ (ozônio) & 3 & 3.9 & $\begin{array}{l}\text { até 2030, reduzir substancialmente o número de mortes e doenças por produtos químicos perigosos, contaminação e poluição do ar } \\
\text { e água do solo }\end{array}$ \\
\hline Meio Ambiente & 08 & 8.6 & Apoio & Concentração de $\mathrm{O}_{3}$ (ozônio) & 11 & 11.6 & $\begin{array}{l}\text { até } 2030 \text {, reduzir o impacto ambiental negativo per capita das cidades, inclusive prestando especial atenção à qualidade do ar, } \\
\text { gestão de residuos municipais e outros }\end{array}$ \\
\hline Meio Ambiente & 08 & 8.7 & Apoio & Poluição sonora & 11 & 11.6 & $\begin{array}{l}\text { até 2030, reduzir o impacto ambiental negativo per capita das cidades, inclusive prestando especial atenção à qualidade do ar, } \\
\text { gestão de resíduos municipais e outros }\end{array}$ \\
\hline Meio Ambiente & 08 & 8.8 & Apoio & $\begin{array}{l}\text { Variação percentual em número de } \\
\text { especies nativas }\end{array}$ & 11 & 11.4 & fortalecer esforços para proteger e salvaguardar o patrimônio cultural e natural do mundo \\
\hline Meio Ambiente & 08 & 8.8 & Apoio & $\begin{array}{l}\text { Variação percentual em número de } \\
\text { espécies nativas }\end{array}$ & 15 & 15.1 & $\begin{array}{l}\text { até 2020, assegurar a conservação, recuperação e uso sustentável de ecossistemas terrestres e de água doce interiores e seus } \\
\text { serviços, em especial, florestas, zonas úmidas, montanhas e terras áridas, em conformidade com as obrigações decorrentes dos } \\
\text { acordos internacionais }\end{array}$ \\
\hline Meio Ambiente & 08 & 8.8 & Apoio & $\begin{array}{l}\text { Variação percentual em número de } \\
\text { espécies nativas }\end{array}$ & 15 & 15.5 & $\begin{array}{l}\text { tomar medidas urgentes e significativas para reduzir a degradação de habitat naturais, estancar a perda de biodiversidade e, até } \\
2020 \text {, proteger e evitar a extinção de espécies ameaçadas }\end{array}$ \\
\hline Finanças & 09 & 9.1 & Essencial & $\begin{array}{l}\text { Taxa de endividamento (expansão } \\
\text { do serviço da dívida como uma } \\
\text { porcentagem da receita própria do } \\
\text { município) }\end{array}$ & 16 & 16.6 & desenvolver instituições eficazes, responsáveis e transparentes em todos os níveis \\
\hline Finanças & 09 & 9.1 & Essencial & $\begin{array}{l}\text { Taxa de endividamento (expansão } \\
\text { do serviço da dívida como uma } \\
\text { porcentagem da receita própria do } \\
\text { município) }\end{array}$ & 17 & 17.1 & $\begin{array}{l}\text { fortalecer a mobilização de recursos internos, inclusive por meio do apoio internacional aos países em desenvolvimento, para } \\
\text { melhorar a capacidade nacional para arrecadação de impostos e outras receitas }\end{array}$ \\
\hline Finanças & 09 & 9.2 & Apoio & $\begin{array}{l}\text { Despesas de capital como } \\
\text { porcentagem de despesas totais }\end{array}$ & 9 & 9.1 & $\begin{array}{l}\text { desenvolver infraestrutura de qualidade, confiável, sustentável e resiliente, incluindo infraestrutura regional e transfronteiriça, para } \\
\text { apoiar o desenvolvimento econômico e o bem-estar humano, com foco no acesso equitativo e a preços acessíveis para todos }\end{array}$ \\
\hline Finanças & 09 & 9.2 & Apoio & $\begin{array}{l}\text { Despesas de capital como } \\
\text { porcentagem de despesas totais }\end{array}$ & 16 & 16.6 & desenvolver instituições eficazes, responsáveis e transparentes em todos os níveis \\
\hline Finanças & 09 & 9.2 & Apoio & $\begin{array}{l}\text { Despesas de capital como } \\
\text { porcentagem de despesas totais }\end{array}$ & 17 & 17.1 & $\begin{array}{l}\text { fortalecer a mobilização de recursos internos, inclusive por meio do apoio internacional aos paises em desenvolvimento, para } \\
\text { melhorar a capacidade nacional para arrecadação de impostos e outras receitas }\end{array}$ \\
\hline Finanças & 09 & 9.3 & Apoio & $\begin{array}{l}\text { Porcentagem da receita própria em } \\
\text { função do total das receitas }\end{array}$ & 16 & 16.6 & desenvolver instituições eficazes, responsáveis e transparentes em todos os niveis \\
\hline Finanças & 09 & 9.3 & Apoio & $\begin{array}{l}\text { Porcentagem da receita própria em } \\
\text { função do total das receitas }\end{array}$ & 17 & 17.1 & $\begin{array}{l}\text { fortalecer a mobilização de recursos internos, inclusive por meio do apoio internacional aos países em desenvolvimento, para } \\
\text { melhorar a capacidade nacional para arrecadação de impostos e outras receitas }\end{array}$ \\
\hline Finanças & 09 & 9.4 & Apoio & $\begin{array}{l}\text { Porcentagem dos impostos } \\
\text { recolhidos em função dos impostos } \\
\text { cobrados }\end{array}$ & 16 & 16.6 & desenvolver instituições eficazes, responsáveis e transparentes em todos os niveis \\
\hline Finanças & 09 & 9.4 & Apoio & $\begin{array}{l}\text { Porcentagem dos impostos } \\
\text { recolhidos em função dos impostos } \\
\text { cobrados }\end{array}$ & 17 & 17.1 & $\begin{array}{l}\text { fortalecer a mobilização de recursos internos, inclusive por meio do apoio internacional aos países em desenvolvimento, para } \\
\text { melhorar a capacidade nacional para arrecadação de impostos e outras receitas }\end{array}$ \\
\hline $\begin{array}{l}\text { Resposta a } \\
\text { incêndios e } \\
\text { Emergências }\end{array}$ & 10 & 10.1 & Essencial & $\begin{array}{l}\text { Número de bombeiros por } 100.000 \\
\text { habitantes }\end{array}$ & 11 & 11.5 & $\begin{array}{l}\text { até 2030, reduzir significativamente o número de mortes e o número de pessoas afetadas por catástrofes climáticas e diminuir } \\
\text { substancialmente as perdas econômicas diretas causadas por elas em relação ao PIB global, incluindo os desastres relacionados à } \\
\text { água, com o foco em proteger os pobres e as pessoas em situação de vulnerabilidade }\end{array}$ \\
\hline
\end{tabular}




\begin{tabular}{|c|c|c|c|c|c|c|c|}
\hline Tema & Seção & No. & Tipo & Descrição & ODS & $\begin{array}{l}\text { Meta } \\
\text { ODS }\end{array}$ & Descrição Meta ODS \\
\hline $\begin{array}{l}\text { Resposta a } \\
\text { incêndios e } \\
\text { Emergências }\end{array}$ & 10 & 10.1 & Essencial & $\begin{array}{l}\text { Número de bombeiros por } 100.000 \\
\text { habitantes }\end{array}$ & 11 & 11.b & $\begin{array}{l}\text { até 2020, aumentar substancialmente o número de cidades e assentamentos humanos adotando e implementando políticas e } \\
\text { planos integrados para a inclusão, a eficiência dos recursos, mitigação e adaptação às alterações climáticas, a resiliência a } \\
\text { desastres; e desenvolver e implementar, de acordo com o "Sendai Framework" para a redução do risco de desastres 2015-2030, o } \\
\text { gerenciamento holístico do risco de desastres em todos os niveis }\end{array}$ \\
\hline $\begin{array}{l}\text { Resposta a } \\
\text { incêndios e } \\
\text { Emergências }\end{array}$ & 10 & 10.2 & Essencial & $\begin{array}{l}\text { Número de mortes relacionadas a } \\
\text { incêndios por } 100.000 \text { habitantes }\end{array}$ & 11 & 11.b & $\begin{array}{l}\text { até 2020, aumentar substancialmente o número de cidades e assentamentos humanos adotando e implementando políticas e } \\
\text { planos integrados para a inclusão, a eficiência dos recursos, mitigação e adaptação às alteraçães climáticas, a resiliência a } \\
\text { desastres; e desenvolver e implementar, de acordo com o "Sendai Framework" para a redução do risco de desastres 2015-2030, o } \\
\text { gerenciamento holístico do risco de desastres em todos os niveis }\end{array}$ \\
\hline $\begin{array}{l}\text { Resposta a } \\
\text { incêndios e } \\
\text { Emergências }\end{array}$ & 10 & 10.3 & Essencial & $\begin{array}{l}\text { Número de mortes relacionadas a } \\
\text { desastres naturais por } 100.000 \\
\text { habitantes }\end{array}$ & 13 & 13.1 & reforçar a resiliência e a capacidade de adaptação a riscos relacionados ao clima e às catástrofes naturais em todos os paises \\
\hline $\begin{array}{l}\text { Resposta a } \\
\text { incêndios e } \\
\text { Emergências }\end{array}$ & 10 & 10.3 & Essencial & $\begin{array}{l}\text { Número de mortes relacionadas a } \\
\text { desastres naturais por } 100.000 \\
\text { habitantes }\end{array}$ & 11 & 11.5 & $\begin{array}{l}\text { até 2030, reduzir significativamente o número de mortes e o número de pessoas afetadas por catástrofes climáticas e diminuir } \\
\text { substancialmente as perdas econômicas diretas causadas por elas em relação ao PIB global, incluindo os desastres relacionados à } \\
\text { água, com o foco em proteger os pobres e as pessoas em situação de vulnerabilidade }\end{array}$ \\
\hline $\begin{array}{l}\text { Resposta a } \\
\text { incêndios e } \\
\text { Emergências }\end{array}$ & 10 & 10.3 & Essencial & $\begin{array}{l}\text { Número de mortes relacionadas a } \\
\text { desastres naturais por } 100.000 \\
\text { habitantes }\end{array}$ & 11 & 11.b & $\begin{array}{l}\text { até 2020, aumentar substancialmente o número de cidades e assentamentos humanos adotando e implementando políticas e } \\
\text { planos integrados para a inclusão, a eficiência dos recursos, mitigação e adaptação às alterações climáticas, a resiliência a } \\
\text { desastres; e desenvolver e implementar, de acordo com o "Sendai Framework" para a redução do risco de desastres 2015-2030, o } \\
\text { gerenciamento holístico do risco de desastres em todos os niveis }\end{array}$ \\
\hline $\begin{array}{l}\text { Resposta a } \\
\text { incêndios e } \\
\text { Emergências }\end{array}$ & 10 & 10.4 & Apoio & $\begin{array}{l}\text { Número de bombeiros voluntários e } \\
\text { em tempo parcial por } 100.000 \\
\text { habitantes }\end{array}$ & 11 & 11.5 & $\begin{array}{l}\text { até 2030, reduzir significativamente o número de mortes e o número de pessoas afetadas por catástrofes climáticas e diminuir } \\
\text { substancialmente as perdas econômicas diretas causadas por elas em relação ao PIB global, incluindo os desastres relacionados à } \\
\text { água, com o foco em proteger os pobres e as pessoas em situação de vulnerabilidade }\end{array}$ \\
\hline $\begin{array}{l}\text { Resposta a } \\
\text { incêndios e } \\
\text { Emergências }\end{array}$ & 10 & 10.4 & Apoio & $\begin{array}{l}\text { Número de bombeiros voluntários e } \\
\text { em tempo parcial por } 100.000 \\
\text { habitantes }\end{array}$ & 11 & 11.b & $\begin{array}{l}\text { até 2020, aumentar substancialmente o número de cidades e assentamentos humanos adotando e implementando políticas e } \\
\text { planos integrados para a inclusão, a eficiência dos recursos, mitigação e adaptação às alteraçães climáticas, a resiliência a } \\
\text { desastres; e desenvolver e implementar, de acordo com o "Sendai Framework" para a redução do risco de desastres 2015-2030, o } \\
\text { gerenciamento holístico do risco de desastres em todos os niveis }\end{array}$ \\
\hline $\begin{array}{l}\text { Resposta a } \\
\text { incêndios e } \\
\text { Emergências }\end{array}$ & 10 & 10.5 & Apoio & \begin{tabular}{|l|}
$\begin{array}{l}\text { Tempo de resposta dos serviços de } \\
\text { emergência a partir do primeiro } \\
\text { chamado }\end{array}$ \\
\end{tabular} & 11 & 11.1 & $\begin{array}{l}\text { até 2030, garantir o acesso de todos a habitação segura, adequada e a preço acessível, e aos serviços básicos e urbanizar as } \\
\text { favelas }\end{array}$ \\
\hline $\begin{array}{l}\text { Resposta a } \\
\text { incêndios e } \\
\text { Emergências }\end{array}$ & 10 & 10.5 & Apoio & $\begin{array}{l}\text { Tempo de resposta dos serviços de } \\
\text { emergência a partir do primeiro } \\
\text { chamado }\end{array}$ & 11 & 11.b & $\begin{array}{l}\text { até 2020, aumentar substancialmente o número de cidades e assentamentos humanos adotando e implementando políticas e } \\
\text { planos integrados para a inclusão, a eficiência dos recursos, mitigação e adaptação às alterações climáticas, a resiliência a } \\
\text { desastres; e desenvolver e implementar, de acordo com o "Sendai Framework" para a redução do risco de desastres 2015-2030, o } \\
\text { gerenciamento holístico do risco de desastres em todos os niveis }\end{array}$ \\
\hline $\begin{array}{l}\text { Resposta a } \\
\text { incêndios e } \\
\text { Emergências }\end{array}$ & 10 & 10.6 & Apoio & $\begin{array}{l}\text { Tempo de resposta do Corpo de } \\
\text { Bombeiros a partir do primeiro } \\
\text { chamado }\end{array}$ & 11 & 11.b & $\begin{array}{l}\text { até 2020, aumentar substancialmente o número de cidades e assentamentos humanos adotando e implementando políticas e } \\
\text { planos integrados para a inclusão, a eficiência dos recursos, mitigação e adaptação às alteraçães climáticas, a resiliência a } \\
\text { desastres; e desenvolver e implementar, de acordo com o "Sendai Framework" para a redução do risco de desastres 2015-2030, o } \\
\text { gerenciamento holístico do risco de desastres em todos os niveis }\end{array}$ \\
\hline Governança & 11 & 11.1 & Essencial & $\begin{array}{l}\text { Porcentagem de participação dos } \\
\text { eleitores nas últimas eleições } \\
\text { municipais em função do total de } \\
\text { eleitores aptos a votar }\end{array}$ & 16 & 16.7 & garantir a tomada de decisão responsiva, inclusiva, participativa e representativa em todos os níveis \\
\hline Governança & 11 & 11.1 & Essencial & $\begin{array}{l}\text { Porcentagem de participação dos } \\
\text { eleitores nas últimas eleições } \\
\text { municipais em função do total de } \\
\text { eleitores aptos a votar }\end{array}$ & 10 & 10.2 & $\begin{array}{l}\text { até } 2030 \text {, empoderar e promover a inclusão social, econômica e política de todos, independentemente da idade, gênero, deficiência, } \\
\text { raça, etnia, origem, religião, condição econômica ou outra }\end{array}$ \\
\hline
\end{tabular}




\begin{tabular}{|c|c|c|c|c|c|c|c|}
\hline Tema & Seção & No. & Tipo & Descrição & ODS & $\begin{array}{l}\text { Meta } \\
\text { ODS }\end{array}$ & Descrição Meta ODS \\
\hline Governança & 11 & 11.1 & Essencial & $\begin{array}{l}\text { Porcentagem de participação dos } \\
\text { eleitores nas últimas eleições } \\
\text { municipais em função do total de } \\
\text { eleitores aptos a votar }\end{array}$ & 11 & 11.3 & $\begin{array}{l}\text { até 2030, aumentar a urbanização inclusiva e sustentável, e as capacidades para o planejamento e gestão de assentamentos } \\
\text { humanos participativos, integrados e sustentáveis, em todos os paises }\end{array}$ \\
\hline Governança & 11 & 11.2 & Essencial & $\begin{array}{l}\text { Porcentagem de mulheres eleitas } \\
\text { em função do número total de } \\
\text { eleitos na gestão da cidade }\end{array}$ & 16 & 16.7 & garantir a tomada de decisão responsiva, inclusiva, participativa e representativa em todos os níveis \\
\hline Governança & 11 & 11.2 & Essencial & $\begin{array}{l}\text { Porcentagem de mulheres eleitas } \\
\text { em função do número total de } \\
\text { eleitos na gestão da cidade }\end{array}$ & 5 & 5.1 & acabar com todas as formas de discriminação contra todas as mulheres e meninas em toda parte \\
\hline Governança & 11 & 11.2 & Essencial & $\begin{array}{l}\text { Porcentagem de mulheres eleitas } \\
\text { em função do número total de } \\
\text { eleitos na gestão da cidade }\end{array}$ & 5 & 5.5 & $\begin{array}{l}\text { garantir a participação plena e efetiva das mulheres e a igualdade de oportunidades para a liderança em todos os níveis de tomada } \\
\text { de decisão na vida política, econômica e pública. }\end{array}$ \\
\hline Governança & 11 & 11.2 & Essencial & $\begin{array}{l}\text { Porcentagem de mulheres eleitas } \\
\text { em função do número total de } \\
\text { eleitos na gestão da cidade }\end{array}$ & 5 & 5.c & $\begin{array}{l}\text { adotar e fortalecer políticas sólidas e legislação exequível para a promoção da igualdade de gênero e o empoderamento de todas as } \\
\text { mulheres e meninas, em todos os níveis }\end{array}$ \\
\hline Governança & 11 & 11.2 & Essencial & $\begin{array}{l}\text { Porcentagem de mulheres eleitas } \\
\text { em função do número total de } \\
\text { eleitos na gestão da cidade }\end{array}$ & 10 & 10.2 & $\begin{array}{l}\text { até } 2030 \text {, empoderar e promover a inclusão social, econômica e politica de todos, independentemente da idade, gênero, deficiência, } \\
\text { raça, etnia, origem, religião, condição econômica ou outra }\end{array}$ \\
\hline Governança & 11 & 11.3 & Apoio & $\begin{array}{l}\text { Porcentagem de mulheres } \\
\text { empregadas na gestão da cidade }\end{array}$ & 5 & 5.1 & acabar com todas as formas de discriminação contra todas as mulheres e meninas em toda parte \\
\hline Governança & 11 & 11.3 & Apoio & $\begin{array}{l}\text { Porcentagem de mulheres } \\
\text { empregadas na gestão da cidade }\end{array}$ & 5 & 5.5 & $\begin{array}{l}\text { garantir a participação plena e efetiva das mulheres e a igualdade de oportunidades para a liderança em todos os níveis de tomada } \\
\text { de decisão na vida política, econômica e pública. }\end{array}$ \\
\hline Governança & 11 & 11.3 & Apoio & $\begin{array}{l}\text { Porcentagem de mulheres } \\
\text { empregadas na gestão da cidade }\end{array}$ & 5 & 5.c & $\begin{array}{l}\text { adotar e fortalecer políticas sólidas e legislação exequivel para a promoção da igualdade de gênero e o empoderamento de todas as } \\
\text { mulheres e meninas, em todos os níveis }\end{array}$ \\
\hline Governança & 11 & 11.3 & Apoio & $\begin{array}{l}\text { Porcentagem de mulheres } \\
\text { empregadas na gestão da cidade }\end{array}$ & 10 & 10.2 & $\begin{array}{l}\text { até 2030, empoderar e promover a inclusão social, econômica e politica de todos, independentemente da idade, gênero, deficiência, } \\
\text { raça, etnia, origem, religião, condição econômica ou outra }\end{array}$ \\
\hline Governança & 11 & 11.3 & Apoio & $\begin{array}{l}\text { Porcentagem de mulheres } \\
\text { empregadas na gestão da cidade }\end{array}$ & 16 & 16.7 & garantir a tomada de decisão responsiva, inclusiva, participativa e representativa em todos os níveis \\
\hline Governança & 11 & 11.4 & Apoio & $\begin{array}{l}\text { Número de condenações de } \\
\text { servidores da cidade por corrupção } \\
\text { e/ou suborno por } 100.000 \\
\text { habitantes }\end{array}$ & 16 & 16.5 & reduzir substancialmente a corrupção e o suborno em todas as suas formas \\
\hline
\end{tabular}




\begin{tabular}{|c|c|c|c|c|c|c|c|}
\hline Tema & Seção & No. & Tipo & Descrição & ODS & $\begin{array}{l}\text { Meta } \\
\text { ODS }\end{array}$ & Descrição Meta ODS \\
\hline Governança & 11 & 11.5 & Apoio & $\begin{array}{l}\text { Representação de cidadãos: } \\
\text { número de autoridades locais } \\
\text { eleitas para o cargo por } 100.000 \\
\text { habitantes }\end{array}$ & 11 & 11.3 & $\begin{array}{l}\text { até } 2030 \text {, aumentar a urbanização inclusiva e sustentável, e as capacidades para o planejamento e gestão de assentamentos } \\
\text { humanos participativos, integrados e sustentáveis, em todos os paises }\end{array}$ \\
\hline Governança & 11 & 11.5 & Apoio & \begin{tabular}{|l|} 
Representação de cidadãos: \\
número de autoridades locais \\
eleitas para o cargo por 100.000 \\
habitantes
\end{tabular} & 16 & 16.7 & garantir a tomada de decisão responsiva, inclusiva, participativa e representativa em todos os níveis \\
\hline Governança & 11 & 11.6 & Apoio & $\begin{array}{l}\text { Porcentagem de eleitores } \\
\text { registrados em função da } \\
\text { população com idade para votar }\end{array}$ & 16 & 16.7 & garantir a tomada de decisão responsiva, inclusiva, participativa e representativa em todos os níveis \\
\hline Governança & 11 & 11.6 & Apoio & $\begin{array}{l}\text { Porcentagem de eleitores } \\
\text { registrados em função da } \\
\text { população com idade para votar }\end{array}$ & 11 & 11.3 & $\begin{array}{l}\text { até 2030, aumentar a urbanização inclusiva e sustentável, e as capacidades para o planejamento e gestão de assentamentos } \\
\text { humanos participativos, integrados e sustentáveis, em todos os paises }\end{array}$ \\
\hline Saúde & 12 & 12.1 & Essencial & Expectativa média de vida & 3 & 3.5 & reforçar a prevenção e o tratamento do abuso de substâncias, incluindo o abuso de drogas entorpecentes e uso nocivo do álcool \\
\hline Saúde & 12 & 12.1 & Essencial & Expectativa média de vida & 3 & 3.4 & $\begin{array}{l}\text { até 2030, reduzir em um terço a mortalidade prematura por doenças não transmissiveis (DNTs) via prevenção e tratamento, e } \\
\text { promover a saúde mental e o bem-estar }\end{array}$ \\
\hline Saúde & 12 & 12.2 & Essencial & $\begin{array}{l}\text { Número de leitos hospitalares por } \\
100.000 \text { habitantes }\end{array}$ & 11 & 11.1 & $\begin{array}{l}\text { até 2030, garantir o acesso de todos a habitação segura, adequada e a preço acessível, e aos serviços básicos e urbanizar as } \\
\text { favelas }\end{array}$ \\
\hline Saúde & 12 & 12.2 & Essencial & $\begin{array}{l}\text { Número de leitos hospitalares por } \\
100.000 \text { habitantes }\end{array}$ & 3 & 3.4 & $\begin{array}{l}\text { até 2030, reduzir em um terço a mortalidade prematura por doenças não transmissiveis (DNTs) via prevenção e tratamento, e } \\
\text { promover a saúde mental e o bem-estar }\end{array}$ \\
\hline Saúde & 12 & 12.2 & Essencial & $\begin{array}{l}\text { Número de leitos hospitalares por } \\
100.000 \text { habitantes }\end{array}$ & 3 & 3.5 & reforçar a prevenção e o tratamento do abuso de substâncias, incluindo o abuso de drogas entorpecentes e uso nocivo do álcool \\
\hline Saúde & 12 & 12.2 & Essencial & $\begin{array}{l}\text { Número de leitos hospitalares por } \\
100.000 \text { habitantes }\end{array}$ & 3 & 3.8 & $\begin{array}{l}\text { atingir a cobertura universal de saúde, incluindo a proteção do risco financeiro, o acesso a serviços de saúde essenciais de } \\
\text { qualidade e o acesso a medicamentos e vacinas essenciais seguros, eficazes, de qualidade e a preços acessiveis para todos }\end{array}$ \\
\hline Saúde & 12 & 12.2 & Essencial & $\begin{array}{l}\text { Número de leitos hospitalares por } \\
100.000 \text { habitantes }\end{array}$ & 3 & $3 . c$ & $\begin{array}{l}\text { aumentar substancialmente o financiamento da saúde e o recrutamento, desenvolvimento e formação, e conservação do pessoal de } \\
\text { saúde nos países em desenvolvimento, especialmente nos países menos desenvolvidos e SIDS }\end{array}$ \\
\hline Saúde & 12 & 12.3 & Essencial & $\begin{array}{l}\text { Número de médicos por } 100.000 \\
\text { habitantes }\end{array}$ & 11 & 11.1 & $\begin{array}{l}\text { até 2030, garantir o acesso de todos a habitação segura, adequada e a preço acessível, e aos serviços básicos e urbanizar as } \\
\text { favelas }\end{array}$ \\
\hline Saúde & 12 & 12.3 & Essencial & $\begin{array}{l}\text { Número de médicos por } 100.000 \\
\text { habitantes }\end{array}$ & 3 & 3.4 & $\begin{array}{l}\text { até 2030, reduzir em um terço a mortalidade prematura por doenças não transmissíveis (DNTs) via prevenção e tratamento, e } \\
\text { promover a saúde mental e o bem-estar }\end{array}$ \\
\hline Saúde & 12 & 12.3 & Essencial & $\begin{array}{l}\text { Número de médicos por } 100.000 \\
\text { habitantes }\end{array}$ & 3 & 3.5 & reforçar a prevenção e o tratamento do abuso de substâncias, incluindo o abuso de drogas entorpecentes e uso nocivo do álcool \\
\hline Saúde & 12 & 12.3 & Essencial & $\begin{array}{l}\text { Número de médicos por } 100.000 \\
\text { habitantes }\end{array}$ & 3 & 3.7 & $\begin{array}{l}\text { até 2030, assegurar o acesso universal aos serviços de saúde sexual e reprodutiva, incluindo o planejamento familiar, informação e } \\
\text { educação, bem como a integração da saúde reprodutiva em estratégias e programas nacionais }\end{array}$ \\
\hline Saúde & 12 & 12.3 & Essencial & $\begin{array}{l}\text { Número de médicos por } 100.000 \\
\text { habitantes }\end{array}$ & 3 & 3.8 & $\begin{array}{l}\text { atingir a cobertura universal de saúde, incluindo a proteção do risco financeiro, o acesso a serviços de saúde essenciais de } \\
\text { qualidade e o acesso a medicamentos e vacinas essenciais seguros, eficazes, de qualidade e a preços acessíveis para todos }\end{array}$ \\
\hline Saúde & 12 & 12.3 & Essencial & $\begin{array}{l}\text { Número de médicos por } 100.000 \\
\text { habitantes }\end{array}$ & 3 & 3.c & $\begin{array}{l}\text { aumentar substancialmente o financiamento da saúde e o recrutamento, desenvolvimento e formação, e conservação do pessoal de } \\
\text { saúde nos países em desenvolvimento, especialmente nos países menos desenvolvidos e SIDS }\end{array}$ \\
\hline
\end{tabular}




\begin{tabular}{|c|c|c|c|c|c|c|c|}
\hline Tema & Seção & No. & Tipo & Descrição & ODS & $\begin{array}{l}\text { Meta } \\
\text { ODS }\end{array}$ & Descrição Meta ODS \\
\hline Saúde & 12 & 12.3 & Essencial & $\begin{array}{l}\text { Número de médicos por } 100.000 \\
\text { habitantes }\end{array}$ & 5 & 5.6 & $\begin{array}{l}\text { assegurar o acesso universal à saúde sexual e reprodutiva e os direitos reprodutivos, como acordado em conformidade com o } \\
\text { Programa de Ação da CIPD e da Plataforma de Ação de Pequim e os documentos resultantes de suas conferências de revisão }\end{array}$ \\
\hline Saúde & 12 & 12.4 & Essencial & $\begin{array}{l}\text { Taxa de mortalidade de crianças } \\
\text { menores de cinco anos a cada } \\
1.000 \text { nascidos vivos }\end{array}$ & 3 & 3.2 & $\begin{array}{l}\text { até } 2030 \text {, acabar com as mortes evitáveis de recém-nascidos e crianças menores de } 5 \text { anos, com todos os países objetivando } \\
\text { reduzir a mortalidade neonatal para pelo menos } 12 \text { por } 1.000 \text { nascidos vivos e a mortalidade de crianças menores de } 5 \text { anos para } \\
\text { pelo menos } 25 \text { por } 1.000 \text { nascidos vivos }\end{array}$ \\
\hline Saúde & 12 & 12.4 & Essencial & $\begin{array}{l}\text { Taxa de mortalidade de crianças } \\
\text { menores de cinco anos a cada } \\
1.000 \text { nascidos vivos }\end{array}$ & 2 & 2.1 & $\begin{array}{l}\text { até } 2030 \text {, acabar com a fome e garantir o acesso de todas as pessoas, em particular os pobres e pessoas em situações vulneráveis } \\
\text { incluindo crianças, a alimentos seguros, nutritivos e suficientes durante todo o ano }\end{array}$ \\
\hline Saúde & 12 & 12.4 & Essencial & $\begin{array}{l}\text { Taxa de mortalidade de crianças } \\
\text { menores de cinco anos a cada } \\
1.000 \text { nascidos vivos }\end{array}$ & 2 & 2.2 & $\begin{array}{l}\text { até } 2030 \text {, acabar com todas as formas de desnutrição, incluindo atingir até } 2025 \text { as metas acordadas internacionalmente sobre } \\
\text { desnutrição crônica e desnutrição em crianças menores de cinco anos de idade, e atender às necessidades nutricionais dos } \\
\text { adolescentes, mulheres grávidas e lactantes e pessoas idosas }\end{array}$ \\
\hline Saúde & 12 & 12.5 & Apoio & $\begin{array}{l}\text { Número de pessoas da equipe de } \\
\text { enfermagem e obstetrícia por } \\
100.000 \text { habitantes }\end{array}$ & 11 & 11.1 & $\begin{array}{l}\text { até 2030, garantir o acesso de todos a habitação segura, adequada e a preço acessivel, e aos serviços básicos e urbanizar as } \\
\text { favelas }\end{array}$ \\
\hline Saúde & 12 & 12.5 & Apoio & $\begin{array}{l}\text { Número de pessoas da equipe de } \\
\text { enfermagem e obstetrícia por } \\
100.000 \text { habitantes }\end{array}$ & 2 & 2.2 & $\begin{array}{l}\text { até } 2030 \text {, acabar com todas as formas de desnutrição, incluindo atingir até } 2025 \text { as metas acordadas internacionalmente sobre } \\
\text { desnutrição crônica e desnutrição em crianças menores de cinco anos de idade, e atender às necessidades nutricionais dos } \\
\text { adolescentes, mulheres grávidas e lactantes e pessoas idosas }\end{array}$ \\
\hline Saúde & 12 & 12.5 & Apoio & $\begin{array}{l}\text { Número de pessoas da equipe de } \\
\text { enfermagem e obstetrícia por } \\
100.000 \text { habitantes }\end{array}$ & 3 & 3.1 & até 2030 , reduzir a taxa de mortalidade materna global para menos de 70 mortes por 100.000 nascidos vivos \\
\hline Saúde & 12 & 12.5 & Apoio & $\begin{array}{l}\text { Número de pessoas da equipe de } \\
\text { enfermagem e obstetrícia por } \\
100.000 \text { habitantes }\end{array}$ & 3 & 3.4 & $\begin{array}{l}\text { até 2030, reduzir em um terço a mortalidade prematura por doenças não transmissiveis (DNTs) via prevenção e tratamento, e } \\
\text { promover a saúde mental e o bem-estar }\end{array}$ \\
\hline Saúde & 12 & 12.5 & Apoio & $\begin{array}{l}\text { Número de pessoas da equipe de } \\
\text { enfermagem e obstetrícia por } \\
100.000 \text { habitantes }\end{array}$ & 3 & 3.5 & reforçar a prevenção e o tratamento do abuso de substâncias, incluindo o abuso de drogas entorpecentes e uso nocivo do álcool \\
\hline Saúde & 12 & 12.5 & Apoio & $\begin{array}{l}\text { Número de pessoas da equipe de } \\
\text { enfermagem e obstetrícia por } \\
100.000 \text { habitantes }\end{array}$ & 3 & 3.7 & $\begin{array}{l}\text { até } 2030 \text {, assegurar o acesso universal aos serviços de saúde sexual e reprodutiva, incluindo o planejamento familiar, informação e } \\
\text { educação, bem como a integração da saúde reprodutiva em estratégias e programas nacionais }\end{array}$ \\
\hline Saúde & 12 & 12.5 & Apoio & $\begin{array}{l}\text { Número de pessoas da equipe de } \\
\text { enfermagem e obstetrícia por } \\
100.000 \text { habitantes }\end{array}$ & 3 & 3.c & $\begin{array}{l}\text { aumentar substancialmente o financiamento da saúde e o recrutamento, } \\
\text { desenvolvimento, treinamento e retenção do pessoal de saúde nos países em desenvolvimento, especialmente nos países de } \\
\text { menor desenvolvimento relativo e nos pequenos Estados insulares em desenvolvimento }\end{array}$ \\
\hline Saúde & 12 & 12.5 & Apoio & $\begin{array}{l}\text { Número de pessoas da equipe de } \\
\text { enfermagem e obstetrícia por } \\
100.000 \text { habitantes }\end{array}$ & 5 & 5.6 & $\begin{array}{l}\text { assegurar o acesso universal à saúde sexual e reprodutiva e os direitos reprodutivos, como acordado em conformidade com o } \\
\text { Programa de Ação da CIPD e da Plataforma de Ação de Pequim e os documentos resultantes de suas conferências de revisão }\end{array}$ \\
\hline Saúde & 12 & 12.6 & Apoio & $\begin{array}{l}\text { Número de profissionais de saúde } \\
\text { mental por } 100.000 \text { habitantes }\end{array}$ & 3 & 3.4 & $\begin{array}{l}\text { até 2030, reduzir em um terço a mortalidade prematura por doenças não transmissiveis (DNTs) via prevenção e tratamento, e } \\
\text { promover a saúde mental e o bem-estar }\end{array}$ \\
\hline Saúde & 12 & 12.6 & Apoio & $\begin{array}{l}\text { Número de profissionais de saúde } \\
\text { mental por } 100.000 \text { habitantes }\end{array}$ & 3 & 3.5 & reforçar a prevenção e o tratamento do abuso de substâncias, incluindo o abuso de drogas entorpecentes e uso nocivo do álcool \\
\hline
\end{tabular}




\begin{tabular}{|c|c|c|c|c|c|c|c|}
\hline Tema & Seção & No. & Tipo & Descrição & ODS & $\begin{array}{l}\text { Meta } \\
\text { ODS }\end{array}$ & Descrição Meta ODS \\
\hline Saúde & 12 & 12.6 & Apoio & $\begin{array}{l}\text { Número de profissionais de saúde } \\
\text { mental por } 100.000 \text { habitantes }\end{array}$ & 3 & $3 . c$ & $\begin{array}{l}\text { aumentar substancialmente o financiamento da saúde e o recrutamento, desenvolvimento, treinamento e retenção do pessoal de } \\
\text { saúde nos países em desenvolvimento, especialmente nos paises de menor desenvolvimento relativo e nos pequenos Estados } \\
\text { insulares em desenvolvimento }\end{array}$ \\
\hline Saúde & 12 & 12.7 & Apoio & $\begin{array}{l}\text { Taxa de suicídio por } 100.000 \\
\text { habitantes }\end{array}$ & 3 & 3.4 & $\begin{array}{l}\text { até 2030, reduzir em um terço a mortalidade prematura por doenças não transmissíveis (DNTs) por meio de prevenção e } \\
\text { tratamento, e promover a saúde mental e o bem-estar }\end{array}$ \\
\hline Recreação & 13 & 13.1 & Apoio & $\begin{array}{l}\text { Área em metros quadrados de } \\
\text { espaços públicos de recreação } \\
\text { cobertos per capita }\end{array}$ & 11 & 11.7 & $\begin{array}{l}\text { até 2030, proporcionar o acesso universal a espaços públicos seguros, inclusivos, acessíveis e verdes, particularmente para as } \\
\text { mulheres e crianças, pessoas idosas e pessoas com deficiência }\end{array}$ \\
\hline Recreação & 13 & 13.2 & Apoio & $\begin{array}{l}\text { Área em metros quadrados de } \\
\text { espaços públicos de recreação ao } \\
\text { ar livre per capita }\end{array}$ & 11 & 11.7 & $\begin{array}{l}\text { até 2030, proporcionar o acesso universal a espaços públicos seguros, inclusivos, acessíveis e verdes, particularmente para as } \\
\text { mulheres e crianças, pessoas idosas e pessoas com deficiência }\end{array}$ \\
\hline Recreação & 13 & 13.2 & Apoio & $\begin{array}{l}\text { Área em metros quadrados de } \\
\text { espaços públicos de recreação ao } \\
\text { ar livre per capita }\end{array}$ & 11 & 11.7 & $\begin{array}{l}\text { até 2030, proporcionar o acesso universal a espaços públicos seguros, inclusivos, acessíveis e verdes, particularmente para as } \\
\text { mulheres e crianças, pessoas idosas e pessoas com deficiência }\end{array}$ \\
\hline Segurança & 14 & 14.1 & Essencial & $\begin{array}{l}\text { Número de agentes de polícia por } \\
100.000 \text { habitantes }\end{array}$ & 16 & 16.1 & reduzir significativamente todas as formas de violência e as taxas de mortalidade relacionada, em todos os lugares \\
\hline Segurança & 14 & 14.1 & Essencial & $\begin{array}{l}\text { Número de agentes de polícia por } \\
100.000 \text { habitantes }\end{array}$ & 11 & 11.1 & $\begin{array}{l}\text { até 2030, garantir o acesso de todos a habitação segura, adequada e a preço acessível, e aos serviços básicos e urbanizar as } \\
\text { favelas }\end{array}$ \\
\hline Segurança & 14 & 14.2 & Essencial & $\begin{array}{l}\text { Número de homicídios por } 100.000 \\
\text { habitantes }\end{array}$ & 16 & 16.1 & reduzir significativamente todas as formas de violência e as taxas de mortalidade relacionada, em todos os lugares \\
\hline Segurança & 14 & 14.3 & Apoio & $\begin{array}{l}\text { Crimes contra a propriedades por } \\
100.000 \text { habitantes }\end{array}$ & 16 & 16.1 & reduzir significativamente todas as formas de violência e as taxas de mortalidade relacionada, em todos os lugares \\
\hline Segurança & 14 & 14.3 & Apoio & $\begin{array}{l}\text { Crimes contra a propriedades por } \\
100.000 \text { habitantes }\end{array}$ & 16 & 16.4 & $\begin{array}{l}\text { até 2030, reduzir significativamente os fluxos financeiros e de armas ilegais, reforçar a recuperação e devolução de recursos } \\
\text { roubados e combater todas as formas de crime organizado }\end{array}$ \\
\hline Segurança & 14 & 14.4 & Apoio & $\begin{array}{l}\text { Tempo de resposta da polícia a } \\
\text { partir do primeiro chamado }\end{array}$ & 11 & 11.1 & $\begin{array}{l}\text { até 2030, garantir o acesso de todos a habitação segura, adequada e a preço acessível, e aos serviços básicos e urbanizar as } \\
\text { favelas }\end{array}$ \\
\hline Segurança & 14 & 14.4 & Apoio & $\begin{array}{l}\text { Tempo de resposta da polícia a } \\
\text { partir do primeiro chamado }\end{array}$ & 16 & 16.1 & reduzir significativamente todas as formas de violência e as taxas de mortalidade relacionada, em todos os lugares \\
\hline Segurança & 14 & 14.4 & Apoio & $\begin{array}{l}\text { Tempo de resposta da polícia a } \\
\text { partir do primeiro chamado }\end{array}$ & 16 & 16.4 & $\begin{array}{l}\text { até 2030, reduzir significativamente os fluxos financeiros e de armas ilegais, reforçar a recuperação e devolução de recursos } \\
\text { roubados e combater todas as formas de crime organizado }\end{array}$ \\
\hline Segurança & 14 & 14.5 & Apoio & $\begin{array}{l}\text { Taxa de crimes violentos por } \\
100.000 \text { habitantes }\end{array}$ & 16 & 16.4 & $\begin{array}{l}\text { até 2030, reduzir significativamente os fluxos financeiros e de armas ilegais, reforçar a recuperação e devolução de recursos } \\
\text { roubados e combater todas as formas de crime organizado }\end{array}$ \\
\hline Segurança & 14 & 14.5 & Apoio & $\begin{array}{l}\text { Taxa de crimes violentos por } \\
100.000 \text { habitantes }\end{array}$ & 5 & 5.2 & $\begin{array}{l}\text { eliminar todas as formas de violência contra todas as mulheres e meninas nas esferas públicas e privadas, incluindo o tráfico e } \\
\text { exploração sexual e de outros tipos }\end{array}$ \\
\hline Segurança & 14 & 14.5 & Apoio & $\begin{array}{l}\text { Taxa de crimes violentos por } \\
100.000 \text { habitantes }\end{array}$ & 16 & 16.1 & reduzir significativamente todas as formas de violência e as taxas de mortalidade relacionada, em todos os lugares \\
\hline Segurança & 14 & 14.5 & Apoio & $\begin{array}{l}\text { Taxa de crimes violentos por } \\
100.000 \text { habitantes }\end{array}$ & 16 & 16.2 & acabar com abuso, exploração, tráfico e todas as formas de violência e tortura contra crianças \\
\hline Habitação & 15 & 15.1 & Essencial & $\begin{array}{l}\text { Porcentagem da população urbana } \\
\text { morando em favelas }\end{array}$ & 11 & 11.1 & $\begin{array}{l}\begin{array}{l}\text { até 2030, garantir o acesso de todos à habitação segura, adequada e a preço acessível, e aos serviços básicos. Urbanizar as } \\
\text { favelas. }\end{array} \\
\text { fol }\end{array}$ \\
\hline Habitação & 15 & 15.1 & Essencial & $\begin{array}{l}\text { Porcentagem da população urbana } \\
\text { morando em favelas }\end{array}$ & 10 & 10.2 & $\begin{array}{l}\text { até 2030, empoderar e promover a inclusão social, econômica e política de todos, independentemente da idade, gênero, deficiência } \\
\text { raça, etnia, origem, religião, condição econômica ou outra }\end{array}$ \\
\hline Habitação & 15 & 15.2 & Apoio & $\begin{array}{l}\text { Número de sem-teto por } 100.000 \\
\text { habitantes }\end{array}$ & 11 & 11.1 & $\begin{array}{l}\text { até 2030, garantir o acesso de todos à habitação segura, adequada e a preço acessível, e aos serviços básicos. Urbanizar as } \\
\text { favelas. }\end{array}$ \\
\hline
\end{tabular}




\begin{tabular}{|c|c|c|c|c|c|c|c|}
\hline Tema & Seção & No. & Tipo & Descrição & ODS & $\begin{array}{l}\text { Meta } \\
\text { ODS }\end{array}$ & Descrição Meta ODS \\
\hline Habitação & 15 & 15.3 & Apoio & $\begin{array}{l}\text { Porcentagem de moradias sem } \\
\text { títulos de propriedade registrados }\end{array}$ & 10 & 10.2 & $\begin{array}{l}\text { até } 2030 \text {, empoderar e promover a inclusão social, econômica e política de todos, independentemente da idade, gênero, deficiência, } \\
\text { raça, etnia, origem, religião, condição econômica ou outra }\end{array}$ \\
\hline Habitação & 15 & 15.3 & Apoio & $\begin{array}{l}\text { Porcentagem de moradias sem } \\
\text { titulos de propriedade registrados }\end{array}$ & 11 & 11.3 & $\begin{array}{l}\text { até } 2030 \text {, aumentar a urbanização inclusiva e sustentável, e a capacidade para o planejamento e a gestão participativa, integrada e } \\
\text { sustentável dos assentamentos humanos, em todos os paises }\end{array}$ \\
\hline $\begin{array}{l}\text { Residuos } \\
\text { sólidos }\end{array}$ & 16 & 16.1 & Essencial & $\begin{array}{l}\text { Porcentagem da população urbana } \\
\text { com coleta regular de lixo } \\
\text { (domiciliar) }\end{array}$ & 12 & 12.2 & até 2030 , alcançar gestão sustentável e uso eficiente dos recursos naturais \\
\hline $\begin{array}{l}\text { Resíduos } \\
\text { sólidos }\end{array}$ & 16 & 16.1 & Essencial & $\begin{array}{l}\text { Porcentagem da população urbana } \\
\text { com coleta regular de lixo } \\
\text { (domiciliar) }\end{array}$ & 11 & 11.6 & $\begin{array}{l}\text { até 2030, reduzir o impacto ambiental negativo per capita das cidades, inclusive prestando especial atenção à qualidade do ar, } \\
\text { gestão de resíduos municipais e outros }\end{array}$ \\
\hline $\begin{array}{l}\text { Resíduos } \\
\text { sólidos }\end{array}$ & 16 & 16.10 & Apoio & $\begin{array}{l}\text { Porcentagem de resíduos urbanos } \\
\text { perigosos que são reciclados }\end{array}$ & 6 & 6.3 & $\begin{array}{l}\text { até 2030, melhorar a qualidade da água, reduzindo a poluição, eliminando despejo e minimizando a liberação de produtos químicos } \\
\text { e materiais perigosos, reduzindo à metade a proporção de águas residuais não tratadas, e aumentando substancialmente a } \\
\text { reciclagem e reutilização segura globalmente }\end{array}$ \\
\hline $\begin{array}{l}\text { Resíduos } \\
\text { sólidos }\end{array}$ & 16 & 16.10 & Apoio & $\begin{array}{l}\text { Porcentagem de resíduos urbanos } \\
\text { perigosos que são reciclados }\end{array}$ & 6 & 6.6 & $\begin{array}{l}\text { até 2020, proteger e restaurar ecossistemas relacionados com a água, incluindo montanhas, florestas, zonas úmidas, rios, aquiferos } \\
\text { e lagos }\end{array}$ \\
\hline $\begin{array}{l}\text { Resíduos } \\
\text { sólidos }\end{array}$ & 16 & 16.10 & Apoio & $\begin{array}{l}\text { Porcentagem de resíduos urbanos } \\
\text { perigosos que são reciclados }\end{array}$ & 12 & 12.4 & $\begin{array}{l}\text { até 2020, alcançar o manejo ambientalmente saudável dos produtos químicos e todos os resíduos, ao longo de todo o ciclo de vida } \\
\text { destes, de acordo com os marcos internacionais acordados, e reduzir significativamente a liberação destes para o ar, água e solo, } \\
\text { para minimizar seus impactos negativos sobre a saúde humana e o meio ambiente }\end{array}$ \\
\hline $\begin{array}{l}\text { Resíduos } \\
\text { sólidos }\end{array}$ & 16 & 16.10 & Apoio & $\begin{array}{l}\text { Porcentagem de resíduos urbanos } \\
\text { perigosos que são reciclados }\end{array}$ & 12 & 12.5 & até 2030 , reduzir substancialmente a geração de resíduos por meio da prevenção, redução, reciclagem e reutilização \\
\hline $\begin{array}{l}\text { Resíduos } \\
\text { sólidos }\end{array}$ & 16 & 16.2 & Essencial & $\begin{array}{l}\text { Total de coleta de resíduos sólidos } \\
\text { municipais per capita }\end{array}$ & 14 & 14.1 & $\begin{array}{l}\text { até 2025, prevenir e reduzir significativamente a poluição marinha de todos os tipos, especialmente a advinda de atividades } \\
\text { terrestres, incluindo detritos marinhos e a poluição por nutrientes }\end{array}$ \\
\hline $\begin{array}{l}\text { Resíduos } \\
\text { sólidos }\end{array}$ & 16 & 16.2 & Essencial & $\begin{array}{l}\text { Total de coleta de resíduos sólidos } \\
\text { municipais per capita }\end{array}$ & 9 & 9.1 & $\begin{array}{l}\text { desenvolver infraestrutura de qualidade, confiável, sustentável e resiliente, incluindo infraestrutura regional e transfronteiriça, para } \\
\text { apoiar o desenvolvimento econômico e o bem-estar humano, com foco no acesso equitativo e a preços acessíveis para todos }\end{array}$ \\
\hline $\begin{array}{c}\text { Resíduos } \\
\text { sólidos }\end{array}$ & 16 & 16.2 & Essencial & $\begin{array}{l}\text { Total de coleta de resíduos sólidos } \\
\text { municipais per capita }\end{array}$ & 11 & 11.6 & $\begin{array}{l}\text { até 2030, reduzir o impacto ambiental negativo per capita das cidades, inclusive prestando especial atenção à qualidade do ar, } \\
\text { gestão de resíduos municipais e outros }\end{array}$ \\
\hline $\begin{array}{c}\text { Resíduos } \\
\text { sólidos }\end{array}$ & 16 & 16.2 & Essencial & $\begin{array}{l}\text { Total de coleta de resíduos sólidos } \\
\text { municipais per capita }\end{array}$ & 12 & 12.2 & até 2030 , alcançar gestão sustentável e uso eficiente dos recursos naturais \\
\hline $\begin{array}{l}\text { Resíduos } \\
\text { sólidos }\end{array}$ & 16 & 16.2 & Essencial & \begin{tabular}{|l|}
$\begin{array}{l}\text { Total de coleta de resíduos sólidos } \\
\text { municipais per capita }\end{array}$ \\
\end{tabular} & 12 & 12.5 & até 2030 , reduzir substancialmente a geração de resíduos por meio da prevenção, redução, reciclagem e reutilização \\
\hline $\begin{array}{l}\text { Resíduos } \\
\text { sólidos }\end{array}$ & 16 & 16.3 & Essencial & $\begin{array}{l}\text { Porcentagem de resíduos sólidos } \\
\text { urbanos que são reciclados }\end{array}$ & 14 & 14.1 & $\begin{array}{l}\text { até } 2025 \text {, prevenir e reduzir significativamente a poluição marinha de todos os tipos, especialmente a advinda de atividades } \\
\text { terrestres, incluindo detritos marinhos e a poluição por nutrientes }\end{array}$ \\
\hline $\begin{array}{l}\text { Resíduos } \\
\text { sólidos }\end{array}$ & 16 & 16.3 & Essencial & $\begin{array}{l}\text { Porcentagem de resíduos sólidos } \\
\text { urbanos que são reciclados }\end{array}$ & 11 & 11.6 & $\begin{array}{l}\text { até 2030, reduzir o impacto ambiental negativo per capita das cidades, inclusive prestando especial atenção à qualidade do ar, } \\
\text { gestão de resíduos municipais e outros }\end{array}$ \\
\hline $\begin{array}{l}\text { Resíduos } \\
\text { sólidos }\end{array}$ & 16 & 16.3 & Essencial & $\begin{array}{l}\text { Porcentagem de resíduos sólidos } \\
\text { urbanos que são reciclados }\end{array}$ & 12 & 12.5 & até 2030 , reduzir substancialmente a geração de resíduos por meio da prevenção, redução, reciclagem e reutilização \\
\hline
\end{tabular}




\begin{tabular}{|c|c|c|c|c|c|c|c|}
\hline Tema & Seção & No. & Tipo & Descrição & ODS & $\begin{array}{l}\text { Meta } \\
\text { ODS }\end{array}$ & Descrição Meta ODS \\
\hline $\begin{array}{l}\text { Resíduos } \\
\text { sólidos }\end{array}$ & 16 & 16.4 & Apoio & $\begin{array}{l}\text { Porcentagem de resíduos sólidos } \\
\text { urbanos dispostos em aterros } \\
\text { sanitários }\end{array}$ & 12 & 12.4 & $\begin{array}{l}\text { até 2020, alcançar o manejo ambientalmente adequado dos produtos químicos e de todos os resíduos, ao longo de todo o ciclo de } \\
\text { vida destes, de acordo com os marcos internacionais acordados, e reduzir significativamente a liberação destes para o ar, água e } \\
\text { solo, para minimizar seus impactos negativos sobre a saúde humana e o meio ambiente }\end{array}$ \\
\hline $\begin{array}{l}\text { Resíduos } \\
\text { sólidos }\end{array}$ & 16 & 16.4 & Apoio & $\begin{array}{l}\text { Porcentagem de resíduos sólidos } \\
\text { urbanos dispostos em aterros } \\
\text { sanitários }\end{array}$ & 6 & 6.6 & $\begin{array}{l}\text { até 2020, proteger e restaurar ecossistemas relacionados com a água, incluindo montanhas, florestas, zonas úmidas, rios, aquiferos } \\
\text { e lagos }\end{array}$ \\
\hline $\begin{array}{l}\text { Resíduos } \\
\text { sólidos }\end{array}$ & 16 & 16.4 & Apoio & $\begin{array}{l}\text { Porcentagem de resíduos sólidos } \\
\text { urbanos dispostos em aterros } \\
\text { sanitários }\end{array}$ & 11 & 11.6 & $\begin{array}{l}\text { até } 2030 \text {, reduzir o impacto ambiental negativo per capita das cidades, inclusive prestando especial atenção à qualidade do ar, } \\
\text { gestão de resíduos municipais e outros }\end{array}$ \\
\hline $\begin{array}{l}\text { Resíduos } \\
\text { sólidos }\end{array}$ & 16 & 16.5 & Apoio & $\begin{array}{l}\text { Porcentagem de resíduos sólidos } \\
\text { urbanos descartados para } \\
\text { incineração }\end{array}$ & 11 & 11.6 & $\begin{array}{l}\text { até } 2030 \text {, reduzir o impacto ambiental negativo per capita das cidades, inclusive prestando especial atenção à qualidade do ar, } \\
\text { gestão de resíduos municipais e outros }\end{array}$ \\
\hline $\begin{array}{l}\text { Resíduos } \\
\text { sólidos }\end{array}$ & 16 & 16.6 & Apoio & $\begin{array}{l}\text { Porcentagem de resíduos sólidos } \\
\text { urbanos queimados a céu aberto }\end{array}$ & 11 & 11.6 & $\begin{array}{l}\text { até 2030, reduzir o impacto ambiental negativo per capita das cidades, inclusive prestando especial atenção à qualidade do ar, } \\
\text { gestão de resíduos municipais e outros }\end{array}$ \\
\hline $\begin{array}{l}\text { Resíduos } \\
\text { sólidos }\end{array}$ & 16 & 16.7 & Apoio & $\begin{array}{l}\text { Porcentagem de resíduos sólidos } \\
\text { urbanos dispostos a céu aberto }\end{array}$ & 11 & 11.6 & $\begin{array}{l}\text { até 2030, reduzir o impacto ambiental negativo per capita das cidades, inclusive prestando especial atenção à qualidade do ar, } \\
\text { gestão de resíduos municipais e outros }\end{array}$ \\
\hline $\begin{array}{l}\text { Resíduos } \\
\text { sólidos }\end{array}$ & 16 & 16.8 & Apoio & $\begin{array}{l}\text { Porcentagem de resíduos sólidos } \\
\text { urbanos dispostos por outros meios }\end{array}$ & 11 & 11.6 & $\begin{array}{l}\text { até 2030, reduzir o impacto ambiental negativo per capita das cidades, inclusive prestando especial atenção à qualidade do ar, } \\
\text { gestão de resíduos municipais e outros }\end{array}$ \\
\hline $\begin{array}{l}\text { Residuos } \\
\text { sólidos }\end{array}$ & 16 & 16.9 & Apoio & $\begin{array}{l}\text { Geração de residuos perigosos per } \\
\text { capita }\end{array}$ & 6 & 6.3 & $\begin{array}{l}\text { até 2030, melhorar a qualidade da água, reduzindo a poluição, eliminando despejo e minimizando a liberação de produtos químicos } \\
\text { e materiais perigosos, reduzindo à metade a proporção de águas residuais não tratadas, e aumentando substancialmente a } \\
\text { reciclagem e reutilização segura globalmente }\end{array}$ \\
\hline $\begin{array}{l}\text { Resíduos } \\
\text { sólidos }\end{array}$ & 16 & 16.9 & Apoio & $\begin{array}{l}\text { Geração de resíduos perigosos per } \\
\text { capita }\end{array}$ & 6 & 6.6 & $\begin{array}{l}\text { até 2020, proteger e restaurar ecossistemas relacionados com a água, incluindo montanhas, florestas, zonas úmidas, rios, aquiferos } \\
\text { e lagos }\end{array}$ \\
\hline $\begin{array}{l}\text { Resíduos } \\
\text { sólidos }\end{array}$ & 16 & 16.9 & Apoio & $\begin{array}{l}\text { Geração de resíduos perigosos per } \\
\text { capita }\end{array}$ & 12 & 12.4 & $\begin{array}{l}\text { até 2020, alcançar o manejo ambientalmente saudável dos produtos químicos e todos os resíduos, ao longo de todo o ciclo de vida } \\
\text { destes, de acordo com os marcos internacionais acordados, e reduzir significativamente a liberação destes para o ar, água e solo, } \\
\text { para minimizar seus impactos negativos sobre a saúde humana e o meio ambiente }\end{array}$ \\
\hline $\begin{array}{l}\text { Resíduos } \\
\text { sólidos }\end{array}$ & 16 & 16.9 & Apoio & $\begin{array}{l}\text { Geração de resíduos perigosos per } \\
\text { capita }\end{array}$ & 12 & 12.5 & até 2030, reduzir substancialmente a geração de resíduos por meio da prevenção, redução, reciclagem e reutilização \\
\hline $\begin{array}{l}\text { Resíduos } \\
\text { sólidos }\end{array}$ & 16 & 16.9 & Apoio & $\begin{array}{l}\text { Geração de resíduos perigosos per } \\
\text { capita }\end{array}$ & 3 & 3.9 & $\begin{array}{l}\text { até 2030, reduzir substancialmente o número de mortes e doenças por produtos químicos perigosos, contaminação e poluição do ar } \\
\text { e água do solo }\end{array}$ \\
\hline $\begin{array}{l}\text { Telecomunicaçõ } \\
\text { es e Inovação }\end{array}$ & 17 & 17.1 & Essencial & $\begin{array}{l}\text { Número de conexões de internet } \\
\text { por } 100.000 \text { habitantes }\end{array}$ & 9 & $9 . c$ & $\begin{array}{l}\text { aumentar significativamente o acesso às tecnologias de informação e comunicação, e procurar ao máximo oferecer acesso } \\
\text { universal e acessivel à internet nos países menos desenvolvidos, até } 2020\end{array}$ \\
\hline $\begin{array}{c}\text { Telecomunicaçõ } \\
\text { es e Inovação }\end{array}$ & 17 & 17.1 & Essencial & $\begin{array}{l}\text { Número de conexões de internet } \\
\text { por } 100.000 \text { habitantes }\end{array}$ & 17 & 17.8 & $\begin{array}{l}\text { operacionalizar plenamente o Banco de Tecnologia e CTI (Ciência, Tecnologia e Inovação) mecanismo de capacitação para os } \\
\text { países menos desenvolvidos até 2017, e aumentar o uso de tecnologias de capacitação, em particular das TIC }\end{array}$ \\
\hline $\begin{array}{c}\text { Telecomunicaçõ } \\
\text { es e Inovação }\end{array}$ & 17 & 17.2 & Essencial & $\begin{array}{l}\text { Número de conexões de telefone } \\
\text { celular por } 100.000 \text { habitantes }\end{array}$ & 17 & 17.8 & $\begin{array}{l}\text { operacionalizar plenamente o Banco de Tecnologia e CTI (Ciência, Tecnologia e Inovação) mecanismo de capacitação para os } \\
\text { países menos desenvolvidos até 2017, e aumentar o uso de tecnologias de capacitação, em particular das TIC }\end{array}$ \\
\hline $\begin{array}{c}\text { Telecomunicaçõ } \\
\text { es e Inovação }\end{array}$ & 17 & 17.2 & Essencial & $\begin{array}{l}\text { Número de conexões de telefone } \\
\text { celular por } 100.000 \text { habitantes }\end{array}$ & 9 & $9 . c$ & $\begin{array}{l}\text { aumentar significativamente o acesso às tecnologias de informação e comunicação, e procurar ao máximo oferecer acesso } \\
\text { universal e acessivel à internet nos países menos desenvolvidos, até } 2020\end{array}$ \\
\hline
\end{tabular}




\begin{tabular}{|c|c|c|c|c|c|c|c|}
\hline Tema & Seção & No. & Tipo & Descrição & ODS & $\begin{array}{l}\text { Meta } \\
\text { ODS }\end{array}$ & Descrição Meta ODS \\
\hline Transporte & 18 & 18.1 & Essencial & \begin{tabular}{|l|} 
Quilômetros de sistema de \\
transporte público de alta \\
capacidade por 100.000 habitantes
\end{tabular} & 11 & 11.2 & $\begin{array}{l}\text { até 2030, proporcionar o acesso a sistemas de transporte seguros, acessíveis, sustentáveis e a preço acessível para todos, } \\
\text { melhorando a segurança rodoviária por meio da expansão dos transportes públicos, com especial atenção para as necessidades } \\
\text { das pessoas em situação de vulnerabilidade, mulheres, crianças, pessoas com deficiência e idosos }\end{array}$ \\
\hline Transporte & 18 & 18.1 & Essencial & $\begin{array}{l}\text { Quilômetros de sistema de } \\
\text { transporte público de alta } \\
\text { capacidade por } 100.000 \text { habitantes }\end{array}$ & 9 & 9.1 & $\begin{array}{l}\text { desenvolver infraestrutura de qualidade, confiável, sustentável e resiliente, incluindo infraestrutura regional e transfronteiriça, para } \\
\text { apoiar o desenvolvimento econômico e o bem-estar humano, com foco no acesso equitativo e a preços acessíveis para todos }\end{array}$ \\
\hline Transporte & 18 & 18.2 & Essencial & $\begin{array}{l}\text { Quilômetros de sistema de } \\
\text { transporte público de média } \\
\text { capacidade por } 100.000 \text { habitantes }\end{array}$ & 11 & 11.2 & $\begin{array}{l}\text { até 2030, proporcionar o acesso a sistemas de transporte seguros, acessiveis, sustentáveis e a preço acessivel para todos, } \\
\text { melhorando a segurança rodoviária por meio da expansão dos transportes públicos, com especial atenção para as necessidades } \\
\text { das pessoas em situação de vulnerabilidade, mulheres, crianças, pessoas com deficiência e idosos }\end{array}$ \\
\hline Transporte & 18 & 18.2 & Essencial & $\begin{array}{l}\text { Quilômetros de sistema de } \\
\text { transporte público de média } \\
\text { capacidade por } 100.000 \text { habitantes }\end{array}$ & 9 & 9.1 & $\begin{array}{l}\text { desenvolver infraestrutura de qualidade, confiável, sustentável e resiliente, incluindo infraestrutura regional e transfronteiriça, para } \\
\text { apoiar o desenvolvimento econômico e o bem-estar humano, com foco no acesso equitativo e a preços acessiveis para todos }\end{array}$ \\
\hline Transporte & 18 & 18.3 & Essencial & $\begin{array}{l}\text { Número anual de viagens em } \\
\text { transporte público per capita }\end{array}$ & 11 & 11.2 & $\begin{array}{l}\text { até 2030, proporcionar o acesso a sistemas de transporte seguros, acessíveis, sustentáveis e a preço acessivel para todos, } \\
\text { melhorando a segurança rodoviária por meio da expansão dos transportes públicos, com especial atenção para as necessidades } \\
\text { das pessoas em situação de vulnerabilidade, mulheres, crianças, pessoas com deficiência e idosos }\end{array}$ \\
\hline Transporte & 18 & 18.4 & Essencial & $\begin{array}{l}\text { Número de automóveis privados } \\
\text { per capita }\end{array}$ & 11 & 11.2 & $\begin{array}{l}\text { até 2030, proporcionar o acesso a sistemas de transporte seguros, acessíveis, sustentáveis e a preço acessível para todos, } \\
\text { melhorando a segurança rodoviária por meio da expansão dos transportes públicos, com especial atenção para as necessidades } \\
\text { das pessoas em situação de vulnerabilidade, mulheres, crianças, pessoas com deficiência e idosos }\end{array}$ \\
\hline Transporte & 18 & 18.5 & Apoio & $\begin{array}{l}\text { Porcentagem de passageiros que } \\
\text { se deslocam para o trabalho de } \\
\text { forma alternativa ao automóvel } \\
\text { privado }\end{array}$ & 11 & 11.2 & $\begin{array}{l}\text { até 2030, proporcionar o acesso a sistemas de transporte seguros, acessíveis, sustentáveis e a preço acessível para todos, } \\
\text { melhorando a segurançaa rodoviária por meio da expansão dos transportes públicos, com especial atenção para as necessidades } \\
\text { das pessoas em situação de vulnerabilidade, mulheres, crianças, pessoas com deficiência e idosos }\end{array}$ \\
\hline Transporte & 18 & 18.6 & Apoio & $\begin{array}{l}\text { Número de veículos motorizados de } \\
\text { duas rodas per capita }\end{array}$ & 11 & 11.2 & $\begin{array}{l}\text { até 2030, proporcionar o acesso a sistemas de transporte seguros, acessiveis, sustentáveis e a preço acessivel para todos, } \\
\text { melhorando a segurança rodoviária por meio da expansão dos transportes públicos, com especial atenção para as necessidades } \\
\text { das pessoas em situação de vulnerabilidade, mulheres, crianças, pessoas com deficiência e idosos }\end{array}$ \\
\hline Transporte & 18 & 18.7 & Apoio & $\begin{array}{l}\text { Quilômetros de ciclovias e } \\
\text { ciclofaixas por } 100.000 \text { habitantes }\end{array}$ & 11 & 11.2 & $\begin{array}{l}\text { até 2030, proporcionar o acesso a sistemas de transporte seguros, acessiveis, sustentáveis e a preço acessivel para todos, } \\
\text { melhorando a segurança rodoviária por meio da expansão dos transportes públicos, com especial atenção para as necessidades } \\
\text { das pessoas em situação de vulnerabilidade, mulheres, crianças, pessoas com deficiência e idosos }\end{array}$ \\
\hline Transporte & 18 & 18.8 & Apoio & $\begin{array}{l}\text { Mortalidades de trânsito por } \\
100.000 \text { habitantes }\end{array}$ & 3 & 3.6 & até 2020 , reduzir pela metade as mortes e os ferimentos globais por acidentes em estradas \\
\hline Transporte & 18 & 18.8 & Apoio & $\begin{array}{l}\text { Mortalidades de trânsito por } \\
100.000 \text { habitantes }\end{array}$ & 11 & 11.2 & $\begin{array}{l}\text { até 2030, proporcionar o acesso a sistemas de transporte seguros, acessiveis, sustentáveis e a preço acessivel para todos, } \\
\text { melhorando a segurança rodoviária por meio da expansão dos transportes públicos, com especial atenção para as necessidades } \\
\text { das pessoas em situação de vulnerabilidade, mulheres, crianças, pessoas com deficiência e idosos }\end{array}$ \\
\hline Transporte & 18 & 18.9 & Apoio & $\begin{array}{l}\text { Conectividade aérea (número de } \\
\text { partidas de voos comerciais sem } \\
\text { escalas) }\end{array}$ & 9 & 9.1 & $\begin{array}{l}\text { desenvolver infraestrutura de qualidade, confiável, sustentável e resiliente, incluindo infraestrutura regional e transfronteiriça, para } \\
\text { apoiar o desenvolvimento econômico e o bem-estar humano, com foco no acesso equitativo e a preços acessíveis para todos }\end{array}$ \\
\hline
\end{tabular}




\begin{tabular}{|c|c|c|c|c|c|c|c|}
\hline Tema & Seção & No. & Tipo & Descrição & ODS & $\begin{array}{l}\text { Meta } \\
\text { ODS }\end{array}$ & Descrição Meta ODS \\
\hline Transporte & 18 & 18.9 & Apoio & $\begin{array}{l}\text { Conectividade aérea (número de } \\
\text { partidas de voos comerciais sem } \\
\text { escalas) }\end{array}$ & 11 & 11.2 & $\begin{array}{l}\text { até 2030, proporcionar o acesso a sistemas de transporte seguros, acessíveis, sustentáveis e a preço acessível para todos, } \\
\text { melhorando a segurança rodoviária por meio da expansão dos transportes públicos, com especial atenção para as necessidades } \\
\text { das pessoas em situação de vulnerabilidade, mulheres, crianças, pessoas com deficiência e idosos }\end{array}$ \\
\hline $\begin{array}{l}\text { Planejamento } \\
\text { Urbano }\end{array}$ & 19 & 19.1 & Essencial & $\begin{array}{l}\text { Áreas verdes (hectares) por } \\
100.000 \text { habitantes }\end{array}$ & 11 & 11.3 & $\begin{array}{l}\text { até 2030, aumentar a urbanização inclusiva e sustentável, e as capacidades para o planejamento e gestão de assentamentos } \\
\text { humanos participativos, integrados e sustentáveis, em todos os paises }\end{array}$ \\
\hline $\begin{array}{l}\text { Planejamento } \\
\text { Urbano }\end{array}$ & 19 & 19.1 & Essencial & $\begin{array}{l}\text { Áreas verdes (hectares) por } \\
100.000 \text { habitantes }\end{array}$ & 11 & 11.7 & $\begin{array}{l}\text { até 2030, proporcionar o acesso universal a espaços públicos seguros, inclusivos, acessiveis e verdes, particularmente para as } \\
\text { mulheres e crianças, pessoas idosas e pessoas com deficiência }\end{array}$ \\
\hline $\begin{array}{l}\text { Planejamento } \\
\text { Urbano }\end{array}$ & 19 & 19.1 & Essencial & $\begin{array}{l}\text { Áreas verdes (hectares) por } \\
100.000 \text { habitantes }\end{array}$ & 13 & 13.2 & integrar medidas da mudança do clima nas políticas, estratégias e planejamentos nacionais \\
\hline $\begin{array}{l}\text { Planejamento } \\
\text { Urbano }\end{array}$ & 19 & 19.1 & Essencial & $\begin{array}{l}\text { Áreas verdes (hectares) por } \\
100.000 \text { habitantes }\end{array}$ & 15 & 15.1 & $\begin{array}{l}\text { até 2020, assegurar a conservação, recuperação e uso sustentável de ecossistemas terrestres e de água doce interiores e seus } \\
\text { serviços, em especial, florestas, zonas úmidas, montanhas e terras áridas, em conformidade com as obrigações decorrentes dos } \\
\text { acordos internacionais }\end{array}$ \\
\hline $\begin{array}{l}\text { Planejamento } \\
\text { Urbano }\end{array}$ & 19 & 19.2 & Apoio & $\begin{array}{l}\text { Número de árvores plantadas } \\
\text { anualmente por } 100.000 \text { habitantes }\end{array}$ & 11 & 11.4 & fortalecer esforços para proteger e salvaguardar o patrimônio cultural e natural do mundo \\
\hline $\begin{array}{l}\text { Planejamento } \\
\text { Urbano }\end{array}$ & 19 & 19.2 & Apoio & $\begin{array}{l}\text { Número de árvores plantadas } \\
\text { anualmente por } 100.000 \text { habitantes }\end{array}$ & 13 & 13.2 & integrar medidas da mudança do clima nas políticas, estratégias e planejamentos nacionais \\
\hline $\begin{array}{l}\text { Planejamento } \\
\text { Urbano }\end{array}$ & 19 & 19.2 & Apoio & $\begin{array}{l}\text { Número de árvores plantadas } \\
\text { anualmente por } 100.000 \text { habitantes }\end{array}$ & 15 & 15.1 & $\begin{array}{l}\text { até 2020, assegurar a conservação, recuperação e uso sustentável de ecossistemas terrestres e de água doce interiores e seus } \\
\text { serviços, em especial, florestas, zonas úmidas, montanhas e terras áridas, em conformidade com as obrigações decorrentes dos } \\
\text { acordos internacionais }\end{array}$ \\
\hline $\begin{array}{l}\text { Planejamento } \\
\text { Urbano }\end{array}$ & 19 & 19.3 & Apoio & $\begin{array}{l}\text { Porcentagem de área de } \\
\text { assentamentos informais em } \\
\text { função da área total da cidade }\end{array}$ & 11 & 11.1 & $\begin{array}{l}\text { até 2030, garantir o acesso de todos a habitação segura, adequada e a preço acessivel, e aos serviços básicos e urbanizar as } \\
\text { favelas }\end{array}$ \\
\hline $\begin{array}{c}\text { Planejamento } \\
\text { Urbano }\end{array}$ & 19 & 19.4 & Apoio & Relação empregos/habitação & 11 & 11.3 & $\begin{array}{l}\text { até 2030, aumentar a urbanização inclusiva e sustentável, e as capacidades para o planejamento e gestão de assentamentos } \\
\text { humanos participativos, integrados e sustentáveis, em todos os paises }\end{array}$ \\
\hline Esgotos & 20 & 20.1 & Essencial & $\begin{array}{l}\text { Porcentagem da população da } \\
\text { cidade atendida por sistemas de } \\
\text { coleta e afastamento de esgoto }\end{array}$ & 6 & 6.2 & $\begin{array}{l}\text { até } 2030 \text {, alcançar o acesso a saneamento e higiene adequados e equitativos para todos, e acabar com a defecação a céu aberto, } \\
\text { com especial atenção para as necessidades das mulheres e meninas e daqueles em situação de vulnerabilidade }\end{array}$ \\
\hline Esgotos & 20 & 20.1 & Essencial & $\begin{array}{l}\text { Porcentagem da população da } \\
\text { cidade atendida por sistemas de } \\
\text { coleta e afastamento de esgoto }\end{array}$ & 11 & 11.1 & $\begin{array}{l}\text { até 2030, garantir o acesso de todos a habitação segura, adequada e a preço acessível, e aos serviços básicos e urbanizar as } \\
\text { favelas }\end{array}$ \\
\hline Esgotos & 20 & 20.1 & Essencial & $\begin{array}{l}\text { Porcentagem da população da } \\
\text { cidade atendida por sistemas de } \\
\text { coleta e afastamento de esgoto }\end{array}$ & 11 & 11.6 & $\begin{array}{l}\text { até } 2030 \text {, reduzir o impacto ambiental negativo per capita das cidades, inclusive prestando especial atenção à qualidade do ar, } \\
\text { gestão de resíduos municipais e outros }\end{array}$ \\
\hline Esgotos & 20 & 20.1 & Essencial & $\begin{array}{l}\text { Porcentagem da população da } \\
\text { cidade atendida por sistemas de } \\
\text { coleta e afastamento de esgoto }\end{array}$ & 14 & 14.1 & $\begin{array}{l}\text { até } 2025 \text {, prevenir e reduzir significativamente a poluição marinha de todos os tipos, especialmente a advinda de atividades } \\
\text { terrestres, incluindo detritos marinhos e a poluição por nutrientes }\end{array}$ \\
\hline
\end{tabular}




\begin{tabular}{|c|c|c|c|c|c|c|c|}
\hline Tema & Seção & No. & Tipo & Descrição & ODS & $\begin{array}{l}\text { Meta } \\
\text { ODS }\end{array}$ & Descrição Meta ODS \\
\hline Esgotos & 20 & 20.1 & Essencial & $\begin{array}{l}\text { Porcentagem da população da } \\
\text { cidade atendida por sistemas de } \\
\text { coleta e afastamento de esgoto }\end{array}$ & 15 & 15.1 & $\begin{array}{l}\text { até 2020, assegurar a conservação, recuperação e uso sustentável de ecossistemas terrestres e de água doce interiores e seus } \\
\text { serviços, em especial, florestas, zonas úmidas, montanhas e terras áridas, em conformidade com as obrigações decorrentes dos } \\
\text { acordos internacionais }\end{array}$ \\
\hline Esgotos & 20 & 20.2 & Essencial & $\begin{array}{l}\text { Porcentagem do esgoto da cidade } \\
\text { que não recebeu qualquer } \\
\text { tratamento }\end{array}$ & 15 & 15.1 & $\begin{array}{l}\text { até 2020, assegurar a conservação, recuperação e uso sustentável de ecossistemas terrestres e de água doce interiores e seus } \\
\text { serviços, em especial, florestas, zonas úmidas, montanhas e terras áridas, em conformidade com as obrigações decorrentes dos } \\
\text { acordos internacionais }\end{array}$ \\
\hline Esgotos & 20 & 20.2 & Essencial & $\begin{array}{l}\text { Porcentagem do esgoto da cidade } \\
\text { que não recebeu qualquer } \\
\text { tratamento }\end{array}$ & 6 & 6.3 & $\begin{array}{l}\text { até 2030, melhorar a qualidade da água, reduzindo a poluição, eliminando despejo e minimizando a liberação de produtos químicos } \\
\text { e materiais perigosos, reduzindo à metade a proporção de águas residuais não tratadas, e aumentando substancialmente a } \\
\text { reciclagem e reutilização segura globalmente }\end{array}$ \\
\hline Esgotos & 20 & 20.2 & Essencial & $\begin{array}{l}\text { Porcentagem do esgoto da cidade } \\
\text { que não recebeu qualquer } \\
\text { tratamento }\end{array}$ & 11 & 11.1 & $\begin{array}{l}\text { até 2030, garantir o acesso de todos a habitação segura, adequada e a preço acessível, e aos serviços básicos e urbanizar as } \\
\text { favelas }\end{array}$ \\
\hline Esgotos & 20 & 20.2 & Essencial & $\begin{array}{l}\text { Porcentagem do esgoto da cidade } \\
\text { que não recebeu qualquer } \\
\text { tratamento }\end{array}$ & 11 & 11.6 & $\begin{array}{l}\text { até } 2030 \text {, reduzir o impacto ambiental negativo per capita das cidades, inclusive prestando especial atenção à qualidade do ar, } \\
\text { gestão de resíduos municipais e outros }\end{array}$ \\
\hline Esgotos & 20 & 20.2 & Essencial & $\begin{array}{l}\text { Porcentagem do esgoto da cidade } \\
\text { que não recebeu qualquer } \\
\text { tratamento }\end{array}$ & 14 & 14.1 & $\begin{array}{l}\text { até } 2025 \text {, prevenir e reduzir significativamente a poluição marinha de todos os tipos, especialmente a advinda de atividades } \\
\text { terrestres, incluindo detritos marinhos e a poluição por nutrientes }\end{array}$ \\
\hline Esgotos & 20 & 20.3 & Essencial & $\begin{array}{l}\text { Porcentagem do esgoto da cidade } \\
\text { que recebe tratamento primário }\end{array}$ & 15 & 15.1 & $\begin{array}{l}\text { até 2020, assegurar a conservação, recuperação e uso sustentável de ecossistemas terrestres e de água doce interiores e seus } \\
\text { serviços, em especial, florestas, zonas úmidas, montanhas e terras áridas, em conformidade com as obrigações decorrentes dos } \\
\text { acordos internacionais }\end{array}$ \\
\hline Esgotos & 20 & 20.3 & Essencial & $\begin{array}{l}\text { Porcentagem do esgoto da cidade } \\
\text { que recebe tratamento primário }\end{array}$ & 6 & 6.3 & $\begin{array}{l}\text { até 2030, melhorar a qualidade da água, reduzindo a poluição, eliminando despejo e minimizando a liberação de produtos químicos } \\
\text { e materiais perigosos, reduzindo à metade a proporção de águas residuais não tratadas, e aumentando substancialmente a } \\
\text { reciclagem e reutilização segura globalmente }\end{array}$ \\
\hline Esgotos & 20 & 20.3 & Essencial & $\begin{array}{l}\text { Porcentagem do esgoto da cidade } \\
\text { que recebe tratamento primário }\end{array}$ & 11 & 11.1 & $\begin{array}{l}\text { até 2030, garantir o acesso de todos a habitação segura, adequada e a preço acessivel, e aos serviços básicos e urbanizar as } \\
\text { favelas }\end{array}$ \\
\hline Esgotos & 20 & 20.3 & Essencial & $\begin{array}{l}\text { Porcentagem do esgoto da cidade } \\
\text { que recebe tratamento primário }\end{array}$ & 11 & 11.6 & $\begin{array}{l}\text { até } 2030 \text {, reduzir o impacto ambiental negativo per capita das cidades, inclusive prestando especial atenção à qualidade do ar, } \\
\text { gestão de resíduos municipais e outros }\end{array}$ \\
\hline Esgotos & 20 & 20.3 & Essencial & $\begin{array}{l}\text { Porcentagem do esgoto da cidade } \\
\text { que recebe tratamento primário }\end{array}$ & 14 & 14.1 & $\begin{array}{l}\text { até 2025, prevenir e reduzir significativamente a poluição marinha de todos os tipos, especialmente a advinda de atividades } \\
\text { terrestres, incluindo detritos marinhos e a poluição por nutrientes }\end{array}$ \\
\hline Esgotos & 20 & 20.4 & Essencial & $\begin{array}{l}\text { Porcentagem do esgoto da cidade } \\
\text { que recebe tratamento secundário }\end{array}$ & 15 & 15.1 & $\begin{array}{l}\text { até 2020, assegurar a conservação, recuperação e uso sustentável de ecossistemas terrestres e de água doce interiores e seus } \\
\text { serviços, em especial, florestas, zonas úmidas, montanhas e terras áridas, em conformidade com as obrigações decorrentes dos } \\
\text { acordos internacionais }\end{array}$ \\
\hline Esgotos & 20 & 20.4 & Essencial & $\begin{array}{l}\text { Porcentagem do esgoto da cidade } \\
\text { que recebe tratamento secundário }\end{array}$ & 6 & 6.3 & $\begin{array}{l}\text { até 2030, melhorar a qualidade da água, reduzindo a poluição, eliminando despejo e minimizando a liberação de produtos químicos } \\
\text { e materiais perigosos, reduzindo à metade a proporção de águas residuais não tratadas, e aumentando substancialmente a } \\
\text { reciclagem e reutilização segura globalmente }\end{array}$ \\
\hline Esgotos & 20 & 20.4 & Essencial & $\begin{array}{l}\text { Porcentagem do esgoto da cidade } \\
\text { que recebe tratamento secundário }\end{array}$ & 11 & 11.1 & $\begin{array}{l}\text { até 2030, garantir o acesso de todos a habitação segura, adequada e a preço acessivel, e aos serviços básicos e urbanizar as } \\
\text { favelas }\end{array}$ \\
\hline Esgotos & 20 & 20.4 & Essencial & $\begin{array}{l}\text { Porcentagem do esgoto da cidade } \\
\text { que recebe tratamento secundário }\end{array}$ & 11 & 11.6 & $\begin{array}{l}\text { até } 2030 \text {, reduzir o impacto ambiental negativo per capita das cidades, inclusive prestando especial atenção à qualidade do ar, } \\
\text { gestão de resíduos municipais e outros }\end{array}$ \\
\hline
\end{tabular}




\begin{tabular}{|c|c|c|c|c|c|c|c|}
\hline Tema & Seção & No. & Tipo & Descrição & ODS & $\begin{array}{l}\text { Meta } \\
\text { ODS }\end{array}$ & Descrição Meta ODS \\
\hline Esgotos & 20 & 20.4 & Essencial & $\begin{array}{l}\text { Porcentagem do esgoto da cidade } \\
\text { que recebe tratamento secundário }\end{array}$ & 14 & 14.1 & $\begin{array}{l}\text { até } 2025 \text {, prevenir e reduzir significativamente a poluição marinha de todos os tipos, especialmente a advinda de atividades } \\
\text { terrestres, incluindo detritos marinhos e a poluição por nutrientes }\end{array}$ \\
\hline Esgotos & 20 & 20.5 & Essencial & $\begin{array}{l}\text { Porcentagem do esgoto da cidade } \\
\text { que recebe tratamento terciário }\end{array}$ & 15 & 15.1 & $\begin{array}{l}\text { até 2020, assegurar a conservação, recuperação e uso sustentável de ecossistemas terrestres e de água doce interiores e seus } \\
\text { serviços, em especial, florestas, zonas úmidas, montanhas e terras áridas, em conformidade com as obrigações decorrentes dos } \\
\text { acordos internacionais }\end{array}$ \\
\hline Esgotos & 20 & 20.5 & Essencial & $\begin{array}{l}\text { Porcentagem do esgoto da cidade } \\
\text { que recebe tratamento terciário }\end{array}$ & 6 & 6.3 & $\begin{array}{l}\text { até 2030, melhorar a qualidade da água, reduzindo a poluição, eliminando despejo e minimizando a liberação de produtos químicos } \\
\text { e materiais perigosos, reduzindo à metade a proporção de águas residuais não tratadas, e aumentando substancialmente a } \\
\text { reciclagem e reutilização segura globalmente }\end{array}$ \\
\hline Esgotos & 20 & 20.5 & Essencial & $\begin{array}{l}\text { Porcentagem do esgoto da cidade } \\
\text { que recebe tratamento terciário }\end{array}$ & 11 & 11.1 & $\begin{array}{l}\text { até 2030, garantir o acesso de todos a habitação segura, adequada e a preço acessível, e aos serviços básicos e urbanizar as } \\
\text { favelas }\end{array}$ \\
\hline Esgotos & 20 & 20.5 & Essencial & $\begin{array}{l}\text { Porcentagem do esgoto da cidade } \\
\text { que recebe tratamento terciário }\end{array}$ & 11 & 11.6 & $\begin{array}{l}\text { até } 2030 \text {, reduzir o impacto ambiental negativo per capita das cidades, inclusive prestando especial atenção à qualidade do ar, } \\
\text { gestão de resíduos municipais e outros }\end{array}$ \\
\hline Esgotos & 20 & 20.5 & Essencial & $\begin{array}{l}\text { Porcentagem do esgoto da cidade } \\
\text { que recebe tratamento terciário }\end{array}$ & 14 & 14.1 & $\begin{array}{l}\text { até } 2025 \text {, prevenir e reduzir significativamente a poluição marinha de todos os tipos, especialmente a advinda de atividades } \\
\text { terrestres, incluindo detritos marinhos e a poluição por nutrientes }\end{array}$ \\
\hline $\begin{array}{l}\text { Água e } \\
\text { Saneamento }\end{array}$ & 21 & 21.1 & Essencial & $\begin{array}{l}\text { Porcentagem da população da } \\
\text { cidade com serviço de } \\
\text { abastecimento de água potável }\end{array}$ & 3 & 3.9 & $\begin{array}{l}\text { até } 2030 \text {, reduzir substancialmente o número de mortes e doenças por produtos químicos perigosos, contaminação e poluição do ar } \\
\text { e água do solo }\end{array}$ \\
\hline $\begin{array}{l}\text { Água e } \\
\text { Saneamento }\end{array}$ & 21 & 21.1 & Essencial & $\begin{array}{l}\text { Porcentagem da população da } \\
\text { cidade com serviço de } \\
\text { abastecimento de água potável }\end{array}$ & 6 & 6.1 & até 2030, alcançar o acesso universal e equitativo à água potável, segura e acessível para todos \\
\hline $\begin{array}{l}\text { Água e } \\
\text { Saneamento }\end{array}$ & 21 & 21.1 & Essencial & $\begin{array}{l}\text { Porcentagem da população da } \\
\text { cidade com serviço de } \\
\text { abastecimento de água potável }\end{array}$ & 11 & 11.1 & $\begin{array}{l}\text { até } 2030 \text {, garantir o acesso de todos a habitação segura, adequada e a preço acessível, e aos serviços básicos e urbanizar as } \\
\text { favelas }\end{array}$ \\
\hline $\begin{array}{l}\text { Água e } \\
\text { Saneamento }\end{array}$ & 21 & 21.2 & Essencial & $\begin{array}{l}\text { Porcentagem da população da } \\
\text { cidade com acesso sustentável a } \\
\text { uma fonte de água adequada para } \\
\text { consumo }\end{array}$ & 3 & 3.9 & $\begin{array}{l}\text { até } 2030 \text {, reduzir substancialmente o número de mortes e doenças por produtos químicos perigosos, contaminação e poluição do ar } \\
\text { e água do solo }\end{array}$ \\
\hline $\begin{array}{l}\text { Água e } \\
\text { Saneamento }\end{array}$ & 21 & 21.2 & Essencial & $\begin{array}{l}\text { Porcentagem da população da } \\
\text { cidade com acesso sustentável a } \\
\text { uma fonte de água adequada para } \\
\text { consumo }\end{array}$ & 6 & 6.1 & até 2030, alcançar o acesso universal e equitativo à água potável, segura e acessível para todos \\
\hline $\begin{array}{l}\text { Água e } \\
\text { Saneamento }\end{array}$ & 21 & 21.2 & Essencial & $\begin{array}{l}\text { Porcentagem da população da } \\
\text { cidade com acesso sustentável a } \\
\text { uma fonte de água adequada para } \\
\text { consumo }\end{array}$ & 11 & 11.1 & $\begin{array}{l}\text { até } 2030 \text {, garantir o acesso de todos a habitação segura, adequada e a preço acessível, e aos serviços básicos e urbanizar as } \\
\text { favelas }\end{array}$ \\
\hline $\begin{array}{l}\text { Água e } \\
\text { Saneamento }\end{array}$ & 21 & 21.3 & Essencial & $\begin{array}{l}\text { Porcentagem da população da } \\
\text { cidade com acesso a saneamento } \\
\text { melhorado }\end{array}$ & 3 & 3.9 & $\begin{array}{l}\text { até } 2030 \text {, reduzir substancialmente o número de mortes e doenças por produtos químicos perigosos, contaminação e poluição do ar } \\
\text { e água do solo }\end{array}$ \\
\hline $\begin{array}{l}\text { Água e } \\
\text { Saneamento }\end{array}$ & 21 & 21.3 & Essencial & $\begin{array}{l}\text { Porcentagem da população da } \\
\text { cidade com acesso a saneamento } \\
\text { melhorado }\end{array}$ & 6 & 6.2 & $\begin{array}{l}\text { até } 2030 \text {, alcançar o acesso a saneamento e higiene adequados e equitativos para todos, e acabar com a defecação a céu aberto, } \\
\text { com especial atenção para as necessidades das mulheres e meninas e daqueles em situação de vulnerabilidade }\end{array}$ \\
\hline
\end{tabular}




\begin{tabular}{|c|c|c|c|c|c|c|c|}
\hline Tema & Seção & No. & Tipo & Descrição & ODS & $\begin{array}{l}\text { Meta } \\
\text { ODS }\end{array}$ & Descrição Meta ODS \\
\hline $\begin{array}{c}\text { Água e } \\
\text { Saneamento }\end{array}$ & 21 & 21.3 & Essencial & $\begin{array}{l}\text { Porcentagem da população da } \\
\text { cidade com acesso a saneamento } \\
\text { melhorado }\end{array}$ & 11 & 11.1 & $\begin{array}{l}\text { até } 2030 \text {, garantir o acesso de todos a habitação segura, adequada e a preço acessível, e aos serviços básicos e urbanizar as } \\
\text { favelas }\end{array}$ \\
\hline $\begin{array}{c}\text { Água e } \\
\text { Saneamento }\end{array}$ & 21 & 21.4 & Essencial & $\begin{array}{l}\text { Consumo doméstico total de água } \\
\text { per capita (litros/dia) }\end{array}$ & 6 & 6.1 & até 2030 , alcançar o acesso universal e equitativo à água potável, segura e acessível para todos \\
\hline $\begin{array}{c}\text { Água e } \\
\text { Saneamento }\end{array}$ & 21 & 21.4 & Essencial & $\begin{array}{l}\text { Consumo doméstico total de água } \\
\text { per capita (litros/dia) }\end{array}$ & 6 & 6.4 & $\begin{array}{l}\text { até } 2030 \text {, aumentar substancialmente a eficiência do uso da água em todos os setores e assegurar retiradas sustentáveis e o } \\
\text { abastecimento de água doce para enfrentar a escassez de água, e reduzir substancialmente o número de pessoas que sofrem com } \\
\text { a escassez de água }\end{array}$ \\
\hline $\begin{array}{c}\text { Água e } \\
\text { Saneamento }\end{array}$ & 21 & 21.4 & Essencial & $\begin{array}{l}\text { Consumo doméstico total de água } \\
\text { per capita (litros/dia) }\end{array}$ & 11 & 11.1 & $\begin{array}{l}\text { até 2030, garantir o acesso de todos a habitação segura, adequada e a preço acessível, e aos serviços básicos e urbanizar as } \\
\text { favelas }\end{array}$ \\
\hline $\begin{array}{l}\text { Água e } \\
\text { Saneamento }\end{array}$ & 21 & 21.4 & Essencial & $\begin{array}{l}\text { Consumo doméstico total de água } \\
\text { per capita (litros/dia) }\end{array}$ & 11 & 11.b & $\begin{array}{l}\text { até 2020, aumentar substancialmente o número de cidades e assentamentos humanos adotando e implementando políticas e } \\
\text { planos integrados para a inclusão, a eficiência dos recursos, mitigação e adaptação às alteraç̃es climáticas, a resiliência a } \\
\text { desastres; e desenvolver e implementar, de acordo com o "Sendai Framework" para a redução do risco de desastres 2015-2030, o } \\
\text { gerenciamento holístico do risco de desastres em todos os niveis }\end{array}$ \\
\hline $\begin{array}{c}\text { Água e } \\
\text { Saneamento }\end{array}$ & 21 & 21.4 & Essencial & $\begin{array}{l}\text { Consumo doméstico total de água } \\
\text { per capita (litros/dia) }\end{array}$ & 12 & 12.2 & até 2030, alcançar gestão sustentável e uso eficiente dos recursos naturais \\
\hline $\begin{array}{c}\text { Água e } \\
\text { Saneamento }\end{array}$ & 21 & 21.5 & Apoio & $\begin{array}{l}\text { Consumo total de água per capita } \\
\text { (litros/dia) }\end{array}$ & 6 & 6.1 & até 2030 , alcançar o acesso universal e equitativo à água potável, segura e acessível para todos \\
\hline $\begin{array}{c}\text { Água e } \\
\text { Saneamento }\end{array}$ & 21 & 21.5 & Apoio & $\begin{array}{l}\text { Consumo total de água per capita } \\
\text { (litros/dia) }\end{array}$ & 6 & 6.4 & $\begin{array}{l}\text { até } 2030 \text {, aumentar substancialmente a eficiência do uso da água em todos os setores e assegurar retiradas sustentáveis e o } \\
\text { abastecimento de água doce para enfrentar a escassez de água, e reduzir substancialmente o número de pessoas que sofrem com } \\
\text { a escassez de água }\end{array}$ \\
\hline $\begin{array}{c}\text { Água e } \\
\text { Saneamento }\end{array}$ & 21 & 21.5 & Apoio & $\begin{array}{l}\begin{array}{l}\text { Consumo total de água per capita } \\
\text { (litros/dia) }\end{array} \\
\end{array}$ & 11 & 11.1 & $\begin{array}{l}\text { até 2030, garantir o acesso de todos a habitação segura, adequada e a preço acessível, e aos serviços básicos e urbanizar as } \\
\text { favelas }\end{array}$ \\
\hline $\begin{array}{c}\text { Água e } \\
\text { Saneamento }\end{array}$ & 21 & 21.5 & Apoio & $\begin{array}{l}\text { Consumo total de água per capita } \\
\text { (litros/dia) }\end{array}$ & 11 & 11.b & $\begin{array}{l}\text { até 2020, aumentar substancialmente o número de cidades e assentamentos humanos adotando e implementando políticas e } \\
\text { planos integrados para a inclusão, a eficiência dos recursos, mitigação e adaptação às alteraç̃̃es climáticas, a resiliência a } \\
\text { desastres; e desenvolver e implementar, de acordo com o "Sendai Framework" para a redução do risco de desastres 2015-2030, o } \\
\text { gerenciamento holístico do risco de desastres em todos os niveis }\end{array}$ \\
\hline $\begin{array}{c}\text { Água e } \\
\text { Saneamento }\end{array}$ & 21 & 21.5 & Apoio & $\begin{array}{l}\text { Consumo total de água per capita } \\
\text { (litros/dia) }\end{array}$ & 12 & 12.2 & até 2030 , alcançar gestão sustentável e uso eficiente dos recursos naturais \\
\hline $\begin{array}{l}\text { Água e } \\
\text { Saneamento }\end{array}$ & 21 & 21.6 & Apoio & $\begin{array}{l}\text { Valor médio anual de horas de } \\
\text { interrupção do abastecimento de } \\
\text { água por domicílio }\end{array}$ & 11 & 11.b & $\begin{array}{l}\text { até 2020, aumentar substancialmente o número de cidades e assentamentos humanos adotando e implementando políticas e } \\
\text { planos integrados para a inclusão, a eficiência dos recursos, mitigação e adaptação às alteraç̃̃es climáticas, a resiliência a } \\
\text { desastres; e desenvolver e implementar, de acordo com o "Sendai Framework" para a redução do risco de desastres 2015-2030, o } \\
\text { gerenciamento holístico do risco de desastres em todos os niveis }\end{array}$ \\
\hline $\begin{array}{c}\text { Água e } \\
\text { Saneamento }\end{array}$ & 21 & 21.6 & Apoio & $\begin{array}{l}\text { Valor médio anual de horas de } \\
\text { interrupção do abastecimento de } \\
\text { água por domicílio }\end{array}$ & 6 & 6.1 & até 2030 , alcançar o acesso universal e equitativo à água potável, segura e acessível para todos \\
\hline $\begin{array}{c}\text { Água e } \\
\text { Saneamento }\end{array}$ & 21 & 21.6 & Apoio & $\begin{array}{l}\text { Valor médio anual de horas de } \\
\text { interrupção do abastecimento de } \\
\text { água por domicílio }\end{array}$ & 9 & 9.1 & $\begin{array}{l}\text { desenvolver infraestrutura de qualidade, confiável, sustentável e resiliente, incluindo infraestrutura regional e transfronteiriça, para } \\
\text { apoiar o desenvolvimento econômico e o bem-estar humano, com foco no acesso equitativo e a preços acessíveis para todos }\end{array}$ \\
\hline $\begin{array}{c}\text { Água e } \\
\text { Saneamento }\end{array}$ & 21 & 21.6 & Apoio & $\begin{array}{l}\text { Valor médio anual de horas de } \\
\text { interrupção do abastecimento de } \\
\text { água por domicílio }\end{array}$ & 11 & 11.1 & $\begin{array}{l}\text { até } 2030 \text {, garantir o acesso de todos a habitação segura, adequada e a preço acessível, e aos serviços básicos e urbanizar as } \\
\text { favelas }\end{array}$ \\
\hline $\begin{array}{c}\text { Água e } \\
\text { Saneamento }\end{array}$ & 21 & 21.7 & Apoio & $\begin{array}{l}\text { Porcentagem de perdas de água } \\
\text { (água não faturada) }\end{array}$ & 6 & 6.1 & até 2030, alcançar o acesso universal e equitativo à água potável, segura e acessível para todos \\
\hline
\end{tabular}




\begin{tabular}{|c|c|c|c|c|c|c|c|}
\hline Tema & Seção & No. & Tipo & Descrição & ODS & $\begin{array}{l}\text { Meta } \\
\text { ODS }\end{array}$ & Descrição Meta ODS \\
\hline $\begin{array}{c}\text { Água e } \\
\text { Saneamento }\end{array}$ & 21 & 21.7 & Apoio & $\begin{array}{l}\text { Porcentagem de perdas de água } \\
\text { (água não faturada) }\end{array}$ & 6 & 6.4 & $\begin{array}{l}\text { até 2030, aumentar substancialmente a eficiência do uso da água em todos os setores e assegurar retiradas sustentáveis e o } \\
\text { abastecimento de água doce para enfrentar a escassez de água, e reduzir substancialmente o número de pessoas que sofrem com } \\
\text { a escassez de água }\end{array}$ \\
\hline $\begin{array}{c}\text { Água e } \\
\text { Saneamento }\end{array}$ & 21 & 21.7 & Apoio & $\begin{array}{l}\begin{array}{l}\text { Porcentagem de perdas de água } \\
\text { (água não faturada) }\end{array} \\
\end{array}$ & 6 & 6.5 & $\begin{array}{l}\text { até 2030, implementar a gestão integrada dos recursos hídricos em todos os níveis, inclusive via cooperação transfronteiriça, } \\
\text { conforme apropriado }\end{array}$ \\
\hline $\begin{array}{c}\text { Água e } \\
\text { Saneamento }\end{array}$ & 21 & 21.7 & Apoio & $\begin{array}{l}\text { Porcentagem de perdas de água } \\
\text { (água não faturada) }\end{array}$ & 11 & 11.b & $\begin{array}{l}\text { até 2020, aumentar substancialmente o número de cidades e assentamentos humanos adotando e implementando políticas e } \\
\text { planos integrados para a inclusão, a eficiência dos recursos, mitigação e adaptação às alterações climáticas, a resiliência a } \\
\text { desastres; e desenvolver e implementar, de acordo com o "Sendai Framework" para a redução do risco de desastres 2015-2030, o } \\
\text { gerenciamento holístico do risco de desastres em todos os niveis }\end{array}$ \\
\hline $\begin{array}{c}\text { Água e } \\
\text { Saneamento }\end{array}$ & 21 & 21.7 & Apoio & $\begin{array}{l}\begin{array}{l}\text { Porcentagem de perdas de água } \\
\text { (água não faturada) }\end{array} \\
\end{array}$ & 12 & 12.2 & até 2030, alcançar gestão sustentável e uso eficiente dos recursos naturais \\
\hline Perfil & B & 6.10 & Perfil & PIB per capita da cidade (USD) & 8 & 8.1 & $\begin{array}{l}\text { sustentar o crescimento econômico per capita, de acordo com as circunstâncias nacionais e, em particular, pelo menos um } \\
\text { crescimento anual de } 7 \% \text { do PIB nos paises menos desenvolvidos }\end{array}$ \\
\hline Perfil & B & 6.10 & Perfil & PIB per capita da cidade (USD) & 8 & 8.2 & $\begin{array}{l}\text { atingir níveis mais elevados de produtividade das economias, por meio da diversificação, modernização tecnológica e inovação, } \\
\text { inclusive por meio de um foco em setores de alto valor agregado e intensivos em mão-de-obra }\end{array}$ \\
\hline Perfil & B & 10.5 & Perfil & $\begin{array}{l}\text { Orçamento operacional bruto per } \\
\text { capita (USD) }\end{array}$ & 1 & 1.a & $\begin{array}{l}\text { garantir uma mobilização significativa de recursos a partir de uma variedade de fontes, inclusive por meio do reforço da cooperação } \\
\text { para o desenvolvimento, para proporcionar meios adequados e previsíveis para que os países em desenvolvimento, em particular } \\
\text { os países menos desenvolvidos (LCDs), implementem programas e políticas para acabar com a pobreza em todas as suas } \\
\text { dimensões }\end{array}$ \\
\hline Perfil & B & 13.5 & Perfil & Número total de domicílios & 11 & 11.1 & $\begin{array}{l}\begin{array}{l}\text { até 2030, garantir o acesso de todos a habitação segura, adequada e a preço acessível, e aos serviços básicos e urbanizar as } \\
\text { favelas }\end{array} \\
\text { f }\end{array}$ \\
\hline
\end{tabular}




\section{Apêndice C - Aplicação da NBR ISO 37120:2017 (ABNT, 2017a) em Sorocaba}

Resultado a partir de dados obtidos diretamente em visitas e ANATEL (2018), ANEEL (2018), BBC (2018), CETESB (2017), DAESP (2017), DATASUS (2017), IBGE (2018), INEP (2018), INP (2013), INPI (2018), MCTIC (2018), MDS (2017), PCS (2017), (PMS, 2014b), SÃO PAULO (2017), SEADE (2018a), SEADE (2018b), SNIS (2016), SSP/SP (2018), TSE (2016), URBES (2014), URBES (2018a) and URBES (2018b). Todos os indicadores foram levantados em bases anuais, de 2010 a 2017. 


\begin{tabular}{|c|c|c|c|c|c|c|c|c|c|c|c|c|c|c|}
\hline Tema & Seção & No. & Tipo & Descrição & 2010 & 2011 & 2012 & 2013 & 2014 & 2015 & 2016 & 2017 & Unidade & $\begin{array}{l}\text { Fonte dos } \\
\text { Dados }\end{array}$ \\
\hline \multirow{7}{*}{ Economia } & \multirow{7}{*}{5} & 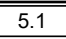 & Essencial & Taxa de desemprego da cidade & $8,10 \%$ & & $3,22 \%$ & & & $6,90 \%$ & & & \% & IBGE/PCS \\
\hline & & 5.2 & Essencial & $\begin{array}{l}\text { Valor de avaliação de propriedades comerciais e industriais como uma porcentagem do } \\
\text { valor de avaliação total de todas as propriedades }\end{array}$ & & & & & & & & & $\%$ & \\
\hline & & 5.3 & Essencial & Porcentagem da população abaixo da linha de pobreza & $0,89 \%$ & & & & & & & & $\%$ & IBGE/MDS \\
\hline & & 5.4 & Apoio & Porcentagem da população com emprego em tempo integral & $29,8 \%$ & $31,2 \%$ & $32,3 \%$ & $32,2 \%$ & $32,6 \%$ & $30,3 \%$ & $33,4 \%$ & & $\%$ & IBGE Cidades \\
\hline & & 5.5 & Apoio & Taxa de desemprego de jovens & & & $21 \%$ & & & & & & $\%$ & PCS \\
\hline & & 5.6 & Apoio & Número de empresas por 100.000 habitantes & 4051 & 4075 & 4111 & 4087 & 3974 & 3868 & 3748 & & empresas/100.000 hab & IBGE Cidades \\
\hline & & 5.7 & Apoio & Número de novas patentes por 100.000 habitantes por ano & 1,2 & 1,9 & 2,5 & 4,9 & 2,5 & 2,3 & 0,8 & 1,5 & patentes/100.000 hab & INPI \\
\hline \multirow{7}{*}{ Educação } & \multirow{7}{*}{6} & 6.1 & Essencial & Porcentagem da população feminina em idade escolar matriculada em escolas & $85,4 \%$ & $90,8 \%$ & $92,1 \%$ & $92,8 \%$ & $94,1 \%$ & $94,4 \%$ & $93,7 \%$ & $93,5 \%$ & $\%$ & \\
\hline & & 6.2 & Essencial & Porcentagem de estudantes com ensino primário completo & & & & & & & & & $\%$ & INEP \\
\hline & & 6.3 & Essencial & Porcentagem de estudantes com ensino secundário completo & & & $69,1 \%$ & $69,7 \%$ & & & & & $\%$ & INEP \\
\hline & & 6.4 & Essencial & Relação estudante/professor no ensino primário & 23,4 & 23,0 & 21,1 & 21,3 & 20,4 & 19,3 & 20,1 & 20,0 & aluno/professor & INEP \\
\hline & & 6.5 & Apoio & Porcentagem de população masculina em idade escolar matriculada em escolas & $84,9 \%$ & $96,9 \%$ & $98,4 \%$ & $99,3 \%$ & $100,0 \%$ & $99,9 \%$ & $99,9 \%$ & $97,3 \%$ & $\%$ & \\
\hline & & 6.6 & Apoio & Porcentagem de população em idade escolar matriculada em escolas & $90,8 \%$ & $94,5 \%$ & $95,8 \%$ & $96,9 \%$ & $98,3 \%$ & $97,7 \%$ & $97,3 \%$ & $94,1 \%$ & $\%$ & INEP \\
\hline & & 6.7 & Apoio & Número de individuos com ensino superior completo por 100.000 habitantes & 10496,5 & 11294,2 & 12171,5 & 12678,5 & 13500,6 & 14103,2 & 14994,5 & 15904,3 & graduados/100.000 hab & IBGE/SEADE \\
\hline \multirow{7}{*}{ Energia } & \multirow{7}{*}{7} & 7.1 & Essencial & Uso de energia elétrica residencial total per capita ( $\mathrm{kWh} / \mathrm{ano}$ ) & 864,3 & 915,6 & 976,3 & 997,4 & 1043,7 & 1018,5 & 982,4 & & kWh/ano.hab & Sec. Energia SP \\
\hline & & 7.2 & Essencial & Porcentagem de habitantes da cidade com fornecimento regular de energia elétrica & $99,7 \%$ & & & & & & & & $\%$ & IBGE \\
\hline & & 7.3 & Essencial & Consumo de energia de edifícios públicos por ano $\left(\mathrm{kWh} / \mathrm{m}^{2}\right)$ & & & & & & & & & $\mathrm{kWh} / \mathrm{m}^{2}$ & \\
\hline & & 7.4 & Essencial & $\begin{array}{l}\text { Porcentagem da energia total proveniente de fontes renováveis, como parte do consumo } \\
\text { total de energia da cidade }\end{array}$ & & & & & & & & & $\%$ & \\
\hline & & 7.5 & Apoio & Uso total de energia elétrica per capita (kWh/ano) & 3198,9 & 3326,1 & 3408,0 & 3440,2 & 3479,4 & 3256,8 & \begin{tabular}{|c|}
3067,1 \\
\end{tabular} & & kWh/ano.hab & Sec. Energia SP \\
\hline & & 7.6 & Apoio & Número médio de interrupções de energia elétrica por consumidor por ano & 9,1 & 6,4 & 4,9 & 14,3 & 11,1 & 10,0 & 18,0 & & interrupçōes & ANEEL \\
\hline & & 7.7 & Apoio & Duração média das interrupções de energia elétrica (em horas) & 12,0 & 9,0 & 5,8 & 9,2 & 15,4 & 13,5 & 56,6 & & horas & ANEEL \\
\hline \multirow{8}{*}{$\begin{array}{l}\text { Meio } \\
\text { Ambiente }\end{array}$} & \multirow{8}{*}{8} & 8.1 & Essencial & Concentração de material particulado fino (PM 2.5) & & & & & & & & & $\mu \mathrm{g} / \mathrm{m}^{3}$ & \\
\hline & & 8.2 & Essencial & Concentração de material particulado (PM 10) & 32 & 34 & 32 & 35 & 39 & 28 & 25 & 24 & $\mu \mathrm{g} / \mathrm{m}^{3}$ & CETESB \\
\hline & & 8.3 & Essencial & Emissão de gases de efeito estufa medida em toneladas per capita & 1,58 & 1,70 & 1,83 & & & & & & thab & SMA-Sorocaba \\
\hline & & 8.4 & Apoio & Concentração de $\mathrm{NO}_{2}$ (dióxido de nitrogênio) & 21 & 25 & 26 & 18 & 18 & 20 & 20 & 15 & $\mu \mathrm{g} / \mathrm{m}^{3}$ & CETESB \\
\hline & & 8.5 & Apoio & Concentração de $\mathrm{SO}_{2}$ (dióxido de enxofre) & & & & & & & & & $\mu \mathrm{g} / \mathrm{m}^{3}$ & \\
\hline & & 8.6 & Apoio & Concentração de $\mathrm{O}_{3}$ (ozônio) & 38 & 36 & 41 & 38 & 54 & 43 & 40 & 42 & $\mu \mathrm{g} / \mathrm{m}^{3}$ & CETESB \\
\hline & & 8.7 & Apoio & Poluição sonora & & & & & & & & & $\%$ & \\
\hline & & 8.8 & Apoio & Variação percentual em número de espécies nativas & & & & & & & & & $\%$ & \\
\hline \multirow{4}{*}{ Finanças } & \multirow{4}{*}{9} & 9.1 & Essencial & $\begin{array}{l}\text { Taxa de endividamento (expansão do serviço da dívida como uma porcentagem da } \\
\text { receita própria do município) }\end{array}$ & $2,07 \%$ & $5,54 \%$ & $6,16 \%$ & $3,94 \%$ & $0,94 \%$ & $5,83 \%$ & $2,79 \%$ & & $\%$ & PMS \\
\hline & & 9.2 & Apoio & Despesas de capital como porcentagem de despesas totais & $11,47 \%$ & $16,50 \%$ & $15,30 \%$ & $8,93 \%$ & $5,81 \%$ & $5,55 \%$ & $5,58 \%$ & & $\%$ & PMS \\
\hline & & 9.3 & Apoio & Porcentagem da receita própria em função do total das receitas & $44,58 \%$ & $46,41 \%$ & $47,76 \%$ & $47,08 \%$ & $54,05 \%$ & $54,68 \%$ & $55,80 \%$ & & $\%$ & PMS \\
\hline & & 9.4 & Apoio & Porcentagem dos impostos recolhidos em função dos impostos cobrados & & $100,00 \%$ & $95,06 \%$ & $98,55 \%$ & $101,35 \%$ & $87,65 \%$ & $87,63 \%$ & & $\%$ & PMS \\
\hline \multirow{6}{*}{$\begin{array}{l}\text { Resposta a } \\
\text { Incêndio e } \\
\text { Emergências }\end{array}$} & \multirow{6}{*}{10} & 10.1 & Essencial & Número de bombeiros por 100.000 habitantes & & & & & & & & & bombeiros/100.000hab & \\
\hline & & 10.2 & Essencial & Número de mortes relacionadas a incêndios por 100.000 habitantes & 0,0 & 0,0 & 0,0 & 0,0 & 0,0 & 0,0 & 0,3 & 0,0 & óbitos/100.000hab & \\
\hline & & 10.3 & Essencial & Número de mortes relacionadas a desastres naturais por 100.000 habitantes & 0,0 & 0,0 & 1,2 & 0,0 & 0,0 & 0,0 & 0,0 & 0,0 & óbitos/100.000hab & $\begin{array}{c}\text { Secretaria da } \\
\text { Segurança e } \\
\text { Defesa Civil - } \\
\text { Sorocaba } \\
\end{array}$ \\
\hline & & 10.4 & Apoio & Número de bombeiros voluntários e em tempo parcial por 100.000 habitantes & & & & & & & & & bombeiros/100.000hab & \\
\hline & & 10.5 & Apoio & Tempo de resposta dos serviços de emergência a partir do primeiro chamado & & & & & & & & & minutos & \\
\hline & & 10.6 & Apoio & Tempo de resposta do Corpo de Bombeiros a partir do primeiro chamado & & & & & & & & & minutos & \\
\hline & & 11.1 & Essencial & $\begin{array}{l}\begin{array}{l}\text { Porcentagem de participação dos eleitores nas últimas eleições municipais em função } \\
\text { do total de eleitores aptos a votar }\end{array} \\
\end{array}$ & & & $84,3 \%$ & $84,3 \%$ & $84,3 \%$ & $84,3 \%$ & $80,5 \%$ & $80,5 \%$ & $\%$ & TSE \\
\hline & & 11.2 & Essencial & $\begin{array}{l}\begin{array}{l}\text { Porcentagem de mulheres eleitas em função do número total de eleitos na gestão da } \\
\text { cidade }\end{array} \\
\end{array}$ & $4,5 \%$ & $4,5 \%$ & $4,5 \%$ & $4,5 \%$ & $4,5 \%$ & $4,5 \%$ & $13,6 \%$ & $13,6 \%$ & $\%$ & TSE \\
\hline
\end{tabular}




\begin{tabular}{|c|c|c|c|c|c|c|c|c|c|c|c|c|c|c|}
\hline Tema & Seção & No. & Tipo & Descrição & 2010 & 2011 & 2012 & 2013 & 2014 & 2015 & 2016 & 2017 & Unidade & $\begin{array}{l}\text { Fonte dos } \\
\text { Dados }\end{array}$ \\
\hline \multirow{4}{*}{ Governança } & \multirow{4}{*}{11} & 11.3 & Apoio & Porcentagem de mulheres empregadas na gestão da cidade & & & $64,65 \%$ & & & & & & $\%$ & PCS \\
\hline & & 11.4 & Apoio & $\begin{array}{l}\text { Número de condenações de servidores da cidade por corrupção e/ou suborno por } \\
100.000 \text { habitantes }\end{array}$ & & & & & & & & & condenações/100.000hab & \\
\hline & & 11.5 & Apoio & $\begin{array}{l}\text { Representação de cidadãos: número de autoridades locais eleitas para o cargo por } \\
100.000 \text { habitantes }\end{array}$ & & & & & & & & & autoridades/100.000hab & \\
\hline & & 11.6 & Apoio & Porcentagem de eleitores registrados em função da população com idade para votar & \begin{tabular}{|l|l}
$87,7 \%$ \\
\end{tabular} & $87,7 \%$ & $89,2 \%$ & $89,2 \%$ & $89,9 \%$ & $89,9 \%$ & $89,6 \%$ & $89,6 \%$ & $\%$ & TSE \\
\hline \multirow{7}{*}{ Saúde } & \multirow{7}{*}{12} & 12.1 & Essencial & Expectativa média de vida & 75,6 & & 74,38 & 74,62 & 74,85 & 74,96 & 74,81 & & anos & IBGE \\
\hline & & 12.2 & Essencial & Número de leitos hospitalares por 100.000 habitantes & 440,3 & 435,9 & 431,2 & 386,3 & 348,9 & 298,3 & 240,9 & 220,5 & leitos/100.000hab & DATASUS/BGE \\
\hline & & 12.3 & Essencial & Número de médicos por 100.000 habitantes & 225,9 & 231,7 & 231,2 & 233,5 & 246,9 & 250,1 & 254,4 & 260,1 & médicos/100.000hab & DATASUS/BGE \\
\hline & & 12.4 & Essencial & Taxa de mortalidade de crianças menores de cinco anos a cada 1.000 nascidos vivos & 14,67 & 14,91 & 12,92 & 14,70 & 13,52 & 11,04 & 11,56 & & óbitos/1000 nascidos vivos & SEADE - IMP \\
\hline & & 12.5 & Apoio & Número de pessoas da equipe de enfermagem e obstetrícia por 100.000 habitantes & 968,4 & 980,5 & 1026,0 & 1036,2 & 1095,1 & 1122,0 & 1153,9 & 1186,0 & enfermeiros/100.000hab & DATASUS/BGE \\
\hline & & 12.6 & Apoio & Número de profissionais de saúde mental por 100.000 habitantes & 133,3 & 144,5 & 152,5 & 156,1 & 163,5 & & & & psicólogos/100.000hab & DATASUS/BGE \\
\hline & & 12.7 & Apoio & Taxa de suicídio por 100.000 habitantes & $5,46 \%$ & $5,73 \%$ & $5,16 \%$ & $7,89 \%$ & $6,01 \%$ & $5,61 \%$ & $6,03 \%$ & & $\%$ & SEADE - IMP \\
\hline \multirow{2}{*}{ Recreação } & \multirow{2}{*}{13} & 13.1 & Apoio & Área em metros quadrados de espaços públicos de recreação cobertos per capita & & & & & & & & & $\mathrm{m}^{2} / \mathrm{hab}$ & \\
\hline & & 13.2 & Apoio & Área em metros quadrados de espaços públicos de recreação ao ar livre per capita & & & & & 2,71 & 2,67 & 2,64 & 2,61 & $\mathrm{~m}^{2} / \mathrm{hab}$ & SIG - Sorocaba \\
\hline \multirow{5}{*}{ Segurança } & \multirow{5}{*}{14} & 14.1 & Essencial & Número de agentes de polícia por 100.000 habitantes & & & & & & & & & policiais/100.000hab & \\
\hline & & 14.2 & Essencial & Número de homicídios por 100.000 habitantes & 15,0 & 13,3 & 11,5 & & & & & & óbitos/100.000hab & PCS \\
\hline & & 14.3 & Apoio & Crimes contra a propriedades por 100.000 habitantes & \begin{tabular}{|l|}
2005,5 \\
\end{tabular} & 1988,8 & 2202,3 & 2148,5 & 2173,0 & 2121,7 & 2105,3 & 1946,9 & crimes/100.000hab & SSP/SP \\
\hline & & 14.4 & Apoio & Tempo de resposta da polícia a partir do primeiro chamado & & & & & & & & & minutos & \\
\hline & & 14.5 & Apoio & Taxa de crimes violentos por 100.000 habitantes & 451,4 & 466,5 & 505,8 & 435,0 & 348,1 & 326,4 & 324,8 & 284,8 & crimes/100.000hab & SSP/SP \\
\hline \multirow{3}{*}{ Habitação } & \multirow{3}{*}{15} & 15.1 & Essencial & Porcentagem da população urbana morando em favelas & 0 & 0 & 0 & 0 & 0 & 0 & 0 & $0,5 \%$ & $\%$ & IBGE \\
\hline & & 15.2 & Apoio & Número de sem-teto por 100.000 habitantes & & & 24,3 & & & & & 86,7 & pessoas/100.000hab & PCS \\
\hline & & 15.3 & Apoio & Porcentagem de moradias sem titulos de propriedade registrados & & & & & & & & & $\%$ & \\
\hline \multirow{10}{*}{$\begin{array}{l}\text { Residuos } \\
\text { sólidos }\end{array}$} & \multirow{10}{*}{16} & 16.1 & Essencial & Porcentagem da população urbana com coleta regular de lixo (domiciliar) & $99,9 \%$ & $100 \%$ & $100 \%$ & $100 \%$ & $100 \%$ & $100 \%$ & $100 \%$ & & $\%$ & SNIS \\
\hline & & 16.2 & Essencial & Total de coleta de residuos sólidos municipais per capita & 0,27 & 0,33 & 0,34 & 0,30 & 0,34 & 0,34 & 0,31 & & ton/hab.ano & SNIS \\
\hline & & 16.3 & Essencial & Porcentagem de residuos sólidos urbanos que são reciclados & & $1,95 \%$ & $1,89 \%$ & $2,06 \%$ & $1,77 \%$ & $1,76 \%$ & $1,87 \%$ & & $\%$ & SNIS \\
\hline & & 16.4 & Apoio & Porcentagem de resíduos sólidos urbanos dispostos em aterros sanitários & & & $97,78 \%$ & $98,13 \%$ & $97,93 \%$ & $97,40 \%$ & $97,00 \%$ & & $\%$ & PCS/PMS \\
\hline & & 16.5 & Apoio & Porcentagem de resíduos sólidos urbanos descartados para incineração & $0,00 \%$ & $0,00 \%$ & $0,00 \%$ & $0,00 \%$ & $0,00 \%$ & $0,00 \%$ & $0,00 \%$ & & $\%$ & PMS \\
\hline & & 16.6 & Apoio & Porcentagem de residuos sólidos urbanos queimados a céu aberto & $0,12 \%$ & $0,00 \%$ & $0,00 \%$ & $0,00 \%$ & $0,00 \%$ & $0,00 \%$ & $0,00 \%$ & & $\%$ & PMGIRS \\
\hline & & 16.7 & Apoio & Porcentagem de resíduos sólidos urbanos dispostos a céu aberto & \begin{tabular}{|c|}
$0,01 \%$ \\
\end{tabular} & $0,00 \%$ & $0,00 \%$ & $0,00 \%$ & $0,00 \%$ & $0,00 \%$ & $0,00 \%$ & & $\%$ & PMGIRS \\
\hline & & 16.8 & Apoio & Porcentagem de residuos sólidos urbanos dispostos por outros meios & \begin{tabular}{|c|}
$0,01 \%$ \\
\end{tabular} & $0,00 \%$ & $0,33 \%$ & $0,00 \%$ & $0,30 \%$ & $0,84 \%$ & $1,13 \%$ & & $\%$ & PMGIRS \\
\hline & & 16.9 & Apoio & Geração de residuos perigosos per capita & & & & & & & & & ton/hab.ano & \\
\hline & & 16.10 & Apoio & Porcentagem de resíduos urbanos perigosos que são reciclados & & & & & & & & & $\%$ & \\
\hline \multirow{3}{*}{$\begin{array}{l}\text { Telecomuni- } \\
\text { cações e } \\
\text { Inovação }\end{array}$} & \multirow{3}{*}{17} & 17.1 & Essencial & Número de conexões de internet por 100.000 habitantes & 18572,5 & 19689,1 & 22659,9 & 23858,8 & 25790,7 & 26851,9 & 27816,3 & 28950,7 & conexões/100.000 hab & ANATEL \\
\hline & & 17.2 & Essencial & Número de conexōes de telefone celular por 100.000 habitantes & & & & & & & & & conexões/100.000 hab & \\
\hline & & 17.3 & Apoio & Número de conexões de telefone fixo por 100.000 habitantes & 21309,4 & 19819,9 & 17071,6 & 15276,6 & 14258,9 & 13470,1 & 25196,0 & 18150,5 & conexões/100.000 hab & ANATEL \\
\hline \multirow{9}{*}{ Transporte } & \multirow{9}{*}{18} & 18.1 & Essencial & Quilômetros de sistema de transporte público de alta capacidade por 100.000 habitantes & 0 & 0 & 0 & 0 & 0 & 0 & 0 & 0 & $\mathrm{~km} / 100.000 \mathrm{hab}$ & URBES \\
\hline & & 18.2 & Essencial & $\begin{array}{l}\text { Quilômetros de sistema de transporte público de média capacidade por } 100.000 \\
\text { habitantes }\end{array}$ & & & 0,5 & 0,5 & 0,5 & 1,1 & 2,2 & & $\mathrm{~km} / 100.000 \mathrm{hab}$ & URBES \\
\hline & & 18.3 & Essencial & Número anual de viagens em transporte público per capita & 91,71 & 93,85 & 98,08 & 92,76 & 94,13 & 88,51 & 82,97 & 67,10 & viagens/hab.ano & URBES \\
\hline & & 18.4 & Essencial & Número de automóveis privados per capita & 0,38 & 0,40 & 0,43 & 0,43 & 0,45 & 0,46 & 0,46 & 0,46 & auto/hab & URBES \\
\hline & & 18.5 & Apoio & $\begin{array}{l}\begin{array}{l}\text { Porcentagem de passageiros que se deslocam para o trabalho de forma alternativa ao } \\
\text { automóvel privado }\end{array} \\
\end{array}$ & & & & $57,6 \%$ & & & & & $\%$ & URBES \\
\hline & & 18.6 & Apoio & Número de veículos motorizados de duas rodas per capita & 0,11 & 0,12 & 0,13 & 0,13 & 0,13 & 0,13 & 0,13 & 0,14 & moto/hab & URBES \\
\hline & & 18.7 & Apoio & Quilômetros de ciclovias e ciclofaixas por 100.000 habitantes & 11,3 & 13,1 & 17,3 & 17,8 & 18,0 & 17,8 & 17,6 & 19,1 & $\mathrm{~km} / \mathrm{hab}$ & URBES \\
\hline & & 18.8 & Apoio & Mortalidades de trânsito por 100.000 habitantes & 9,38 & 9,09 & 9,82 & 14,30 & 7,53 & 8,06 & 7,36 & 5,46 & óbitos/100.000 hab & SSP/SP \\
\hline & & 18.9 & Apoio & Conectividade aérea (número de partidas de voos comerciais sem escalas) & 0 & 0 & 0 & 0 & 0 & 0 & 0 & 0 & vôos comerciais & DAESP \\
\hline
\end{tabular}




\begin{tabular}{|c|c|c|c|c|c|c|c|c|c|c|c|c|c|c|}
\hline Tema & Seção & No. & Tipo & Descrição & 2010 & 2011 & 2012 & 2013 & 2014 & 2015 & 2016 & 2017 & Unidade & $\begin{array}{l}\text { Fonte dos } \\
\text { Dados }\end{array}$ \\
\hline \multirow{4}{*}{$\begin{array}{l}\text { Planejamento } \\
\text { Urbano }\end{array}$} & \multirow{4}{*}{19} & 19.1 & Essencial & Áreas verdes (hectares) por 100.000 habitantes & & & & & & & 269,5 & & ha/100.000 hab & PMS \\
\hline & & 19.2 & Apoio & Número de árvores plantadas anualmente por 100.000 habitantes & 16.772 & 31.128 & 29.819 & 16.828 & 10.644 & 7.660 & 6.156 & & árvores/100.000 hab & PCS \\
\hline & & 19.3 & Apoio & Porcentagem de área de assentamentos informais em função da área total da cidade & & & & & & & & & $\%$ & \\
\hline & & 19.4 & Apoio & Relação empregos/habitação & 0,98 & 1,01 & 1,04 & 1,06 & 1,06 & 0,97 & 1,06 & & empregos/domicilios & IBGE/SEADE-IMP \\
\hline \multirow{5}{*}{ Esgotos } & \multirow{5}{*}{20} & 20.1 & Essencial & 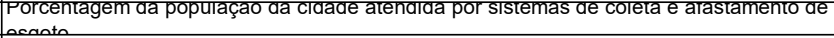 & $97,6 \%$ & $96,4 \%$ & $97,7 \%$ & $90,0 \%$ & $97,1 \%$ & $97,1 \%$ & $97,1 \%$ & & $\%$ & SNIS \\
\hline & & 20.2 & Essencial & Porcentagem do esgoto da cidade que não recebeu qualquer tratamento & $4,0 \%$ & $4,0 \%$ & $4,0 \%$ & $5,7 \%$ & $10,9 \%$ & $9,9 \%$ & $9,2 \%$ & & $\%$ & SNIS \\
\hline & & 20.3 & Essencial & Porcentagem do esgoto da cidade que recebe tratamento primário & $100 \%$ & $100 \%$ & $100 \%$ & $100 \%$ & $100 \%$ & $100 \%$ & $100 \%$ & & $\%$ & SAAE \\
\hline & & 20.4 & Essencial & Porcentagem do esgoto da cidade que recebe tratamento secundário & 0 & 0 & 0 & 0 & 0 & 0 & 0 & & $\%$ & SAAE \\
\hline & & 20.5 & Essencial & Porcentagem do esgoto da cidade que recebe tratamento terciário & 0 & 0 & 0 & 0 & 0 & 0 & 0 & & $\%$ & SAAE \\
\hline \multirow{7}{*}{$\begin{array}{c}\text { Água e } \\
\text { Saneamento }\end{array}$} & \multirow{7}{*}{21} & 21.1 & Essencial & Porcentagem da população da cidade com serviço de abastecimento de água potável & $99,1 \%$ & $97,9 \%$ & $97,8 \%$ & $97,8 \%$ & $98,8 \%$ & $99,1 \%$ & $99,5 \%$ & & $\%$ & SNIS \\
\hline & & 21.2 & Essencial & $\begin{array}{l}\text { Porcentagem da população da cidade com acesso sustentável a uma fonte de água } \\
\text { adequada para consumo }\end{array}$ & $99,1 \%$ & $97,9 \%$ & $97,8 \%$ & $97,8 \%$ & $98,8 \%$ & $99,1 \%$ & $99,5 \%$ & & $\%$ & \\
\hline & & 21.3 & Essencial & Porcentagem da população da cidade com acesso a saneamento melhorado & $97,4 \%$ & $96,4 \%$ & $97,7 \%$ & $90,0 \%$ & $97,1 \%$ & $97,1 \%$ & $97,1 \%$ & & $\%$ & IBGE \\
\hline & & 21.4 & Essencial & Consumo doméstico total de água per capita (litros/dia) & 174,8 & 181,0 & & 182,6 & 152,7 & 137,3 & 150,8 & & litros/hab.dia & SNIS \\
\hline & & 21.5 & Apoio & Consumo total de água per capita (litros/dia) & 194,5 & 201,2 & 208,8 & 203,0 & 193,9 & 177,0 & 181,3 & & litros/hab.dia & SNIS \\
\hline & & 21.6 & Apoio & Valor médio anual de horas de interrupção do abastecimento de água por domicilio & 0,00 & 0,00 & 0,00 & 0,00 & 0,02 & 0,00 & 0,01 & & horas/domicilio.ano & SNIS/SEADE-IMP \\
\hline & & 21.7 & Apoio & Porcentagem de perdas de água (água não faturada) & $41,5 \%$ & $39,5 \%$ & $37,2 \%$ & $34,7 \%$ & $36,6 \%$ & $41,3 \%$ & $41,0 \%$ & & $\%$ & SNIS \\
\hline
\end{tabular}




\section{ANEXOS}

Anexo A - Folheto do IBGE sobre Sorocaba, para ocasião das eleições de 2016. 


\section{FELITES}

Qual o papel do(a) prefeito(a)?

Ele(a) tem o dever de cumprir as atribuições previstas na Cos recursos de impostos e demais verbas repassadas pelo Estado e pela União. A Constituição Federal determina, por exemplo, que cabe ao prefeito e à sua equipe: administrar o transporte coletivo da cidade, manter programas de educação infantil e ensino fundamental, prestar serviços de atendimento à saúde da população, promover $\mathrm{o}$ adequado patrimônio histórico-cultural do munićpio.

patrimônio his

A aplicação dos recursos públicos deve obedecer à Lei de Responsabilidade Fiscal e o que for fixado na lei orçamentária vereadores, que representam o Poder Legislativo municipal.

\section{$\mathrm{O}$ que fazem os vereadores?}

Na Câmara Municipal, os vereadores decidem o futuro do município, discutem e votam projetos que serăo

transformados em leis. Cabe a eles fiscalizar a forma como a prefeitura administra os recursos públicos. Também devem população, ouvindo suas sugestões.

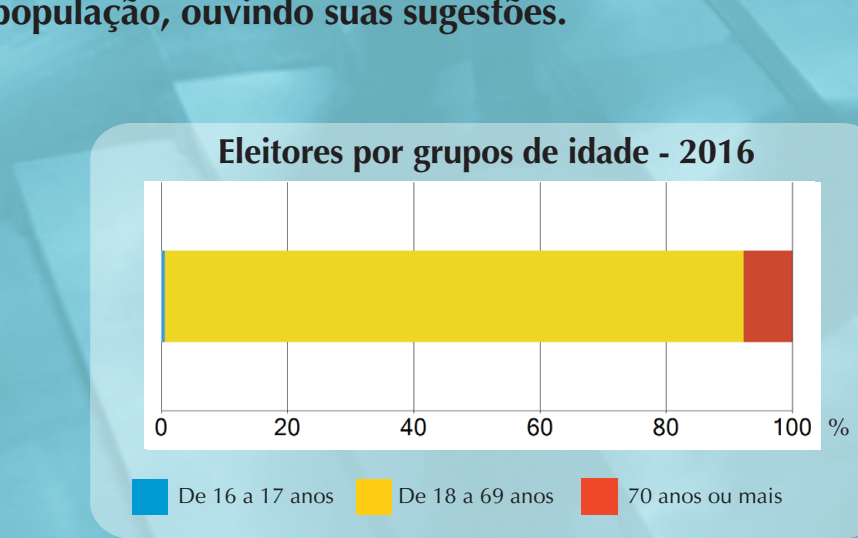

Fonte: Tribunal Superior Eleitoral - TSE Registros Administrativos 2016 .

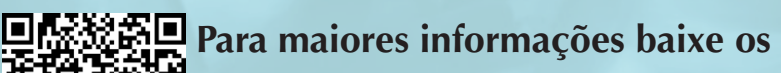
APPs das eleições 2016 - TSE

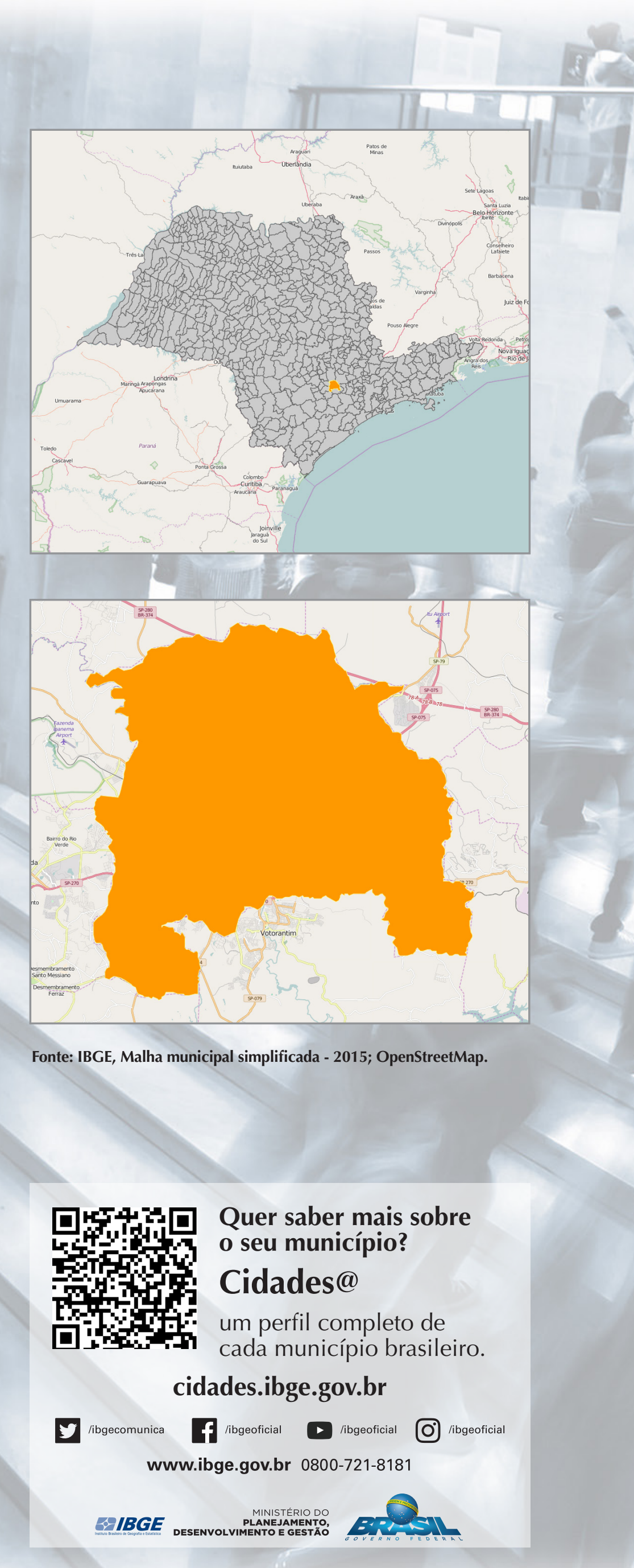

- SÃOPAULO

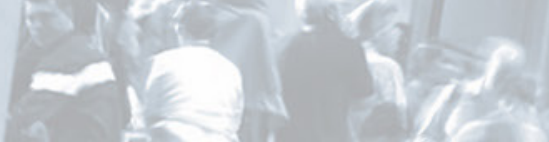
S

0 sel Munitipio em Nímeros 2016

\section{Sorocalba}




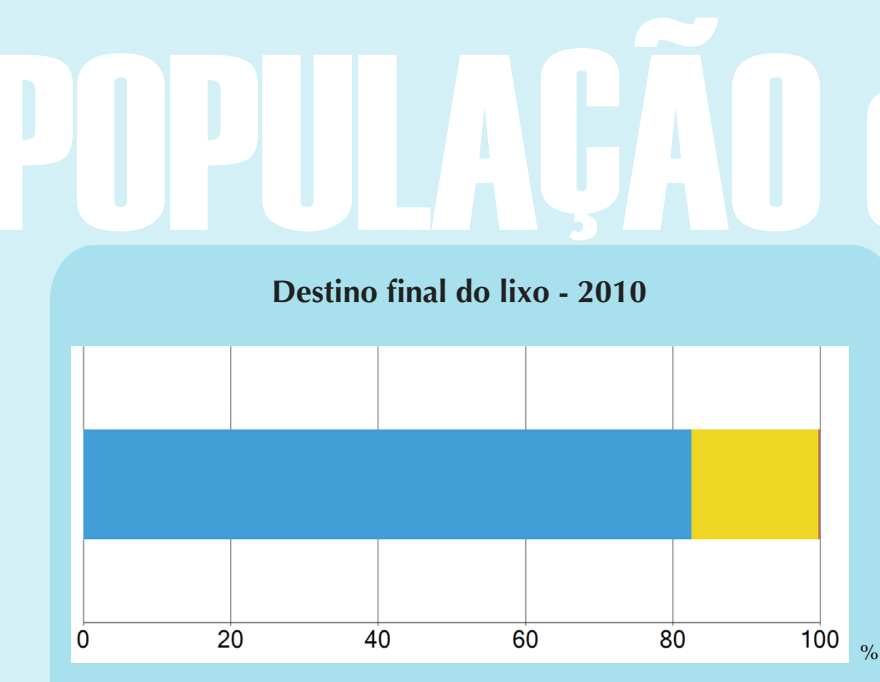

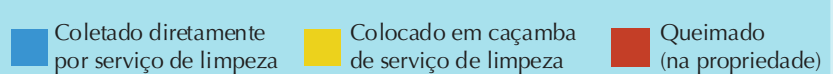
$\begin{array}{ll}\text { Enterrado } \\ \text { (na propriedade) } & \text { Outro destino }\end{array}$

Fonte: IBGE, Censo Demográíico 2010.

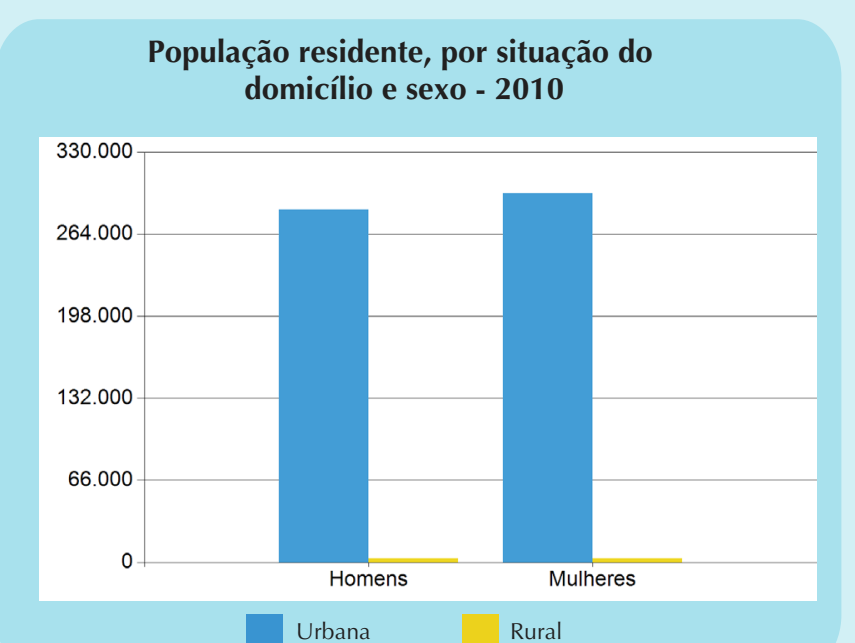

Fonte: IBGE, Censo Demográfico 2010.
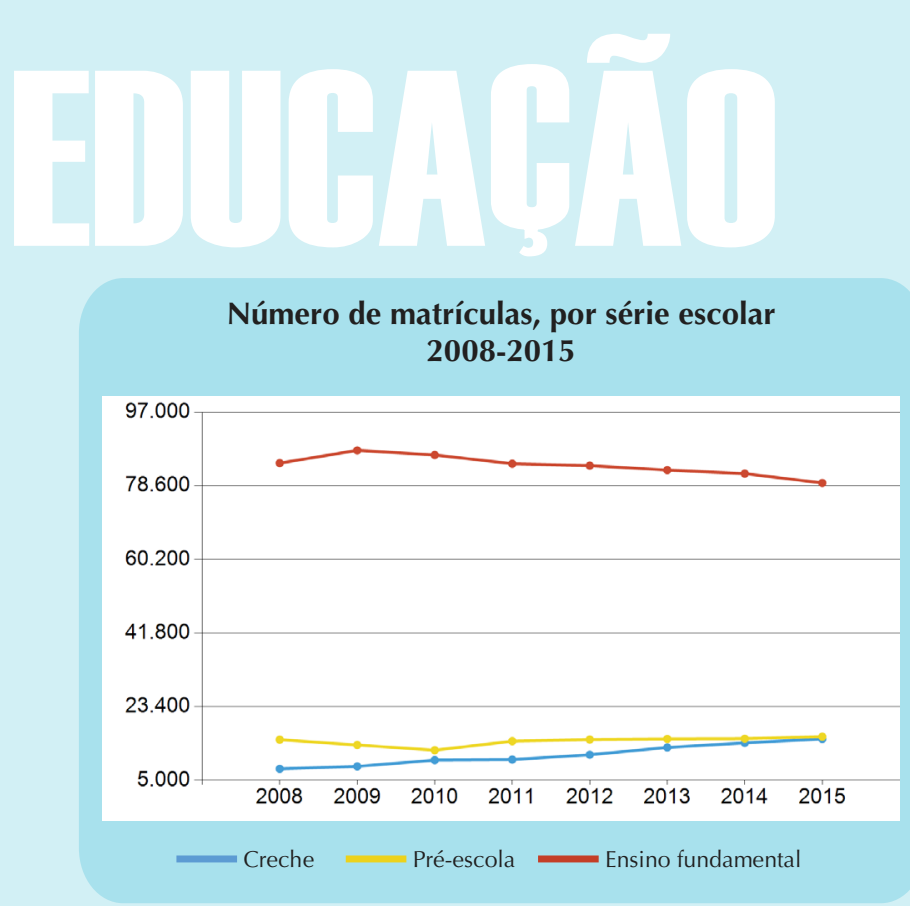

Fonte: Instituto Nacional de Estudos e Pesquisas Educacionais - INEP - Censo
Educacional 2008-2015.

\section{Rendimento domiciliar per capita - 2010}

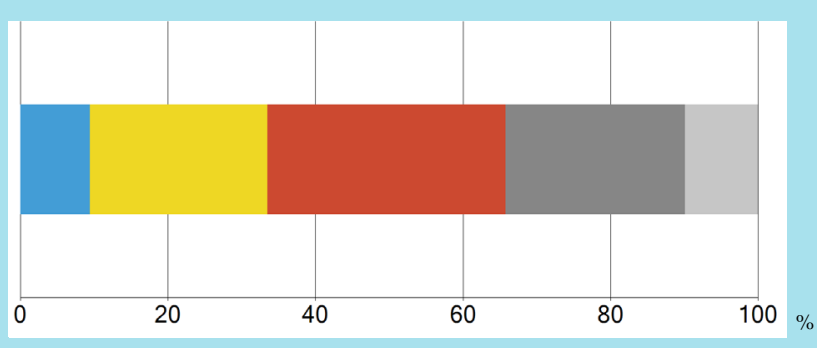

$\begin{array}{ll}\text { Até } 1 / 2 \text { salário mínimo } & \text { De } 1 / 2 \text { a } 1 \text { salário mínimo } \\ \text { De } 1 \text { a } 2 \text { salários minimimos } & \text { De } 2 \text { a salarios minimos }\end{array}$

De 1 a 2 salários mínimos

Fonte: IBGE, Censo Demográíico 2010.

\section{População residente, por grupos de idade - 2010}

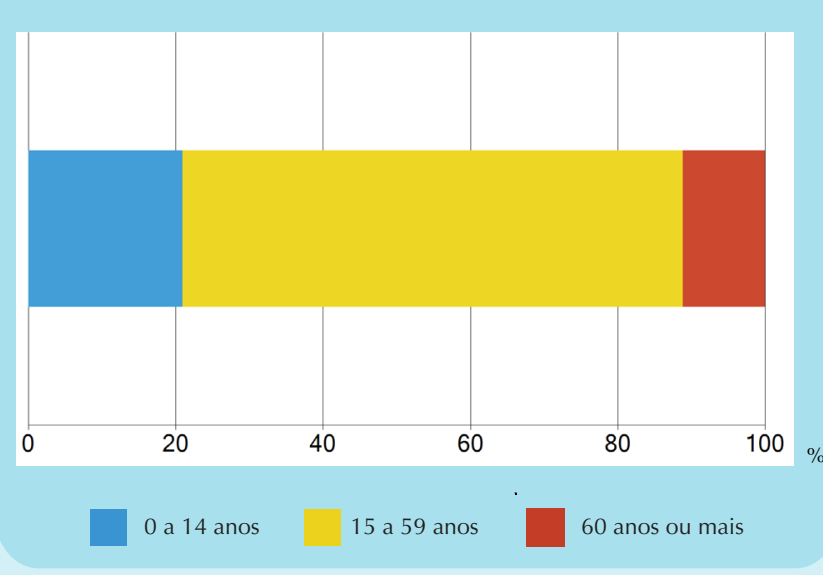

Fonte: IBGE, Censo Demográfico 2010

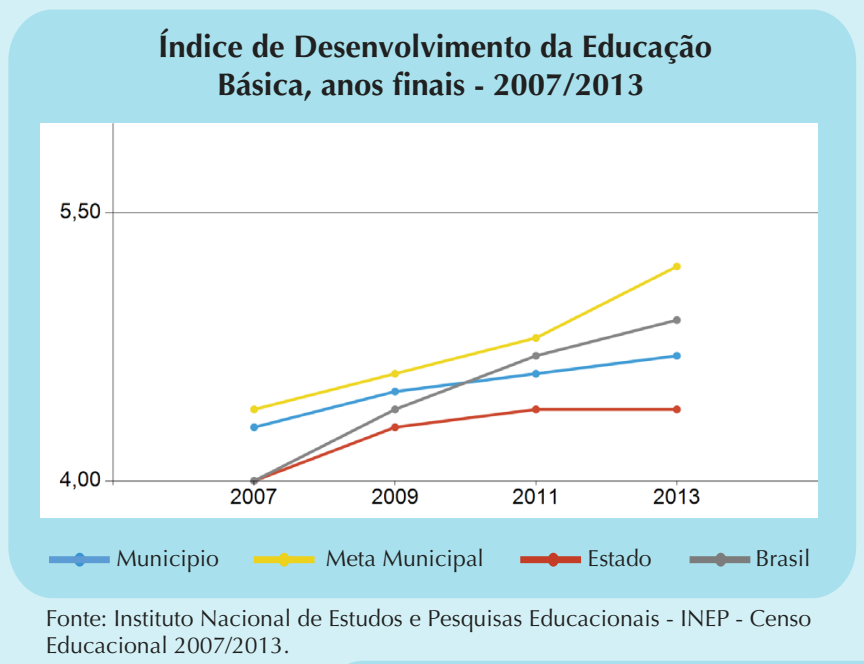

Fonte: Instituto Nacional de Estudos e Pesquisas Educacionais - INEP - Censo
Educacional $2007 / 2013$
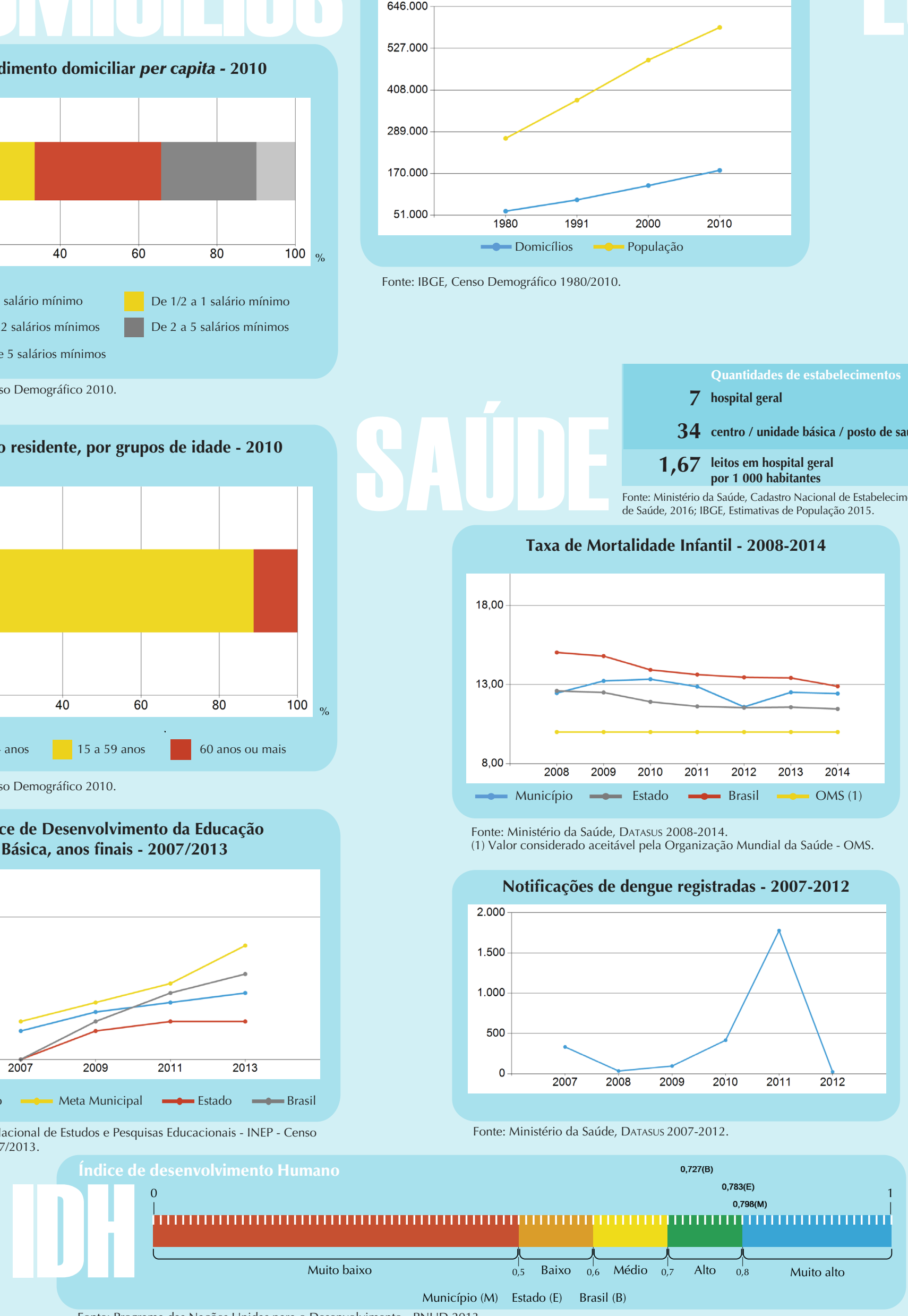

Fonte: BBGE, Censo Demográfico 1980/2010.

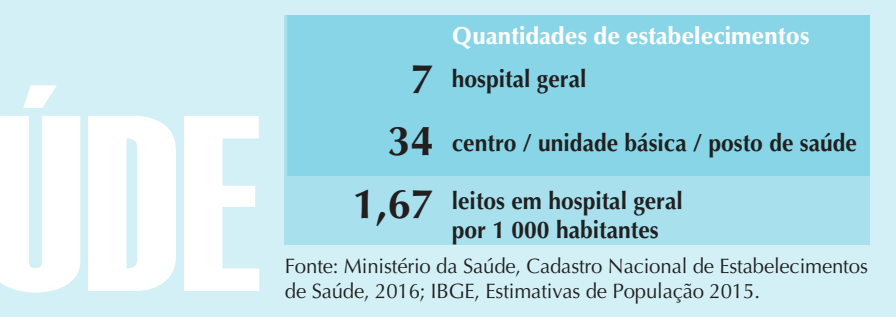

Taxa de Mortalidade Infantil - 2008-2014

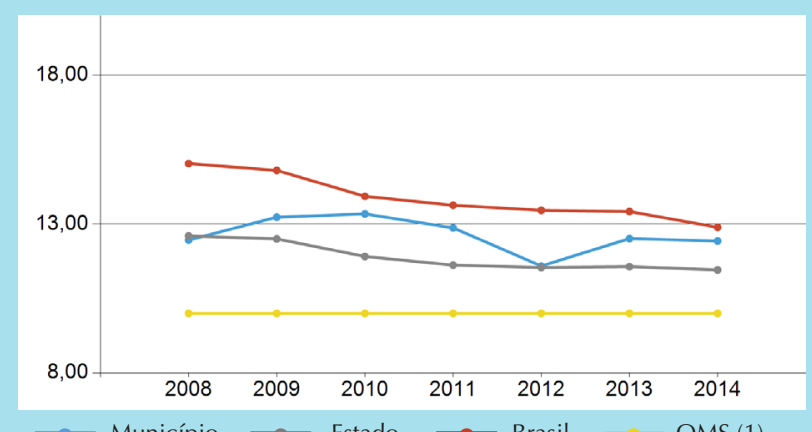

$\rightarrow$ Município $\rightarrow$ Estado $\rightarrow$ Brasil $\longrightarrow$ OMS (1)

Fonte: Ministério da Saúde, DATAsus 2008 -2014.
(1) Valor considerado aceitável pela Organizaçăo Mundial da Saúde - OMS.

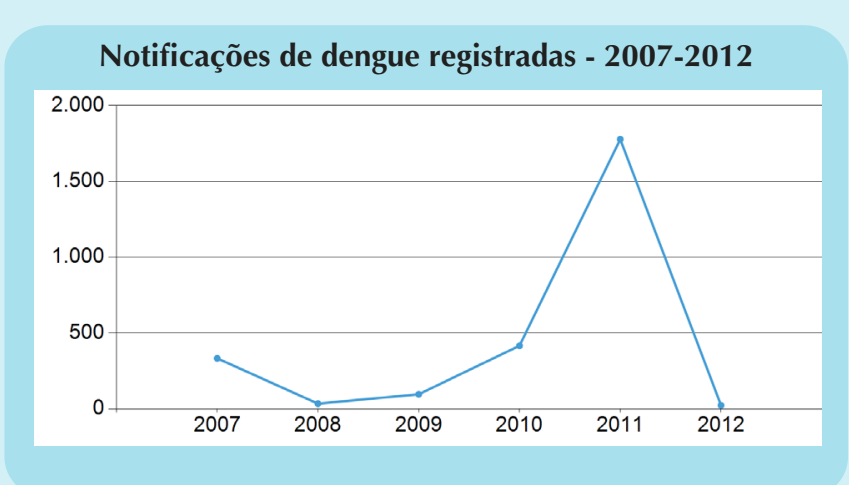

Fonte: Ministério da Saúde, Darasus 2007-2012.
Produto Interno Bruto dos Municípios - 2013 R\$1.000,00

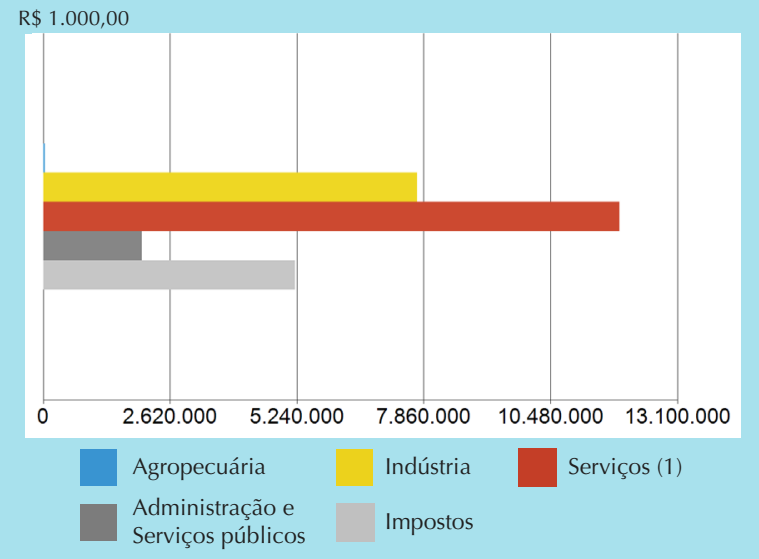

Servicos públicos Impostos

Fonte: IBCE, em parceria com os Órgăo Estaduais de Estátistica,
Secretarias Estaduais de Governo e Superintendencia da Zona Franca de Manaus- SurRAM, 2013 ã o Sericos públicos.
(1) Exclusive Administraça

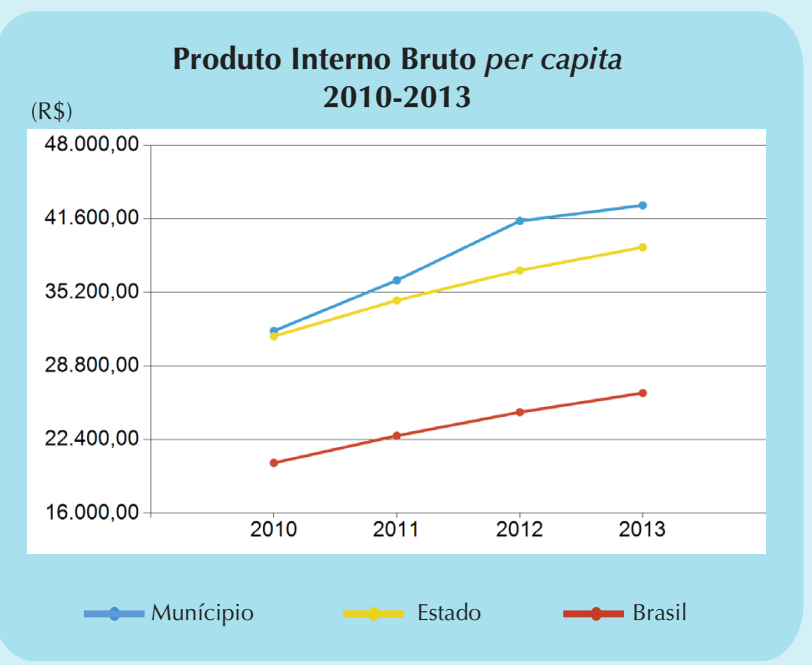

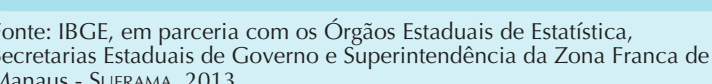

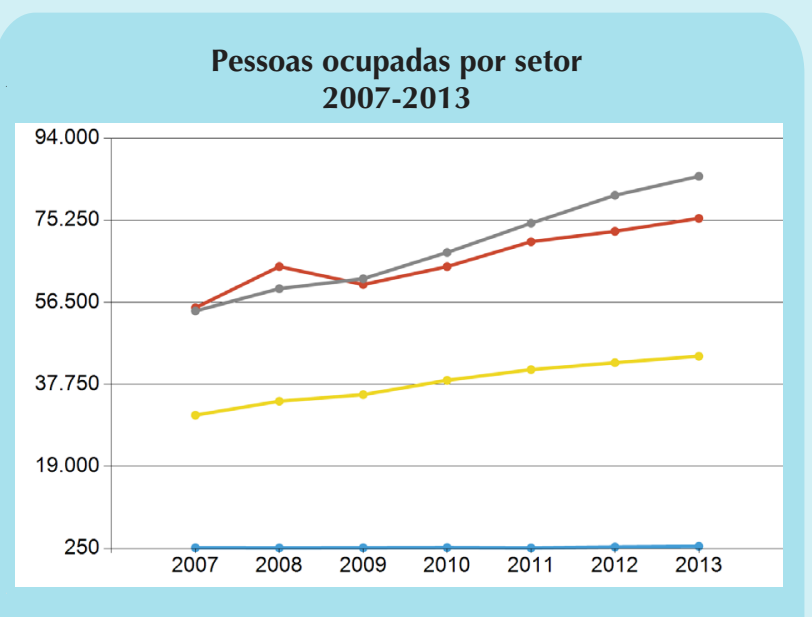

$\rightarrow$ Agricultura $\rightarrow$ Comércio $\rightarrow$ Indústria $\rightarrow$ Serviços Fonte: IBGE,Cadastro Central de Empresas 2014.

B) IBGE 